\title{
Compositional Effects on Microsegregation Behaviour In Single Crystal Superalloy Systems
}

\author{
by
}

Richard M. Kearsey

M. Eng.

A thesis submitted to the Faculty of Graduate Studies and Research in partial fulfillment of the requirements for the degree of

Doctor of Philosophy

Department of Mechanical and Aerospace Engineering, Ottawa-Carleton Institute for Mechanical and Aerospace Engineering

\author{
Carleton University \\ Ottawa, Ontario \\ December 2004 \\ (c) Copyright \\ 2004 R.M. Kearsey
}




$\begin{array}{ll}\begin{array}{l}\text { Library and } \\ \text { Archives Canada }\end{array} & \begin{array}{l}\text { Bibliothèque et } \\ \text { Archives Canada }\end{array} \\ \begin{array}{l}\text { Published Heritage } \\ \text { Branch }\end{array} & \begin{array}{l}\text { Direction du } \\ \text { Patrimoine de l'édition }\end{array} \\ \begin{array}{l}\text { 395 Wellington Street } \\ \text { Ottawa ON K1A ON4 }\end{array} & \begin{array}{l}\text { 395, rue Wellington } \\ \text { Ottawa ON K1A ON4 } \\ \text { Canada }\end{array}\end{array}$

Your file Votre référence

ISBN: 0-494-00798-2

Our file Notre référence

ISBN: 0-494-00798-2

NOTICE:

The author has granted a nonexclusive license allowing Library and Archives Canada to reproduce, publish, archive, preserve, conserve, communicate to the public by telecommunication or on the Internet, loan, distribute and sell theses worldwide, for commercial or noncommercial purposes, in microform, paper, electronic and/or any other formats.

The author retains copyright ownership and moral rights in this thesis. Neither the thesis nor substantial extracts from it may be printed or otherwise reproduced without the author's permission.
AVIS:

L'auteur a accordé une licence non exclusive permettant à la Bibliothèque et Archives Canada de reproduire, publier, archiver, sauvegarder, conserver, transmettre au public par télécommunication ou par l'Internet, prêter, distribuer et vendre des thèses partout dans le monde, à des fins commerciales ou autres, sur support microforme, papier, électronique et/ou autres formats.

L'auteur conserve la propriété du droit d'auteur et des droits moraux qui protège cette thèse. $\mathrm{Ni}$ la thèse ni des extraits substantiels de celle-ci ne doivent être imprimés ou autrement reproduits sans son autorisation.
In compliance with the Canadian

Privacy Act some supporting forms may have been removed from this thesis.

While these forms may be included in the document page count, their removal does not represent any loss of content from the thesis.
Conformément à la loi canadienne sur la protection de la vie privée, quelques formulaires secondaires ont été enlevés de cette thèse.

Bien que ces formulaires aient inclus dans la pagination, il n'y aura aucun contenu manquant.

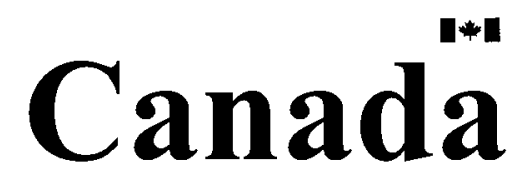




\begin{abstract}
This study investigates the effect of modifying refractory addition levels on the solidification behaviour of SX superalloys systems. Specifically, a series of six Ni-base alloy compositions are set in a controlled manner, such that the chemical microsegregation effects of Re, W, and Ru can be independently assessed. Fabrication of grain-free SX bars from each alloy composition is achieved utilizing a modified Bridgman casting process, with subsequent compositional analysis of the solidification structures via electron microprobe analysis (EPMA) methods. Further validation of these EPMA microsegregation results are supported by means of eutectic phase fraction analysis and differential scanning calorimetry (DSC) methods. Qualitative partitioning results indicate typical SX alloy segregation behavior with elements such as $\mathrm{Cr}, \mathrm{Co}, \mathrm{Re}$, Mo, and $\mathrm{W}$ all segregating towards the dendrite core regions, while the $\gamma^{\prime}$ forming elements of $\mathrm{Al}, \mathrm{Ti}$, and $\mathrm{Ta}$ partition to the interdendritic $\gamma-\gamma^{\prime}$ eutectic regions. Both $\mathrm{Ni}$ and $\mathrm{Ru}$ exhibit ideal segregation behaviour with no favorable partitioning to either liquid or solid phase. Quantitative EPMA results indicate that as the nominal Re level increases, the severity of microsegregation to the dendrite core regions rises dramatically for Mo, $\mathrm{Cr}$, and $\mathrm{Re}$. Evidence is presented that demonstrates the role that $\mathrm{Ru}$ plays in counteracting the microsegregation effects of both increased Re and higher overall total refractory levels. In addition to experimental trials, chemical segregation predictions are also presented for the alloy system, utilizing several solid-liquid phase equilibria models generated using complex thermodynamic databases. Using this CALPHAD approach, a comparison of the computational predictions and the actual experimental segregation results is also provided for discussion.
\end{abstract}




\section{Acknowledgements}

I would like to express my sincere gratitude to my thesis supervisor, Dr. Jonathan Beddoes, for his continued guidance and advice while working on this stimulating project. He has constantly supported me in my research endeavors and has always given me free rein to make my own mistakes. Through his direction and by his example, he has unknowingly influenced my career aspirations to become a dedicated "researcher" while still retaining the pride of an engineer.

I would also like to thank my colleague, Dr. Henry Saari for his invaluable assistance with the single crystal casting facility located at Carleton University. His sympathetic ear and moral support were key to preventing many nervous breakdowns during catastrophic failures. Many thanks to Dr. Bill Thompson and Dr. Kevin Jaansalu for their extreme patience while trying to explain the black magic of computational thermodynamics of multi-component systems. Their expertise, and Kevin's superb thermodynamic database saved me years of toil and turmoil. I would also like to thank Dr. Peter Au, who made it possible for the completion of this thesis in a reasonable amount of time. Extreme gratitude to Mr. Peter Jones for his invaluable expertise and assistance in the microprobe analysis studies. Finally, and certainly not least, special thanks to my future wife Stephanie, who has stood by me all these years and has made me realize that there are better things in life than work. 


\section{Table of Contents}

LIST OF FIGURES ........................................................................................................................ VI

LIST OF TABLES.............................................................................................................................................. XXII

LIST OF APPENDICES .........................................................................................................................XXIV

NOMENCLATURE ..................................................................................................................................... XXV

1. INTRODUCTION ................................................................................................................................

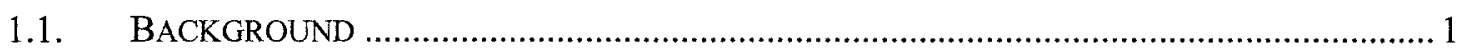

1.2. PRESENT SX SUPERALLOY DESIGN CONSTRAINTS .............................................. 2

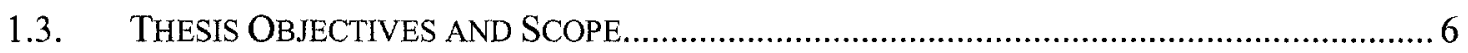

2. Literature Review - Properties and Processing of Gas Turbine Blades ........9

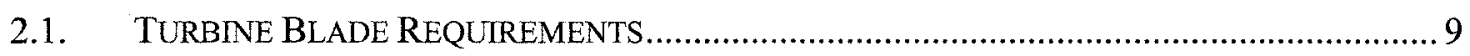

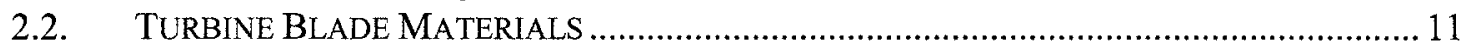

2.2.1. HISTORY OF SINGLE CRYSTAL SUPERALLOYS IN GAS TURBINE ENGINES.......... 13

2.2.1.1. First Generation Single Crystals............................................................. 13

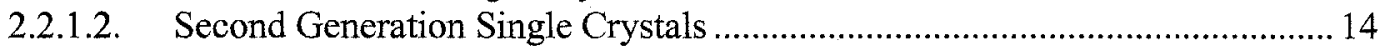

2.2.1.3. Third Generation Single Crystals ............................................................. 15

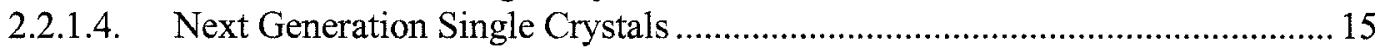

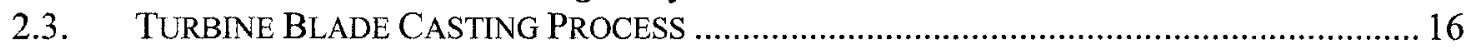

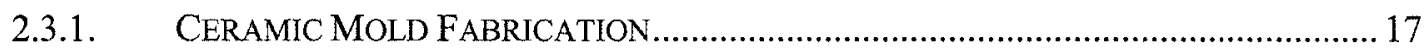

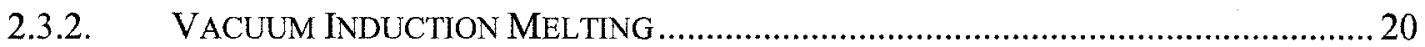

2.3.3. DIRECTIONAL SOLIDIFICATION CASTING PROCESS ............................................ 22

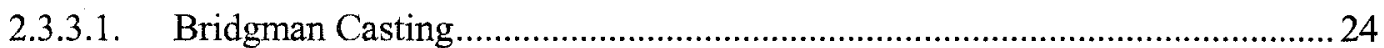

2.3.3.1.1. Single Crystal Selection Process ............................................................2 26

3. Literature ReVieW - Microstructural Stability OF SX Materials ............... 28

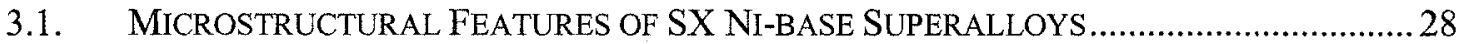

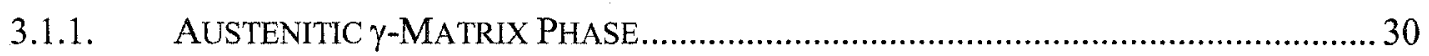

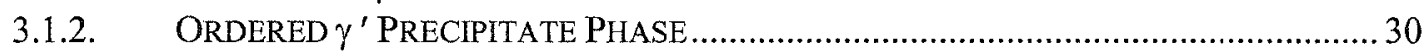

3.1.2.1. Changes in $\gamma^{\prime}$ Morphology After Service Exposure ........................................ 32

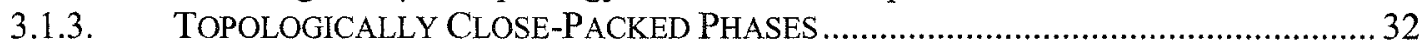

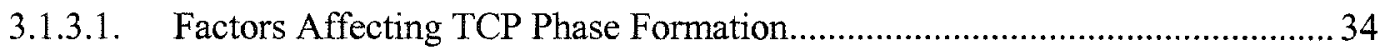

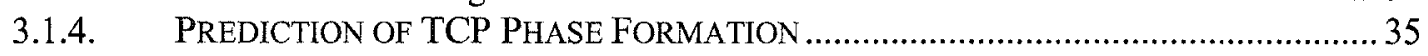

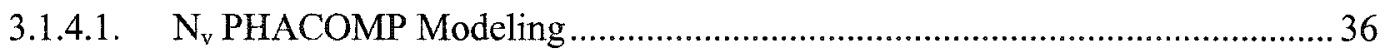

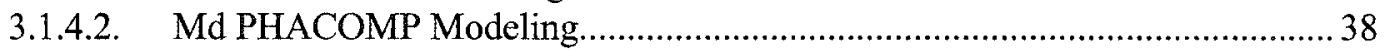

3.1.4.3. Empirical Based Modeling .................................................................... 41

3.1.4.4. Computational Thermodynamic Modeling ................................................. 43

3.1.4.4.1. Fundamentals of Phase Diagram Thermodynamics................................. 44

3.1.4.4.2. Thermodynamic Modeling of Binary Solution Phases ............................. 48

3.1.4.4.3. Interpolation of Excess Gibbs Energy to Multi-Component Systems ...... 54

4. Literature ReVIEW - Microsegregation IN SX SUPERAlloys ............................... 57 


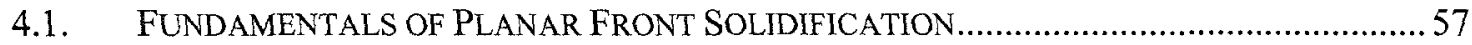

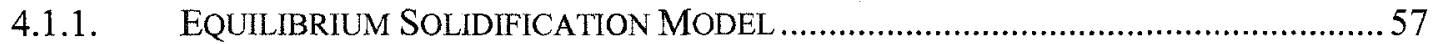

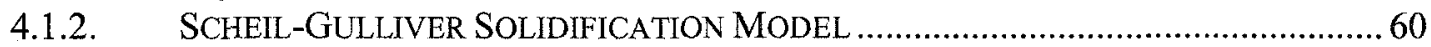

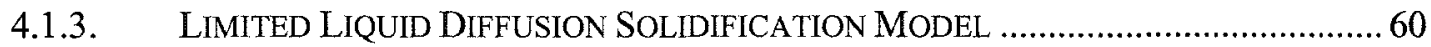

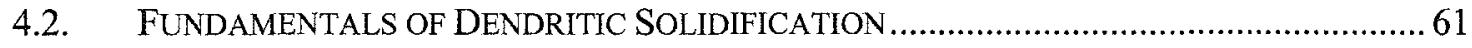

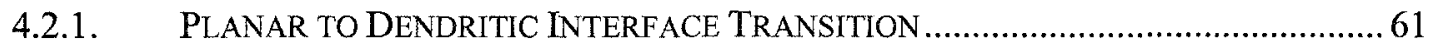

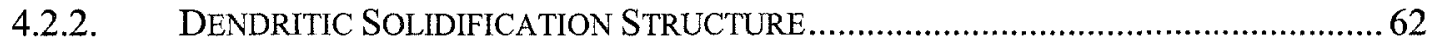

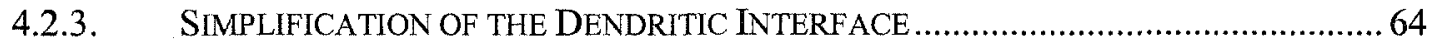

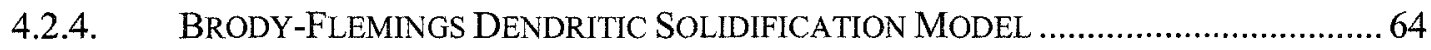

4.3. OBSERVED MICROSEGREGATION IN INDUSTRIAL SX SUPERALLOYS ..........................66

5. EXPERIMENTAL MATERIALS ....................................................................................... 70

5.1. MATERIAL SELECTION AND PROCUREMENT ….......................................................... 70

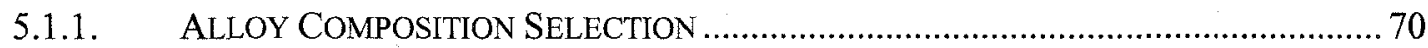

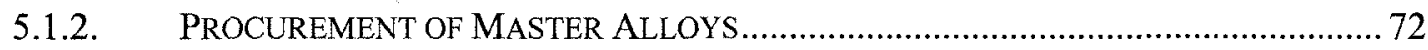

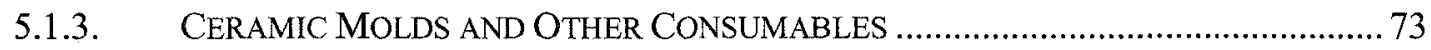

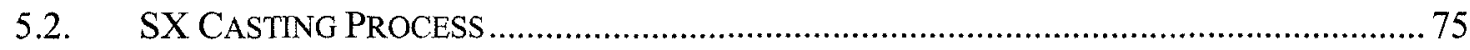

5.2.1. CARLETON UNIVERSITY DIRECTIONAL SOLIDIFICATION CASTING FACILITY .... 75

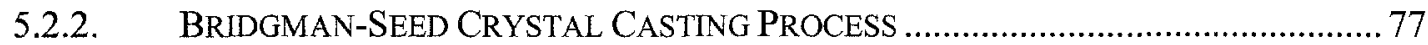

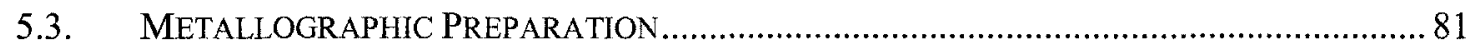

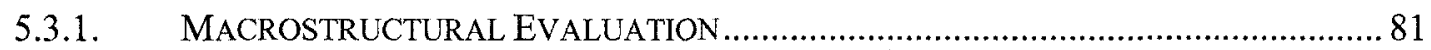

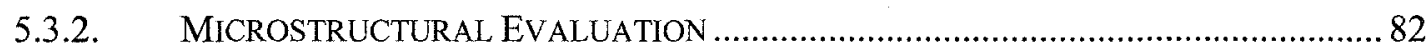

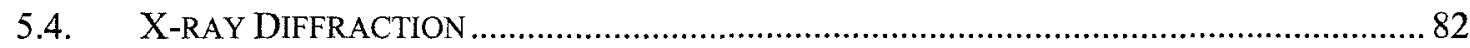

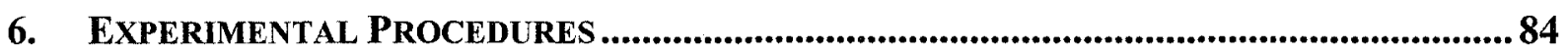

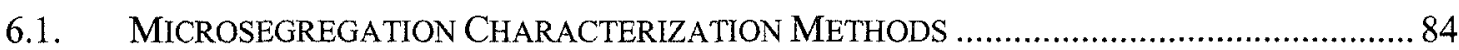

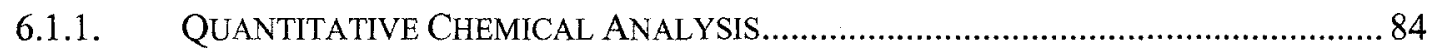

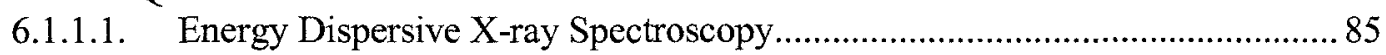

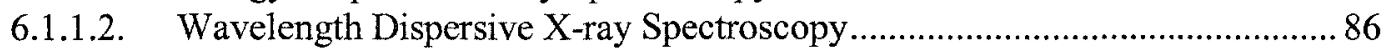

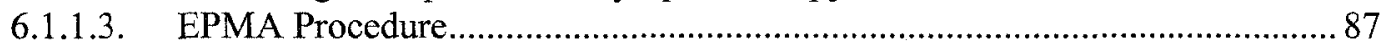

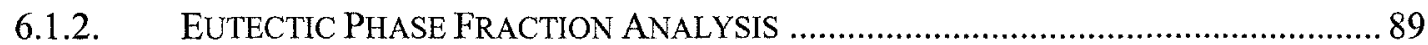

6.1.3. DSC ANALYSIS AND THERMO-PHYSICAL CHARACTERIZATION ..........................90

6.1.4. THERMODYNAMIC SOLIDIFICATION MODELING ...............................................92

7. Development of the Bridgman Casting Process Parameters .............................96

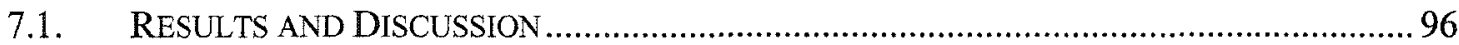

7.1.1. QUALIFICATION OF SEED CRYSTAL CASTING PROCESS ....................................96

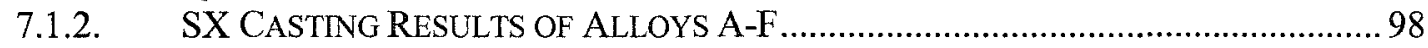

7.1.2.1. Determination of Superheat Temperature ........................................................ 98

7.1.2.2. Determination of the Protective Casting Environment ................................ 100

7.1.2.3. Final Optimization of Superheat Temperature ............................................. 102

8. Macro/Microstructural Response to Bridgman Casting Process............... 104

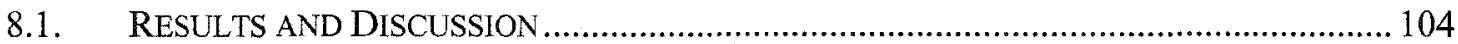

8.1.1. FINAL SOLIDIFICATION MACROSTRUCTURES ................................................... 104

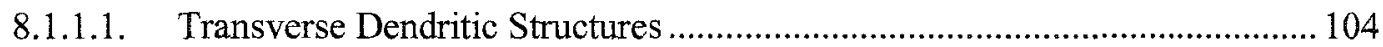

8.1.1.2. Longitudinal Dendritic Structures ............................................................ 108

8.1.1.3. Three Dimensional Images of Solidification Structures .............................. 109

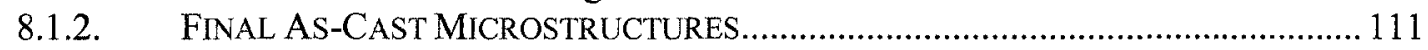

8.1.2.1. Transition of $\gamma^{\prime}$ Precipitate Structure Near the Dendritic Boundaries ............ 111 
8.1.2.2. Primary $\gamma^{\prime}$ Morphology Within the Transverse Dendritic Structure ............. 114

8.1.2.3. Primary $\gamma^{\prime}$ Morphology Across the Longitudinal Solid-Liquid Interface ..... 120

8.1.2.4. Various Eutectic Morphologies Within the Interdendritic Region................ 121

8.1.2.5. Minor Carbide Precipitate Phases .............................................................. 123

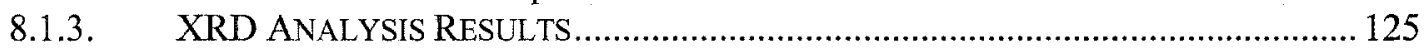

9. EPMA Microsegregation MEASUREMENTS ...................................................... 127

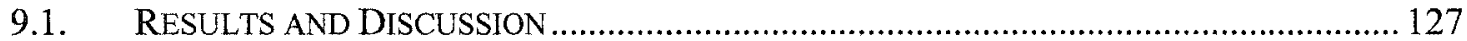

9.1.1. CHEMICAL SEGREGATION COEFFICIENT ....................................................... 127

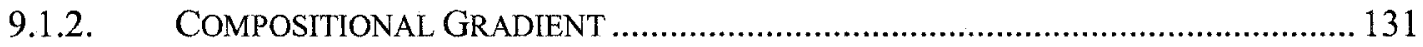

9.1.2.1. EPMA Profile: Parallel to Secondary Arms ............................................... 132

9.1.2.2. EPMA Profile: Diagonally Across the Core-Eutectic Region ....................... 133

9.1.2.3. EPMA Profile: Across the Width of the Secondary Arm............................... 136

10. DSC ANALYSIS AND THERMO-PHYSICAL ChaRACTERIZATION..................................138

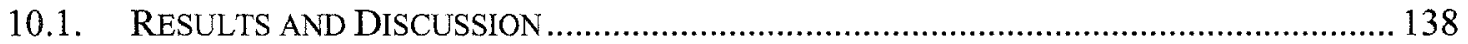

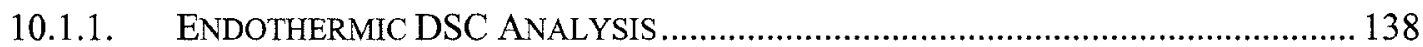

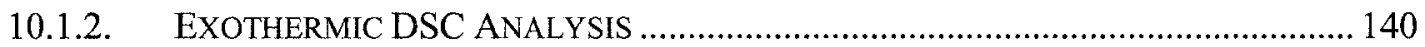

10.1.3. ADDITIONAL THERMO-PHYSICAL CHARACTERIZATION RESULTS .................... 142

10.1.3.1. Characterization of $\mathrm{T}_{0}$ by Furnace-Quenching Trials .............................. 142

10.1.3.2. Microsegregation Inspection Using In-situ DSC Solutioning .................. 144

11. Eutectic Phase Fraction Analysis .................................................................... 147

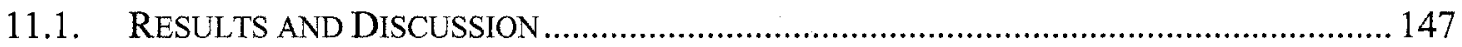

11.1.1. EUTECTIC FRACTION WITH RESPECT TO NOMINAL ALLOY LEVELS ................. 148

11.1.2. EUTECTIC FRACTION WITH RESPECT TO INTERDENDRITIC LEVELS .................... 149

12. Thermodynamic Solidification PREDICTIONS .................................................151

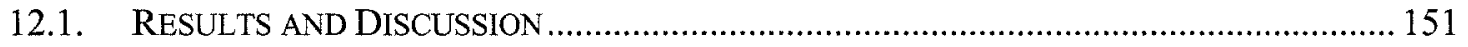

12.1.1. TRANSFORMATION TEMPERATURE PREDICTIONS ........................................... 151

12.1.2. PHASE COMPOSITION PREDICTIONS .............................................................. 153

12.1.3. COMPARISON OF MEASURED AND PREDICTED SEGREGATION COEFFICIENTS.. 154

12.1.4. SCHEIL-GULLIVER SOLIDIFICATION BEHAVIOUR.......................................... 155

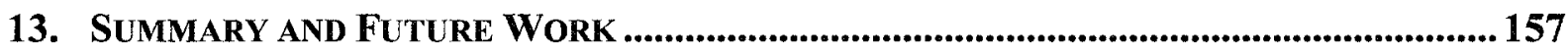

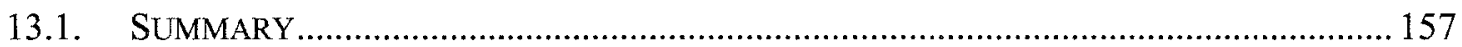

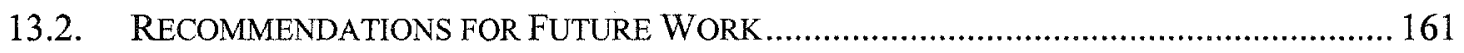

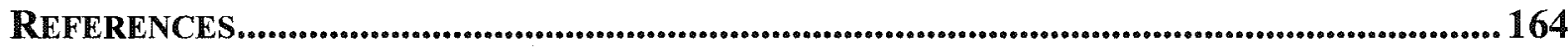

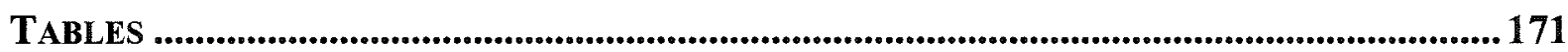

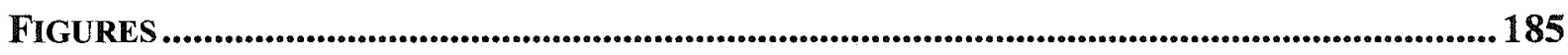

APPENDIX A: FUNDAMENTALS OF CALPHAD MODELING.................................................. 314

APPENDIX B: 1-SigMa ERRoR ANALYSIS OF MICROPROBE RESUlTS ............................. 326 


\section{List of Figures}

FIGURE 1: REPRESENTATION OF THE MICROSEGREGATION PATTERN TYPICAL IN MOST ASCAST SX SUPERALLOYS ILLUSTRATING PREFERENTIAL PARTITIONING OF SPECIFIC REFRACTORY ELEMENTS TO THE CORE AND $\gamma^{\prime}$ ELEMENTS TO INTERDENDRITIC (ID) REGIONS. 186

FIGURE 2: SCHEMATIC OF THE TYPICAL ROTATING COMPONENTS IN A GAS TURBINE ENGINE (ADAPTED FROM CERVENKA) [15]. 186

FIGURE 3: CROSS-SECTIONAL MAP OF JET ENGINE ILLUSTRATING THE TEMPERATURE AND PRESSURE PROFILE FROM THE COMPRESSOR SIDE TO THE TURBINE SECTION [15].

FIGURE 4: SCHEMATIC ILLUSTRATING THE PROXIMITY OF THE NOZZLE GUIDE VANE AND $1^{\text {ST }}$ STAGE BLADE SECTION TO THE COMBUSTION FLAME [16].

FIGURE 5: TYPICAL GAS TURBINE BLADE 188

FIGURE 6: (A) TEMPERATURE AND (B) STRESS PROFILES FOR A TYPICAL GAS TURBINE BLADE [17] 188

FIGURE 7: TEMPERATURE EVOLUTION OF SUPERALLOY BLADE MATERIALS [25]. 189

FigURE 8: EVOLUTION OF SUPERALLOY BLADE MICROSTRUCTURES [14]. 190

FiguRE 9: DisPOSABLE WAX PATTERN USED TO CAST FOUR SX BLADES IMPLEMENTING A PIGTAIL SX SELECTOR [35].

FIgURE 10: ALTERNATIVE MOLD METHOdS FOR PRODUCING SX BLADES, A) PIGTAIL SELECTOR, B) TWO-TURN SELECTOR, AND C) SEED CRYSTAL SELECTOR [33].. 192

FiguRE 11: CERAMIC MOLD USED FOR SX BLADE CASTING [35] ............................... 192

Figure 12: SCHEMATIC ILLUSTRATION OF THE INVESTMENT CASTING PROCESS [33]...... 193

FIGURE 13: SCHEMATIC OF VIM PROCESS USED TO PRODUCE CLEAN SUPERALLOY MASTER ALLOY (ADAPTED FROM SCHAFRIK) [24]. 
FiguRE 14: SCHEMATIC OF SIMPLE DS CASTING PROCESS COOLED BY A HEAT SINK FROM THE BOTTOM END. GROWTH DIRECTION OPPOSES THE DIRECTION OF HEAT-FLUX.

FIGURE 15: CONSARC INDUSTRIAL BRIDGMAN CASTING FURNACE [44] ........................ 195

FIGURE 16: INTERNAL COMPONENTS OF A TYPICAL BRIDGMAN CASTING FURNACE [33]. 195

FigURE 17: GRAIN STRUCTURE EVOLUTION USING PROBABILISTIC MODELING, A) TURBINE BLADE STRUCTURE CAST DIRECTLY ON THE CHILL PLATEN WITH NO SX GRAIN SELECTOR, B) GROWTH OF A SINGLE $<100>$ GRAIN (BLUE) AT THE EXPENSE OF THE LESS FAVORABLY ORIENTED GRAINS WITHIN A PIGTAIL [46] ..................... 196

Figure 18: EVoLUtION OF Ni-BASE SUPERALLOY MICROSTRUCTURE [47]..................... 196

FIGURE 19: INCREASE IN TEMPERATURE-STRENGTH CAPABILITY OF SUPERALLOYS WITH

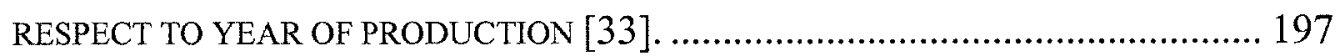

FIGURE 20: FCC CRYSTAL STRUCTURE OF THE AUSTENITIC $\gamma$-MATRIX PHASE. ................. 198

FIGURE 21: ORDERED FCC CRYSTAL STRUCTURE OF THE L $1_{2}-\gamma^{\prime}$ INTERMETALLIC PRECIPITATE PHASE 198

FIGURE 22: SCHEMATIC ILLUSTRATING THE CHANGE IN $\gamma^{\prime}$ MORPHOLOGY WITH INCREASING PRECIPITATE SIZE (ADAPTED FROM GROSDIDIER) [50]... 199

FIGURE 23: SEM IMAGE OF AS-CAST PWA 1484 SINGLE CRYSTAL MICROSTRUCTURE $(30,000 \mathrm{X})$. 199

FIGURE 24: CREEP STRENGTH AS A FUNCTION OF $\gamma^{\prime}$ VOLUME FRACTION [53] 200

FIGURE 25: TEMPERATURE-STRESS CROSS-SECTIONAL PROFILE OF AN AM1 SX BLADE. THE TOP TWO SEM IMAGES CORRESPOND TO THE RED COMPRESSION ZONE (30MPA), WHEREAS THE LOWER MICROGRAPHS CORRESPOND TO THE CRACKED, TENSILE ZONE (+20MPA) [6] .............................................................. 201

FIGURE 26: SEM MICROGRAPH SHOWING $\sigma$ PHASE IN RR2071 [55]................................. 202

FIGURE 27: SEM MICROGRAPH SHOWING $\mu$ PHASE IN RR2071 [55]................................ 202

FIGURE 28: SEM MICROGRAPH SHOWING P PHASE IN RR2071 [55]............................... 202

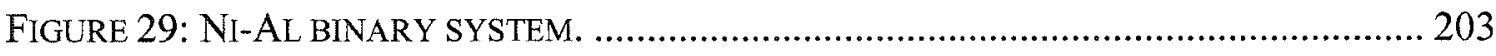

vii 
FIGURE 30: THE EFFECTS OF TEMPERATURE AND COMPOSITION ON GIBBS FREE ENERGY [71] 203

FIGURE 31: THERMODYNAMIC GEOMETRIC SCHEMES FOR INTERPOLATING BINARY POLYNOMIAL TERMS IN THE TERNARY A-B-C SYSTEM. 204

FIGURE 32: SCHEMATIC REPRESENTATION OF THE CALPHAD ASSESSMENT METHOD [86].204 FIGURE 33: SOLIDIFICATION OF AN ALLOY WITH EQUILIBRIUM AT THE SOLID-LIQUID INTERFACE: (A) EQUILIBRIUM PHASE DIAGRAM, (B) COMPOSITION PROFILE ACROSS THE INTERFACE [90]. 205

FIGURE 34: SOLUTE REDISTRIBUTION DURING EQUILIBRIUM SOLIDIFICATION (A) AT THE START, (B) AT TEMPERATURE T*, (C) AFTER SOLIDIFICATION (D) CORRESPONDING PHASE DIAGRAM. 205

FIGURE 35: SOLUTE REDISTRIBUTION DURING SCHEIL SOLIDIFICATION- NO SOLID DIFFUSION AND COMPLETE LIQUID DIFFUSION (A) AT THE START, (B) AT TEMPERATURE T*, (C) AFTER SOLIDIFICATION (D) CORRESPONDING PHASE DIAGRAM [90]. 206

FIGURE 36: SOLUTE REDISTRIBUTION IN SOLIDIFICATION WITH LIMITED LIQUID DIFFUSION AND NO CONVECTION: (A) COMPOSITION PROFILE DURING STEADY-STATE SOLIDIFICATION,(B) COMPOSITION PROFILE AFTER COMPLETE SOLIDIFICATION, (C) CORRESPONDING PHASE DIAGRAM [90] 207

FIGURE 37: SCHEMATIC OF THE VARIATION IN LIQUIDUS TEMPERATURE DUE TO THE SOLUTE BOUNDARY LAYER IN THE LIQUID [89]. 208

Figure 38: Transition of INTERFACE STABility: (A) Stable PlanE FRont. (B) UNSTABLE PLANE FRONT DUE TO CONSTITUTIONAL SUPERCOOLING [90]. ...... 208

FIGURE 39: SHAPE TRANSITION OF GROWTH STRUCTURE AS SOLIDIFICATION RATE INCREASES, (A) CELLULAR STRUCTURE, (B) PARTIAL RADIAL GROWTH, (C) MALTESE CROSS AND (D) DENDRITIC STRUCTURE [90]. 208

FIGURE 40: TYPICAL SX SUPERALLOY AS-CAST DENDRITIC STRUCTURE; (A) SEM MICROGRAPH DEPICTING THE TRANSVERSE MALTESE-CROSS MORPHOLOGY, (B) SEM MICROGRAPH SHOWING THE LONGITUDINAL CROSS-SECTION ALONG THE

viii 
$<100>$ CRYSTALLOGRAPHIC DIRECTION, (C) TYPICAL AS CAST CUBOIDAL PRECIPITATE STRUCTURE.

FigurE 41: CHARACTERISTICS OF THE MUSHY ZONE IN COLUMNAR GROWTH. THE SMALL VOLUME ELEMENT OF LENGTH $\lambda / 2$, IS SIMILAR TO THE LARGER PLANAR-FRONT MODELS (E.G. FIGURE 34). THIS VOLUME ELEMENT SOLIDIFIES PERPENDICULAR TO THE PRIMARY DENDRITE AXIS (I.E. <100>) OF THE SX ALLOY. THE DISTANCE $A$ IS DEFINED AS THE LENGTH OF THE MUSHY ZONE. NOW THE VALUE OF FS CORRESPONDS TO THE FRACTION OF THE SOLID IN THE SMALLER VOLUME ELEMENT [43].

FIGURE 42: MiCROSEGREGATION OBSERVED IN SX SUPERALLOY CMSX-10; (A) OPTICAL MICROGRAPH SHOWING DENDRITIC SOLIDIFICATION STRUCTURE, (B) SEM IMAGE OF SAME THE STRUCTURE SHOWING LARGE FRACTION OF COARSE INTERDENDRITIC EUTECTIC PHASE[].

FIGURE 43: SEM MICROGRAPH OF AM1 ALLOY SHOWING BRIGHTER DENDRITE CORES DUE TO HIGH LOCALIZED CONCENTRATION OF W. DARK REGION SURROUNDING DENDRITES IS THE W DEPLETED REGIONS. THE DARKER INTERDENDRITIC PHASE CONTAINS COARSE EUTECTIC $\gamma^{\prime}$ PRECIPITATES [6].

FIGURE 44: (A) ELECTRON MICROGRAPH OF LONGITUDINAL CROSS-SECTION OF AS-CAST AM1, (B) EPMA LINE SCAN RESULTS FOR A 1MM SAMPLING SIZE (C) FOR A 10MM SAMPLING SIZE WITH A CLOSE-UP OF THE MO, W AND TA PROFILES SHOW IN (D) [6]. 212

FIGURE 45: DISTRIBUTION OF CERTAIN ALLOYING ELEMENTS AS A FUNCTION OF FRACTION SOLID IN DIRECTIONALLY SOLIDIFIED AM1. THE F $=0$ POINT CORRESPONDS TO THE LOCATION OF THE DENDRITE CORE AND $F_{S}=1$ IS THE LOCATION OF INTERDENDRITIC EUTECTIC PHASE [6]. 213

Figure 46: DTA of AM1 AT A HeAting RATE of $12.5^{\circ} \mathrm{C} / \mathrm{MIN}[6]$. 213

FIGURE 47: SEM IMAGE OF MC2 ALLOY SHOWING THE PRECIPITATION OF THE M-PHASE WITHIN THE W-RICH DENDRITE CORE REGIONS AFTER HIGH TEMPERATURE EXPOSURE [6]. 
FIGURE 48: AS-RECEIVED VACUUM CAST BARS FROM SOPHISTICATED ALLOYS............. 214

FIGURE 49: DOUBLE OPEN-ENDED ALUMNA MOLD USED FOR SX CASTING................... 214

FIGURE 50: CERAMIC MOLD SUPPORT-STAND FOR 7/8-INCH DIAMETER MOLDS.............. 215

FIGURE 51: NEW ZIRCONIA BAFFLES PRIOR TO INSTALLATION.................................... 216

FIGURE 52: MOLD ASSEMBLY SITTING IN SUPPORT STAND ON TOP OF THE COPPER CHILL

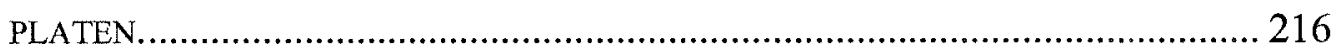

FIGURE 53: CARLETON UNIVERSITY DS FURNACE. ............................................ 217

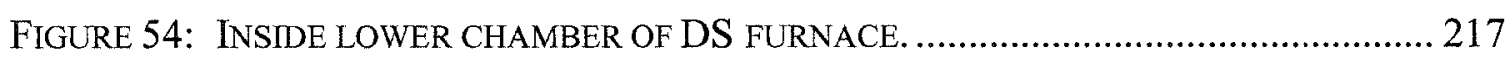

FIGURE 55: SCHEMATIC OF EXPERIMENTAL BRIDGMAN-SEED CASTING SET-UP.............. 218

FIGURE 56: SCHEMATIC OF TEMPERATURE GRADIENT $\left(\mathrm{G}_{\mathrm{L}}\right)$ WITHIN THE CASTING AS

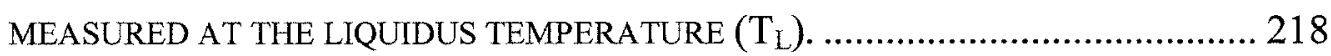

FIGURE 57: LEFT: TYPICAL SOLIDIFICATION BEHAVIOUR OF AN INDIVIDUAL DENDRITE. AT THE START OF SOLIDIFICATION, TIME $T_{S}$, THE NUCLEATION OF THE DENDRITE CORE FIRST APPEARS WITH THE COMPOSITION, $\mathrm{C}_{\text {CORE. AT THE END OF }}$ SOLIDIFICATION, TIME $T_{F}$, THE FINAL INTERDENDRITIC LIQUID SOLIDIFIES TO FORM THE $\gamma-\gamma^{\prime}$ EUTECTIC PHASE OF COMPOSITION C CID. RIGHT: A PSEUDO PHASE DIAGRAM ILLUSTRATING THE SOLIDIFICATION PATH OF THE ALLOY OF COMPOSITION, $\mathrm{C}_{0}$, FROM THE LIQUID PHASE THROUGH THE SOLID+LIQUID PHASE FIELD UNTIL THE FINAL SOLIDIFICATION TEMPERATURE OF THE SOLIDUS IS REACHED AS TS. THE MICROSEGREGATION COEFFICIENT, $\mathrm{K}^{\prime}$, IS DEFINED AS THE RATIO OF THE COMPOSITION OF THE $1^{\text {ST }}$ SOLID PHASE THAT FORMS TO THE COMPOSITION OF THE LAST LIQUID PHASE TO SOLIDIFY. 219

Figure 58: SEM IMAGE OF UNETCHED ALLOY B SOLIDIFICATION STRUCTURE USING THE BSE DETECTOR OF THE PHILIPS XL-30S SEM. 220

FIGURE 59: EDX SPECTRUM SHOWING PEAK OVERLAP OF W, RE AND TA FOR A REPRESENTATIVE SPOT ANALYSIS PERFORMED ON ALLOY B....................... 220

FIGURE 60: EDX SPECTRUM FOR A HIGH TEMPERATURE SUPERALLOY [97] ..................... 221 
FIGURE 61: WDX SPECTRUM FOR THE SAME SUPERALLOY, A) SCAN USING LIF CRYSTAL AND B) SCAN USING TAP CRYSTAL [97]. 222

Figure 62: Camebax MBX Electron Microprobe located at Carleton

UNIVERSITY EQUIPPED WITH 4 WDX SPECTROMETERS 223

FIGURE 63: SCHEMATIC OF A TYPICAL ELECTRON MICROPROBE HIGHLIGHTING THE WDX DETECTOR ARRANGEMENT. 223

FIGURE 64: SCHEMATIC OF EPMA SPOT-ANALYSIS PROCEDURE, ILLUSTRATING THE SAMPLING METHOD USED TO DETERMINE THE DENDRITE CORE AND INTERDENDRITIC $\gamma-\gamma^{\prime}$ EUTECTIC COMPOSITIONS 224

FIGURE 65: SCHEMATIC OF EPMA LINE SCAN PROCEDURE, ILLUSTRATING THE DIFFERENT CRYSTALLOGRAPHIC DIRECTIONS USED TO DETERMINE COMPOSITIONAL GRADIENTS ACROSS THE DENDRITIC SOLIDIFICATION STRUCTURE 224

FIGURE 66: SCHEMATIC OF SOLUTE REJECTION ACROSS THE SOLID-LIQUID INTERFACE DURING DENDRITIC GROWTH. AT TIME, $T_{E}$, THE LIQUID COMPOSITTON REACHES THE FINAL EUTECTIC COMPOSITION AND THE REMAINING LIQUID SOLIDIFIES AS THE $\gamma-\gamma^{\prime}$ EUTECTIC PHASE. 225

FIGURE 67: SCHEMATIC OF THE DSC SAMPLE PREPARATION PROCEDURE 226

Figure 68: A) Netzsch ${ }^{\text {TM }}$ 404-C Pegasus DSC, B) Close-up of DSC MEASURING-HEAD SHOWING THE REFERENCE AND SPECIMEN CRUCIBLE LOCATIONS. 226

Figure 69: PARTIAL LONGITUdinal CROSS-SECTION OF SX PWA-1484 TEST BAR SHOWING DENDRITIC TRANSITION FROM THE SEED, THROUGH THE MUSHY ZONE INTO THE NEW SX REGION. 227

FIGURE 70: TRANSVERSE SECTIONS OF SX PWA 1484 TEST BAR SHOWING DENDRITIC TRANSITION FROM THE SEED TO THE NEW SX GROWTH REGION. APPARENT IN THE MICROGRAPHS IS THE CONSERVATION OF DENDRITE ORIENTATION THROUGHOUT THE NEW SX BAR. 228

FIGURE 71: MORPHOLOGY AND DISTRIBUTION OF $\gamma^{\prime}$ IN CARLETON UNIVERSITY TRIAL SX CASTING (HEAT-TREATED PWA-1484). 229 
Figure 72: MORPHOLOGY AND DISTRIBUTION OF $\gamma^{\prime}$ IN PCC SX CASTING (HEAT-TREATED PWA-1484)

FIGURE 73: TRANSVERSE MICROGRAPH OF SX-A1 SHOWING THE DIRECTIONALLY SOLIDIFIED COLUMNAR GRAIN STRUCTURE DUE TO INSUFFICIENT SUPERHEAT CONDITIONS. 230

FIGURE 74: HIGHER MAGNIFICATION IMAGE OF SX-A1 SHOWING THE GRAIN BOUNDARIES HEAVILY DECORATED IN THE $\gamma-\gamma^{\prime}$ EUTECTIC PHASE. 230

FIGURE 75: UNSUCCESSFUL CASTING OF ALLOY A DUE TO INSUFFICIENT SUPERHEAT PRESENT TO PARTIALLY MELT THE SEED.

Figure 76: PARTIAL LONGITUdinAL CROSS-SECTION OF BOTTOM-END OF CAST BAR SX-A2, ILLUSTRATING TRANSITION FROM THE LARGE DENDRITIC STRUCTURE OF SEED MATERIAL, THROUGH THE PARTIALLY MELTED MUSHY ZONE, INTO THE NEW REGION OF SX GROWTH. LARGE WHITE AREAS ARE INTERDENDRITIC $\gamma / \gamma^{\prime}$ EUTECTIC.

FIGURE 77: TRANSVERSE OPTICAL MICROGRAPH SHOWING THE MORPHOLOGY AND SIZE OF THE INTERDENDRITIC $\gamma-\gamma^{\prime}$ EUTECTIC PHASE IN COMPARISON TO THE PRIMARY $\gamma^{\prime}$ PHASE.

FIGURE 78: PHOTOGRAPH OF SX-A3 SHOWING EXCELLENT SURFACE FINISH WITH ONLY MINOR AMOUNTS OF GAS POROSITY PRESENT AT THE END OF THE CAST BAR DUE TO VACUUM ENVIRONMENT 232

Figure 79: MACROSCOPIC IMAGE OF SX-A3 ILLUSTRATING EXTENSIVE SEED MELTING TO THE BASE OF THE SEED MATERIAL. 233

FIGURE 80: CLOSE-UP OF SPURIOUS GRAIN GROWTH REGION RESULTING FROM LIQUID METAL RUN-OFF BETWEEN THE MOLD AND SX SEED.

FIGURE 81: SPURIOUS GRAIN FORMATION WITHIN THE PARTIALLY MELTED SX SEED DEPICTING THE PRESENCE OF LOW ANGLE GRAIN BOUNDARIES AND SIGNIFICANT AMOUNTS OF EUTECTIC $\gamma-\gamma^{\prime}$ PHASE. 234

FIGURE 82: UNAFFECTED SX STRUCTURE LOCATED DIRECTLY ABOVE THE GRAIN DEFECTS IN THE SEED. 
FIGURE 83: TRANSVERSE OPTICAL MICROGRAPH OF ALLOY A FROM THE MIDDLE SECTION OF THE CAST BAR. 235

Figure 84: UNETCHED VIEW OF TA-CARBIDE PHASE PRESENT IN ALLOY A (SCRIPT LIKE MORPHOLOGY). 235

Figure 85: EDX SPECTRUM OF TA-RICH CARBIDE PHASE FOUND IN ALLOY A. 236

FIGURE 86: TRANSVERSE OPTICAL MICROGRAPH OF ALLOY B FROM THE MIDDLE SECTION OF THE CAST BAR. 236

FIGURE 87: TRANSVERSE OPTICAL MICROGRAPH OF ALLOY C FROM THE MIDDLE SECTION OF THE CAST BAR. 237

FIGURE 88: TRANSVERSE OPTICAL MICROGRAPH OF ALLOY D FROM THE MIDDLE SECTION OF THE CAST BAR. 237

FIGURE 89: TRANSVERSE OPTICAL MICROGRAPH OF ALLOY E FROM THE MIDDLE SECTION OF THE CAST BAR. 238

FIGURE 90: CLOSE-UP VIEW OF TRANSVERSE SECTION OF ALLOY E REVEALING THE PRESENCE OF TA-RICH CARBIDE PHASE (NEEDLE-LIKE IN APPEARANCE). ........ 238

FIGURE 91: TRANSVERSE OPTICAL MICROGRAPH OF ALLOY F FROM THE MIDDLE SECTION OF THE CAST BAR. 239

FIGURE 92: LONGITUDINAL CROSS-SECTIONAL IMAGE OF THE DENDRITIC SOLIDIFICATION STRUCTURE OF ALLOY D TAKEN IN THE MID-LENGTH REGION OF THE CAST BAR. 239

Figure 93: Low-MAGNIFICATION SEM IMAGE OF ALLOY B SHOWING THE TRANSVERSE 3DIMENSIONAL MORPHOLOGY OF THE SX DENDRITIC STRUCTURE $(<100>$ OUT OF PAGE). 240

FIGURE 94: TRANSVERSE SEM IMAGE OF AN INDIVIDUAL DENDRITE FROM ALLOY B IN THE FINAL STAGES OF SX SOLIDIFICATION (INTERDENDRITIC REGION NOT PRESENT).

FigURE 95: LoW-MAGNIFICATION SEM IMAGE OF ALLOY F SHOWING THE TRANSVERSE 3DIMENSIONAL MORPHOLOGY OF THE SX DENDRITIC STRUCTURE $(<100>$ OUT OF PAGE).

xiii 
FIGURE 96: TRANSVERSE SEM IMAGE OF AN INDIVIDUAL DENDRITE FROM ALLOY F IN THE FINAL STAGES OF SX SOLIDIFICATION (INTERDENDRITIC REGION NOT PRESENT).

FIGURE 97: LOW MAGNIFICATION SEM IMAGE OF ALLOY F ALONG THE LONGITUDINAL DIRECTION, SHOWING THE DIRECTION OF CRYSTAL GROWTH AND THE EQUIDISTANT SPACING OF THE DENDRITES. 242

FiguRe 98: Close-UP VIEW OF Alloy F SHOWING THE CLOSE-PACKED STACKING OF THE SECONDARY DENDRITE ARMS AND THEIR RELATIVELY EQUAL ARM LENGTHS. 242

FIGURE 99: SECONDARY ELECTRON SEM IMAGES OF TRANSVERSE DENDRITIC STRUCTURES of Alloy A-F as Resolved using the $\gamma$-Matrix eXtraction etchant. All SIX IMAGES DEMONSTRATE A LIGHTER DENDRITIC INTERIOR SURROUNDED BY A DARKER GREY TRANSITION BOUNDARY LAYER. 243

FIGURE 100:VARIATION IN PRIMARY $\gamma^{\prime}$ SIZE ALONG THE DENDRITIC STRUCTURE OF ALLOY A. FINER $\gamma^{\prime}$ STRUCTURE EXISTS WITHIN THE LIGHTER COLOURED INTERIOR WITH A NOTICEABLY LARGER $\gamma^{\prime}$ SIZE WITHIN THE DARK GREY BOUNDARY. 244

FIGURE 101: TRANSITION SIZES IN PRIMARY $\gamma^{\prime}$ PRECIPITATE: 1) FINE-UNIFORM MORPHOLOGY LOCATED WITHIN THE LIGHTER DENDRITE INTERIORS, 2) COARSE $\gamma$ ' WITHIN THE DARK GREY BOUNDARIES OF THE DENDRITES, AND 3) VERY FINE $\gamma$ ' LOCATED IMMEDIATELY ADJACENT TO RELATIVELY LARGE EUTECTIC $\gamma^{\prime}$ PHASE. 245

FIGURE 102: ALLOY A $-\gamma^{\prime}$ WITHIN PRIMARY DENDRITE CORE.................................... 246

FIGURE 103: ALLOY A $-\gamma^{\prime}$ WITHIN LEFT SECONDARY DENDRITE ARM........................... 247

FIGURE 104: ALLOY A $-\gamma^{\prime}$ WITHIN RIGHT SECONDARY DENDRITE ARM. ........................ 248

FIGURE 105: ALLOY A $-\gamma^{\prime}$ WITHIN TOP SECONDARY DENDRITE ARM. .......................... 249

FIGURE 106: ALLOY A $-\gamma^{\prime}$ WITHIN BOTTOM SECONDARY DENDRITE ARM..................... 250

FIGURE 107: ALLOY B $-\gamma^{\prime}$ WITHIN PRIMARY DENDRITE CORE................................... 251

FIGURE 108: ALLOY B $-\gamma^{\prime}$ WITHIN LEFT SECONDARY DENDRITE ARM........................ 252

FIGURE 109: ALLOY B $-\gamma^{\prime}$ WITHIN RIGHT SECONDARY DENDRITE ARM....................... 253

xiv 


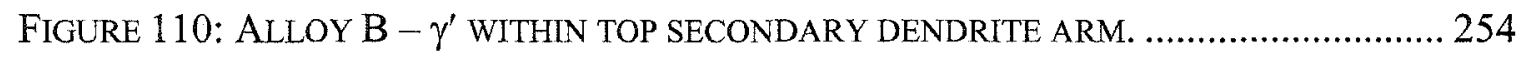

FIGURE 111: ALLOY B $-\gamma^{\prime}$ WITHIN BOTTOM SECONDARY DENDRITE ARM.................... 255

FIGURE 112: ALLOY C $-\gamma^{\prime}$ WITHIN PRIMARY DENDRITE ARM. .....................................256

FIGURE 113: ALLOY C $-\gamma^{\prime}$ WITHIN LEFT SECONDARY DENDRITE ARM.......................... 257

FIGURE 114: ALLOY $\mathrm{C}-\gamma^{\prime}$ WITHIN RIGHT SECONDARY DENDRITE ARM.......................... 258

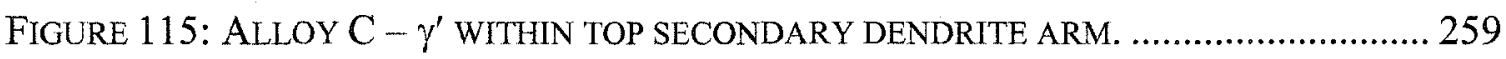

FIGURE 116: ALLOY $\mathrm{C}-\gamma^{\prime}$ WITHIN BOTTOM SECONDARY DENDRITE ARM.......................260

FIGURE 117: ALLOY D $-\gamma^{\prime}$ WITHIN PRIMARY DENDRITE ARM ................................ 261

FIGURE 118: ALLOY D $-\gamma^{\prime}$ WITHIN LEFT SECONDARY DENDRITE ARM........................... 262

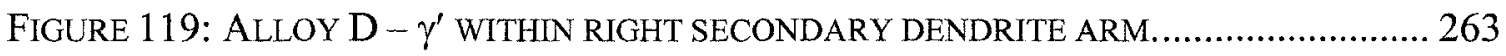

FIGURE 120: ALLOY D $-\gamma^{\prime}$ WITHIN TOP SECONDARY DENDRITE ARM. .......................... 264

FIGURE 121: ALLOY D $-\gamma^{\prime}$ WITHIN BOTTOM SECONDARY DENDRITE ARM........................265

FIGURE 122: ALLOY E $-\gamma^{\prime}$ WITHIN PRIMARY DENDRITE CORE................................. 266

FIGURE 123: ALLOY E $-\gamma^{\prime}$ WITHIN LEFT SECONDARY DENDRITE ARM.......................... 267

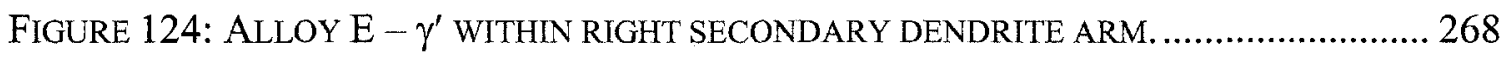

FIGURE 125: ALLOY E $-\gamma^{\prime}$ WITHIN TOP SECONDARY DENDRITE ARM.............................269

FIGURE 126: ALLOY E $-\gamma^{\prime}$ WITHIN BOTTOM SECONDARY DENDRITE ARM. ...................2 270

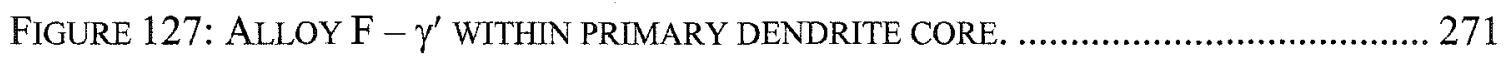

FIGURE 128: ALLOY F $-\gamma^{\prime}$ WITHIN LEFT SECONDARY DENDRITE ARM. ....................... 272

FIGURE 129: ALLOY F $-\gamma^{\prime}$ WITHIN RIGHT SECONDARY DENDRITE ARM. ........................ 273

FIGURE 130: ALLOY F - $\gamma^{\prime}$ WITHIN TOP SECONDARY DENDRITE ARM........................... 274

FIGURE 131: ALLOY F $-\gamma^{\prime}$ WITHIN BOTTOM SECONDARY DENDRITE ARM. ..................... 275

Figure 132: Precipitate STRUCTURE IN THE LONGITUdinAL DiRECTION. A) LoW MAGNIFICATION IMAGE OF ALLOY E SHOWING TRANSITION FROM THE PWA1484 SEED, ACROSS THE MUSHY ZONE, INTO THE NEW SX GROWTH REGION, B) $\gamma$ 
' IN THE NEW SX REGION, C) JUST ABOVE THE SOLID-LIQUID INTERFACE, D) WITHIN THE INTERFACE REGION, E) JUST BELOW THE INTERFACE IN THE MUSHY ZONE, F) WITHIN THE SOLID 1484 SEED STRUCTURE. 276

FIGURE 133: TYPICAL EUTECTIC $\gamma-\gamma^{\prime}$ MORPHOLOGY COMMONLY SEEN WITHIN THE INTERDENDRITIC REGION OF ALLOYS A-F. REGION A: EUTECTIC CAP IS THE COARSE FAN STRUCTURE OF $\gamma^{\prime}$ THAT OCCURS DURING THE FINAL STAGES OF EUTECTIC GROWTH, REGION B: EUTECTIC CORE CONTAINS EXTREMELY FINE EUTECTIC $\gamma^{\prime}$ DURING THE INITIAL GROWTH STAGES.

Figure 134: Alternative eutectic StRucture obServed in Alloy A. The STRUCTURE APPEARS TO BE SHORT $\gamma$-LIKE RODS IN A MATRIX OF POSSIBLY $\gamma^{\prime}$ (RODS HAVE BEEN REMOVED DURING ETCHING)

FIGURE 135: EUTECTIC STRUCTURE OBSERVED IN A RAPIDLY COOLED Ni-27.6 AL-9.7 TA ALLOY. CONSISTS OF $\beta$ (NIAL) RODS $\mathrm{N}$ A $\delta\left(\mathrm{NI}_{3}\right.$ TA) MATRIX [100]. 279

FIGURE 136: BACK-SCATTERED ELECTRON SEM IMAGES OF TRANSVERSE DENDRITIC STRUCTURES OF ALLOY A-F. THE PRESENCE OF SMALL AMOUNTS OF TA-RICH CARBIDE PHASE (BRIGHT WHITE IN COLOUR) APPEARS N MOST OF THE ALLOYS, BUT IS SLIGHTLY HIGHER IN ALLOYS A AND E 280

FIGURE 137: (A) SCRIPT-LIKE TA-RICH CARBIDE MORPHOLOGY OBSERVED WITHIN ALLOY A, (B) LARGE NEEDLE-LIKE MORPHOLOGY LOCATED WITHIN THE EUTECTIC $\gamma^{\prime}$ OF ALLOY E. 281

FIGURE 138: XRD $2 \theta$ DIFFRACTION PATTERNS FOR ALLOYS A-F SHOWING A PREFERRED FCC SINGLE CRYSTAL STRUCTURE. 282

FIGURE 139: XRD POWDER DIFFRACTION PATTERN FOR THE $\gamma$-PHASE [102] ................ 282

FIGURE 140: XRD POWDER DIFFRACTION PATTERN FOR THE $\gamma^{\prime}$ PHASE [102] .................. 283

Figure 141: SEgREgation BeHAVIOR of Alloys A-F. THE K' VALUES GREATER THAN UNITY INDICATE SEGREGATION TO THE DENDRITE CORES, LESS THAN UNITY INDICATES INTERDENDRITIC SEGREGATION 283

xvi 
Figure 142: MeAsured Segregation BeHAVior of Cr, Re and Mo. Alloys A-E SHOW INCREASED MICROSEGREGATION WITH ELEVATED NOMINAL RE LEVELS. ALLOY F SHOWS DECREASED SEGREGATION AS A RESULT OF AN ADDITIONAL 4 WT.\% RU 284

Figure 143: EPMA LiNE-SCAN PROFILES OF ALLOYS A-F (YELLOW LINE: DIRECTION \#1, RED LINE: DIRECTION \#3, GREEN LINE: DIRECTION \#4)... 284

FIGURE 144: EPMA COMPOSITION PROFILES OF ALLOYS A-F ALONG DIRECTION \#1. THE SCANS START AT THE END OF ONE SECONDARY ARM, PASS THROUGH THE DENDRITE CORE, TO END OF THE OPPOSITE SECONDARY ARM. EACH SCAN DEMONSTRATES RELATIVELY FLAT CONCENTRATION PROFILES, EXCEPT AT THE BEGINNING AND END OF THE SECONDARY ARMS WHERE THERE IS SOME INTERFERENCE DUE TO NEIGHBORING EUTECTIC $\gamma-\gamma^{\prime}$ 285

FIGURE 145: EPMA PROFILE FOR ALLOY A IN DIRECTION \#3 ACROSS THE DENDRITE CORE AND INTERDENDRITIC (ID) EUTECTIC REGION. 286

FIGURE 146: EPMA PROFILE FOR ALLOY B IN DIRECTION \#3 ACROSS THE DENDRITE CORE AND INTERDENDRITIC (ID) EUTECTIC REGION. 287

FIGURE 147: EPMA PROFILE FOR ALLOY C IN DIRECTION \#3 ACROSS THE DENDRITE CORE AND INTERDENDRITIC (ID) EUTECTIC REGION. 288

FIGURE 148: EPMA PROFILE FOR ALLOY D IN DIRECTION \#3 ACROSS THE DENDRITE CORE AND INTERDENDRITIC (ID) EUTECTIC REGION. 289

Figure 149: EPMA PROFILE FOR Alloy E IN DIRECTION \#3 ACROSS THE DENDRITE CORE AND INTERDENDRITIC (ID) EUTECTIC REGION. 290

FIGURE 150: EPMA PROFILE FOR ALLOY F IN DIRECTION \#3 ACROSS THE DENDRITE CORE AND INTERDENDRITIC (ID) EUTECTIC REGION. 291

FIGURE 151: EPMA PROFILE FOR ALLOY A IN DIRECTION \#4 ACROSS THE THICKNESS OF THE SECONDARY DENDRITE ARM (SDA). 292

FIGURE 152: EPMA PROFILE FOR ALLOY B IN DIRECTION \#4 ACROSS THE THICKNESS OF THE SECONDARY DENDRITE ARM (SDA). 292

xvii 
FIGURE 153: EPMA PROFILE FOR ALLOY C IN DIRECTION \#4 ACROSS THE THICKNESS OF THE SECONDARY DENDRITE ARM (SDA). 293

FIGURE 154: EPMA PROFILE FOR ALLOY D IN DIRECTION \#4 ACROSS THE THICKNESS OF THE SECONDARY DENDRITE ARM (SDA). 293

FIGURE 155: EPMA PROFILE FOR ALLOY E IN DIRECTION \#4 ACROSS THE THICKNESS OF THE SECONDARY DENDRITE ARM (SDA). 294

FIGURE 156: EPMA PROFILE FOR ALLOY F IN DIRECTION \#4 ACROSS THE THICKNESS OF THE SECONDARY DENDRITE ARM (SDA). 294

FIGURE 157: DSC ENERGETIC CURVES FOR AS-CAST ALLOY-F AT HEATING RATES OF 5, 10 AND $20^{\circ} \mathrm{C} / \mathrm{MIN}$. 295

FIGURE 158: $T_{0}$ EXTRAPOLATION FROM DSC HEATING RATE RESULTS.........................295

FIGURE 159: T $T_{1}$ EXTRAPOLATION FROM DSC HEATING RATE RESULTS. ........................ 296

FIGURE 160: TS EXTRAPOLATION FROM DSC HEATING RATE RESULTS. ........................ 296

FIGURE 161: T $T_{L}$ EXTRAPOLATION FROM DSC HEATING RATE RESULTS. ........................ 297

FiguRE 162: DSC ENERGETIC CURVES FOR AS-CAST ALLOY-F AT COOLING RATES OF 5, 10 AND $20^{\circ} \mathrm{C} / \mathrm{MIN}$. 297

Figure 163: OPTICAL MICROGRAPHS OF ALLOY F QUENCHING EXPERIMENTS: A) $\left.\left.1160^{\circ} \mathrm{C} / 2 \mathrm{HRS} / \mathrm{WQ}, \mathrm{B}\right) 1180^{\circ} \mathrm{C} / 2 \mathrm{HRS} / \mathrm{WQ}, \mathrm{C}\right) 1220^{\circ} \mathrm{C} / 2 \mathrm{HRS} / \mathrm{WQ}$. 298

FIGURE 164: MiCROGRAPHS FROM $1250^{\circ} \mathrm{C} / 2 \mathrm{HR} /$ WQ. (LEFT) OPTICAL MICROGRAPH OF ALLOY F SHOWING EXTENSIVE $\gamma^{\prime}$ SOLUTIONING AND MINOR INTERDENDRITIC MELTING. (RIGHT) SEM IMAGE SHOWING THE RESULTING $\gamma^{\prime}$ DENUDED ZONE [A] SURROUNDING THE BLOCKY EUTECTIC PHASE AND REGION B CONTAINING FINE $\gamma$ ' LOCATED WITHIN THE DENDRITIC REGION. 299

FIGURE 165: ADDITIONAL ENDOTHERMIC PEAK, $\mathrm{T}_{1}$, IDENTIFIED AFTER 10 HR HOLD AT 1280 ${ }^{\circ} \mathrm{C}$. 299

FIGURE 166: SOLUTE REDISTRIBUTION OF LOWER $\gamma^{\prime}$ SOLVUS PRECIPITATE USING 10 AND 20 HOUR SOAK TIMES. 300

xviii 
FIGURE 167: TRANSVERSE CROSS-SECTION OF AlLOYS A TO C: (LEFT) ETCHED OPTICAL IMAGES (RIGHT) BLACK \& WHITE THRESHOLD IMAGES USED TO DETERMINE THE FRACTION OF EUTECTIC PHASE PRESENT 301

FIGURE 168: TRANSVERSE CROSS-SECTION OF ALLOYS D TO F: (LEFT) ETCHED OPTICAL IMAGES (RIGHT) BLACK \& WHITE THRESHOLD IMAGES USED TO DETERMINE THE FRACTION OF EUTECTIC PHASE PRESENT. 302

FIGURE 169: EUTECTIC PHASE FRACTION AS A FUNCTION OF NOMINAL ALLOYING ADDITION LEVEL. 303

FIGURE 170: COMPARISON OF EUTECTIC PHASE FRACTION AND ASSOCIATED EUTECTIC COMPOSITION LEVELS. 303

FIGURE 171: COMPARISON OF LIQUIDUS TEMPERATURE PREDICTIONS AND DSC MEASUREMENTS. 304

FIGURE 172: COMPARISON OF SOLIDUS TEMPERATURE PREDICTIONS AND DSC MEASUREMENTS. 304

FIGURE 173: COMPARISON OF SOLIDIFICATION TEMPERATURE RANGES. 305

FIGURE 174: COMPARISON OF THE COMPOSITION PREDICTIONS FOR THE DENDRITE CORE IN

Alloy A. 305

FIGURE 175: COMPARISON OF THE COMPOSITION PREDICTIONS FOR THE DENDRITE CORE IN ALLOY B. 306

FIGURE 176: COMPARISON OF THE COMPOSITION PREDICTIONS FOR THE DENDRITE CORE IN Alloy C. 306

FIGURE 177: COMPARISON OF THE COMPOSITION PREDICTIONS FOR THE DENDRITE CORE IN ALLOY D. 307

FIGURE 178: COMPARISON OF THE COMPOSITION PREDICTIONS FOR THE DENDRITE CORE IN ALLOY E. 307

FIGURE 179: COMPARISON OF THE COMPOSITION PREDICTIONS FOR THE DENDRITE CORE IN ALLOY F. 308

FIGURE 180: COMPARISON OF THE COMPOSITION PREDICTIONS FOR THE INTERDENDRITIC REGION IN ALLOY A. 308

$$
\text { xix }
$$


FIGURE 181: COMPARISON OF THE COMPOSITION PREDICTIONS FOR THE NTERDENDRITIC REGION IN ALLOY B. 309

FIGURE 182: COMPARISON OF THE COMPOSITION PREDICTIONS FOR THE INTERDENDRITIC REGION IN ALLOY C. 309

FIGURE 183: COMPARISON OF THE COMPOSITION PREDICTIONS FOR THE INTERDENDRITIC REGION IN ALLOY D 310

FIGURE 184: COMPARISON OF THE COMPOSITION PREDICTIONS FOR THE INTERDENDRITIC REGION IN ALLOY E. 310

FIGURE 185: COMPARISON OF THE COMPOSITION PREDICTIONS FOR THE INTERDENDRITIC REGION IN ALLOY F. 311

FIGURE 186: COMPARISON OF PREDICTED K' SEGREGATION COEFFICIENTS TO MEASURED EPMA K' RESULTS. 311

FIGURE 187: RMC SEGREGATION RESULTS FOR RE OVER $T_{L}-T_{S}$ RANGE. 312

FIGURE 188: RMC SEGREGATION RESULTS FOR TA OVER $T_{L}-T_{S}$ RANGE. 312

FIGURE 189: RMC SEGREGATION RESULTS FOR MO OVER T $T_{L}-T_{S}$ RANGE. 313

FIGURE 190: RMC SEGREGATION RESULTS FOR CR OVER $T_{L}-T_{S}$ RANGE. 313

FIGURE 191: NI-RU SYSTEM [NASH 1991-ASM INTERNATIONAL]. 315

FIGURE 192: PRELIMINARY Ni-RU PHASE DIAGRAM DEPICTING THE L+HCP PHASE REGION. DUE TO THE ABSENCE OF THE NI SOLID SOLUTION PHASE, THE $L+\beta$ PHASE EXTENDS TO THE NI RICH SIDE OF THE DIAGRAM SUGGESTING A METASTABLE NIHCP REGION. 320

Figure 193: Preliminary Ni-Ru PHASE Diagram DePiCting THE L + $\beta(\mathrm{HCP})+\alpha(\mathrm{FCC})$ PHASE FIELDS. THE NI SOLID SOLUTION PHASE, $\alpha-F C C$, HAS NOW BEEN ADDED EFFECTIVELY CUTTING THE $L+\beta$ PHASE REGION ALONG THE PERITECTIC LINE AT $1550^{\circ} \mathrm{C}$ 323

FIGURE 194: FINAL ITERATION OF THE MODELED NI-RU PHASE DIAGRAM. 325

FIGURE 195: PARTITIONING COEFFICIENT RANGE FOR ALLOY-A.............................. 331

Figure 196: PARTITIONING COEFFICIENT RANGE FOR ALLOY-B. 331 
FIGURE 197: PARTITIONING COEFFICIENT RANGE FOR ALLOY-C................................ 332

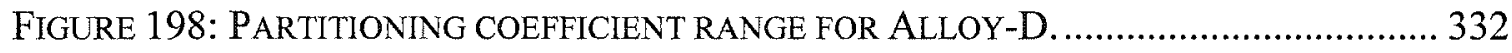

FIGURE 199: PARTITIONING COEFFICIENT RANGE FOR ALLOY-E. ............................... 333

FIGURE 200: PARTITIONING COEFFICIENT RANGE FOR ALLOY-F................................ 333 


\section{List of Tables}

TABLE 1: EFFECTS OF ALLOYING ELEMENTS IN Ni-BASE SUPERALLOYS [25]. 171

TABLE 2: COMPOSITION (WT.\%) AND DENSITY OF SOME COMMONLY USED $1^{\text {ST }}$ GENERATION SINGLE CRYSTAL SUPERALLOYS. (ADAPTED FROM BROOMFIELD ET AL.) [13]. 171

TABLE 3: COMPOSITION (WT.\%) AND DENSITY OF SOME COMMONLY USED $2^{\mathrm{ND}}$ GENERATION SINGLE CRYSTAL SUPERALLOYS (ADAPTED FROM DURANDE-CHARRE) [25] .. 172

TABLE 4: COMPOSITION (WT.\%) AND DENSITY OF TYPICAL $3^{\text {RD }}$ GENERATION SINGLE CRYSTAL SUPERALLOYS.

TABle 5: Potential $4^{\text {TH }}$ Generation RU-BEARING SINGLE CRYSTAL ALloys. 172

TABLE 6: TYPICAL COMPOSITIONS (AT.\%) OF $\gamma$ AND $\gamma^{\prime}$ PHASES IN SX SUPERALLOYS AS DETERMINED BY ATOM MICROPROBE ANALYSIS $[51,52]$

TABLE 7: COMPOSITIONAL RANGES OF MAJOR ALLOYING ADDITIONS IN NI-BASE SUPERALLOYS FROM THE LATE 1940'S TO PRESENT (ADAPTED FROM DONACHIE) [33].

TABLE 8: AVERAGE COMPOSITION OF DENDRITE AND INTERDENDRITIC REGIONS, INCLUDING PARTITIONING COEFFICIENTS FOR AS-CAST CMSX-10 [92]. 174

TABLE 9: TARGET COMPOSITIONS, TOTAL REFRACTORY LEVEL, AND ALLOY DENSITY FOR EXPERIMENTAL ALLOYS.

TABLE 10: FINAL ALLOY COMPOSITIONS AND TOTAL REFRACTORY LEVELS AS DETERMINED USING WET CHEMICAL ANALYSIS. 175

TABLE 11: SX CASTING RESULTS FOR ALLOYS A-F. 176

TABLE 12: EPMA POINT-SCAN RESULTS FOR AS-CAST ALLOYS A-C (WT.\%). 177

TABLE 13: EPMA POINT-SCAN RESULTS FOR AS-CAST ALLOYS D-F (WT.\%). 178

TABLE 14: AVERAGE POINT-SCAN COMPOSITIONS (WT.\%) FOR DENDRITE CORE AND INTERDENDRITIC $\gamma-\gamma^{\prime}$ WITH CORRESPONDING K' COEFFICIENTS 179

TABLE 15: ENDOTHERMIC TRANSFORMATION TEMPERATURES $\left({ }^{\circ} \mathrm{C}\right)$ UPON HEATING. 179

xxii 
TABLE 16: TRANSFORMATION TEMPERATURES $\left({ }^{\circ} \mathrm{C}\right)$ DETERMINED USING HEATING RATE EXTRAPOLATION. 180

TABLE 17: EXOTHERMIC TRANSFORMATION TEMPERATURES $\left({ }^{\circ} \mathrm{C}\right)$ UPON COOLING. 180

TABLE 18: EUTECTIC FRACTION IMAGE ANALYSIS RESULTS FOR ALLOYS A THROUGH F. 181

TABLE 19: EUTECTIC FRACTION AS A FUNCTION OF NOMINAL RE, W, AND RU COMPOSITION 182

TABLE 20: EUTECTIC FRACTION AS A FUNCTION OF LOCALIZED INTERDENDRITIC EUTECTIC PHASE COMPOSITION. 182

TABLE 21: TRANSFORMATION TEMPERATURES AS PREDICTED BY ALL THREE THERMODYNAMIC MODELS IN COMPARISON TO MEASURED DSC VALUES. ..... 182

TABLE 22: COMPOSITION PREDICTIONS OF THE FIRST SOLID AND LAST LIQUID TO SOLIDIFY FOR ALLOYS A-C AS DETERMINED BY THE RMC, NIST AND SGTE MODELS. 183

TABLE 23: COMPOSITION PREDICTIONS OF THE FIRST SOLID AND LAST LIQUID TO SOLIDIFY FOR ALLOYS D-F AS DETERMINED BY THE RMC, NIST AND SGTE MODELS. 184

TABLE 24: FINALIZED THERMODYNAMIC PARAMETERS FOR THE NI-RU SYSTEM USING THE IDEAL SOLUTION MODEL FOR THE L-PHASE AND REGULAR SOLUTION MODELS FOR NI AND RU SOLID PHASES 325

TABLE 25: 1-SIGMA ERROR VALUES FOR THE POINT-SCANS PERFORMED ON ALLOY A-C.327

TABLE 26: 1-SIGMA ERROR VALUES FOR THE POINT-SCANS PERFORMED ON ALLOY A-C.328

TABLE 27: AVERAGED 1-SigMA ERROR VALUES FOR ALLOYS A-F. 329

TABLE 28: RANGE OF SEGREGATION COEFFICIENT VALUES BASED ON 1-SIGMA ERROR... 329

xxiii 


\section{List of Appendices}

APPENDIX A: FUNDAMENTALS OF CALPHAD MODELING.

313

APPENDIX B: HEAT TREATMENT STUDY OF EXPERIMENTAL ALLOYS

.325

xxiv 


\section{Nomenclature}

\begin{tabular}{|c|c|}
\hline SX: & single crystal \\
\hline DOE: & design on experiment \\
\hline TCP: & topologically close-packed \\
\hline EPMA: & electron probe microanalysis \\
\hline DSC: & differential scanning calorimetry \\
\hline MC-NG: & Mono Cristal Nouvelle Génération \\
\hline TMF: & thermal mechanical fatigue \\
\hline DS: & directional solidification \\
\hline VIM: & vacuum induction melting \\
\hline PWA: & Pratt and Whitney Aircraft \\
\hline $\mathrm{E}:$ & Modulus of elasticity \\
\hline $\mathrm{HCF}:$ & high cycle fatigue \\
\hline G: & temperature gradient \\
\hline $\mathrm{V}:$ & growth velocity \\
\hline$\gamma:$ & gamma solid solution phase \\
\hline$\gamma^{\prime}:$ & gamma prime precipitate phase \\
\hline $\mathrm{FCC}:$ & face-centered cubic \\
\hline$\sigma:$ & tetragonal sigma TCP phase \\
\hline$\mu:$ & rhombohedral mu TCP phase \\
\hline P: & orthorhombic TCP phase \\
\hline$V_{f}:$ & volume fraction \\
\hline GCP: & geometrically close-packed \\
\hline
\end{tabular}


PHACOMP: PHAse COMPutation

$\mathrm{N}_{\mathrm{v}}: \quad$ electron vacancies

$\overline{N v}: \quad$ average vacancy number

$\overline{N v}_{c}: \quad$ critical average vacancy number

$\overline{M d}: \quad$ average energy level of d-orbitals of alloying transition metals

$\overline{M d_{c}}: \quad$ critical value of average energy level of d-orbitals

CTM : $\quad$ computational thermodynamic modeling

FACT: $\quad$ Facility for the Analysis of Chemical Thermodynamics

FACT-Sage: latest version of FACT (uses CHEMSAGE equilibrium calculator)

G : $\quad$ Gibbs free energy

$H: \quad$ enthalpy

$S: \quad$ entropy

$\Delta G^{\circ}: \quad$ lattice stability free energy term of pure element

$\Delta G_{m i x}^{D}: \quad$ ideal mixing component of free energy

$\Delta G_{m i x}^{E}: \quad$ excess free energy of mixing term

L : $\quad$ liquid phase

G-x : $\quad$ Gibbs energy versus composition

SGTE : $\quad$ Scientific Group Thermodata Europe

$\mathrm{p}_{\mathrm{i}}: \quad \quad$ represent the thermal part of the excess Gibbs energy

$\mathrm{C}_{0:} \quad$ nominal composition

$\mathrm{T}_{\mathrm{L}}: \quad$ liquidus temperature

$\mathrm{T}_{\mathrm{S}}: \quad$ solidus temperature

$\mathrm{C}_{\mathrm{L}}{ }^{*}$ : composition of the liquid at the interface 


\begin{tabular}{|c|c|}
\hline $\mathrm{C}_{\mathrm{S}}{ }^{*}:$ & composition of the solid at the interface \\
\hline $\mathrm{k}$ : & equilibrium partition ratio \\
\hline $\mathrm{f}_{\mathrm{S}}$ : & fraction solid \\
\hline $\mathrm{f}_{\mathrm{L}}$ : & fraction liquid \\
\hline$D_{L}:$ & liquid diffusion coefficient \\
\hline$D_{S}:$ & diffusivity in solid \\
\hline$t_{f}:$ & local time of solidification \\
\hline$\lambda:$ & dendrite arm spacing \\
\hline $\mathrm{k}^{\prime}:$ & microsegregation coefficient \\
\hline $\mathrm{G}_{\mathrm{L}}$ : & temperature gradient across the liquidus temperature \\
\hline XRD : & X-Ray diffraction \\
\hline EDX : & Energy Dispersive X-ray \\
\hline SEM : & Scanning Electron Microscope \\
\hline BSE : & Back-Scattered Electron \\
\hline WDX : & Wavelength Dispersive X-ray \\
\hline$f_{E}:$ & eutectic phase fraction \\
\hline EDM : & electrical discharge machining \\
\hline$\Delta \mathrm{T}:$ & solidification temperature ranges $=T_{L}-T_{S}$ \\
\hline NIST : & National Institute of Standards and Technology \\
\hline RMC: & Royal Military College of Canada \\
\hline SD : & secondary dendrite arm \\
\hline$\delta:$ & $\mathrm{Ni}_{3} \mathrm{Ta}$ phase \\
\hline$\beta:$ & NiAl phase \\
\hline
\end{tabular}

xxvii 


\section{Introduction}

\subsection{Background}

The metallurgical contribution of Ni-base superalloys to the gas turbine field was perhaps one of the most significant turning points in the history of turbine materials technology. Today, some 50 years since their initial inception, almost all modern gas turbine engines utilize Ni-base superalloys for selected hot-section components including turbine blades and vanes. In particular, the relentless demand by engine manufacturers for blade materials with even greater strength and high temperature capability has led designers to develop progressively more advanced Ni-base superalloys. This has resulted in an enormous aggregate of Ni-base alloy derivatives along with numerous production techniques ranging from simple conventional casting methods to the more complex directional solidification techniques.

The current state-of-the-art in Ni-base superalloy design, is the production of single crystal (SX) turbine blades using complex casting processes in conjunction with alloy composition modifications. The development of these SX superalloys has been an ongoing process over the last 30 years, during which several generations of alloys have been produced with each successive group having superior mechanical and thermal properties to its predecessor. The major advancements of the most recently developed SX superalloys can be attributed to the introduction of higher levels of specific refractory elements into the base compositions. 
As with all high temperature alloys, the mechanical properties of SX superalloys are highly dependent on the material microstructure. In turn, the microstructural properties of these alloys are governed by the alloy chemistry as well as the processing history of the component. In addition to meeting the general mechanical requirements associated with turbine blade applications, the microstructures and compositions of these alloys must also be capable of accommodating a certain degree of phasial stability. However, due to the complexity of these highly alloyed compositions and the elaborate SX microstructures, it is highly unlikely that these features have been developed in the optimum condition. This is largely due to the Design On Experiment (DOE) approach commonly used by material producers, which does not directly rely on complete micro-mechanical characterization of SX alloys for successful design results. In fact, many SX superalloys suffer from microstructural instability during application, with an attendant degradation of properties due to the formation of embrittling topologically close-packed (TCP) phases. This is somewhat problematic for SX superalloys as the propensity of formation of these deleterious phases is largely associated with the total refractory level in the alloy composition. Understanding the formation of these phases is particularly important, since alloy developers are generally working on the edge of phase instability. Hence, the addition of heavy elements such as $\mathrm{Re}$ and $\mathrm{Cr}$ into $\mathrm{SX}$ superalloy compositions must be incorporated such that a suitable balance of mechanical properties and microstructural stability is maintained.

\subsection{Present SX Superalloy Design Constraints}

The next generation of advanced fighters and transport aircraft stipulates the use of advanced SX superalloys for critical turbine components to accommodate peak 
performance demands. In the case of jet fighter applications, the turbine must be able to accommodate extreme changes in engine loads required for combat maneuvers and high take-off power demands. Transport aircraft are not subjected to the same accelerated loading fluctuations, however; operating conditions require turbine materials that are capable of functioning for extended durations at moderate speeds with minimal maintenance downtime. Modern SX superalloys are capable of meeting these performance demands, however the technology is not mature. The interdependent relationships between alloy composition, processing parameters, microstructure, phasial/environmental stability, and mechanical properties of SX superalloys are not fully understood and require additional characterization [1].

Perhaps one of the most difficult tasks of the modern day turbine blade manufacturer is the selection of a suitable alloy composition that is capable of withstanding the arduous environment of the engine. Selection of a suitable alloy composition must be made on the basis of both mechanical and microstructural stability over extended periods of use. Advancement in mechanical and thermal properties of SX superalloy blades has been primarily attributed to the increased addition of specific refractory elements into base alloy compositions. In particular, numerous studies $[2,3,4,5]$ have shown $\mathrm{Re}$ additions to be useful for optimizing thermal-mechanical properties for many of the SX Ni-base superalloys. Although improvements in strength and high temperature capability are desirable, increased levels of such refractory additions in nominal alloy compositions result in an associated increase in the degree of non-homogeneous chemical distribution within the alloy microstructure. 
In general, most solidification processes result in some degree of non-homogeneous chemical distribution due to naturally occurring mass transport phenomena. The degree or severity of segregation within most cast alloys is usually dependent on one or more of the following variables:

1. Nominal alloy composition

2. Metal cooling rate

3. Thermal gradient at the solid-liquid interface

4. Growth rate

5. Fluid flow within the mold

6. Mold geometry.

Directional solidification processes, such as Bridgman or Czochralski methods, utilize a narrow range of specific casting parameters required to yield defect-free, homogeneous products. Hence, casting experimentation and/or predictive solidification modeling are required to determine suitable casting parameters necessary to control the influence of each of these variables on both microsegregation and macrosegregation.

Microsegregation results from the uneven mass transport phenomenon that occurs on a microscopic level during solidification at the solid-liquid interface. The localized, nonuniform chemical distribution that occurs is due to the rejection of solute atoms by the recently formed solid phase into the more diffusive interdendritic liquid region [6]. This produces a localized compositional gradient across the dendritic solidification structure of the alloy, ranging from the initial dendrite core region to the final interdendritic liquid 
region that solidifies. Furthermore, depending on the casting parameters used and the number of diffusing solute species (i.e. alloying additions), this compositional gradient can change gradually across the $\sim 150$ to $250 \mu \mathrm{m}$ segregation zone, or a major inflection in the chemical gradient may result. The first case is the desired casting result that can usually be easily homogenized with post-casting heat treatments. The latter case can result in major changes in microstructural constituents due to severe microsegregation. In fact, it is not uncommon to see eutectic phase formation during the final stages of planar solidification due to the favorable partitioning of eutectic forming species in the final interdendritic region [7].

The severity of microsegregation can be quantified by measuring the difference in composition between the dendrite cores and the interdendritic regions by performing Electron Probe Micro-Analysis (EPMA). In addition to quantifying the degree of chemical partitioning within the solidification structure, the extent of microsegregation may also be gauged based on the fraction of eutectic phase that is formed. In general, the greater the fraction of eutectic phase present in the as-cast microstructure, the greater the degree of microsegregation. Therefore, it is important to quantify both the degree of chemical partitioning and the phase fraction of eutectic in the cast alloy in order to characterize the severity of microsegregation. Depicted in Figure 1 is an exaggerated representation of the microsegregation pattern typically observed in most as-cast SX superalloys [8]. Highlighted are the concentrated levels of $\mathrm{Re}, \mathrm{Cr}, \mathrm{Mo}, \mathrm{W}, \mathrm{Co}$ at the dendrite cores and elevated levels of $\mathrm{Al}, \mathrm{Ti}$ and Ta within the interdendritic regions. 
An undesirable by-product of these localized concentrations of solute atoms is the increased tendency for the formation of deleterious TCP phases [9]. These phases degrade the mechanical properties of SX Ni-base superalloys, counteracting the original purpose for increasing refractory levels [10]. For this reason, the severity of microsegregation as a function of individual and overall alloy addition levels is a vital design factor for SX casting vendors and turbine blade manufacturers. For the most part, completely avoiding the formation of these deleterious phases has proven to be almost impossible; hence, the main objective has been to reduce the fraction of TCP phase formation at various high temperatures and to delay the onset of nucleation. This is achieved by carefully selecting alloy compositions such that a uniform duplex $\gamma-\gamma^{\prime}$ microstructure is easily attained via standard homogenization heat treatments. In general, alloy compositions that yield less as-cast microsegregation are more easily homogenized and result in delayed TCP phase nucleation and growth kinetics. The end results are lesscomplex furnace heat treatment processes and extended microstructural stability lifetimes for gas turbine components.

\subsection{Thesis Objectives and Scope}

This thesis is part of a collaborative research program established between Carleton University and the Institute for Aerospace Research of the National Research Council of Canada. The main goal of this research is to develop microstructural and compositional guidelines that may be utilized for future SX superalloy development programs. With this in mind, the main objectives of this thesis are: 
1. To ascertain and procure a series of experimental alloys of varying chemical composition such that a complete range of microsegregation properties can be investigated,

2. To determine the Bridgman casting and thermal processing parameters required to recast these polycrystalline alloys into the SX condition,

3. To investigate the compositional effects of various alloying additions on chemical microsegregation within the as-cast structures utilizing several different characterization techniques.

4. To develop a multi-component thermodynamic model for the complex SX superalloy system that may be used to predict the effects of specific alloy additions on phase transformation during alloy solidification.

5. To compare and evaluate the experimentally measured and model predicted microsegregation results for each of the alloy compositions investigated.

The first chapter in the following literature review is provided to give an overview of the fundamental requirements of turbine blade materials. A detailed history of the evolution of SX superalloy development is described with reference to composition modification and casting procedures. The second literature review chapter describes the typical microstructural features inherent to SX superalloy materials. This section includes a description of the different types of TCP phases that may form in SX superalloys as well as some of the methods used by designers to predict the formation of these phases. The final chapter in the literature review covers alloy microsegregation in SX superalloys and includes some of the basic solute redistribution solidification models. 
Immediately following the literature review, an explanation of the experimental alloy composition selection and casting process is provided. The main characterization methods used to measure the severity of microsegregation are presented; specifically, the EPMA quantitative analysis, eutectic phase fraction analysis, and DSC thermo-physical results. The effects of $\mathrm{Re}, \mathrm{Ru}$ and $\mathrm{W}$ on microsegregation are discussed based on these results. A comparative study is also presented, based on the measured EPMA microsegregation values and the theoretical CALPHAD predictions generated using multi-component thermodynamic models [11]. Details of the development and implementation of the thermodynamic models are also provided. 


\section{Literature Review - Properties and Processing of Gas Turbine Blades}

\subsection{Turbine Blade Requirements}

Since the initial implementation of Whittle's W-1 engine in 1941, turbine blades have always been one of the most critical components of the gas turbine, strongly influencing the overall engine life, efficiency, and reliability characteristics [12]. By virtue of the mechanical rotation of these blades and their location in the hot-gas section of the engine, these components are subjected to high stresses, high gas velocities, and hot corrosive/erosive environments. The actual mechanical and thermal loads that a particular row of blades experiences is dependent on the type of engine in which they are used and blade proximity from the turbine inlet. For instance, some presently used commercial turbofan engines [13] require first row turbine blades that are capable of accommodating turbine inlet temperatures in excess of $1650^{\circ} \mathrm{C}$ and thrust levels greater than $445 \mathrm{kN}$. Similarly, the fleet of turbine engines developed by Rolls-Royce [14] have a wide range of blade requirements, where blade rotational speeds may be over $460 \mathrm{~m} / \mathrm{s}$, turbine inlet temperatures may be in the range of $850^{\circ} \mathrm{C}$ to $1700^{\circ} \mathrm{C}$, and gas flow velocities may be in excess of $770 \mathrm{~m} / \mathrm{s}$.

A general description of a typical gas turbine engine has been provided in Figure 2, illustrating the major rotating components; the fan, the compressor, and the turbine sections [15]. Figure 3 shows the general temperature and pressure distributions across the engine, with particular emphasis on the location of the $1^{\text {st }}$ stage turbine blade section. It is apparent from this figure that blades in the first row of the turbine are subjected to 
the highest combination of temperature and pressure, thus necessitating critical design practices for these components. A close-up schematic [16] of the $1^{\text {st }}$ stage turbine section is shown in Figure 4. This image illustrates the close proximity of the combustion flame to the first turbine stage. Although the vane section is closer to the flame than the blade, it is a stationary component and thus is not subjected to the centrifugal loads experienced during rotation. Hence, the life of $1^{\text {st }}$ stage turbine blades is usually the service-limiting factor with respect to engine maintenance and inspection intervals. Presented in Figure 5 is a typical turbine blade as well as some of the standard loading conditions experienced across its face. Also provided in Figure 6 are the independent temperature and stress profiles that are commonly seen in typical turbine blades when subjected to standard loading conditions [17]. It is apparent from this figure that the blade tip is highly temperature sensitive (i.e. erosion/oxidation) whereas the fir tree or blade root life is governed by the localized stress concentration at the notch. In most cases, the actual blade life is limited in the mid-chord region of the blade where the highest combination of stress/strain and temperature is endured.

The typical life requirements of a turbine blade are upwards of 20,000 hours for civil aircraft practice and approximately 2000 hours for more arduous military applications [18]. For these expected lifetimes, the blades must endure several service limiting conditions including:

1. High cycle fatigue: Aerodynamic forces can induce vibrations that produce cyclic stresses at high frequencies causing microscopic strain in the blade components. 
2. Creep: Permanent deformation of the blade due to high temperature stresses or strain applied for extended periods of time.

3. Low cycle fatigue: Fatigue due to thermal and mechanical cycling resulting in high plastic strain deformation in the blade microstructure.

4. Surface attack: This may be due to oxidation, hot corrosion, or erosion as a result of the harsh environment that the blades are subjected to in the turbine section [18].

From a design point of view, the overall performance and efficiency of any gas turbine is directly related to the ability of the turbine section to accommodate higher stresses and temperatures. However, as these service conditions become more severe the effects of such factors as high temperature creep and thermal fatigue become increasingly problematic. Hence, designers are constantly seeking ways to improve blade components to increase operating limits so that overall engine efficiency is optimized. The current level of performance has been reached by the combination of such features as advanced design in turbine blade cooling, optimization of alloy casting processes, and the improvement of alloy compositions. Regardless, the selection of a suitable turbine blade material in its optimum condition is the main governing factor that stipulates the maximum operating levels that may be implemented in the engine.

\subsection{Turbine Blade Materials}

Initial turbine blade materials were produced using conventional casting/forging processes utilizing high temperature stainless steels. Then in the late 1950's these steels were replaced with superior polycrystalline superalloy components. An extensive volume 
of literature $[19,20,21,22,23]$ is available covering the wide variation of superalloys designed during these early pioneering stages. The fundamental research and development initiated by these early investigators on superalloy programs such as the Nimonic and Inconel series, resulted in an accelerated materials revolution that has lasted for over 50 years [24]. During the last 30 years, an abundant amount of research has been performed aimed at designing and improving cast turbine blade materials, the net result of which has been the production of several "generations" of sophisticated SX superalloys. The main driving force behind the development of these more advanced SX alloys was the discovery that the presence of grain boundaries in early blade components acted as weak points for crack initiation and detrimental diffusional processes [25]. Initially it was discovered that creep strength and ductility could be improved by using columnar-grained materials that were cast using directional solidification techniques, as opposed to the conventional equiaxed casting methods [25]. It was then later revealed that even greater improvements in mechanical properties were attainable by completely removing the grain boundaries altogether, using controlled directional solidification processes and by modifying the alloy compositions. The high temperature superiority of these SX materials as compared to their polycrystalline and columnar-grained predecessors is graphically represented below in Figure 7. An illustration of the difference between the microstructures and mechanical properties of these three material conditions (i.e. equiaxed, columnar, and single crystal) is provided in Figure 8.

It is apparent that the advancement in turbine blade materials from the traditional equiaxed condition to the SX form has been essential in attaining higher turbine engine 
efficiencies. Furthermore, the development of SX superalloys from the first generation alloys that were produced in the 1980 's, up to the more recent Re-containing third generation class has also played a significant role in further engine optimization. For this reason, a brief discussion of the development history of SX superalloys relative to the turbine blade industry will be presented in the following section.

\subsubsection{History of Single Crystal Superalloys in Gas Turbine Engines}

\subsubsection{First Generation Single Crystals}

Perhaps the most significant aspect that has accompanied the transition of turbine blade materials from polycrystalline to SX form was the modification of the alloy compositions. The first generation of SX superalloys was developed by modifying traditional polycrystalline superalloy chemistries to suit the superior microstructural features of the SX blade materials. This was achieved by removing the grain boundary strengthening elements such as $\mathrm{C}, \mathrm{B}$, and $\mathrm{Zr}$ and increasing the refractory levels of elements such as $\mathrm{W}, \mathrm{Ta}$, and Mo [26]. It is obvious as to why the grain boundary elements were removed from the SX compositions; however, a brief description of the role of the major alloying additions typically incorporated into SX compositions has been provided in Table 1 for review.

As previously stated, the grain boundary strengthening elements were removed from the first generation of SX superalloys. The advantage of removing these melting point depressants allowed for higher temperature solution heat treatments without the onset of incipient melting. In other words, the alloy's primary and secondary precipitates, as well 
as any eutectic phase, could be fully solutionized due to the resulting increase in solidus temperature [27]. Having a higher solidus temperature effectively increases the heat treatment window between the solvus and solidus temperatures allowing for an improved homogenization of the alloy chemistry and a uniform distribution of fine precipitates upon subsequent cooling. The ability to fully solutionize and subsequently control the precipitate distribution and morphology upon cooling led to dramatic improvements in creep-rupture strength of the first generation single crystals as compared to equiaxed and columnar precursors [27].

Provided in Table 2 is a list of some of the more commonly used first generation SX superalloys. Noteworthy is PWA 1480, which was the first SX superalloy developed and utilized in commercial application by Pratt and Whitney Aircraft [28].

\subsubsection{Second Generation Single Crystals}

Major improvements in blade creep strength were also gained by the introduction of Re into SX alloy compositions. The major distinction between the first and secondgeneration alloys is the inclusion of $\sim 3 \mathrm{wt} . \% \mathrm{Re}$ as shown in Table 3 . The introduction of Re into this new generation of single crystals resulted in strength/temperature capability improvements between $31-36{ }^{\circ} \mathrm{C}$ above polycrystalline standards [27]. Numerous studies were performed to examine the effects of Re additions on SX properties. In 1985, research conducted by Giamei and Anton on modified SX alloys showed that Re additions substantially lowered the precipitate coarsening kinetics and also resulted in large matrix-precipitate misfits [29]. Atom probe studies conducted by Blavette et al. also 
showed that the Re atoms formed clusters within the parent matrix, which effectively impede dislocation movement [30]. This type of atomic clustering (short-range order) is a well-established strengthening mechanism and is commonly seen to occur with elements such as Mo and W to a certain degree [25].

\subsubsection{Third Generation Single Crystals}

With the success of microalloying $\mathrm{Re}$ into the second generation alloys, material designers continued to experiment with the addition levels until a new, third generation of SX alloys was created. As shown in Table 4, designers have succeeded in producing these new single crystals with Re levels as high as 6 wt.\%. As a direct result of the composition modifications, designers were capable of increasing the high temperature capability (e.g. creep strength) by almost $30^{\circ} \mathrm{C}$ over the second-generation alloy norm [27]. However, the improved creep strength of these new SX alloys has in many cases been achieved at the expense of increased density, higher alloy cost, and unwanted microstructural instabilities due to the addition of substantial Re levels. The phasial stability and microsegregation of the third generation alloys are even more critical due to the higher refractory content of these materials and will be discussed in more detail in Section 3.1.3.

\subsubsection{Next Generation Single Crystals}

Although a fourth generation of SX superalloys has not been categorized definitively, there exits a group of recently developed alloys that may be the initial forerunners of this new class. This potential fourth generation of SX alloys is characterized by substantial ruthenium + rhenium additions into the base chemistry. Provided in Table 5 is a short list 
of some of these newly developed alloys describing the major compositional differences. The first of these alloys, designated as MC-NG (Mono Cristal Nouvelle Génération), was developed and patented by ONERA in 2000 for use by the French engine manufacturers SNECMA and Turbomeca [31]. The key advantage of this new generation of alloys is the partial substitution of $\mathrm{Re}$ with $\mathrm{Ru}$. In terms of weight savings, $\mathrm{Ru}$ has only half the density of Re, which is critical for thrust-to-weight ratio design considerations of aeroengines [32]. Furthermore, preliminary studies have shown that alloys that contain both $\mathrm{Re}$ and $\mathrm{Ru}$ are less prone to the precipitation of deleterious phases as compared to those that contain $\mathrm{Re}$ additions alone [32]. It should be mentioned however, that the underlying reasons for this have not been well established.

Although there are significant differences in the chemistry and microstructure between each of the aforementioned SX superalloy generations, the one common prerequisite is a well-controlled, repeatable casting process that can yield defect-free blade components.

\subsection{Turbine Blade Casting Process}

As previously mentioned, single crystal casting is required to optimize the mechanical and high temperature strength of the $1^{\text {st }}$ stage turbine blades. Although the compositional improvements in these newer alloys are largely responsible for the enhanced creep strength that is obtained, the crystallographic nature of the SX component is also responsible for improving such properties as thermal mechanical fatigue (TMF) strength. This is achieved by a reduction in the elastic modulus of the blade by orienting the component in a preferred crystallographic direction that is parallel to the airfoil axis [33]. Furthermore, turbine blades are commonly cast in relatively thin sections to support 
aerodynamic requirements and cooling path geometries. In general, as the section thickness decreases, the sensitivity to imperfections and discontinuities in the blade increases dramatically. These thin section effects are largely reduced when using SX cast components, as the end product is more homogeneous and defect-free than their polycrystalline and directionally solidified (DS) columnar-grained equivalents [33]. Hence the ability to produce SX components that are reliably defect-free and microstructurally homogeneous throughout is of prime importance to sustain extended turbine blade lifetimes.

The following sections will give a brief overview of the SX casting process; including the initial stages of ceramic mold fabrication, vacuum induction melting (VIM) and directional solidification processing methods.

\subsubsection{Ceramic Mold Fabrication}

The common practice used to fabricate SX blades is a derivation of the conventional investment casting process, also known as "lost-wax" casting. The first step in the process is the production of the ceramic mold. The initial stage of ceramic mold fabrication is the same for both SX and polycrystalline investment casting processes, as it involves applying or "investing" a ceramic slurry around a disposable was pattern. In brief, the ceramic slurry is allowed to harden with subsequent removal of the wax pattern using high temperature steam [33]. 
The geometry of the disposable wax pattern is customized for specific casting processes such as the implementation of a single crystal grain selector and gating for liquid metal delivery. A steel or aluminum die is usually fabricated for each turbine blade geometry that can then be subsequently used to produce an unlimited number of wax patterns. These dies are machined with tolerances to conform to the part shape, with allowances accounting for wax shrinkage, metal shrinkage, and ceramic mold expansion [34]. It is important to produce accurate wax patterns as dimensional tolerances for many investment cast superalloys [33] are generally $\pm 0.075 \mathrm{~mm}(0.003 \mathrm{in}$.) with section thicknesses as low as $1.25 \mathrm{~mm}(0.05 \mathrm{in}$.$) . An example of a typical wax pattern [35] used$ for SX blade casting is shown in Figure 9. This particular image illustrates the use of a pigtail SX grain selector attached at the bottom of each wax blade form. A metal delivery system has been attached at the middle-top of the wax blade pattern. Noteworthy in this image is the incorporation of a ceramic filter above the pigtail that is used to decrease liquid flow speeds and prevent debris from passing into the entrance of the blade section during metal delivery. Also illustrated in this image is a lower ceramic mold stand, which conforms to the geometry of the copper chill platen of the associated casting furnace. The stand sits directly above the copper chill and is responsible for heat extraction from the liquid metal/mold assembly during the casting process. The mold stand is of suitable thickness such that sufficient thermal insulation from the chill platen is present to produce the necessary thermal gradient (i.e. heat flow) required for SX casting. A more detailed explanation of the required thermal gradient and casting parameters is presented later in section 2.3.3.1. Several mold configurations are available that may be used to promote the SX microstructure in the blade component. Figure 10 depicts three possible 
mold geometries, the previously mentioned pigtail grain selector, the two-turn grain selector, and the seed crystal selector methods [33]. The mechanisms of the various grain selection processes will be discussed later in section 2.3.3.1.1.

Once the wax mold has been formed and additional components have been added (e.g. filters, support rods, cooling cores, etc.) the wax assembly is then invested in ceramic slurry for a specified time period. The slurry coating is then dusted with a stucco sand to increase the shell strength. The investing-stucco process is repeated until a desired thickness is obtained, the shell is then dried and the wax pattern is removed from the ceramic shell with high temperature steam or another form of liquid solvent. Figure 11 depicts a finished ceramic mold with the wax form build-up removed [35]. The general procedure used to produce ceramic molds for SX casting is as follows:

1. Machine multiple steel or aluminum split-dies conforming to the shapes of the turbine blade and SX grain selector.

2. Fabrication of a disposable blade pattern using high-pressure injection of the die with a dissolvable wax or plastic.

3. Coat the wax form with a ceramic slurry (usually high purity alumina or zirconia) for an appropriate amount of time. Using a fluidized bed, apply a stucco sand layer to the outside of the slurry. Repeat the slurry application and stuccoing process until a reasonable section thickness of the ceramic mold is attained ( $\sim 6-10$ $\mathrm{mm})$.

4. Cure the ceramic mold to increase the shell density and remove the green-body porosity.

5. Dissolve the internal wax pattern using a high temperature steam autoclave or a liquid solvent extraction method. 
6. Clean the mold and apply a high temperature curing process if the ceramic shell still retains excess porosity. This will also remove any residual wax that is embedded inside the ceramic mold. This high temperature sintering process provides the majority of the shell strength by vitrifying the silicate binder [33].

A more complete illustration of the investment casting process has also been provided in Figure 12 [33].

\subsubsection{Vacuum Induction Melting}

Prior to using the ceramic mold in the SX casting process, the raw alloy used to produce the turbine blades must first be processed. The production of high quality ingots for superalloy fabrication did not become commercially feasible until the method of Vacuum Induction Melting (VIM) was perfected. In fact, the major advancements in VIM technology evolved due to problems experienced by turbine blade manufacturers when trying to obtain air-melted superalloy bar stock [34]. Air melting processes were yielding poor quality ingots with excessive scrap rates dictating a need for a more effective and less costly solution. This was to melt the raw alloy in an inert vacuum environment.

Simply described, VIM is performed in an induction furnace situated in an enclosed vacuum chamber. The major advantages of the VIM process over the alternative atmospheric melting procedure is the simplistic design and the ability to control alloy composition levels very accurately. Utilizing VIM provides the capability to add certain reactive alloying additions (e.g. $\mathrm{Ni}, \mathrm{Cr}, \mathrm{Mo}, \mathrm{Al}, \mathrm{Ti}$, and $\mathrm{Co}$ ) to the melt that normally oxidize or outgas in air. The undesirable formation of these oxide inclusions seriously impairs the final material properties of the cast alloy. 
The most successful application of VIM in superalloy production was the added ability to produce high-strength precipitation-hardened superalloys. This was achieved through the addition of higher volume fractions of $\mathrm{Al}$ and $\mathrm{Ti}$, which are the primary elemental additions responsible for the major precipitation-hardening phase in Ni-based superalloys. Up until the successful implementation of VIM, controlling the final alloying levels of $\mathrm{Al}+\mathrm{Ti}$ in the alloy melt was imprecise and unrepeatable due to off gassing and oxidation.

Figure 13 is a simple schematic depicting the VIM process used to produce master alloy ingots [24]. Although the raw alloy is melted in a vacuum furnace, a small amount of oxide slag still forms at the top of the molten melt, which fortunately is separated from the liquid metal during the pouring process. In the case where large VIM ingots are produced, these large pieces are usually sectioned into smaller units that are subsequently remelted during the directional solidification (DS) casting process. A secondary VIM process may be used within the DS furnace to remelt the parent material prior to metal delivery into the ceramic molds. The advantage of using a double VIM process is the additional microcleanliness that it attained. However, secondary melting may result in minor compositional losses due to volatile element reactivity. In the case where large heats are required for casting large turbine buckets, a single VIM process may be performed within the industrial size DS furnace. 


\subsubsection{Directional Solidification Casting Process}

In the early 1960's, VerSnyder and his colleagues at Pratt and Whitney Aircraft (PWA) developed the DS casting process to overcome material creep deficiencies experienced along transverse grain boundaries in many of the cast turbine blade components $[36,37,38,39,40]$. At the time, it was clearly evident that two distinct fracture modes were present in the polycrystalline blades with respect to low and high temperature applications. Low temperature fracture almost always occurred transgranularly, indicating superior grain boundary strength, whilst high temperature fracture occurred predominantly intergranularly [41]. During high temperature service conditions, intergranular failure usually resulted from non-ideal grain boundary characteristics such as excessive precipitation, cavitation, and void formation. More significantly, failure at the grain boundaries usually initiated at the interfaces oriented normal to the applied stress (i.e. along the transverse direction). Hence, it was logically reasoned that the removal of the transverse grain boundaries should improve material properties and extend blade component lifetimes.

In addition to imparting longer crack initiation lifetimes, DS processing also offered additional benefits such as a preferred crystallography and reduced microporosity. As previously mentioned, preferred crystallographic orientation of components $(<100>$ longitudinal direction) yielded materials with a modulus (E) that was $40 \%$ lower than the polycrystalline equivalent resulting in much better resistance to thermal fatigue [42]. Improvements in high cycle fatigue (HCF) life were obtained due to reduced 
microporosity that resulted from better liquid metal feeding because of the constant supply of molten alloy at the solidification front during the DS casting process [42].

During the development stages of DS processing there were two main types of furnace designed for production of DS cast products. The stationary DS casting process involves no relative movement of either the furnace or the mold-cast assembly until complete solidification is achieved [43]. The process simply involves pouring the melt into a ceramic mold that is in contact with a cooling chill. Solidification begins once the melt closest to the chill drops below the liquidus temperature of the alloy. Solidification continues in the opposite direction of the heat flux (i.e. away from the chill). In this process, the heat flux decreases with time, which coincides with a decrease in the temperature gradient $(\mathrm{G})$ across the solid-liquid interface and slower interface movement (V) away from the chill [43]. A schematic of this simple DS casting arrangement is provided in Figure 14. The net result is a DS structure that varies microstructurally and chemically along the length of the final product. This stationary DS process is not capable of producing homogeneous castings that are suitable for advanced turbine blade applications. The "power down" method is an alternative to this simple DS process, in which the raw alloy is superheated in a resistance or induction crucible [36]. The power to the crucible is then reduced in a controlled fashion until the liquid metal is completely solidified. This process allows for better control of the solidification front as the cooling process can proceed in a preferred direction at a specific rate if multiple furnace zones are implemented and controlled independently. However, even with this improvement in controlled solidification, the process is still not idyllic with respect to maintaining a 
precise temperature gradient and solidification rate required for high quality DS columnar-grained and SX cast products.

More precise control is achievable using the other type of DS casting furnace, which involves movement of the casting (or the furnace itself) during solidification so that the temperature gradient and growth rate can be carefully controlled. The most commonly used dynamic DS process for the fabrication of SX materials is the Bridgman casting technique. Almost all industrial practices use the Bridgman method for casting SX components, ranging from the relatively small SX blades used for aero-engines up to the larger SX buckets used in land-based power generation units. A more detailed description of the Bridgman casting process will be provided in the following section.

\subsubsection{Bridgman Casting}

Bridgman casting, or controlled vacuum precision investment casting, as it is commonly referred to within industry, is the most commonly used process in the production of SX components for gas turbine applications. Many of the process components used to produce polycrystalline blades are also utilized in the Bridgman furnace. The major structural component is the water-cooled steel vacuum vessel. There are usually three major zones within the vessel. The upper hot-zone is usually where an induction crucible is located, that can be charged with pre-alloyed bars of master alloy produced from the initial VIM process. The next lower zone is also heated as it contains the ceramic mold and a mold pre-heater. The ceramic molds are usually preheated in excess of the alloy liquidus temperature to prevent premature solidification during the pouring process. 
Once the pre-alloyed bars have been melted using a suitable superheat temperature, the charge is tilted and poured into the preheated mold assembly. This is the point where the Bridgman casting furnace deviates from the traditional polycrystalline casting process.

Furnaces used for directional solidification have additional design features used to exercise a high level of control over the solidification process within the mold. The major additions include a water-cooled chill platen on which the mold assembly is placed, and a baffled cooling zone located directly below the copper chill platen. The copper chill platen is used to extract heat from the bottom end of the casting assembly creating a large temperature gradient. The baffling is used to separate the upper pre-heat zone and lower cold-zone so that the high thermal gradient that is required for planar solidification is maintained. Once a stable, planar solid-liquid interface is produced within the casting, the mold assembly is then withdrawn from the furnace hot-zone into the lower cold-zone. The mold assembly is usually withdrawn using an electro-mechanical or hydraulic drive. The speed at which the mold is withdrawn is carefully controlled so that the temperature gradient across the baffled region is kept constant so that planar solidification does not breakdown. Excessive withdrawal rates and insufficient thermal gradients usually result in SX breakdown with the onset of stray grain formation. A more detailed explanation of the solidification fundamentals will be provided later in section 4.1 .

Provided in Figure 15 is an example of a vacuum precision casting furnace produced by Consarc $^{\mathrm{TM}}$ Corporation [44]. This particular furnace is relatively large in size, as the control unit located at the top left hand comer of the image is approximately 6 - $\mathrm{ft}$ in 
height. The VIM crucible located in the upper-zone of the furnace has a $50 \mathrm{~kg}$ charge capacity. However, the actual amount of raw alloy used depends on the mold capacity for each particular heat. In this particular image, the copper chill platen is in the fully withdrawn position located in the bottom of the cold-zone. The hydraulic mechanism used to lower and raise the mold assembly is almost completely submerged below the surface of the foundry floor, required to minimize the necessary height restrictions of the furnace. A generalized schematic [33] of the internal components of the Bridgman furnace is illustrated in Figure 16. This particular furnace design uses an induction heater for both charge melting and mold pre-heating applications, however, resistance type furnaces may be utilized in alternative designs.

\subsection{Single Crystal Selection Process}

The ability to produce a single grain (i.e. single crystal) within the cast component is largely governed by three main factors; 1) a stable thermal gradient required to produce a planar solid-liquid interface, 2) a suitable slow withdrawal rate to avoid interface breakdown, and 3) appropriate ceramic mold geometry. During the withdrawal process, solidification begins at the melt end closest to the copper chill platen. Because the rate of solidification is much faster in the $<100>$ direction than other crystallographic directions, those crystals (i.e. grains) within the melt that are aligned with this orientation, (i.e. normal to the planar solidification front), become dominant and progressively eliminate less favored grains [45]. Eventually, only grains oriented in the $<100>$ direction persist. The selection of one single $<100>$ grain is controlled by means of the mold geometry. The various methods used for single grain selection [33] were previously described in Figure 10. The most common grain selection method used is the pigtail starter block. The 
elimination of the non $\langle 100\rangle$ grains occurs within the confines of the pigtail starter, where usually after traversing one complete turn of solidification the resulting microstructure consists of one single $<100>$ crystal.

The effectiveness of the pigtail selector is best demonstrated in Figure 17 illustrating the probabilistic model predictions of grain growth [46]. Figure 17(a) depicts the columnar grain structure that evolves when the turbine blade is cast in direct contact with the chill, without the use of a grain selector. It is apparent that the initial stages of solidification result in a fine equiaxed structure that is eventually eliminated with the onset of columnar growth in the longitudinal direction. Figure 17(b) illustrates the process of fine grain elimination within the pigtail selector and the eventual domination of a single $<100>$ crystal, which occurs after completing one full helical turn (represented in blue) [46].

Microstructurally, the most important aspect of the SX cast product is the certainty that only one grain exists and that no freckles or spurious grains have nucleated on the surface of the casting during the Bridgman withdrawal process. However, although the complexity of grain boundary metallurgy has been removed from the SX product, the actual SX microstructure is not as simplistic as the name suggests. The following section will provide a description of the typical microstructural constituents inherent to SX superalloys, as well as the microstructural stability issues to which all SX Ni-base superalloys are subjected. 


\section{Literature Review - Microstructural Stability of SX Materials}

Prior to discussing the microstructural mass transport phenomena of SX Ni-base alloys during casting, it is first imperative to briefly review the microstructural characteristics of these materials. The following will describe the basic chemistry and microstructural constituents present in most SX superalloys. A description of the major deleterious phases that may precipitate will also be discussed, along with several prediction methods that are commonly used in alloy compositional design practices.

\subsection{Microstructural Features of SX Ni-base Superalloys}

It is important to note that the microstructural evolution of Ni-base superalloys from the earliest turbine disc varieties to the modern SX blade structures required over 60 years of development. In many cases, modifications to alloy microstructures were largely governed by improvements in alloy processing routes, such as VIM, hot isothermal forging and DS casting. Experimental evaluation and in-service testing of alloys with varying levels of elemental additions has led to major changes in commercial alloy chemistries, which in turn greatly affected the resulting microstructures that were produced and utilized. Since the late 1940's, the compositional range of Ni-base superalloys has varied quite substantially, as summarized in Table 7 [33]. The progressive change in Ni-base superalloy microstructures has also been quite remarkable, as illustrated in the graphic timeline presented in Figure 18 [47]. As alloy microstructures and nominal compositions were optimized, there was an associated gradual increase in the temperature-strength capability over time, as depicted in Figure 19 [33]. It is apparent that during the initial period of superalloy development, more emphasis was placed on microstructural optimization of grain boundary morphology and grain boundary 
strengthening phases. Later, as processing methods evolved and the addition of precipitate forming elements became more abundant and commonplace, alloy designers concentrated on maximizing the precipitate volume fraction and precipitate morphology as the primary strengthening mechanisms for these alloys. Ultimately, with the development of columnar grained and SX alloys, microstructural designers concentrated completely on the development of alloys with extremely high precipitate volume fractions while controlling alloy composition levels so as to avoid the formation of secondary embrittlement phases. At the end of Figure 18 there is reference to the use of TaC fibers as a reinforcement agent in SX superalloys, however, this novel approach has since been abandoned. In fact, the high volume fraction-cuboidal precipitate structure developed in the 1980's, as shown in Figure 18, is still the industry norm with respect to turbine blade applications.

In general, the microstructural constituents of Ni-base single crystals are comparable to those of conventionally cast polycrystalline superalloys with the exception that no internal grain boundaries or grain boundary species (i.e. carbides or borides) are intentionally present. The major micro-constituents present in SX Ni-base superalloys are:

1) The $\gamma$ phase, the face-centered cubic (FCC) austenitic matrix (see Figure 20),

2) The $\gamma^{\prime}$ phase, the ordered $\mathrm{L} 1_{2}-\mathrm{FCC}$ intermetallic precipitate (see Figure 21),

3) The undesirable Topologically Close-Packed (TCP) phases - such as sigma ( $\sigma$-tetragonal), mu ( $\mu$-rhombohedral), and P (orthorhombic). 


\subsubsection{Austenitic $\gamma$-Matrix Phase}

The $\gamma$ phase, as already mentioned, is the continuous austenitic matrix generally consisting of nickel and varying amounts of solid-solution strengthening elements. In general, the solid-solution strengthening mechanism is partly due to the lattice distortion of the $\gamma$ matrix caused by the substituting atomic species. Hence, solid-solution strength is increased with increasing atomic size difference up to a maximum difference of $10 \%$. Although a significant amount of strength is attained by the solid-solution mechanism of the matrix, Ni-base SX superalloys receive considerable strength and hardening from the existence of the $\gamma^{\prime}$ precipitate phase.

\subsubsection{Ordered $\gamma^{\prime}$ Precipitate Phase}

The $\gamma^{\prime}$ phase is an ordered intermetallic FCC structure, empirically represented as an $\mathrm{A}_{3} \mathrm{~B}$-type compound. Generally, the precipitate has the nominal composition of $\mathrm{Ni}_{3}(\mathrm{Al}, \mathrm{Ti})$, with nickel occasionally being substituted by cobalt and titanium with tantalum. Due to their similar lattice parameter features, the matrix-precipitate mismatch is usually less than $1.3 \%$ [48]. Precipitate morphology is governed by the degree of this $\gamma$ $\gamma^{\prime}$ mismatch. Small mismatches of $\sim 0.05 \%$ result in spherical $\gamma^{\prime}$. As the degree of mismatch increases, $\gamma^{\prime}$ occurs in cuboidal form, followed by semi-coherent plate morphology when mismatches are greater than $1.25 \%$ [48]. Fundamentally, the precipitate shape is determined by its ability to lower the overall free energy of the system. The free energy of the system is governed by the competing variables of surface energy and strain energy. In short, the surface energy value varies with the square of the characteristic precipitate dimension, whereas the strain energy term varies with the cube 
of this dimension. Hence, at small sizes where the surface energy dominates, the precipitates assume a spherical shape to lower this value. Likewise, at larger sizes where the strain energy dominates, the precipitate assumes a more complex shape that reduces the overall strain [49]. A schematic [50] illustrating this sequential change in precipitate morphology is provided in Figure 22. In SX superalloy practice, the $\gamma^{\prime}$ precipitate size usually falls within the range of $0.2 \mu \mathrm{m}$ to $5 \mu \mathrm{m}$, depending on the heat treatment cooling rate [6]. An example of a typical SX microstructure showing the cuboidal $\gamma$ ' precipitate morphology and ordered distribution within the $\gamma$ matrix is depicted in Figure 23. Also, the general trend in phase composition between the $\gamma$ and $\gamma^{\prime}$ precipitate phases in typical SX superalloys can be seen from the atom probe results recorded in Table $6[51,52]$.

The volume fraction $\left(\mathrm{V}_{\mathrm{f}}\right)$ and size of the $\gamma^{\prime}$ particles are the two main variables that influence the degree of precipitation hardening. In $S X$ superalloys, the $V_{f}$ of $\gamma^{\prime}$ that can precipitate is quite large, reaching levels of $70 \%$ and even higher [6]. It is believed that a $\gamma^{\prime} V_{\mathrm{f}}$ of $70 \%$ is the optimal limit for these alloys, as precipitate fractions in excess of this value proportionally reduce the critical fraction of $\gamma$ matrix phase present. The precipitate $\mathrm{V}_{\mathrm{f}}$ of these alloys is governed by the relative amounts of $\mathrm{Al}, \mathrm{Ti}, \mathrm{Ta}$ and other $\gamma^{\prime}$ forming elements (described in Table 1) that are added to the parent material. By producing SX alloys with a high $V_{f}$ of fine precipitate, the creep strength of blade components can be significantly improved for high temperature applications, as illustrated in Figure 24 [53]. However, once subjected to the combination of high temperature and stress for extended periods of time, there is almost always an associated change in $\gamma^{\prime}$ precipitate morphology. 


\subsubsection{Changes in $\gamma^{\prime}$ Morphology After Service Exposure}

When SX blades are subjected to applied loads during service, the cuboidal $\gamma^{\prime}$ tends to coarsen, or raft, in a favorable crystallographic direction. The rafting phenomenon depends on the direction of applied stress and the lattice misfit of the $\gamma-\gamma^{\prime}$ phases [6]. In general, the $\gamma^{\prime}$ rafts are always parallel or perpendicular to the applied principal stress direction, depending on whether the load is tensile or compressive in nature [6]. Cuboidal $\gamma^{\prime}$ coalesces to form plates oriented normal to the turbine blade axis, which is perpendicular to the direction of centrifugal stress along the $<100>$ crystal axis [6].

In the case of SX turbine blade applications, the stress and temperature loads that a single blade experiences are by no means unidirectional or isothermal. It has been shown that the effect of a non-uniform temperature gradient plays little or no role in the mechanism of $\gamma^{\prime}$ rafting; however, the direction and magnitude of applied stress is far more critical [54]. Provided in Figure 25 is the temperature-stress profile of a service exposed, $1^{\text {st }}$ stage SX turbine blade, illustrating the effects of compressive and tensile loading on $\gamma^{\prime}$ precipitate rafting [6]. Fortunately, the incorporation of Re in the $2^{\text {nd }}$ and $3^{\text {rd }}$ generation SX alloys effectively impedes the coarsening kinetics of the $\gamma^{\prime}$ rafts, preventing solute dissolution from the $\gamma$ matrix.

\subsubsection{Topologically Close-Packed Phases}

In addition to the $\gamma^{\prime}$ precipitate phase, undesirable secondary precipitate phases may also appear in SX superalloys when suitable thermodynamic and kinetic conditions exist for nucleation and growth. Most multi-phase superalloys are used in a "metastable" condition 
consisting of the $\gamma$ and $\gamma^{\prime}$ phases. However, phase changes (e.g. morphology and composition) may occur due to thermal or thermo-mechanical exposure as a result of high-temperature service conditions. The formation of deleterious TCP phases is one of the main inhibiting factors in SX alloy development as they usually define the compositional limits to which an alloy can be modified. Hence, the development of new SX alloys does not only involve the improvement of high-temperature mechanical properties, but it must also include phasial stability over extended periods of service.

TCP phases are basically intermetallic compounds, which can be found in simple binary and ternary transition element systems, as well as the complex multi-component superalloy systems [6]. The three main TCP phases that may precipitate are sigma $(\sigma)$, $\mathrm{mu}(\mu)$, and $\mathrm{P}$ as illustrated in Figure 26, Figure 27, and Figure 28 respectively [55]. These are generally unwanted, brittle phases that can form during heat treatment or service exposure. In addition to their inherent brittle nature, these phases, which consist primarily of $\mathrm{Cr}, \mathrm{Mo}, \mathrm{Re}$ and $\mathrm{W}$, can also deplete the $\gamma$ matrix of potential solid solution strengthening elements [56]. The cell structure of these phases has close-packed atoms in layers separated by relatively large interatomic distances. The layers of close-packed atoms are displaced from one another by sandwiched larger atoms, developing a characteristic "topology" [57]. This is the main distinguishing feature of TCP phases as compared to $\gamma^{\prime}\left(\mathrm{Ni}_{3} \mathrm{Al}\right)$, which has close-packed atoms in all directions, hence its geometrically close-packed (GCP) structure. 


\subsubsection{Factors Affecting TCP Phase Formation}

As already mentioned, one of the main factors that affects the propensity of TCP phase formation is the alloy chemistry. SX alloys that contain high levels of refractory elements such as Re, W, and Mo are good candidates for TCP phase precipitation. Perhaps the most influential of these elements is $\mathrm{Re}$, due to its presence in the general composition of the TCP phases that form. For example, Re-rich TCP phases have been widely reported to occur in alloys such as CMSX-4 and CMSX-10 [32,58]. Furthermore, an elaborate research endeavor by Darolia et al. has shown that three types of TCP phases $(\sigma, \mu$, and P) can co-exist in the same alloy having similar $\mathrm{Re}+\mathrm{Cr}$ rich compositions [59]. Their findings also suggest that unlike other TCP formers such as $\mathrm{W}$ and $\mathrm{Mo}, \mathrm{Re}$ tends to promote formation by substituting for $\mathrm{Cr}$ atoms in the TCP phases [59]. This effect was seen to occur to an even greater extent in alloys with increased levels of Re additions. Therefore, to keep the high Re-levels required for improved creep strength, other $\gamma$ matrix elements such as $\mathrm{Cr}, \mathrm{Mo}, \mathrm{Co}$, and $\mathrm{W}$ must be reduced. This careful balance must be achieved to avoid localized supersaturation of the matrix, which is the predominant reason of Re-rich TCP precipitation.

The phasial stability effects of increased Re content have been traversed in the second and third generation alloys by decreasing the nominal $\mathrm{Cr}$ levels. Second generation $\mathrm{Cr}$ levels were dropped to 5-7 wt.\% (c.f. 8 wt.\% in first generation) and even further reduction in $\mathrm{Cr}$ levels for the third generation alloys where nominal compositions contain as little as $2-4 \mathrm{wt} . \% \mathrm{Cr}[26]$. It should be noted that the increased phasial stability gained 
by decreasing $\mathrm{Cr}$ content usually results in a reduction of hot corrosion-oxidation resistance, hence, a suitable balance must be maintained.

Although the level of refractory solid-solution elements mainly influences the formation of TCP phases, the amount of $\gamma^{\prime}$ forming elements (see Table 1) present also plays an important role. Generally, higher concentrations of $\gamma^{\prime}$ forming elements result in an overall increase of $\gamma^{\prime}$ volume fraction. As the $\gamma^{\prime}$ volume fraction increases it is obvious that the $\gamma$ matrix volume fraction must decrease proportionally. Hence, if an excessive amount of $\gamma^{\prime}$ phase precipitates (i.e. large $\mathrm{V}_{\mathrm{f}}$ ) then the $\gamma$ matrix is likely to become more prone to TCP phase formation [32]. In other words, as the matrix volume fraction decreases, the effective level of $\gamma$ partitioning elements increases. This results in a decreased solubility limit of the matrix for the refractory elements and thus precipitation of TCP phases due to supersaturation.

\subsubsection{Prediction of TCP Phase Formation}

The development of prediction methods for TCP phase formation has been an ominous task since the presence of these deleterious phases was first discovered. Phase prediction using simple binary or ternary phase diagrams is not a viable option due to the complex nature of these highly alloyed metals, which are largely governed by a multitude of binary, ternary, and higher order element interactions. Hence, researchers have been forced to develop phasial stability models based on fundamental material physics and chemistry approaches that usually incorporate some degree of experimentally determined material properties. Two of the oldest and more commonly used prediction models 
currently utilized by material designers are the $\mathrm{N}_{\mathrm{v}}$ PHACOMP and Md PHACOMP methods.

\subsubsection{1. $\quad N_{\vee}$ PHACOMP Modeling}

The first of the prediction models produced was the $\mathrm{N}_{\mathrm{v}}$ PHACOMP (PHAse COMPutation) method developed by Rideout et al. [60]. This was soon followed by two modified derivatives produced by Boesch and Slaney [61] and Woodyatt, Sims and Beattie [62]. These models rely heavily on the close-packed nature of the alloys, such that the electron interactions of the different electronic structures of each constituent atom can be used to estimate phasial stability. The theory is based on the number of unpaired delectrons $\left(\mathrm{N}_{\mathrm{v}}\right.$ - electron vacancies) for each element within the $\gamma$-matrix chemistry [63]. In cases where the experimental values of $\mathrm{N}_{\mathrm{v}}$ are not known for a particular element, the general procedure, based on Pauling theory [64], is to subtract the number of electrons outside the closed inert-gas core from 10.66, which is the maximum electron concentration for the $3 \mathrm{~d}$ sub-shell. Once the $\mathrm{N}_{\mathrm{v}}$ number for each element has been defined, the average vacancy number, $(\overline{N v})$, for the alloy matrix can be calculated by [65]:

$$
\overline{N v}=\sum_{i=1}^{n} f_{i}(N v)_{i}
$$

where: $\overline{N \nu}=$ average electron-vacancy number

$f_{i}=$ the atom fraction of the $i^{\text {th }}$ element in the $\gamma$-matrix

$n=$ the number of elements in the matrix

$(N v)_{i}=$ electron vacancy number of element $\mathrm{i}$. 
Experimental studies have shown that there is a good correlation between the propensity for TCP phase formation with increasing values of $\overline{N v}$. Therefore, alloys that have an $\overline{N v}$ value above some critical average vacancy number, $\left(\overline{N v}_{c}\right)$, will theoretically result in phase instability. The $\overline{N v}_{c}$ value is somewhere in the range of 2.45-2.5 depending on which model is used to determine the $\overline{N v}$ [25]. Since the method was originally introduced, there have been numerous modifications to the formula used to determine the residual $\gamma$-matrix $\overline{N v}$ values. The most recent and perhaps widely used method for determining $\overline{N v}$ is that proposed by Sims, Stoloff, and Hagel, which is defined by the following empirical formula [66]:

$$
\begin{gathered}
\overline{N v}=4.66(\mathrm{Cr})+2.66(\mathrm{Fe})+1.71(\mathrm{Co})+0.66(\mathrm{Ni})+3.66(\mathrm{Mn})+5.66(\mathrm{~V})+6.66(\mathrm{Si}) \\
+9.66(\mathrm{~W}+\mathrm{Mo})+7.66(\mathrm{Al})+6.66(\mathrm{Ti})+5.66(\mathrm{Ta}+\mathrm{Nb})+9.66(\mathrm{Re})
\end{gathered}
$$

Where: values in bracket are in atomic percentages.

It is apparent from the above equation that the method is critically dependent on knowledge of the composition of the $\gamma$-matrix. In cases where the residual matrix composition is not known, it is usually determined based on several assumptions that are used to predict the fraction of $\gamma^{\prime}$ that forms. (In the case of polycrystalline materials where carbides and borides may precipitate, these phases are usually accounted for prior to determining the $\gamma^{\prime}$ precipitate volume fraction.) This is accomplished by using experimental partitioning coefficients together with an empirical formula for the $\gamma^{\prime}$ 
precipitate phase. Once the atomic fraction of constituent elements required to form the $\gamma^{\prime}$ phase is calculated, the remainder of the alloy's nominal composition is used to define the $\gamma$-matrix chemistry.

One of the main drawbacks of this prediction model is that it was initially conceived for TCP phase prediction in wrought polycrystalline superalloys. The $\overline{N v}_{c}$ values are known to change with respect to the type of TCP phase that forms, and generally have lower critical values for SX alloys due to dendrite segregation [26]. In addition, the segregation effects and the slower diffusion of Re atoms present in the new generation SX alloys are not well accounted for in the present models [26].

\subsubsection{Md PHACOMP Modeling}

A more recent predictive model, commonly referred to as New PHACOMP, has been developed by Morinaga et al. [67]. The model uses the parameter, $\overline{M d}$, which is an average energy level of d-orbitals of alloying transition metals. The advantage of using this model is that the $\overline{M d}$ parameter not only takes into account electronegativity effects, but it also includes the influence of atomic size factors [67]. This is accomplished by using the DV-X $\alpha$ Cluster method [67]. The calculation involves determining the energy levels of transition metals $(\mathrm{M})$ substituted into a hypothetical $\mathrm{MNi}_{12} \mathrm{Al}_{6}$ cluster. Although this approach only approximates the actual bonding sequence that may occur in the $\gamma$ matrix, theoretically it should yield more accurate results than the Nv method, which determines transition metal energy levels based on isolated atoms alone. In general, the calculated energy levels tend to increase with atomic radius of metal M. In a manner 
similar to the $\mathrm{N}_{\mathrm{v}}$ PHACOMP method, the characteristic $\overline{M d}$ value can be calculated using [67]:

$$
\overline{M d}=\sum_{i=1}^{n} X_{i}(M d)_{i}
$$

where: $\overline{M d}=$ average Md parameter

$X_{i}=$ the atom fraction of the $\mathrm{i}^{\text {th }}$ element in the alloy

$n=$ the number of elements in the alloy

$(M d)_{i}=\quad$ the metal-d level for element $\mathrm{i}$.

This equation can be expressed empirically based on the atomic concentration of the transition elements in the overall alloy composition as [25]:

$$
\begin{aligned}
\overline{M d}= & 0.717(\mathrm{Ni})+1.142(\mathrm{Cr})+1.90(\mathrm{Al})+1.655(\mathrm{~W})+1.55(\mathrm{Mo})+0.777(\mathrm{Co})+2.271(\mathrm{Ti}) \\
& +2.224(\mathrm{Ta})+2.11(\mathrm{Nb})+1.267(\mathrm{Re})
\end{aligned}
$$

where: critical value, $\overline{M d} \leq 0.991$ for $\sigma$ phase in SX alloys.

Similar calculations to those above can be performed using the atomic fractions of the $\gamma$ matrix composition as opposed to the nominal levels. However, the critical values $\left(\overline{M d_{c}}\right)$ for the average metal- $\mathrm{d}$ levels must be re-evaluated to determine the associated limits for TCP phase formation. 
As with the Nv method presented earlier, the primary disadvantage of this model is that the characteristic segregation effects that occur during solidification are not considered. Even after solutionizing heat treatments are implemented, SX alloys still contain some measure of chemical inhomogeneity. This usually results in localized regions that have compositions close to, or above the supersaturation limits favorable for TCP phase precipitation. Another common problem associated with both PHACOMP models is the inability to predict synergistic effects of combined alloying additions. For example, research has shown increased partitioning of $\operatorname{Re}$ into the $\gamma^{\prime}$ phase with respect to increasing W concentration levels in SX alloys [59]. This is contrary to current model parameters that use fixed partitioning values over a wide range of SX alloy compositions, which do not account for such pair wise interaction effects. It becomes apparent that further work is still required to account for these types of phenomena with respect to their altering effects on critical $\mathrm{Md}$ and $\mathrm{N}_{\mathrm{v}}$ levels.

Another shortcoming of both PHACOMP prediction models is the inability to predict the kinetic behaviour of TCP phase formation. Both the $\mathrm{N}_{\mathrm{v}}$ and Md models are only capable of predicting the likelihood of formation of embrittling TCP phases based on equilibrium conditions. As both prediction methods are based solely on electronic compound behaviour, absolutely no information with respect to the kinetics of TCP phase nucleation and diffusional growth processes can be ascertained. In reality, the eventual formation of harmful TCP phases may not be deemed as critical if it is shown that growth kinetics are extremely slow. For the most part, kinetic properties have to be determined 
experimentally, advocating the necessity for further research with respect to phase stability behaviour.

\subsubsection{Empirical Based Modeling}

In addition to the PHACOMP models presented above, there have been more recent efforts to predict alloy phase stability using empirically based models. The advantage of using this type of model is that it does not directly rely on $\gamma$-matrix or $\gamma^{\prime}$ precipitate compositions, which are difficult to compute or measure accurately. Ritzert et al. studied the effects of element interaction on TCP phase formation [68]. The approach consisted of producing an experimental database using 44 superalloy derivatives of the third generation SX alloy René N6. Representative samples from each alloy were homogenized above the solutionizing temperature and then subsequently heat-treated using the turbine blade exposure temperature of $1093^{\circ} \mathrm{C}$ for 400 hours. The samples were then removed and examined for TCP phase volume fraction. Based on the experimental results, an empirical formula was generated that accounts for singular elemental effects as well as pair wise interactions of alloying additions. The empirical relationship of volume percent TCP phase as a function of the alloy composition is as follows:

$$
\begin{aligned}
\text { Vol.\% TCP }= & {[16.344782-1.019587(\mathrm{Al})-2.624322(\mathrm{Cr})-3.821997(\mathrm{Mo})+1.109575(\mathrm{Re})} \\
& -3.207295(\mathrm{Ta})+6.462984(\mathrm{~W})-2.271803(\mathrm{Co})+0.052884\left(\mathrm{Al}{ }^{*} \mathrm{Co}\right) \\
& +0.214059\left(\mathrm{Al}{ }^{*} \mathrm{Cr}\right)+0.300698\left(\mathrm{Al}{ }^{*} \mathrm{Mo}\right)+0.80011\left(\mathrm{Co}^{*} \mathrm{Re}\right) \\
& \left.+0.257108(\mathrm{Cr} * \mathrm{Mo})-5.081598\left(\mathrm{Re}^{*} \mathrm{~W}\right)+1.824441\left(\mathrm{Ta}^{*} \mathrm{~W}\right)\right]^{2}
\end{aligned}
$$


Where: values in brackets are nominal alloy addition levels in at.\%.

Compared to the experimental results, the empirical model has been found to predict accurately within the $95 \%$ confidence interval [68]. As seen in equation (5), the model predicts the volume fraction of TCP phase formation based on seven pair wise interaction terms, namely, $\mathrm{Co} / \mathrm{Re}, \mathrm{Mo} / \mathrm{Cr}, \mathrm{Cr} / \mathrm{Al}, \mathrm{Co} / \mathrm{Al}, \mathrm{Mo} / \mathrm{Al}, \mathrm{W} / \mathrm{Re}$, and W/Ta. Several important findings emerged from the model development process, including the following synergistic effects:

1. At low Co levels, Re inclusion has little effect on TCP formation,

2. At high Co levels, Re directly affects TCP formation as its level is increased,

3. At high $\mathrm{Cr}$ levels, high Mo or high $\mathrm{Al}$ content strongly influences TCP formation,

4. At high $\mathrm{Al}$ levels, increasing levels of $\mathrm{Cr}$, $\mathrm{Co}$, or Mo advances TCP formation,

5. At low W levels, Ta or Re levels provide for subtle TCP response.

There are two main problems with this model. First, the 44 alloys that were used in the phase stability test matrix were cast in the polycrystalline condition. In this condition, the likelihood of TCP phase formation is greater due to the increased amount of high-energy grain boundary area that effectively acts as ideal TCP phase nucleation sites [68]. The second major drawback is the narrow compositional range chosen for the experimental alloys. Although the model is very accurate for compositions comparable to René N6, it does not correctly predict TCP formation for other nominal alloy levels. In fact, the suggested model highly over-predicts the volume fraction of TCP phase formation for the second generation SX alloy, René N5 [68]. This suggests that further model development 
is required to incorporate additional alloy compositions that fall outside the present alloy design space.

An alternative approach that does not restrict itself to narrow alloy compositional ranges is the method of computational thermodynamic modeling. This method is more robust in the sense that it is based on fundamental thermodynamic principles for the smaller binary and ternary systems, which are then interpolated to fit the higher order multi-component systems.

\subsubsection{Computational Thermodynamic Modeling}

In the case of simple binary or ternary alloys, it is quite easy to use experimentally determined phase diagrams for the prediction of phase equilibria at a specific temperature and composition. In fact, one can even predict the solidification path and relative phase fractions of a specific alloy composition by using simple tie-line and lever rule interpolations. For example, upon examining the Ni-Al binary system shown in Figure 29 , it is apparent that to produce a binary alloy consisting of only the $\gamma$ and $\gamma^{\prime}$ phases, a minimum of $\sim 85 \mathrm{wt} \% \mathrm{Ni}$ (i.e. maximum of $15 \mathrm{wt} \% \mathrm{Al}$ ) would be required. Unfortunately, when dealing with multi-component systems, such phase equilibria predictions are not trivial. The amount of experimental data that exists for these complex systems as a function of varying composition levels is extremely small. The ability to predict the presence of such TCP phases as $\sigma$ or $\mu$ in SX superalloys for specific compositions is a complex problem that requires more sophisticated solutions. With the advent of faster computers and commercially available software packages, the prediction 
of phase equilibria for complex multi-component systems is now attainable using the combination of experimentally determined thermodynamic data-sets and computational thermodynamic modeling. The following briefly explains the complexity of multicomponent thermodynamic modeling and how it can be used as a design tool in the selection of SX superalloy compositions.

\subsection{Fundamentals of Phase Diagram Thermodynamics}

It is obvious that when considering the number of solute species present in a typical SX alloy composition (up to 10 elements), it is impossible to graphically represent all the individual effects of temperature and composition in one phase equilibria diagram. If one considers the difficulty and aptitude required to decipher a comparatively simple quaternary phase diagram the degree of difficulty associated with higher order systems becomes apparent. For example, if we consider an alloy that contains 10 elements and 4 constituent phases (e.g. $\gamma, \gamma^{\prime}, \sigma$ and L) then there are 8 degrees of freedom for the system. Even if the variables of pressure and temperature are fixed, there are still 6 degrees of freedom remaining, which are impossible to represent graphically. However, the difficulty in graphically representing multi-component systems is immaterial if the necessary information (i.e. phase equilibria) can be determined using the actual phase diagram calculations. In other words, it is possible to predict the likelihood of a specific phase within a system by performing the actual phase diagram calculations, even though the multi-component phase diagram cannot be graphically represented. These thermodynamic calculations are performed based on fundamental phase equilibria relationships. This approach is often referred to as the CALPHAD method, which is an acronym for the CALculation of PHAse Diagrams [69]. The CALPHAD method, more 
recently referred to as computational thermodynamic modeling (CTM), relies heavily on the concept of Gibbs free energy $(G)$ and how free energy algebraic expressions can be used to define the equilibrium state of a system.

For alloy systems at a specific temperature, there is a maximum concentration of solute atoms that may dissolve in the solvent to form a solid solution. If this solubility limit is surpassed, the addition of excess solute atoms results in the formation of another solid solution phase or compound that has a distinctly different composition. For example, there is a maximum amount of $\mathrm{Cr}$ that can be handled in the $\mathrm{Ni}$ solid solution ( $\gamma$-matrix) of SX superalloy systems, above which results in the formation of the harmful, $\mathrm{Cr}$-rich $\sigma-$ phase. This solubility limit can vary with temperature and may also be affected by the levels of other solute atoms in the alloy composition. Nonetheless, this solubility limit, or phase boundary line, can be represented mathematically. In fact, all the boundary lines on a phase diagram can be mathematically represented using algebraic expressions. However, instead of using simple algebraic expressions to describe the boundaries of phase equilibria, it is more useful to define these expressions in terms of thermodynamic properties of the phases themselves. This is where the concept of Gibb's free energy is incorporated into the method of computational thermodynamics.

In brief, free energy is the thermodynamic quantity that defines the state of equilibrium of a system. Thermodynamically, a system is said to be in equilibrium when its free energy 
is a minimum. In its most simple definition, the free energy of an alloy system under constant pressure is defined as [70]:

$$
G=H-T S
$$

$$
\text { Where: } \begin{array}{rll}
\mathrm{G} & = & \text { Gibb's free energy } \\
H & = & \text { enthalpy (heat content) } \\
S & = & \text { entropy (atomic disorder). }
\end{array}
$$

It is apparent from equation (6) that for any given alloy system, equilibrium is attained when the free energy is at a minimum for the appropriate combination of low enthalpy and high atomic disorder. Hence, in terms of meeting equilibrium requirements, the existence of a specific phase at a given temperature depends on the total free energy level of the system, where the presence of the phase results in minimization of the systems free energy. For example, the nucleation of $\sigma$ phase from the $\gamma$-matrix solid solution will only occur if the formation of the $\sigma$ phase lowers (i.e. minimizes) the free energy of the total system.

This concept of minimum Gibbs free energy as a function of temperature and composition is more clearly demonstrated using the example of a simple A-B binary alloy, illustrated in Figure 30 [71]. For this particular system, there are three stable phases present, $\alpha, \beta$, and liquid. Upon examining the bottom free energy diagram in Figure 30(a), it is apparent that at $T_{1}$, three independent Gibbs energy curves exist for all three phases. Curve a-g is the free energy of mixing for the $\alpha$-phase at $T_{1}$ as a function of composition. Similarly, curves b-c and d-h represent the G-x properties for the liquid and 
$\beta$-phases respectively. In this diagram, it is apparent that at a high concentration of A, $\left(C_{1}\right)$, the $\Delta G_{M I X}$ for the $\alpha$-phase is lower than $\Delta G_{M I X}$ for the liquid phase, hence, according to the thermodynamic conditions of equilibrium, minimization of the Gibbs free energy occurs when the $\alpha$-phase is present. This corresponds to the dominant $\alpha$ phase field in the upper equilibrium phase diagram of Figure 30(a). Also in Figure 30(a), at a high $B$ concentration level, $\left(C_{2}\right)$, it is apparent that $\Delta \mathrm{G}_{\mathrm{MIX}}$ for the liquid phase is less than $\Delta \mathrm{G}_{\mathrm{MIX}}$ for the $\beta$-phase. This implies that at $\mathrm{T}_{1}$ and high levels of $\mathrm{B}$ the most stable equilibrium phase is liquid, corresponding to the dominant liquid phase field in the associated equilibrium phase diagram. The effect of temperature on $\Delta \mathrm{G}_{\mathrm{MIX}}$ is clearly demonstrated when comparing the change in G-x curves from temperature $T_{1}$ to $T_{3}$. In Figure 30(d), at the same high concentration level $\mathrm{C}_{2}$, there is a change in $\Delta \mathrm{G}_{\mathrm{MIX}}$ at the lower temperature $T_{3}$. In this example, the $\Delta G_{\mathrm{MIX}}$ for the $\beta$-phase is now lower than the free energy of the liquid phase, corresponding to the dominant $\beta$-phase field in the phase diagram at $\mathrm{T}_{3}$ for $\mathrm{C}_{2}$. It is evident from this example, that if the $\mathrm{G}-\mathrm{x}$ properties for all phases at all temperatures are known for a given alloy system, it is then possible to predict the equilibrium state for the system at specific composition levels based on the concept of Gibbs energy minimization. Hence, the accuracy of prediction of phase equilibria for a system relies heavily on the accuracy of the free energy of mixing terms derived for each solution phase over specific temperature and composition ranges.

The simple free energy expression provided in equation (6) requires expansion to illustrate how this concept of thermodynamic modeling can be used to predict such phase 
equilibria conditions. The following section will elaborate on the Gibbs energy expressions used to model a simple binary system, with a succeeding section explaining the concept of interpolation to a multi-component system.

\subsection{Thermodynamic Modeling of Binary Solution Phases}

When dealing with non-pure systems containing more than one species (i.e. alloys), the free energy of the system immediately becomes dependant on the solute concentration level. This mixture of atoms can usually be represented by the general Gibbs free energy expression of the random substitutional solution model [72]:

$$
\Delta G=\Delta G^{\circ}+\Delta G_{m i x}^{I D}+\Delta G_{m i x}^{E}
$$

Where for a binary system (A-B):

$$
\begin{array}{ll}
\Delta G^{\circ}=X_{A}\left(H_{A}^{\circ}-T S_{A}^{\circ}\right)+X_{B}\left(H_{B}^{\circ}-T S_{B}^{\circ}\right): & \text { Lattice stabilities } \\
\Delta G_{m i x}^{I D}=X_{A} R T \ln X_{A}+X_{B} R T \ln X_{B}: & \text { Ideal mixing term } \\
\Delta G_{m i x}^{E}=\sum_{i=0}^{n} X_{A} X_{B}\left(\left(h_{i}-s_{i} T\right) X_{B}^{i}:\right. & \text { Excess mixing term }
\end{array}
$$

Prior to discussing each of the terms in equation (7), it is important to note that Gibbs energy values are always calculated with respect to a reference phase. In terms of phase diagram calculations for a binary alloy, the liquid phase (L) is almost always selected as the reference phase for the metallic components, (i.e. Gibbs energy of $\mathrm{L}$ is zero at all $\mathrm{T}$ and $\mathrm{P})$. 


\section{Lattice Stability Free Energy}

The first term in equation (7) is often referred to as the lattice stability of the phase. The concept of lattice stability was first recognized in the early works of Kaufman, one of the pioneers in phase diagram calculation methodologies [73]. In brief, the lattice stability term corresponds to the Gibbs energy of a mechanical mixture of the pure components. The CALPHAD approach relies heavily on the concept that complete Gibbs energy versus composition (G-x) curves can be constructed for all crystal structures of the elements for the whole alloy system [69]. To do this, the G-x curves must be extrapolated into regions where they are either metastable or unstable. In other words, because phase equilibria diagrams contain only the known stable phases for specific compositions, the existence of the unstable structure must be determined using scientific conjecture. For example, the enthalpy and entropy of fusion values for pure fcc $\mathrm{Ni}$ are easily determined experimentally, however, the lattice stability values for hep $\mathrm{Ni}$ would have to be extrapolated as this crystal structure is unstable for Ni. Hence, the lattice stabilities for various crystal structures of the pure elements of the system must be established in a selfconsistent manner in order to perform phase diagram calculations. For example, the extrapolated lattice stability values for hcp $\mathrm{Ni}$ derived from the $\mathrm{Ni}-\mathrm{Ru}$ phase diagram must also be consistent with the hep Ni values that would be used in the Ni-Ti and Ni-Co systems (both $\mathrm{Ti}$ and $\mathrm{Co}$ are naturally hcp).

There are numerous methods for determining the unknown lattice stability values, but most are deduced partially from the characteristics of existing phase diagram data where 
lattice stability values are known for a given crystal structure, in conjunction with lattice stability trends observed in the periodic table [69]. Fortunately, an extensive amount of work has been conducted by Dinsdale et al. of the Scientific Group Thermodata Europe (SGTE) in compiling such lattice stability data for the pure elements [74]. In general, the lattice stability of a pure component relative to the liquid phase can be represented by the linear term [11]:

$$
G_{A}^{\alpha}=h^{t}+s^{t} T
$$

Where at the melting point of element $\mathrm{A}$ in the $\alpha$ phase, $T=T_{M}$, the value of $G$ goes to zero and the coefficients $h^{t}$ and $s^{t}$ represent the heat and entropy of fusion respectively [11]. The lattice stability free energy equation (8) incorporates these linear relationships for both species in the phase, as a function of their atomic fractions.

\section{Ideal Free Energy of Mixing}

The mixing term provided in equation (9) represents the Gibbs free energy of mixing for the solution phase assuming that an ideal, perfectly random solution of the atomic fractions of species A and B exists. By definition, an ideal substitutional solution is characterized by the random atomic distribution of components on a lattice with an interchange energy equal to zero [69]. In other words, for an ideal solution there are no additional thermodynamic effects of interacting species within the equilibrium phase. However, in reality there is almost always some deviation from ideal solution behaviour when two or more different species are mixed together.

\section{Excess Free Energy of Mixing}


In general, any "excess" thermodynamic function is a measure of the systems departure from ideal solution behaviour. In this case, the non-ideal free energy of mixing, or excess energy of mixing, is due to the attractive and repulsive interaction forces that occur between different atomic species (e.g. A and B atoms). If there is a strong attractive bond between dissimilar atoms (i.e. A-B bond strength > A-A or B-B bond strength) then the effective concentrations of the two dissimilar metals in solution are reduced. An increase in the effective concentration of the dissimilar atoms results from the opposite scenario, where repulsive forces exist between A and B atoms. The excess free energy of mixing, described in equation (10), accounts for these additional interaction energies and their overall effect on the Gibbs free energy of the solution phase. It is imperative that the excess energy expressions are such that they can be used to estimate the properties of higher order systems based on experimental information gathered from lower order systems (e.g. estimation of ternary solution properties from the three component binary sets) [75].

There have been various forms of equation suggested to represent the excess Gibbs energy of a binary solution phase. The easiest way to represent this term is a polynomial description of concentration. The following four equations are commonly used examples of $\Delta G_{m i x}^{E}$ models implemented in phase diagram calculations.

$$
\begin{array}{ll}
\Delta G_{m i x}^{E}=X_{A} X_{B} \sum_{i=0}^{n} p_{i} X_{B}^{i}: & \text { Margules [76] } \\
\Delta G_{m i x}^{E}=X_{A} X_{B} \sum_{i=0}^{n} B_{i}\left(X_{A}-X_{B}\right)^{i}: & \text { Redlich \& Kister [77] }
\end{array}
$$




$$
\begin{array}{ll}
\Delta G_{m i x}^{E}=X_{A} X_{B} \sum_{i=0}^{n} C_{i} X_{A}^{(n-i)}-X_{B}^{i}: & \text { Borelius [78] } \\
\Delta G_{m i x}^{E}=X_{A} X_{B} \sum_{i=0}^{n} D_{i} P_{i}\left(X_{A}-X_{B}\right)^{i}: & \text { Bale \& Pelton [79] }
\end{array}
$$

Although numerous polynomial models exist, they can all be transformed into each other with some mathematical manipulation. Hence, selection of a suitable polynomial is not of prime importance. The Margules polynomial formalism described in equation (12) is probably the simplest description that can be provided for $\Delta G_{\text {mix }}^{E}$. Although the choice of formalism is not important for excess energy modeling, the order of the polynomial is critical. If the $\Delta G_{\text {mix }}^{E}$ expression is expanded using the Margules formalism, several important model features are visible.

$$
\Delta G_{m i x}^{E}=X_{A} X_{B} \sum_{i=0}^{n} p_{i} X_{B}^{i}=X_{A} X_{B}\left(p_{0}+p_{1} X_{B}+p_{2} X_{B}^{2}+\ldots\right)
$$

For the most part, binary solution phases (e.g. liquid and disordered solid solutions) can usually be adequately described as random mixtures of the elements using a "regular" solution type model. Hildebrand first suggested the mathematical concept of a regular solution model in 1929 , but implementation with respect to phase diagram calculations did not occur until 30 years later [80]. Nonetheless, the use of the regular solution methodology to represent binary solution phases is still the most commonly used method for excess Gibbs energy modeling. From equation (16) it is apparent that the regular 
solution model exists when $\mathrm{n}=0$. When $\mathrm{n}=1$ we have the so-called subregular solution, and when $\mathrm{n}=2$ we have the sub-subregular solution model [81].

$$
\begin{aligned}
& \Delta G_{m i x}^{E} \quad=X_{A} X_{B} p_{0} \quad \text { Regular } \\
& =X_{A} X_{B}\left(p_{0}+p_{1} X_{B}\right) \quad \text { Subregular } \\
& =X_{A} X_{B}\left(p_{0}+p_{1} X_{B}+p_{2} X_{B}^{2}\right) \quad \text { Sub-subregular }
\end{aligned}
$$

Model selection (i.e. equation 17,18 or 19) is based on how well each algebraic expression fits the experimental data. In other words, if a regular solution model can be used to produce the necessary topological features shown in the binary phase diagram then including additional terms is not necessary. In general, the inclusion of a fourth parameter (i.e. $n=3$ ) would result in mathematical artifacts that do not represent the true nature of the system (so, $\mathrm{p}_{3}=0$ etc...)[81]. In the Margules formalism, the $\mathrm{p}_{\mathrm{i}}$ terms represent the thermal part of the excess Gibbs energy of the alloys. They can consist of two parts; the enthalpy and thermal entropy terms such that:

$$
\begin{aligned}
& \text { e.g.: } \quad p_{0}=a_{0}+b_{0} T \\
& p_{1}=a_{1}+b_{1} T \\
& p_{2}=a_{2}+b_{2} T
\end{aligned}
$$

Once all three free energy terms $\left(\Delta G^{\circ}+\Delta G_{m i x}^{I D}+\Delta G_{m i x}^{E}\right)$ have been defined for each possible phase in the binary system over the relative temperature and composition ranges, it is then possible to perform comparative Gibbs energy minimization calculations. For 
example, if the phase equilibria results for a specific binary alloy are to be determined at a given temperature, then the relative fractions of $\mathrm{A}$ and $\mathrm{B}$ are entered into the free energy equations for each phase. The phase calculation that results in the minimum free energy for the specific temperature and composition would then be the resulting equilibrium phase. Also, with all the G-x properties for the solution phases defined, one may produce a binary phase diagram by performing the minimization calculations over the complete composition and temperature ranges of interest. Obviously, computer assistance is helpful to perform such mapping tasks, and compulsory when dealing with larger multi-component systems. One such computer program specifically tailored for such applications is the Facility for the Analysis of Chemical Thermodynamics $\left(\mathrm{F}^{*} \mathrm{~A}^{*} \mathrm{C}^{*} \mathrm{~T}\right)$ [82]. This program was conceived in 1976 as a joint research project between two universities, the École Polytechnique (Professors Christopher W. Bale \& Arthur D. Pelton) and McGill University (Professor William T. Thompson), for treating thermodynamic properties and calculations in chemical metallurgy. Since 2001, the latest version of this software-database package has been called FACT-Sage ${ }^{\mathrm{TM}}$ [83].

\subsection{Interpolation of Excess Gibbs Energy to Multi-Component Systems}

As previously stated, most SX superalloy systems may contain up to 10 elements in their nominal compositions. Therefore, the associated free energy of mixing models required for the $\gamma$-matrix solid solution and liquid phases must incorporate the interaction effects of all the constituent solute species. Since both of these phases are nicely represented by the random substitutional solution formalism, interpolation from the constituent binary systems to the multi-component system is a relatively simple procedure. Several 
geometric thermodynamic models, based on regular solution theory, have been proposed to accomplish this interpolation task [84]. Depicted in Figure 31 are three such proposed models for interpolating the binary excess polynomials into the ternary A-B-C system. Although the choice of interpolation model is arbitrary for regular solution theory, the Kohler scheme will be utilized for the present study. For the Kohler scheme provided in Figure 31 , it is apparent that the ternary excess free energy at point $p$ is calculated based on the weighted contributions from the binary sub-systems. This Kohler representation for the ternary excess free energy of the $\alpha$-phase can be represented algebraically by the following equation:

$$
\begin{aligned}
\Delta G_{p}^{E, \alpha} & =\left(1-X_{C}\right)^{2} \Delta G_{A B}^{E, \alpha}+\left(1-X_{A}\right)^{2} \Delta G_{B C}^{E, \alpha}+\left(1-X_{B}\right)^{2} \Delta G_{A C}^{E, \alpha} \\
& + \text { required ternary terms. }
\end{aligned}
$$

Where for the ternary system, the mole fractions of $A+B+C=1$ and the excess Gibbs energy for the A-B, B-C, and A-C binary systems are calculated at composition points $a$, $b$, and $c$ respectively. In some cases it may be necessary to add an additional ternary term to account for the supplementary effect of a three-element interaction parameter, which may be responsible for known deviations in the system properties. In the case of higher component systems (i.e. C $>3$ ), experience has shown that no additional higher order terms are required for correction [85]. In other words, experimental results have shown that if the multi-component Gibbs energy model correctly predicts the phase equilibria for the constituent binary and ternary systems then the prediction of the higher order system is usually accurate, requiring no additional correction terms. Hence, when assessing the accuracy of a computational thermodynamic model, one need only confirm 
the correctness of phase stability results for the lower order binary and ternary systems. This CALPHAD assessment procedure is schematically represented in Figure 32 for clarification [86]. 


\section{Literature Review - Microsegregation in SX Superalloys}

Prior to discussing the actual microsegregation behaviour of SX superalloys, it is first necessary to discuss some of the fundamental concepts of alloy solidification.

\subsection{Fundamentals of Planar Front Solidification}

The basic casting method used to produce SX blades was presented in section 2.3. However, optimization of alloy chemistry and casting processes requires a more comprehensive understanding of the underlying mass and thermal transport phenomenon that occur during the casting process. For this reason, some of the fundamental solidification terminology and models will be provided with a more thorough literature review covered elsewhere by Davies [87], Flemings [90], McLean [89], and Kurz [43].

The solidification behaviour of SX superalloys is comparable to the solidification of single-phase alloys under plane-front interface conditions. This is because the transformation from the liquid phase to $\gamma$-matrix phase occurs much earlier during cooling than the processes of $\gamma^{\prime}$ or TCP precipitation. There are several models that can be used to describe the controlled plane-front solidification of single-phase alloys, ranging from the earliest equilibrium solidification model to the latest models that incorporate more realistic variable diffusion properties across the solid-liquid interface.

\subsubsection{Equilibrium Solidification Model}

In general, the solidification of most single-phase metals can be approximated by the theory that a state of equilibrium exists at the solid-liquid interface during growth. The assumption that equilibrium exists at the interface infers that there is no resistance to 
atom transport between the solid and liquid phases and their respective compositions at a specific temperature can be directly read from the equilibrium phase diagram, as shown in Figure 33 [90]. From this diagram it is apparent that if a single crystal of nominal composition $\left(\mathrm{C}_{0}\right)$ is cooled to some temperature $\left(\mathrm{T}^{*}\right)$ below the liquidus temperature $\left(\mathrm{T}_{\mathrm{L}}\right)$, then according to equilibrium solidification theory, the compositions of the liquid and solid at the interface must be $\mathrm{C}_{\mathrm{L}} *$ and $\mathrm{C}_{\mathrm{S}} *$ respectively. At any given point during solidification, the equilibrium partition ratio may be defined as:

$$
k=\frac{C_{S}^{*}}{C_{L}^{*}}
$$

It becomes immediately obvious from this example that these alloys solidify over a range of temperatures due to the dependency of the liquidus temperature on the changing liquid composition. The initial solid nuclei that form will have a composition $\left(\mathrm{kC}_{\mathrm{O}}\right)$ proportional to that of the nominal alloy composition [90]. However, as the solid phase begins to grow, solute rejection of certain atomic species into the more diffusive liquid phase occurs. This results in a higher concentration of solute in the remaining liquid phase, which in turn provides for a lower liquidus temperature than that of the initial composition. This incremental solute rejection process is what leads to the development of segregation within the alloy microstructure. In general, the more time an alloy has to perform solute rejection (i.e. time required to cool from $T_{L}$ to $T_{S}$ ) the greater the severity of segregation in the cast bar. However, residual composition gradients and microsegregation theoretically should be completely removed if strict equilibrium solidification theory is observed. 
In general, the casting behaviour of SX superalloys does not abide by the conditions of equilibrium solidification. In other words, the optimum SX solidification rate is comparatively too fast with respect to equilibrium diffusional processes. Hence, insufficient time is allowed for complete diffusion of solute atoms in the solid and liquid phases during the solidification process. If equilibrium conditions were achievable, then the final SX product would be completely homogeneous with all artifacts of microsegregation removed. The amount of solute redistribution during equilibrium solidification can be determined by using the equilibrium lever rule [90], $C_{S} f_{S}+C_{L} f_{L}=C_{0}$. This rule may be rewritten in the following form of equation (22) to describe the composition of the solid phase with respect to the fraction of solid that has been solidified.

$$
C_{S}=\frac{k \cdot C_{0}}{\left(1-f_{S}\right)+k \cdot f_{S}}
$$

Where: $C_{S}=$ solute concentration in solid (wt.\%)

$C_{0}=$ initial solute concentration (wt.\%)

$k=$ partition coefficient

$f_{S}=$ fraction solid.

Although equation (22) indicates that there is a change in solute level across the interface, the equilibrium model assumes complete diffusion in the liquid and solid phases so that the final product will have a homogeneous composition $\mathrm{C}_{\mathrm{S}}=\mathrm{C}_{0}$. A schematic of the complete equilibrium solidification process is provided in Figure 34 [90]. 


\subsubsection{Scheil-Gulliver Solidification Model}

The next solidification model that was developed follows all the rules of equilibrium solidification except that it strictly prohibits the occurrence of solid diffusion. This removes the occurrence of back diffusion of solute atoms from the enriched liquid phase into the initial fraction of solid that has formed. The end result is a steady rise in rejected solute level in the liquid phase until the final liquid region has reached the eutectic composition, as shown in Figure 35 [90]. Earlier works by Gulliver and Scheil have produced this "non-equilibrium lever rule" often referred to as the Scheil equation, which can be represented as follows,

$$
C_{S}=k \cdot C_{0}\left(1-f_{S}\right)^{(k-1)}
$$

The Scheil equation can be used to determine the fraction of eutectic formed, $f_{E}$, by substituting in the experimentally measured values of $C_{S}$ and $k$ at the solid-liquid interface when $\mathrm{T}=\mathrm{T}_{\mathrm{E}}$. In other words, $f_{E}=1-f_{S}$ and $\mathrm{C}_{\mathrm{E}}=\mathrm{C}_{\mathrm{S}} / k$ when $\mathrm{T}_{\mathrm{L}}=\mathrm{T}_{\mathrm{E}}$.

A further extension of the Scheil solidification model is the limiting case where diffusion in the liquid phase is incomplete.

\subsubsection{Limited Liquid Diffusion Solidification Model}

This particular model differs from Scheil solidification in that liquid diffusion is assumed to be limited and mixing by means of convection is not permitted. As in the two previous solidification models, the equilibrium condition is also assumed to exist at the solidliquid interface. Hence, the same initial solidification behaviour occurs where the initial solid nuclei form with a composition of $\mathrm{kC}_{0}$, as depicted in Figure 36 [90]. This results in 
the same rejection of solute atoms across the interface into the neighboring liquid phase. In this case however, an enriched solute boundary layer is formed in the liquid ahead of the solidification front due to the limited liquid diffusion condition. During solidification, an initial transient period exists where the solid composition increases from $\mathrm{kC}_{0}$ to a steady-state value of $\mathrm{C}_{0}$. To maintain equilibrium conditions at the interface during steady-state, the composition of the liquid boundary layer must be $\mathrm{C}_{0} / \mathrm{k}$ with solidification occurring at the solidus temperature $\mathrm{T}_{\mathrm{S}}$. Steady-state solidification continues in this manner until the final stages of solidification when the solute boundary layer is restrained by the end of the cast bar, resulting in an increase of solute concentration from $\mathrm{C}_{0}$ to $\mathrm{C}_{\mathrm{E}}$. Except for during the initial and final transients of solidification, the composition of the solid during steady-state growth can be calculated as:

$$
\begin{aligned}
C_{S}=C_{0} & {\left[1-(1-k) e^{-\left(\frac{k V x}{D_{L}}\right)}\right] } \\
\text { Where: } & V=\text { growth velocity } \\
& D_{L}=\text { liquid diffusion coefficient } \\
& X=\text { distance required to reach steady state. }
\end{aligned}
$$

\subsection{Fundamentals of Dendritic Solidification}

\subsubsection{Planar to Dendritic Interface Transition}

Up to this point, solidification and solute redistribution have only been considered for relatively large systems under controlled directional solidification involving planar solidliquid interfaces. The situation becomes more complex when considering the effects of 
dendritic solidification. As previously described in section 4.1 .3 for planar front solidification with limited liquid diffusion, an enriched solute boundary layer exists ahead of the interface. The existence of the boundary layer results in a localized instability that is responsible for the onset of cellular or dendritic growth. This instability causes a localized variation in the liquidus temperature as illustrated in Figure 37 [89]. The transition from a stable plane front to a dendritic front depends on the actual temperature profile of the liquid. If the actual temperature in the liquid is above the local liquidus temperature then the plane front remains stable, as shown in Figure 38(a) [90]. In this case, any nodule formation at the planar front will be in a superheated zone and thus remelted prior to further growth. On the other hand, if the actual liquid temperature is below the localized liquidus temperature, a condition of constitutional supercooling exists and nodule formation on the planar interface will result in subsequent growth, as illustrated in Figure 38(b). The ability to control the stability of the interface is thus dependant on two main casting parameters, the temperature gradient in the liquid, $\mathrm{G}_{\mathrm{L}}$, and the solidification rate, $V$. If the ratio of $G_{I} / V$ falls below a critical value, due to a decrease in the temperature gradient or an increase in the solidification rate, then planar front solidification becomes unstable and a cellular-dendritic morphology proceeds [88].

\subsubsection{Dendritic Solidification Structure}

In general, when sufficiently high solidification rates are present in the casting process the planar interface becomes unstable and the formation of a cellular structure results [89]. As the solidification rate increases, crystallographic effects begin to exert an influence and the cell growth direction diverges toward the preferred crystallographic growth direction, which is $\langle 100\rangle$ for cubic superalloy materials [90]. Concurrently, the 
cross-sections of the cells change from a long-columnar shape to a flange or Maltese cross morphology [90]. As the solidification rate of these single crystals increases even further, the flanges break down to form secondary and higher order arms, resulting in the typical SX superalloy dendritic structure. An illustration of this microstructure transition with respect to solidification rate is provided in Figure 39. One inherent feature that is characteristic of almost all SX superalloy-casting processes is the formation of this dendritic solidification structure. The schematic shown in Figure 40 is of a typical SX superalloy depicting the general as-cast dendritic structure. Figure 40(a) is an SEM micrograph depicting the transverse Maltese-cross morphology of the dendritic cast structure. Figure $40(\mathrm{~b})$ is the corresponding SEM micrograph showing the typical longitudinal cross-section of the cast structure along the $<100>$ crystallographic direction. In this image, the long rows of primary dendrite arms extend continuously from top to bottom of the casting with secondary dendrite arms branching out from the dendrite core normal to the $<100>$ direction. Also provided in Figure 40 (c) is the typical as-cast $\gamma^{\prime}$ precipitate structure as a frame of reference to illustrate the much larger scale of the dendritic size.

Now that the general mechanism responsible for dendritic solidification has been reviewed, it is now possible to describe some of the more complex dendritic solidification models used to describe the localized solute distribution that occurs in the interface region. 


\subsubsection{Simplification of the Dendritic Interface}

In a manner similar to the models used for plane front solidification, physical representation of the dendritic solidification process requires simplification. This is achieved in the schematic [43] presented in Figure 41. In this figure, the mushy zone of length $a$, is defined as the region that contains both solid and liquid phases coexisting at various temperatures due to the different concentration levels resulting from solute redistribution. Two major assumptions are made to simplify the dendrite form. Firstly, it is assumed that there are no side branches in the model. Secondly, the dendrite shape is plate-like rather than needle-like [43]. It can then be assumed that the directional solidification process is occurring within the narrow volume element located between and perpendicular to neighboring dendrites, as shown in Figure 41. It is now possible to apply the previous solidification models (i.e. equilibrium and Scheil) to predict microsegregation within this interdendritic region. With this respect, the length of the volume element is now $L=\lambda / 2$, which is half the dendrite arm spacing.

\subsubsection{Brody-Flemings Dendritic Solidification Model}

Perhaps the largest leap in dendritic microsegregation modeling was accomplished by the work of Brody and Flemings [91]. Their research demonstrated that the primary reason for discrepancy between experimental microsegregation measurements and those values predicted using the Scheil model was due to the presence of finite solid-state diffusion. In other words, an appreciable amount of back diffusion into the initial solid phase (i.e. dendrite core) occurs both during and after solidification resulting in lower solute levels as predicted by the Scheil model. The extent of back-diffusion is determined by the 
dimensionless parameter, $\alpha$, as shown in the integration of the differential solute balance equation for a parabolic growth rate as follows,

$$
\left.C_{S}=k \cdot C_{0}\left[1-(1-2 \alpha \cdot k) f_{S}\right] \frac{k-1}{1-2 \alpha k}\right)
$$

$$
\begin{aligned}
& \text { Where: } \quad \alpha=\frac{4 D_{s} t_{f}}{\lambda^{2}} \\
& D_{S}=\text { diffusivity in solid }\left(\mathrm{m}^{2} \mathrm{~s}^{-1}\right) \\
& t_{f}=\text { local time of solidification (s) } \\
& \lambda=\text { dendrite arm spacing }(\mathrm{m}) \text {. }
\end{aligned}
$$

This particular equation is important because it contains two limiting cases that were described earlier for plane front solidification. It is apparent that when $\alpha$ is set to 0.5 , then equation (25) becomes the equilibrium lever rule (equation 22). Similarly, when $D_{S}$ is set to zero (i.e. no solid-state diffusion), $\alpha$ goes to zero, and the result is the Scheil equation (equation 23). There are additional microsegregation models available in literature; however, most are simply modifications of the Brody-Flemings model. In reality, such models are only approximations of the actual microsegregation behaviour that occurs during the casting process. The ability to make accurate microsegregation predictions for a complex SX superalloy system is almost impossible when considering the number of diffusing solute species and their relative interaction effects, which are not included in these simplified models. For the most part, the degree or severity of microsegregation within SX superalloy systems must be measured experimentally, with subsequent model modifications based on observed microsegregation quantities. 


\subsection{Observed Microsegregation in Industrial SX Superalloys}

The as-cast dendritic structure of SX superalloys plays a significant role in the chemical homogeneity of the final alloy composition. As previously mentioned, during solidification, some elements favorably partition to the core of the dendrites, while other elements preferentially segregate to the interdendritic region. Studies have shown that certain refractory elements such as $\mathrm{W}$ and Re segregate preferentially to the dendrite core, while others such as $\mathrm{Ta}, \mathrm{Al}$, and $\mathrm{Ti}$ partition to the interdendritic region [25]. This results in a non-homogeneous chemical balance throughout the alloy's as-cast microstructure. Moreover, this is further amplified with the inclination of new SX alloys

to contain even higher levels of $\mathrm{W}, \mathrm{Re}$, and Ta, required to improve solid solution and creep strength properties. Hence, these higher refractory-containing alloys (i.e. slower diffusing alloys) usually necessitate higher and longer solutionizing heat treatments to homogenize the chemical composition [92].

An example of this microsegregation behaviour for the $3^{\text {rd }}$ generation SX alloy, CMSX10, is provided in Figure 42 [92]. From the EPMA results recorded in Table 8, it is apparent that the dendrite cores are enriched in $\mathrm{W}$ and $\mathrm{Re}$ and depleted in $\mathrm{Ta}, \mathrm{Al}$ and $\mathrm{Ti}$, while for the interdendritic region the opposite segregation behaviour is exhibited. This preferential segregation behaviour is denoted using the microsegregation coefficient $\mathrm{k}^{\prime}$, (where $\mathrm{k}^{\prime}=\mathrm{C}_{\mathrm{S}} / \mathrm{C}_{\mathrm{L}}$ ). For the CMSX-10 example provided in Table 8, elements that segregate preferentially to the dendrite core have $\mathrm{k}^{\prime}$ values greater than unity and those elements that partition to the liquid phase (i.e. eventually solidify interdendritically) have values less than one. 
Another example [6] of the typical microsegregation behaviour observed in SX superalloys can be seen in Figure 43 for the Ni-based alloy AM1. This SEM micrograph illustrates the presence of brighter dendrite cores due to a high-localized concentration of tungsten and the associated atomic number contrast. The dark region immediately surrounding the dendrites is the associated $W$ depleted region. The darker interdendritic phase contains a coarse eutectic $\gamma^{\prime}$ structure, due to the microsegregation of the precipitate forming elements of $\mathrm{Al}, \mathrm{Ti}$ and $\mathrm{Ta}$ to this region.

A quantitative analysis was also performed for this alloy using EPMA line scans across several dendrites from a longitudinal cross-section of the SX casting. The general microstructure and EPMA line scan results are provided in Figure 44 [6]. It is apparent in the electron micrograph that a typical microsegregation pattern is present. The dark banding that runs diagonally across the image corresponds to the interdendritic region of the cast structure. Therefore, the thicker light grey regions between the dark bands are the corresponding dendrite cores. Also observable in this micrograph are very large eutectic $\gamma-\gamma^{\prime}$ regions that are located interdendritically. Upon examining the EPMA line scan results in Figure $44(\mathrm{~b}-\mathrm{d})$, it is apparent that typical SX microsegregation trends are present. In the dark banded interdendritic regions, increased levels of $\mathrm{Al}, \mathrm{Ti}$ and $\mathrm{Ta}$ are observed, along with decreased levels of $\mathrm{Cr}$ and $\mathrm{W}$. The dendrite core regions show increased levels of $\mathrm{W}$ with an associated solute depletion of $\mathrm{Ta}, \mathrm{Al}$, and $\mathrm{Ti}$. The scatter observed in the EPMA line scans is due to the detection of localized differences in the compositions of the $\gamma$ and $\gamma^{\prime}$ phases within the small sampling areas. 
A more precise representation of this solute distribution is available in Figure 45 [6]. This plot utilizes a large number of measurements distributed over a representative area of the specimen. These values are then plotted as a function of the fraction solid, where $f_{s}$ $=0$ corresponds to the dendrite core region (i.e. first phase to solidify) and $f_{\mathrm{s}}=1$ corresponds to the last liquid to solidify (i.e. the interdendritic eutectic $\gamma-\gamma^{\prime}$ phase). This image clearly illustrates the solute rejection of $\mathrm{Ti}$ and $\mathrm{Ta}$ from the dendrite cores into the surrounding liquid phase. There is also a sharp increase in $\mathrm{Ti}$ and $\mathrm{Ta}$ after $95 \%$ of the liquid has been solidified. The elevated levels of $\mathrm{Ti}$ and $\mathrm{Ta}$ in the last $5 \%$ of the solid phase, indicates that a eutectic has formed during the final stages of solidification. The opposite microsegregation behavior is seen to occur for $\mathrm{W}$, where initially the dendrite core regions contain as much as $8.25 \mathrm{wt} \% \mathrm{~W}$, with a much smaller concentration in the final eutectic phase of only $0.75 \mathrm{wt} \% \mathrm{~W}$.

The effect of microsegregation on the precipitate solvus temperature was also examined for the AM1 SX blade material [6]. Variations in the precipitate transformation temperature resulted due to the non-uniform composition distribution that was present across the as-cast alloy microstructure. This resulted in a $\gamma^{\prime}$ precipitate solvus range of approximately $40^{\circ} \mathrm{C}$, as illustrated in the DTA results of Figure 46 . The major reason for this range in solvus temperature is due to the variance in $\gamma^{\prime}$ precipitate size, which is much finer in the dendrite cores and progressively larger towards the interdendritic region. In general, it can be assumed that if a wide range in solvus temperature exists then the severity of microsegregation is proportional. 
Finally, the last critical effect of microsegregation observed in SX superalloys is the propensity for harmful TCP phase formation in areas of concentrated solute levels. Alloys such as MC2 contain relatively high nominal levels of $\mathrm{W}$ and $\mathrm{Ta}$ in their composition [6]. Even after performing substantially long homogenization heat treatments, the segregation of $\mathrm{W}$ to the dendrite cores results in the precipitation of the $\mu$ phase during service application. This is illustrated in Figure 47, which depicts a very high volume fraction of the $\mu$-phase (white in colour) concentrated in the dendrite cores and along the insides of the secondary dendrite arms. This same behaviour is also observed in the SX alloy Rene N6, however the localized concentration of Re in the dendrite cores is the prime driving force responsible for cellular precipitation of the TCP phase.

Based on the preceding observations, it becomes apparent that the best way to avoid the negative effects of microsegregation on SX superalloy phase stability, is to develop tailored alloy compositions that result in less extensive solute rejection across the dendritic solidification structure. It is impossible to completely eliminate the presence of microsegregation; however, with careful selection of solute levels it is possible to produce less localized segregation that can subsequently be more easily homogenized without extensive heat treatment procedures. 


\section{Experimental Materials}

\subsection{Material Selection and Procurement}

As with any complex alloy system, the ability to precisely relate changes in material properties to individual or even combinations of elemental additions is extremely difficult [93]. This is due to the unpredictable binary, ternary, and higher order synergistic effects present in these highly alloyed systems that may contain in excess of ten or more elemental species in typical alloy compositions. In addition to having this large number of chemical interaction parameters, the uncertainty in quantifying specific chemical effects is even further magnified by the compositional variation inherent within SX microstructures due to selective element partitioning that occurs upon solidification. Although grain boundary segregation is not an issue, the distinctive solidification structure that is produced in these SX alloys during the slow cooling process results in microsegregation between the dendritic and interdendritic regions. Therefore, for the purpose of this study, it was necessary to ascertain a series of experimental alloy compositions that could be used for comparison testing to differentiate the effects of specific alloying additions. Furthermore, it was also necessary to determine which elements would be of prime importance for industrial designers for present and future blade alloy applications.

\subsubsection{Alloy Composition Selection}

Through the development of new SX alloy design initiatives, researchers have indirectly determined the independent effects of Re on phase stability and high temperature creep properties [94]. Of particular interest are the combined effects of Re and W, which are 
known to participate in topologically close-packed (TCP) phase formation [10]. Prevention of TCP phase formation is critical, as the performance of these alloys depreciates with increasing TCP volume fraction. More recently, some of the $4^{\text {th }}$ generation of SX superalloys (e.g. MC-NG) have demonstrated improvements in microstructural stability while decreasing overall alloy density due to the addition of $\mathrm{Ru}$ [95]. Hence, the selection of a series of experimental alloys was determined based on two major requirements: 1) the compositions must yield a full range of microsegregation properties required for comparison purposes, and 2) the alloy compositions must be set in a controlled manner such that changes in chemical segregation can be directly attributed to the specific elemental additions of $\mathrm{Re}, \mathrm{W}$, and $\mathrm{Ru}$. With these criteria in mind, the target alloy compositions listed in Table 9 were selected.

Alloys A through D represent a complete range of compositional variance with respect to $\mathrm{W}$ and $\mathrm{Re}$ while maintaining a constant total refractory level of $21 \mathrm{wt} . \%$. The composition of Alloy E was specifically chosen to examine the combined effects of high $\mathrm{W}$ and Re addition levels. Finally, the composition of Alloy F was selected based on the new generation of SX superalloys that effectively incorporate substantial $\mathrm{Ru}$ additions to aid in phase stability and to decrease overall alloy density. For comparison purposes, Alloy $\mathrm{F}$ was designed to contain the same overall total refractory level as Alloy E with a total refractory content of 24 wt.\%. The composition of Alloy $\mathrm{F}$ was also chosen to be similar to that of Alloy $\mathrm{C}$ with the exception of $4 \mathrm{wt} . \% \mathrm{Ru}$, which allows for independent assessment of the effect of Ru on microsegregation behaviour. Also included in Table 9 are the calculated densities for the target alloy compositions. 
It should also be mentioned that the high levels of Ta (12 wt.\%) incorporated in the target alloy compositions is much higher than would be used in conventional alloy chemistries. This is to ensure that the alloys are near the solute saturation points so that high levels of microsegregation can be observed in the as-cast microstructures. Also, the experimental alloys are derived essentially from modifications of PWA-1480, a first generation SX alloy. The initial series of SX alloys (e.g. PWA-1480 and Alloy 454) were designed with high levels of $\mathrm{Ta}$ as they were shown to improve creep strength and oxidation resistance [96]. Equally important, by using high levels of Ta in the experimental alloys the tendency to form casting defects (e.g. freckling) is drastically reduced [96]. This should result in a much easier casting process with respect to yielding defect-free cast bars in the pristine SX condition.

\subsubsection{Procurement of Master Alloys}

Having finalized the target alloy compositions, several vendors were approached for SX procurement. PCC Airfoils ${ }^{\mathrm{TM}}$ and the Whitehall Casting Group of Howmet $^{\mathrm{TM}}$ were contacted with respect to casting $60 \mathrm{SX}$ bars (10 for each of the six alloy compositions). PCC Airfoils ${ }^{\mathrm{TM}}$ provided a quotation for the SX castings at a cost of $\$ 2300 \mathrm{CDN}$ per bar, $\$ 138,000$ total. The second vendor, Howmet ${ }^{\mathrm{TM}}$, responded to the request for quotation with a price of $\$ 1400 \mathrm{CDN}$ per SX bar, $\$ 84,000$ total. Unfortunately, the project budget was limited and could not support such a highly priced consumable. For this reason, it was decided to purchase less expensive polycrystalline ingots of the master alloy compositions and recast these alloys in the SX condition using the directional solidification furnace located at Carleton University. Details of the SX casting procedure 
will be provided later in section 5.2. Subsequently, the master alloys were then purchased from Sophisticated Alloys ${ }^{\mathrm{TM}}$, a custom casting company located in Pennsylvania, USA. Each of the $10-\mathrm{lb}(4.5 \mathrm{~kg})$ heats was vacuum induction melted and cast in $5 / 8$ " $(1.6 \mathrm{~cm})$ diameter bar stock with bar lengths of approximately 36" $(91 \mathrm{~cm})$, as shown in Figure 48. The total cost for $60 \mathrm{lbs}(27 \mathrm{~kg})$ of master alloy material was $\$ 15,600 \mathrm{CDN}$, considerably less than purchasing the alloys in the SX condition. The compositions of the vacuum cast ingots were very close to the requested target chemistries. Table 10 lists the wet chemical analysis results of the delivered master alloys.

\subsubsection{Ceramic Molds and Other Consumables}

In addition to alloy procurement, 75 high purity alumina molds were purchased from Vesuvius McDanel ${ }^{\mathrm{TM}}$ for SX casting. The mold geometry consisted of a simple double open-ended tube shape with a very smooth internal surface finish. The dimensions chosen were 5/8" $(1.6 \mathrm{~cm})$ inner diameter, $7 / 8 "(2.2 \mathrm{~cm})$ outer diameter, with two overall lengths of $8 "(20 \mathrm{~cm})$ and $12 "(46 \mathrm{~cm})$. The $12 "$ long molds proved to be useful in reducing the number of required castings, however, the larger mold length was susceptible to tipping in the mold support stand during the furnace withdrawal procedure. For this reason, the 8 " long molds were preferred as they were not as top-heavy and did not result in any offaxis tipping. Provided in Figure 49 is a picture of the alumina mold depicting the openended geometry of the tubes.

Once the mold geometry was finalized, it was then necessary to produce a mold support stand that would sit on the copper chill platen of the Bridgman furnace. A simple design 
was chosen and the part was machined at NRC from heat resistant stainless steel. Provided in Figure 50 is the machine drawing for the mold support stand.

Modification to the ceramic baffles within the casting furnace was also required to accommodate the new mold geometry. Two new baffles were made using $1 / 2$ " $(13 \mathrm{~mm})$ thick ZYFB zirconia board, purchased from Zircar Fibrous Ceramics. A 10-1/4" (260 $\mathrm{mm}$ ) diameter disk with a 1-1/4" $(32 \mathrm{~mm})$ diameter mold pass-through hole was cut from the board. Eight $1 / 4 "(6.4 \mathrm{~mm})$ mounting holes were drilled to mount the baffle to the retractable skids located within the furnace. Figure 51 shows the new baffles prior to installation.

Other minor consumables were also required for the casting process. Each casting required a high purity, ceramic spacer that sits between the SX seed material and the copper chill platen within the bottom of the ceramic mold. These $1 / 2 \%(13 \mathrm{~mm})$ spacers were prepared from machinable alumina bar stock ordered from Cotronics Ceramics. The advantage of using the $\mathrm{Al}_{2} \mathrm{O}_{3}$ spacers is the inherent strength and flatness of the material. This prevents crumbling during specimen loading and also allows for a level seating of the seed crystal once placed in the ceramic mold. The only drawback to using $\mathrm{Al}_{2} \mathrm{O}_{3}$ instead of $\mathrm{ZrO}_{2}$ is that higher furnace superheat temperatures are required during casting due to the higher thermal conductivity of the more dense $\mathrm{Al}_{2} \mathrm{O}_{3}$ spacers. 
To prevent damage to the inside of the furnace, several rolls of molybdenum foil were purchased for containment purposes in the case of accidental mold failure. The foil was tightly wrapped around each ceramic mold and twist-tied in place using three pieces of molybdenum wire. This containment precaution was deemed necessary as previous mold failures resulted in damage to the tungsten furnace elements. Figure 52 shows a ceramic mold wrapped in the molybdenum foil, sitting in the support stand within the furnace.

Upon receipt of the master alloys, ceramic molds, and casting consumables, an extensive amount of experimental work was performed aimed at producing a viable SX casting procedure.

\subsection{SX Casting Process}

Prior to discussing the details of the developed casting process, a short description of the furnace specifications and operating limits will be provided.

\subsubsection{Carleton University Directional Solidification Casting Facility}

Provided in Figure 53 is the complete furnace arrangement highlighting all the major furnace and vacuum components. Centorr Vacuum Industries ${ }^{\mathrm{TM}}$, $\mathrm{Nashua,} \mathrm{NH}$, originally manufactured the furnace with subsequent modifications performed by Dr. Henry Saari of Carleton University. The shell of the furnace chamber is constructed of stainless steel with a surrounding water-cooling jacket. The upper chamber, or furnace hot zone, is heated by two independently controlled, tungsten-mesh heating elements. Both upper and lower heating elements are capable of supplying in excess of superalloy melting 
temperatures. The upper heating element is rated at $25 \mathrm{kVA}\left(\max 2200^{\circ} \mathrm{C}\right)$ and the bottom at $20 \mathrm{kVA}\left(\max 2000^{\circ} \mathrm{C}\right)$. The lower heating element is situated close enough to the lower-cold zone such that a suitable high thermal gradient at the solid-liquid interface can be provided, as required for DS casting. Furnace temperatures are measured by Type-C thermocouples, controlled by a closed-loop Honeywell DCP 700 dual channel programmable controller, and monitored by a Honeywell DPR 1000 multi-channel recorder. The power supply consists of isolated step-down transformers and silicon controlled rectified (SCR) power packs. The heaters are isolated from the cold walls of the furnace by multi-layer tungsten and molybdenum radiation shields. The lower furnace chamber is used for loading and unloading through a hinged rectangular door. A 3" (75 mm) diameter sight port, located on the door of the cooling chamber, and a small sight window on the top access lid provide for visual observation of the melt and the mold. Additional access ports are also provided for control and monitoring thermocouples, a gas inlet, vacuum gauges, and temperature pyrometers. Retractable baffles separate the hot and cold zones of the furnace, helping to maintain alloy superheat temperatures and to maximize the thermal gradient. A water-cooled copper chill plate is used to support the mold and provides directional heat transfer from the melt. The chill plate is supported by the pedestal travel system that allows the mold to be raised into the hot zone of the furnace and also provides for withdrawal to the cooling chamber at a controlled rate during casting, as shown in Figure 54. The pedestal travel system is of ball screw design and is powered by a DC stepping motor and electric gearbox-speed reduction. The furnace also includes a low vacuum roughing pump (Leybold ${ }^{\mathrm{TM}}$ D30A dual-stage rotary vane mechanical pump) in combination with a high vacuum diffusion 
pump. For cleanliness, casting can be performed either in a high vacuum environment, $\sim 10^{-5}$ torr $\left(1.33 \times 10^{-2} \mathrm{~Pa}\right)$, or in inert gas.

\subsubsection{Bridgman-Seed Crystal Casting Process}

As previously mentioned, the common industrial practice for casting SX alloys is to use complex ceramic molds that incorporate a pigtail crystal selector design. However, an alternative SX casting method was chosen that implements a seed crystal to nucleate crystal growth. The main reasons for choosing this alternative method were the exaggerated cost of purchasing suitable pigtail molds and also because an adequate supply of SX PWA-1484 seed material was readily available at the NRC. A schematic of the utilized Bridgman-seed casting arrangement is provided in Figure 55.

In short, the developed casting procedure involves several general steps. First the alloy charge and mold are prepared and installed in the furnace. Secondly, the vacuum chamber is purged and cleaned to provide for a protective casting environment. The furnace is then turned on and brought to the appropriate superheat temperature. Finally, the molten metal is withdrawn from the furnace in a controlled manner to produce the SX structure. The following will provide a more detailed description of each step in the final casting procedure.

The first step in the casting process involves preparation of the master alloy charge and the ceramic mold. Each mold is tightly wrapped in molybdenum foil so that three complete layers surround the exterior surface. The foil is then held in place using 3 pieces 
of molybdenum wire. Prior to placing the master alloy into the ceramic mold, the surface of each bar is rough ground to remove the exterior oxide layer that is present after vacuum casting. This procedure also removes any residual mold debris that may have been deposited on the surface of the bars at the Sophisticated Alloys casting foundry. The vacuum cast bars are then cut into smaller $2 "(5 \mathrm{~cm})$ lengths with an abrasive cutting wheel and cleaned ultrasonically in acetone. The alumina mold is then temporarily filled with the alloy charge, the $1.0 "(2.54 \mathrm{~cm}) \mathrm{SX}$ seed, and a $1 / 2 "(13 \mathrm{~mm}) \mathrm{Al}_{2} \mathrm{O}_{3}$ spacer to verify that all components fit properly.

As previously mentioned, the developed casting procedure involves using SX PWA-1484 as starter seed material for the new alloys. Preparation of the SX seed material requires a tight tolerance fit $(-0.005 "(-0.13 \mathrm{~mm}))$ of the seed diameter with the internal diameter of the ceramic mold. Also, to ensure that the $<100>$ crystallographic direction of the seed coincides with the mold length direction, both ends of the seed are machined parallel to each other and perpendicular to the longitudinal direction of the seed itself. The seed is finally cleansed in an ultrasonic bath of acetone.

With the support stand in place, the mold is positioned in the cold zone of the furnace on top of the copper chill platen. The alumina spacer is then inserted into the top of the mold followed by the SX seed. Finally, several pieces of the alloy charge are individually inserted into the top of the mold until the charge is flush with the top of the tube. The mold is then raised into the upper chamber of the furnace using the pedestal drive. Once in place, the retractable furnace baffles are closed around the mold, ensuring that enough 
clearance is present for subsequent withdrawal during casting. The furnace is then closed and sealed from the external environment.

Prior to melting the alloy, a protective casting environment is required within the furnace. The protective casting atmosphere is attained by chamber evacuation using the roughing pump and argon back-fill operations. Rough evacuation and back-filling are performed twice with a final evacuation step using the diffusion pump to attain a final clean environment of $4 \times 10^{-4}$ torr $\left(4.7 \times 10^{-2} \mathrm{~Pa}\right)$. The upper and lower furnace elements are then turned on and the upper hot zone is heated in several incremental steps to the final casting temperature.

The furnace temperature is slowly raised to $100^{\circ} \mathrm{C}, 500^{\circ} \mathrm{C}, 1400^{\circ} \mathrm{C}, 1500^{\circ} \mathrm{C}$ and 1585 ${ }^{\circ} \mathrm{C}$ at heating rates of $5,10,20,10$, and $5^{\circ} \mathrm{C} / \mathrm{min}$ respectively. Slow initial heating rates were used to prevent thermal shock damage of the heating elements, shields, and the mold. Once the final superheat temperature is reached, the charge is held at the casting temperature for a minimum of 15 minutes to ensure a homogeneous temperature in the melt with a stable solid-liquid interface. The total time required to bring the furnace up to the final set-point temperature is $\sim 2.5$ hours.

To promote SX crystal growth in the new alloy, the top $5-10 \mathrm{~mm}$ of the starter seed is positioned partially within the furnace hot-zone and melted by using the superheat temperature of $1585^{\circ} \mathrm{C}$. The selection of a suitable furnace superheat temperature, seed 
length and spacer length were all determined by performing casting trials and will be discussed in section 7 . To achieve a suitable solid/liquid interface, it was necessary to place a $13-\mathrm{mm} \mathrm{Al}_{2} \mathrm{O}_{3}$ spacer between the seed crystal and chill plate so that a thermal gradient of $\sim 50{ }^{\circ} \mathrm{C} / \mathrm{cm}$ was obtained at the liquidus temperature in the melted alloy. This thermal gradient, as measured from the top of the furnace baffles to the liquid metal region, was previously determined to be the optimum temperature profile for producing SX castings. A schematic of the measured temperature gradient $\left(\mathrm{G}_{L}\right)$ has been provided in Figure 56, illustrating the measurement location just above the mushy zone (i.e. $\mathrm{S}+\mathrm{L}$ region) of the seed. Temperature gradients were determined experimentally by Dr. Henry Saari using strategically placed Type-C thermocouples and theoretically by running casting simulations using ProCast ${ }^{\mathrm{TM}}$ solidification models. Once a stable solid/liquid interface is established, the ceramic mold containing the partially melted seed and liquid metal charge is withdrawn from the hot-zone into the cold-zone of the furnace at a rate of $20 \mathrm{~cm} / \mathrm{hr}(8.0 \mathrm{in} / \mathrm{hr})$ to prevent $\mathrm{SX}$ breakdown. Once fully withdrawn into the cold zone of the furnace and the operating temperature has dropped below $100^{\circ} \mathrm{C}$, the vacuum seal is broken and the mold is removed. It is then necessary to examine each $5 / 8$ " (16 mm) diameter bar to ensure a SX microstructure throughout its entire $8 "(20 \mathrm{~cm})$ length.

To summarize the developed casting procedure, the following procedural list has been provided.

1. Prepare alloy charge and SX seed material

2. Load alumina mold and seal furnace

3. Evacuate and purge chamber using argon (repeat twice) 
4. Perform final high-vacuum using diffusion pump: $\sim 4.0 \times 10^{-4}$ torr

5. Heat furnace up slowly to the final superheat temperature: $1585^{\circ} \mathrm{C}$

6. Melt at least $1 / 8$ th inch into seed to promote SX growth in liquid metal

7. Hold at superheat temperature for 15 minutes

8. Withdraw liquid charge from hot-zone to cold-zone: $8.0 \mathrm{in} / \mathrm{hr}$

9. Examine each bar to ensure SX microstructure throughout:

It should be mentioned that an extensive amount of experimental work was required to determine and optimize the final casting parameters. Although the final process can be described in a few short paragraphs, experimental casting required almost a year of developmental work with unfortunately, many unsuccessful castings. A detailed description of the preliminary casting trials and optimization results will be provided in section 7 .

\subsection{Metallographic Preparation}

\subsubsection{Macrostructural Evaluation}

As mentioned, after each casting metallographic examination is required to ensure that a SX structure is obtained. Transverse and longitudinal samples are taken from each bar, polished to a 1- $\mu \mathrm{m}$ finish, and etched for 65 seconds in a solution of $10 \mathrm{ml} \mathrm{HCl}, 10 \mathrm{ml}$ $\mathrm{HNO}_{3}, 0.3 \mathrm{~g}$ molybdic acid, and $15 \mathrm{ml} \mathrm{H} \mathrm{H}_{2} \mathrm{O}$. This $\gamma^{\prime}$ removing etchant produces suitable image contrast for both optical and SEM microscopy. At low magnifications the dendritic solidification structure and any undesirable spurious grains are easily resolved. An alternative macroetchant that can be used to produce similar results is a solution of $50 \mathrm{ml}$ $\mathrm{H}_{2} \mathrm{O}_{2}, 100 \mathrm{ml} \mathrm{HCl}$, and $150 \mathrm{ml}$ of distilled $\mathrm{H}_{2} \mathrm{O}$. 


\subsubsection{Microstructural Evaluation}

Inspection of the $\gamma^{\prime}$ precipitate structure is achieved by electrolytically etching polished specimens for 30 seconds at 6.5 volts in a solution of $48 \mathrm{ml} \mathrm{H}_{2} \mathrm{SO}_{4}, 12 \mathrm{ml} \mathrm{H}_{3} \mathrm{PO}_{4}$, and 48 $\mathrm{ml} \mathrm{HNO}_{3}$. This etchant effectively removes the $\gamma$-matrix leaving behind the $\gamma^{\prime}$ precipitates and any other secondary phases that may be present. Shorter etching times $(\sim 5$ to 10 seconds) may be used to reduce the depth of $\gamma$-matrix attack so that ideal 2-D images can be produced for $\gamma^{\prime}$ volume fraction determination.

In addition to standard metallographic analysis, specimens were also prepared for electron microprobe investigation. These specimens were mechanically polished to a 0.1 $\mu \mathrm{m}$ finish and left in an un-etched condition so that precise quantitative analysis results could be acquired. Due to the large fraction of eutectic phase present in each of the alloys, the metallographic specimens were susceptible to precipitate pull-out if excessive polishing times were implemented. To avoid this, each sample required hand polishing at slow rotational speeds and minimum time intervals. Also, a gold sputter-coat for all EPMA samples produced ideal back-scattered electron imaging results. The EPMA specimen stage limitations required all microprobe samples to be mounted in 11/4" ( 3.2 $\mathrm{cm})$ diameter Bakelite holders that were no greater than 0.16 " $(4 \mathrm{~mm})$ thick.

\subsection{X-ray Diffraction}

To compliment the metallographic examination of each cast bar, additional crystallographic inspection was performed using X-Ray Diffraction (XRD) analysis. 
$\mathrm{XRD}$ was required to confirm the preferred $<100>$ crystallographic orientation of the FCC SX bars. This was accomplished by taking a small sample disk from the mid-length region of each casting. The polished samples were positioned in the XRD stage with the longitudinal growth direction perpendicular to the stage datum plane. The XRD specimens were $\sim 4 \mathrm{~mm}$ thick with a final machined diameter of $\sim 13 \mathrm{~mm}(\sim 1 / 2 ”)$. Removal of the external surface layer of the cast bars was required to avoid any XRD detection of possible residual casting defects located in this region. Each XRD analysis was performed using a Rigaku ${ }^{T M}$ XRD with a $\mathrm{Cu} \mathrm{K}_{\alpha}$ radiation source $(1.542 \AA)$. X-ray diffraction intensity was recorded over a $2 \theta$ range of $20^{\circ}$ to $100^{\circ}$. A step size of $0.02^{\circ}$ was used, with a 4.0 second dwell time and a scan rate of $1.2 \%$ min. X-ray peak identification was performed using the Jade ${ }^{\text {TM }} 3.0$ software package. 


\section{Experimental Procedures}

\subsection{Microsegregation Characterization Methods}

Upon successfully casting each alloy in the SX condition, it was then necessary to ascertain and quantify the severity of microsegregation present in the as-cast SX microstructures. Several characterization techniques were employed to determine the extent of chemical inhomogeneity, including EPMA, eutectic phase fraction analysis, and DSC analysis. In addition to these physically based measurement techniques, theoretical modeling of the solidification behaviour for the alloy system was performed using several self-consistent thermodynamic databases and the traditional CALPHAD modeling approach. The following sections will describe each of the aforementioned procedures that were used to characterize the severity of microsegregation.

\subsubsection{Quantitative Chemical Analysis}

One method used to determine the degree of microsegregation present in the as-cast alloy microstructures is to perform an accurate compositional analysis between the dendrite core and interdendritic $\gamma-\gamma^{\prime}$ eutectic regions. As previously mentioned, the easiest way to quantify the severity of microsegregation for a particular element is to measure its compositional levels at the beginning and end of the dendritic solidification process. In the case of dendritic solidification, the composition of the first solid to form would be in the center of the dendrite core, whereas the last liquid to solidify would be in the interdendritic $\gamma-\gamma^{\prime}$ eutectic region. The schematic provided in Figure 57 illustrates the method used to quantify the degree of microsegregation present in the as-cast SX alloys. As mentioned, the method involves determining the composition of the first and the last 
phases to solidify. The ratio of these compositions, $\mathrm{k}^{\prime}$, can then be used to determine if an element preferentially segregates to the core at the beginning of solidification (i.e. $k^{\prime}>1$ ) or if the element has a tendency to remain in the liquid phase until the final stages of dendritic solidification (i.e. $\mathrm{k}^{\prime}<1$ ). Hence, it is very important that the localized compositions of the dendritic core and interdendritic eutectic regions be accurately measured to produce meaningful segregation results.

The two most common quantitative analysis methods used in conjunction with electron beam instrumentation are Energy and Wavelength Dispersive X-ray Spectroscopy.

\subsubsection{Energy Dispersive X-ray Spectroscopy}

Initial attempts at quantitative compositional analysis were performed using an Energy Dispersive X-ray (EDX) spectrometer, a detector that is commonly interfaced on most electron beam instrumentation. Representative samples were polished and installed in the Philips XL-30S FEG scanning electron microscope (SEM) located at the NRC. It should be noted that EDX analysis requires the Back-Scattered Electron (BSE) mode to be used in the SEM. Hence, it was important to achieve significant atomic number contrast between the different regions of the solidification microstructure so that sufficient image resolution could be acquired. Although the extent of image contrast was low in the BSE mode, differentiation between the dendrite cores and interdendritic regions was possible, as shown in Figure 58. However, upon performing a simple spot analysis on the specimen surface it became immediately obvious that accurate chemical analysis was not possible using the EDX detector. Provided in Figure 59 are the chemical analysis results from a 
representative EDX point scan performed on Alloy B within the dendrite core region. It is apparent in this figure that considerable energy peak overlap exists for such heavy elements as Re, W and Ta. Because of the limitations of the EDX solid-state detector, the required peak resolution for each of these elements is not possible and produces inaccurate quantitative results, as the volume fraction of each element is directly proportional to the intensity of each peak. Considering that the levels of $\operatorname{Re}$ and $\mathrm{W}$ are of prime interest in this study, an alternative chemical analysis method that yields more widely resolved spectral dispersion data (i.e. greater spacing between neighboring elemental peaks) is required.

\subsubsection{Wavelength Dispersive X-ray Spectroscopy}

An alternative to using EDX is the Wavelength Dispersive X-ray (WDX) spectroscopy method. WDX analysis provides for superior wavelength resolution for elements of interest, as the crystal spectrometer is capable of providing higher peak-to-background ratios and better spectral dispersion, thereby minimizing the possibility of peak overlap. The only downfall of using WDX is that several different spectrometers are required for elements of different characteristic energy levels (i.e. wavelengths). This does result in much longer analysis times required for the calibration of each spectrometer and general equipment setup. However, the ability to identify specific elements as a function of their characteristic wavelengths (i.e. $\lambda=2 \mathrm{~d} \sin \theta$ ) offers the ultra-fine resolution required when performing trace analysis on such elements as $\mathrm{W}, \mathrm{Re}$ and Ta. The superiority of WDX over EDX detection is clearly demonstrated when comparing the chemical analysis results of Figure 60 and Figure 61 [97]. Figure 60 shows the EDX energy spectrum 
produced for a sample Ni-base superalloy, demonstrating the typical energy peak overlap condition for the elements Re, W and Ta. Figure 61 shows the comparable WDX analysis results for the same Ni-base superalloy, highlighting the superior wavelength dispersion capability, as clearly demonstrated in Figure 61(b), where the W, Re, and $\mathrm{Ta}$ M $\alpha$ peaks are finely resolved leaving no room for interpretation error [97].

From the previous discussion, it becomes evident that the standard method of using EDX for chemical analysis would be inadequate for complete element characterization. Also, the WDX method was identified as a much more accurate means for determining the trace levels of interest. Regrettably, both scanning electron microscopes located at the NRC do not possess WDX detection capability. Fortunately, the electron microprobe located at Carleton University was available and possessed 4-WDX crystal detectors capable of covering the complete elemental range of interest. For the aforementioned reasons, all subsequent spot and line scan chemical analysis was performed using EPMA WDX detection.

\subsubsection{EPMA Procedure}

As previously mentioned, to determine the degree of microsegregation present between the dendrite core and interdendritic $\gamma-\gamma^{\prime}$ eutectic regions, an accurate compositional analysis was required for each alloy. All chemical analysis results were obtained using a Camebax MBX Electron Microprobe equipped with 4 WDX spectrometers. The microprobe itself, shown in Figure 62, operates on the same fundamental principles as an 
SEM, except that it is specifically tailored for compositional analysis purposes. Also, the microprobe features include a 4-quadrant BSE detector allowing for greater image resolution with respect to atomic number contrast. Provided in Figure 63 is a schematic of the internal components of a typical electron microprobe. This figure illustrates the fundamental processes of sample bombardment with high-energy electrons, subsequent $\mathrm{X}$-ray generation from the sample, followed by spectral analysis of the characteristic $\mathrm{X}$ rays using one or more WDX detectors.

Once all the EPMA specimens for each alloy were produced, multiple WDX point scans on representative sample areas were performed to obtain a better statistical representation of the different localized compositions. No less than 20 WDX scans were performed for each alloy, 10 within the dendrite core regions and 10 within the interdendritic regions. These point analyses were executed from multiple locations on the sample surface. A schematic of the spot analysis procedure is provided in Figure 64, illustrating the sampling method used to determine the dendrite core and eutectic compositions. During $\mathrm{X}$-ray sampling, the probe was operated at $20 \mathrm{kV}$ accelerating potential, a beam current of $35 \mathrm{nA}$, with the beam rastered over a $10 \times 10 \mu \mathrm{m}$ area. Peak counting times for each element were 30 seconds or 40,000 counts. Background counting times were $t /-15$ seconds on each side of the peak. Wavelength scans were made around the peak position of each analyzed element to check for X-ray interferences and to choose optimum (i.e. interference-free) background positions. X-ray data were converted to elemental wt.\% by the Cameca PAP matrix correction software. A suite of well-characterized pure metals 
and minerals was employed to provide calibration standards for all the constituent elements in each alloy.

In addition to the extensive number of point scans performed, a series of line scans was also gathered for each alloy to determine the change in chemical gradient across the dendritic solidification structure. For each alloy, line scans were performed parallel and perpendicular to the secondary dendrite arm directions as well as diagonally across the dendrite core into the interdendritic regions. A schematic of the line scan procedure is presented in Figure 65, illustrating the 4 scanning directions examined for each alloy. This procedure was duplicated to ensure repeatability. Accelerating potential, beam current and spot size equipment settings were the same as for the previously mentioned point scan procedure.

\subsubsection{Eutectic Phase Fraction Analysis}

To further elaborate on the effects of microsegregation within the group of experimental alloys, a full analysis of the eutectic phase fraction present in each of the as-cast microstructures was conducted. In theory, during solidification when the rejected solute level in the liquid phase reaches the eutectic composition of the alloy, the remaining liquid solidifies with this specific composition. Hence, alloys that exhibit faster solute rejection (i.e. higher partitioning) reach the required eutectic composition sooner and thereby solidify with a greater fraction of eutectic phase as there is more interdendritic liquid available for transformation. A schematic of this process is presented in Figure 66, illustrating the remaining fraction of eutectic phase $\left(\mathrm{f}_{E}\right)$ that is present after complete 
dendritic solidification. The volume element used in this schematic is the same as that described in Figure 41. Comparison of the eutectic phase volume fractions in a family of alloys can then be used to rank the degree of microsegregation for each alloy. Experimentally, this was accomplished by analyzing a number of low-magnification optical images for each as-cast SX microstructure. Samples were prepared using traditional metallographic techniques and etched to reveal the dendritic/eutectic solidification structure. The image analysis software, Image Tool ${ }^{\mathrm{TM}}$, was used to process and analyze each image. The procedure involved capturing the optical image, converting it to 16-bit grayscale format, and adjusting the brightness and contrast settings so that the eutectic and dendritic regions were clearly delineated. Once the image was prepared for analysis, a black and white threshold image was generated using an Image Tool ${ }^{\mathrm{TM}}$ subroutine. It was determined that to remove any residual pixels due to variation in dendrite colour (i.e. contrasting artifact due to precipitate texturing), a $3 \times 3$ median filter was applied to the threshold image. This effectively filled in the dendrites making them solid black in color. In the case of variation in eutectic color, a pixel-editing tool was used to remove any black areas that would be incorrectly counted as dendritic area. This process was performed manually and proved to be very time consuming in the case where high volume fractions of interdendritic eutectic phase were present.

\subsubsection{DSC Analysis and Thermo-Physical Characterization}

An extensive DSC (differential scanning calorimetry) study was performed for each of the experimental alloy compositions. A total of six 25-mm (1.0") longitudinal sections were machined from each as-cast SX alloy for DSC sample preparation. From each section, several 3-mm (0.12") diameter rods were produced by electrical discharge 
machining $(\mathrm{EDM})$. The rough EDM surface was removed from each rod using a conventional lathe. Representative samples weighing approximately $80-100 \mathrm{mg}$ were prepared from the SX rods using a low-speed diamond saw. A schematic of the DSC sample preparation procedure is shown in Figure 67.

Each DSC test was conducted using a Netzsch ${ }^{\mathrm{TM}}$ 404-C Pegasus DSC, as shown in Figure 68. In short, the heat-flux DSC test method involves measurement of the amount of energy absorbed or released by a sample when it is heated or cooled, providing quantitative and qualitative data on endothermic (i.e. heat absorption) and exothermic (i.e. heat evolution) processes. The procedure involves placing a sample in an alumina pan that sits upon a constantan disc on a platform in the DSC cell with a chromel wafer immediately underneath. A temperature thermocouple located under the constantan disc measures the sample temperature. An empty alumina reference pan sits on a symmetric platform with its own underlying chromel wafer and thermocouple. Heat flow is measured by comparing the difference in temperature across the sample and the reference chromel wafers during the controlled heating and cooling segments.

DSC samples were tested at thermal heating and cooling rates of $20^{\circ} \mathrm{C} / \mathrm{min}, 10^{\circ} \mathrm{C} / \mathrm{min}$, and $5^{\circ} \mathrm{C} / \mathrm{min}$ under a $50 \mathrm{ml} / \mathrm{min}$ flowing argon atmosphere. A full temperature range calibration set and a typical baseline subtraction method were used for all DSC tests. Resulting energetic curves were analyzed for endothermic phase transformation processes using the accompanying Proteus ${ }^{\mathrm{TM}}$ software package. Each solidus temperature measurement was resolved by using the onset temperature for the endothermic liquidus 
peak, which is determined by using the intercept of the upper slope tangent and the horizontal baseline. The corresponding liquidus temperature was resolved as the maximum endothermic peak value where no subsequent phase transformations occurred thereafter. Additional sub-liquidus transformation phenomena were identified by using maximum peak value measurements.

Endothermic peak characterization was confirmed by means of isothermal furnace heat treatment experiments with subsequent metallographic analysis. DSC results were also quantified in terms of solidification time (i.e. liquidus-solidus window), which indirectly can be used to characterize the degree of microsegregation. Each as-cast alloy was ranked based on its respective solidification temperature ranges (i.e. $\Delta T=T_{L}-T_{S}$ ) with larger $\Delta T$ values indicative of more severe microsegregation.

\subsubsection{Thermodynamic Solidification Modeling}

In conjunction with the aforementioned experimental characterization methods, theoretical predictions were also obtained utilizing a computational thermodynamics approach. Initially, a phenomenological model was developed that was used to predict the degree of chemical partitioning between the liquid phase and the $\gamma$-solid solution phase that occurs during alloy solidification for the 10 component species. The $\gamma$-solid solution and liquid phases were modeled by using a substitutional solution formalism with the aid of an extensive thermodynamic database constructed specifically for SX superalloy applications [11]. The thermodynamic lattice and excess mixing energy parameters for this streamlined multi-component model were derived from a more 
advanced multiphase model. This multiphase model, developed by Jaansalu of the Royal Military College of Canada, is capable of determining complete energetic transformation processes and has proven to be extremely useful and accurate in the calculation of equilibrium compositions and transformation temperatures for both CMSX-10 and PWA1484 turbine blade alloys [11].

Streamlining the robust RMC thermodynamic database involved careful selection of the data relevant only to the liquid and $\gamma$ phases, updating specific model parameters that were released in more recent publications, conversion of the data into the required FACTSage format, and final verification of the database and model parameters for the temperature and compositional ranges of interest. Additional work was performed to investigate alternative solution models for specific data within the RMC database. Unfortunately, details of the final model parameters are considered proprietary; hence the thermodynamic database cannot be included for discussion. However, contained in Appendix $\mathrm{A}$ is an example of the methodology used in the solution modeling work performed for the Ni-Ru system. Finally, after assessing the relevant binary and ternary interaction parameters, the streamlined model data was entered into the FACT-Sage ${ }^{\mathrm{TM}}$ software environment and solidification-microsegregation predictions were determined using the EQUILIB Gibbs-free energy minimization utility [98].

In addition to the streamlined RMC model, two other thermodynamic databases were later purchased and implemented in the FACT-Sage environment. An extensive 
thermodynamic database (SGTE SOLN) was purchased from the Scientific Group Thermodata Europe. The assessed SGTE database consists of model parameters that describe as accurately as possible, experimental data on binary, ternary and higher order systems. As with the preceding RMC model, the SGTE self-consistent models are based on physical principles, which make it possible to extrapolate to the higher order multicomponent systems. The new SGTE multi-component database was developed for general alloy applications (e.g. Al alloys, Ti alloys, Ni-based alloys, etc.) and contains over 300 binaries, 150 higher order systems, 177 solution phases (e.g. liquid, FCC, BCC, HCP etc.), and 588 intermetallic compound phases. It should be mentioned that although the SGTE database is quite elaborate and very detailed, the thermodynamic solution data itself is proprietary and closed to the user. In other words, although the database can be used for thermodynamic predictions, the user cannot view or alter specific database information. This forces the user to blindly accept the model predictions without knowing such model details as lattice stability values and excess Gibbs free energy mixing terms.

The second database obtained at a later date was produced by the Metallurgy Division of the National Institute of Standards and Technology (NIST). This NIST database was specifically tailored for superalloy applications for systems that contain Al-Co-Cr-HfMo-Ni-Re-Ta-Ti-W. The assessed database consists of 42 binaries, 20 ternaries, and 14 ternary sub-systems specific to Ni-based superalloys. The NIST database doesn't contain as many solution phase models as the SGTE database, however, more emphasis was placed on the accuracy of the liquid, $\gamma$, and $\gamma^{\prime}$ precipitate solution phases. Unlike the SGTE solution database, the NIST database is open to the user for examination and 
modification, as most of the self-consistent thermodynamic data has been published in readily available NIST literature. The only drawback of the NIST database is that the solution models do not contain $\mathrm{Ru}$, which is one of the elements of interest in the present study.

Using all three thermodynamic databases, each alloy composition was entered into the FACT-Sage environment and a series of thermodynamic solidification predictions were generated as determined by all three solid-liquid phase equilibria models. Using the EQUILIB Gibbs-free energy minimization utility, dominant phase and transformation temperature calculations were performed for each alloy composition, starting from a temperature of $1300{ }^{\circ} \mathrm{C}$ to $1550{ }^{\circ} \mathrm{C}$ in $50{ }^{\circ} \mathrm{C}$ increments. Hence, three sets of thermodynamic data (RMC, SGTE, and NIST) were generated with respect to predicted solidus and liquidus temperatures and the associated compositions of the first solid phase to appear and the last liquid to solidify. Additional calculations were also performed to determine the predicted partitioning behaviour of each element in each alloy during solidification. 


\section{Development of the Bridgman Casting Process Parameters}

\subsection{Results and Discussion}

\subsubsection{Qualification of Seed Crystal Casting Process}

Prior to casting Alloys A-F in the SX condition, it was first necessary to ascertain if the seed crystal selector method was viable using the Carleton DS furnace. Hence, to qualify the seeding process, a trial casting was performed using the well-known commercial alloy, PWA-1484.

A two inch $(5 \mathrm{~cm})$ SX seed of PWA-1484 purchased from PCC Airfoils ${ }^{\mathrm{TM}}$ was used to act as a starter crystal for a re-melted bar of the same alloy. This oversized-seed crystal length was chosen due to the uncertainty of the extent of seed melting in the furnace. In addition, the casting process was performed in an argon atmosphere using a 3/8-inch (9.5 mm) $\mathrm{ZrO}_{2}$ spacer, a furnace superheat temperature of $1500^{\circ} \mathrm{C}$, and a withdrawal rate of $6.0 \mathrm{in} / \mathrm{hr}(15.2 \mathrm{~cm} / \mathrm{hr})$.

Using the predetermined casting parameters, the test material was cast, sectioned, and prepared for metallographic analysis. The analysis results revealed a well-defined SX structure with no freckles, irregular grain defects, or extensive porosity. Provided in Figure 69 is the partial longitudinal cross-section of the trial SX casting showing the dendritic transition from the seed crystal, through the mushy zone, into the new SX structure. In terms of relative size, the provided longitudinal image is only $1 / 16^{\text {th }}$ of the total diameter and $\sim 1 / 40^{\text {th }}$ of the overall length of the full SX bar. It is apparent from the 
optical micrograph that the original dendritic structure of the seed crystal governs the direction of crystal growth and predefines dendrite nucleation sites. Evidence of this template-like behavior can be seen by the presence of long continuous, primary dendrites (white in colour) extending from the seed through the transition zone into the new SX growth area. The dendritic transition along the length of the trial casting is more clearly visible in the transverse micrographs provided in Figure 70. It is evident that the new SX growth area contains a much finer dendritic morphology than the SX seed obtained from PCC Airfoils ${ }^{\mathrm{TM}}$. This is most likely due to the faster withdrawal rate or higher temperature-gradient capability of the pilot scale furnace, as compared to PCC Airfoils ${ }^{\mathrm{TM}}$ industrial size SX furnace. Also noteworthy from Figure 70 is the consistent dendrite orientation throughout the length of the trial casting, providing further evidence of the influence of the seed crystal structure.

The preliminary results from this trial casting show that it is possible to produce a defect free SX bar using the Carleton DS furnace. It was also deemed necessary to determine the influence of the finer dendritic structure of the new casting process on the size and distribution of the $\gamma^{\prime}$ precipitate strengthening phase. This was determined by applying the standard PWA-1484 heat treatment to both the newly cast SX bar and a PCC ${ }^{\text {TM }}$ SX casting and subsequently comparing the final $\gamma^{\prime}$ precipitate morphologies. The standard PWA-1484 heat treatment applied to both castings was $1316^{\circ} \mathrm{C} / 4 \mathrm{hr} /$ air-cooled + $1080^{\circ} \mathrm{C} / 4 \mathrm{hr} /$ air-cooled $+705^{\circ} \mathrm{C} / 24 \mathrm{hr} /$ air-cooled. It is apparent that the trial casting and the PCC casting have a very similar primary $\gamma^{\prime}$ size and cuboidal morphology, as illustrated in Figure 71 and Figure 72 respectively. The average precipitate size was 
approximately $0.5 \mu \mathrm{m}$ for both castings with a precipitate fraction of about $70 \mathrm{vol} \%$. This shows that the Carleton University casting process does not directly affect the precipitate morphology and distribution of the $\gamma^{\prime}$ precipitate phase and further validates the use of the pilot-scale DS furnace for SX superalloy casting applications.

\subsubsection{SX Casting Results of Alloys A-F}

With the success of the PWA-1484 trial run, developmental casting of the experimental alloys using the Bridgman-seed method soon followed. Located in Table 11 is a list of all the casting runs performed using the DS furnace. A total of 30 castings were performed, 2 trial runs, 8 castings for Alloy A, 6 castings for Alloy B, 4 castings each for Alloys $\mathrm{C}$ and $\mathrm{D}$, and 3 castings each for Alloys $\mathrm{E}$ and F. During the initial casting process, it was necessary to determine and optimize specific casting parameters such as furnace superheat temperature, casting atmosphere, and ceramic spacer (i.e. thermal conductivity) properties. The following sections will describe the results obtained during the casting parameter optimization process.

\subsubsection{Determination of Superheat Temperature}

Initial development and optimization of the casting process was performed using Alloy A. The first important parameter to be determined was the minimum superheat temperature required for complete melting of the master alloy charge and partial melting of the SX seed. The first casting, designated as SX-A1, was cast under a positive-pressure argon atmosphere using a superheat temperature of $1500^{\circ} \mathrm{C}$ with a furnace withdrawal rate of $6.0 \mathrm{in} / \mathrm{hr}$. A 3/4" $(\sim 2 \mathrm{~cm})$ long starter seed of PWA-1484 was used in combination with a $12 "(30 \mathrm{~cm})$ mold filled with $\sim 10 "(25 \mathrm{~cm})$ of master alloy. After solidification 
was complete, preliminary inspection of the casting revealed incomplete melting of the seed/alloy pair, resulting in a columnar DS product. Illustrated in Figure 73 is the resulting columnar grain structure of SX-A1 representative of the center of the cast bar showing several grain boundary triple points due to the insufficient superheat condition. The appearance of lighter and darker coloured grains is due to the variation in crystallographic orientation revealed after the macro etching process. Figure 74 is a higher magnification transverse image illustrating the segregation and preferential nucleation of the eutectic phase along the grain boundaries, which are heavily decorated in almost a continuous chain of the $\gamma-\gamma^{\prime}$ eutectic. Closer inspection of the casting surface at the seed/alloy interface showed that no portion of the seed material had been melted and therefore did not serve as a template for new SX growth. In addition to the unsuccessful columnar microstructure that was obtained, a large amount of surface porosity was also quite noticeable on the casting surface, as shown in Figure 75 . Although the surface condition was not ideal, the first important factor to consider was a suitable superheat temperature for Alloy A that would result in partial melting of the seed. Therefore a second SX casting, designated as SX-A2, was performed using Alloy A under the same casting conditions described earlier with the exception of a higher superheat temperature of $1600^{\circ} \mathrm{C}$.

Once cast, inspection of SX-A2 revealed that there was indeed partial melting of the seed crystal. To ensure that the alloy was successfully cast in the SX condition, a full metallographic analysis of the solidification structure was performed. Provided in Figure 76 is a partial longitudinal cross-section of SX-A2, illustrating the transition from the 
large dendritic structure of the seed material, through the partially melted mushy zone, into the new region of SX growth. The most noticeable difference between the PWA1484 seed structure and the new SX growth area is the large fraction of interdendritic $\gamma-\gamma^{\prime}$ eutectic (white in colour) present in Alloy A. Provided in Figure 77 is a transverse optical micrograph showing the typical size and morphology of the $\gamma-\gamma^{\prime}$ eutectic structure.

\subsubsection{Determination of the Protective Casting Environment}

Upon successfully casting Alloy A in the SX condition, a third casting was performed using the same parameters as $\mathrm{SX}-\mathrm{A} 2$, except the casting environment was altered to investigate the effects of the argon atmosphere on the casting process. The positivepressure ( $\sim 3 \mathrm{psi})$ argon backfill, used previously for SX-A1 and SX-A2, was believed to have resulted in major surface porosity due to entrapment of argon gas bubbles between the mold and liquid metal interface. Another theory is that the observed surface porosity may have resulted from oxygen gas evolution released from the center of the alloy charge during the melting process. However, the latter is less likely as the material was initially fabricated using a vacuum induction melting process. In any case, the questionable surface porosity effects of the argon gas environment needed to be resolved. Therefore, the third casting, SX-A3, was performed using an alternative high-vacuum environment of $4 \times 10^{-4}$ torr $\left(4.7 \times 10^{-2} \mathrm{~Pa}\right)$. It should also be mentioned that the furnace withdrawal rate was increased slightly to $8.0-\mathrm{in} / \mathrm{hr}(20 \mathrm{~cm} / \mathrm{hr})$ to decrease the casting time required for each SX bar. Post-cast inspection of SX-A3 showed remarkable improvement in the cast surface with very little evidence of bubble porosity present. As can be seen in Figure 78 , the surface finish is relatively pristine with only minor amounts of gas porosity located at the top end of the cast bar, as compared to the rutted surface of SX-A2 shown 
in Figure 75. Hence, all subsequent castings were performed using a clean, high-vacuum environment as opposed to the previously used argon atmosphere.

Further metallographic analysis of the SX-A3 bar revealed that a lower superheat temperature is sufficient for castings produced under high vacuum conditions (due to the lower thermal conductivity of vacuum compared to argon gas). Inspection of the bar along the longitudinal axis revealed extensive melting into the seed crystal. In fact, the mushy zone of the seed started almost immediately above the base end of the crystal as shown in Figure 79. Also located within this large mushy zone were areas of spurious grain formation as indicated in Figure 80 . These undesirable grains most likely nucleated as a result of the extensive superheat that was used and also because of the small gap between the inside mold wall and the external diameter of the SX seed. This small space allows for liquid metal to run past the seed and solidify below the mushy zone. Although this breakdown in SX structure was located within the center of the seed cross-section, it did not appear to drastically affect the crystal structure residing above the spurious grains. Figure 81 is a longitudinal micrograph taken just at the edge of the grain defect illustrating that the presence of low angle grain boundaries and non-uniform dendrite orientation. Figure 82 shows the uniform dendritic structure that resides just above the grain defects, indicating that the localized breakdown in SX structure is contained within the mushy zone of the seed. To control the extent of excessive metal seepage between the mold and seeds a much tighter tolerance fit was selected for future external seed diameters. Also, the excessive seed melting indicated that a much lower superheat temperature was required with respect to vacuum casting conditions. 


\subsubsection{Final Optimization of Superheat Temperature}

Due to the lower heat transfer conditions within the vacuum environment, a lower furnace superheat temperature was required to prevent excessive seed melting and liquid metal seepage. For this reason, SX-A5 was cast using the same parameters as SX-A3 however a superheat of $1550{ }^{\circ} \mathrm{C}$ was implemented. Post casting inspection revealed minimal surface porosity with a defect free SX structure. To further validate the chosen casting parameters, an additional casting was performed designated as SX-A6. Identical results were produced indicating that the casting parameters were sufficient for yielding defect-free SX bars.

Having determined all the necessary casting parameters, additional SX bars were cast from Alloys B and C. An initial attempt at casting SX-B1 resulted in the undetectable crushing of the delicate zirconia spacer during the mold-charging step. Post analysis revealed that because the spacer was crushed on loading, an insufficient thermal gradient resulted between the copper chill and the seed, resulting in a DS columnar product. Additional zirconia spacers were fabricated and castings SX-B2 through SX-B4 were produced using the same casting parameters resulting in successful SX products. However it should be mentioned that in some cases the zirconia spacers were damaged and subsequently replaced several times prior to charging the molds successfully. It became apparent that to ensure repeatability between castings, the fragile zirconia spacers needed to be replaced by a more robust ceramic material that was not subject to crushing. 
After conducting a brief thermal analysis, it was concluded that the use of alumina spacers would be sufficient in providing a suitable temperature gradient across the solidliquid interface. A supply of alumina rod was ordered and machined into $1 / 2 "(1.75 \mathrm{~cm})$ spacers. The new alumina spacers had the added advantage that they could be precisely machined with flat, parallel ends providing for level seating of the SX seeds. The only disadvantage of using the new alumina spacers is that a higher superheat temperature would be required to account for the higher thermal conductivity of the more dense ceramic material. Preliminary hand calculations predicted that a superheat temperature of $1585{ }^{\circ} \mathrm{C}$ was required to achieve the desired $50^{\circ} \mathrm{C} / \mathrm{cm}$ temperature gradient. The first successful casting using the new $1585^{\circ} \mathrm{C}$ superheat temperature with the new alumina spacers was conducted using Alloy $\mathrm{C}$, designated as SX-C3. Post casting inspection revealed an excellent SX structure with minimal surface porosity.

Having completed the final iteration of the casting development process, the casting parameters were finalized as: $1585{ }^{\circ} \mathrm{C}$ superheat, 8.0 in/hour withdrawal rate, a $1 / 2$ " alumina spacer, and a high vacuum casting environment of $4 \times 10^{-4}$ torr. It should be mentioned that the remainder of the castings were performed using these finalized casting parameters. Also, four additional castings from Alloy A (SX-A7, SX-A8) and Alloy B (SX-B5, SX-B6) were performed using the finalized parameters to ensure differences in material properties could not be attributed to differences in the casting process. Final qualification of the casting process involved macrostructural and microstructural inspection of each cast bar as well as X-ray diffraction analysis to ensure that ideal single crystals were achieved. 


\section{Macro/Microstructural Response to Bridgman Casting Process}

\subsection{Results and Discussion}

\subsubsection{Final Solidification Macrostructures}

Upon casting all six alloys in the SX condition, a full metallographic inspection of the casting macrostructures was performed using traditional optical microscopy. Inspection of the solidification structures was required to 1) determine if there were any observable differences between the alloys and to 2) confirm that each alloy was produced in the SX condition with a uniform dendritic morphology, free from any major casting defects. Using the previously described polishing and macro-etching procedures, metallographic specimens were prepared from each casting along both the transverse and longitudinal directions from the bottom, middle, and top sections of each bar.

\subsubsection{Transverse Dendritic Structures}

As previously stated, transverse cross-sections were examined in each bar from three separate locations: 1) $1 / 2$ inch $(1.75 \mathrm{~cm})$ just above the starter seed, 2) in the mid-length region of the casting, and 3) $1 / 2$ inch $(1.75 \mathrm{~cm}$ ) from the top end. Optically, there were no observable differences in the transverse solidification structures from either location throughout the length of the SX bars. This suggests that the degree of macrosegregation along the length of the castings was minimal, which is not uncommon in controlled Bridgman casting processes. 
To avoid repetition, only the transverse images taken from the mid-length region of representative cast bars will be provided for discussion. Shown in Figure 83 is a transverse optical micrograph of Alloy A taken from the mid-length region. It is apparent from this micrograph that a uniform dendritic structure exists with a primary dendrite arm spacing of $\sim 330 \mu \mathrm{m}( \pm 31 \mu \mathrm{m})$. Also apparent in this micrograph are the large colonies of eutectic $\gamma-\gamma^{\prime}$ phase contained within the interdendritic regions, which is not uncommon in as-cast alloys that contain high levels of $\gamma^{\prime}$ forming elements. The presence of an additional script-like phase is also noticeable within the interdendritic regions. Figure 84 is a higher magnification optical image of this phase taken from a sample of Alloy A prepared in the un-etched condition. The morphology exhibits a segmented needle-like shape with multiple preferred crystallographic orientations. This phase was later identified using EDX analysis as Ta-rich carbide, as shown in Figure 85.

The transverse dendritic structure of Alloy B, shown in Figure 86, exhibits a similar Maltese cross morphology as Alloy A, with an average primary dendrite arm spacing of $\sim 346 \mu \mathrm{m}( \pm 38 \mu \mathrm{m})$. However, there is a more evident transition in colour from the dendrite core region to the final interdendritic region. The dark cross-interiors of the dendrites appear to be surrounded by lighter grey regions containing a fan-like $\gamma-\gamma^{\prime}$ eutectic phase, located interdendritically. The difference in colour contrast of Alloy B may be due to varying degrees of surface attack during the macro etching process, most likely related to the inherent compositional variance incurred during dendritic solidification. 
Figure 87 shows the transverse structure of Alloy C, which again demonstrates a uniform dendritic morphology, homogeneous distribution, and a preferred crystallographic orientation. The average spacing between the primary dendrite arms was determined to be $\sim 320 \mu \mathrm{m}( \pm 12 \mu \mathrm{m})$. The most noticeable difference between Alloy $\mathrm{C}$ and the first two alloys is the higher volume fraction of the interdendritic eutectic phase. A detailed analysis of the $\gamma-\gamma^{\prime}$ eutectic phase properties will be provided later in section 11 .

The transverse solidification structure of Alloy D, shown in Figure 88, is comparable to that of Alloy C. The interdendritic eutectic phase appears to be more abundant and continuous in morphology as compared to the globular discrete distribution of the eutectic $\gamma-\gamma^{\prime}$ phase exhibited in Alloys A and B. The primary dendrite arm spacing is similar to all three preceding alloys with an average value of $334 \mu \mathrm{m}( \pm 22 \mu \mathrm{m})$. Noteworthy in Figure 88 is the very fine fan structure of the eutectic $\gamma-\gamma^{\prime}$ phase that appears dark black in colour. The dark rings that surround the eutectic fan structures are due to the presence of extra-fine $\gamma^{\prime}$ precipitates that are not resolvable using optical microscopy.

Shown in Figure 89 is a transverse cross-section of Alloy E, depicting a uniform SX solidification structure with a comparable primary dendrite arm spacing of $\sim 310 \mu \mathrm{m}( \pm 45$ $\mu \mathrm{m})$. It is apparent that there is an associated increase in the eutectic volume fraction due to the extremely high refractory content in this alloy (24 wt.\%). As highlighted in Figure 89 , in some locations the eutectic $\gamma-\gamma^{\prime}$ phase almost completely surrounds the individual 
dendrites. Although the eutectic phase consists of a variety of eutectic morphologies (e.g. fan-like $\gamma-\gamma^{\prime}$ structure, coarse blocky $\gamma^{\prime}$, and very fine $\gamma^{\prime}$ ), the phase appears almost filmlike in nature, with a continuous network of branches stretching over numerous dendritic distances. In addition to the high eutectic volume fraction, there also appears to be a very small fraction of a secondary carbide phase, as illustrated in Figure 90. Although the volume fraction of this phase is much smaller, the chemical nature and morphology is comparable to that of the Ta-rich script carbide identified in Alloy A.

Finally, the transverse dendritic structure in Figure 91 is of Alloy F, demonstrating the same typical uniform dendritic morphology with an average primary arm spacing of $\sim 326$ $\mu \mathrm{m}( \pm 43 \mu \mathrm{m})$. Noteworthy of this image was the large difference in etching time that was required to reveal the dendritic macrostructure. The previous etching routine used for Alloys A-E required $\sim 65$ seconds to reveal the solidification structure. However, Alloy F required almost 300 seconds to attain the same degree of etching. The molybdic acid etchant that was used achieves image contrast by removing the $\gamma^{\prime}$ precipitate phase (as described in section 5.3.1). In the case of Alloy F, preferential attack of the $\gamma^{\prime}$ phase may have been inhibited by the presence of $\mathrm{Ru}$, which is known to modify the composition of the precipitate phase due to its reverse partitioning effects on elements such as $\mathrm{Al}$ and $\mathrm{Ti}$ [99].

Based on the transverse metallographic inspection results, it appears that each alloy was successfully cast in the SX condition. Each alloy exhibited a typical as-cast dendritic 
morphology and the range of primary dendrite arm spacing was $\sim 310 \mu \mathrm{m}$ to $\sim 350 \mu \mathrm{m}$, indicating a well-controlled withdrawal/solidification rate from casting to casting. To compliment the transverse inspection results, additional macrostructural characterization was performed along the longitudinal axis to confirm that SX breakdown was not occurring in the $<100>$-growth direction.

\subsubsection{Longitudinal Dendritic Structures}

Longitudinal cross-sectional images were also obtained from each alloy at all three previously described locations along the length of the cast bars. Inspection of the images revealed that a uniform SX structure was obtained from each representative alloy, with no evidence of secondary grains or freckle chains present along the $<100>$ casting direction. Dendrite arm spacing measurements were also performed on the longitudinal images and agreed with the values obtained from the transverse image analysis results. To avoid excessive repetition, a representative image illustrating the typical longitudinal solidification structure of the cast alloys is provided in Figure 92. Although it is not shown in this image, the primary dendrite arms extend continuously from the bottom end of the cast bar to the top, with no evidence of deviation from the $<100>$ preferred crystal growth direction. The interdendritic regions are also heavily decorated with the $\gamma-\gamma^{\prime}$ eutectic phase along the whole length of the bars, except in the final stages of solidification (i.e. last $5-10 \mathrm{~mm}$ of SX bar) where there is insufficient liquid metal remaining to supply the final interdendritic liquid phase. Hence, inspection of the solidification structure within this region is useful for determining the 3-D shape of the dendrites, as there is no surrounding interdendritic region present providing for a greater depth of field. 


\subsubsection{Three Dimensional Images of Solidification Structures}

As previously mentioned, during the final stages of solidification only the dendrites themselves are present. Inspection of this final solidification zone was performed on several castings using an SEM to reveal the 3-D nature of the dendritic structure. Provided in Figure 93 and Figure 94 are two transverse secondary electron images of Alloy B during the final stages of solidification. The uniform dendritic structure as well as the precise crystallographic orientation of the dendrites themselves is clearly identifiable in Figure 93. The primary dendrites are growing out of the page along the $<100>$ direction, whereas the secondary dendrite arms are growing along two perpendicular cubic directions, both normal to the $<100>$ primary axis. Also, close inspection and interpretation of Figure 94 reveals the sequence of dendritic growth within the alloys. As indicated in this image, crystal growth proceeds out of the page along the $<100>$ direction. As the primary dendrites grow, secondary arms nucleate and branch off from the main core in preferred orthogonal directions. As these secondary dendrite arms grow in size (e.g. $\mathrm{SD}_{1}$ ), the primary arm continues to grow along the $<100>$ direction until a $2^{\text {nd }}$ set of secondary arms develop and coarsen (e.g. $\mathrm{SD}_{2}$ ). The process repeats itself and a $3^{\text {rd }}$ set of secondary dendrite arms $\left(\mathrm{SD}_{3}\right)$ nucleates and begins radial growth. During this process, at any one time there may be numerous sets of secondary arms of incremental lengths surrounded by interdendritic liquid, which will continue to grow in a radial direction until the localized liquid metal temperature reaches the final eutectic solidification temperature. Because the solidification time is carefully controlled by maintaining accurate furnace withdrawal and temperature gradient parameters, the sequence of solidification is such that the decrease in the localized liquid metal 
temperature is slow enough so that $\mathrm{SD}_{1}$ has enough time to reach the average dendrite arm size, followed shortly after by $\mathrm{SD}_{2}, \mathrm{SD}_{3}$, etc.

For comparison purposes, two additional transverse images showing a similar dendritic structure have been provided for Alloy F. Figure 95 and Figure 96 both depict a similar trend in SX dendritic growth as previously described for Alloy B. There does appear to be a larger fraction of tertiary branching from the secondary arms, however this difference may be due to slight deviations in temperature gradients from casting to casting.

Three-dimensional longitudinal images were also captured using the SEM, as shown in Figure 97 and Figure 98. Further evidence of the SX nature of the castings is shown in Figure 97 as indicated by the long primary dendrites that are aligned perfectly parallel to each other throughout the length of the SX bars. Similarly, the secondary dendrite arms also demonstrate preferred bi-directional crystallographic orientation throughout the sample space provided. If SX breakdown was present, various dendrite orientations would be observed due to the different crystallographic grain properties, resulting in various growth directions and eventual dendrite impingement on each other (i.e. grain boundary formation). Figure 98 provides for a closer look at the typical longitudinal dendritic structure of the SX alloys, illustrating the extremely close-packed stacking of the secondary arms along the $\langle 100\rangle$ direction. This image also demonstrates the relatively equal lengths of the secondary arms indicating a well-controlled solidification process. 


\subsubsection{Final As-Cast Microstructures}

The previous macrostructural inspection results all indicated that each alloy was successfully cast in the SX condition with approximately equivalent dendritic structures. Due to the relatively smaller size of the alloy microconstituents, additional metallographic inspection was required using more powerful scanning electron microscopy methods. Representative samples were prepared as per the guidelines described in section 5.3.2. The electrolytic etchant used in this procedure precisely removes the $\gamma$-matrix phase from the as-cast microstructures, allowing for excellent resolution of the $\gamma^{\prime}$ precipitate phase, the interdendritic eutectic $\gamma^{\prime}$ phase, as well as any minor carbide phases that are present. The following microstructural inspection results describe the changes in precipitate morphology from the initial solidification point of the dendrite cores, along the secondary dendrite arms, and within the final solidification zone of the interdendritic eutectic region.

\subsubsection{Transition of $\gamma^{\prime}$ Precipitate Structure Near the Dendritic Boundaries}

Prior macrostructural inspection results using optical microscopy and $\gamma^{\prime}$ etching ( $\gamma^{\prime}$ removal) revealed a contrast in colour within the dendritic structure of each alloy. Due to the low-resolution capability of the optical microscope, it was not possible to determine the underlying reason for the different shaded regions within the dendrites. Hence, additional samples were prepared for inspection in the SEM. The secondary electron images provided in Figure 99 show the individual dendrite structures of Alloys A-F, highlighting the dark grey boundary layers surrounding the lighter dendrite interiors. Since the contrast in these images was produced by removing the $\gamma$-matrix phase, the 
observed transition boundaries in each alloy must be related to differences in the residing $\gamma^{\prime}$ precipitate structures.

To elucidate the nature of this observed $\gamma^{\prime}$ transition boundary, a collage containing numerous higher magnification images of Alloy A has been compiled, as shown in Figure 100. From this figure it is immediately obvious that there are several distinct regions of varying $\gamma^{\prime}$ precipitate size. It appears that within the primary core and along the interiors of the secondary dendrite arms, the primary $\gamma^{\prime}$ size is relatively uniform and cubic in morphology. However, upon approaching the dark grey boundaries surrounding the dendritic interiors, there is a noticeable change in $\gamma^{\prime}$ size and shape. Upon closer inspection of the rectangular area highlighted in Figure 100, there are three major regions of varying $\gamma^{\prime}$ precipitate size. Figure 101 clearly illustrates the variation in $\gamma^{\prime}$ size and morphology within these three major zones. Within the dendrite interiors, a finer cuboidal morphology exists demonstrating almost complete separation of the ogdoadically diced cube structures. The average precipitate size (complete ogdoad) in this region ranges from 0.8 to $1.0 \mu \mathrm{m}$. In the neighboring dark grey boundary layer the $\gamma^{\prime}$ are much larger, ranging in size from 1.2 to $1.6 \mu \mathrm{m}$, although the degree of ogdoadically cubic separation appears to be less extensive. In fact, the precipitates appear to have coarsened favorably in non-cubic directions, resulting in asymmetrically distorted cubes with varying degrees of incomplete ogdoad separation. Finally, immediately adjacent to the large $\gamma^{\prime}$ precipitate of the eutectic structure, is a very small region containing very fine $\gamma^{\prime}$ precipitate. The precipitate in this region appear to have undergone far less coarsening compared to the 
two previous regions, with an average length of $\sim 0.5 \mu \mathrm{m}$. These smaller $\gamma^{\prime}$ do not appear cubic in nature and their preferential growth direction is normal to the large $\gamma^{\prime}$ eutectic interface. It should be mentioned that this final region is very small, in most cases less than $10 \mu \mathrm{m}$ wide. Therefore, for all intensive purposes the general trend in precipitate evolution is an increase in $\gamma^{\prime}$ size from the initial dendrite core to the massively large $\gamma^{\prime}$ contained within the final eutectic structure.

This variation in $\gamma^{\prime}$ precipitate size is a direct result of chemical microsegregation that occurs during the casting process. Faster solidification times would result in an even larger variation in precipitate size due to inhibited diffusional processes that require more time for exchange across the solid-liquid interface. In fact, when solidification is rapid the microsegregation profile approaches that predicted by the Scheil-Gulliver solidification model where back diffusion in the solid phase does not occur [6]. Fortunately, SX casting processes incorporate suitably slow solidification rates such that the extent of segregation is limited by allowing a finite amount of back diffusion to proceed for such elements as $\mathrm{Ta}, \mathrm{Ti}$ and $\mathrm{Al}$. In addition to this variation in precipitate size, microsegregation also results in an associated change in the $\gamma^{\prime}$ solvus temperature [6]. The compositional gradient that exists from the cores to the dendrite edges results in both a transition in $\gamma^{\prime}$ size and an associated broadening of the effective $\gamma^{\prime}$ solvus temperature. The range in solvus can be as high as $40{ }^{\circ} \mathrm{C}[6]$ with the larger eutectic $\gamma^{\prime}$ usually requiring the upper limit of the range for complete solutioning. 
Hence, the variation in $\gamma^{\prime}$ precipitate size and the solvus temperature range may be directly related to the extent of microsegregation that occurs in each alloy, assuming that the solidification conditions have been kept constant between castings. For this reason, further analysis of the localized $\gamma^{\prime}$ structure within the dendrites was performed. Additional DSC analysis of the microsegregation effects on such endothermic processes as $\gamma^{\prime}$ solutioning will be examined later in section 10 .

\subsubsection{Primary $\gamma^{\prime}$ Morphology Within the Transverse Dendritic Structure} As previously mentioned, the variation in primary $\gamma^{\prime}$ precipitate size may be directly related to the extent of microsegregation within the as-cast alloy structures. For comparison purposes, analysis of the representative $\gamma^{\prime}$ structures for each alloy within the dendrite interiors was performed. High magnification SEM images were taken from five locations in each alloy microstructure within the center of the primary dendrite core and within the center of each secondary arm.

\section{Alloy A}

Figure 102 illustrates the primary $\gamma^{\prime}$ size and shape within the center of the dendrite core of Alloy A. The precipitate shape is roughly cuboidal in nature with almost complete ogdoad formation. The corners of the cubes show signs of extended dendritic growth resulting in distortion and rounding of the overall cuboidal structure. There is also evidence of even further division of the individual ogdoad cubes due to the preferential dendritic growth at the cube corners. The presence of these deformed cubes with extended corners is indicative of the precipitate's lower interfacial energy (c.f. perfect 
cubes). The preferential growth of the cube corners is due to the presence of higher localized stresses. It is not uncommon to find a large number of dislocations in the corners, which act as "short circuit" diffusion paths and promote faster corner growth [50]. In terms of quantifying the precipitate size, it is difficult to determine as some cubes show complete ogdoadic separation and some do not. The average individual ogdoad cube is $0.55 \mu \mathrm{m}$ in width, whereas the larger precipitate structures are on the order of $1.10 \mu \mathrm{m}$

Figure 103 to Figure 106 reveal a common $\gamma^{\prime}$ precipitate size and morphology for the left, right, top, and bottom secondary dendrite arms respectively. Compared to the dendrite core, the secondary arms exhibit a slightly larger $\gamma^{\prime}$ size with even greater distortion of the cuboidal corners. There also appears to be even less complete ogdoadic separation. This may be due to coalescence of the neighboring ogdoad cubes due to precipitate dendritic growth (as shown in Figure 22) or due to insufficient cooling time (i.e. diffusion) required to allow the cubes to coarsen and eventually split. In any case, the slightly larger and more complex precipitate structure in the secondary arms indicates that the localized strain fields are slightly higher so that the precipitate assumes a more complex shape that reduces the overall strain.

\section{Alloy B}

Figure 107 shows the primary $\gamma^{\prime}$ size and shape within the center of the dendrite core of Alloy B. In this particular image, the primary $\gamma^{\prime}$ demonstrate near perfect cuboidal morphology with complete ogdoadically diced cubes. There is some evidence of dendritic corner growth of the cubes, but far less than that exhibited in Alloy A within the dendrite 
core. This would suggest that the localized strain fields surrounding the primary $\gamma^{\prime}$ are higher than that in Alloy A. Hence, the $\gamma^{\prime}$ morphology in the dendrite core of Alloy B is more heavily influenced by the strain energy of the system, which would explain the well-defined ogdoadically diced cuboidal structure of the precipitates. The average individual cube size is $0.62 \mu \mathrm{m}$, with the overall structure measuring at $1.24 \mu \mathrm{m}$. The $\gamma^{\prime}$ precipitates of the secondary arms, shown in Figure 109 to Figure 111, demonstrate a similar behaviour as that shown for Alloy A. The precipitates in the secondary arms have grown larger in size and in the process have developed an unevenly distributed blocky morphology. This is due to the various directions of cuboidal growth required to "fill-in" the spaces between the neighboring precipitates. It should be mentioned however, that although the $\gamma^{\prime}$ have coarsened extensively in the secondary arms, the extent of cuboidal corner growth exhibited in Alloy A appears to be at a minimum. For the most part, the $\gamma^{\prime}$ morphology is cuboidal, distorted mainly by the close packed nature of the impinging $\gamma^{\prime}$ neighbors.

\section{Alloy C}

The primary $\gamma^{\prime}$ shape and size within the center of the dendrite core of Alloy $\mathrm{C}$ is shown in Figure 112. In comparison to Alloy B, the $\gamma^{\prime}$ morphology in the core of Alloy C exhibits exactly the same shape and degree of complete ogdoadic splitting. The main difference is the smaller size of the primary precipitate. The average cube dimension is $0.48 \mu \mathrm{m}$ with an overall ogdoad structure width of $0.97 \mu \mathrm{m}$. Figure 113 through Figure 116 show the relative $\gamma^{\prime}$ size and shape within the secondary dendrite arms of Alloy C. Once again, it is evident that the $\gamma^{\prime}$ size is much larger in these secondary arms compared to the dendrite core, exhibiting almost complete consumption of the $\gamma$-matrix phase after 
$\gamma^{\prime}$ coarsening. The $\gamma^{\prime}$ morphology has still retained its cuboidal morphology with minor indications of dendritic corner growth of the $\gamma^{\prime}$ cubes, however the extent is far less than that observed in Alloy A.

\section{Alloy D}

Upon examining the primary $\gamma^{\prime}$ within the dendrite core of Alloy $\mathrm{D}$, it is apparent that a major decrease in precipitate size has occurred with respect to the size of the previously examined alloys, as shown in Figure 117. The average cube length is $0.34 \mu \mathrm{m}$ with an ogdoad dimension measuring $\sim 0.69 \mu \mathrm{m}$. This decrease in $\gamma^{\prime}$ size is nearly $50 \%$ smaller than that observed in the cores of Alloys A and B. This may be due to the fact that Alloy $\mathrm{D}$ contains the highest amount of $\mathrm{Re}$ of all the alloys being investigated. This is significant, as it has been reported by many researchers that the addition of substantial Re levels into base alloy compositions results in a decrease in the $\gamma^{\prime}$ coarsening kinetics [29]. Although this Re interface effect was determined based on the minimization of $\gamma^{\prime}$ rafting in high temperature creep tests, the same diffusion control effect might be applicable during alloy solidification. Additional testing would be required to confirm this hypothesis. With respect to the $\gamma^{\prime}$ precipitate shape, once again the precipitate morphology exhibits an excellent ogdoadic cubic structure with well-delineated edges.

Figure 118 to Figure 121 shows the $\gamma^{\prime}$ properties within the secondary arms of the as-cast structure of Alloy D. All four secondary arms exhibit a similar increase in $\gamma^{\prime}$ size, however, the extent of coarsening is much smaller than that previously seen in Alloys A, 
$\mathrm{B}$, or $\mathrm{C}$. The precipitates have retained their cuboidal morphology and the extent of dendritic corner growth is negligible.

\section{Alloy E}

Shown in Figure 122 is the primary $\gamma^{\prime}$ structure of Alloy E within the center of the dendrite core region. The size of the precipitate is close to that of Alloy $\mathrm{D}$, with a slightly larger cube length of $0.41 \mu \mathrm{m}$ and an overall ogdoad dimension of $0.83 \mu \mathrm{m}$. The small $\gamma^{\prime}$ size may also be related to the relatively high $3 w t . \%$ Re content in this alloy. The most noticeable difference between Alloy $\mathrm{E}$ and the previous four alloys is the more defined cuboidal morphology of the $\gamma^{\prime}$ precipitates. The edges of the individual cubes are extremely straight with sharply defined cubic corners. This would imply that precipitate growth in this alloy is dominated by interface energy control as opposed to diffusional growth control.

Figure 123 to Figure 126 reveal the $\gamma^{\prime}$ structure within the secondary arms of Alloy E. Coarsening of the $\gamma^{\prime}$ structure does occur within the arms, however, the extent is limited mainly to growth in preferred cubic directions. The perpendicular precipitate morphology is still retained, however there is some evidence of rectangular, as opposed to cuboidal, precipitate evolution.

\section{Alloy F}

Finally, the SEM image shown in Figure 127 depicts the primary $\gamma^{\prime}$ structure observed within the dendrite core of Alloy F. The morphology of the precipitate structure in this alloy is comparable to that of Alloys $\mathrm{B}, \mathrm{C}$ and $\mathrm{D}$, demonstrating an ogdoadically divided 
cuboidal structure with slightly rounded corners. The most significant difference is the very fine size of the $\gamma^{\prime}$ within the primary arm. This alloy exhibits the smallest precipitate size of all the alloys, with a cube length of $0.21 \mu \mathrm{m}$ and an overall ogdoad dimension of $0.48 \mu \mathrm{m}$. In comparison to Alloy $\mathrm{C}$, which has the same nominal alloy composition with the exception of $3 \mathrm{wt} . \% \mathrm{Ru}$, the $\gamma^{\prime}$ precipitate size is $\sim 50 \%$ smaller.

Figure 128 to Figure 131 show the general increase in $\gamma^{\prime}$ size within the secondary arms of Alloy F. The extent of $\gamma^{\prime}$ coarsening is relatively small with respect to the dendrite core size. In fact, the secondary arm precipitate dimensions are smaller than those of the primary dendrite $\gamma^{\prime}$ of Alloys A, B, and C.

After examining all the relevant $\gamma^{\prime}$ size and shape parameters within the various dendritic locations of each alloy, it has become obvious that relating the precipitate size to the extent of microsegregation is not possible for several reasons. The first most important reason is the difficulty in measuring the precipitate dimensions of each alloy in each location. In some cases the $\gamma^{\prime}$ have not completed ogdoadic division making it impossible to measure the $\gamma^{\prime}$ size via computational image analysis procedures. The second important reason for not relating the $\gamma^{\prime}$ size to the extent of microsegregation within this group of alloys is the influence of specific compositional effects. For example, as it was suggested in the case of Alloy D, the higher Re content appears to have retarded the coarsening kinetics of the $\gamma^{\prime}$ precipitate, resulting in a finer $\gamma^{\prime}$ size than in Alloys A, B, and $\mathrm{C}$. However, it has already been well documented that the addition of Re to alloy 
compositions results in an increase in microsegregation within SX superalloys [59]. Therefore, although the $\gamma^{\prime}$ size is smaller in Alloy D, the precipitate size cannot be used as a means of gauging the severity of microsegregation with respect to other alloys of different chemical composition (i.e. Alloys A-C). Hence, the connection between increasing $\gamma^{\prime}$ size and increasing microsegregation can only be used when comparing the microstructures of an individual alloy composition that have undergone different solidification rates. Ranking the extent of microsegregation between the alloys must be made using other means such as compositional analysis, eutectic fraction measurements, and thermo-physical characterization.

\subsubsection{Primary $\gamma^{\prime}$ Morphology Across the Longitudinal Solid-Liquid Interface} In addition to characterizing the $\gamma^{\prime}$ precipitate coarsening behaviour along the transverse growth direction (secondary arm growth direction), the $\gamma^{\prime}$ size and morphology in the longitudinal $<100>$ direction was also examined. To avoid excessive repetition, only the longitudinal inspection results for Alloy E will be presented for discussion.

The collection of SEM images shown in Figure 132 illustrates the general trend in $\gamma^{\prime}$ size and shape across the solid-liquid interface of a typical SX bar. The left side of this figure depicts a partial longitudinal cross-section of Alloy E, showing the dendritic transition from the solid PWA-1484 seed structure at the bottom of the page, into the neighboring mushy zone of the partially melted seed, and finally crossing the interface region into the region of new SX growth. Examination of the corresponding $\gamma^{\prime}$ images on the right-hand side of Figure 132 shows several regions of slightly different precipitate morphology. As 
shown in Figure 132(f), it is apparent that within the PWA-1484 seed crystal region that the typical 0.5 to $1.0 \mu \mathrm{m}$ cuboidal $\gamma^{\prime}$ precipitate morphology exists. It should be noted that none of the cube faces of the $\gamma^{\prime}$ in this image are parallel to the page as the longitudinal cross-section was not made along the preferred cubic growth direction of the precipitate. Hence, the $\gamma^{\prime}$ appear to be skewed due to the visibility of cube side faces. Figure $132(\mathrm{e})$ is taken just below the solid-liquid interface region within the partially melted mushy zone of the seed. This image shows no indication of $\gamma^{\prime}$ distortion when compared to the $\gamma^{\prime}$ in the un-melted seed structure. However, upon inspection of Figure 132(d), it is apparent that the primary $\gamma^{\prime}$ drastically changes morphology within the center of the solid-liquid interface region. This image indicates a complete breakdown of the cuboidal $\gamma^{\prime}$ morphology, resulting in a large globular precipitate phase. Remarkably, just $0.5 \mathrm{~mm}$ above this region, as shown in Figure 132(c), the cuboidal $\gamma^{\prime}$ structure reappears and exhibits the same preferred orientation as that portrayed within the seed material. Figure 132(b) shows even further refinement of the new $\gamma^{\prime}$ structure within the new SX growth region of the cast bar. The differences in $\gamma^{\prime}$ structure between the top image (new SX region) and the bottom image (PWA-1484 seed) can be attributed to either differences in alloy compositions and possibly differences in the solidification rate of the original seed material.

\subsubsection{Various Eutectic Morphologies Within the Interdendritic Region}

One of the most serious side effects of microsegregation in SX superalloys is the formation of embrittling eutectic $\gamma-\gamma^{\prime}$ phases. The presence of residual $\gamma-\gamma^{\prime}$ eutectic has been known to contribute to premature blade failure due to initial cleavage fracture 
within the brittle eutectic microstructure. Due to the as-cast condition of Alloys A-F, a substantial amount of eutectic $\gamma-\gamma^{\prime}$ phase exists within the interdendritic regions of the solidification structure. The typical eutectic structure commonly observed within the alloys is shown in Figure 133.

In most cases, when the remaining liquid within the interdendritic region reaches the required eutectic composition, liquid decomposition into the eutectic $\gamma+\gamma^{\prime}$ two-phase structure usually occurs relatively fast. During the initial growth period of the eutectic, fine cuboidal $\gamma^{\prime}$ are homogeneously distributed between narrow $\gamma$ matrix channels, as shown in Region B of Figure 133. Initially, this eutectic core region doesn't require any additional help by means of long-range diffusion as the solidification rate is fast resulting in the fine eutectic $\gamma-\gamma^{\prime}$ structure. As the eutectic core region continues to grow, the concentration of $\gamma^{\prime}$ forming elements (e.g. Al+Ti) decreases in the liquid and begins to rise in the solid phase. Towards the latter stages of eutectic formation, Region A, the $\gamma-\gamma^{\prime}$ structure becomes predominantly coarse $\gamma^{\prime}$ with very fine channels of $\gamma$ separating the large fan-like dendritic arms. This eutectic cap region develops due to the decreasing concentration levels of $\gamma^{\prime}$ forming elements directly ahead of the solid interface, which means slower growth on the eutectic front. Hence, the $\gamma^{\prime}$ in the cap region tends to thicken, which results in the larger fan structure with an increased concentration of $\mathrm{Al}+\mathrm{Ti}$. In general, alloys that exhibit a high volume fraction of this eutectic phase usually have undergone significant microsegregation during solidification. Hence, the severity of 
microsegregation within the family of alloys may be ranked based on the measured eutectic phase fraction. This analysis method will be addressed later in section 11 .

An alternative eutectic structure was also observed to occur in Alloy A, as shown in Figure 134. This pockmarked structure forms during the last stages of eutectic solidification due to its presence between two neighboring, eutectic cap structures. The phase consists of a coarse matrix with sporadic precipitate nucleation. The nucleation sites eventually grow into short rods, as indicated by the presence of $\gamma^{\prime}$ just below the surface of the etched pits. This particular phase was not observed in any of the other alloys investigated. It is believed that the rods are similar in composition to the $\gamma$-phase, as they have been removed during etching, which would also indicate that the surrounding matrix is chemically similar to the $\gamma^{\prime}$ phase. After performing an extensive literature search, further evidence of the existence of such a eutectic phase in industrial SX superalloys could not be found to support the current findings. However, a similar eutectic phase was reported to occur in the rapidly quenched ternary alloy, Ni-27.6 Al-9.7 $\mathrm{Ta}$ [100]. Figure 135 shows this eutectic structure, which consists of a $\delta\left(\mathrm{Ni}_{3} \mathrm{Ta}\right)$ matrix mottled with $\beta$ (NiAl) rods, almost identical in appearance to the eutectic phase observed to occur in Alloy A. Additional EPMA analysis and possibly TEM-XRD of this eutectic phase is required to confirm the presence of this $\delta-\beta$ eutectic structure in Alloy A.

\subsubsection{Minor Carbide Precipitate Phases}

Although the carbon concentration for the alloys was restricted to very low impurity levels, the occurrence of minor carbide phases was observed in several of the as-cast 
microstructures. The easiest way to resolve the presence of such phases is by SEM inspection using the BSE detector. Provided in Figure 136 are selected BSE images from each alloy along the transverse direction. These images were recorded from the exact same locations as those provided in Figure 99, which were collected using the secondary electron detector. It is evident from the BSE images that a small amount of carbide phase (appears bright white due to the atomic number contrast) is present in most of the alloys, except Alloy F. Alloy A and Alloy E exhibited the highest fraction of carbide amongst the alloys, usually residing within the interdendritic regions indicating formation during the final stages of solidification. Figure 137(a) shows the typical script-like carbide morphology present in Alloy A, whereas Figure 137(b) depicts the needle-like morphology observed in Alloy $\mathrm{E}$ within the interdendritic eutectic $\gamma^{\prime}$ phase. As previously mentioned, based on Figure 136, Alloy $F$ appears to contain no carbide phase within its microstructure. However, a more thorough inspection across the sample surface did reveal extremely small amounts of the Ta-rich carbide phase found in Alloys A-E. However, the relative fraction is still much smaller. Previous studies have shown that the addition of $\mathrm{Ru}$ in Ni-base superalloys not only improved the long-term structural stability of the alloys, but it was also responsible for delaying the formation of $\mathrm{M}_{6} \mathrm{C}$ carbides [101]. Although the exact mechanism was not determined, the same Ru addition effects may explain the low carbide content of Alloy F.

As previously mentioned, the presence of carbides are usually only required to improve grain boundary strength in polycrystalline or DS columnar-grained alloys. For the most part, the addition of carbon is usually kept as low as possible in SX alloys to prevent 
crack nucleation along these sites and also to prevent the nucleation of stray grains during the casting process. The microstructural analysis results seem to indicate that the minor amount of carbide phase that is present in Alloys A-F is suitably low such that SX breakdown did not occur during casting. However, it should be mentioned that the scriptlike carbide present in Alloy A did appear to distort the dendrite shape in some locations within the as-cast microstructure.

\subsubsection{XRD Analysis Results}

In addition to characterizing the cast structures metallographically, room temperature Xray diffraction tests were conducted on representative samples from each alloy to ensure that SX bars were produced. The XRD samples were taken from the mid-length region of the cast bars along the transverse direction. Crystallographic inspection at the bottom and top of the bars was not deemed necessary as it was already proven by metallographic inspection that there were was no difference in microstructure throughout the length of each bar. X-ray diffraction intensity was recorded for each alloy over a $2 \theta$ range of $20^{\circ}$ to $100^{\circ}$ with subsequent peak identification performed using the $\mathrm{Jade}^{\mathrm{TM}} 3.0$ software package. The results from the six diffraction scans were combined and plotted in Figure 138 for comparison.

It is apparent that for all six alloys, there is a dominant diffraction peak at a $2 \theta$ angle of 50.97 degrees. This diffraction angle corresponds to the (200) plane in the FCC crystal structure, as diffraction of the (100) planes is not observed due to destructive X-ray interference. Since a $\mathrm{Cu}-\mathrm{K} \alpha$ radiation source was used (i.e. $\lambda=1.54 \AA$ ) the 
corresponding d-spacing is $1.79 \AA$ and the calculated cubic lattice parameter is $3.58 \AA$. It should be noted that the intensity scale in Figure 138 is in logarithmic units; hence, the intensity of the $(200)$ peak at $50.97^{\circ}$ is much greater than the other identified peaks.

The presence of one major peak for all six diffraction patterns is indicative of the single crystal structure of each sample inspected. Each alloy consists primarily of an FCC $\gamma-$ matrix embedded with a high volume fraction of coherent FCC $\gamma^{\prime}$ precipitate phase. Since each sample was positioned in the XRD stage with the longitudinal growth direction perpendicular to the stage datum plane, and since the $<100>$ crystallographic direction is the preferred growth direction for FCC single crystal materials, it is not surprising that the resulting diffraction patterns all indicate diffraction only from the (200) planes (i.e. (100) planes). If the samples contained multiple crystallographic orientations (i.e. nonsingle crystal) then diffraction from additional FCC planes would appear on the patterns according to Bragg's law. This is demonstrated in the two powder XRD patterns provided in Figure 139 and Figure 140 showing the $2 \theta$-intensity data for the $\gamma$ and $\gamma^{\prime}$ phases respectively [102]. Both figures show comparable XRD patterns with the exception of additional peaks present for the $\gamma^{\prime}$ phase due to weak superlattice reflections. 


\section{EPMA Microsegregation Measurements}

\subsection{Results and Discussion}

As previously mentioned, to determine the degree of microsegregation present between the dendrite core and interdendritic $\gamma-\gamma^{\prime}$ eutectic regions, an accurate compositional analysis was required for each alloy. The EPMA involved two tasks: 1) determination of the chemical segregation coefficients for each alloy, and 2) determination of the compositional gradients across the dendritic structures. The following sections will discuss the results obtained.

\subsubsection{Chemical Segregation Coefficient}

Provided in Table 12 and Table 13 are the EPMA point-scan results for Alloys A-C and Alloys D-F respectively. To aid in the interpretation of the tabulated segregation data, the degree of microsegregation between the dendrite cores and interdendritic regions can be better characterized with the use of the chemical segregation coefficient $\left(k^{\prime}\right)$. By definition, $k^{\prime}$ is taken to be the ratio of the dendrite core composition over the interdendritic composition level. Using the averaged composition values derived from the point-scan results, the average segregation coefficient for each alloy was determined and recorded in Table 14. The suitability of using the average composition values as a means to quantify segregation behaviour was justified after completing a thorough error analysis of the EPMA results. To prevent distraction from the present discussion, details of the 1Sigma error analysis have been provided for review in Appendix B. 
From the tabulated results of Table 14, it is apparent that the typical segregation behavior of most SX superalloy systems is present [6]. The elements $\mathrm{Cr}, \mathrm{Co}, \mathrm{Re}, \mathrm{Mo}$, and $\mathrm{W}$ all exhibit segregation towards the dendrite core regions during solidification, as indicated by the greater than unity $k^{\prime}$ values. In other words, these elements are the first to solidify within the dendrite cores during the casting process. The $\gamma^{\prime}$ forming elements of $\mathrm{Al}, \mathrm{Ti}$, and Ta, all segregate in a contrasting manner as indicated by their $k^{\prime}$ values less than unity. These elements are present in greater quantity in the last liquid phase to solidify and are responsible for the large fraction of eutectic $\gamma-\gamma^{\prime}$ phase that forms within the interdendritic regions. Other elements that do not favorably segregate to either region have $k^{\prime}$ values close to unity and represent the ideal segregation behavior sought by material designers. For the alloy compositions examined here, this would include the elements $\mathrm{Ni}$ and $\mathrm{Ru}$, which have $k^{\prime}$ values of 1.0 and 1.03 respectively. Controlling the extent of this segregation behavior is critical to SX microstructural stability, as high levels of Re, W, Cr, and Mo within the dendrite cores are known to promote TCP phase formation [10]. The formation of these deleterious phases in high temperature turbine applications results in premature creep properties, due to the resulting depletion of solid solution strengthening elements from the alloy matrix and also because of their brittle nature.

Upon examining the $k^{\prime}$ values in Table 14 , it can be seen that Alloys A and F appear to have the lowest degree of chemical segregation of the six compositions examined. Alloys $\mathrm{B}, \mathrm{C}, \mathrm{D}$ and $\mathrm{E}$ all show extensive segregation of Re, W, Mo and $\mathrm{Cr}$ to the dendrite core regions, as commonly observed in commercial alloys $[9,103,104,105,106]$. The 
maximum and minimum $k^{\prime}$ coefficients for each alloy are provided at the bottom of Table 14 , illustrating the degree of microsegregation variance. Based on the max-min $k^{\prime}$ values reported, it is apparent that elements such as $\mathrm{Al}, \mathrm{Ti}, \mathrm{Ni}, \mathrm{Co}, \mathrm{Ta}$, and $\mathrm{Ru}$ all segregate with approximately the same behavior, independent of the alloy composition, as denoted by the small ranges in $k^{\prime}$ values. The lack of deviation of $k^{\prime}$ for $\mathrm{Al}$ and Ti may be explained by the narrow range of nominal levels of these elements among the alloys examined. Likewise, the $\mathrm{Ni}$, Co and $\mathrm{Ta}$ levels do not vary considerably and yield relatively consistent segregation coefficients. However, the partitioning terms for these three elements are of the same magnitude as reported elsewhere for other SX Ni-based superalloys of that contain a wide range of varying Ni-Co-Ta alloy composition levels $[103,103,105,106]$. There does not seem to be any synergistic effects on segregation within these species due to element-element interactions or multi-element interactions based on the $k^{\prime}$ values for the six alloys examined. Conversely, elements such as $\operatorname{Re}, \mathrm{W}$, $\mathrm{Cr}$ and Mo seem to have varying segregation properties with respect to nominal composition levels.

The overall segregation of the alloys is more easily interpreted with the aid of a bar chart, as shown in Figure 141. From this figure it is can be seen that Alloys A and F appear to have the lowest degree of segregation of the dendrite core prone elements. Alloys B, C, D and $\mathrm{E}$ all show extensive partitioning of $\mathrm{Re}, \mathrm{W}, \mathrm{Mo}$ and $\mathrm{Cr}$ to the dendrite core regions. Of particular interest in the EPMA microsegregation results is the superior segregation behavior of Alloy F. Not only does this alloy have a higher total refractory content than most of the alloys, but it also contains a greater amount of segregation-prone elements. It 
appears that the addition of $4 \mathrm{wt} . \% \mathrm{Ru}$ plays a major role in counteracting the segregation behavior of elements such as $\mathrm{Cr}, \mathrm{Re}$ and $\mathrm{Mo}$. This is clearly demonstrated in Figure 142 showing the drastic decrease in preferential segregation in Alloy $F$ as compared to all five of the other alloys. Alloys A through D all show an increase in chemical segregation as the level of Re is increased from 1 to 4 wt.\%. Despite Alloys A to $\mathrm{D}$ containing the same $21 \mathrm{wt} . \%$ total refractory content, the $\mathrm{Cr}, \mathrm{Re}$ and Mo segregation coefficients increase from Alloy A to D, consistent with the increasing nominal $\mathrm{Re}$ content from Alloy A to D and despite the concurrent decreasing W content. Therefore, it appears that Re has a much greater influence on segregation behavior compared to $\mathrm{W}$. Alloy E shows even stronger core segregation with the presence of both high $\mathrm{Re}$ and $\mathrm{W}$ content (i.e. greater refractory content). However, Alloy F, which has the same total refractory level of Alloy E, shows remarkable improvement in overall microsegregation. The lower segregation coefficient of Alloy $\mathrm{F}$ is not due to the lower $\mathrm{W}$ content compared to Alloy E, since Alloy F exhibits a lower partitioning coefficient than Alloy C, which contains the same W level. Again, this indicates that $\mathrm{W}$ does not have a large influence on element segregation. Moreover, it appears that the severity of microsegregation is controlled to a greater extent by $\mathrm{Re}$, which increases the element segregation, and the addition of $\mathrm{Ru}$, which significantly reduces the extent of microsegregation.

Although further supporting experimentation is required, preliminary results from the microsegregation analysis of the six experimental compositions indicate that $\mathrm{Ru}$ plays a major role in controlling the forward and back diffusion properties of the heavier TCP forming elements of $\mathrm{Cr}, \mathrm{Mo}$, and Re. A recent study has reported similar improvements 
in diffusion processes due to the addition of $\mathrm{Ru}$ [105]. Their findings indicated that $\mathrm{Ru}$ additions were responsible for increasing the solid solubility of $\operatorname{Re}$ in the first solid phase that forms during casting and it was also responsible for increasing the liquidus temperature of the alloys investigated. In theory, such improvements should lead to a more homogeneous alloy chemistry with respect to $\mathrm{Re}$, and should result in improved creep and high temperature microstructural stability. Indirect evidence of this $\mathrm{Ru}$ effect has also been observed by Caron et al., where their studies have reported improvements in long-term phase stability by using $\mathrm{Ru}$ additions in nominal alloy compositions [94]. The microsegregation results found in the present study tend to support such findings, as it is well known that alloys containing extensive segregation tend to precipitate harmful TCP phases prematurely and vice versa $[10]$.

\subsubsection{Compositional Gradient}

As previously mentioned, additional EPMA line scans were performed on each alloy along the major crystallographic directions in order to characterize the segregation behaviour during dendritic growth, as shown in Figure 65. Unlike the previous point-scan analysis that was used primarily to quantify the degree of segregation based on measurements taken from the beginning and end of solidification, the advantage to performing a line-scan is the ability to profile microsegregation along the solidification path.

From the line-scan results, it was observed that along both secondary arm directions (i.e. line direction \#1 and direction \#2 in Figure 65) there was a negligible difference in 
concentration profiles. Therefore, direction $\# 2$ results will be omitted to avoid repetition. The following discussion will describe the EPMA profile results as determined along directions $\# 1, \# 3$, and \#4, as shown in Figure 143.

\title{
9.1.2.1. EPMA Profile: Parallel to Secondary Arms
}

Provided in Figure 144 are the composition profiles for Alloys A-F as measured along direction \#1 (yellow line-scans in Figure 143). The line-scans in this figure indicate minor changes in concentration profiles along the length of the secondary arms. Most of the alloys demonstrate a detectable drop in $\mathrm{Ta}, \mathrm{Al}$, and $\mathrm{Ti}$ concentrations upon crossing the dendrite core region (i.e. middle of the scan) with an increase in concentration at both ends of the scan line. This is not surprising as the ends of the secondary dendrite arms are usually neighboring eutectic $\gamma-\gamma^{\prime}$ phases, which contain relatively higher concentrations of the $\gamma^{\prime}$ forming elements.

\begin{abstract}
Also notable in each profile is the increase in concentration of Re and W within the dendrite core region as compared to the secondary arm levels. In fact, Re and $\mathrm{W}$ appear to follow exactly the same segregation pattern along each concentration profile. This mimicking behaviour is more obvious when the appropriate scale is used along the ordinate axis. It was also observed that the segregation behavior of $\mathrm{Ta}$ is completely the opposite of both Re and $\mathrm{W}$ along each alloy concentration profile. Points of maximum $\mathrm{Ta}$ concentration almost always appear to coincide with minimum levels of Re and W. Even minor discontinuities in their respective profiles demonstrate opposing chemical gradients.
\end{abstract}




\subsubsection{EPMA Profile: Diagonally Across the Core-Eutectic Region}

The second set of EPMA line-scans were performed to profile the element concentration levels diagonally across the dendrite core region and continuing through the neighboring interdendritic eutectic structure, as indicated by the red lines in Figure 143. The EPMA concentration profiles recorded along this direction for Alloys A to F are plotted in Figure 145 to Figure 150 respectively. Each figure is divided into two regions; the upper plot shows the concentration gradients of the dendrite core segregating elements whereas the lower plot describes the segregation behaviour of those elements that preferentially segregate to the interdendritic region.

In general, the segregation behaviour of each alloy follows a similar trend along each concentration profile. Therefore, to avoid repetition the segregation behavior of Alloy E along direction \#3 will be used for discussion. The top graph plotted in Figure 149 demonstrates the non-linear segregation pattern exhibited by the elements $\mathrm{Cr}, \mathrm{Co}, \mathrm{Re}, \mathrm{W}$, and Mo. As all of these elements follow a very similar segregation pattern, a general description of the element behavior will be made. Starting from the right end of the concentration profiles and tracing left, there is a gradual rise in element concentration up to the $90 \mu \mathrm{m}$ position, where the concentration peaks coincides with the middle dendrite core position. Moving to the left of this position, the concentration levels begins to drop off at a relatively constant gradient until an inflection point is reached at the $60 \mu \mathrm{m}$ position. At this point, the concentration profiles dramatically increase over a very short distance and reach a maximum at the $50 \mu \mathrm{m}$ position. This sharp transition in composition over the small $10 \mu \mathrm{m}$ range indicates that there is a concentrated solute 
boundary layer just ahead of the interdendritic eutectic region. It is important to note that this concentrated boundary layer contains elevated levels of $\mathrm{Cr}, \mathrm{Co}, \mathrm{Re}, \mathrm{Mo}$, and $\mathrm{W}$. Continuing to the left of the boundary layer and passing into the interdendritic eutectic region, there is a sharp negative concentration gradient that eventually reaches a minimum at the $30 \mu \mathrm{m}$ position. This is in the vicinity of the center of the eutectic region. Finally, to the left of this position the concentration profiles increase slightly and then level out. Remarkably, for all the alloys examined (except Alloy F), this same trend in segregation behaviour is demonstrated for $\mathrm{Cr}, \mathrm{Re}, \mathrm{W}, \mathrm{Co}$, and $\mathrm{Mo}$ when traversing the dendrite core into the eutectic region. The following is a short summary for clarification of the major segregation trends observed along direction \#3:

1. Positive parabolic gradient around the dendrite core region

2. Sharp increase in concentration (boundary layer) just ahead of the eutectic region 3. Negative gradient across interdendritic interface region.

Based on the previous point-scan results, it was expected that the concentration of $\mathrm{Cr}, \mathrm{Co}$, $\mathrm{Re}, \mathrm{W}$, and Mo to be maximum at this center core location, with an eventual decrease in element concentration upon crossing into the interdendritic region. Fortunately, the presence of a concentrated solute boundary layer was detected during the EPMA linescans just ahead of the interdendritic region, which obviously could not be predicted from the simple point-scan analysis. The presence of such a concentrated boundary layer suggests that these elements are being rejected into the liquid ahead of the advancing solidification front and then suddenly freezing prior to $\gamma-\gamma^{\prime}$ eutectic solidification. No evidence of such a phenomenon was located in literature for SX superalloys; however, the formation of a solute rich band has been reported for the case of single-phase alloys 
during planar front solidification [90]. This particular transient effect was seen to occur as a direct result of an increase in the interface velocity, $\mathrm{R}$, during solidification. This would suggest that for the alloys investigated in the present study that a sudden change in the dendrite interface velocity occurs just prior to the final eutectic solidification transient.

As shown in the top plot of Figure 150, Alloy $\mathrm{F}$ exhibits a similar trend in segregation behaviour for $\mathrm{Cr}, \mathrm{Re}, \mathrm{W}, \mathrm{Mo}$ and $\mathrm{Co}$, except the presence of a solute boundary later just ahead of the interdendritic region is not observed. Further investigation and experimental casting is required to investigate the effects of $\mathrm{Ru}$ on the formation of the solute rich boundary layer ahead of the eutectic phase field. Also, as expected, the difference in concentration between the core and eutectic regions of $\mathrm{Cr}$, Mo, and $\mathrm{Re}$ is not as dramatic when compared to the other alloy profiles (i.e. smaller gradient $\equiv$ less segregation). Also noteworthy in this plot is the extremely linear concentration profile of $\mathrm{Ru}$, indicating ideal partitioning behaviour with no preference for segregation to either region within the dendritic structure.

In terms of the segregation behaviour of the $\gamma^{\prime}$ forming elements across this region, the concentration profiles for Alloys A-F have been recorded in the bottom plots of Figure 145 to Figure 150. Because the $\gamma^{\prime}$ forming elements are known to partition to the interdendritic region, their segregation behaviour is expected to be the opposite of the previously described set of elements. Once again, using Alloy E as an example, the 
concentration profiles of $\mathrm{Ta}, \mathrm{Al}$, and $\mathrm{Ti}$ can be observed in the bottom plot of Figure 149. As expected, the segregation profiles exhibit the opposite behaviour as described previously for Re, Cr, W, Mo and Co. Noteworthy are the decreased levels of Ta, Al and $\mathrm{Ti}$ in the solute boundary layer. This same behaviour is also observed for $\mathrm{Al}$, Ti and Ta in Alloys A to D; however, Alloy F still does not exhibit a solute boundary layer ahead of the interdendritic region. In fact, Alloy F demonstrates the most uniform profiles of Ta, $\mathrm{Al}$, and $\mathrm{Ti}$ across the core-eutectic interface, indicating less severe microsegregation along this line-scan direction.

\subsubsection{EPMA Profile: Across the Width of the Secondary Arm}

The final set of EPMA line-scans were performed across the width of the secondary dendrite arms (in direction \#4) to determine the extent of microsegregation during dendritic coarsening, as indicated by the green lines in Figure 143. The EPMA concentration profiles have been recorded for Alloys A to F in Figure 151 to Figure 156 respectively.

In general, the microsegregation patterns exhibited by each alloy across the width of the secondary arms were very similar. The behaviour observed resembled the parabolic gradients seen when traversing diagonally across the dendrite core in direction \#3 linescans, however the order of magnitude is less severe. Using the results from Alloy B as an example, the EPMA profiles shown in Figure 152 indicate heavier concentrations of $\mathrm{Re}, \mathrm{Cr}$ and $\mathrm{W}$ in the center of the secondary arms, with diminished levels of $\mathrm{Ta}, \mathrm{Ti}$ and $\mathrm{Al}$ in the same vicinity. At the boundaries of the secondary arms the opposite scenario 
occurs, exhibiting elevated levels of $\gamma^{\prime}$ forming elements and decreased levels of dendritic coring elements. It should be mentioned that the end points of each line-scan usually terminated at a eutectic $\gamma-\gamma^{\prime}$ phase region, however, in some cases carbides or neighboring arms were present. This may account for the non-ideal parabolic curves demonstrated in some of the alloys across this region of interest. 


\section{DSC Analysis and Thermo-Physical Characterization}

\subsection{Results and Discussion}

The following section discusses the thermo-physical analysis results obtained from an extensive DSC study performed on all six alloy compositions. Representative samples from each alloy were analyzed at thermal heating and cooling rates of $20^{\circ} \mathrm{C} / \mathrm{min}, 10$ ${ }^{\circ} \mathrm{C} / \mathrm{min}$, and $5{ }^{\circ} \mathrm{C} / \mathrm{min}$ under a $50 \mathrm{ml} / \mathrm{min}$ flowing argon atmosphere. To avoid confusion, the results from heating and cooling experiments are discussed separately with emphasis on the major thermodynamic findings, including the correlation between the extent of microsegregation and the alloy solidification window.

\subsubsection{Endothermic DSC Analysis}

Provided in Table 15 is a complete list of all the thermo-physical data collected from each DSC energetic curve upon heating. The tabulated values of $T_{0}, T_{1}, T_{S}$, and $T_{L}$ are those measurements extracted from each DSC curve as illustrated in Figure 157 for Alloy F. Upon heating, the first endothermic peak, $T_{0}$, is associated with the initial interdendritic solutioning of the $\gamma^{\prime}$ phase, the determination of which will be discussed in more detail in section 10.1.3. The second endothermic reaction, identified as $T_{1}$, is related to the $\gamma-\gamma^{\prime}$ eutectic transformation temperature. It should be mentioned that this particular value is barely noticeable for the heating rates of $20^{\circ} \mathrm{C} / \mathrm{min}$ and $10^{\circ} \mathrm{C} / \mathrm{min}$. However, better resolution is attained at the slower rate of $5^{\circ} \mathrm{C} / \mathrm{min}$ due to less significant superheating effect. The $T_{1}$ values are resolved for the two faster rates by inspection of the $1^{\text {st }}$ derivative curves in each case. Finally, the values for $T_{S}$ and $T_{L}$ correspond to the solidus and liquidus points of each alloy for each particular DSC heating rate. For the most part, 
the reported liquidus temperatures are very reliable, as the values are characterized from the maximum endothermic peak temperatures as determined by the Proteus analysis software. On the other hand, the extrapolated solidus temperatures, as determined by the tangent-onset method, provide for a much larger range of operator error $\left(\sim 2-3^{\circ} \mathrm{C}\right)$. In an attempt to reduce this unavoidable human error, additional data processing was completed to find "zero" heating rate transformation temperatures by extrapolating the data of all three heating rates.

The DSC heating results for each alloy were analyzed in a similar manner as described above for Alloy F. The transformation temperature results were then plotted as a function of heating rate for all six alloys. A linear-fit was then made for each set of data points and the extrapolated intercept temperature at $0{ }^{\circ} \mathrm{C} / \mathrm{min}$ was calculated to mitigate the heating rate effect. These corrected heating-rate values were determined for $T_{0}, T_{1}, T_{S}$ and $T_{L}$, as shown in Figure 158 to Figure 161 respectively. A summary of the extrapolated transformation temperatures is provided in Table 16.

Also recorded in Table 16 are the solidus-liquidus temperature ranges for each alloy. These $T_{L}-T_{S}$ values represent the solidification temperature range for each alloy during which solid-liquid diffusion processes occur. In general, the greater the solidification temperature range (i.e. the longer it takes for the alloy to solidify completely), the greater the severity of microsegregation. In theory, shorter solidification times should result in less solute redistribution across the solid-liquid interface. Perfect chemical homogeneity could be achieved via liquid quenching methods, however, single crystal stability 
requirements and Bridgman furnace temperature gradients command a much slower growth rate. Hence, the smaller $\Delta \mathrm{T}\left(\mathrm{T}_{\mathrm{L}}-\mathrm{T}_{\mathrm{S}}\right)$ values provided in Table 16 should indicate less severe microsegregation behavior. With this in mind, each alloy is ranked as a function of $\Delta \mathrm{T}$. The results predict that Alloy $\mathrm{A}$ should exhibit the least amount of microsegregation $\left(\Delta \mathrm{T}=28^{\circ} \mathrm{C}\right)$ with Alloy $\mathrm{E}$ having the highest degree of predicted segregation $\left(\Delta \mathrm{T}=35^{\circ} \mathrm{C}\right)$. Alloys $\mathrm{B}, \mathrm{C}$ and $\mathrm{F}$ all have the same ranking as they were determined to have a $\Delta \mathrm{T}$ range of $32{ }^{\circ} \mathrm{C}$. Alloy $\mathrm{D}$ was predicted to have a slightly higher degree of microsegregation than Alloys $\mathrm{B}, \mathrm{C}$ and $\mathrm{F}$ as denoted by the $\Delta \mathrm{T}$ value of $33^{\circ} \mathrm{C}$, generally agreeing with the EPMA results of Figure 142. However, due to the rather small differences in predicted solidification ranges and the likelihood of human error in measuring $\mathrm{T}_{\mathrm{S}}$ onset values from the DSC plots, microsegregation tendencies should not be based solely on extrapolated DSC $\triangle \mathrm{T}$ results.

\subsubsection{Exothermic DSC Analysis}

In addition to the endothermic transformation temperatures examined during heating, exothermic transformation energetic results were also recorded for cooling rates of 5,10 and $20^{\circ} \mathrm{C} / \mathrm{min}$ during the controlled re-solidification process. Provided in Table 17 is a complete list of all the thermo-physical data collected from each DSC energetic curve upon cooling from $1400^{\circ} \mathrm{C}$ to $700^{\circ} \mathrm{C}$. The tabulated values of $T_{0}, T_{1}, T_{2}, T_{3}, T_{S}$, and $T_{L}$ are those measurements extracted from the DSC results as illustrated in Figure 162 for Alloy-F in the as-cast condition. To avoid congestion, some of the $\mathrm{T}_{\mathrm{S}}$ onset construction lines have been removed for clarity. 
Upon examining Figure 162 it is apparent that for Alloy F, there are two additional phase transformation processes occurring during re-solidification. This is most likely due to the different transformation kinetics that occur upon cooling (c.f. heating) and also because of the completely different solidification parameters that are present in the DSC environment as opposed to the controlled directional solidification process within the Bridgman furnace. These additional transformation processes were also observed in each of the other alloy compositions, as recorded in Table 17. For some of the alloys, not all the exothermic peaks could be resolved during cooling. The absence of such peaks may be explained by the variation in microsegregation present in each alloy or it may be the case that the corresponding phase reactions are not favorable for specific alloy compositions. A more detailed analysis involving incremental solidification-quenching experiments would be required to accurately determine the observed and missing exothermic transformation reactions.

Examination of the corresponding transformation temperatures obtained during heating and cooling experiments show that the re-solidification values are always significantly less than the temperatures obtained during heating (e.g. For Alloy $\mathrm{F}, \mathrm{T}_{0}$ heating $=1187^{\circ} \mathrm{C}$ and $T_{0}$ cooling $=1157^{\circ} \mathrm{C}$ ). Once again, this difference is due to diffusion effects and the true equilibrium transformation temperatures reside somewhere in between the measured heating and cooling values [107]. The procedure used to extrapolate the transformation temperatures back to the $0^{\circ} \mathrm{C} / \mathrm{min}$-heating rate therefore should account for this observed thermal diffusion effect. Hence, the back-extrapolation procedure was deemed unnecessary for the exothermic data, as the initial $0^{\circ} \mathrm{C} / \mathrm{min}$ results should be adequate for 
comparison purposes. Also, the measured DSC cooling data may not represent the true thermo-physical properties of the SX material, as melting and re-solidification in the calorimeter produces a polycrystalline microstructure. Hence, the transformation data obtained during heating of the SX samples are more representative than the data obtained from polycrystalline re-solidification. In reality, determination of the exact transformation temperatures would require furnace-quenching experiments that account for thermal effects due to larger sample sizes that are comparable to the scale of the actual blade component.

\subsubsection{Additional Thermo-Physical Characterization Results}

Upon completion of all the DSC heating and cooling experiments, it was apparent that additional work was required to identify some of the unknown transformation reactions. One such study involved an in-depth examination of the endothermic reaction that occurs at $\mathrm{T}_{0}\left(1175^{\circ} \mathrm{C}\right.$ to $\left.1185^{\circ} \mathrm{C}\right)$ during the DSC heating process, as shown in Figure 157 . The first step in characterizing the unknown endothermic reaction was to perform a series of furnace-quenching experiments around the temperature range of interest.

\subsubsection{Characterization of $T_{0}$ by Furnace-Quenching Trials}

A series of 2-hour heat treatments were performed on representative SX samples from each alloy at temperatures above and below the endothermic transition temperature. Samples were heat-treated at $1160^{\circ} \mathrm{C}, 1180^{\circ} \mathrm{C}, 1220^{\circ} \mathrm{C}$, and $1250^{\circ} \mathrm{C}$ for 2 hours followed by water quenching. To avoid repetition, only the microstructural results from Alloy $\mathrm{F}$ samples will be used for discussion. The results from the first three heat treatments performed on Alloy $\mathrm{F}$ are provided in Figure 163 . The $1160^{\circ} \mathrm{C}$ quenched 
microstructure in Figure 163(a) shows no indication of any major phase change. The higher magnification image seen on the right hand side, illustrates the typical $\gamma-\gamma^{\prime}$ eutectic structure surrounded by fine primary $\gamma^{\prime}$ precipitate. Figure 163(b) shows the effects of heat-treating at $1180{ }^{\circ} \mathrm{C}$ for 2 hours, revealing some possible changes in precipitate population around the interdendritic regions. This is seen by the growing fraction of white space around the blocky eutectic phase. This featureless area is evidence of the increasing fraction of a $\gamma^{\prime}$ denuded zone. It appears that either the very fine $\gamma^{\prime}$ is being solutioned into the matrix or is being absorbed by the larger eutectic precipitate phase. Figure $163(\mathrm{c})$ shows the resulting microstructure produced by the third heat treatment of $1220^{\circ} \mathrm{C}$. It is more apparent in these two micrographs that there is dissolution of the finer precipitate phase surrounding the larger eutectic constituents.

Up to this point, there does not appear to be an alternative explanation for the $T_{0}$ endothermic peak other than solutioning of the fine interdendritic $\gamma^{\prime}$ that is surrounding the eutectic. Previous studies have shown that in some as-cast alloys, a low melting interdendritic eutectic phase has been found to produce an endothermic reaction in the vicinity of 1100 to $1150{ }^{\circ} \mathrm{C}$ [107]. However, no evidence of eutectic liquation has been observed in any of the alloys up to the $1220^{\circ} \mathrm{C}$ heat treatment temperature. In fact, the first indication of incipient melting is not observed until the $1250^{\circ} \mathrm{C}$ heat treatment is applied. 
The micrographs shown in Figure 164 show the effects of heat-treating Alloy $F$ at 1250 ${ }^{\circ} \mathrm{C}$ for 2 hours. The extent of interdendritic solutioning is much more advanced and there is also indication of $\gamma^{\prime}$ dissolution within the dendrite core interior. Closer inspection of the SEM image on the right also reveals evidence of eutectic melting. However, this small fraction of incipient melting at $1250{ }^{\circ} \mathrm{C}$ does not coincide with the large endothermic reaction observed at $\mathrm{T}_{0}$.

The main conclusion that can be derived from this quenching study is that there appears to be a very wide range in solvus temperature for the as-cast SX structures. Initial solutioning of the $\gamma^{\prime}$ precipitate was observed as low as $1180^{\circ} \mathrm{C}$ and even after soaking at $1250^{\circ} \mathrm{C}$ there was still a large population of $\gamma^{\prime}$ residing within the dendrite arms. The extent of the $\gamma^{\prime}$ solvus range is obviously due to the microsegregation effect on localized precipitate chemistry as well as precipitate morphology and size (as discussed in microstructural analysis section 8.1.2).

As a result of the findings discovered during the furnace-quenching experiments, it was decided to perform additional in-situ solutioning heat treatments within the DSC. The intent was to determine the effects of solutioning heat treatments on the precipitate solvus range. The following section will discuss the results.

\subsubsection{Microsegregation Inspection Using In-situ DSC Solutioning}

The first set of additional DSC experiments was aimed at further characterization of the endothermic reaction at temperature $\mathrm{T}_{0}$. Illustrated in Figure 165 is one such DSC test 
that consisted of heating an as-cast sample of Alloy- $\mathrm{F}$ up to $1280^{\circ} \mathrm{C}$ (above the $\mathrm{T}_{0}$ value) at a rate of $5^{\circ} \mathrm{C} / \mathrm{min}$ and holding for 10 hours. The sample heating rate was kept slow enough to avoid incipient melting. Subsequently, the sample was cooled down to $800{ }^{\circ} \mathrm{C}$ while recording any exothermic processes. Upon inspection, it is apparent that an additional peak, identified as $T_{1}$, is present within the cooling segment. This additional peak corresponds to one of the additional exothermic peaks observed earlier in Figure 162. Although a lower value of $\mathrm{T}_{0}$ is observed during cooling, the offset can be explained due to solutioning and super-cooling effects. The new peak, $T_{1}$, is a result of new primary $\gamma^{\prime}$ precipitation due to the comparatively fast cooling rate of the DSC. The advantage to using the slow heating rate during the DSC test is that the observed exothermic reaction at $T_{1}$ cannot be confused with eutectic re-solidification. The higher solvus temperature of this new $\gamma^{\prime}$ phase may be explained by the redistribution of higher melting-point elements that occurred during the 10-hour solution heat treatment. The key finding from this series of DSC runs was that the $1280^{\circ} \mathrm{C}$ solutioning temperature was capable of removing some of the as-cast microsegregation effects. The results demonstrated that soaking heat treatments partially break down the $\mathrm{T}_{0} \gamma^{\prime}$ and produce a corresponding fraction of higher solvus precipitate.

Further investigation of this solute redistribution effect (i.e. microsegregation removal) was performed via pseudo-homogenization heat treatments within the DSC. The DSC temperature profile consisted of the following steps:

1. Heat from $100^{\circ} \mathrm{C}$ to $1280^{\circ} \mathrm{C}$ at $20^{\circ} \mathrm{C} / \mathrm{min}$

2. Hold at $1280^{\circ} \mathrm{C}$ for $(2,10$, or 20 hours $)$ 
3. Cool from $1280^{\circ} \mathrm{C}$ to $750^{\circ} \mathrm{C}$ at $20^{\circ} \mathrm{C} / \mathrm{min}$ and hold for 10 minutes

4. Heat from $750^{\circ} \mathrm{C}$ to $1550^{\circ} \mathrm{C}$ at $5^{\circ} \mathrm{C} / \mathrm{min}$ and hold for 10 minutes

5. Cool from $1550^{\circ} \mathrm{C}$ to $550^{\circ} \mathrm{C}$ at $20^{\circ} \mathrm{C} / \mathrm{min}$.

The results from the DSC homogenization runs for Alloy $\mathrm{F}$ have been plotted in Figure 166. The effects of soaking time on solute redistribution are more clearly illustrated in this example. As can be seen from the 10-hour and 20-hour DSC curves, the presence of low solvus interdendritic $\gamma^{\prime}$ at $T_{0}$ has almost been completely removed from the DSC samples. The re-precipitated $\gamma^{\prime}$ do not demonstrate such a wide variation in localized solvus temperatures. Also notable in this figure is the increase in liquidus and solidus temperatures due to solute redistribution during the DSC homogenization runs.

From this discussion it is apparent that DSC heat treatment similar to that shown in Figure 166 can be used to help design future solution heat treatments for the alloys. This procedure is relatively straightforward, provides a means of measuring the extent of solutioning for each heat treatment, and does not require time-consuming furnace heat treatments and tedious metallographic analysis procedures. 


\section{Eutectic Phase Fraction Analysis}

\subsection{Results and Discussion}

As previously mentioned, it is possible to gauge the extent of microsegregation within a group of alloys based on the relative fraction of eutectic phase that is formed during the final stages of SX solidification. In general, alloys that exhibit more severe microsegregation usually attain sufficient $\mathrm{Al}+\mathrm{Ti}+\mathrm{Ta}$ liquid composition levels required for eutectic solidification sooner than those alloys that demonstrate slower solute rejection. Hence, eutectic nucleation commences earlier in the solidification process, which results in a relatively larger fraction of the eutectic phase due to the larger supply of liquid that resides interdendritically. The following section will discuss the eutectic phase fraction results obtained for Alloys A-F, as well as the significance of the nominal alloy and localized interdendritic composition levels.

Provided in Figure 167 and Figure 168 are examples of the image analysis process used to determine the eutectic fraction for Alloys A to C and Alloys D to F respectively. For each alloy, 6 to10 images were analyzed using different areas of each sample. The image magnification and analysis area was kept constant for each set of images. Lower magnification images would most likely yield better statistical results, however the ability to differentiate between eutectic and dendritic areas was drastically reduced below the magnification chosen. 
Once a black and white threshold image was produced that clearly resolved the dendritic and eutectic regions, a pixel counting subroutine was implemented to quantify the number of black and white (eutectic) pixels. For each image, the number of black and white pixels was measured with the corresponding fractions recorded. The fraction of eutectic phase present in the image was approximated by dividing the number of white pixels in the image by the total number of black and white pixels present. The process was repeated for numerous sample areas and the corresponding mean eutectic fraction and standard deviation values for each alloy were recorded in Table 18.

\subsubsection{Eutectic Fraction with Respect to Nominal Alloy Levels}

The eutectic fraction results are summarized in Table 19 with respect to corresponding nominal wt.\% of $\mathrm{Re}, \mathrm{W}$, and $\mathrm{Ru}$ content. To better visualize these results, a bar graph illustrating the fraction of eutectic present in each as-cast alloy along with corresponding nominal refractory levels has been provided in Figure 169. It can be seen from these results that for Alloys $\mathrm{A}$ through $\mathrm{D}$, as the level of Re content is increased (corresponding decrease in $\mathrm{W}$ level) the eutectic phase fraction rises significantly. The maximum eutectic fraction, $17 \%$, is present for Alloy $E$, which contains both high levels of $\operatorname{Re}$ and $W$ nominally. In fact, if the results for Alloy $\mathrm{C}$ and Alloy $\mathrm{E}$ are compared, it is apparent that there is an associated $4 \%$ increase in eutectic phase fraction due to the additional $3 \mathrm{wt} . \%$ $\mathrm{W}$ that is added in Alloy E. Hence, for Alloy $\mathrm{E}$, the additional increase in eutectic phase fraction when compared to Alloy $C$ is due to either the elemental effects of $W$ or due to the higher overall total refractory content (i.e. more eutectic present because of $24 \mathrm{wt} . \%$ total refractory in Alloy E compared to the 21 wt. \% for Alloy C). In any case, based on this comparison, it can be concluded that the increasing fraction of eutectic phase for 
Alloys A through $\mathrm{D}$ is due to the increasing level of Re content of each alloy and not due to the decreasing $\mathrm{W}$ content. A comparison can also be made between Alloy $\mathrm{C}$ and Alloy $F$ where there appears to be a decrease in eutectic phase fraction, from $13 \%$ to $11 \%$. This reduction in eutectic fraction may be due to the addition of $4 \mathrm{wt} \% \mathrm{Ru}$ in Alloy $\mathrm{F}$ or possibly due to the $1 \mathrm{wt} . \%$ lower Ta level.

\subsubsection{Eutectic Fraction with Respect to Interdendritic Levels}

The previous comparison of eutectic phase fraction is made with respect to the overall composition levels for each alloy. It may also be useful to compare the eutectic levels of each alloy with respect to the actual interdendritic eutectic compositions measured in prior EPMA studies. Recorded in Table 20 is a list of the eutectic phase fraction and associated interdendritic EPMA compositions for each alloy. Figure 170 illustrates these

results in the form of an area graph. Based on the information plotted, some preliminary findings can be stated. The graph clearly shows an increase in eutectic fraction as the wt.\% level of eutectic Al increases. This behavior can also be seen in Alloy F, as there is an associated drop in the eutectic fraction curve, which coincides with a drop in Al level. The same pattern can also be seen to some degree for the eutectic Ti level. Alloys A and $\mathrm{F}$ show decreased levels of $\mathrm{Ti}$ in the eutectic composition that may be related to their lower eutectic fraction levels. These findings are not unrealistic, as it is generally known that both $\mathrm{Al}$ and $\mathrm{Ti}$ strongly promote $\gamma^{\prime}$ precipitation, which is one of the main constituents in the $\gamma-\gamma^{\prime}$ eutectic phase. Another observation is the associated increase in eutectic fraction as a function of rising Ta level in the eutectic composition. Once again, Alloy $\mathrm{F}$ shows a decrease in eutectic fraction with a corresponding decrease in Ta level. This may be due to Ta substituting for $\mathrm{Ti}$ or $\mathrm{Al}$ in the $\mathrm{Ni}_{3} \mathrm{Al}-\mathrm{Ti}$ structure. Finally, another 
interesting finding is the inverse effects of interdendritic $\mathrm{Cr}$ content on the fraction of eutectic present. Figure 170 clearly shows that as the level of $\mathrm{Cr}$ content decreases for Alloys A through $\mathrm{E}$, there is an inverse increase in relative eutectic fraction. This is further validated by observing the similar high $\mathrm{Cr}$ - low eutectic relationship present for Alloy F.

At this point, it should be mentioned that the effects of individual concentration levels on eutectic fraction can only be discussed. In reality, it is most likely that the synergistic effects of two or more interacting atomic species influence eutectic levels. Nonetheless, the following preliminary microsegregation findings can be presented:

1. Eutectic fraction increases with nominal Re content

2. W level does not appear to play a direct role in eutectic levels

3. Increased total refractory level appears to increase eutectic fraction

4. $\mathrm{Ru}$ appears to decrease the overall eutectic fraction

5. Increasing interdendritic $\mathrm{Al}, \mathrm{Ti}$, and $\mathrm{Ta}$ levels result in an increase in eutectic fraction

6. Decreasing interdendritic Cr results in an increase in eutectic. 


\section{Thermodynamic Solidification Predictions}

\subsection{Results and Discussion}

Using all three thermodynamic databases (RMC, NIST and SGTE), each alloy composition was entered into the FACT-Sage environment and a series of thermodynamic solidification predictions were generated as determined by all three solidliquid phase equilibria models. The following section will discuss the three sets of solidification simulation data (RMC, SGTE, and NIST) that were generated. Emphasis will be placed on the predicted solidus and liquidus temperatures and the associated compositions of the first solid phase to appear and the last liquid to solidify. An additional discussion will be made with respect to the calculations that were performed to determine the predicted element partitioning behaviour in each alloy during solidification simulations.

\subsubsection{Transformation Temperature Predictions}

Provided in Table 21 is a summary of the predicted liquidus and solidus transformation temperatures for each alloy using all three of the thermodynamic solidification models. Figure 171 illustrates the extent of over-estimation of the liquidus temperature predictions. It is apparent from this figure that the RMC and SGTE models predict melting temperatures in excess of those measured using the DSC. In some instances, the difference is as high as $60^{\circ} \mathrm{C}$. One possible reason is the inability of the thermodynamic models to accommodate localized microsegregation effects. Extensive segregation of lower melting elements to the interdendritic region can result in areas of localized melting at temperatures lower than expected. Closer examination of this figure shows that 
the liquidus temperature predictions using the NIST model are much closer to the measured values. In addition, not only are the NIST predictions closer approximations (less than $20^{\circ} \mathrm{C}$ over), but the temperature trend line is similar to that displayed by the DSC curve. Unfortunately however, because the NIST database does not contain Ru, predictions for Alloy F could not be obtained.

In a similar manner, Figure 172 shows the accuracy of solidus temperature predictions of each model, as compared to the DSC values. Once again, the models all seem to overpredict the actual transformation temperatures, with the NIST model displaying the closest approximations. The large difference in solidus predictions with respect to the measured values is expected, as the effect of localized microsegregation is more severe with respect to the premature onset of incipient melting. It is important to note that in both liquidus and solidus temperature predictions, the values for Alloy A appear to be in greater error than for the rest of the alloys. The lower solidus and liquidus temperatures measured in the DSC may be due to the higher carbon content contained within Alloy A, compared to the other alloys. Carbon is a well-documented melting point depressant and may play some role in the overestimated solidus and liquidus predictions of all three models. It should be noted that the effects of carbon additions are not incorporated into the present thermodynamic models.

In section 10.1.1, the correlation between microsegregation and the alloy solidification window $\left(\Delta T=T_{L}-T_{S}\right)$ as determined by DSC measurements was discussed. The alloys were ranked based on the their measured $\Delta T$ values, with lower values indicative of less 
severe microsegregation. In a similar manner, the predicted solidification windows have been plotted and compared to the experimental values in Figure 173. From this graph it is obvious that the results from the SGTE and RMC models do not exhibit a similar solidification range with respect to the measured values. However, the NIST predictions follow almost exactly the same pattern as the DSC results. Hence, the $\Delta \mathrm{T}$ results from the NIST model agree with the DSC measurements and therefore rank the alloys in the same order with respect to propensity for microsegregation. The apparent accuracy of the NIST model may be a result of its tailored design to handle superalloys specifically. The RMC model is also developed for specific superalloy applications, but its thermodynamic database has not been fully optimized with respect to a few binary subsets (e.g. Ni-W system). The SGTE model seems to yield poor temperature predictions, possibly because it is designed to be a generic alloy solution model.

\subsubsection{Phase Composition Predictions}

Using the EQUILIB Gibbs-free energy minimization utility in FACT-Sage, dominant phase and transformation temperature calculations were performed for each alloy composition, starting from a temperature of $1300^{\circ} \mathrm{C}$ to $1550^{\circ} \mathrm{C}$. The compositions of the first solid to form and the last liquid to solidify were extracted from the output data files generated for each alloy. As previously mentioned, these solidification simulations were performed using all three databases; hence an extensive amount of raw data was produced. To avoid congestion, a summary of the predicted phase compositions has been provided in Table 22 and Table 23 for Alloys A-C and Alloys D-F respectively. In theory, these two compositions should represent the chemistry of the dendrite cores and 
interdendritic $\gamma-\gamma^{\prime}$ eutectic regions. The accuracy of the composition predictions is more easily assessed with the aid of bar charts. Figure 174 to Figure 179 contain the composition predictions of the dendrite core region for Alloys A to $F$ respectively. Likewise, Figure 180 to Figure 185 illustrate the degree of accuracy of composition predictions for the interdendritic eutectic region of Alloys A to F respectively. In both sets of bar charts, the measured EPMA data has been included for comparison purposes.

In general, the model composition predictions for each alloy are reasonably close to the measured EPMA values. There does exist some degree of error with respect to the predicted $\mathrm{W}$ and Re levels that may require further CALPHAD analysis of the $\mathrm{W}-\mathrm{X}$ and Re-X binary systems. With respect to the dendrite core compositions, it appears that the SGTE model predicts the initial W solidification level better, whereas the Re levels are better approximated using the NIST results. Analysis of the interdendritic composition predictions indicates that the privately developed RMC model is better suited for approximation of the eutectic levels, especially for the elements $\mathrm{W}, \mathrm{Re}, \mathrm{Cr}$ and $\mathrm{Mo}$.

\subsubsection{Comparison of Measured and Predicted Segregation Coefficients}

Using the same concept of $k^{\prime}$ that was presented in Figure 142 for the Cr-Re-Mo EPMA results, the same $k^{\prime}$ calculations were performed on the RMC, SGTE and NIST composition results. The actual $k^{\prime}$ values are located on the right side of Table 22 and Table 23, with the corresponding bar charts presented in Figure 186. The predicted $k^{\prime}$ results clearly do not match the EPMA $k^{\prime}$ values for $\mathrm{Cr}, \mathrm{Re}$, and Mo. The RMC results do demonstrate $k^{\prime}$ values that are close in magnitude to the measured EPMA results; 
however, the SGTE and NIST $k^{\prime}$ values differ quite substantially. It is clear from the charts that the partitioning results from none of the models are capable of detecting the effects of subtle changes in nominal alloy compositions. In general, it appears each model predicts almost the same $k^{\prime}$ levels of each element for Alloys A-F. Either model does not demonstrate the measured increase in microsegregation with respect to increasing $\operatorname{Re}$ content. Similarly, the benefits of adding $\mathrm{Ru}$ to decrease microsegregation are also not observed in the predicted results. On a positive note, the models do seem to predict the ranking of microsegregation correctly between $\mathrm{Re}, \mathrm{Cr}$, and Mo. Each model indicates that Re exhibits the worse microsegregation properties, followed by Mo, and then $\mathrm{Cr}$. The difference in predicted and measured $k^{\prime}$ values may be due to diffusional kinetic effects not accounted for in thermodynamic equilibrium calculations. The incorporation of kinetic interaction parameters into the thermodynamic models would require a substantial amount of additional work.

\subsubsection{Scheil-Gulliver Solidification Behaviour}

In addition to the static $k^{\prime}$ calculations presented in the previous section, a ScheilGulliver-treatment was also generated for each alloy utilizing the RMC thermodynamic solidification model. The segregation behavior for all 10 components was mapped as a function of each alloy's solidification temperature range. In this case, the segregation coefficient, $k$, is defined as $k_{\mathrm{i}}=\mathrm{X}_{\mathrm{i}}^{\mathrm{S}} / \mathrm{X}_{\mathrm{i}}^{\mathrm{L}}$ for the solid and liquid phases on either side of the solid-liquid solidification interface. Figure 187 through Figure 190 illustrate the dynamic segregation behavior for $\mathrm{Re}, \mathrm{Ta}, \mathrm{Mo}$ and $\mathrm{Cr}$ respectively. From Figure 187 it is evident that the predicted partitioning behaviour for Re does not vary much with temperature, as indicated by the slightly U-shaped trend for each curve. However, there is a noticeable 
deviation in $k_{\mathrm{Re}}$ due to differences in nominal alloy composition, which range from $\sim 2.3$ for Alloy D to 2.6 for Alloy F. It should be mentioned, however, that this range of $k$ is relatively small and does not resemble the EPMA measured segregation behavior, which indicates a large increase in Re segregation with increased nominal levels of $\mathrm{Re}$ in the base alloys. Figure 188 indicates that Ta segregation is more sensitive to temperature effects as indicated by the sharp rises in $k_{\mathrm{Ta}}$ over the plotted solidification range. For the most part, Ta does not demonstrate major differences in segregation as a consequence of nominal alloy levels, as designated by the densely packed $k$ curves. The predicted $k_{\mathrm{Mo}}$ and $k_{\mathrm{Cr}}$ results shown in Figure 189 and Figure 190 behave in a similar manner to that of Ta. However, there is a noticeable difference in segregation of Alloy $\mathrm{F}$ in Figure 189, suggesting a possible negative effect of $\mathrm{Ru}$ addition on Mo segregation. However, these theoretical predictions require experimental assessment before any sound conclusions on specific elemental effects can be derived. In fact, a previous comparison of the RMC and EPMA results shown in Figure 186 indicate that the RMC model does not accurately predict the segregation effects of Mo in the as-cast alloys. 


\section{Summary and Future Work}

\subsection{Summary}

A successful Bridgman casting process has been developed that is capable of producing experimental SX Ni-base superalloys utilizing a novel seed-crystal directional solidification methodology. The successful casting of six experimental alloy compositions has confirmed the ability to process SX test bars for future alloy design initiatives. The research, design, and fabrication of next generation turbine blade materials can now be conducted at a fraction of the commercial purchasing cost.

In addition to developing a successful casting process, a thorough characterization methodology has been devised that can be used to qualitatively and quantitatively determine the extent of microsegregation within SX castings. The characterization methodology involved using several techniques; including extensive point and line scan EPMA analysis, eutectic phase fraction analysis, thermo-physical DSC analysis, and computational thermodynamic modeling.

After performing this extensive microsegregation characterization routine, several important findings were revealed with respect to fundamental alloy compositional effects on casting segregation behaviour. The following section will list the major relevant findings revealed during the microsegregation analysis study. 
The major conclusions derived from the EPMA study are:

- Increasing Re addition levels in SX superalloy compositions drastically increases the severity of casting microsegregation. This effect is more severe with respect to the dendrite core segregating elements of $\mathrm{Mo}, \mathrm{Cr}$, and more significantly, Re.

- Higher total refractory contents within the nominal alloy compositions also result in increased microsegregation behavior.

- $\mathrm{Ru}$ additions effectively reduce the severity of microsegregation observed within the dendrite cores due to elevated Re and higher total refractory levels.

- EPMA line scans revealed the presence of a solute boundary layer (high in $\mathrm{Cr}, \mathrm{Re}, \mathrm{W}, \mathrm{Mo}$ ) just ahead of the interdendritic eutectic region within the dendritic area. This dense boundary layer was not observed in Alloy F and may be related to the reduced segregation behaviour in $\mathrm{Ru}$ containing alloys.

The major conclusions derived from the eutectic phase fraction study are:

- The quantity of as-cast eutectic fraction levels increases with nominal Re content in SX superalloy compositions.

- The $\mathrm{W}$ level of the nominal alloy compositions does not appear to play a direct role in the final as-cast eutectic fraction. 
- Increased total refractory level appears to increase the final as-cast eutectic fraction.

- $\mathrm{Ru}$ additions appear to decrease the overall eutectic fraction in the as-cast structures.

The major conclusions derived from the thermo-physical DSC analysis results are:

- The ranking of microsegregation as a function of the alloys measured solidification window $\left(\Delta T=T_{L}-T_{S}\right)$ qualitatively agrees with EPMA and eutectic phase fraction results.

- Independent DSC characterization of microsegregation is insufficient due to the susceptibility to human error in determining $\Delta \mathrm{T}$ and the small differences in measured solidification ranges.

- DSC homogenization tests revealed an extensive $\gamma^{\prime}$ solvus range for all the as-cast alloys due to extensive casting microsegregation.

- Dissolution of fine interdendritic $\gamma^{\prime}$ surrounding the blocky $\gamma-\gamma^{\prime}$ eutectic phase occurs first during solutioning heat treatments, contrary to published findings.

The major conclusions derived from the thermodynamic modeling results are: 
- The typical trend in SX microsegregation behaviour was observed in the compositional predictions, indicating preferential segregation of $\mathrm{Re}, \mathrm{Cr}, \mathrm{Mo}$, and $\mathrm{Co}$ to the dendrite cores and $\mathrm{Al}, \mathrm{Ti}$ and $\mathrm{Ta}$ to the interdendritic regions.

- The calculated composition levels of the dendrite core and interdendritic eutectic regions were fairly accurately approximated, deviating mostly in $\mathrm{Re}$ and $\mathrm{W}$ levels.

- The thermodynamic models used in the present study were not capable of determining the as-cast transformation temperatures for SX superalloys, as predictions were seen to substantially over-estimate the measured liquidus and solidus temperatures.

- Although fairly accurate composition predictions were achieved using the thermodynamic models, neither set of results exhibited similar $k^{\prime}$ segregation coefficients. This indicates that the models are not precise enough to detect changes in solidification behaviour for small changes in nominal alloy composition levels.

- The addition of kinetic interaction parameters (i.e. diffusion) is required to account for the observed microsegregation effects within the as-cast alloys.

Based on EPMA, eutectic phase fraction, and DSC results, the most signification finding from the completed work, was the effect of $\mathrm{Ru}$ additions on reducing casting microsegregation. $\mathrm{Ru}$ was responsible for a reduction in both dendritic and interdendritic segregation due to elevated $\mathrm{Re}$ and overall total refractory levels. Also, the addition of $\mathrm{Ru}$ 
played a role in the reduction of the $\gamma-\gamma^{\prime}$ eutectic phase fraction, which is known to result in premature fatigue life in turbine blades due to its brittle properties. The industrial significance of such a finding is that the reverse microsegregation effects of $\mathrm{Ru}$ should result in easier homogenization and therefore improved phase stability for future SX alloy systems. This can also be accomplished without having to decrease the essential Re levels required for improved high temperature creep capability in turbine blades. Recently, several new $4^{\text {th }}$ generation SX alloys have been produced, which effectively incorporate $\mathrm{Ru}$ in the base alloy compositions. Material vendors have reported improvements in phase stability properties, however, very little evidence has been provided in literature explaining the actual role that $\mathrm{Ru}$ plays in providing these benefits. This is mostly due to the "design on experiment" approach to which most material vendors subscribe. Therefore, the major industrial and research contributions of this body of work is to help explain some of the outstanding questions regarding the benefits of $\mathrm{Ru}$ additions in advanced SX superalloy materials.

\subsection{Recommendations for Future Work}

During the completion of the work, it had become obvious that many more opportunities for continued research on this subject are available. Ideally it would be of interest to perform heat treatments on the as-cast alloys and implement additional microsegregation analysis studies to further characterize the effects of $\mathrm{Ru}$ additions. Hence, the following is a list of recommendations for proposed future work: 
1. Develop suitable homogenization and aging heat treatments for the alloys so that the materials can be characterized based on post-heat treatment residual microsegregation.

2. Perform a series of high temperature phase stability tests on each of the experimental alloys required to map the propensity of TCP phase formation with respect to temperature and time.

3. Using sophisticated atom probe compositional analysis techniques, investigate the influence of compositional effects on element segregation on an even finer scale between the $\gamma$-matrix and $\gamma^{\prime}$ precipitate phases (for both as-cast and heat treated materials).

4. Perform a series of high temperature creep-rupture tests to determine the effects of composition and microstructure on mechanical properties (e.g. Ru effects on $\gamma^{\prime}$ rafting).

5. Perform another series of castings using Alloys A-F, but modify the solidification rate (i.e. increase withdrawal rate) so that various dendritic sizes can be produced. The effect of dendrite size can then be related to the extent of as-cast microsegregation with the intent of determining the ideal casting superheat/ withdrawal rate. 
6. Incorporate the kinetic effects of diffusion into the computational thermodynamic models, and determine if the observed as-cast microsegregation effects can be replicated. 


\section{References}

1 Kearsey, R.M., Beddoes, J.C., Au, P., Jones, P., and P. Patnaik, "Processing and Properties of Single Crystal Ni-Base Superalloys", Report LTR-ST-SMPL-2003-0109, IAR-NRC, 2003.

2 Erickson, G., "Overview: a new, third-generation, single-crystal, casting superalloy", J. of Metals, April 1995, Vol. 47, No.4, pp.36-39.

3 Gell, M., "The Science and Technology of Single Crystal Superalloys", In: Japan--U.S. Seminar on Superalloys. Susono, Japan: Japan Inst. of Met., Dec. 1984. pp. 457-473.

4 Giamei, A.F., Anton, D.L., "Rhenium Additions to a Nickel-Base Superalloy: Effects on Microstructure", Metall. Trans. A, 1985, Vol. 16A No.11, pp.1997-2005.

5 Blavette, D., Caron, P., and T. Khan, "An Atom-Probe Study of Some Fine-Scale Microstructural Features in Nickel-Based Single Crystal Superalloys", In: Reichman, S. et al., Eds. Superalloys 1988. Warrendale, USA: TMS, 1988. p.305-314.

6 Durand-Charre, M., The Microstructure of Superalloys. Amsterdam, The Netherlands: Gordon and Breach Science Pub, 1997.

7 Du, W., Li, J., Li, J., Fu, H., and P. Wei, "Dendrite refining and eutectic transformation behavior of nickel-base single crystal (NBSC) superalloy", Chinese J Aeronautics 1998; Vol.11 No.1, pp.61-65.

8 Kearsey, R.M. Beddoes, J.C., Jones, P., and P. Au, "Compositional Design Considerations for Microsegregation in Single Crystal Superalloy Systems", J of Intermetallics, (12), 2004, pp.903910.

9 Karunaratne, M.S.A., Rae, C.M.F., and R.C. Reed, "On the microstructural instability of an experimental nickel-based single-crystal superalloy", Met \& Mat Trans A, 32A (6), 2001, pp. 2409-2421.

10 Darolia, R., Lahrman, D.F., and R.D. Field, "Formation of topologically closed packed phases in nickel base single crystal superalloys", In: Reichman S et al., Eds. Superalloys 1988.

Warrendale, USA: TMS, 1988. p.255.

11 Jaansalu, K.M., "A Thermodynamic Model for Ni-based SX Gas Turbine Alloys", $\mathrm{PhD}$. Thesis, November 2002, Royal Military College of Canada.

12 Oakes, G., Barraclough, K.C., Steels, The Development of Gas Turbine Materials, Ed. by G.W. Meetham, Applied Science Publishers, London, 1981, Chapter 2, p.32.

13 Broomfield, R.W., et al., Development and Turbine Engine Performance of Three Advanced Rhenium Containing Superalloys for Single Crystal and Directionally Solidified Blades and Vanes, International Gas Turbine and Aeroengine Congress and Exhibition, Orlando, FL, June 25, 1997, ASME-97-GT-117, 1997, pp. 1-18. 
14 The Jet Engine, $5^{\text {th }}$ Edition, Rolls-Royce Technical Publications Department, Renault Printing Company, Birmingham, England, 1996, pp. 45-59.

15 Cervenka, M., Modeling of Materials, The Rolls Royce Trent Engine, Website: http:/www.msm.cam.ac.uk/phase-trans/mphil/Trent1/index.htm, Nov 2000.

16 U.S. Dept of Energy, Advanced Turbine Systems, Website:

http:/www.net.doe.gov/publications/brochures/pdfs/scng/ATS Brochure.pdf, June 2004.

17 Bullough, C., and Piercey, B., "An On-line Materials Database for the Design of Gas Turbine Components”, ASME Paper No. 97-GT-167, June 1997.

18 Bagnall, S.M., "Aspects of Turbine Blade Design for Integrity", Proceedings of the Aero Engine Reliability, Integrity and Safety Conference, Bristol, United Kingdom, Oct. 17-18, 1991, London Royal Aeronautical Society, 1991, pp. 6.1-6.13.

19 Betteridge, W., The Nimonic Alloys, London: Edward Arnold Publishers Ltd., 1959.

20 Sims, C. T., "Nickel Alloys - The Heart of Gas Turbine Engines", Paper 70-GT-24, ASME, NY, 1970.

21 Sims, C. T., "A History of Superalloy Metallurgy for Superalloy Metallurgists", M. Gell, et al., (Eds.) Superalloys 1984, The Metallurgical Society, Warrendale, PA, USA, 1984, pp. 399 419.

22 Sims, C. T., Superalloys II, Toronto: John Wiley and Sons, 1987.

23 Bradley, E. F., Superalloys: A Technical Guide, Metals Park, Oh: ASM International, 1988.

24 Schafrik, R., Sprague, R., "Saga of Gas Turbine Materials: Part I, Advanced Materials and Processes", Vol. 162, No. 3, Mar. 2004, pp. 33-39.

25 Durand-Charre, M., The Microstructure of Superalloys, Gordon and Breach Science Publishers, 1997, pp. 10-12.

26 Caron, P., and Khan, T., "Evolution of Ni-based Superalloys for Single Crystal Gas Turbine Blade Applications", Aerospace Science and Technology, Vol. 3, No. 8, Dec. 1999, pp. 513-523.

27 Erickson, G., "A New Third Generation Single Crystal Casting Superalloy", Journal of Metals, Vol. 47, No. 4, April, 1995, pp. 36-39.

28 Gell, M., "The Science and Technology of Single Crystal Superalloys", Proceedings of the Japan-U.S. Seminar on Superalloys, International Iron and Steels Institute, 1984.

29 Giamei, A.F. and Anton, D.L., "Rhenium Additions to a Ni-base Superalloy: Effects on Microstructure", Metallurgical Transactions A, No. 16A, 1985.

30 Blavette, D., Caron, P., and Khan, T., "An Atom Probe Study of Some Fine-scale Microstructural Features in Ni-based Single Crystal Superalloys", Reichman, S., et al., (Eds.), Superalloys 1988, The Metallurgical Society, Warrendale, PA, USA, 1988, pp. 305-314. 
31 Didier, A., Vernault, C., Desvallees, Y., and D. Fournier, "MC-NG: A $4^{\text {th }}$ Generation Single Crystal Superalloy for Future Aeronautical Turbine Blades and Vanes", Pollock, T.M., et al., (Eds.), Superalloys 2000, The Metallurgical Society, Warrendale, PA, USA, 2000, pp. 829-838.

32 Caron, P., High $\gamma^{\prime}$ Solvus New Generation Nickel-Based Superalloys for Single Crystal Turbine Blade Applications, Pollock, T.M., et al., (Eds.), Superalloys 2000, The Metallurgical Society, Warrendale, PA, USA, 2000, pp. 737-746.

33 Donachie, M. and Donachie, S., Superalloys: A Technical Guide, Second Edition, ASM International, 2003, pp. 22-89.

34 Hebeisen, M.C., et al., "Vacuum Melting and Casting of Superalloys", Report NASA SP5095, Washington D.C., 1971, p. 82.

35 Hicks, M., University of Cambridge webpage, Website: http://www.msm.cam.ac.uk/phasetrans/2003/Superalloys/wax/wax.html, Mar 2003.

36 VerSnyder, F.L. and R. W. Guard, Trans. ASM, 1960, v. 52, 1960, p.485.

37 VerSnyder, F.L. and B. J. Piearcey, "A new development in gas turbine materials - The properties and characteristics of PWA 664", Journal of Aircraft, Vol. 3, 1966, pp. 390-397.

38 Kear, B. H. and B. J. Piearcey, "Tensile and Creep Properties of Single Crystals of the Ni-base Superalloy MAR-M200”, Trans. Metall. Soc. AIME, v. 239, 1967, p.1209.

39 B. J. Piearcey and B. E. Terkelson, "The Effect of Unidirectional Solidification on the Properties of Cast Ni-base Superalloys", Trans. Metall. Soc. AIME, v. 239, 1967, p.1143.

40 VerSnyder, F. L. and M. E. Shank, "The development of columnar grain and single crystal high temperature materials through directional solidification", Materials Science and Engineering, V. 6, 1970, pp. 213-247.

41 Dieter, G. E., Mechanical Metallurgy, $2^{\text {nd }}$ ed., Toronto: McGraw-Hill Book Company, 1976.

42 Saari, H., The Processing of Gas Turbine Engine Hot Section Materials Through Directional Solidification, Masters Thesis, Carleton University, Oct. 1999, pp. 17-21.

43 Kurz, W., Fisher, D.J., Fundamentals of Solidification, Trans Tech Publications, Switzerland, 1986.

44 Consarc: An Inductotherm Group Company, Rancocas, N.J. USA, website: http://www.consarc.com/home.him, June 2004.

45 Ford, D.A., Casting Technology, The Development of Gas Turbine Materials, Ed. by G.W. Meetham, Applied Science Publishers, London, 1981, Chapter 6, pp.147-166.

46 Gandin, Ch. A., Rappaz, M., and R. Tintillier, "Three Dimensional Probabilistic Simulation of Solidification Grain Structures: Application to Superalloy Precision Castings", Metall. Trans. A, $24 \mathrm{~A}, \mathrm{pp} .467-479$. 
47 Sims, C.T., Stoloff, N.S., Hagel, W.C., Superalloys II-High Temperature Materials for Aerospace and Industrial Power, John Wiley and Sons, New York, 1997.

48 Smith, W.F., Nickel and Cobalt Alloys, Structures and Properties of Engineering Alloys, McGraw-Hill Inc., 1993, Chapter 11, pp.487-536.

49 Antolovich, B.F, Fatigue and Fracture of Nickel-Base Superalloys, ASM Handbook-Fatigue and Fracture, Vol. 19, 1996, pp. 855-866.

50 Grosdidier, T., Hazotte, A., Simon, A., "Precipitation and Dissolution Processes $\gamma / \gamma$ ' Single Crystal Nickel Based Superalloys", Elsevier Pub, Materials Science and Eng., A256, (1998), pp.183-196.

51 Duval, S., Chambrelland, S., Caron, P., and Blavette, D., "Phase Composition and Chemical Order in the Single Crystal Ni-base Superalloy MC2", Acta Metall. Mater., Vol.42, No.1, pp.185194.

52 Blavette, D., Buchon, A., and Chambrelland, S., "Influence of Heat Treatment on Phase Composition and Fine Scale Features of Some Nickel Base Superalloys: A FIM Atom Probe Investigation", In: Euromat 1989, (Eds.) Exner, H.E., and Schumacher, V., Pub. DGM, Informations Gesellschaft, Verlag, pp. 419-424.

53 Bradley, E.F., Metallurgy of Superalloys, Superalloys: A Technical Guide, Ed. by E.F. Bradley, ASM International, Ohio, 1990, Chapter 2, p. 44.

54 Biermann, H. et al., "Investigation of the $\gamma / \gamma$ ' Morphology and Internal Stresses in a Monocrystalline Turbine Blasé After Service", Kissinger, R.D. et al., (Eds.), Superalloys 1996, The Metallurgical Society, Warrendale, PA, USA, 1996, pp. 201-210.

55 Rae, C.M.F., and Reed. R.C., “ The Precipitation of Topologically Close-Packed Phases in Rhenium -Containing Superalloys", Acta Mater., Vol.49, (2001), pp.4113-4125.

56 Walston, W.S., Ross, W., O’Hara, K.S., and Pollock, T.M., U.S. Patent Number 5,270,123, December 14, 1993.

57 Bowman, R., "Superalloys: A Primer and History", The Minerals, Metals, and Materials Society, website:

http:/www.tms.org/Meetings/Specialty/Superalloys2000/SuperalloysHistory.html gammaprime, May 2000.

58 Harris, K., Erickson, G.L., Sikkenga, S.L., Brentnall, W.D., Aurrecoechea, J.M., and K.G. Kubarych, Development of the Re Containing Superalloys CMSX-4 and CM-186 LC doe Single Crystal Blade and Directionally Solidified Blade Vane Applications in Advanced Turbine Engines, Antolovich S.D. et al., (Eds.), Superalloys 1992, The Metallurgical Society, Warrendale, PA, USA, 1992, pp. 297-306.

59 Darolia, R., Lahrman, D.F., and Field, R.D., Formation of TCP Phases in Nickel Base Single Crystal Superalloys, Reichman, S., et al., (Eds.), Superalloys 1988, The Metallurgical Society, Warrendale, PA, USA, 1988, pp. 255-267. 
60 Rideout, S., Manly, W.D., Kamen, E.L., Lement, B.S., and P.A. Beck, "Intermediate Phases in Ternary Alloy Systems of Transition Elements”, Trans. A.I.M.E., Vol. 191, 1951, pp. 872-880.

61 Boesch. W.J., and Slaney, J.S., "Preventing Sigma Phase Embrittlement in Nickel-Base Superalloys", Metals Progress, Vol. 86, No. 1, 1964, pp. 109-113.

62 Woodyatt, L.R., Sims, C.T., and Beattie, H.J., Jr., "Prediction of Sigma-Type Phase Occurrence from Compositions in Austenitic Superalloys", Trans. Met. Soc. AIME, Vol. 236, April 1969, pp.519-527.

63 Murphy, H.J., Sims, C.T., and A.M. Beltran, "Phacomp Revisited, Proceedings of the International Symposium on Structural Stability in Superalloys", Sept. 4-6, 1968, Vol.1, pp. 4766.

64 Pauling, L., Physical Review, Vol. 54, 1938, pg. 899.

65 Wallace, W., "Prediction of Sigma Phase Formation in High Temperature Alloys", National Research Council of Canada, Report No. IRN12274513, 1974, pp. 1-21.

66 Sims, C.T., Stoloff, N.S., and Hagel, W.C., (Eds.) Superalloys II, John Wiley and Sons, N.Y., USA, 1987, pp. 217-240.

67 Morinaga, M., Yukawa, N., Adachi, H., and Ezaki, H., "New Phacomp and its Applications to Alloy Design", Superalloys 1984, The Metallurgical Society, Warrendale, PA, USA, 1984, pp. 523-532.

68 Ritzert, F., Arenas, D., Keller, D., and Vasudevan, V., "The Effect of Alloying on Topologically Close Packed Phase Instability in Advanced Nickel-Base Superalloy Rene N6", Proceedings of TMS International Symposium, IN: Processing of Metals and Advanced Materials: Modeling, Design, and Properties, San Antonio, TX, Feb, 16-19, 1998, pp.163-174.

69 Saunders, N., Miodownik, A.P., "CALPHAD-Calculation of Phase Diagrams", Pergamon Materials Series, Vol.1, Cahn, R.W., (Ed.), Oxford: Elsevier Science, 1998.

70 Prince, A, Alloy Phase Equilibria, Elsevier Publishing Company, Netherlands, 1966.

71 Gaskell, D.R., Introduction to Metallurgical Thermodynamics, $2^{\text {nd }}$ Edition, Taylor and Francis Pub., 1981.

72 Saunders, N., "Phase Diagram Calculations for Ni-Based Superalloys", ", Kissinger, R.D. et al., (Eds.), Superalloys 1996, The Metallurgical Society, Warrendale, PA, USA, 1996, pp. 101110.

73 Kaufman, L., Bernstein, H., "Computer Calculation of Phase Diagrams, Academic Press, New York, 1970.

74 Dinsdale, A.T., "SGTE Data for Pure Elements", CALPHAD, Vol. 15, No. 4, 1991, pp. 317 425. 
75 Hack, K., The SGTE Casebook: Thermodynamics at Work, GTT Technologies, Germany, Materials Modeling Series, The Institute of Materials, 1996.

76 Margules, M., Sitzungsbar. Akad. Wiss. Wien, Mathem. Naturwiss, K1, Vol. 104, No. 11a, 1895 , pg. 1243.

77 Redlich, O., Kister, A.T., Ind. Engng., Chem., No. 40, 1948, pg. 345.

78 Borelius, A., Physik, Series 5, No. 20, 1934, pg. 57.

79 Bale, C., Pelton, A.D., Met. Trans. No. 5, 1974, pg. 2323.

80 Hildebrand, J.H., J. Amer. Chem. Soc., No. 51, 1929, pp. 66-80.

81 Sano, N., Advanced Physical Chemistry for Process Metallurgy, Academic Press, 1997.

82 Bale, C.W., Pelton, A.D., and W.T. Thompson, "Facility for the Analysis of Chemical Thermodynamics”, McGill Univ.-Ecole Polytechnique, 1996.

83 Bale, C.W. et al., "FactSage Thermochemical Software and Databases", Calphad, Elsevier Sciences Pub., Vol. 26, No. 2, 2002, pp.189-228

84 Chartrand, P., Pelton, A.D., "On the Choice of Geometric Thermodynamic Models", J. Phase Equilibria, No. 21, 2000, pp. 141-147.

85 Kattner, U.R., "Thermodynamic Modeling of Multicomponent Phase Equilibria", JOM Vol. 49 , No. 12,1997 , pp.14-19.

86 Luoma, R., "A Thermodynamic Analysis of the System Fe-Cr-Ni-C-O", Acta Polytechnica Scandinavica, Chemical Technology Series, No. 292, 2002.

87 Davies, G.J., Solidification and Casting, John Wiley \& Sons, Halsted Press, 1973.

88 Rutter, J.W. and B. Chalmers, Can. J. Phys., Vol. 31, No.15, 1953.

89 McLean, M., Directionally Solidified Materials for High Temperature Service, London: The Metals Society, 1983.

90 Flemings, M.C., Solidification Processing, U.S.A., McGraw-Hill Series in Materials Science and Engineering, 1974.

91 Brody, H.D., and Flemings, M.C., "Solute Redistribution in Dendritic Solidification", Trans. of AIME, Vol. 236, 1966, pp. 615-624.

92 Fuchs, G.E., "Solution Heat Treatment Response of a Third Generation Single Crystal Ni-base Superalloy", Journal of Materials Science and Engineering A, A300, 2001, pp. 52-60.

93 Ritzert, F., Arenas, D., Keller, D., and V. Vasudevan, "The effect of alloying on topologically close packed phase instability in advanced nickel-base superalloy Rene N6", In: Processing of 
Metals and Advanced Materials: Modeling, Design, and Properties. San Antonio, TX: TMS, 1998, p.163-174.

94 Caron, P., "High $\gamma^{\prime}$ Solvus New Generation Nickel-Based Superalloys for Single Crystal Turbine Blade Applications", In: Pollock TM et al., Eds. Superalloys 2000, Warrendale, USA: TMS, 2000. p.737-746.

95 Didier, A., et al., "MC-NG: A 4 ${ }^{\text {th }}$ Generation Single Crystal Superalloy for Future Aeronautical Turbine Blades and Vanes", In: Pollock TM et al., Eds. Superalloys 2000, Warrendale, USA: TMS, 2000. p.829-838.

96 Gell, M., Duhl, D.N., and A.F. Giamei, "The Development of Single Crystal Superalloy Turbine Blades", Superalloys 1980, The Metallurgical Society, Warrendale, PA, USA, 1980, pp. 205-214.

97 Goldstein, J.I. et al., Scanning Electron Microscopy and X-ray Microanalysis, $2^{\text {nd }}$ Ed., Plenum Press, New York, 1992.

98 C.W. Bale, A.D. Pelton, W.T. Thompson, "Facility for the Analysis of Chemical Thermodynamics", McGill Univ.-Ecole Polytechnique, 1996.

99 O'Hara, K., Walston, W.S., Ross, E.W., and R. Darolia, in US Patent \#5482789, (1996).

100 Willemin, P et al., "Experimental Determination of the Ni-rich Corner of the Ni-Al-Ta Phase Diagram", Materials Science and Tech., No.2, 1986, pp. 344-346.

101 Zheng, Y.R. et al., "The Effects of Ru Addition on Cast Nickel Base Superalloy with Low Content of Cr and High Content of W", Superalloys 2000, The Metallurgical Society, Warrendale, PA, USA, 2000, p. 305.

102 Bhadeshia, H. K. D. H., University of Cambridge webpage, Website: http://www.msm.cam.ac.uk/phase-trans/2003/Superalloys/superalloys.html, Oct. 2004.

103 Tewari, S.N. et al., "Dendritic morphology and microsegregation in directionally solidified superalloy, PWA-1480, single crystal: Effect of gravity; center director's discretionary fund report", Tech Report: NASA-TM-103518, 1990. p.1.

104 Overfelt, R., Tech Report: AD-a384 209, Auburn Univ. Al Space Power Inst, 2000. p.98.

105 Feng, Q, Nandy, T. K., Tin, S., and T.M. Pollock, "Solidification of high-refractory ruthenium-containing superalloys", Acta Mat 2003; Vol.51, pp.269-284.

106 Fuchs, G.E., "Solution heat treatment response of a third generation single crystal Ni-base superalloy, Mater Sci. Eng A 2001; A300: pp.52-60.

107 Sponseller, D.L., "Differential Thermal Analysis of Nickel-Base Superalloys", Superalloys 1996, The Metallurgical Society, Warrendale, PA, USA, 1996, pp. 259-270. 


\begin{tabular}{llll}
\hline Element & $\begin{array}{l}\text { Matrix } \\
\text { Strengthening }\end{array}$ & $\begin{array}{l}\text { Increase in } \gamma^{\prime} \\
\text { volume fraction }\end{array}$ & Other Effects \\
\hline $\mathrm{Cr}$ & moderate & moderate & $\begin{array}{l}\text { improves corrosion resistance } \\
\text { promotes TCP phases } \\
\text { increases density }\end{array}$ \\
$\mathrm{Mo}$ & high & moderate & $\begin{array}{l}\text { promotes TCP phases } \\
\mathrm{W}\end{array}$ \\
$\mathrm{Ta}$ & high & moderate & raises solidus temperature \\
$\mathrm{Nb}$ & high & large & promotes $\gamma^{\prime}$ and $\delta$ phases \\
$\mathrm{Ti}$ & moderate & very large & \\
$\mathrm{Al}$ & moderate & very large & improves oxidation resistance \\
$\mathrm{Co}$ & slight & moderate & raises solidus \\
$\mathrm{Re}$ & moderate & & retards $\gamma^{\prime}$ coarsening \\
& & & increases misfit \\
\hline
\end{tabular}

Table 1: Effects of alloying elements in Ni-base superalloys [25].

\begin{tabular}{lcccccccccc}
\hline Alloy & $\mathrm{Ni}$ & $\mathrm{Cr}$ & $\mathrm{Co}$ & $\mathrm{Mo}$ & $\mathrm{W}$ & $\mathrm{Al}$ & $\mathrm{Ti}$ & $\mathrm{Ta}$ & $\mathrm{Hf}$ & Density \\
\hline PWA 1480 & 62.5 & 10 & 5 & 2 & 4 & 5 & 1.5 & 12 & - & 8.70 \\
René N4 & 62.6 & 9 & 8 & 0.6 & 6 & 3.7 & 4.2 & 4 & - & 8.56 \\
CMSX-2 & 65.4 & 8 & 5 & 0.6 & 8 & 6.0 & 1 & 6 & - & 8.56 \\
CMSX-6 & 70.4 & 10 & 5 & 3 & - & 4.8 & 4.7 & 2 & 0.1 & 7.98 \\
SRR 99 & 66.5 & 8.5 & 5 & 2 & 9.5 & 5.5 & 2.2 & 2.8 & & 8.52 \\
AM 1 & 63.8 & 7.8 & 6.5 & 0.5 & 5.7 & 5.2 & 1.1 & 7.9 & & 8.60 \\
& & & & & & & & & & \\
\hline
\end{tabular}

Table 2: Composition (wt.\%) and density of some commonly used $1^{\text {st }}$ generation single crystal superalloys. (Adapted from Broomfield et al.) [13]. 


\begin{tabular}{lccccccccccc}
\hline Alloy & $\mathrm{Ni}$ & $\mathrm{Cr}$ & $\mathrm{Co}$ & $\mathrm{Mo}$ & $\mathrm{W}$ & $\mathrm{Al}$ & $\mathrm{Ti}$ & $\mathrm{Ta}$ & $\mathrm{Re}$ & $\mathrm{Hf}$ & Density \\
\hline CMSX-4 & 61.8 & 6.5 & 9 & 0.6 & 6 & 5.6 & 1 & 6.5 & 3 & 0.1 & 8.7 \\
PWA 1484 & 59.4 & 5 & 10 & 2 & 6 & 5.6 & & 9 & 3 & & 8.95 \\
SC 180 & 60.2 & 5 & 10 & 2 & 5 & 5.2 & 1 & 8.5 & 3 & 0.1 & 8.84 \\
René N5 & 61.8 & 7 & 8 & 2 & 5 & 6.2 & & 7 & 3 & 0.2 & 8.65
\end{tabular}

Table 3: Composition (wt.\%) and density of some commonly used $2^{\text {nd }}$ generation single crystal superalloys (adapted from Durande-Charre) [25].

\begin{tabular}{lcccccccccccc}
\hline Alloy & $\mathrm{Ni}$ & $\mathrm{Cr}$ & $\mathrm{Co}$ & $\mathrm{Mo}$ & $\mathrm{W}$ & $\mathrm{Al}$ & $\mathrm{Ti}$ & $\mathrm{Ta}$ & $\mathrm{Re}$ & $\mathrm{Nb}$ & $\mathrm{Hf}$ & Density \\
\hline CMSX-10 & 69.6 & 2 & 3 & 0.4 & 5 & 5.7 & 0.2 & 8 & 6 & 0.1 & 0.03 & 9.05 \\
Rene N6 & 57.4 & 4.2 & 12.5 & 1.4 & 6 & 5.75 & & 7.2 & 5.4 & 0.15 & 8.97 \\
TMS-75 & 58.9 & 3 & 12 & 3 & 6 & 6 & & 6 & 5 & 0.1 & \\
\hline
\end{tabular}

Table 4: Composition (wt. \%) and density of typical $3^{\text {rd }}$ generation single crystal superalloys.

\begin{tabular}{lccccccccccccc}
\hline Alloy & Ni & Cr & Co & Mo & W & Al & Ti & Ta & Re & Ru & Hf & C & B \\
\hline MC-NG & 70.2 & 4 & 0.2 & 1 & 5 & 6 & 0.5 & 5 & 4 & 4 & 0.1 & & \\
Alloy\#11 & 56.0 & 5 & 12.65 & 1.55 & 5.65 & 6 & 0.4 & 6.4 & 4.5 & 1.6 & 0.15 & 0.05 & 0.004
\end{tabular}

Table 5: Potential $4^{\text {th }}$ Generation Ru-bearing single crystal alloys. 


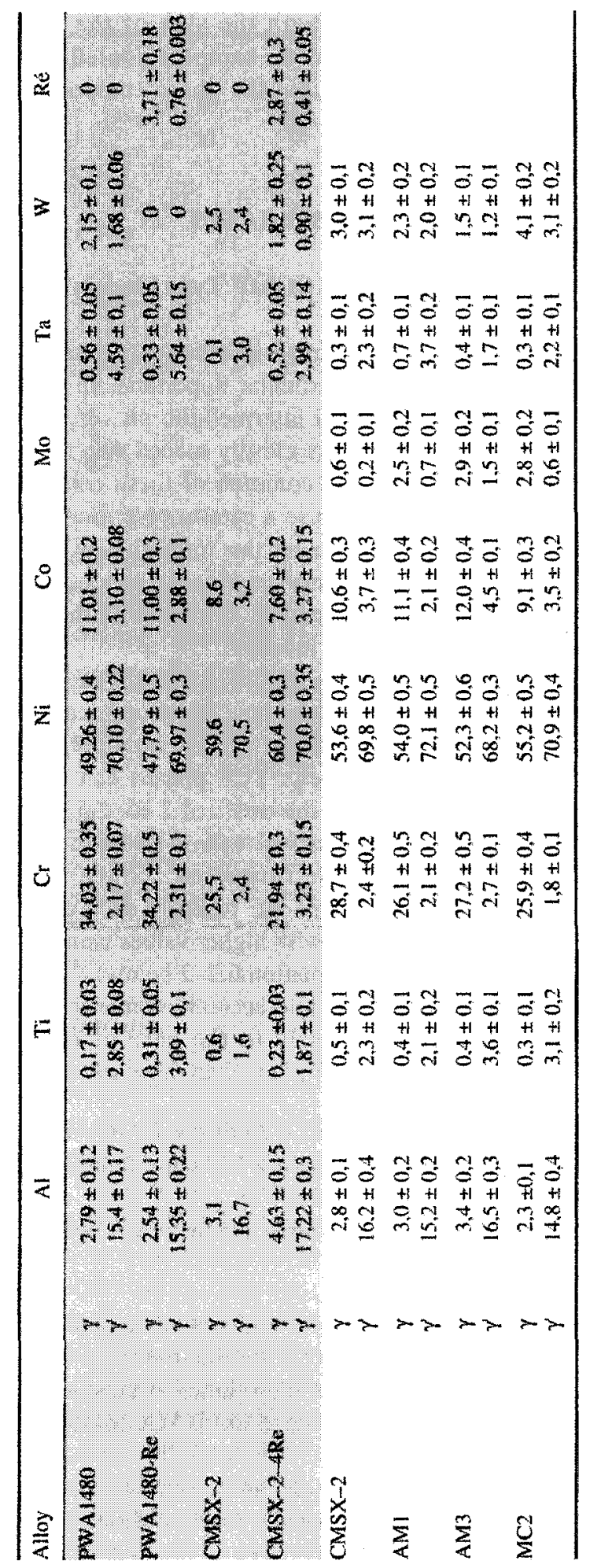

Table 6: Typical compositions (at.\%) of $\gamma$ and $\gamma^{\prime}$ phases in SX superalloys as determined by atom microprobe analysis $[51,52]$. 


\begin{tabular}{cc}
\hline Element & $\begin{array}{c}\text { Range } \\
\text { wt. \% }\end{array}$ \\
\hline $\mathrm{Ni}$ & balance \\
$\mathrm{Cr}$ & $5-25$ \\
$\mathrm{Mo}$ & $0-12$ \\
$\mathrm{~W}$ & $0-12$ \\
$\mathrm{Ta}$ & $0-12$ \\
$\mathrm{Nb}$ & $0-5$ \\
$\mathrm{Ti}$ & $0-6$ \\
$\mathrm{Al}$ & $0-6$ \\
$\mathrm{Co}$ & $0-20$ \\
$\mathrm{Re}$ & $0-6$ \\
$\mathrm{Ru}$ & $0-4$
\end{tabular}

Table 7: Compositional ranges of major alloying additions in Ni-base superalloys from the late 1940's to present (adapted from Donachie) [33].

\begin{tabular}{lcccccccc}
\hline Region & Cr & Co & Mo & W & Ta & Re & Al & Ti \\
\hline $\begin{array}{l}\text { wt.\% } \\
\text { Dendrite core }\end{array}$ & 1.1 & 2.39 & 0.79 & 9.19 & 6.49 & 19.54 & 3.48 & 0.16 \\
interdendritic & 1.09 & 2.31 & 0.79 & 8.31 & 8.28 & 13.71 & 4.1 & 0.21 \\
\hline & 1.09 & 1.11 & 1.03 & 1.25 & 0.60 & 1.98 & 0.72 & 0.49 \\
\hline $\begin{array}{l}\left.k^{\prime}\right) \text { partitioning } \\
\text { coefficient }\end{array}$ & & & & & & & &
\end{tabular}

Table 8: Average composition of dendrite and interdendritic regions, including partitioning coefficients for as-cast CMSX-10 [92]. 


\begin{tabular}{lccccccc}
\hline Alloy & \multicolumn{1}{c}{ Chemical composition* (wt.\%) } & & & & Total refractory (wt.\%) & Alloy density \\
\cline { 2 - 7 } & $\mathrm{Ni}$ & $\mathrm{Ta}$ & $\mathrm{W}$ & $\mathrm{Re}$ & $\mathrm{Ru}$ & $\mathrm{W}+\mathrm{Ta}+\mathrm{Co}+\mathrm{Re}+\mathrm{Ru}$ & $\left(\mathrm{g} / \mathrm{cm}^{3}\right)$ \\
\hline Alloy A & 63.5 & 12 & 3 & 1 & 0 & 21 & 9.77 \\
Alloy B & 63.5 & 12 & 2 & 2 & 0 & 21 & 9.78 \\
Alloy C & 63.5 & 12 & 1 & 3 & 0 & 21 & 9.80 \\
Alloy D & 63.5 & 12 & 0 & 4 & 0 & 21 & 9.81 \\
Alloy E & 60.5 & 12 & 4 & 3 & 0 & 24 & 10.11 \\
Alloy F & 60.5 & 11 & 1 & 3 & 4 & 24 & 9.85 \\
\hline
\end{tabular}

* In addition, each alloy also contains: $7.5 \% \mathrm{Cr}+5 \% \mathrm{Co}+2 \% \mathrm{Mo}+1 \% \mathrm{Ti}+5 \% \mathrm{Al}$.

Table 9: Target compositions, total refractory level, and alloy density for experimental alloys.

\begin{tabular}{|c|c|c|c|c|c|c|c|c|c|c|c|}
\hline \multirow[t]{2}{*}{ Alloy } & \multicolumn{10}{|c|}{ Chemical composition (wt.\%) } & \multirow{2}{*}{$\begin{array}{c}\begin{array}{c}\text { Total refractory } \\
(w t . \%)\end{array} \\
\text { W+Ta+Co+Re+Ru }\end{array}$} \\
\hline & $\mathrm{Ni}$ & $\mathrm{Ta}$ & W & $\mathrm{Re}$ & $\mathrm{Ru}$ & $\mathrm{Cr}$ & $\mathrm{Co}$ & Mo & $\mathrm{Ti}$ & Al & \\
\hline Alloy A & 63.93 & 11.87 & 2.95 & 1.10 & 0.00 & 7.53 & 5.01 & 1.85 & 1.01 & 4.75 & 21 \\
\hline Alloy B & 63.33 & 12.04 & 2.05 & 2.07 & 0.00 & 7.49 & 5.16 & 1.90 & 1.01 & 4.95 & 21 \\
\hline Alloy C & 63.79 & 11.76 & 1.19 & 3.02 & 0.00 & 7.53 & 5.11 & 1.87 & 0.96 & 4.77 & 21 \\
\hline Alloy D & 64.08 & 11.72 & 0.00 & 4.00 & 0.00 & 7.53 & 5.05 & 1.90 & 0.98 & 4.74 & 21 \\
\hline Alloy $\mathrm{E}$ & 61.41 & 11.62 & 3.99 & 3.06 & 0.00 & 7.43 & 4.97 & 1.84 & 0.93 & 4.75 & 24 \\
\hline Alloy F & 60.9 & 10.82 & 1.16 & 2.91 & 3.81 & 7.53 & 5.03 & 2.01 & 1.00 & 4.83 & 24 \\
\hline
\end{tabular}

Table 10: Final alloy compositions and total refractory levels as determined using wet chemical analysis. 


\begin{tabular}{|c|c|c|c|c|c|c|c|}
\hline designation & alloy & seed & spacer & temperature & withdrawal & atmosphere & results \\
\hline trial 1 & PWA -1484 & PWA $-1484-2.0$ in. & $3 / 8$ in. $\mathrm{Zr}_{2} \mathrm{O}_{3}$ & $1500^{\circ} \mathrm{C}$ & $6.0 \mathrm{in} / \mathrm{hr}$ & argon & SX, seed method successful \\
\hline trial 2 & ternary & PWA - $1484-1.0 \mathrm{in}$. & $3 / 8$ in $\mathrm{Zr}_{2} \mathrm{O}_{3}$ & $1500^{\circ} \mathrm{C}$ & $6.0 \mathrm{in} / \mathrm{hr}$ & argon & $S X$, no neg effects due to diff comp \\
\hline$S X-A 1$ & Alloy - A & PWA - $1484-3 / 4$ in. & $3 / 8$ in. $\mathrm{Zr}_{2} \mathrm{O}_{3}$ & $1500^{\circ} \mathrm{C}$ & $6.0 \mathrm{in} / \mathrm{hr}$ & argon & DS, did not melt into seed \\
\hline$S X-A 2$ & Alloy - A & PWA -1484 - $3 / 4$ in. & $3 / 8$ in. $\mathrm{Zr}_{2} \mathrm{O}_{3}$ & $1600^{\circ} \mathrm{C}$ & $6.0 \mathrm{in} / \mathrm{hr}$ & argon & $S X$, large surface porosity \\
\hline$S X-A 3$ & Alloy - A & PWA -1484 - 3/4 in. & $3 / 8$ in. $\mathrm{Zr}_{2} \mathrm{O}_{3}$ & $1600^{\circ} \mathrm{C}$ & $8.0 \mathrm{in} / \mathrm{hr}$ & $\mathrm{Hi}-\mathrm{Vac}$ & $S X$, reduced porosity, grain defects \\
\hline$S X-A 4$ & Alloy - A & PWA $-1484-3 / 4$ in. & $3 / 8$ in. $\mathrm{Zr}_{2} \mathrm{O}_{3}$ & $1550^{\circ} \mathrm{C}$ & $8.0 \mathrm{in} / \mathrm{hr}$ & $\mathrm{Hi}-\mathrm{Vac}$ & mold failure \\
\hline$S X-A 5$ & Alloy - A & PWA $-1484-7 / 8$ in. & $3 / 8$ in. $\mathrm{Zr}_{2} \mathrm{O}_{3}$ & $1550^{\circ} \mathrm{C}$ & $8.0 \mathrm{in} / \mathrm{hr}$ & Hi-Vac & SX, good surface finish, no defects \\
\hline$S X-A 6$ & Altoy - A & PWA $-1484-3 / 4$ in. & $3 / 8$ in. $\mathrm{Zr}_{2} \mathrm{O}_{3}$ & $1550^{\circ} \mathrm{C}$ & $8.0 \mathrm{in} / \mathrm{hr}$ & $\mathrm{Hi}-\mathrm{Vac}$ & SX, good surface finish, no defects \\
\hline$S X-A 7$ & Alloy - A & PWA - $1484-3 / 4$ in. & $1 / 2$ in. $\mathrm{Al}_{2} \mathrm{O}_{3}$ & $1585^{\circ} \mathrm{C}$ & $8.0 \mathrm{in} / \mathrm{hr}$ & $\mathrm{Hi}-\mathrm{Vac}$ & SX, good surface finish, no defects \\
\hline$S X-A 8$ & Alloy - A & PWA $-1484-3 / 4$ in. & $1 / 2$ in. $\mathrm{Al}_{2} \mathrm{O}_{3}$ & $1585^{\circ} \mathrm{C}$ & $8.0 \mathrm{in} / \mathrm{hr}$ & $\mathrm{Hi}-\mathrm{Vac}$ & $S x$, good surface finish, no defects \\
\hline SX-B1 & Alloy - B & PWA $-1484-3 / 4$ in. & $3 / 8$ in. $\mathrm{Zr}_{2} \mathrm{O}_{3}$ & $1550^{\circ} \mathrm{C}$ & $8.0 \mathrm{in} / \mathrm{hr}$ & $\mathrm{Hi}-\mathrm{Vac}$ & DS, spacer fell apart on loading \\
\hline$S X-B 2$ & Alloy - B & PWA -1484 - $3 / 4$ in. & $3 / 8$ in. $\mathrm{Zr}_{2} \mathrm{O}_{3}$ & $1550^{\circ} \mathrm{C}$ & $8.0 \mathrm{in} / \mathrm{hr}$ & $\mathrm{Hi}-\mathrm{Vac}$ & SX, good surface finish, no defects \\
\hline SX-B3 & Alloy - B & PWA $-1484-3 / 4$ in. & $3 / 8$ in. $\mathrm{Zr}_{2} \mathrm{O}_{3}$ & $1550^{\circ} \mathrm{C}$ & $8.0 \mathrm{in} / \mathrm{hr}$ & $\mathrm{Hi}-\mathrm{Vac}$ & $S X$, spurious grain at top section \\
\hline$S X-B 4$ & Alloy - B & PWA -1484 - $3 / 4$ in. & $3 / 8$ in. $\mathrm{Zr}_{2} \mathrm{O}_{3}$ & $1550^{\circ} \mathrm{C}$ & $8.0 \mathrm{in} / \mathrm{hr}$ & $\mathrm{Hi}-\mathrm{Vac}$ & $S X$, good surface finish, no defects \\
\hline SX-B5 & Alloy - B & PWA $-1484-3 / 4$ in. & $1 / 2$ in. $\mathrm{Al}_{2} \mathrm{O}_{3}$ & $1585^{\circ} \mathrm{C}$ & $8.0 \mathrm{in} / \mathrm{hr}$ & Hi-Vac & $s \times$, good surface finish, no defects \\
\hline SX-B6 & Alloy - B & PWA $-1484-3 / 4$ in. & $1 / 2$ in. $\mathrm{Al}_{2} \mathrm{O}_{3}$ & $1585^{\circ} \mathrm{C}$ & $8.0 \mathrm{in} / \mathrm{hr}$ & $\mathrm{Hi}-\mathrm{Vac}$ & SX, good surface finish, no defects \\
\hline$S x-C 1$ & Alloy - C & none & $3 / 8$ in. $\mathrm{Zr}_{2} \mathrm{O}_{3}$ & $1550^{\circ} \mathrm{C}$ & $8.0 \mathrm{in} / \mathrm{hr}$ & $\mathrm{Hi}-\mathrm{Vac}$ & DS, no seed crystal used \\
\hline$s x-C 2$ & Alloy - C & PWA $-1484-3 / 4$ in. & $3 / 8$ in $\mathrm{Zr}_{2} \mathrm{O}_{3}$ & $1550^{\circ} \mathrm{C}$ & $8.0 \mathrm{in} / \mathrm{hr}$ & $\mathrm{Hi}-\mathrm{Vac}$ & SX, good surface finish, no defects \\
\hline$S x-C 3$ & Alloy - C & PWA $-1484-3 / 4$ in. & $1 / 2$ in $\mathrm{Al}_{2} \mathrm{O}_{3}$ & $1585^{\circ} \mathrm{C}$ & $8.0 \mathrm{in} / \mathrm{hr}$ & $\mathrm{Hi}-\mathrm{Vac}$ & SX, good surface finish, no defects \\
\hline $\mathrm{SX}-\mathrm{C} 4$ & Alloy - C & PWA $-1484-3 / 4$ in. & $1 / 2$ in. $\mathrm{Al}_{2} \mathrm{O}_{3}$ & $1585^{\circ} \mathrm{C}$ & $8.0 \mathrm{in} / \mathrm{hr}$ & Hi-Vac & SX, good surface finish, no defects \\
\hline SX-D1 & Alloy - D & PWA -1484 - $3 / 4$ in. & $1 / 2$ in. $\mathrm{Al}_{2} \mathrm{O}_{3}$ & $1585^{\circ} \mathrm{C}$ & $8.0 \mathrm{in} / \mathrm{hr}$ & Hi-Vac & $S X$, spurious grain at top section \\
\hline$S x-D 2$ & Alloy - D & PWA $-1484-3 / 4$ in. & $1 / 2$ in. $\mathrm{Al}_{2} \mathrm{O}_{3}$ & $1585^{\circ} \mathrm{C}$ & $8.0 \mathrm{in} / \mathrm{hr}$ & Hi-Vac & $S X$, some reaction with mold walls \\
\hline SX-D3 & Alloy - D & PWA - $1484-3 / 4$ in. & $1 / 2$ in. $\mathrm{Al}_{2} \mathrm{O}_{3}$ & $1585^{\circ} \mathrm{C}$ & $8.0 \mathrm{in} / \mathrm{hr}$ & Hi-Vac & SX, good surface finish, no defects \\
\hline SX-D4 & Alloy - D & PWA -1484 - 3/4 in. & $1 / 2$ in. $\mathrm{Al}_{2} \mathrm{O}_{3}$ & $1585^{\circ} \mathrm{C}$ & $8.0 \mathrm{in} / \mathrm{hr}$ & $\mathrm{Hi}-\mathrm{Vac}$ & SX, good surface finish, no defects \\
\hline SX-E1 & Alloy $-E$ & PWA - $1484-3 / 4$ in. & $1 / 2$ in. $\mathrm{Al}_{2} \mathrm{O}_{3}$ & $1585^{\circ} \mathrm{C}$ & $8.0 \mathrm{in} / \mathrm{hr}$ & $\mathrm{Hi}-\mathrm{Vac}$ & $S X$, some reaction with mold walls \\
\hline$S X-E 2$ & Alloy - E & PWA $-1484-3 / 4$ in. & $1 / 2$ in. $\mathrm{Al}_{2} \mathrm{O}_{3}$ & $1585^{\circ} \mathrm{C}$ & $8.0 \mathrm{in} / \mathrm{hr}$ & $\mathrm{Hi}-\mathrm{Vac}$ & $S x$, good surface finish, no defects \\
\hline SX-E3 & Alloy - $E$ & PWA $-1484-3 / 4$ in. & $1 / 2$ in. $\mathrm{Al}_{2} \mathrm{O}_{3}$ & $1585^{\circ} \mathrm{C}$ & $8.0 \mathrm{in} / \mathrm{hr}$ & $\mathrm{Hi}-\mathrm{Vac}$ & SX, good surface finish, no defects \\
\hline$S X-F 1$ & Alloy - F & PWA $-1484-3 / 4$ in. & $1 / 2$ in. $\mathrm{Al}_{2} \mathrm{O}_{3}$ & $1585^{\circ} \mathrm{C}$ & $8.0 \mathrm{in} / \mathrm{hr}$ & Hi-Vac & $S X_{\text {, some reaction with mold walls }}$ \\
\hline$S X-F 2$ & Alloy - F & PWA -1484 - $3 / 4$ in. & $1 / 2$ in $\mathrm{Al}_{2} \mathrm{O}_{3}$ & $1585^{\circ} \mathrm{C}$ & $8.0 \mathrm{in} / \mathrm{hr}$ & $\mathrm{Hi}-\mathrm{Vac}$ & $S x$, good surface finish, no defects \\
\hline$S X-F 3$ & Alloy - F & PWA -1484 - $3 / 4$ in. & $1 / 2$ in $\mathrm{Al}_{2} \mathrm{O}_{3}$ & $1585^{\circ} \mathrm{C}$ & $8.0 \mathrm{in} / \mathrm{hr}$ & Hi-Vac & SX, good surface finish, no defects \\
\hline
\end{tabular}

Table 11: SX casting results for Alloys A-F. 


\begin{tabular}{|c|c|c|c|c|c|c|c|c|c|c|c|}
\hline Description & Al & $\mathrm{Cr}$ & $\mathrm{Ni}$ & Co & Ti & $\mathbf{R e}$ & $\mathrm{Ta}$ & Mo & $\mathbf{W}$ & $\mathbf{R u}$ & Total \\
\hline A-CORE & 4.60 & 7.65 & 64.39 & 5.17 & 0.83 & 1.12 & 10.57 & 1.84 & 2.92 & 0.00 & 99.09 \\
\hline A-CORE & 4.79 & 7.48 & 65.44 & 5.14 & 0.77 & 1.19 & 10.30 & 1.69 & 3.45 & 0.00 & 100.25 \\
\hline A-CORE & 4.74 & 7.47 & 65.17 & 5.24 & 0.73 & 1.34 & 9.75 & 1.60 & 3,77 & 0.00 & 99.82 \\
\hline A-CORE & 4.55 & 7.68 & 64.87 & 5.35 & 0.67 & 1.30 & 9.37 & 1.65 & 3.81 & 0.00 & 99.26 \\
\hline A-CORE & 4.72 & 7.28 & 65.65 & 5.27 & 0.66 & 1.18 & 9.59 & 1.56 & 3.60 & 0.00 & 99.50 \\
\hline A-CORE2 & 4.79 & 7.52 & 64.18 & 5.19 & 0.79 & 1.06 & 10.62 & 1.69 & 3.14 & 0.02 & 98.99 \\
\hline A-CORE2 & 4.62 & 7.85 & 64.20 & 5.26 & 0.78 & 1.33 & 10.03 & 1.70 & 3.39 & 0.07 & 99.21 \\
\hline A-CORE2 & 4.72 & 7.86 & 64.93 & 5.38 & 0.75 & 1.38 & 9.76 & 1.58 & 3.64 & 0.06 & 100.04 \\
\hline A-CORE2 & 4.69 & 7.57 & 64.97 & 5.18 & 0.77 & 1.31 & 10.00 & 1.58 & 3.44 & 0.04 & 99.55 \\
\hline A-CORE2 & 4.58 & 7.88 & 64.55 & 5.27 & 0.71 & 1.23 & 9.55 & 1.71 & 3.52 & 0.02 & 99.01 \\
\hline A-CORE (avg) & 4.68 & 7.62 & 64.83 & 5.24 & 0.75 & 1.24 & 9.95 & 1.66 & 3.47 & 0.00 & 99.47 \\
\hline A-INTER & 6.16 & 3.32 & 66.90 & 3.78 & 1.46 & 0.27 & 16.05 & 0.66 & 0.87 & 0.00 & 99.46 \\
\hline A-INTER & 5.76 & 4.63 & 65.62 & 4.13 & 1.32 & 0.53 & 14.98 & 0.93 & 1.21 & 0.00 & 99.12 \\
\hline A-INTER & 5.48 & 5.38 & 65.39 & 4.45 & 1.27 & 0.72 & 14.12 & 1.32 & 1.41 & 0.01 & 99.55 \\
\hline A-INTER & 5.45 & 5.72 & 64.88 & 4.45 & 1.21 & 0.64 & 13.71 & 1.44 & 1.63 & 0.00 & 99.14 \\
\hline A-INTER & 5.39 & 5.76 & 64.20 & 4.49 & 1.21 & 0.62 & 13.91 & 1.43 & 1.64 & 0.00 & 98.66 \\
\hline A-INTER2 & 5.15 & 6.35 & 64.37 & 4.67 & 1.19 & 0.73 & 13.27 & 1.51 & 1.78 & 0.04 & 99.05 \\
\hline A-INTER2 & 5.17 & 6.31 & 64.88 & 4.75 & 1.15 & 0.79 & 13.02 & 1.48 & 1.91 & 0.04 & 99.48 \\
\hline A-INTER2 & 5.26 & 6.05 & 64.25 & 4.57 & 1,24 & 0.76 & 13.60 & 1.44 & 1.68 & 0.04 & 98.89 \\
\hline A-INTER2 & 5.43 & 5.61 & 64.02 & 4.42 & 1.28 & 0.68 & 14.13 & 1.39 & 1.60 & 0.04 & 98.59 \\
\hline A-INTER2 & 5.68 & 5.01 & 65.35 & 4.28 & 1.35 & 0.52 & 14.65 & 1.15 & 1.45 & 0.02 & 99.45 \\
\hline A-INTER (avg) & 5.49 & 5.41 & 64.99 & 4.40 & $1: 27$ & 0.63 & 14.14 & 1.27 & 1.52 & 0.00 & 99.14 \\
\hline B-CORE & 4.78 & 7.68 & 64.42 & 5.30 & 0.73 & 2.63 & 9.92 & 1.67 & 2.26 & 0.00 & 99.39 \\
\hline B-CORE & 4.63 & 7.87 & 64.05 & 5.43 & 0.69 & 2.89 & 9.42 & 1.73 & 2.37 & 0.00 & 99.09 \\
\hline B-CORE & 4.79 & 7.54 & 64.78 & 5.35 & 0.74 & 2.72 & 9.69 & 1.66 & 2.23 & 0.00 & 99.50 \\
\hline B-CORE & 4.65 & 7.80 & 64.09 & 5.40 & 0.72 & 2.83 & 9.64 & 1.74 & 2.39 & 0.00 & 99.26 \\
\hline B-CORE & 4.76 & 7.63 & 63.88 & 5.25 & 0.79 & 2.59 & 10.36 & 1.73 & 2.31 & 0.00 & 99.29 \\
\hline B-CORE2 & 4.87 & 7.83 & 63.78 & 5.37 & 0.71 & 2.85 & 9.69 & 1.68 & 2.40 & 0.00 & 99.17 \\
\hline B-CORE2 & 4.83 & 7.53 & 64.22 & 5.29 & 0.71 & 2.79 & 9.75 & 1.65 & 2.39 & 0.00 & 99.16 \\
\hline B-CORE2 & 4.64 & 7.81 & 63.92 & 5.54 & 0.68 & 3.02 & 9.38 & 1.74 & 2.62 & 0.00 & 99.34 \\
\hline B-CORE2 & 4.58 & 7.83 & 63.89 & 5.49 & 0.67 & 2.91 & 9.50 & 1.72 & 2.50 & 0.02 & 99.11 \\
\hline 8-CORE2 & 4.75 & 7.67 & 63.85 & 5.40 & 0.76 & 2.71 & 9.99 & 1.73 & 2.31 & 0.00 & 99.16 \\
\hline B-CORE (avg) & 4.73 & 7.72 & 64.09 & 5.38 & 0.72 & 2.79 & 9.73 & 1.71 & 2.38 & 0.00 & 99.25 \\
\hline B-INTER & 5.86 & 4.44 & 64.32 & 4.17 & 1.46 & 0.80 & 16.24 & 1.02 & 0.65 & 0.00 & 98.96 \\
\hline B-INTER & 5.69 & 5.12 & 63.93 & 4.29 & 1.42 & 1.06 & 15.67 & 1.12 & 0.63 & 0.05 & 98.99 \\
\hline B-INTER & 5.77 & 5.07 & 64.05 & 4.33 & 1.40 & 1.04 & 15.50 & 1.20 & 0.57 & 0.02 & 98.95 \\
\hline B-INTER & 5.93 & 4.71 & 64.88 & 4.16 & 1.46 & 0.91 & 15.96 & 1.06 & 0.44 & 0.01 & 99.50 \\
\hline B-INTER & 5.77 & 4.61 & 64.03 & 4.14 & 1.48 & 0.83 & 16.27 & 1.14 & 0.51 & 0.01 & 98.79 \\
\hline B-INTER2 & 6.13 & 2.73 & 65.10 & 3.83 & 1.85 & 0.35 & 18.60 & 0.48 & 0.10 & 0.02 & 99.19 \\
\hline B-INTER2 & 6.26 & 2.73 & 64.96 & 3.87 & 1.75 & 0.42 & 18.31 & 0.50 & 0.16 & 0.00 & 98.90 \\
\hline B-INTER2 & 6.23 & 2.94 & 65.58 & 3.77 & 1.62 & 0.55 & 17.86 & 0.58 & 0.23 & 0.00 & 99.34 \\
\hline B-INTER2 & 6.18 & 3.28 & 65.17 & 3.86 & 1.54 & 0.61 & 17.24 & 0.67 & 0.34 & 0.03 & 98.91 \\
\hline B-INTER2 & 6.04 & 3.97 & 64.42 & 4.11 & 1.45 & 0.73 & 16.85 & 0.86 & 0.52 & 0.01 & 98.95 \\
\hline B-INTER (avg) & 5.98 & 3.96 & 64.64 & 4.05 & 1.54 & 0.73 & 16.85 & 0.86 & 0.41 & 0.00 & 99.05 \\
\hline G-CORE & 4.50 & 7.97 & 62.08 & 5.25 & 0.79 & 3.92 & 10.27 & 1.82 & 1.45 & 0.00 & 97.64 \\
\hline C-CORE & 4.75 & 7.57 & 63.34 & 5.22 & 0.75 & 4.07 & 9.92 & 1.66 & 1.50 & 0.02 & 98.40 \\
\hline C-CORE & 4.54 & 7.83 & 63.59 & 5.33 & 0.76 & 4.28 & 10.01 & 1.70 & 1.49 & 0.00 & 99.13 \\
\hline C-CORE & 4.48 & 7.97 & 63.85 & 5.37 & 0.69 & 4.36 & 9.54 & 1.79 & 1.49 & 0.01 & 99.26 \\
\hline C-CORE & 4.58 & 7.91 & 62.66 & 5.41 & 0.69 & 4.40 & 9.77 & 1.78 & 1.45 & 0.00 & 98.35 \\
\hline C-CORE & 4.71 & 8.00 & 63.01 & 5.35 & 0.77 & 4.40 & 9.99 & 1.66 & 1.46 & 0.00 & 98.94 \\
\hline C-CORE2 & 4.65 & 7.80 & 63.56 & 5.32 & 0.84 & 3.58 & 10.89 & 1.78 & 1.19 & 0.04 & 99.36 \\
\hline G-CORE2 & 4.66 & 7.96 & 63.62 & 5.30 & 0.79 & 4.11 & 10.43 & 1.80 & 1.43 & 0.00 & 99.70 \\
\hline C-CORE2 & 4.59 & 8.08 & 63.65 & 5.33 & 0.75 & 4.28 & 10.30 & 1.73 & 1.56 & 0.02 & 99.89 \\
\hline C-CORE2 & 4.47 & 8.05 & 63.63 & 5.49 & 0.69 & 4.49 & 9.75 & 1.81 & 1.56 & 0.00 & 99.52 \\
\hline C CORE2 & 4.60 & 7.81 & 63.80 & 5.32 & 0.70 & 4.32 & 9.86 & 1.74 & 1.52 & 0.01 & 99.27 \\
\hline C-CORE (avg) & 4.59 & 790 & 63.34 & 5.33 & 0.75 & 4.20 & 10.07 & 1.75 & 1.46 & 0.00 & 99.04 \\
\hline C-INTER & 5.66 & 4.89 & 63.81 & 4.26 & 1.38 & 1.44 & 15.68 & 1.15 & 0.55 & 0.03 & 98.54 \\
\hline C-INTER & 5.69 & 4.77 & 63.96 & 4.21 & 1.38 & 1.50 & 15.70 & 1.12 & 0.41 & 0.02 & 98.46 \\
\hline C-INTER & 5.81 & 4.28 & 64.91 & 4.12 & 1.36 & 1.28 & 16.14 & 0.94 & 0.42 & 0.00 & 98.95 \\
\hline C-INTER & 5.83 & 4.49 & 64.27 & 4.17 & 1.37 & 1.37 & 16.05 & 0.96 & 0.33 & 0.00 & 98.52 \\
\hline C-INTER & 5.71 & 4.64 & 63.49 & 4.19 & 1.37 & 1.45 & 15.83 & 1.03 & 0.48 & 0.00 & 97.87 \\
\hline C-INTER2 & 6.17 & 2.77 & 65.14 & 3.81 & 1.66 & 0.61 & 17.85 & 0.56 & 0.30 & 0.00 & 98.57 \\
\hline C-INTER2 & 6.19 & 2.86 & 64.95 & 3.79 & 1.64 & 0.68 & 17.64 & 0.56 & 0.30 & 0.01 & 98.30 \\
\hline C-INTER2 & 6.07 & 3.07 & 64.67 & 3.81 & 1.62 & 0.80 & 17.36 & 0.63 & 0.30 & 0.02 & 98.04 \\
\hline C-INTER2 & 6.08 & 3.03 & 65.55 & 3.81 & 1.63 & 0.73 & 17.48 & 0.62 & 0.31 & 0.00 & 98.94 \\
\hline C-INTER2 & 6.16 & 2.73 & 65.67 & 3.68 & 1.64 & 0.64 & 17.96 & 0.51 & 0.30 & 0.00 & 98.98 \\
\hline C-INTER (avg) & 5.94 & 3.75 & 64.64 & 3.98 & 1.50 & 1.05 & 16.77 & 0.81 & 0.37 & 0.00 & 98.52 \\
\hline
\end{tabular}

Table 12: EPMA point-scan results for as-cast Alloys A-C (wt.\%). 


\begin{tabular}{|c|c|c|c|c|c|c|c|c|c|c|c|}
\hline Description & $\bar{A}$ & $\mathrm{Cr}$ & $\mathrm{Ni}$ & $\mathrm{Co}$ & $\mathrm{Ti}$ & $\mathrm{Re}$ & $\mathrm{Ta}$ & Mo & $\mathbf{W}$ & $\mathrm{Ru}$ & Total \\
\hline D-CORE & 4,52 & 7.82 & 64.33 & 5.49 & 0.66 & 6.03 & 9.28 & 1.88 & 0.00 & 0.00 & 100.02 \\
\hline D-CORE & 4.55 & 7.74 & 63.58 & 5.45 & 0.68 & 5.76 & 9.41 & 1.74 & 0.00 & 0.01 & 98.92 \\
\hline D-CORE & 4.61 & 7.51 & 63.62 & 5.40 & 0.69 & 5.80 & 9.49 & 1.88 & 0.00 & 0.02 & 99.01 \\
\hline D-CORE & 4.58 & 7.85 & 63.62 & 5.50 & 0.67 & 6.20 & 9.38 & 1.87 & 0.00 & 0.02 & 99.69 \\
\hline D-CORE & 4.68 & 7.51 & 63.60 & 5.36 & 0.70 & 5.81 & 9.50 & 1.66 & 0.00 & 0.00 & 98.81 \\
\hline D-CORE2 & 4.46 & 7.57 & 64.37 & 5.47 & 0.67 & 6.24 & 9.30 & 1.78 & 0.04 & 0.04 & 99.93 \\
\hline D-CORE2 & 4.81 & 7.72 & 63.75 & 5.36 & 0.69 & 5.78 & 9.97 & 1.71 & 0.00 & 0.00 & 99.78 \\
\hline D-CORE2 & 4.70 & 7.47 & 64.43 & 5.37 & 0.70 & 5.76 & 9.91 & 1.79 & 0.00 & 0.02 & 100.15 \\
\hline D-CORE2 & 4.80 & 7.52 & 63.93 & 5.25 & 0.73 & 5.56 & 10.06 & 1.70 & 0.04 & 0.02 & 99.61 \\
\hline D-CORE2 & 4.47 & 7.96 & 64.07 & 5.48 & 0.68 & 6.13 & 9.60 & 1.81 & 0.03 & 0.00 & 100.22 \\
\hline D-CORE (avg) & 4,62 & 7.67 & 63.93 & 5.41 & 0.69 & 5.91 & 9.59 & 1.78 & 0.00 & 0.00 & 99.61 \\
\hline D-INTER2 & 6.13 & 2.69 & 66.04 & 3.74 & 1.68 & 0.67 & 18.15 & 0.49 & 0.02 & 0.00 & 99.61 \\
\hline D-INTER2 & 6.18 & 2.61 & 65.12 & 3.71 & 1.64 & 0.61 & 18.20 & 0.51 & 0.07 & 0.00 & 98.65 \\
\hline D-INTER2 & 6.18 & 2.69 & 66.80 & 3.70 & 1.65 & 0.70 & 18.09 & 0.53 & 0.07 & 0.00 & 100.40 \\
\hline D-INTER2 & 6.03 & 2.82 & 66.49 & 3.84 & 1.66 & 0.81 & 18.08 & 0.53 & 0.00 & 0.02 & 100.25 \\
\hline D-INTER2 & 6.16 & 2.90 & 65.93 & 3.83 & 1.69 & 0.73 & 18.05 & 0.51 & 0.00 & 0.03 & 99.92 \\
\hline D-INTER1 & 6.08 & 2.61 & 66.18 & 3.78 & 1.70 & 0.58 & 18.28 & 0.51 & 0.00 & 0.04 & 99.76 \\
\hline D-INTER1 & 5.42 & 5.73 & 64.57 & 4.50 & 1.31 & 2.50 & 14.79 & 1.32 & 0.02 & 0.05 & 100.20 \\
\hline D-INTER1 & 5.45 & 5.67 & 64.31 & 4.46 & 1.33 & 2.30 & 15.04 & 1.36 & 0.00 & 0.00 & 99.92 \\
\hline D-INTER1 & 5.56 & 5.11 & 64.25 & 4.29 & 1.41 & 2.13 & 15.63 & 1.18 & 0.04 & 0.00 & 99.59 \\
\hline D-INTER1 & 6.23 & 2.66 & 66.32 & 3.67 & 1.63 & 0.63 & 17.80 & 0.52 & 0.03 & 0.00 & 99.50 \\
\hline D-INTER (avg) & 5.94 & 3.55 & 65.60 & 3.95 & 1.57 & 1.16 & 17.21 & 0.75 & 0.00 & 0.00 & 99.78 \\
\hline E-CORE1 & 4.75 & 7.03 & 61.62 & 5.42 & 0.71 & 3.71 & 9.81 & 1.52 & 5.08 & 0.00 & 99.64 \\
\hline E-CORE1 & 4.36 & 7.94 & 60.16 & 5.67 & 0.65 & 4.32 & 8.85 & 1.68 & 5.63 & 0.02 & 99.28 \\
\hline E-CORE1 & 4.58 & 7.50 & 61.43 & 5.54 & 0.67 & 3.99 & 9.22 & 1.55 & 5.43 & 0.00 & 99.91 \\
\hline E-CORE1 & 4.43 & 7.58 & 61.33 & 5.60 & 0.65 & 4,19 & 8.90 & 1.64 & 5.55 & 0.02 & 99.88 \\
\hline E-CORE1 & 4.59 & 7.84 & 60.86 & 5.64 & 0.69 & 3.93 & 9.25 & 1.65 & 5.20 & 0.00 & 99.64 \\
\hline E-CORE2 & 4.41 & 7.95 & 60.53 & 5.72 & 0.68 & 4.12 & 9.08 & 1.69 & 5.62 & 0.02 & 99.82 \\
\hline E-CORE2 & 4.23 & 8.10 & 60.08 & 5.74 & 0.68 & 3.88 & 9.10 & 1.78 & 5.09 & 0.01 & 98.68 \\
\hline E-CORE2 & 4.67 & 7.21 & 61.72 & 5.55 & 0.70 & 3.95 & 9.47 & 1.69 & 5.24 & 0.01 & 100.22 \\
\hline E-CORE2 & 4.62 & 7.30 & 61.51 & 5.47 & 0.69 & 3.96 & 9.27 & 1.48 & 5.33 & 0.01 & 99.65 \\
\hline E-CORE2 & 4.77 & 7.68 & 60.89 & 5.48 & 0.78 & 3.60 & 10.29 & 1.67 & 4.91 & 0.00 & 100.06 \\
\hline$E-C O R E$ (avg) & 4.54 & 7.61 & 61.01 & 5.58 & 0.69 & 3.97 & 9.32 & 1.64 & 5.31 & 0.00 & 99.68 \\
\hline E-INTER1 & 6.22 & 3.12 & 65.37 & 4.07 & 1.44 & 0.76 & 16.66 & 0.57 & 1.56 & 0.01 & 99.77 \\
\hline E-INTER1 & 6.20 & 3.17 & 64.93 & 4.25 & 1.37 & 0.90 & 16.70 & 0.57 & 1.80 & 0.01 & 99.89 \\
\hline E-INTER1 & 6.31 & 2.75 & 65.83 & 4.02 & 1.48 & 0.79 & 17.02 & 0.52 & 1.41 & 0.02 & 100.14 \\
\hline E-INTERT & 6.20 & 2.79 & 64.97 & 4.01 & 1.54 & 0.63 & 17.47 & 0.60 & 1.58 & 0.05 & 99.83 \\
\hline E-INTER 1 & 6.17 & 2.67 & 65.17 & 4.04 & 1.63 & 0.42 & 17.70 & 0.47 & 1.33 & 0.05 & 99.64 \\
\hline E-INTER2 & 6.32 & 2.53 & 65.36 & 3.94 & 1.54 & 0.58 & 17.78 & 0.43 & 1.28 & 0.05 & 99.79 \\
\hline E-INTER2 & 6.35 & 2.67 & 65.45 & 3.96 & 1.46 & 0.57 & 17.38 & 0.41 & 1.37 & 0.00 & 99.61 \\
\hline E-INTER2 & 6.37 & 2.69 & 65.02 & 3.94 & 1.47 & 0.59 & 17.31 & 0.49 & 1.62 & 0.00 & 99.50 \\
\hline E-INTER2 & 6.34 & 2.78 & 66.38 & 3.93 & 1.46 & 0.60 & 17.19 & 0.46 & 1.37 & 0.01 & 100.52 \\
\hline E-INTER2 & 6.27 & 3.00 & 65.41 & 4.01 & 1.50 & 0.78 & 17.30 & 0.57 & 1.65 & 0.00 & 100.48 \\
\hline E-INTER (avg) & 6.28 & 2.82 & 65.39 & 4.02 & 1.49 & 0.66 & 17.25 & 0.51 & 1.50 & 0.00 & 99.92 \\
\hline F-CORE1 & 4.50 & 7.95 & 59.88 & 5.34 & 0.69 & 4.70 & 8.66 & 1.79 & 1.38 & 3.87 & 98.76 \\
\hline F-CORE 1 & 4.33 & 7.93 & 60.30 & 5.35 & 0.68 & 4.51 & 8.56 & 1.78 & 1.53 & 3.97 & 98.93 \\
\hline F-CORE1 & 4.33 & 7.98 & 59.93 & 5.39 & 0.65 & 4.70 & 8.31 & 1.78 & 1.56 & 3.90 & 98.51 \\
\hline E-CORE1 & 4.34 & 7.92 & 59.61 & 5.33 & 0.71 & 4.51 & 8.60 & 1.82 & 1.50 & 3.92 & 98.26 \\
\hline E-CORE1 & 4.37 & 8.16 & 59.54 & 5.29 & 0.75 & 4.54 & 8.69 & 1.90 & 1.53 & 3.95 & 98.72 \\
\hline F-CORE2 & 4.34 & 8.17 & 58.04 & 5.38 & 0.67 & 4,81 & 8.21 & 2.00 & 1.59 & 3.91 & 97.09 \\
\hline F-CORE2 & 4.38 & 8.05 & 59.17 & 5.31 & 0.69 & 4,59 & 8.46 & 1.82 & 1.51 & 3.98 & 97.94 \\
\hline F-CORE2 & 4.35 & 8.04 & 59.25 & 5.24 & 0.71 & 4.34 & 8.57 & 1.84 & 1.51 & 3.91 & 97.76 \\
\hline F-CORE2 & 4.56 & 8.05 & 60.17 & 5.38 & 0.70 & 4.52 & 8.48 & 1.82 & 1.62 & 3.80 & 99.09 \\
\hline F-CORE2 & 4.50 & 8.41 & 58.98 & 5.31 & 0.74 & 4.75 & 8.67 & 1.95 & 1.51 & 3.92 & 98.74 \\
\hline F-CORE (avg) & 4.40 & 8.06 & 59.49 & 5.33 & 0.70 & 4.60 & 8.52 & 1.85 & 1.52 & 3.91 & 98.38 \\
\hline F.INTER1 & 5.12 & 6.23 & 59.62 & 4.47 & 1.28 & 2.12 & 13.61 & 1.59 & 0.85 & 3.86 & 98.75 \\
\hline F-INTER 1 & 5.19 & 5.99 & 60.59 & 4.45 & 1.29 & 2.12 & 13.97 & 1.52 & 0.79 & 3.88 & 99.80 \\
\hline F-INTER 1 & 5.17 & 6.06 & 60.10 & 4.38 & 1.29 & 1.98 & 13.91 & 1.58 & 0.83 & 3.78 & 99.07 \\
\hline F-INTER1 & 5.02 & 6.57 & 59.60 & 4.80 & 1.25 & 2.18 & 12.85 & 1.61 & 0.75 & 3.98 & 98.61 \\
\hline F-INTER 1 & 5.44 & 6.17 & 60.35 & 4.46 & 1.27 & 2.12 & 13.66 & 1.62 & 0.82 & 3.79 & 99.40 \\
\hline F-INTER2 & 4.98 & 6.62 & 60.35 & 4.54 & 1.24 & 2.25 & 13.11 & 1.70 & 0.89 & 3.83 & 99.52 \\
\hline F-INTER2 & 5.14 & 6.12 & 60.38 & 4.39 & 1.26 & 2.16 & 13.63 & 1.50 & 0.78 & 3.79 & 99.15 \\
\hline F-INTER2 & 5.11 & 5.95 & 60.43 & 4.35 & 1.27 & 2.00 & 13.87 & 1.51 & 0.80 & 3.80 & 99.08 \\
\hline F-INTER2 & 5.09 & 6.00 & 60.70 & 4.36 & 1.28 & 2.10 & 13.67 & 1.59 & 0.80 & 3.76 & 99.33 \\
\hline F-INTER2 & 5.38 & 5.31 & 61.59 & 4.16 & 1.35 & 1.71 & 14.42 & 1.32 & 0.83 & 3.54 & 99.60 \\
\hline F-INTER (avg) & 5.13 & 6.10 & 60.37 & 4.44 & 1.28 & 2.07 & 13.67 & 1.55 & 0.81 & 3.80 & 99.23 \\
\hline
\end{tabular}

Table 13: EPMA point-scan results for as-cast Alloys D-F (wt.\%). 


\begin{tabular}{|c|c|c|c|c|c|c|c|c|c|c|}
\hline Alloy-Region & $\mathrm{Ni}$ & $\mathrm{Cr}$ & $\mathrm{Co}$ & Mo & W & $\mathrm{Ta}$ & $\mathrm{Re}$ & $\mathrm{Al}$ & $\mathrm{Ti}$ & $\mathrm{Ru}$ \\
\hline A-core & 64.83 & 7.62 & 5.24 & 1.66 & 3.47 & 9.95 & 1.24 & 4.68 & 0.75 & 0.00 \\
\hline A-interdendritic & 64.99 & 5.41 & 4.40 & 1.27 & 1.52 & 14.14 & 0.63 & 5.49 & 1.27 & 0.00 \\
\hline B-core & 64.09 & 7.72 & 5.38 & 1.71 & 2.38 & 9.73 & 2.79 & 4.73 & 0.72 & 0.00 \\
\hline B-interdendritic & 64.64 & 3.96 & 4.05 & 0.86 & 0.41 & 16.85 & 0.73 & 5.98 & 1.54 & 0.00 \\
\hline C-core & 63.34 & 7.90 & 5.33 & 1.75 & 1.46 & 10.07 & 4.20 & 4.59 & 0.75 & 0.00 \\
\hline C-interdendritic & 64.64 & 3.75 & 3.98 & 0.81 & 0.37 & 16.77 & 1.05 & 5.94 & 1.50 & 0.00 \\
\hline D-core & 63.93 & 7.67 & 5.41 & 1.78 & 0.00 & 9.59 & 5.91 & 4.62 & 0.69 & 0.00 \\
\hline D-interdendritic & 65.60 & 3.55 & 3.95 & 0.75 & 0.00 & 17.21 & 1.16 & 5.94 & 1.57 & 0.00 \\
\hline E-core & 61.01 & 7.61 & 5.58 & 1.64 & 5.31 & 9.32 & 3.97 & 4.54 & 0.69 & 0.00 \\
\hline E-interdendritic & 65.39 & 2.82 & 4.02 & 0.51 & 1.50 & 17.25 & 0.66 & 6.28 & 1.49 & 0.00 \\
\hline F-core & 59.49 & 8.06 & 5.33 & 1.85 & 1.52 & 8.52 & 4.60 & 4.40 & 0.70 & 3.91 \\
\hline F-interdendritic & 60.37 & 6.10 & 4.44 & 1.55 & 0.81 & 13.67 & 2.07 & 5.13 & 1.28 & 3.80 \\
\hline \multicolumn{11}{|l|}{ Segregation k' } \\
\hline Alloy A & 1.00 & 1.41 & 1.19 & 1.30 & 2.29 & 0.70 & 1.99 & 0.85 & 0.59 & $\mathrm{n} / \mathrm{a}$ \\
\hline Alloy B & 0.99 & 1.95 & 1.33 & 1.98 & 5.75 & 0.58 & 3.83 & 0.79 & 0.47 & $\mathrm{n} / \mathrm{a}$ \\
\hline Alloy C & 0.98 & 2.11 & 1.34 & 2.17 & 3.96 & 0.60 & 4.00 & 0.77 & 0.50 & $\mathrm{n} / \mathrm{a}$ \\
\hline Alloy D & 0.97 & 2.16 & 1.37 & 2.39 & $\mathrm{n} / \mathrm{a}$ & 0.56 & 5.07 & 0.78 & 0.44 & $\mathrm{n} / \mathrm{a}$ \\
\hline Alloy $\mathrm{E}$ & 0.93 & 2.70 & 1.39 & 3.22 & 3.55 & 0.54 & 5.99 & 0.72 & 0.46 & $\mathrm{n} / \mathrm{a}$ \\
\hline Alloy $\mathrm{F}$ & 0.99 & 1.32 & 1.20 & 1.19 & 1.87 & 0.62 & 2.22 & 0.86 & 0.55 & 1.03 \\
\hline $\min k^{\prime}$ & 0.93 & 1.32 & 1.19 & 1.19 & 1.87 & 0.54 & 1.99 & 0.72 & 0.44 & 1.03 \\
\hline $\max \mathrm{k}^{\prime}$ & 1.00 & 2.70 & 1.39 & 3.22 & 5.75 & 0.70 & 5.99 & 0.86 & 0.59 & 1.03 \\
\hline
\end{tabular}

Table 14: Average point-scan compositions (wt.\%) for dendrite core and interdendritic $\gamma-\gamma^{\prime}$ with corresponding $k^{\prime}$ coefficients.

\begin{tabular}{lccccc}
\hline designation & rate $\left({ }^{\circ} \mathbf{C} / \mathbf{m i n}\right)$ & $\mathrm{T}_{\mathbf{0}}$ & $\mathrm{T}_{\mathbf{1}}$ & $\mathrm{T}_{\mathbf{S}}$ & $\mathrm{T}_{\mathrm{L}}$ \\
\hline \hline Alloy $\mathrm{A}$ & 5.0 & 1186.3 & 1295.8 & 1307.7 & 1336.0 \\
& 10.0 & 1187.7 & 1296.2 & 1307.2 & 1339.3 \\
& 20.0 & 1192.7 & $\mathrm{n} / \mathrm{a}$ & 1316.5 & 1349.3 \\
\hline Alloy B & 5.0 & 1174.8 & 1314.6 & 1314.9 & 1347.3 \\
& 10.0 & 1177.1 & 1316.0 & 1314.0 & 1350.9 \\
& 20.0 & 1181.0 & 1318.0 & 1323.8 & 1361.1 \\
\hline Alloy C & 5.0 & 1188.9 & 1303.9 & 1312.3 & 1345.8 \\
& 10.0 & 1189.4 & 1305.1 & 1312.4 & 1349.0 \\
& 20.0 & 1193.6 & 1312.0 & 1318.0 & 1357.4 \\
\hline Alloy D & 5.0 & 1185.6 & 1313.8 & 1315.7 & 1349.4 \\
& 10.0 & 1185.6 & 1314.5 & 1317.2 & 1352.5 \\
& 20.0 & 1192.0 & 1319.2 & 1322.3 & 1362.4 \\
\hline Alloy $\mathrm{E}$ & 5.0 & 1174.8 & 1308.9 & 1306.3 & 1342.9 \\
& 10.0 & 1176.4 & 1309.9 & 1306.0 & 1346.2 \\
& 20.0 & 1182.2 & 1316.6 & 1312.2 & 1355.6 \\
\hline Alloy F & 5.0 & 1182.2 & 1293.2 & 1311.7 & 1346.7 \\
& 10.0 & 1183.5 & 1294.7 & 1314.3 & 1351.1 \\
& 20.0 & 1187.4 & 1297.3 & 1317.0 & 1359.3 \\
\hline
\end{tabular}

Table 15: Endothermic transformation temperatures $\left({ }^{\circ} \mathrm{C}\right)$ upon heating. 


\begin{tabular}{lcccccc}
\hline designation & $\mathrm{T}_{\mathbf{0}}$ & $\mathrm{T}_{\mathbf{1}}$ & $\mathrm{T}_{\mathbf{S}}$ & $\mathrm{T}_{\mathrm{L}}$ & $\mathrm{T}_{\mathrm{L}} \mathrm{T}_{\mathrm{S}}{ }^{*}$ & rank \\
\hline \hline Alloy A & 1184 & 1295 & 1303 & 1331 & 28 & 1 \\
Alloy B & 1173 & 1314 & 1310 & 1342 & 32 & 2 \\
Alloy C & 1187 & 1301 & 1310 & 1342 & 32 & 2 \\
Alloy D & 1182 & 1312 & 1312 & 1345 & 33 & 3 \\
Alloy E & 1172 & 1306 & 1303 & 1338 & 35 & 4 \\
Alloy F & 1180 & 1292 & 1310 & 1343 & 32 & 2
\end{tabular}

Table 16: Transformation temperatures $\left({ }^{\circ} \mathrm{C}\right)$ determined using heating rate extrapolation.

\begin{tabular}{lccccccc}
\hline designation & rate $\left({ }^{\circ} \mathbf{C} / \mathbf{m i n}\right)$ & $\mathrm{T}_{0}$ & $\mathrm{~T}_{\mathbf{1}}$ & $\mathrm{T}_{\mathbf{2}}$ & $\mathrm{T}_{3}$ & $\mathrm{~T}_{\mathbf{S}}$ & $\mathbf{T}_{\mathrm{L}}$ \\
\hline \hline Alloy $\mathrm{A}$ & 5.0 & 1156.2 & 1240.9 & 1278.5 & 1309.6 & 1322.2 & 1335.3 \\
& 10.0 & 1158.3 & 1239.0 & 1276.9 & 1301.3 & 1300.1 & 1329.7 \\
& 20.0 & 1157.0 & 1244.0 & 1280.8 & 1305.0 & 1303.8 & 1331.4 \\
\hline Alloy B & 5.0 & $\mathrm{n} / \mathrm{a}$ & 1242.9 & 1284.5 & 1293.7 & 1328.4 & 1342.8 \\
& 10.0 & $\mathrm{n} / \mathrm{a}$ & 1246.8 & 1280.0 & 1293.7 & 1302.1 & 1337.4 \\
& 20.0 & $\mathrm{n} / \mathrm{a}$ & 1247.1 & 1286.0 & 1296.5 & 1306.8 & 1338.4 \\
\hline Alloy C & 5.0 & 1154.5 & 1235.1 & 1284.5 & 1305.6 & 1333.8 & 1341.9 \\
& 10.0 & 1148.2 & 1233.2 & 1285.5 & 1299.6 & 1307.8 & 1338.5 \\
& 20.0 & 1153.0 & 1242.0 & $\mathrm{n} / \mathrm{a}$ & 1287.2 & 1312.9 & 1331.4 \\
\hline Alloy D & 5.0 & $\mathrm{n} / \mathrm{a}$ & 1242.5 & $\mathrm{n} / \mathrm{a}$ & 1293.0 & 1330.1 & 1340.9 \\
& 10.0 & $\mathrm{n} / \mathrm{a}$ & 1241.1 & $\mathrm{n} / \mathrm{a}$ & 1293.4 & 1302.1 & 1338.6 \\
& 20.0 & $\mathrm{n} / \mathrm{a}$ & 1239.4 & $\mathrm{n} / \mathrm{a}$ & 1294.9 & 1314.8 & 1339.0 \\
\hline Alloy $\mathrm{E}$ & 5.0 & 1163.0 & 1239.9 & $\mathrm{n} / \mathrm{a}$ & 1287.6 & 1329.6 & 1339.1 \\
& 10.0 & 1157.2 & 1242.3 & $\mathrm{n} / \mathrm{a}$ & 1287.4 & 1307.6 & 1335.4 \\
& 20.0 & 1162.0 & 1245.9 & $\mathrm{n} / \mathrm{a}$ & 1290.2 & 1313.8 & 1332.3 \\
\hline Alloy F & 5.0 & 1157.1 & 1223.6 & 1284.7 & 1311.8 & 1330.8 & 1342.6 \\
& 10.0 & 1152.8 & 1223.5 & 1285.6 & 1306.7 & 1316.9 & 1340.8 \\
& 20.0 & 1155.9 & 1227.9 & 1286.0 & 1304.7 & 1316.5 & 1336.8 \\
\hline
\end{tabular}

Table 17: Exothermic transformation temperatures $\left({ }^{\circ} \mathrm{C}\right)$ upon cooling. 


\begin{tabular}{|c|c|c|c|c|}
\hline & Black Coun & White Count & $\%$ dendritic & $\%$ entectic \\
\hline \multicolumn{5}{|l|}{ Alloy $-\mathrm{A}$} \\
\hline$\# 1$ & 237606 & 17594 & 93.11 & 6.89 \\
\hline$\# 2$ & 239193 & 16007 & 93.73 & 6.27 \\
\hline$\# 3$ & 234804 & 20396 & 92.01 & 7.99 \\
\hline$\# 4$ & 238342 & 16858 & 93.39 & 6.61 \\
\hline$\# 5$ & 240328 & 14872 & 94.17 & 5.83 \\
\hline \#6 & 241874 & 13326 & 94.78 & 5.22 \\
\hline Mean & 238691 & 16509 & 93.53 & 6.47 \\
\hline Stal. Dev. & 2428 & 2428 & 0.95 & 0.95 \\
\hline \multicolumn{5}{|l|}{ Alloy-B } \\
\hline$\# 1$ & 248677 & 19283 & 92.8 & 7.2 \\
\hline$\# 2$ & 253130 & 14830 & 94.47 & 5.53 \\
\hline$\# 3$ & 249378 & 18582 & 93.07 & 6.93 \\
\hline$\# 4$ & 250079 & 17881 & 93.33 & 6.67 \\
\hline 115 & 244764 & 23196 & 91.34 & 8.66 \\
\hline$\# 6$ & 249378 & 18582 & 93.07 & 6.93 \\
\hline Mean & 249234 & 18726 & 93.01 & 6.99 \\
\hline Std. Dev. & 2692 & 2692 & 1.01 & 1.01 \\
\hline \multicolumn{5}{|l|}{$\mathrm{Alloy}-\mathrm{C}$} \\
\hline$\# 1$ & 239955 & 32045 & 88.22 & 11.78 \\
\hline \#2 & 231092 & 40908 & 84.96 & 15.04 \\
\hline \#3 & 235491 & 36509 & 86.58 & 13.42 \\
\hline$\# 4$ & 233667 & 38333 & 85.91 & 14.09 \\
\hline$\# 5$ & 237811 & 34189 & 87.43 & 12.57 \\
\hline \#6 & 236677 & 35323 & 87.01 & 12.99 \\
\hline Mean & 235782 & 36218 & 86.69 & 13.32 \\
\hline Stol. Dev. & 3127 & 3127 & 1.15 & 1.15 \\
\hline \multicolumn{5}{|l|}{ Alloy-DD } \\
\hline$\# 1$ & 229183 & 45377 & 83.47 & 16.53 \\
\hline$\# 2$ & 242394 & 32166 & 88.28 & 11.72 \\
\hline$\# 3$ & 232091 & 42469 & 84.53 & 15.47 \\
\hline$\# 4$ & 225988 & 48572 & 82.31 & 17.69 \\
\hline$\# 5$ & 222777 & 51783 & 81.14 & 18.86 \\
\hline$\# 6$ & 229183 & 45377 & 83.47 & 16.53 \\
\hline Mean & 230269 & 44291 & 83.87 & 16.13 \\
\hline Sed. Dev. & 6740 & 6740 & 2.45 & 2.45 \\
\hline \multicolumn{5}{|l|}{ Alloy-E } \\
\hline$\# 1$ & 232727 & 33319 & 87.48 & 12.52 \\
\hline$\# 2$ & 222895 & 43151 & 83.78 & 16.22 \\
\hline$\# 3$ & 233892 & 32154 & 87.91 & 12.09 \\
\hline$\# 4$ & 218088 & 47958 & 81.97 & 18.03 \\
\hline$\# 5$ & 223186 & 42860 & 83.89 & 16.11 \\
\hline$\# 6$ & 207738 & 58308 & 78.08 & 21.92 \\
\hline$\# 7$ & 227735 & 38311 & 85.6 & 14.4 \\
\hline$\# 8$ & 223186 & 42860 & 83.89 & 16.11 \\
\hline$\# 9$ & 214241 & 51805 & 80.53 & 19.47 \\
\hline$\# 10$ & 200181 & 65865 & 77.24 & 22.76 \\
\hline Mean & 222013 & 44033 & 82.84 & 17.16 \\
\hline Std. Dev. & 11458 & 11458 & 2.01 & 2.01 \\
\hline \multicolumn{5}{|l|}{ Alloy $F$} \\
\hline$\# 1$ & 250164 & 27162 & 90.21 & 9.79 \\
\hline \#2 & 242566 & 34760 & 87.47 & 12.53 \\
\hline$\# 3$ & 246685 & 30641 & 88.95 & 11.05 \\
\hline$\# 4$ & 239404 & 37922 & 86.33 & 13.67 \\
\hline$\# 5$ & 247063 & 30263 & 89.09 & 10.91 \\
\hline$\# 6$ & 250164 & 27162 & 90.21 & 9.79 \\
\hline$\# 7$ & 244903 & 32423 & 88.31 & 11.69 \\
\hline$\$ 8$ & 246685 & 30641 & 88.95 & 11.05 \\
\hline Mean & 245854 & 31372 & 88.69 & 11.31 \\
\hline Std. Dev. & 3650 & 3650 & 1.32 & 1.32 \\
\hline
\end{tabular}

Table 18: Eutectic fraction image analysis results for Alloys $A$ through $F$. 


\begin{tabular}{cccccc}
\hline as-cast & \% eutectic & Std. Dev. & wt.\% Re & wt.\% W & wt.\% Ru \\
\hline \hline Alloy-A & 6.47 & 0.95 & 1 & 3 & 0 \\
Alloy-B & 6.99 & 1.01 & 2 & 2 & 0 \\
Alloy-C & 13.32 & 1.15 & 3 & 1 & 0 \\
Alloy-D & 16.13 & 2.45 & 4 & 0 & 0 \\
Alloy-E & 17.16 & 2.01 & 3 & 4 & 0 \\
Alloy-F & 11.31 & 1.32 & 3 & 1 & 4
\end{tabular}

Table 19: Eutectic fraction as a function of nominal Re, W, and Ru composition.

\begin{tabular}{lccccc}
\hline as-cast & \% eutectic & wt.\% Cr & wt.\% Al & wt.\% Ti & wt.\% Ta \\
\hline \hline Alloy-A & 6.47 & 5.41 & 5.49 & 1.27 & 14.14 \\
Alloy-B & 6.99 & 3.96 & 5.98 & 1.54 & 16.85 \\
Alloy-C & 13.32 & 3.75 & 5.94 & 1.50 & 16.77 \\
Alloy-D & 16.13 & 3.55 & 5.94 & 1.57 & 17.21 \\
Alloy-E & 17.16 & 2.82 & 6.28 & 1.49 & 17.25 \\
Alloy-F & 11.31 & 6.10 & 5.13 & 1.28 & 13.67
\end{tabular}

Table 20: Eutectic fraction as a function of localized interdendritic eutectic phase composition.

note: the DSC values from extraploated $0^{\circ} \mathrm{C} /$ min heating rate

\begin{tabular}{cccccc} 
Tliquidus & FACT-RMC & RMC & NIST & SGTE & DSC \\
\hline \hline Alloy A & 1397 & 1399 & 1357 & 1378 & 1331 \\
Alloy B & 1394 & 1393 & 1354 & 1386 & 1342 \\
Alloy C & 1396 & 1395 & 1360 & 1403 & 1342 \\
Alloy D & 1393 & 1392 & 1362 & 1417 & 1345 \\
Alloy E & 1412 & 1412 & 1357 & 1401 & 1338 \\
Alloy F & 1403 & 1402 & $n / a$ & 1411 & 1343 \\
& & & & & \\
Tsolidus & FACT-RMC & RMC & NIST & SGTE & DSC \\
\hline \hline Alloy A & 1356 & 1356 & 1320 & 1327 & 1303 \\
Alloy B & 1351 & 1351 & 1314 & 1324 & 1310 \\
Alloy C & 1356 & 1356 & 1321 & 1333 & 1310 \\
Alloy D & 1356 & 1355 & 1322 & 1337 & 1312 \\
Alloy E & 1359 & 1359 & 1314 & 1328 & 1303 \\
Alloy F & 1354 & 1354 & $\mathrm{n} / \mathrm{a}$ & 1334 & 1310
\end{tabular}

Table 21: Transformation temperatures as predicted by all three thermodynamic models in comparison to measured DSC values. 
Composition of 1st solid phase to form

Alloy A $\quad 1397^{\circ} \mathrm{C} \quad 1398.8^{\circ} \mathrm{C} \quad 1357^{\circ} \mathrm{C} \quad 1378^{\circ} \mathrm{C}$

RMC-KJ RMC NIST SGTE

\begin{tabular}{|c|r|r|r|r|}
\hline Element & Wt \% & Wt \% & Wt \% & \multicolumn{1}{c|}{ Wt \% } \\
\hline $\mathrm{Ni}$ & 61.98 & 62.00 & 65.97 & 65.60 \\
\hline $\mathrm{Cr}$ & 7.97 & 7.98 & 7.51 & 7.66 \\
\hline $\mathrm{Al}$ & 3.77 & 3.78 & 3.98 & 4.30 \\
\hline $\mathrm{Co}$ & 5.00 & 5.01 & 5.69 & 4.74 \\
\hline $\mathrm{Mo}$ & 2.23 & 2.22 & 2.01 & 2.10 \\
\hline $\mathrm{Re}$ & 2.63 & 2.63 & 1.67 & 4.47 \\
\hline $\mathrm{Ta}$ & 8.05 & 8.06 & 8.56 & 6.80 \\
\hline $\mathrm{Ti}$ & 0.64 & 0.64 & 0.64 & 0.72 \\
\hline $\mathrm{W}$ & 7.66 & 7.67 & 3.97 & 3.61 \\
\hline
\end{tabular}

$\begin{array}{llll}99.93 & 100.00 & 100.00 & 100.00\end{array}$

Composition of 1 st solid phase to form

Alloy B $\quad 1394^{\circ} \mathrm{C} \quad 1393^{\circ} \mathrm{C} \quad 1354^{\circ} \mathrm{C} \quad 1386^{\circ} \mathrm{C}$

\begin{tabular}{|c|c|c|c|c|}
\hline & RMC-KJ & RMC & NIST & SGTE \\
\hline Element & $\mathrm{Wt} \%$ & Wt $\%$ & Wt \% & $\mathrm{Wt} \%$ \\
\hline$\overline{\mathrm{Ni}}$ & 60.83 & 60.86 & 65.20 & 62.78 \\
\hline$\overline{\mathrm{Cr}}$ & 7.96 & 7.97 & 7.57 & 7.68 \\
\hline Al & 3.82 & 3.83 & 4.11 & 4.18 \\
\hline Co & 5.20 & 5.21 & 5.94 & 5.03 \\
\hline Mo & 2.37 & 2.30 & 2.08 & 2.17 \\
\hline $\mathrm{Re}$ & 4.99 & 4.99 & 3.11 & 8.59 \\
\hline $\mathrm{Ta}$ & 8.46 & 8.47 & 8.57 & 6.40 \\
\hline $\mathrm{Ti}$ & 0.64 & 0.64 & 0.63 & 0.70 \\
\hline$W$ & 5.74 & 5.74 & 2.79 & 2.47 \\
\hline
\end{tabular}

$\begin{array}{llll}100.01 & 100.00 & 100.00 & 100.00\end{array}$

Composition of 1st solid phase to form

Alloy C $\quad 1396^{\circ} \mathrm{C} \quad 1395^{\circ} \mathrm{C} \quad 1360^{\circ} \mathrm{C} \quad 1403^{\circ} \mathrm{C}$

\begin{tabular}{|c|c|c|c|c|}
\hline & RMC-KJ & $\mathrm{RMC}$ & NIST & SGTE \\
\hline Element & $W t \%$ & $\mathrm{Wt} \%$ & Wt $\%$ & Wt $\%$ \\
\hline $\mathrm{Ni}$ & 61.14 & 61.17 & 65.36 & 60.97 \\
\hline $\mathrm{Cr}$ & 8.06 & 8.08 & 7.66 & 7.70 \\
\hline $\mathrm{Al}$ & 3.65 & 3.66 & 3.92 & 3.78 \\
\hline $\mathrm{Co}$ & 5.21 & 5.23 & 5.92 & 5.08 \\
\hline Mo & 2.34 & 2.26 & 2.06 & 2.13 \\
\hline $\operatorname{Re}$ & 7.15 & 7.15 & 4.62 & 12.53 \\
\hline $\mathrm{Ta}$ & 8.38 & 8.39 & 8.24 & 5.78 \\
\hline $\mathrm{Ti}$ & 0.61 & 0.61 & 0.58 & 0.63 \\
\hline$W$ & 3.46 & 3.46 & 1.65 & 1.41 \\
\hline & 100.00 & 100.00 & 100.00 & 100.00 \\
\hline
\end{tabular}

Composition of last liquid to solidify

Alloy A $\quad 1356^{\circ} \mathrm{C} \quad 1356^{\circ} \mathrm{C} \quad 1320^{\circ} \mathrm{C} \quad 1327^{\circ} \mathrm{C}$

RMC-KJ RMC NIST SGTE

\begin{tabular}{|r|r|r|r|r|}
\hline Element & Wt $\%$ & Wt $\%$ & Wt $\%$ & \multicolumn{1}{c|}{ Wt $\%$} \\
\hline $\mathrm{Ni}$ & 63.75 & 63.71 & 61.16 & 58.17 \\
\hline $\mathrm{Cr}$ & 6.56 & 6.55 & 7.51 & 7.13 \\
\hline $\mathrm{Al}$ & 5.79 & 5.78 & 5.59 & 4.50 \\
\hline $\mathrm{Co}$ & 4.85 & 4.85 & 4.46 & 5.83 \\
\hline $\mathrm{Mo}$ & 1.45 & 1.50 & 1.72 & 1.54 \\
\hline $\mathrm{Re}$ & 0.45 & 0.45 & 0.79 & 0.25 \\
\hline $\mathrm{Ta}$ & 14.70 & 14.68 & 15.18 & 19.12 \\
\hline $\mathrm{Ti}$ & 1.59 & 1.59 & 1.52 & 1.23 \\
\hline $\mathrm{W}$ & 0.89 & 0.89 & 2.08 & 2.23 \\
\hline
\end{tabular}

RMC

NIST

SGTE

Alloy A Alloy A Alloy A

$\mathrm{k}^{1} \quad \mathrm{k}^{\prime} \quad \mathrm{k}^{1}$

$0.973 \quad 1.079 \quad 1.128$

$\begin{array}{lll}1.218 & 0.999 & 1.074\end{array}$

$\begin{array}{lll}0.653 & 0.712 & 0.955\end{array}$

$\begin{array}{lll}1.034 & 1.278 & 0.814\end{array}$

$\begin{array}{lll}1.483 & 1.166 & 1.363\end{array}$

$5.842 \quad 2.113 \quad 17.986$

$\begin{array}{lll}0.549 & 0.564 & 0.356\end{array}$

$\begin{array}{lll}0.406 & 0.422 & 0.586\end{array}$

$8.610 \quad 1.912 \quad 1.623$

$\begin{array}{llll}100.03 & 100.00 & 100.00 & 100.00\end{array}$

Composition of last liquid to solidify

Alloy B $\quad 1351^{\circ} \mathrm{C} \quad 1351^{\circ} \mathrm{C} \quad 1314^{\circ} \mathrm{C} \quad 1324^{\circ} \mathrm{C}$

\begin{tabular}{|c|c|c|c|c|}
\hline & RMC-KJ & RMC & NIST & SGTE \\
\hline Element & $\mathrm{Wt} \%$ & $\mathrm{Wt} \%$ & Wt $\%$ & $\mathrm{Wt} \%$ \\
\hline$\overline{\mathrm{Ni}}$ & 63.39 & 63.37 & 60.57 & 57.86 \\
\hline $\mathrm{Cr}$ & 6.50 & 6.49 & 7.40 & 7.02 \\
\hline $\mathrm{Al}$ & 6.15 & 6.14 & 5.86 & 4.75 \\
\hline $\mathrm{Co}$ & 5.00 & 4.99 & 4.56 & 5.97 \\
\hline Mo & 1.48 & 1.54 & 1.76 & 1.57 \\
\hline $\mathrm{Re}$ & 0.84 & 0.84 & 1.50 & 0.46 \\
\hline $\mathrm{Ta}$ & 14.52 & 14.44 & 15.38 & 19.61 \\
\hline$\overline{\mathrm{Ti}}$ & 1.61 & 1.61 & 1.53 & 1.23 \\
\hline $\bar{W}$ & 0.59 & 0.59 & 1.43 & 1.54 \\
\hline
\end{tabular}

$\mathrm{RMC}$

NIST

SGTE

Alloy B Alloy B Alloy B

$k^{\prime} \quad k^{\prime}$

$0.960 \quad 1.076$

$1.228-1.022$

$0.623 \quad 0.701$

1.303

1.179

2.070

0.557

0.410

1.955

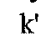

1.085

1.095

0.881

0.842

1.380

18.687

0.327

0.569

1.601

$\begin{array}{lll}100.08 & 100.00 \quad 100.00 \quad 100.00\end{array}$

Composition of last liquid to solidify

Alloy C $\quad 1356^{\circ} \mathrm{C} \quad 1356^{\circ} \mathrm{C} \quad 1321^{\circ} \mathrm{C} \quad 1333^{\circ} \mathrm{C}$

\begin{tabular}{|c|c|c|c|c|}
\hline & $\mathrm{RMC}-\mathrm{KJ}$ & RMC & NIST & SGTE \\
\hline Element & $\mathrm{Wt} \%$ & $\mathrm{Wt} \%$ & Wt $\%$ & $\mathrm{Wt} \%$ \\
\hline $\mathrm{Ni}$ & 63.87 & 63.85 & 61.16 & 58.90 \\
\hline $\mathrm{Cr}$ & 6.54 & 6.53 & 7.39 & 7.00 \\
\hline Al & 5.92 & 5.91 & 5.65 & 4.62 \\
\hline $\mathrm{Co}$ & 4.92 & 4.92 & 4.48 & 5.83 \\
\hline Mo & 1.46 & 1.51 & 1.73 & 1.54 \\
\hline $\mathrm{Re}$ & 1.24 & 1.24 & 2.15 & 0.67 \\
\hline $\mathrm{Ta}$ & 14.19 & 14.18 & 15.15 & 19.36 \\
\hline$T \hat{T i}$ & 1.52 & 1.52 & 1.48 & 1.19 \\
\hline$W$ & 0.34 & 0.34 & 0.82 & 0.88 \\
\hline
\end{tabular}

RMC NIST SGTE Alloy C Alloy C Alloy C

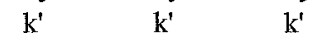

$0.958 \quad 1.069 \quad 1.035$

$0.619 \quad 0.695 \quad 0.816$

$1.063 \quad 1.321-0.871$

$1.496 \quad 1.196 \quad 1.379$

$\begin{array}{lll}5.755 & 2.152 & 18.589\end{array}$

$\begin{array}{lll}0.592 & 0.543 & 0.299\end{array}$

$\begin{array}{lll}10.135 & 2.016 \quad 1.603\end{array}$ $\begin{array}{lll}1.236 & 1.036 & 1.099\end{array}$

$\begin{array}{lll}0.397 & 0.391 & 0.532\end{array}$

Table 22: Composition predictions of the first solid and last liquid to solidify for Alloys A-C as determined by the RMC, NIST and SGTE models. 
Composition of 1st solid phase to form

Alloy D $\quad 1393^{\circ} \mathrm{C} \quad 1392.2^{\circ} \mathrm{C} \quad 1362^{\circ} \mathrm{C} \quad 1417^{\circ} \mathrm{C}$

\begin{tabular}{|c|r|r|r|r|}
\multicolumn{2}{r}{ RMC-KJ } & \multicolumn{1}{c}{ RMC } & \multicolumn{1}{c|}{ NIST } & \multicolumn{1}{c|}{ SGTE } \\
\hline Element & Wt $\%$ & Wt $\%$ & Wt $\%$ & Wt $\%$ \\
\hline $\mathrm{Ni}$ & 61.82 & 61.85 & 65.45 & 58.91 \\
\hline $\mathrm{Cr}$ & 8.26 & 8.28 & 7.76 & 7.71 \\
\hline $\mathrm{Al}$ & 3.62 & 3.63 & 3.88 & 3.49 \\
\hline $\mathrm{Co}$ & 5.26 & 5.27 & 5.92 & 5.13 \\
\hline $\mathrm{Mo}$ & 2.29 & 2.31 & 2.12 & 2.15 \\
\hline $\mathrm{Re}$ & 9.28 & 9.29 & 6.17 & 16.69 \\
\hline $\mathrm{Ta}$ & 8.74 & 8.75 & 8.12 & 5.30 \\
\hline $\mathrm{Ti}$ & 0.62 & 0.62 & 0.58 & 0.62 \\
\hline $\mathrm{W}$ & 0.00 & 0.00 & 0.00 & 0.00 \\
\hline & 9 & 100.00 & 100.00 & 100.00
\end{tabular}

Composition of 1st solid phase to form

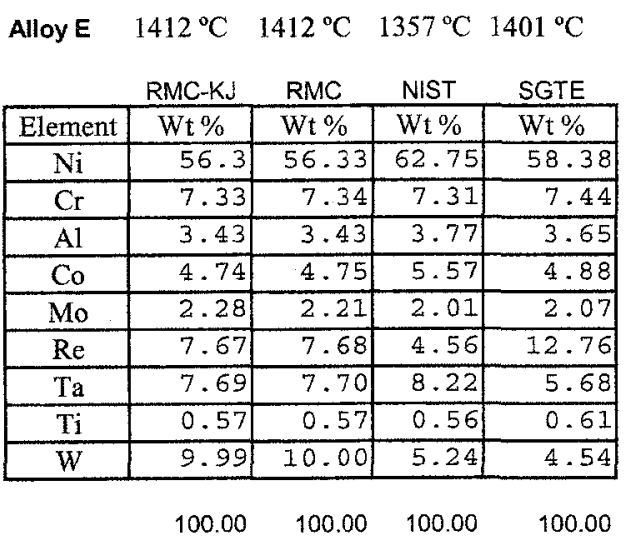

Composition of 1st solid phase to form

\begin{tabular}{|c|c|c|c|c|}
\hline \multirow{2}{*}{ Alloy F } & $1403^{\circ} \mathrm{C}$ & $1402{ }^{\circ} \mathrm{C}$ & & $411^{\circ} \mathrm{C}$ \\
\hline & $\mathrm{RMC}-\mathrm{KJ}$ & RMC & NIST & SGTE \\
\hline Element & Wt $\%$ & Wt $\%$ & $\mathrm{Wt} \%$ & $\mathrm{Wt} \%$ \\
\hline $\mathrm{Ni}$ & 56.39 & 56.42 & & 55.70 \\
\hline $\mathrm{Cr}$ & 7.93 & 7.94 & & 7.77 \\
\hline$\overline{\mathrm{Al}}$ & 3.4 & 3.41 & & 3.37 \\
\hline $\mathrm{Co}$ & 5.11 & 5.12 & & 5.34 \\
\hline Mo & 2.58 & 2.50 & & 2.27 \\
\hline $\operatorname{Re}$ & 7.3 & 7.31 & & 12.68 \\
\hline $\mathrm{Ta}$ & 7.33 & 7.35 & & 4.72 \\
\hline $\mathrm{Ti}$ & 0.62 & 0.62 & & 0.61 \\
\hline$W$ & 3.44 & 3.44 & & 1.34 \\
\hline $\mathrm{Ru}$ & 5.91 & 5.91 & & 6.19 \\
\hline
\end{tabular}

Composition of last liquid to solidify

\begin{tabular}{|c|c|c|c|c|c|c|c|}
\hline Alloy D & $\begin{array}{l}1356^{\circ} \mathrm{C} \\
\text { RMC-KJ }\end{array}$ & $\begin{array}{c}1355.4^{\circ} \mathrm{C} \\
\text { RMC }\end{array}$ & $1322^{\circ} \mathrm{C}$ & $337^{\circ} \mathrm{C}$ & $\begin{array}{c}\text { RMC } \\
\text { Alloy D }\end{array}$ & $\begin{array}{c}\text { NIST } \\
\text { Alloy D }\end{array}$ & $\begin{array}{c}\text { SGTE } \\
\text { Alloy D }\end{array}$ \\
\hline Element & Wt $\%$ & Wt \% & $\mathrm{Wt} \%$ & $\mathrm{Wt} \%$ & $k^{\prime}$ & $\mathrm{k}^{\prime}$ & $\mathrm{k}^{\prime}$ \\
\hline $\mathrm{Ni}$ & 64.16 & 64.14 & 61.49 & 59.63 & 0.964 & 1.064 & 0.988 \\
\hline $\mathrm{Cr}$ & 6.5 & 6.49 & 7.32 & 6.93 & 1.275 & 1.061 & 1.112 \\
\hline $\mathrm{Al}$ & 5.9 & 5.89 & 5.60 & 4.63 & 0.616 & 0.693 & 0.754 \\
\hline $\mathrm{Co}$ & 4.83 & 4.83 & 4.40 & 5.70 & 1.092 & 1.346 & 0.900 \\
\hline Mo & 1.48 & 1.54 & 1.75 & 1.56 & 1.507 & 1.213 & 1.381 \\
\hline $\mathrm{Re}$ & 1.66 & 1.66 & 2.82 & 0.89 & 5.607 & 2.188 & 18.759 \\
\hline $\mathrm{Ta}$ & 13.92 & 13.91 & 15.11 & 19.44 & 0.630 & 0.538 & 0.273 \\
\hline $\mathrm{Ti}$ & 1.55 & 1.55 & 1.53 & 1.22 & 0.401 & 0.380 & 0.505 \\
\hline
\end{tabular}

Composition of last liquid to solidify

Alloy E $\quad 1359^{\circ} \mathrm{C} \quad 1359^{\circ} \mathrm{C} \quad 1314^{\circ} \mathrm{C} \quad 1328^{\circ} \mathrm{C}$

\begin{tabular}{|c|c|c|c|c|}
\hline & RMC-KJ & RMC & NIST & SGTE \\
\hline Element & Wt $\%$ & $\mathrm{Wt} \%$ & $\mathrm{Wt} \%$ & Wt $\%$ \\
\hline $\mathrm{Ni}$ & 62.6 & 62.58 & 59.06 & 56.80 \\
\hline $\mathrm{Cr}$ & 6.66 & 6.65 & 7.46 & 7.07 \\
\hline $\mathrm{Al}$ & 6.04 & 6.03 & 5.79 & 4.72 \\
\hline $\mathrm{Co}$ & 4.92 & 4.91 & 4.46 & 5.74 \\
\hline Mo & 1.44 & 1.49 & 1.70 & 1.53 \\
\hline $\mathrm{Re}$ & 1.22 & 1.22 & 2.24 & 0.68 \\
\hline $\mathrm{Ta}$ & 14.44 & 14.43 & 14.97 & 19.22 \\
\hline $\mathrm{Ti}$ & 1.5 & 1.50 & 1.45 & 1.15 \\
\hline W & 1.19 & 1.19 & 2.87 & 3.10 \\
\hline
\end{tabular}

$\mathrm{RMC}$

Alloy $\mathrm{E}$ Alloy $\mathrm{E}$ Alloy $\mathrm{E}$

$\mathrm{k}^{\prime} \quad \mathrm{k}^{\prime} \quad \mathrm{k}^{\prime}$

$0.900 \quad 1.063 \quad 1.028$

$1.103 \quad 0.979 \cdot 1.051$

$0.569 \quad 0.651 \quad 0.775$

$0.966 \quad 1.251 \quad 0.850$

$1.483 \quad 1.181 \quad \uparrow .355$

$6.303 \quad 2.040 \quad 18.811$

$\begin{array}{lll}0.534 & 0.549 & 0.296\end{array}$

$0.379 \quad 0.385 \quad 0.529$

$\begin{array}{lll}8.382 & 1.828 & 1.463\end{array}$

Composition of last liquid to solidify

Alloy $\mathrm{F} \quad 1354^{\circ} \mathrm{C} \quad 1354^{\circ} \mathrm{C} \quad 1334^{\circ} \mathrm{C}$

\begin{tabular}{|c|c|c|c|c|}
\hline & RMC-KJ & $\mathrm{RMC}$ & NIST & SGTE \\
\hline Element & Wt $\%$ & $\mathrm{Wt} \%$ & Wt $\%$ & $\mathrm{Wt} \%$ \\
\hline $\mathrm{Ni}$ & 62.12 & 62.10 & & 57.49 \\
\hline $\mathrm{Cr}$ & 6.54 & 6.54 & & 6.90 \\
\hline $\mathrm{Al}$ & 6.28 & 6.28 & & 5.04 \\
\hline $\mathrm{Co}$ & 4.86 & 4.85 & & 5.41 \\
\hline $\mathrm{Mo}$ & 1.53 & 1.59 & & 1.65 \\
\hline$\overline{\mathrm{Re}}$ & 1.14 & 1.14 & & 0.62 \\
\hline $\mathrm{Ta}$ & 13.16 & 13.15 & & 18.43 \\
\hline $\mathrm{Ti}$ & 1.61 & 1.61 & & 1.27 \\
\hline$W$ & 0.32 & 0.32 & & 0.86 \\
\hline $\mathrm{Ru}$ & 2.43 & 2.43 & & 2.31 \\
\hline
\end{tabular}

$\begin{array}{ccc}\begin{array}{c}\text { RMC } \\ \text { Alloy F }\end{array} & \begin{array}{c}\text { NIST } \\ \text { Alloy F }\end{array} & \begin{array}{c}\text { SGTE } \\ \text { Alloy F } \\ \mathbf{k}^{\prime}\end{array} \\ 0.908 & 0.969 \\ 1.215 & 1.125 \\ 0.543 & 0.669 \\ 1.055 & 0.986 \\ 1.573 & 1.375 \\ 6.435 & 20.377 \\ 0.559 & 0.256 \\ 0.384 & 0.482 \\ 10.792 & 1.558 \\ 2.429 & 2.675\end{array}$

Table 23: Composition predictions of the first solid and last liquid to solidify for Alloys D-F as determined by the RMC, NIST and SGTE models. 
Figures 


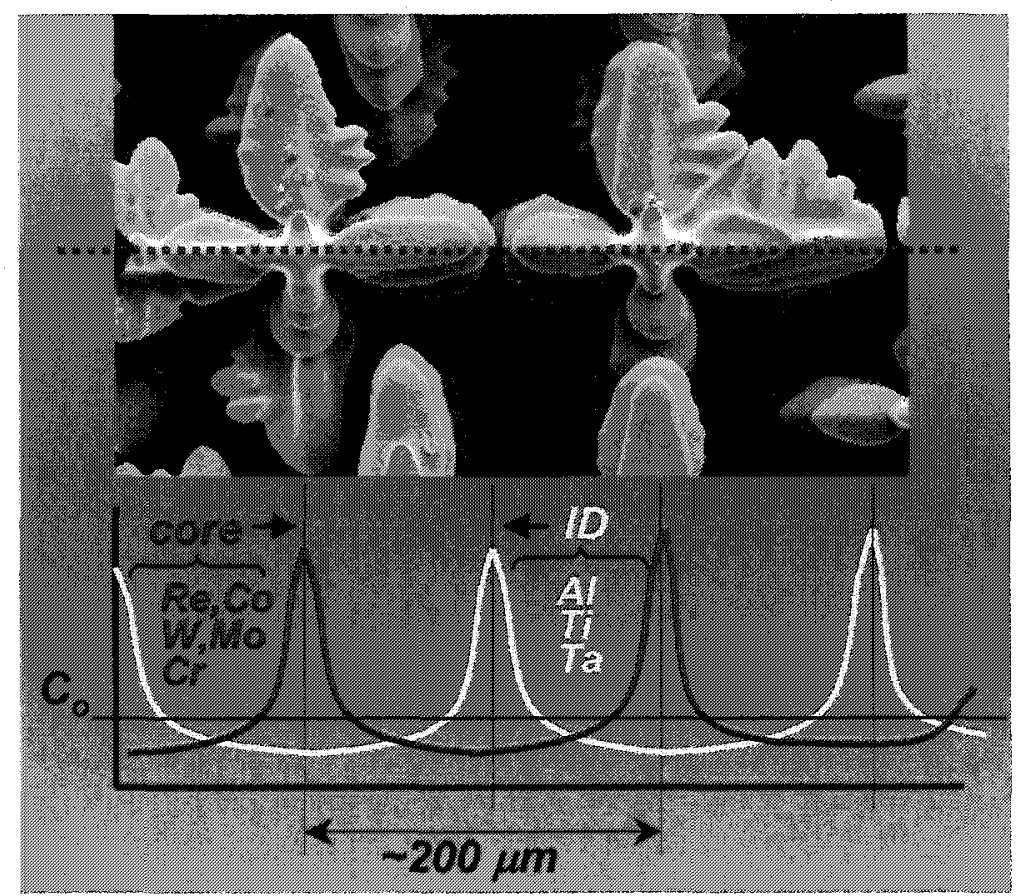

Figure 1: Representation of the microsegregation pattern typical in most as-cast SX superalloys illustrating preferential partitioning of specific refractory elements to the core and $\gamma^{\prime}$ elements to interdendritic (ID) regions.

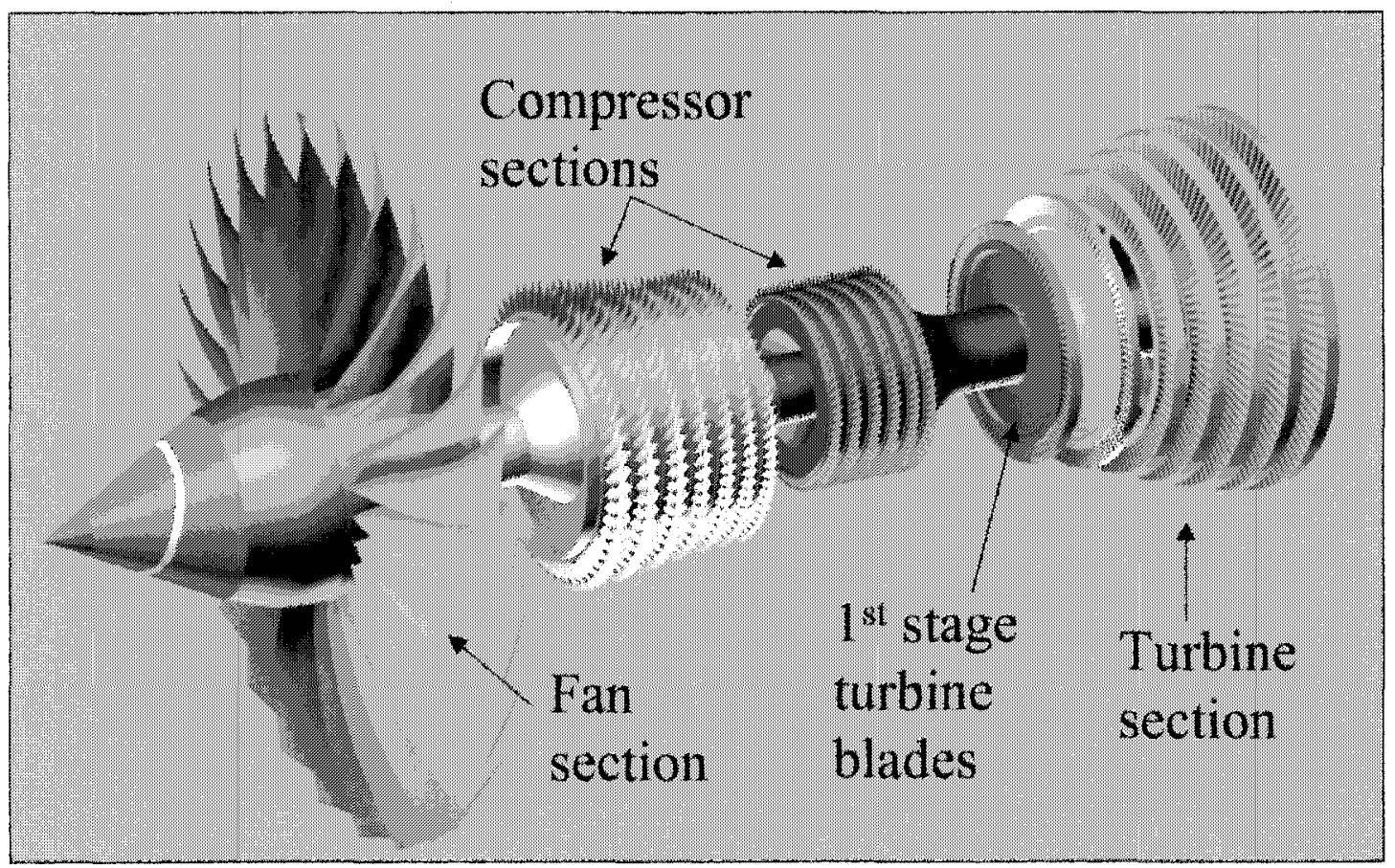

Figure 2: Schematic of the typical rotating components in a gas turbine engine (adapted from Cervenka) [15]. 


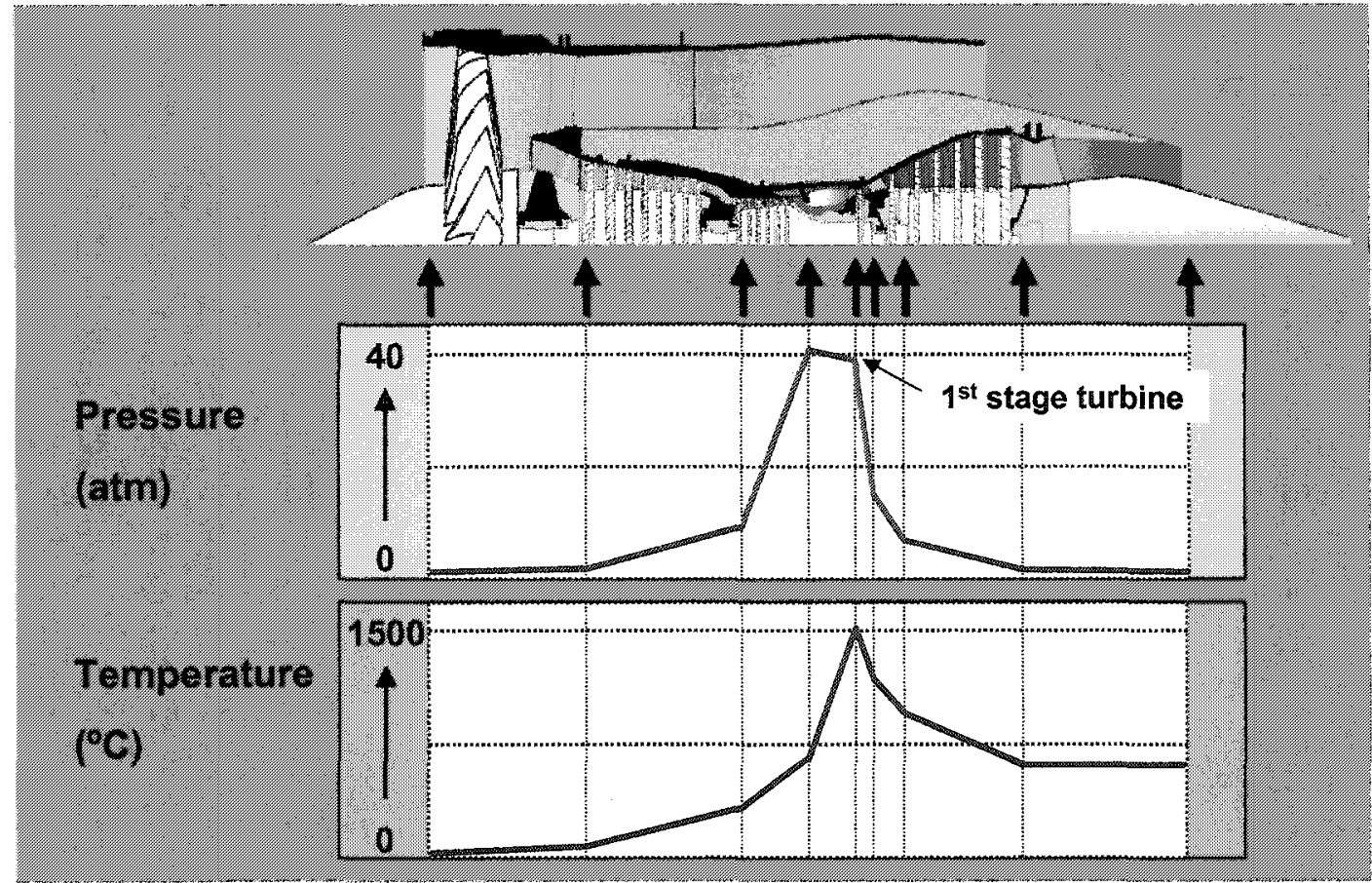

Figure 3: Cross-sectional map of jet engine illustrating the temperature and pressure profile from the compressor side to the turbine section [15].

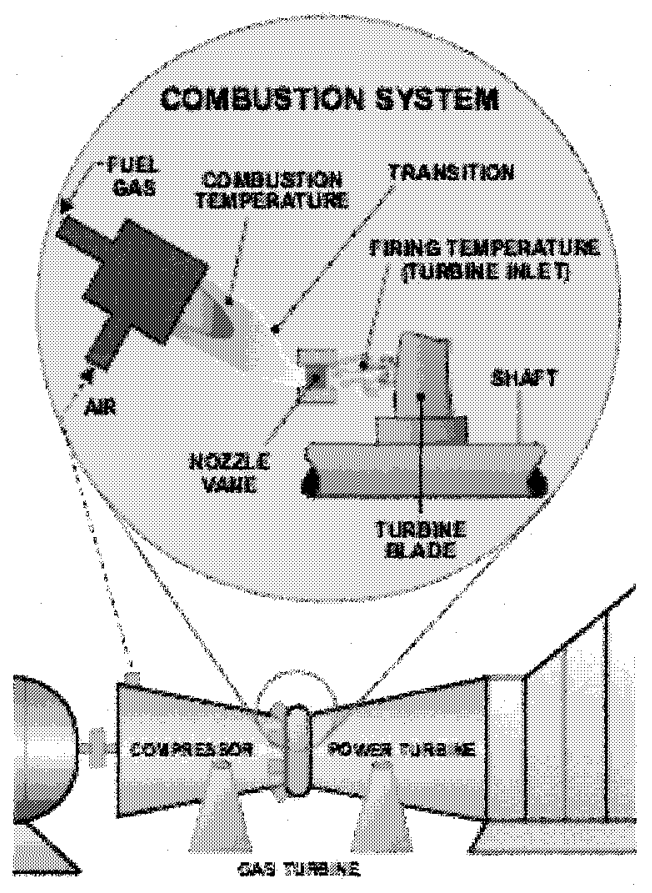

Figure 4: Schematic illustrating the proximity of the nozzle guide vane and $1^{\text {st }}$ stage blade section to the combustion flame [16]. 


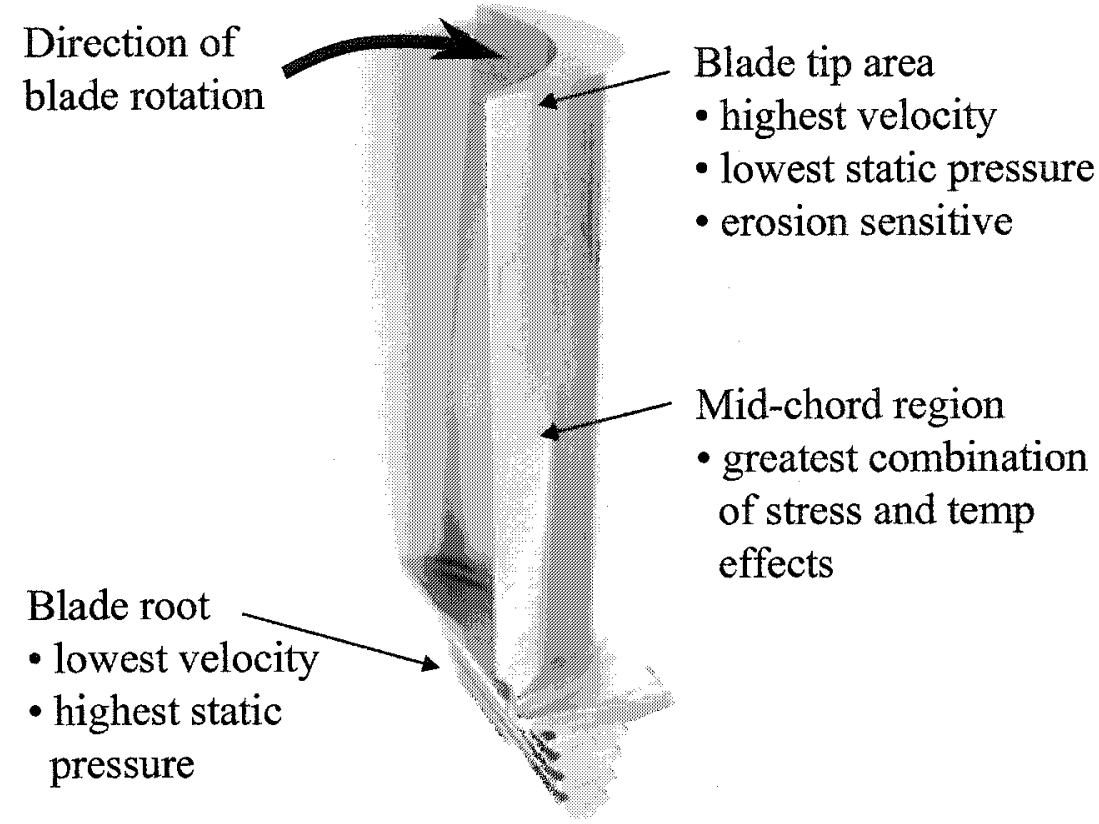

Figure 5: Typical gas turbine blade.

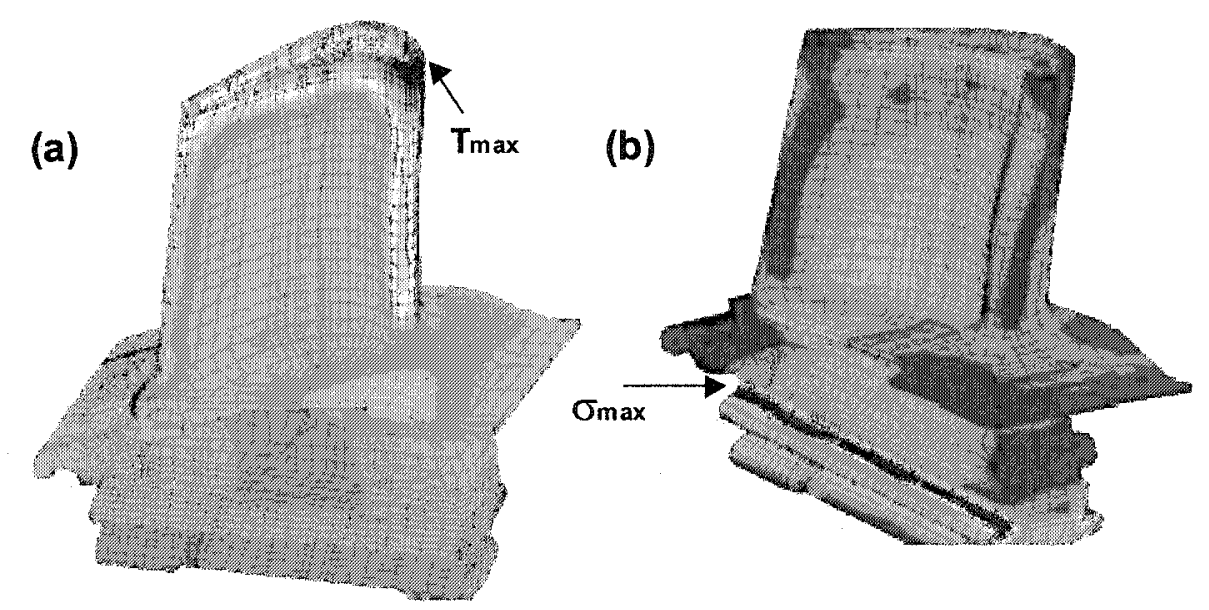

Figure 6: (a) Temperature and (b) stress profiles for a typical gas turbine blade [17]. 


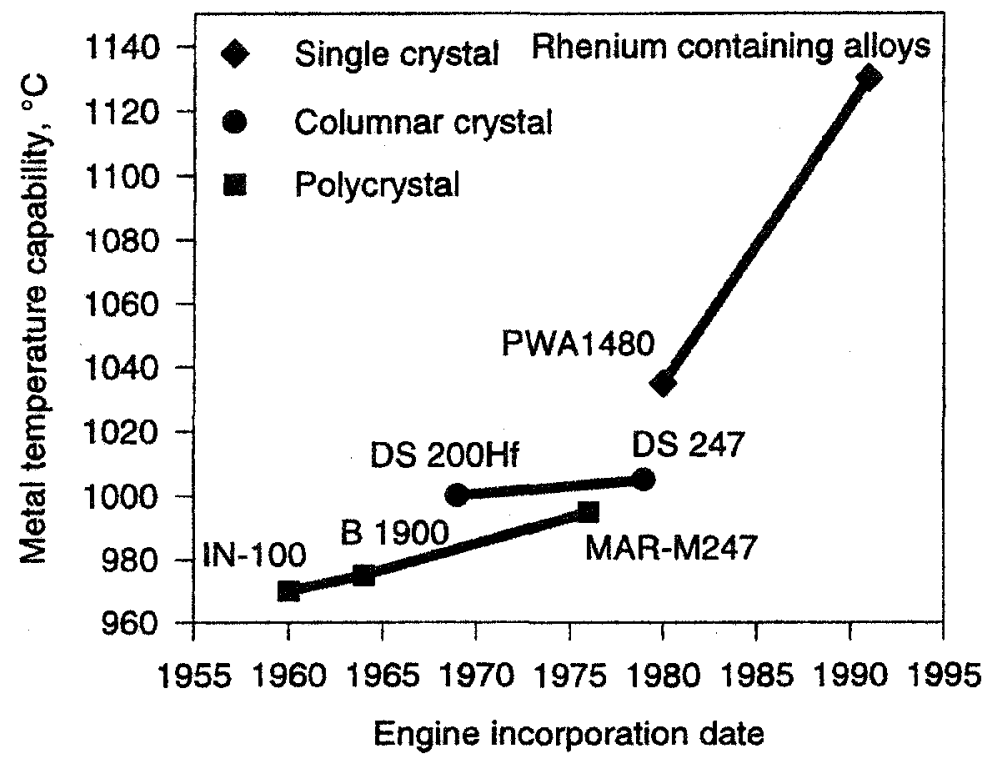

Figure 7: Temperature evolution of superalloy blade materials [25]. 


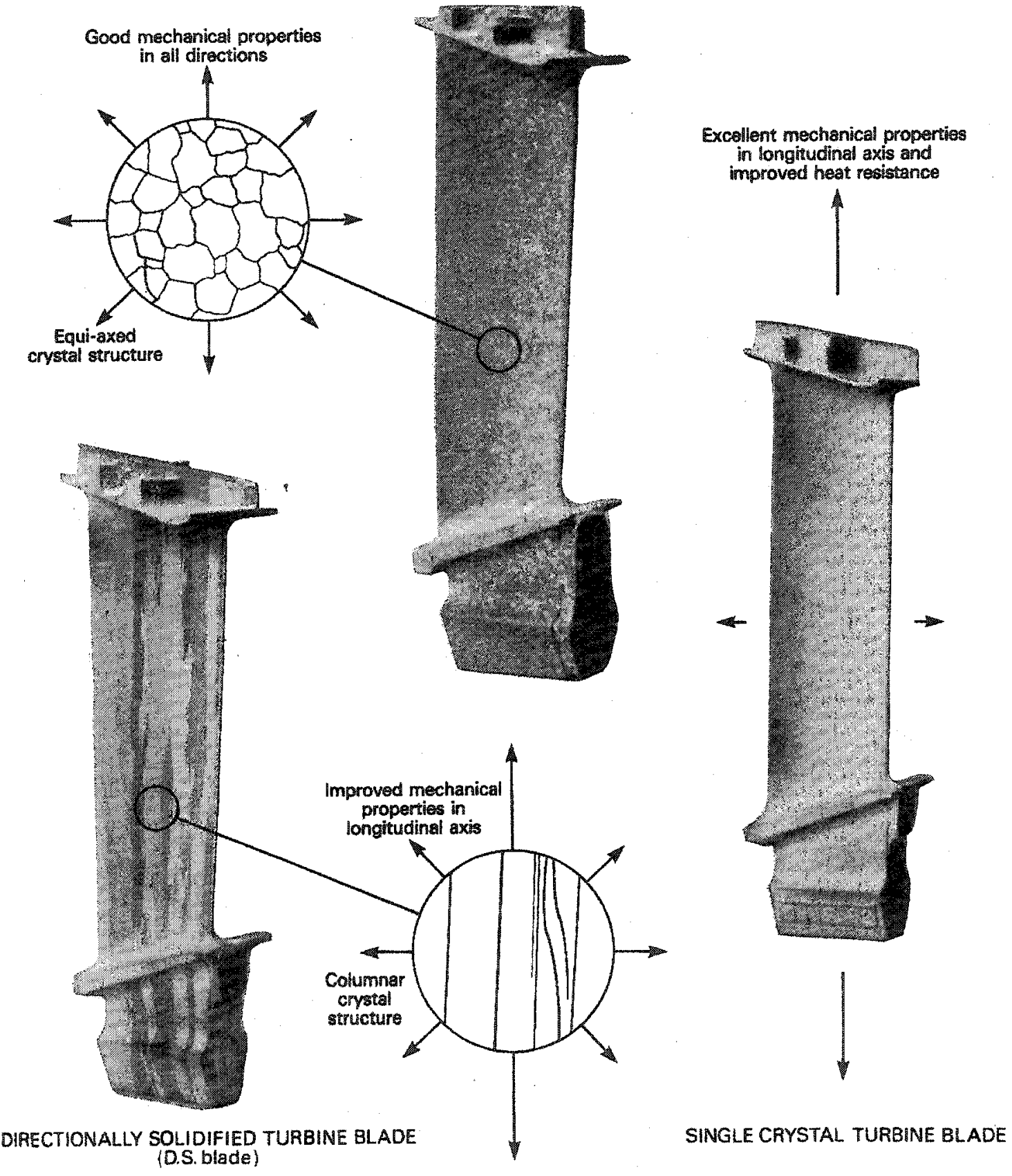

Figure 8: Evolution of superalloy blade microstructures [14]. 


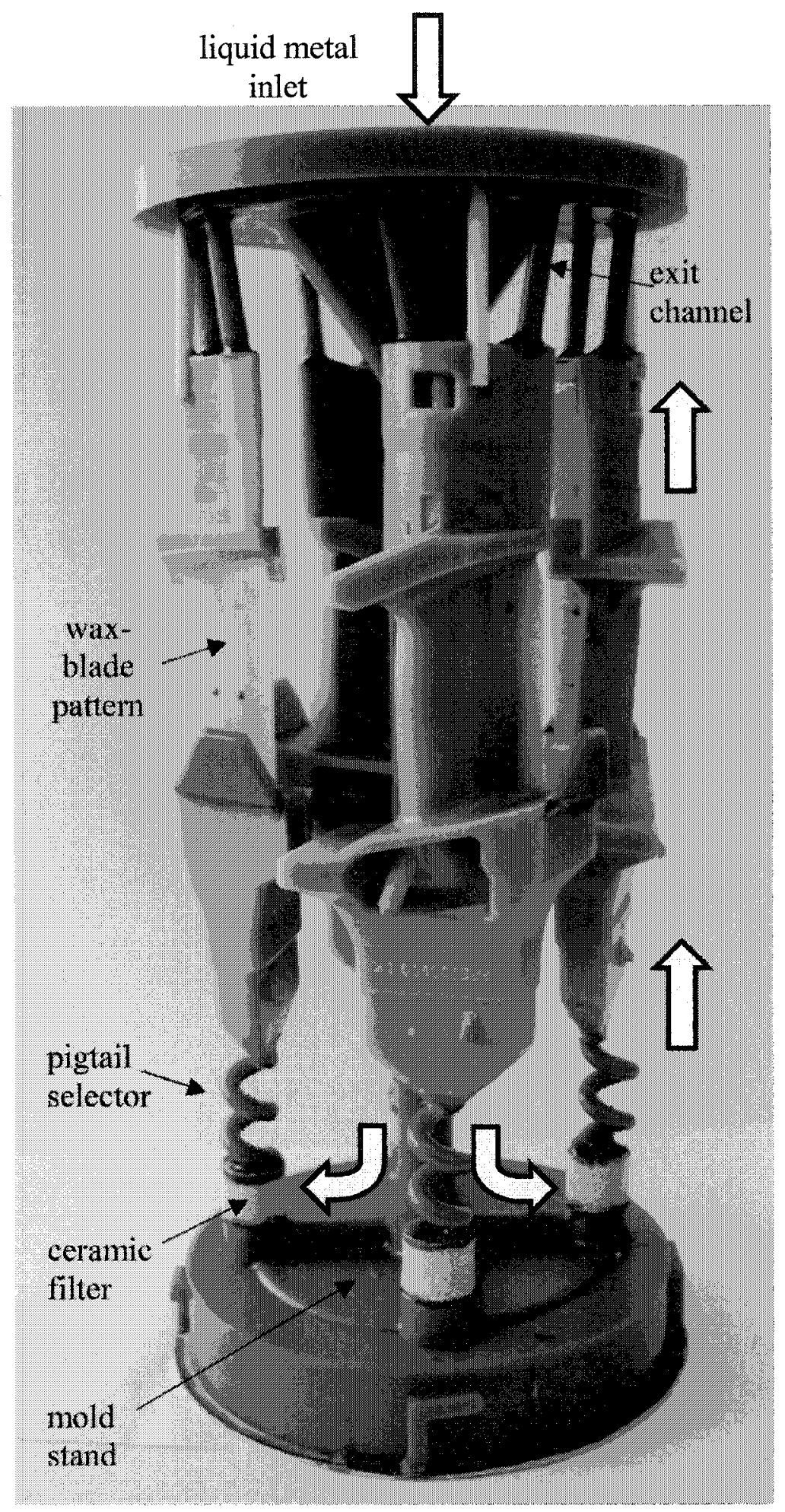

Figure 9: Disposable wax pattern used to cast four SX blades implementing a pigtail SX selector [35]. 

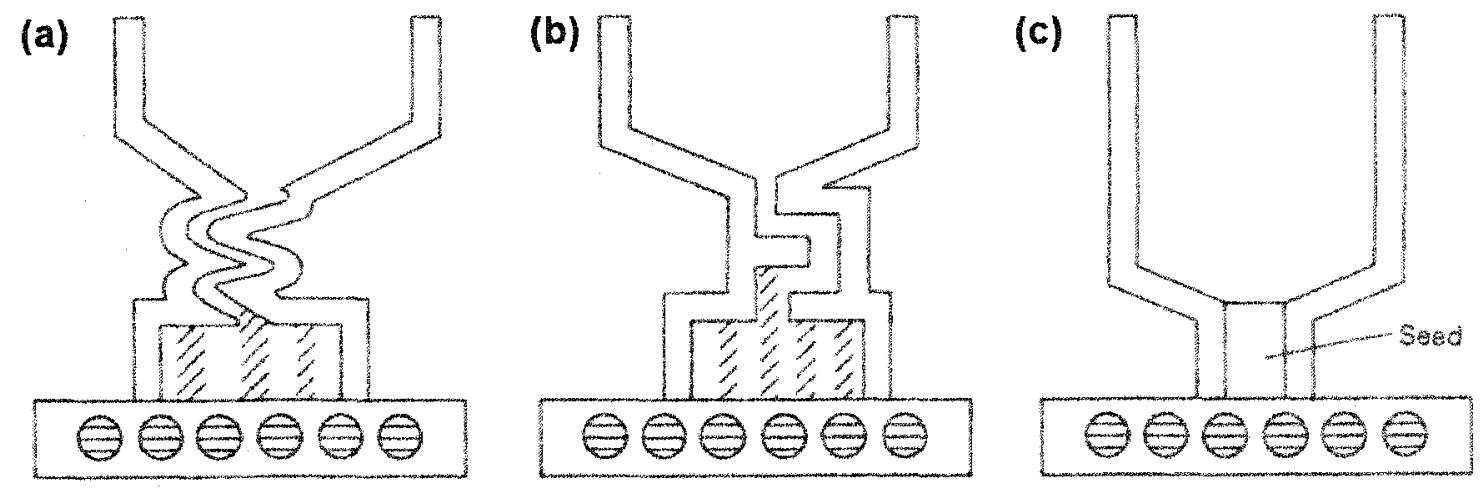

Figure 10: Alternative mold methods for producing SX blades, a) pigtail selector, b) two-turn selector, and c) seed crystal selector [33].

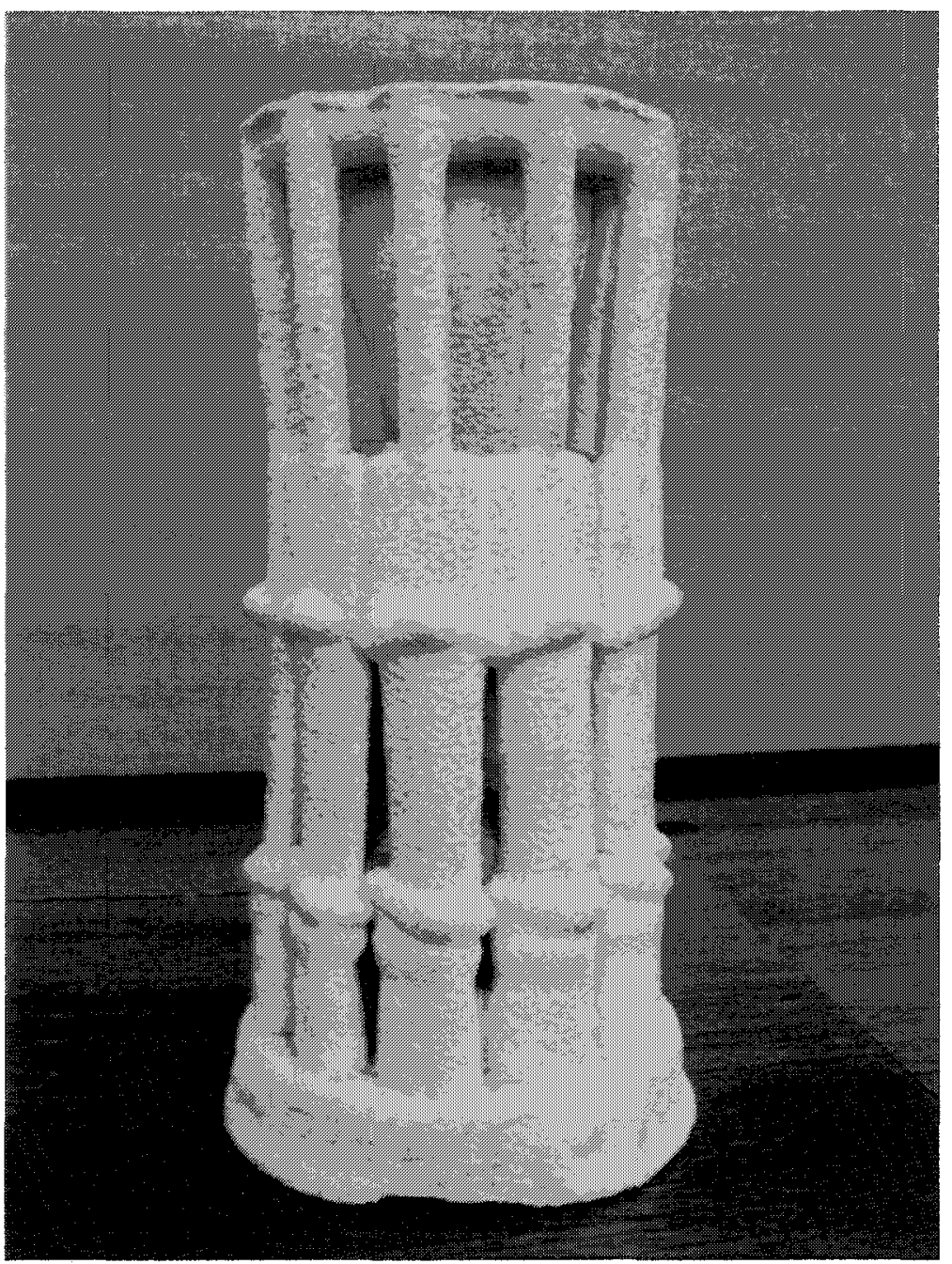

Figure 11: Ceramic mold used for SX blade casting [35]. 


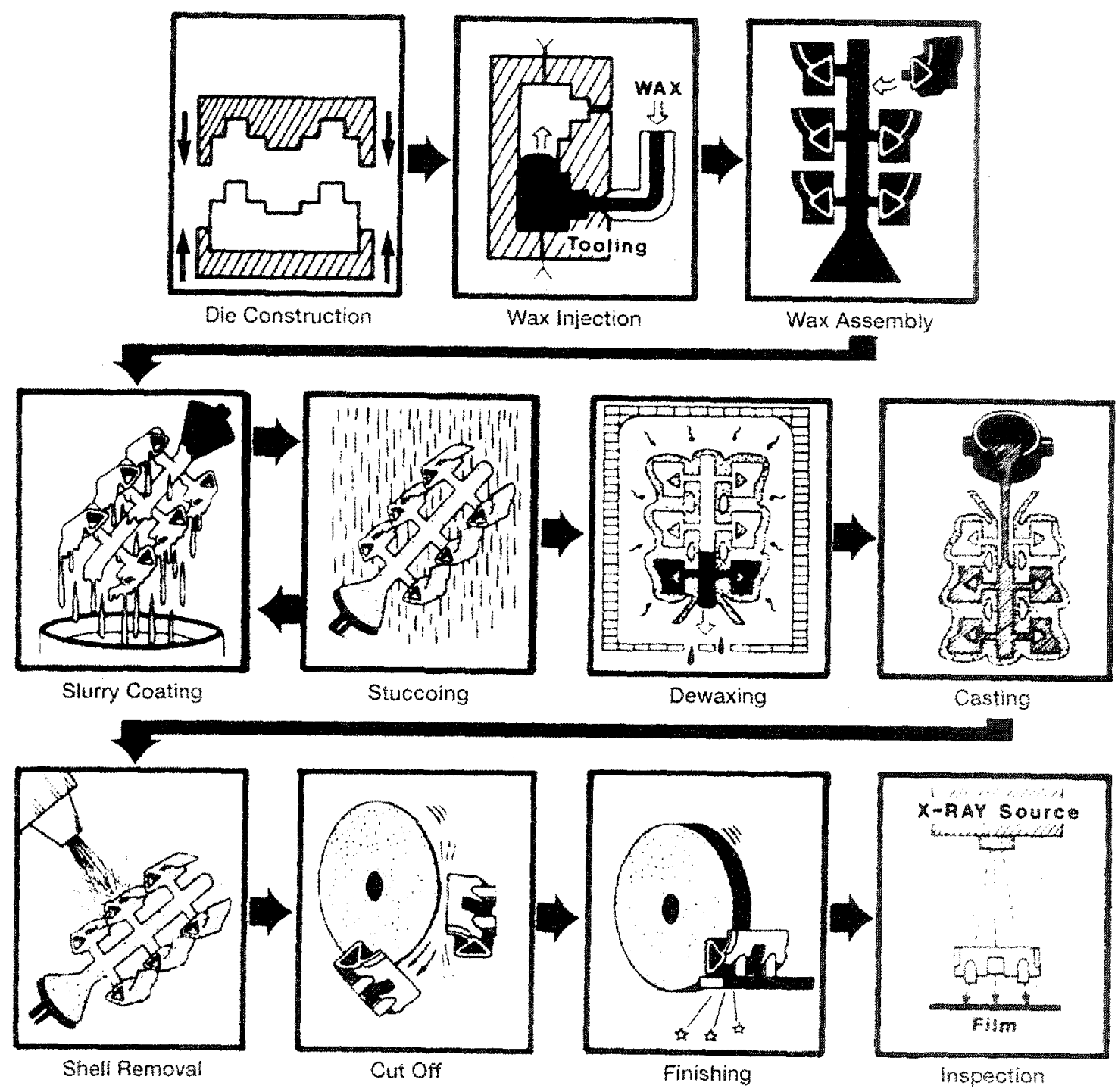

Figure 12: Schematic illustration of the investment casting process [33]. 


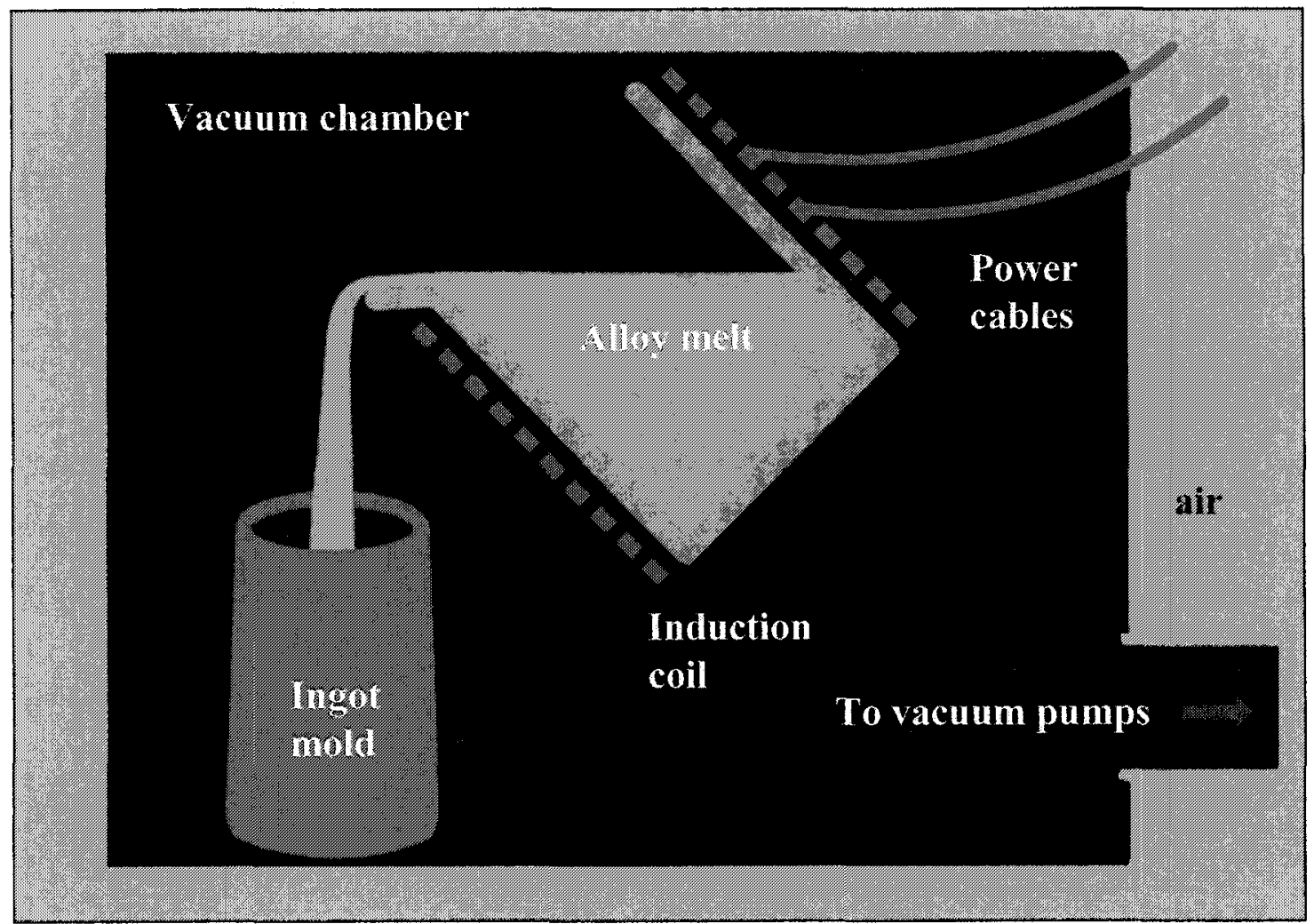

Figure 13: Schematic of VIM process used to produce clean superalloy master alloy (adapted from Schafrik) [24].

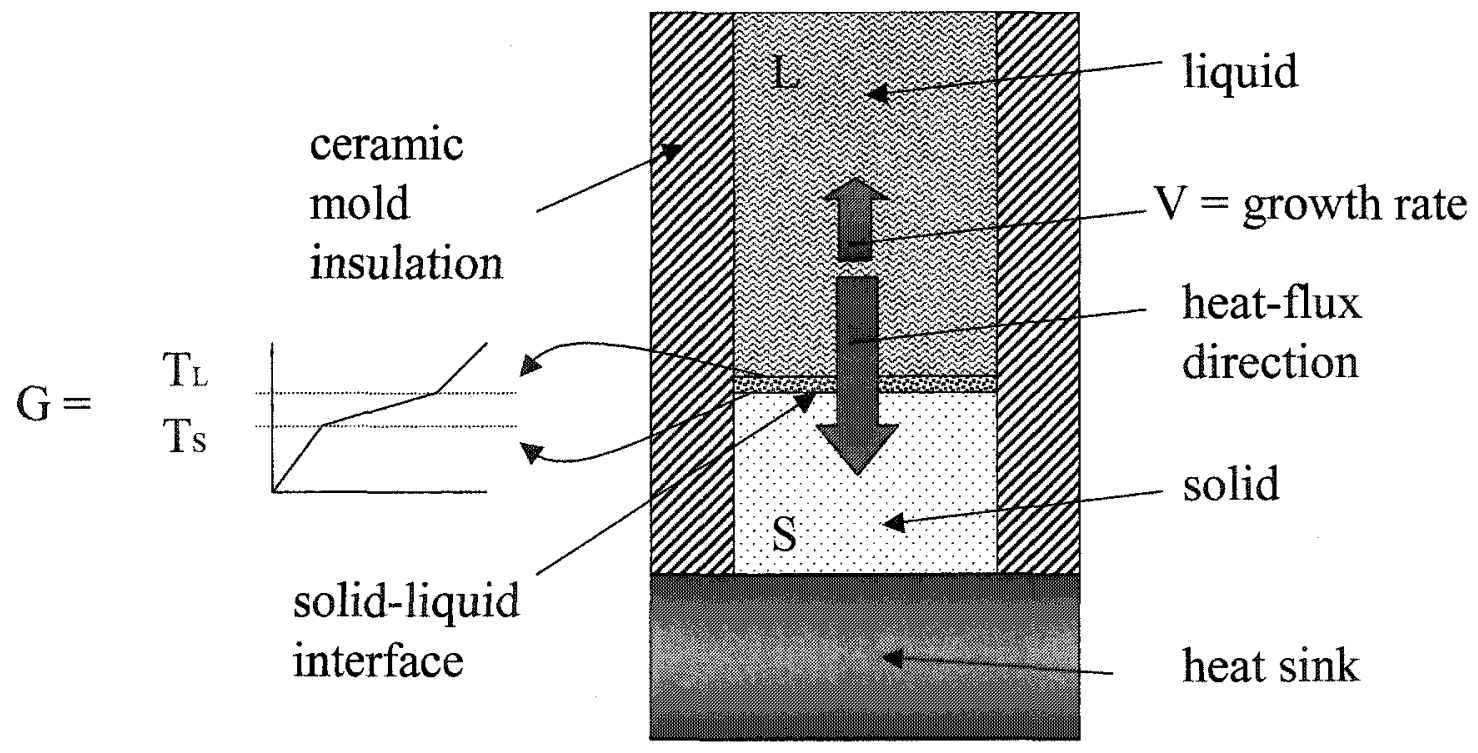

Figure 14: Schematic of simple DS casting process cooled by a heat sink from the bottom end. Growth direction opposes the direction of heat-flux. 


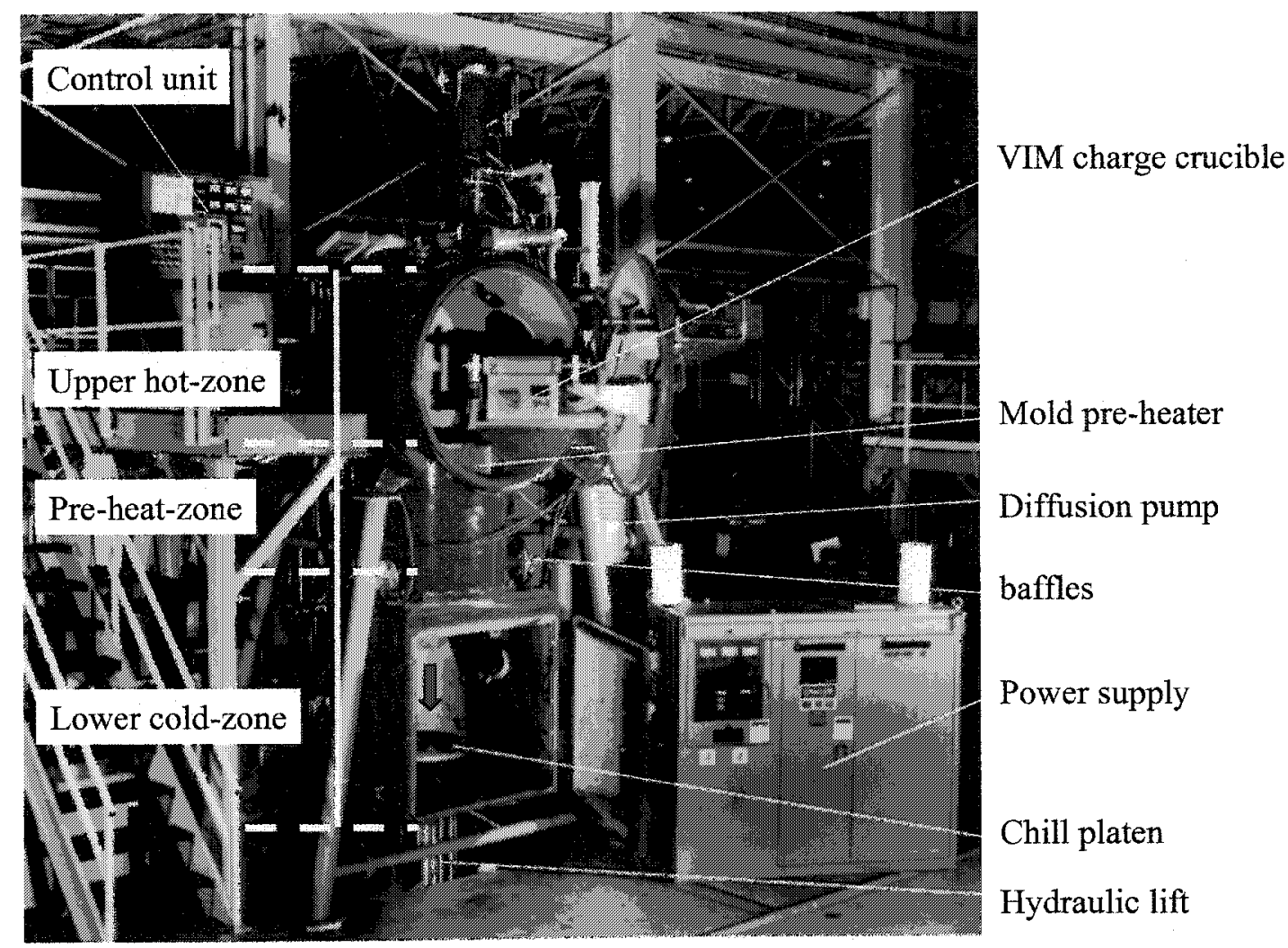

Figure 15: Consarc industrial Bridgman casting furnace [44].

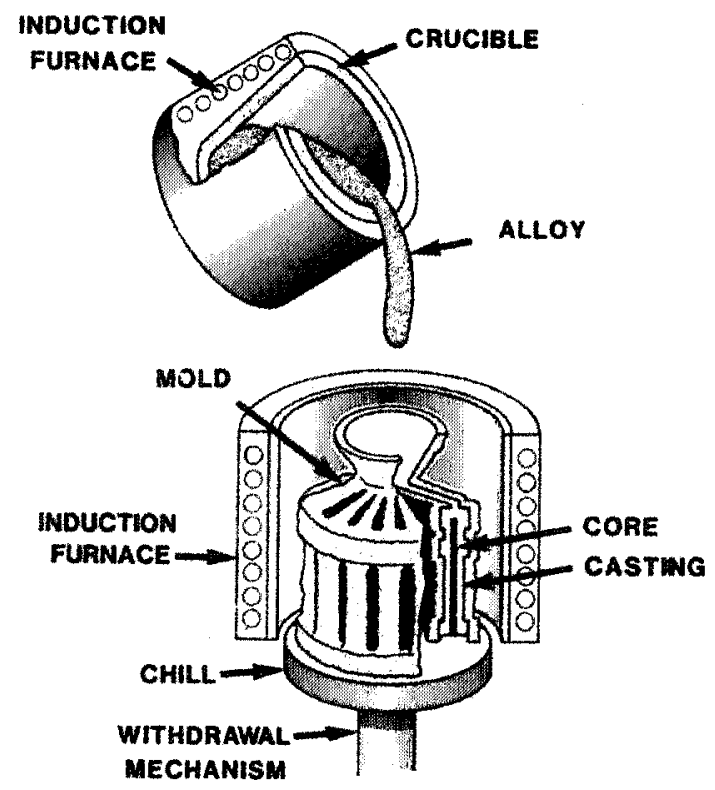

Figure 16: Internal components of a typical Bridgman casting furnace [33]. 
a)

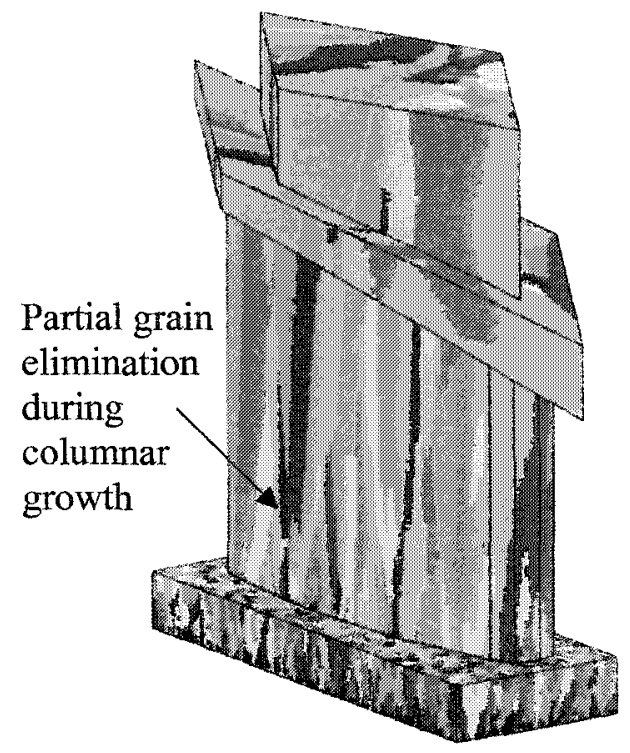

b)

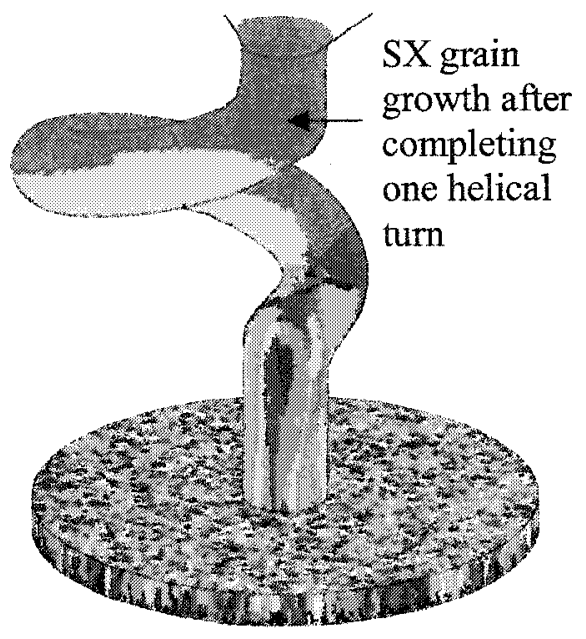

Figure 17: Grain structure evolution using probabilistic modeling, a) turbine blade structure cast directly on the chill platen with no SX grain selector, b) growth of a single $<100>$ grain (blue) at the expense of the less favorably oriented grains within a pigtail [46].

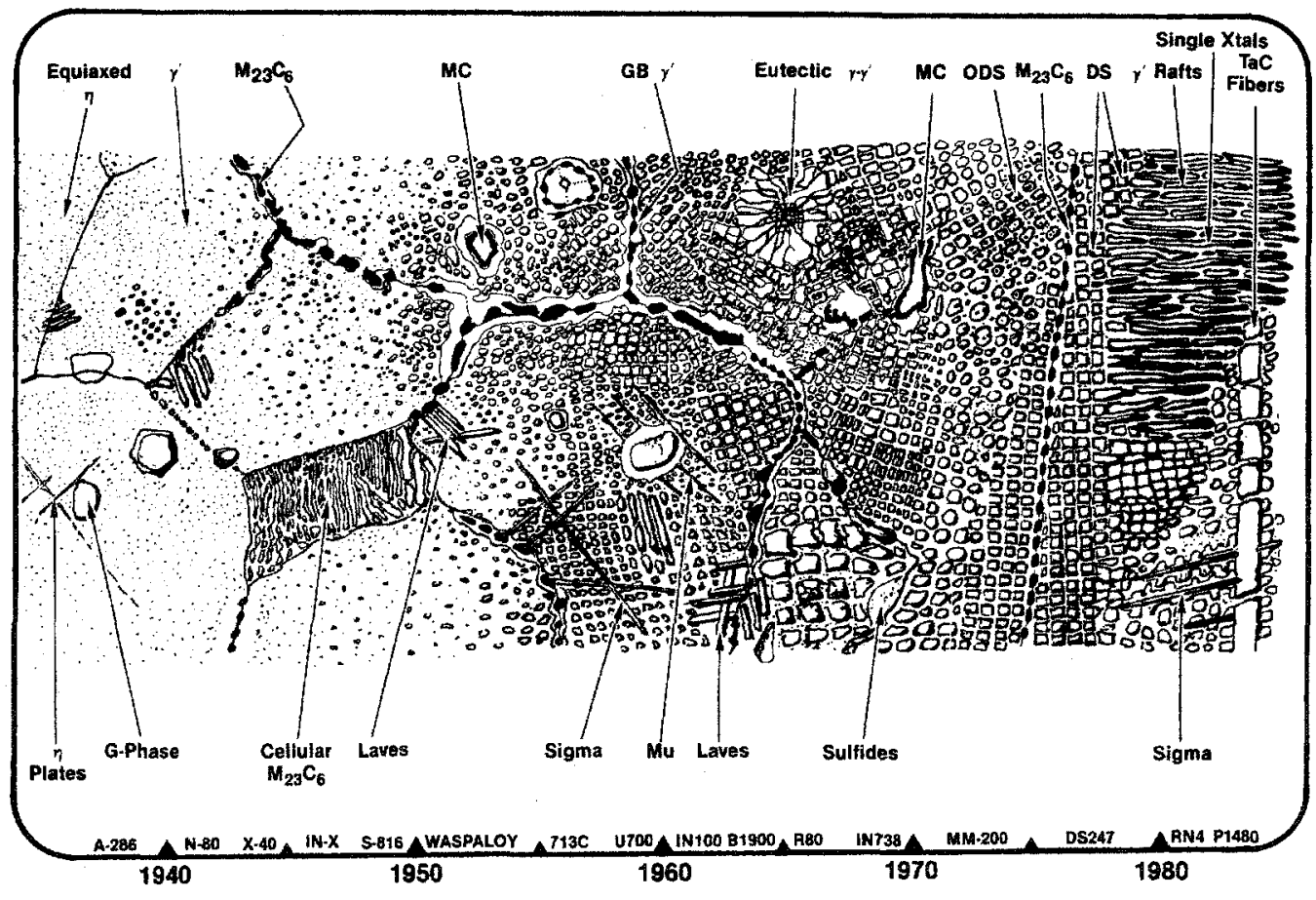

Figure 18: Evolution of Ni-base superalloy microstructure [47]. 


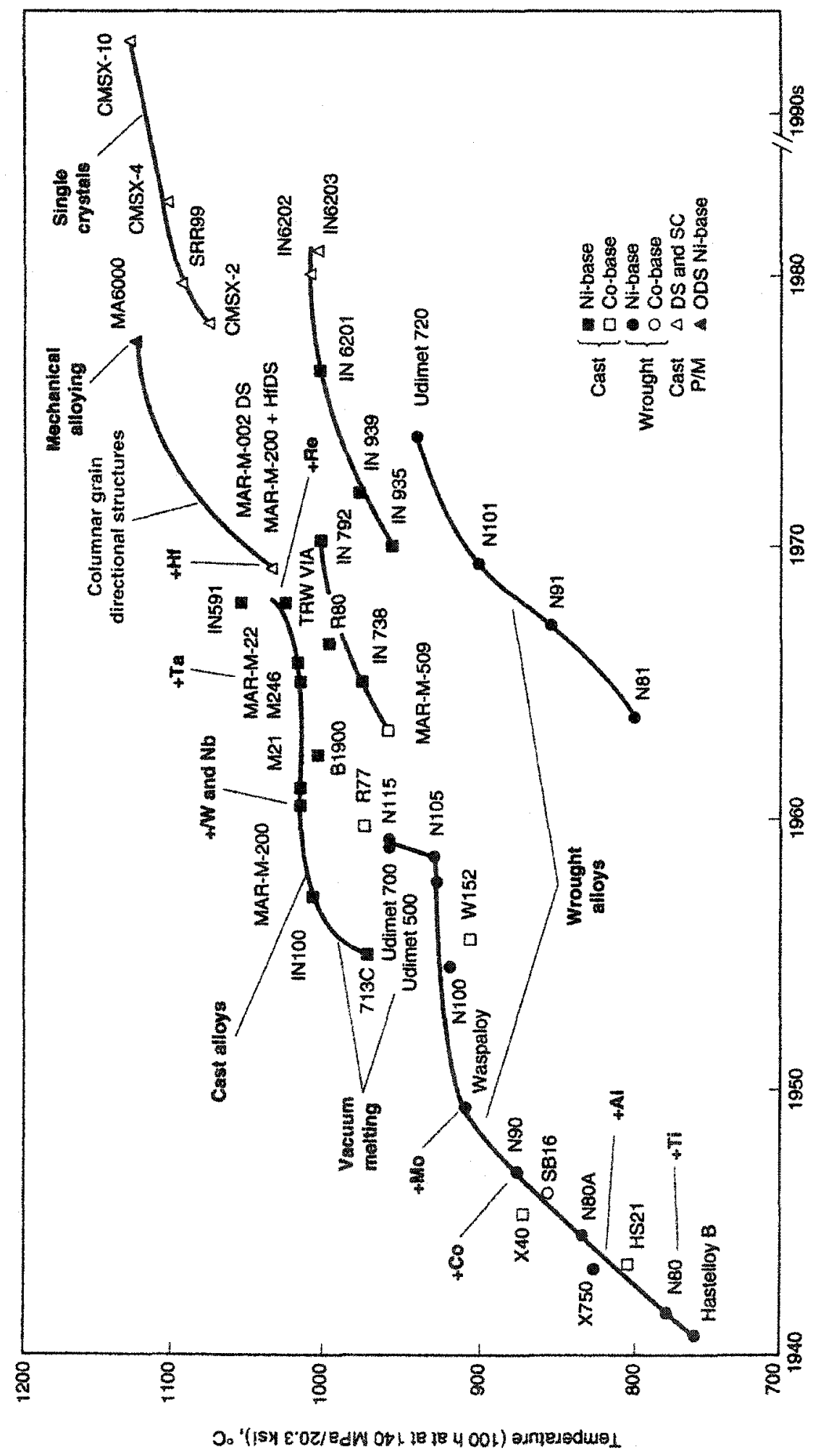

Figure 19: Increase in temperature-strength capability of superalloys with respect to year of production [33]. 

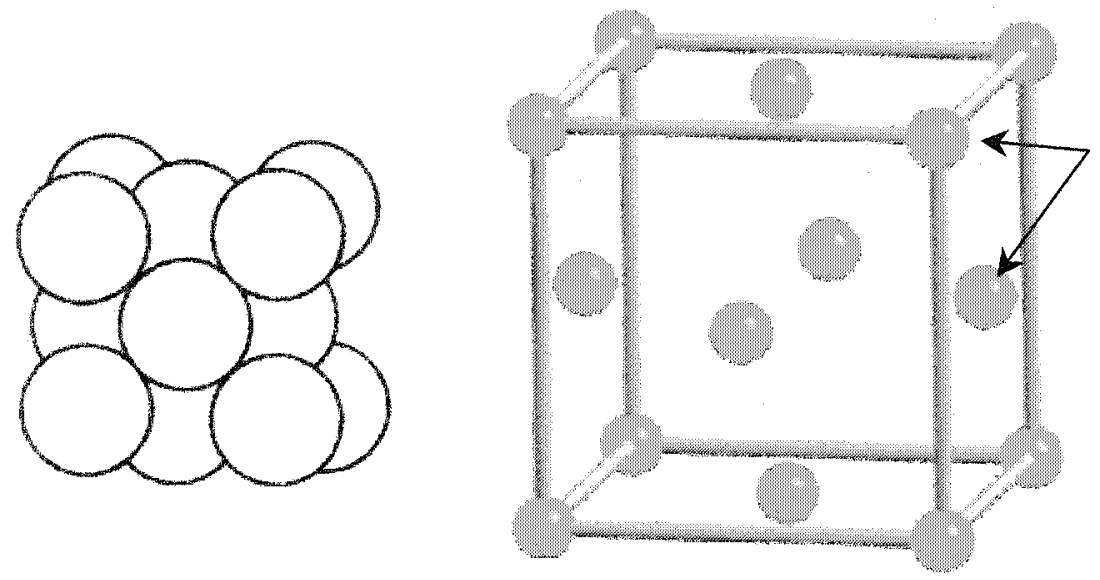

$\mathrm{Al}, \mathrm{Ni}$, or $\mathrm{Ti}$ atoms may reside at any lattice location

Figure 20: FCC crystal structure of the austenitic $\gamma$-matrix phase.

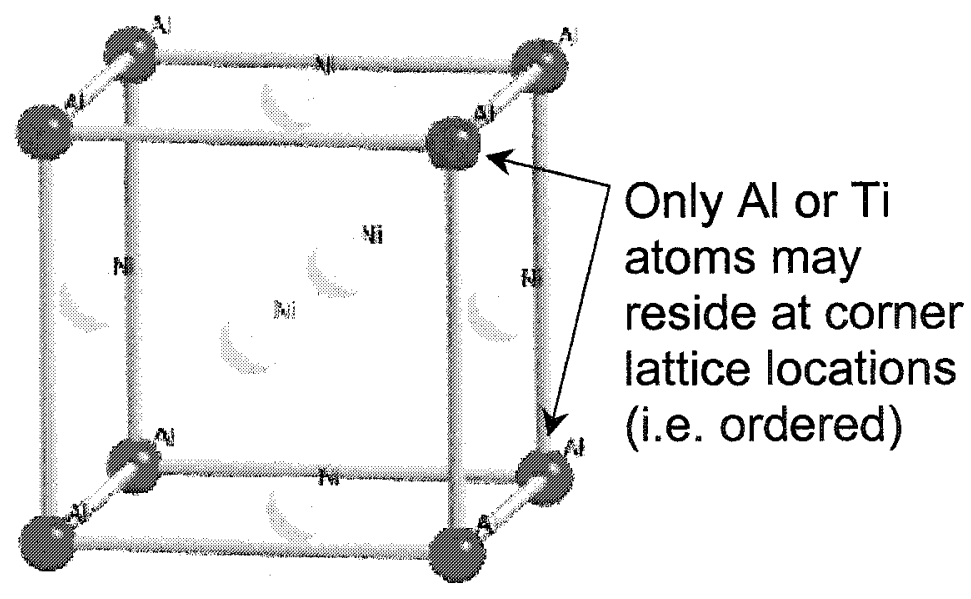

Figure 21: Ordered FCC crystal structure of the $\mathrm{L1}_{2}-\gamma^{\prime}$ intermetallic precipitate phase. 


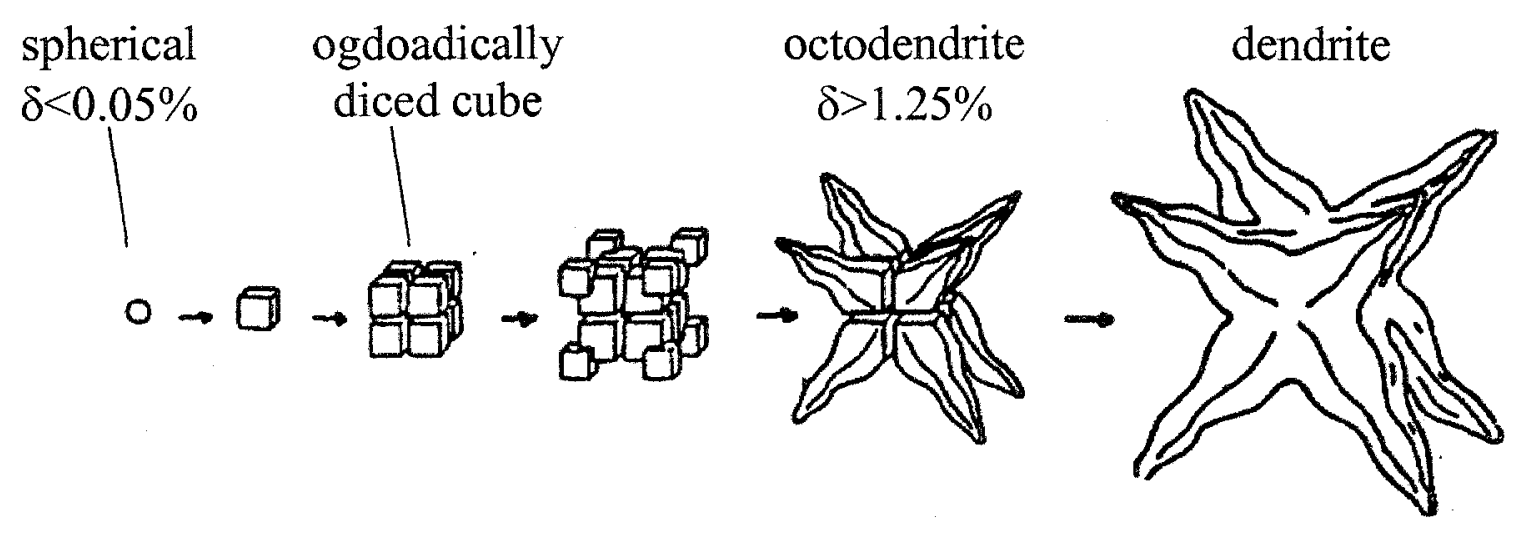

Figure 22: Schematic illustrating the change in $\gamma^{\prime}$ morphology with increasing precipitate size (adapted from Grosdidier) [50].

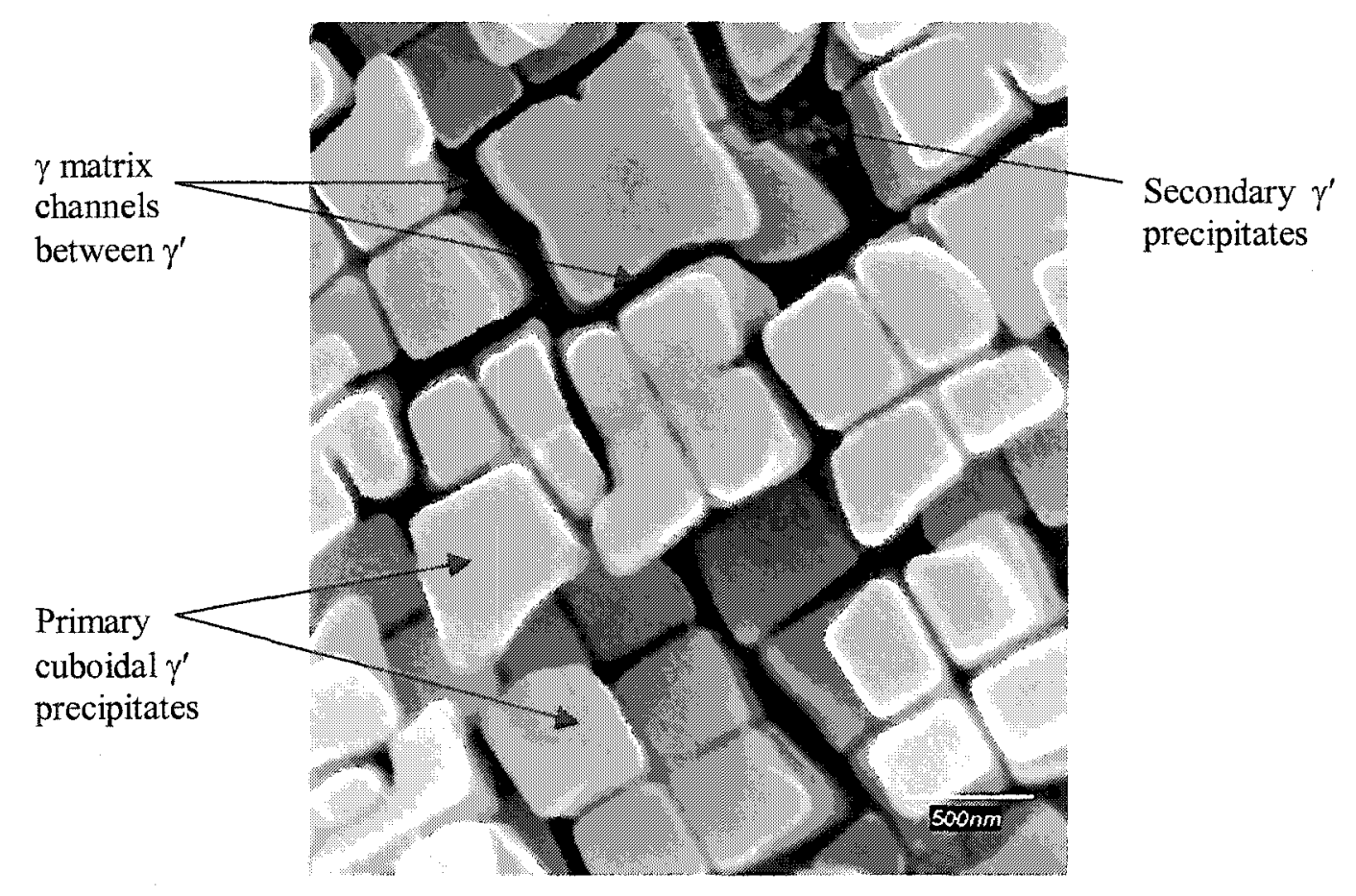

Figure 23: SEM image of as-cast PWA 1484 single crystal microstructure (30,000X). 


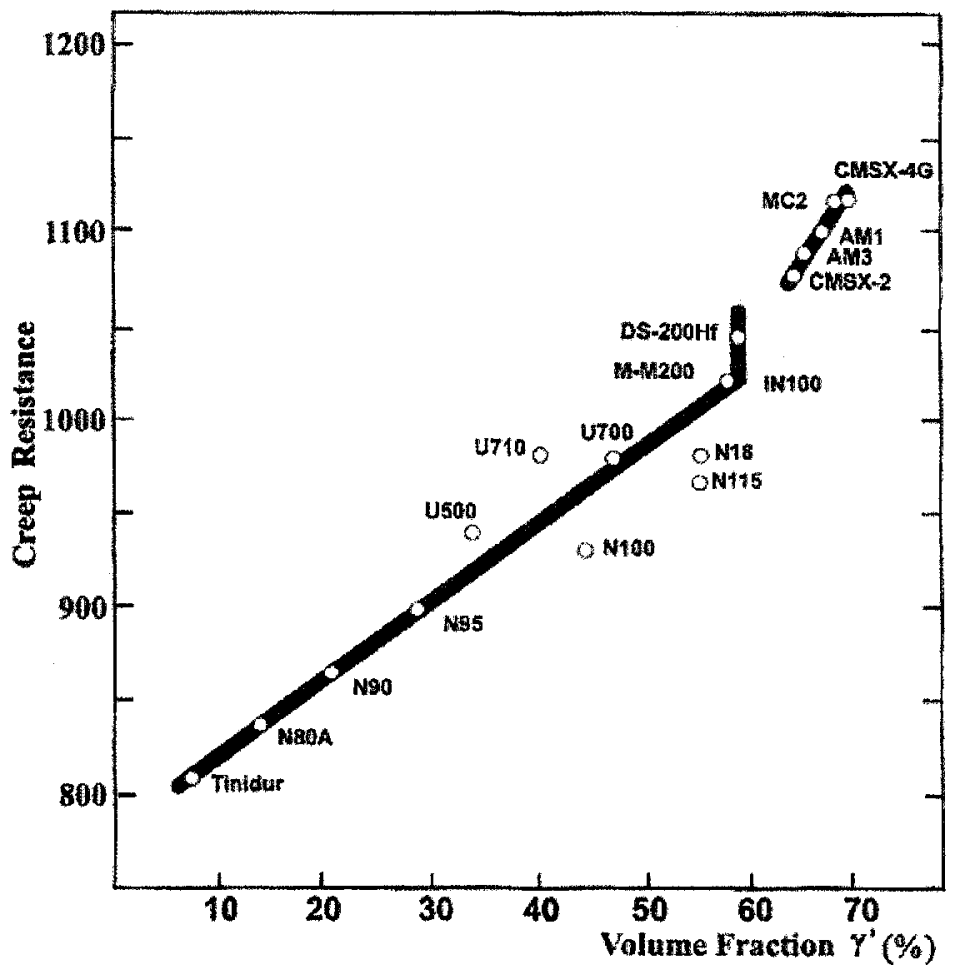

Figure 24: Creep strength as a function of $\gamma^{\prime}$ volume fraction [53]. 

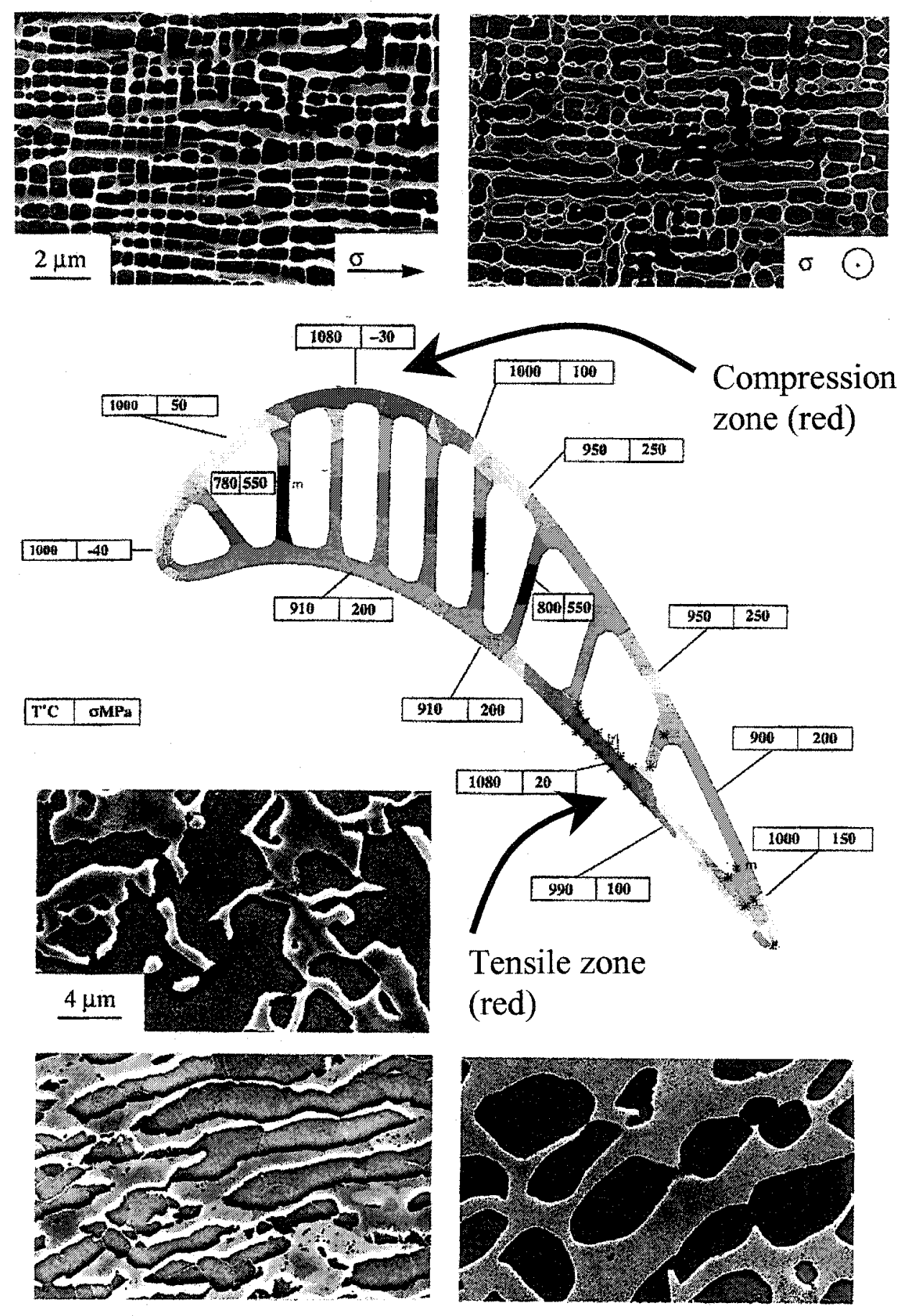

Figure 25: Temperature-stress cross-sectional profile of an AM1 SX blade. The top two SEM images correspond to the red compression zone $(-30 \mathrm{MPa})$, whereas the lower micrographs correspond to the cracked, tensile zone $(+20 \mathrm{MPa})[6]$. 


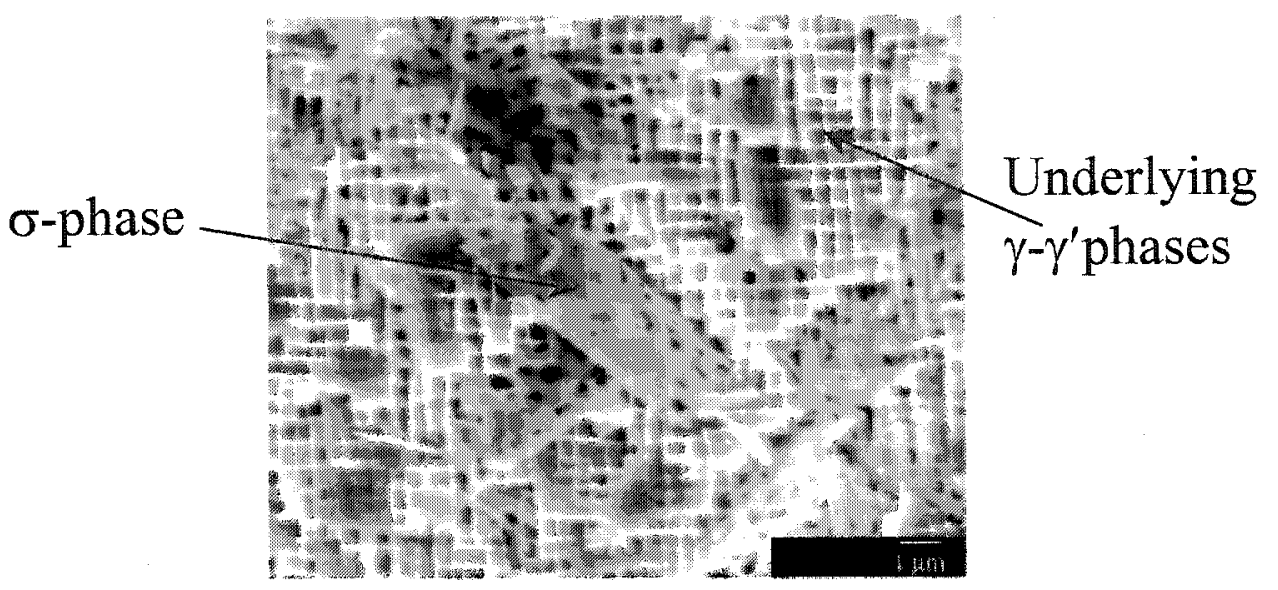

Figure 26: SEM micrograph showing $\sigma$ phase in RR2071 [55].

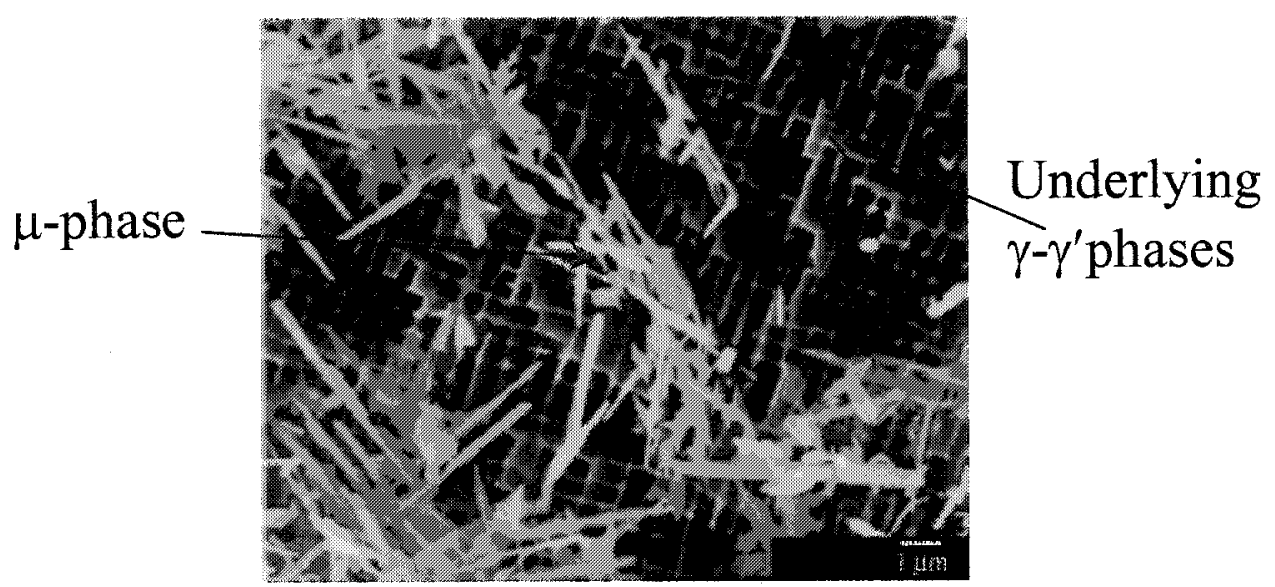

Figure 27: SEM micrograph showing $\mu$ phase in RR2071 [55].

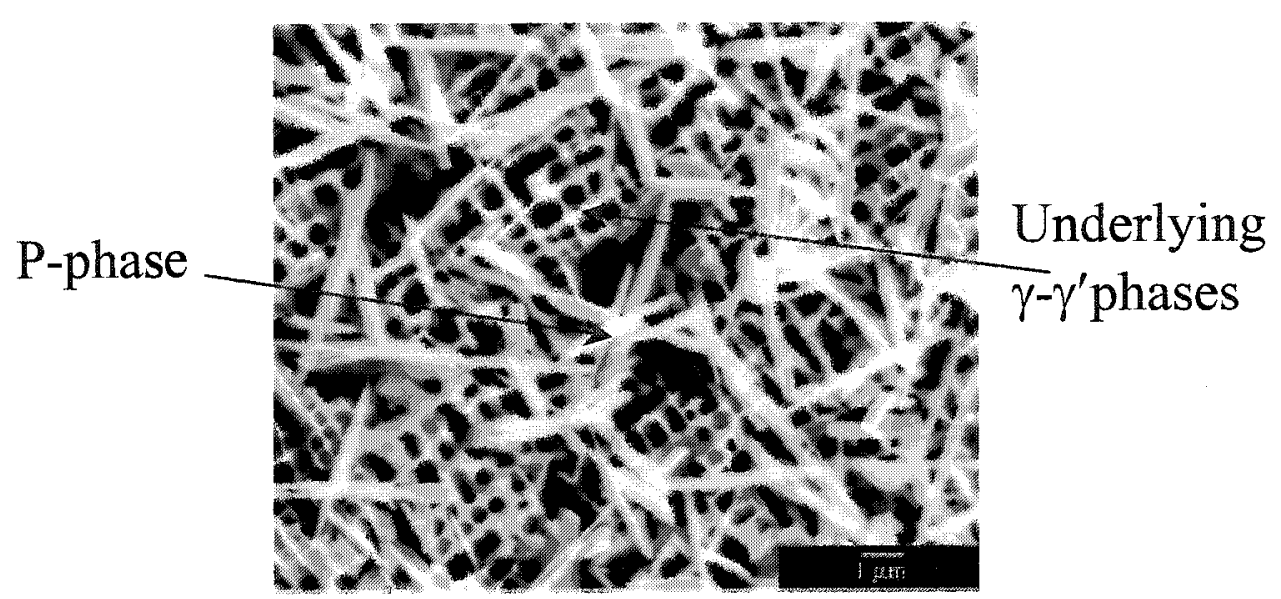

Figure 28: SEM micrograph showing P phase in RR2071 [55]. 


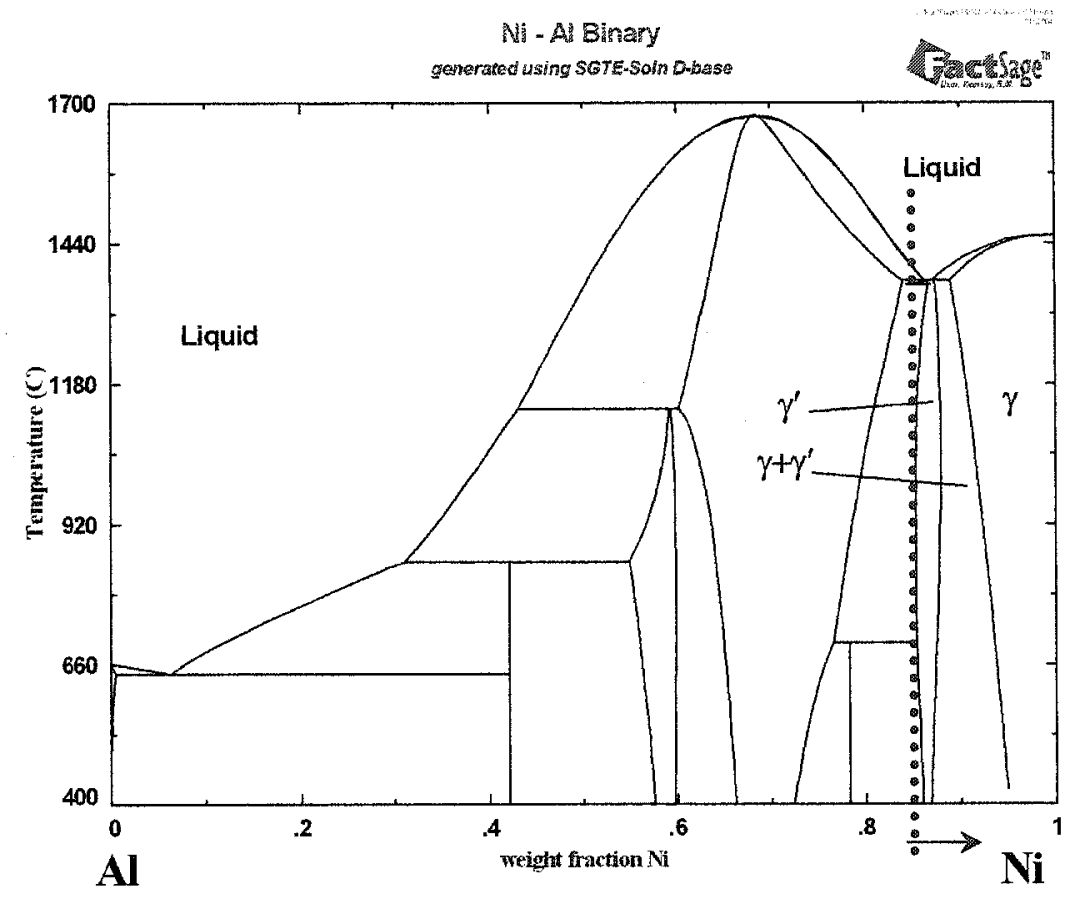

Figure 29: Ni-Al binary system.

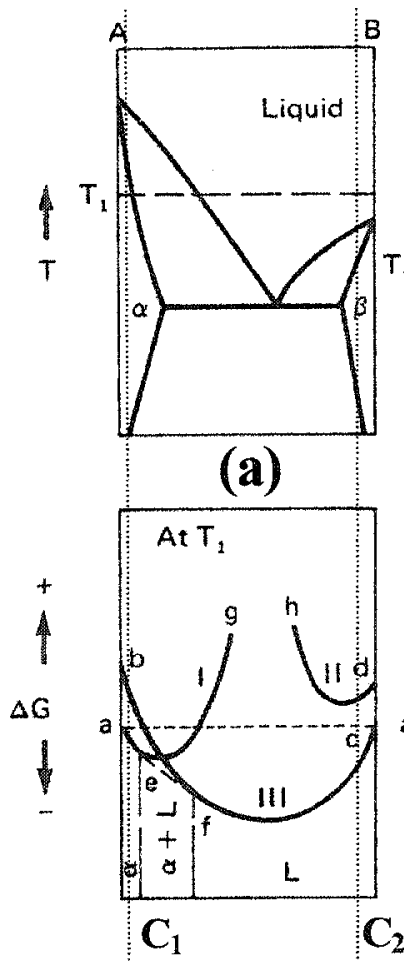

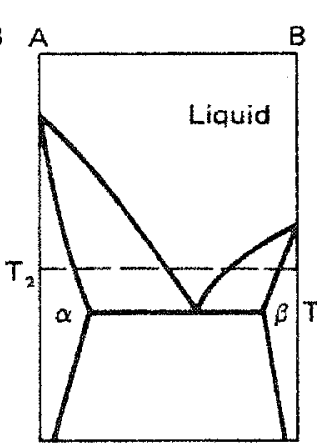

(b)

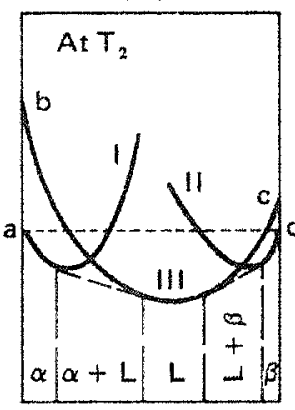

$\mathrm{C}_{2}$

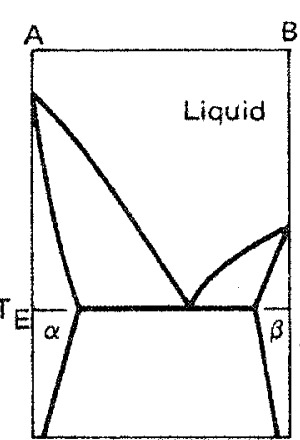

(c)

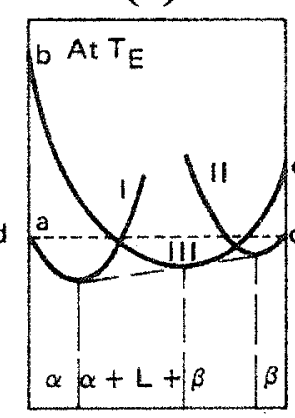

$\alpha \beta+L+\beta \quad \beta$

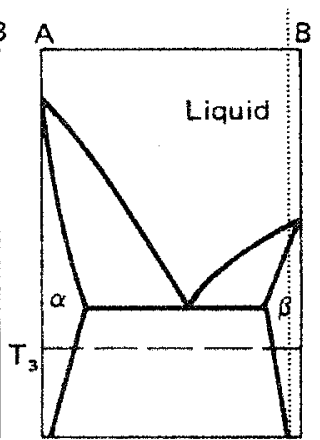

(d)

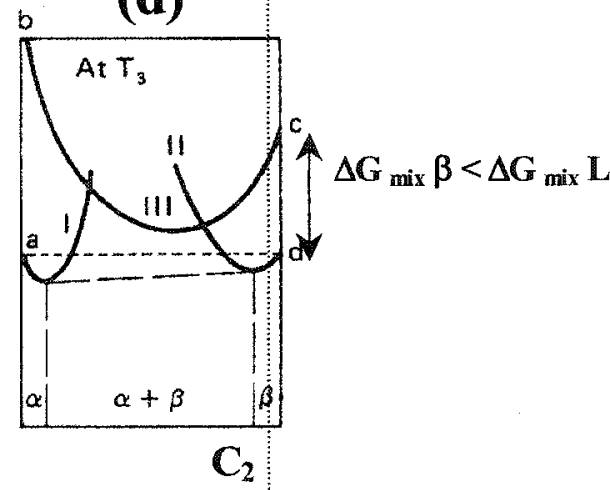

Figure 30: The effects of temperature and composition on Gibbs free energy [71]. 

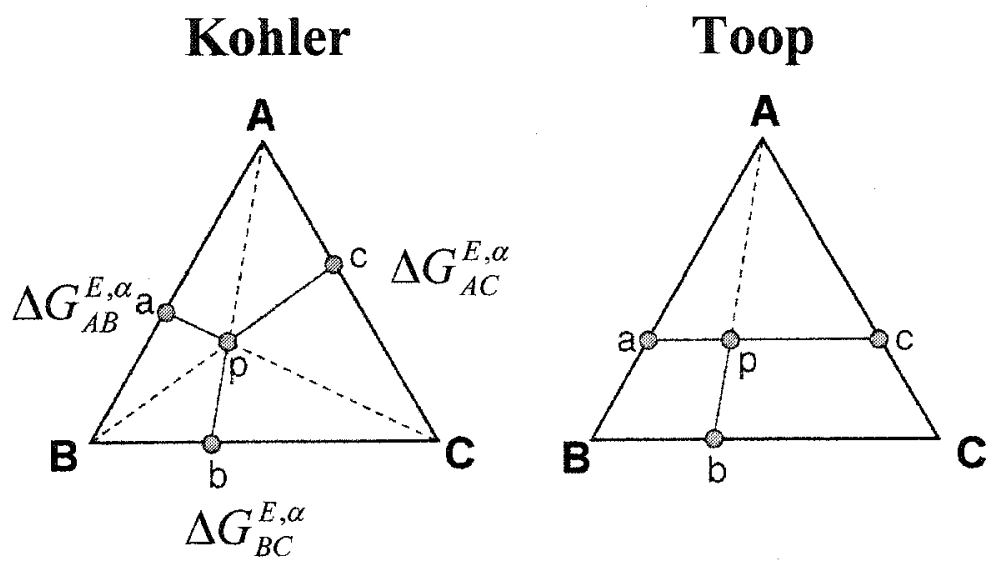

Muggianu

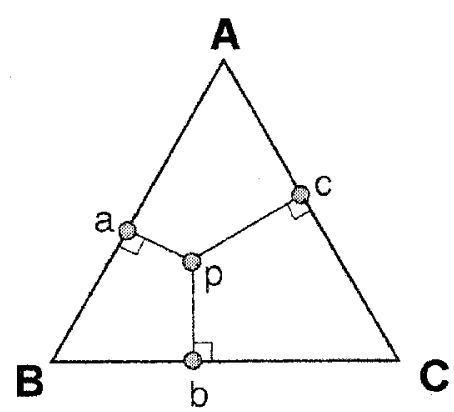

Figure 31: Thermodynamic geometric schemes for interpolating binary polynomial terms in the ternary A-B-C system.

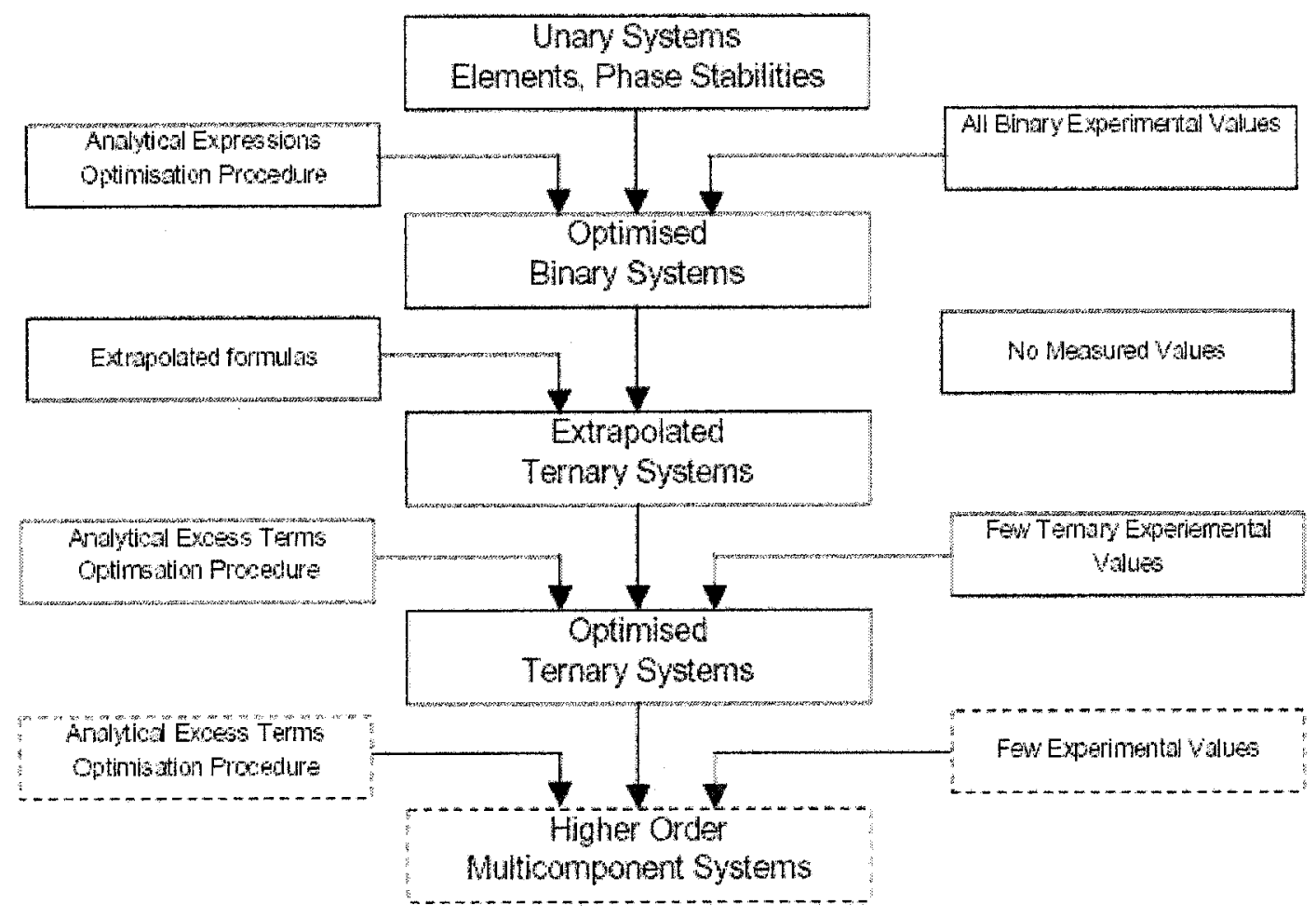

Figure 32: Schematic representation of the Calphad assessment method [86]. 


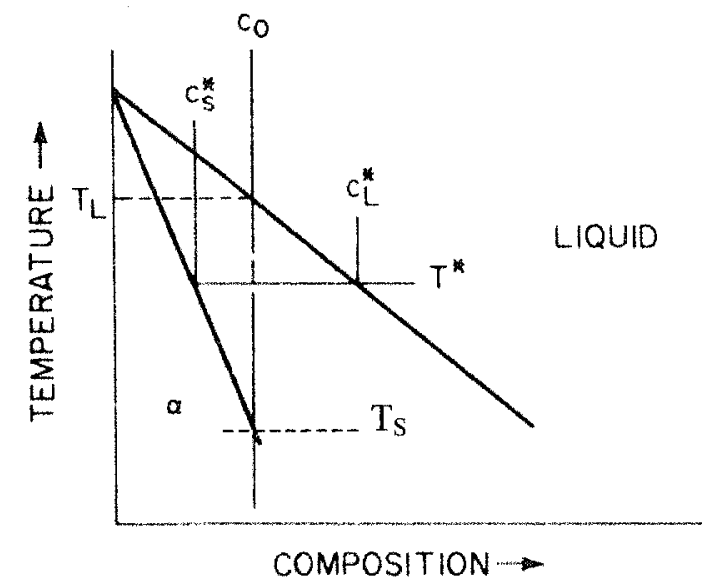

(o)

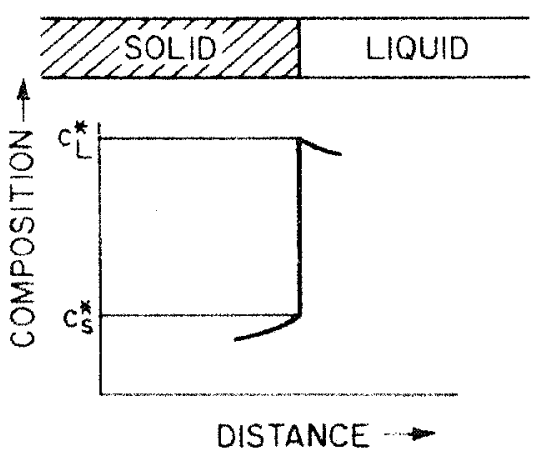

(b)

Figure 33: Solidification of an alloy with equilibrium at the solid-liquid interface: (a) equilibrium phase diagram, (b) composition profile across the interface [90].

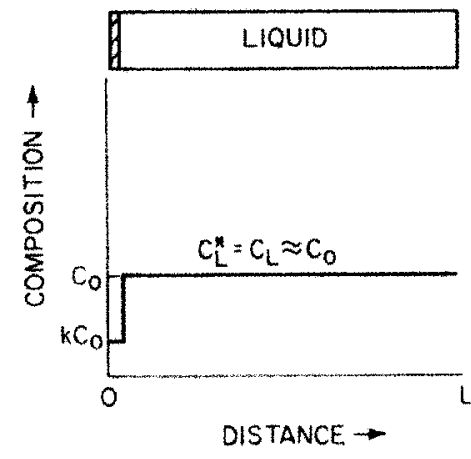

(a) START OF SOLIDIFICATION

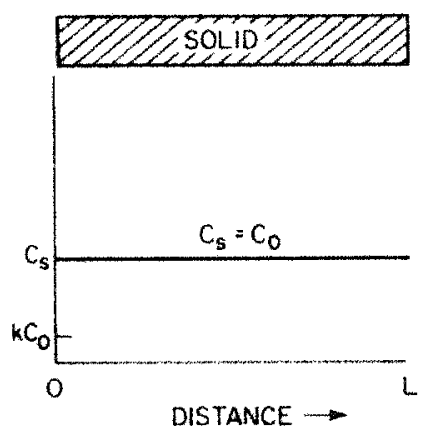

(c) AFTER SOLIDIFICATION

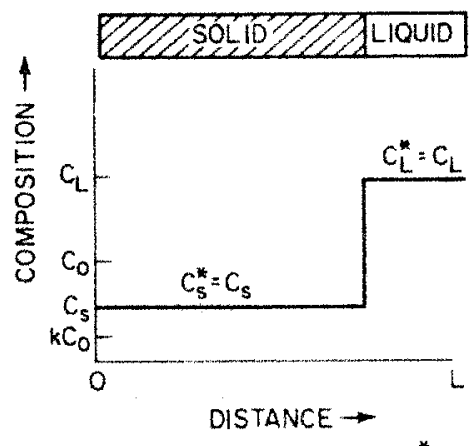

(b) AT TEMPERATURE T*

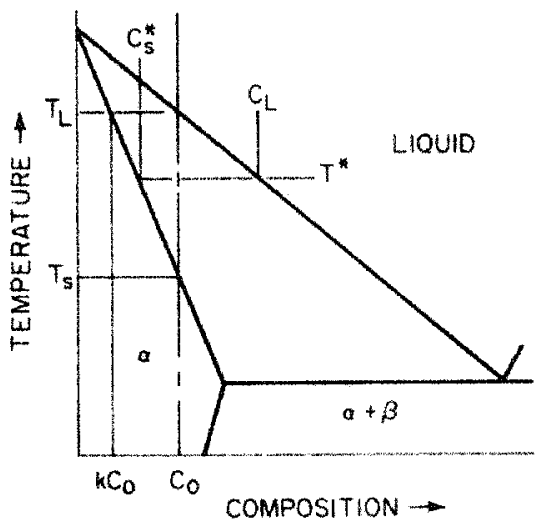

(d)

Figure 34: Solute redistribution during equilibrium solidification (a) at the start, (b) at temperature $T^{*}$, (c) after solidification (d) corresponding phase diagram. 


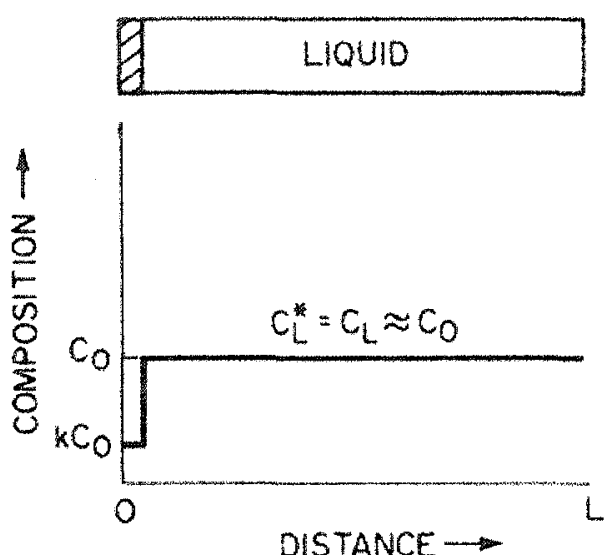

(0)

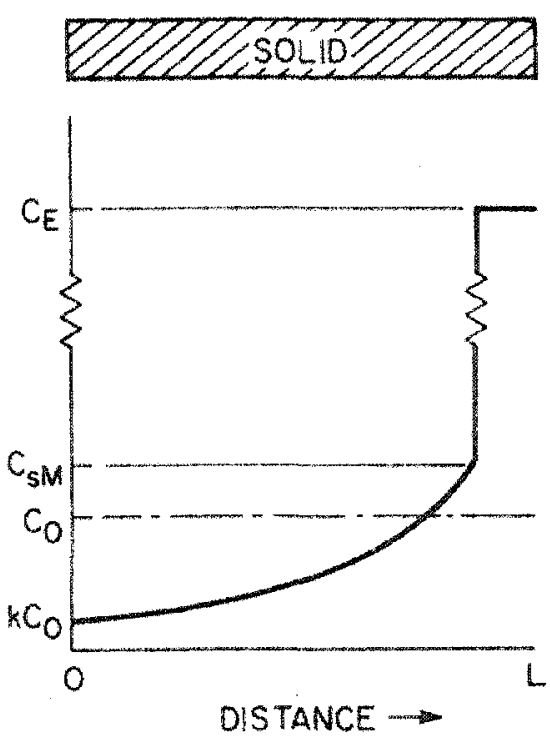

(c)

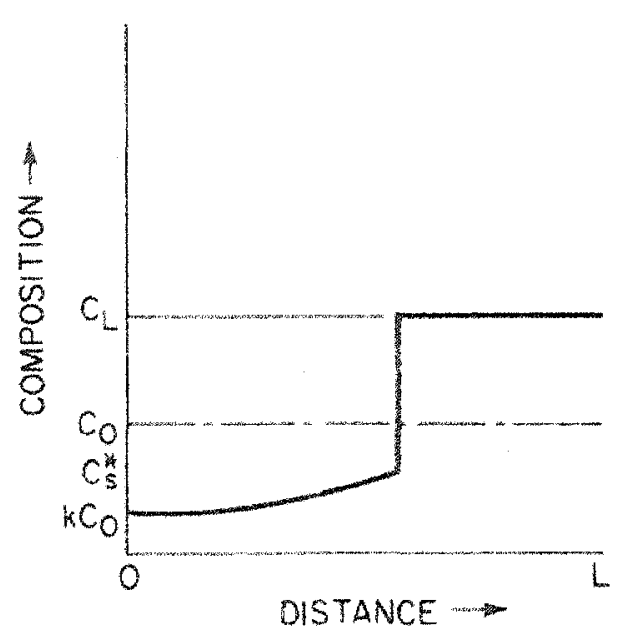

(b)

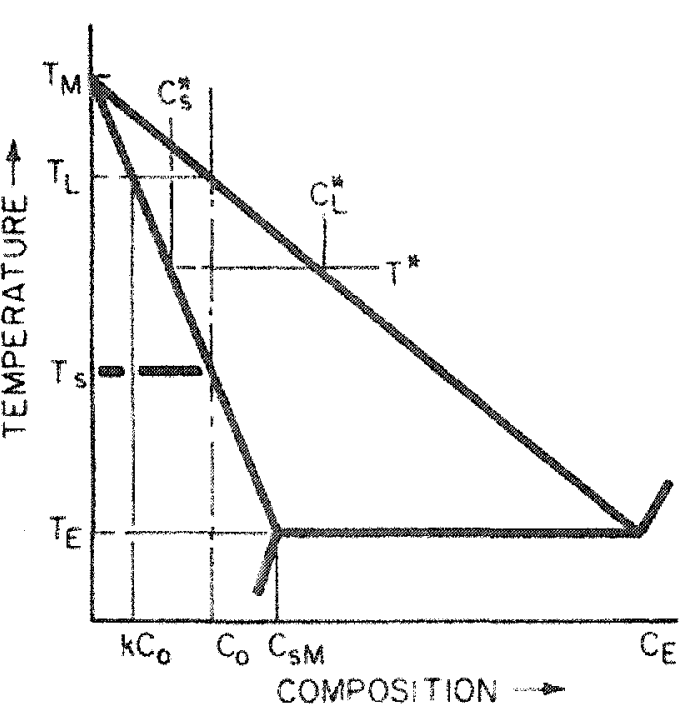

(d)

Figure 35: Solute redistribution during Scheil solidification- no solid diffusion and complete liquid diffusion (a) at the start, (b) at temperature $T^{*}$, (c) after solidification (d) corresponding phase diagram $[90]$. 

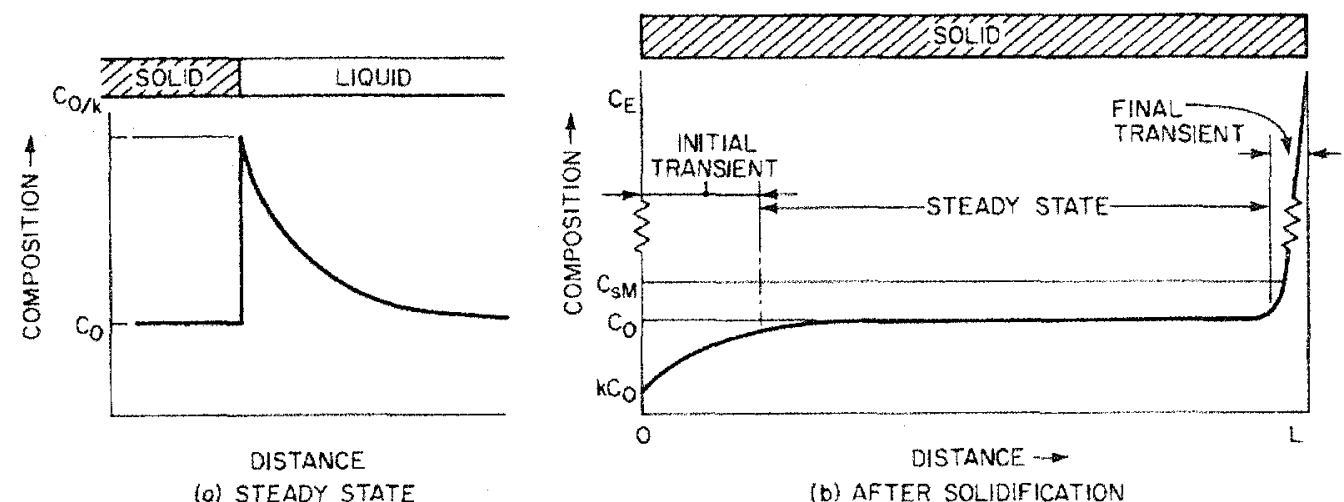

(b) AFTER SOLIDIFICATION

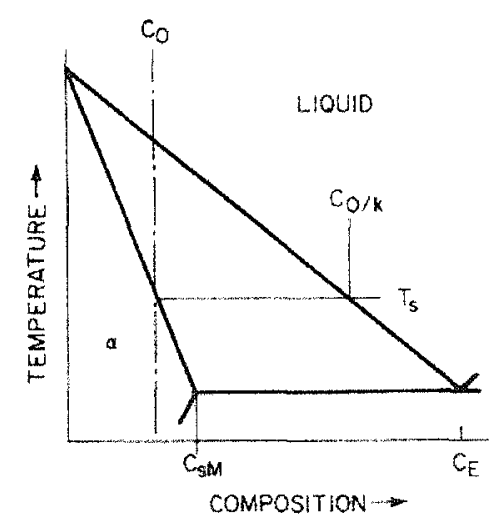

Figure 36: Solute redistribution in solidification with limited liquid diffusion and no convection: (a) composition profile during steady-state solidification,(b) composition profile after complete solidification, (c) corresponding phase diagram [90]. 


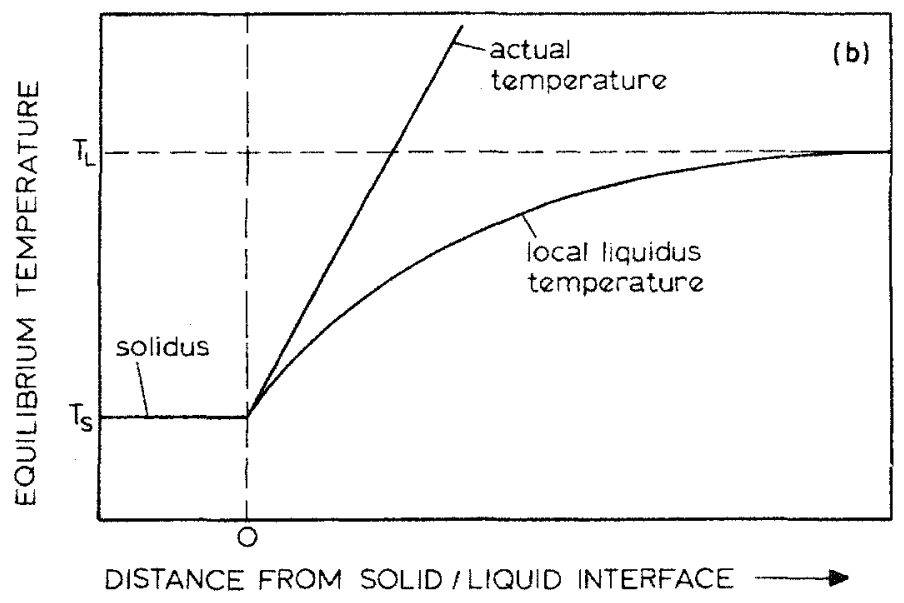

Figure 37: Schematic of the variation in liquidus temperature due to the solute boundary layer in the liquid [89].
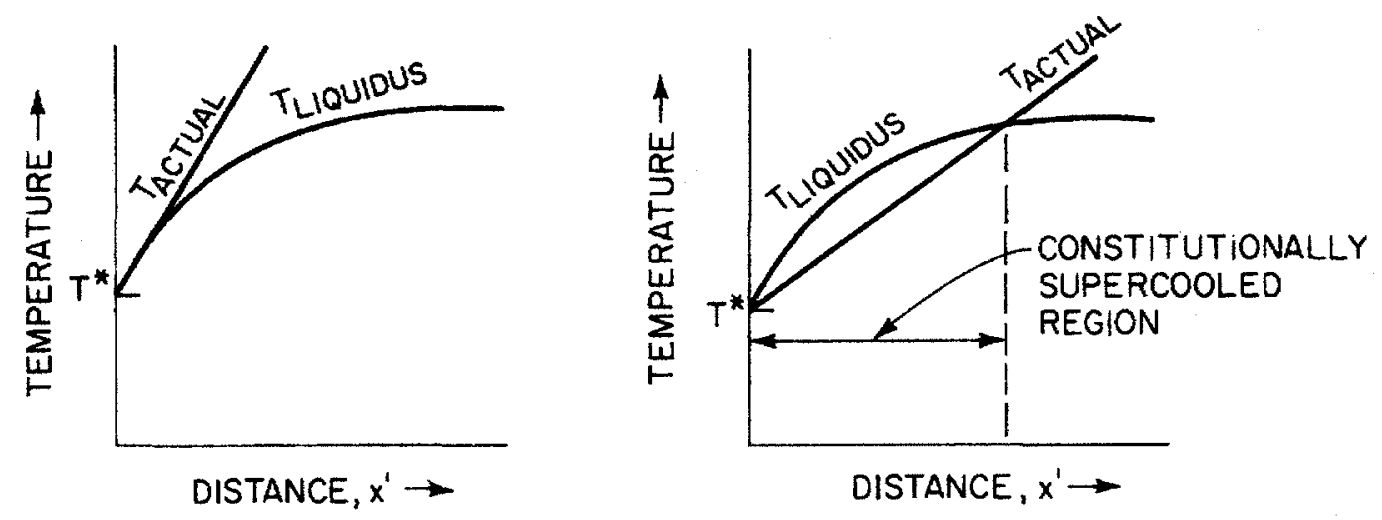

Figure 38: Transition of interface stability: (a) Stable plane front. (b) Unstable plane front due to constitutional supercooling [90].

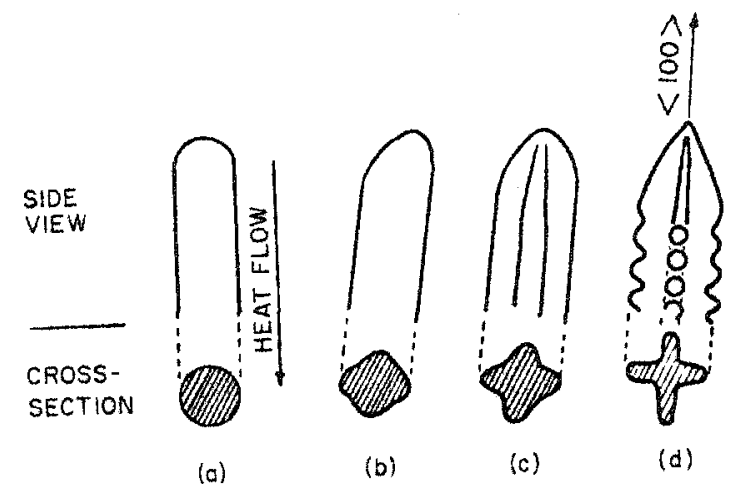

Figure 39: Shape transition of growth structure as solidification rate increases, (a) cellular structure, (b) partial radial growth, (c) Maltese cross and (d) dendritic structure [90]. 


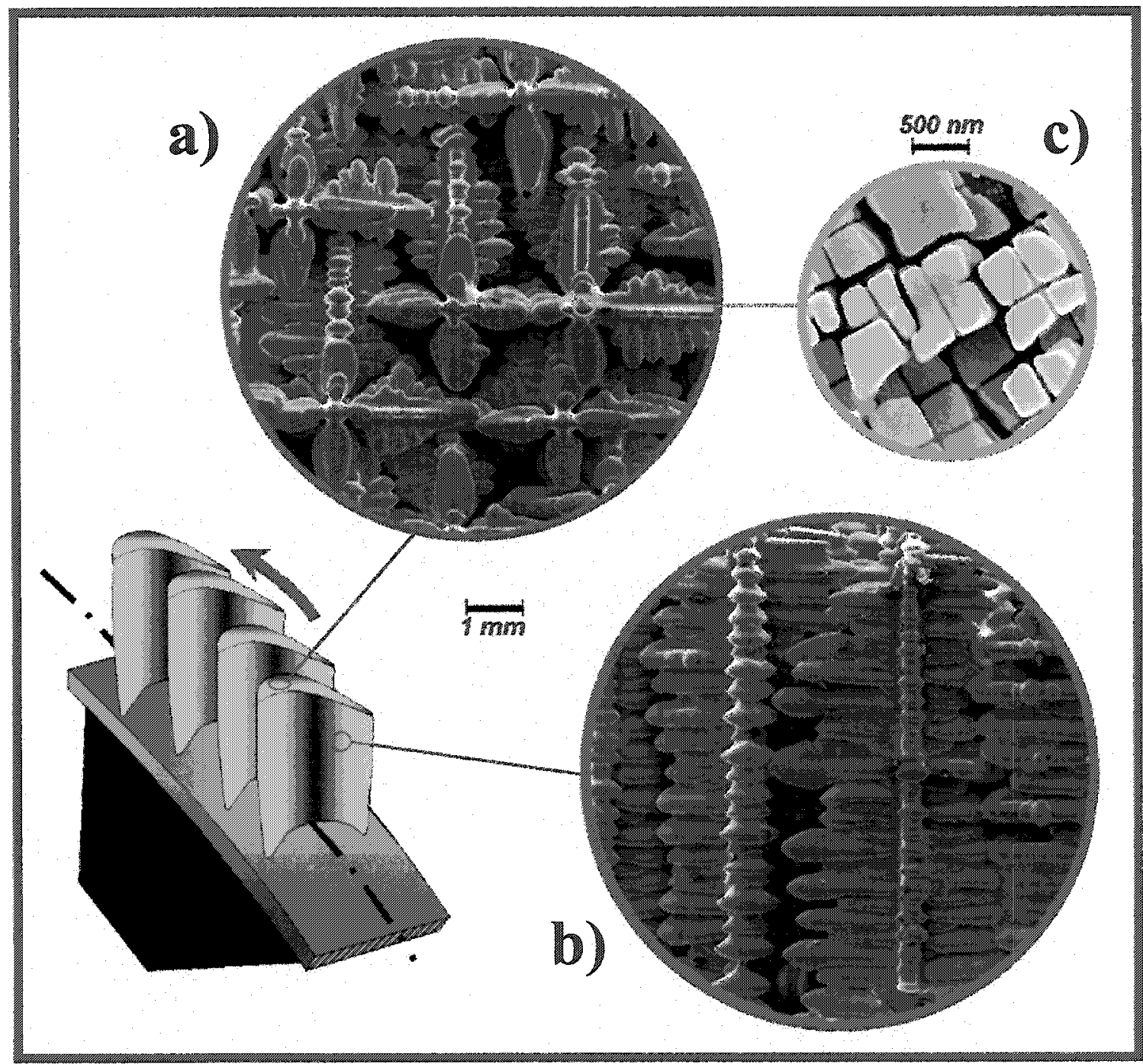

Figure 40: Typical SX superalloy as-cast dendritic structure; (a) SEM micrograph depicting the transverse Maltese-cross morphology, (b) SEM micrograph showing the longitudinal cross-section along the $<100>$ crystallographic direction, (c) typical as cast cuboidal precipitate structure. 


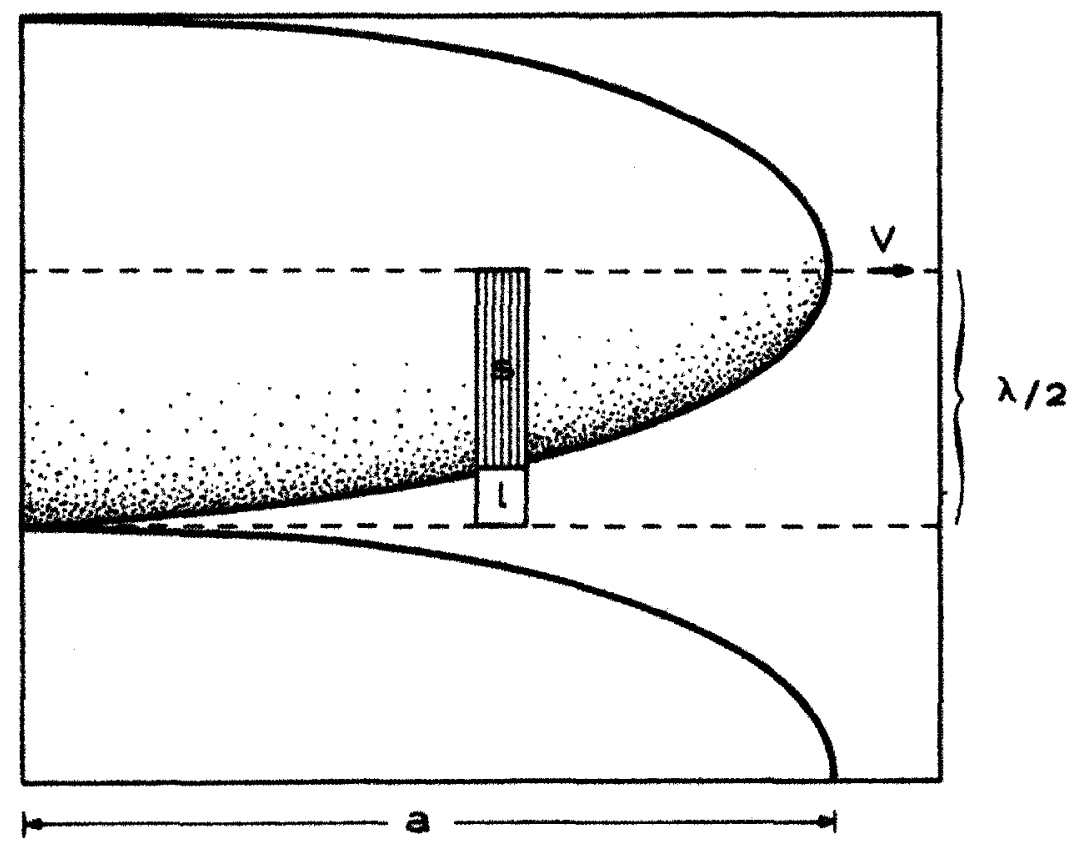

Figure 41: Characteristics of the mushy zone in columnar growth. The small volume element of length $\lambda / 2$, is similar to the larger planar-front models (e.g. Figure 34). This volume element solidifies perpendicular to the primary dendrite axis (i.e. $<100>$ ) of the SX alloy. The distance $a$ is defined as the length of the mushy zone. Now the value of $f s$ corresponds to the fraction of the solid in the smaller volume element [43]. 


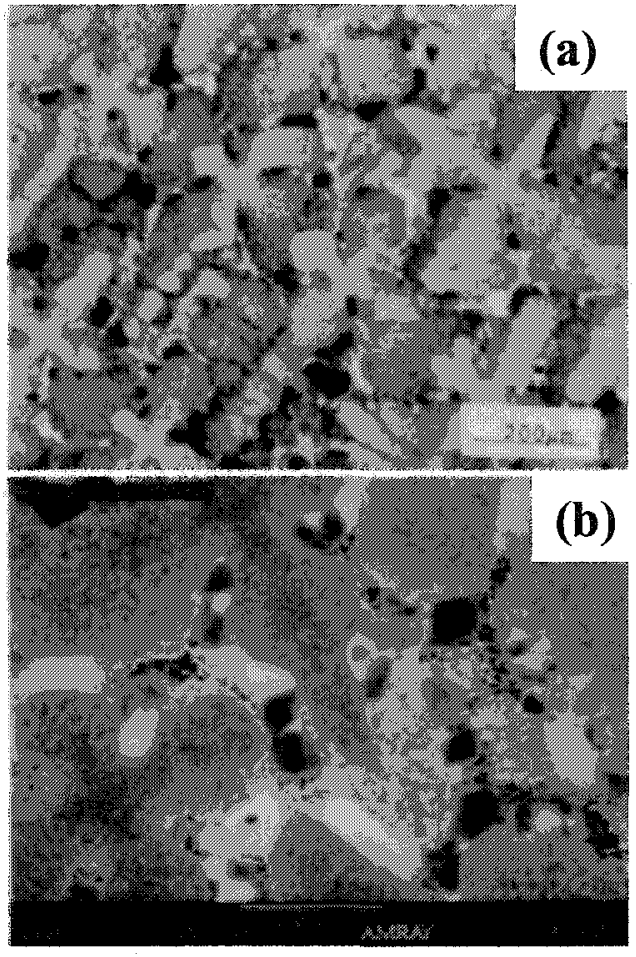

Figure 42: Microsegregation observed in SX superalloy CMSX-10; (a) optical micrograph showing dendritic solidification structure, (b) SEM image of same the structure showing large fraction of coarse interdendritic eutectic phase [92].

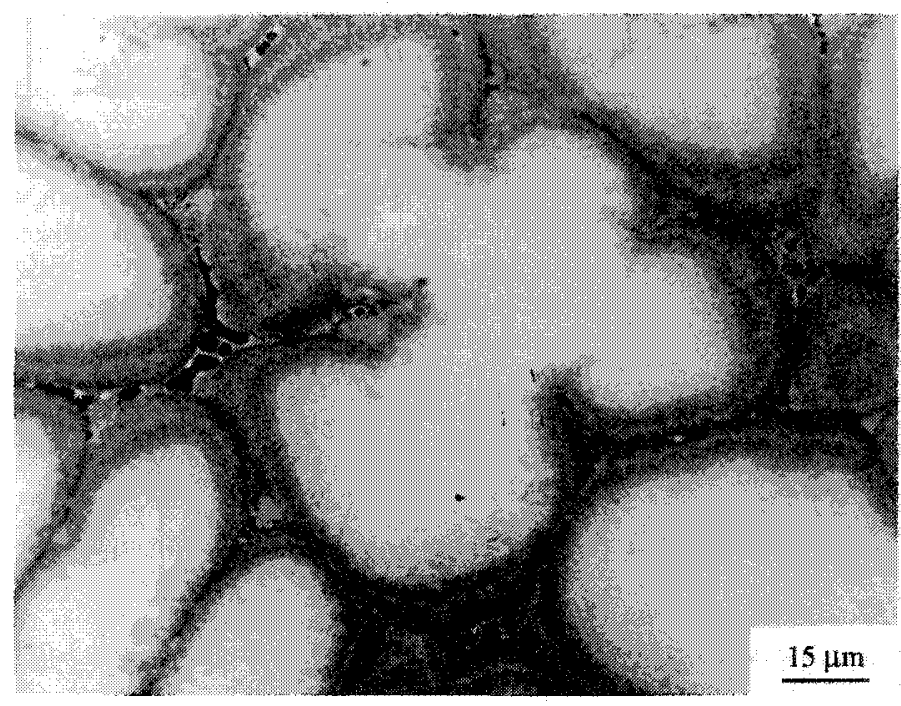

Figure 43: SEM micrograph of AM1 alloy showing brighter dendrite cores due to high localized concentration of $W$. Dark region surrounding dendrites is the $W$ depleted regions. The darker interdendritic phase contains coarse eutectic $\gamma^{\prime}$ precipitates [6]. 

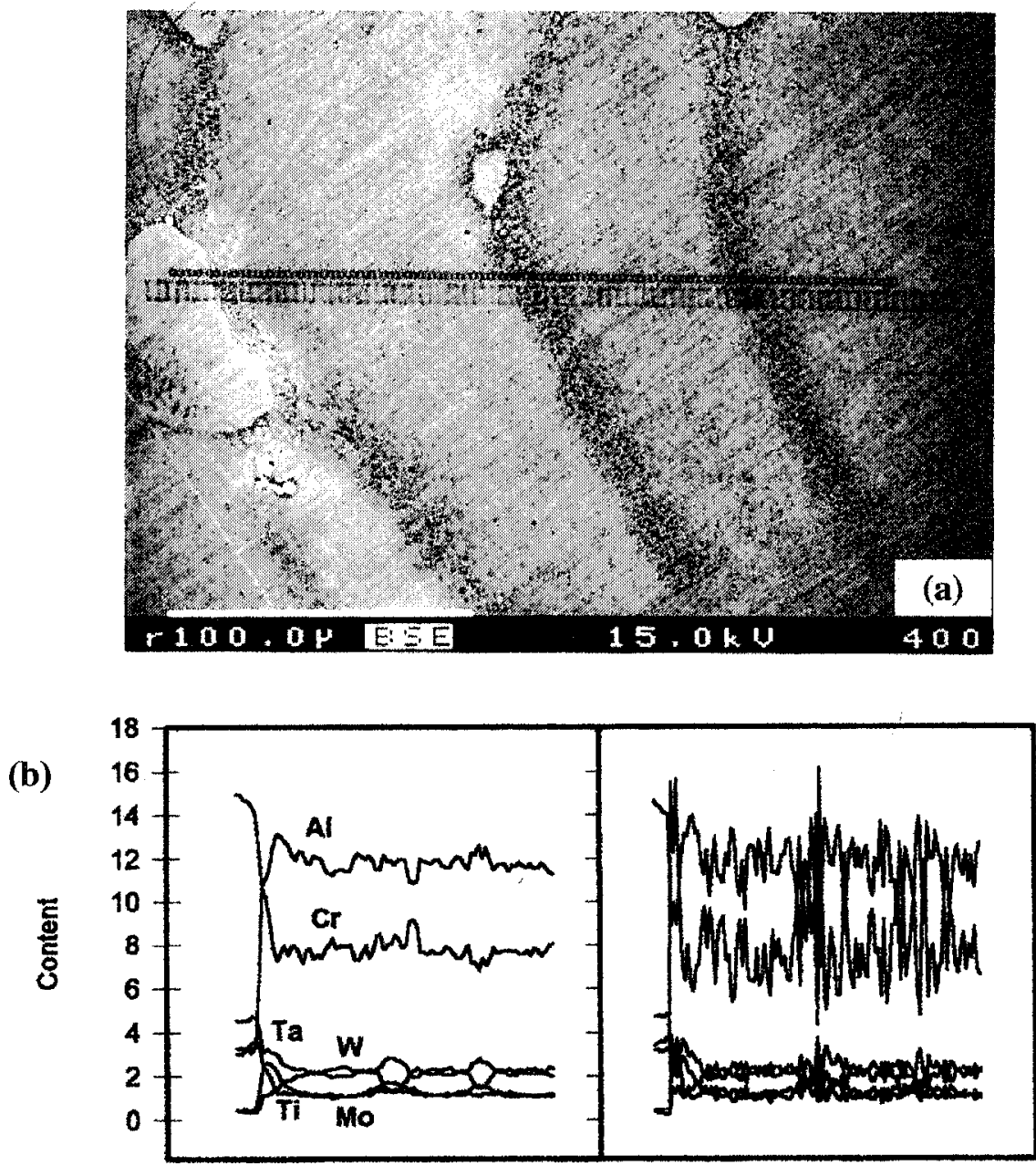

(c)

(d)

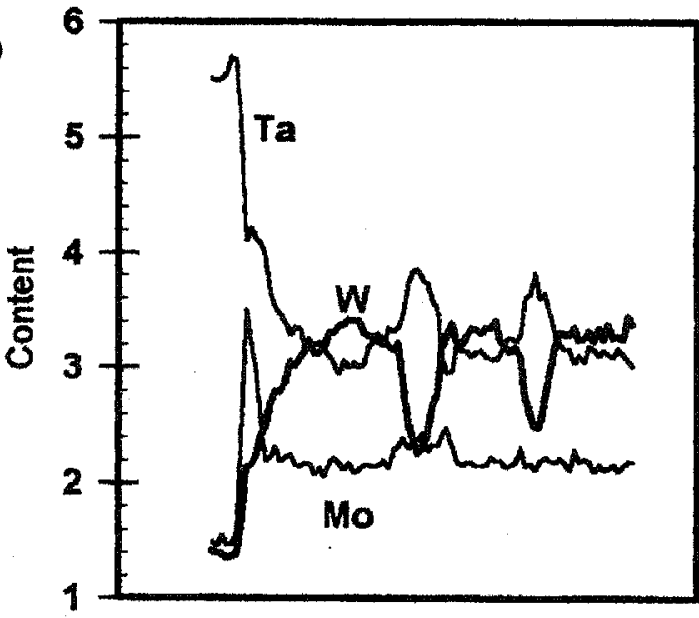

Figure 44: (a) Electron micrograph of longitudinal cross-section of as-cast AM1, (b) EPMA line scan results for a $1 \mu \mathrm{m}$ sampling size (c) for a $10 \mu \mathrm{m}$ sampling size with a close-up of the Mo, W and Ta profiles show in (d) [6]. 


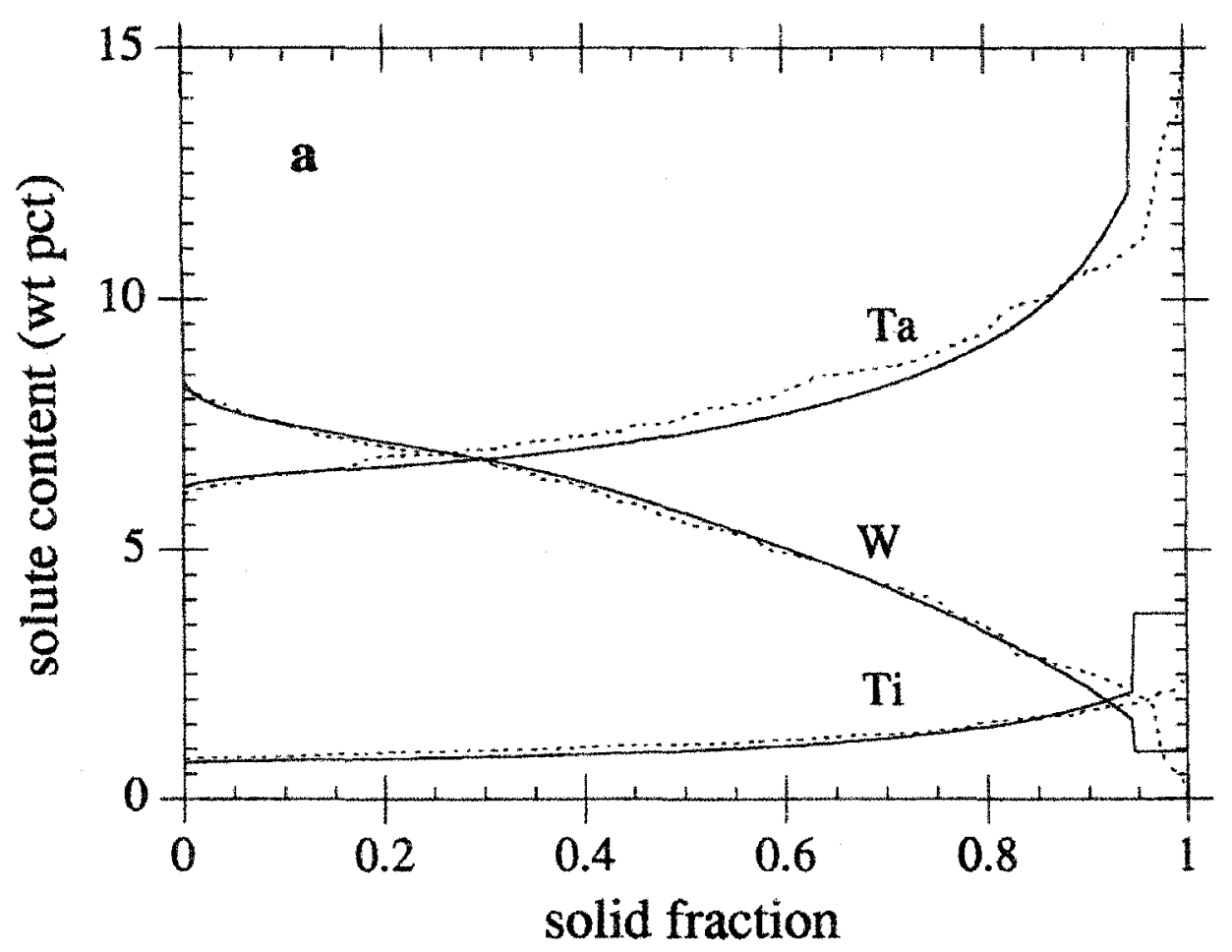

Figure 45: Distribution of certain alloying elements as a function of fraction solid in directionally solidified AM1. The $f_{s}=0$ point corresponds to the location of the dendrite core and $f_{s}=1$ is the location of interdendritic eutectic phase [6].

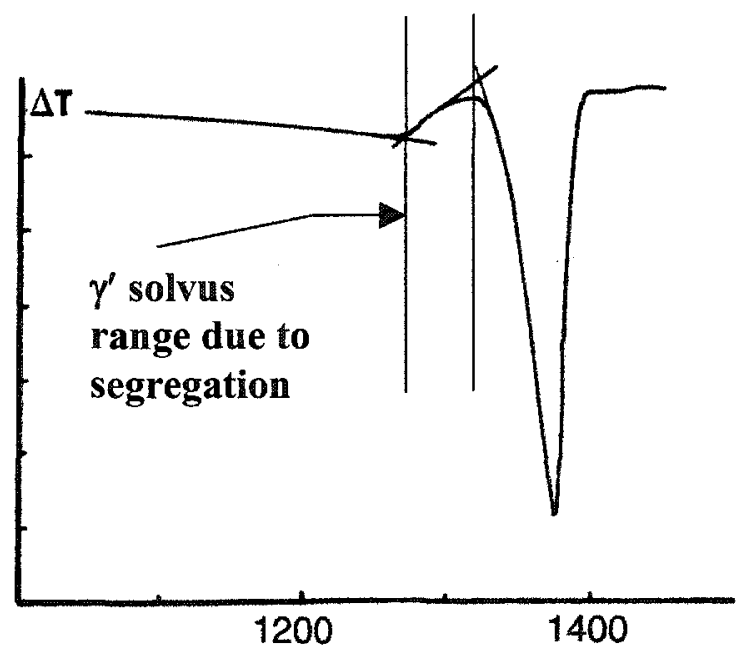

Figure 46: DTA of AM1 at a heating rate of $12.5^{\circ} \mathrm{C} / \mathrm{min}[6]$. 


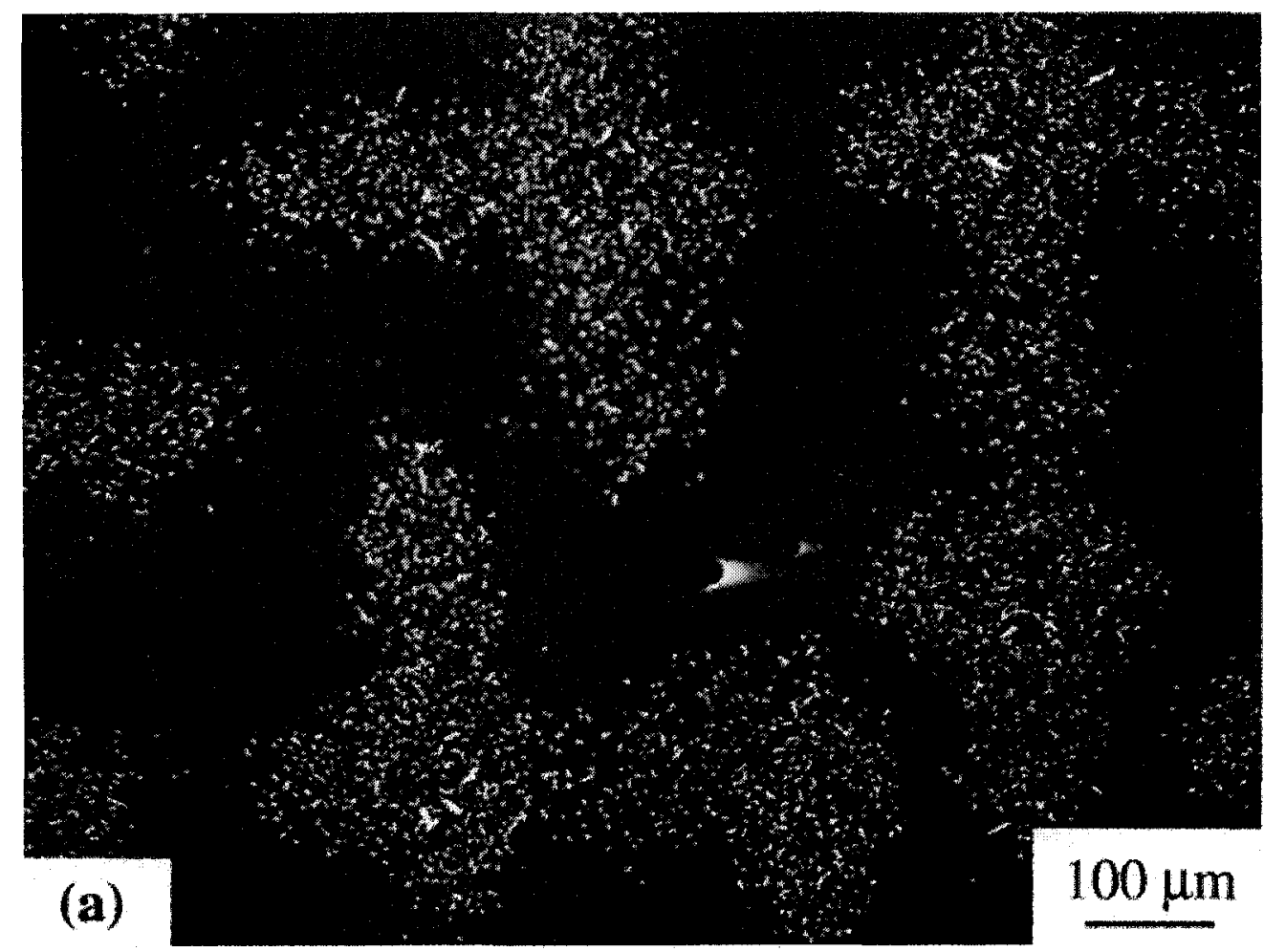

Figure 47: SEM image of MC2 alloy showing the precipitation of the $\mu$-phase within the Wrich dendrite core regions after high temperature exposure [6].

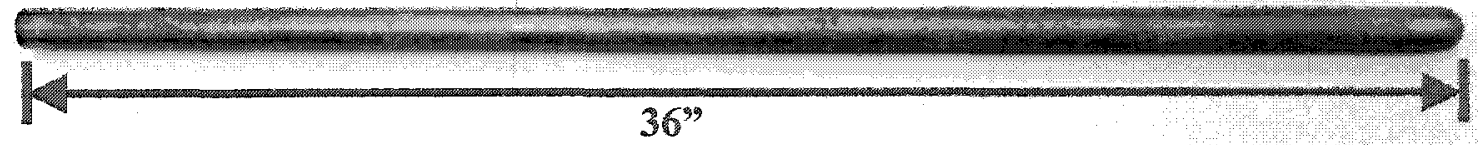

Figure 48: As-received vacuum cast bars from Sophisticated Alloys.
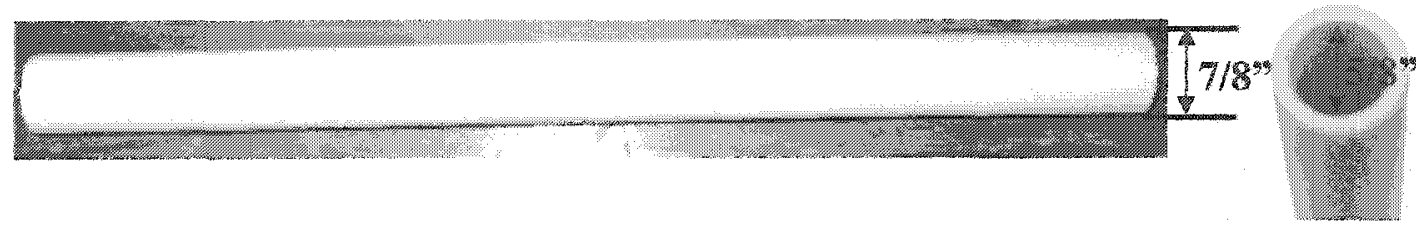

Figure 49: Double open-ended alumina mold used for SX casting. 


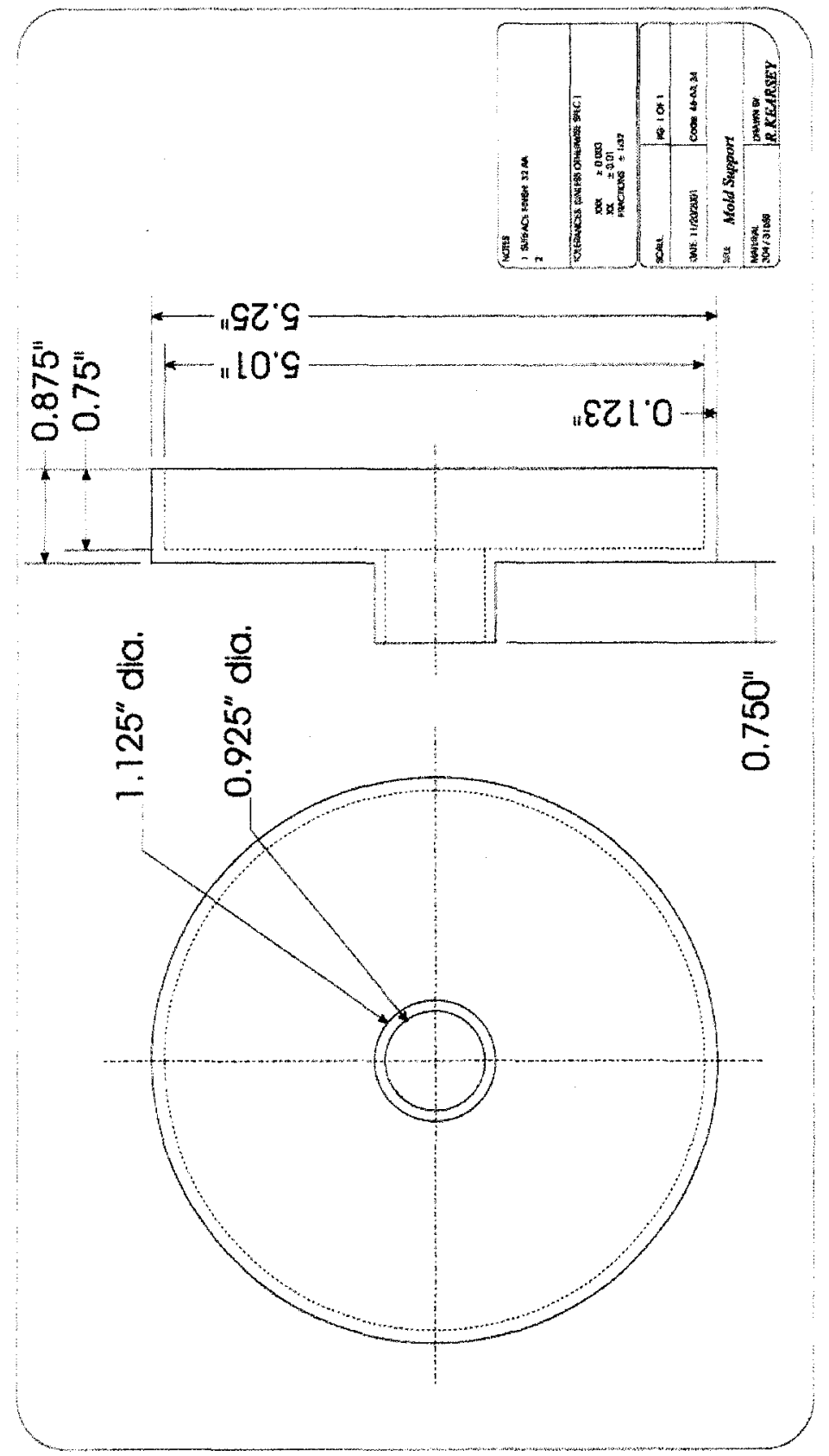

Figure 50: Ceramic mold support-stand for 7/8-inch diameter molds. 


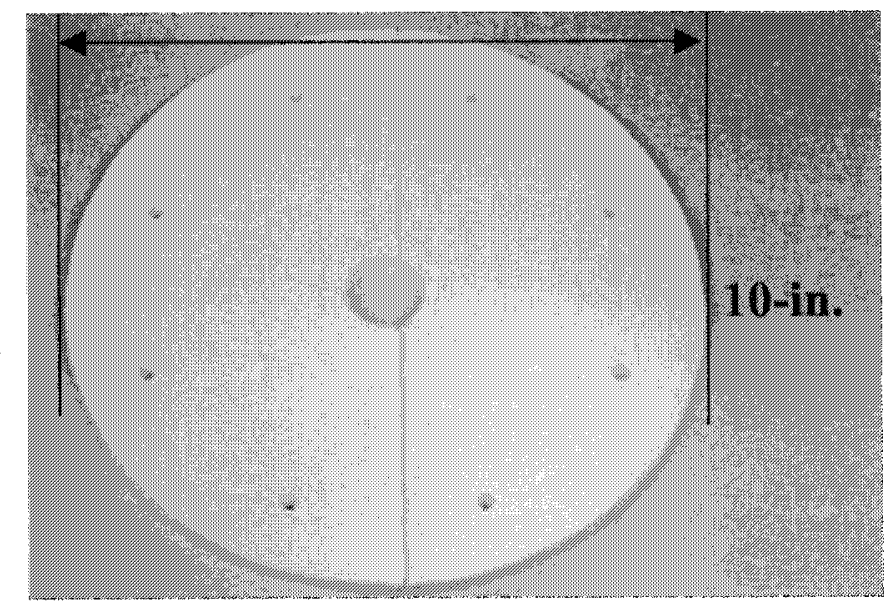

Figure 51: New zirconia baffles prior to installation.

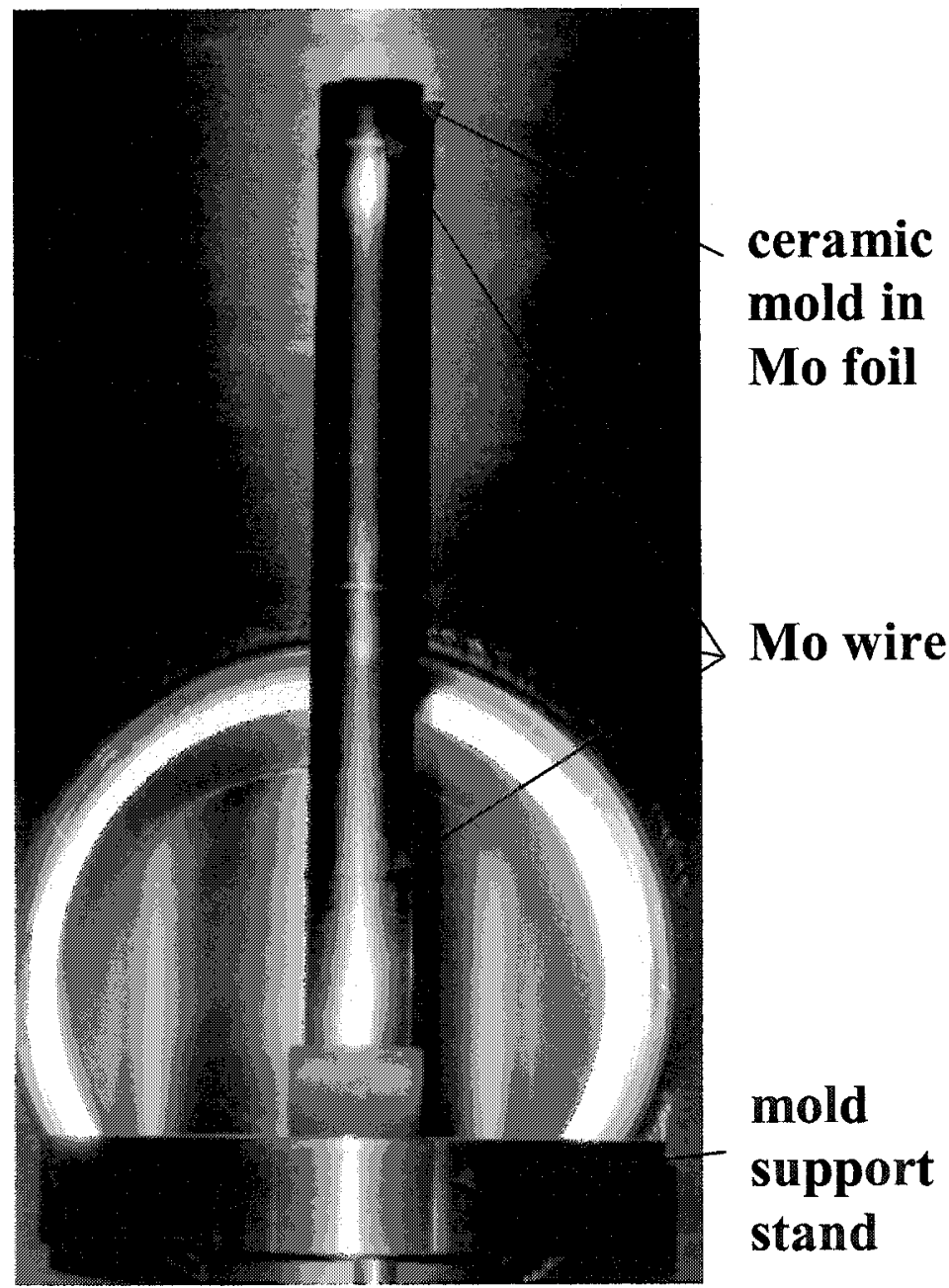

Figure 52: Mold assembly sitting in support stand on top of the copper chill platen. 


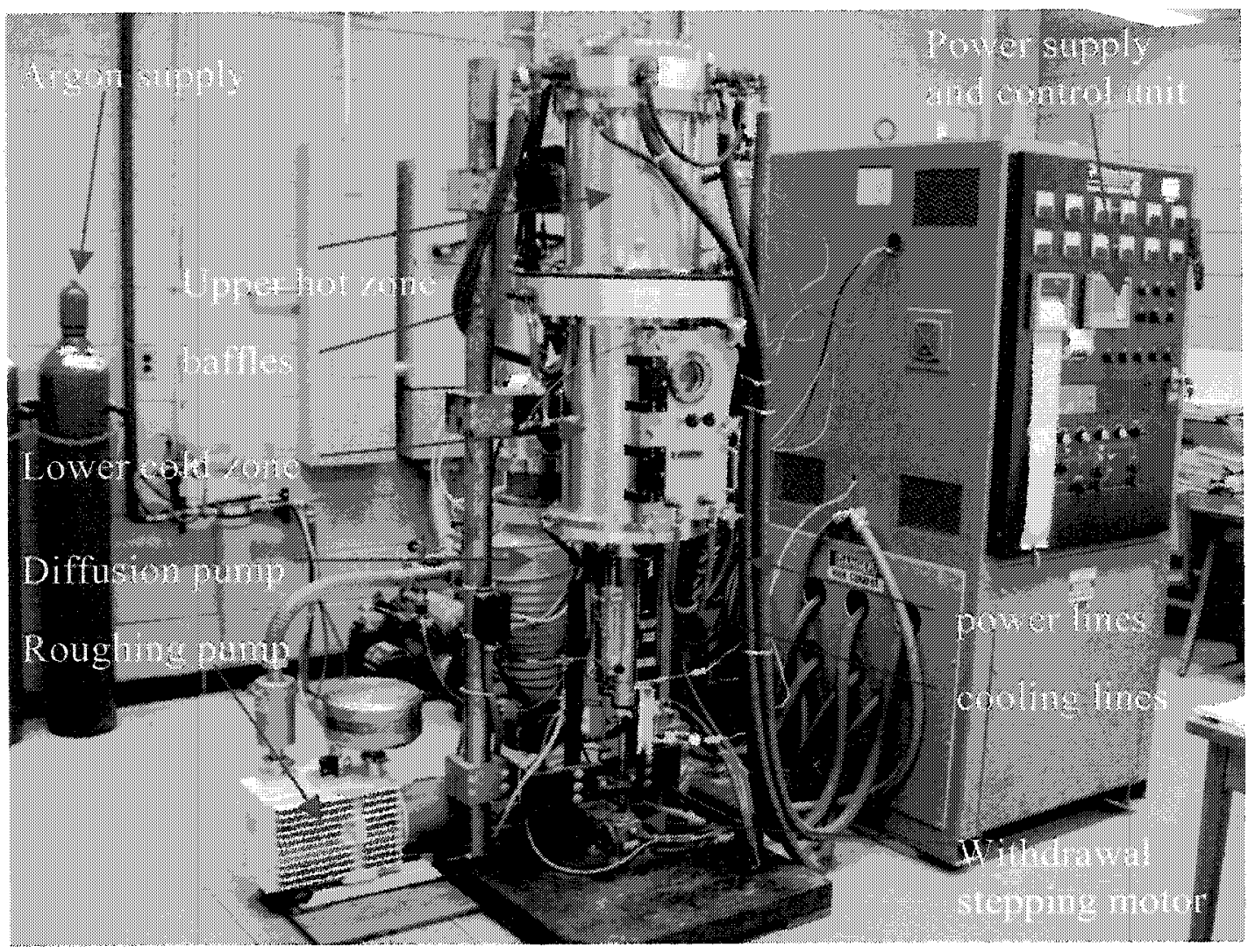

Figure 53: Carleton University DS furnace.

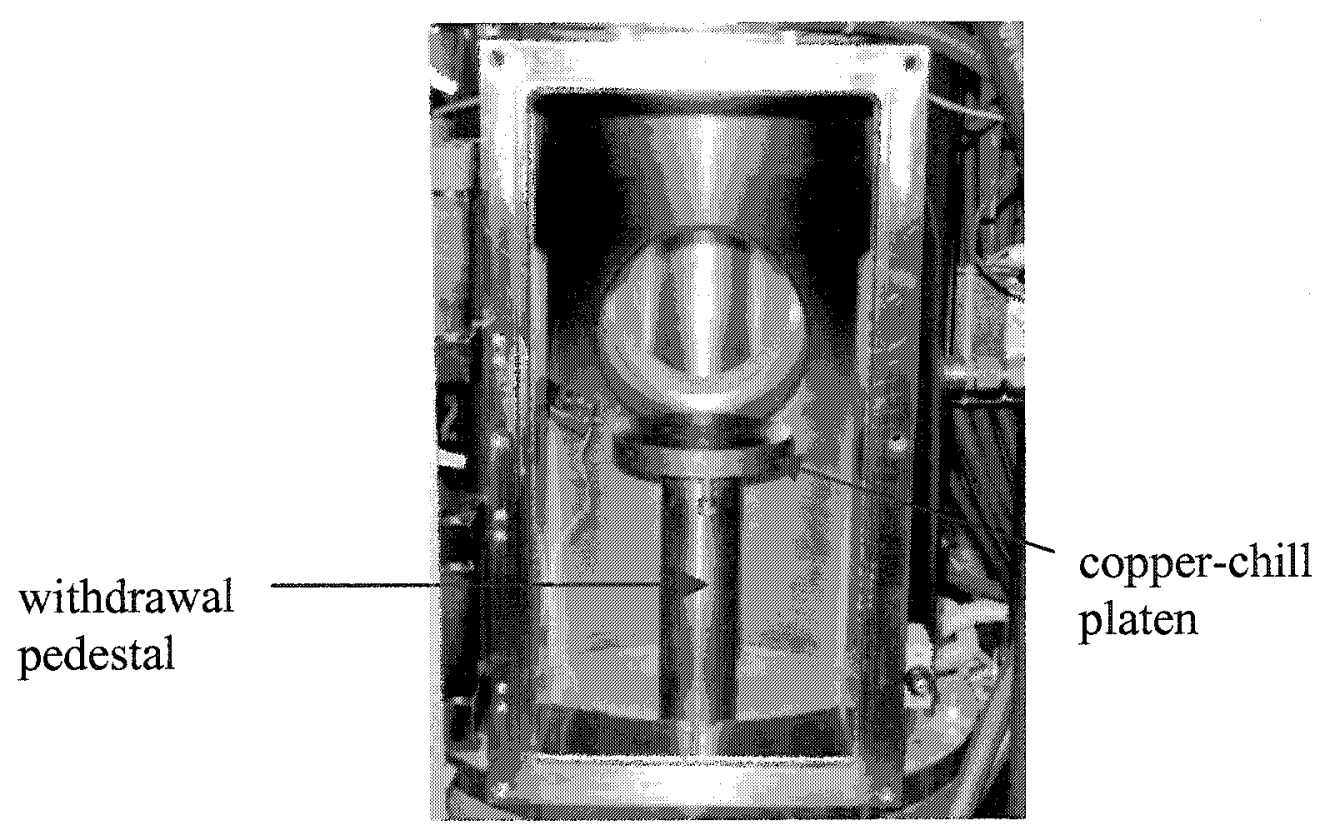

Figure 54: Inside lower chamber of DS furnace. 


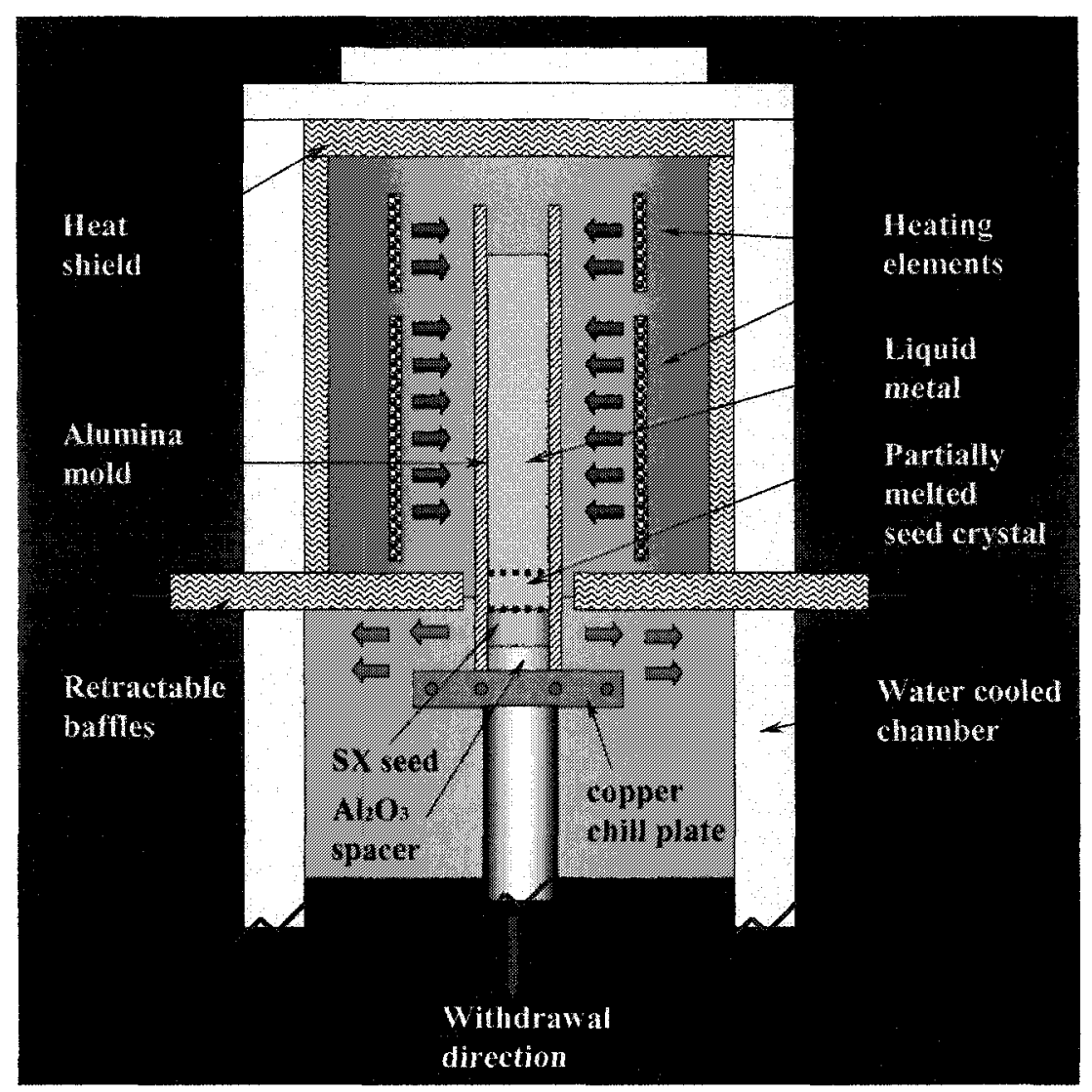

Figure 55: Schematic of experimental Bridgman-seed casting set-up.

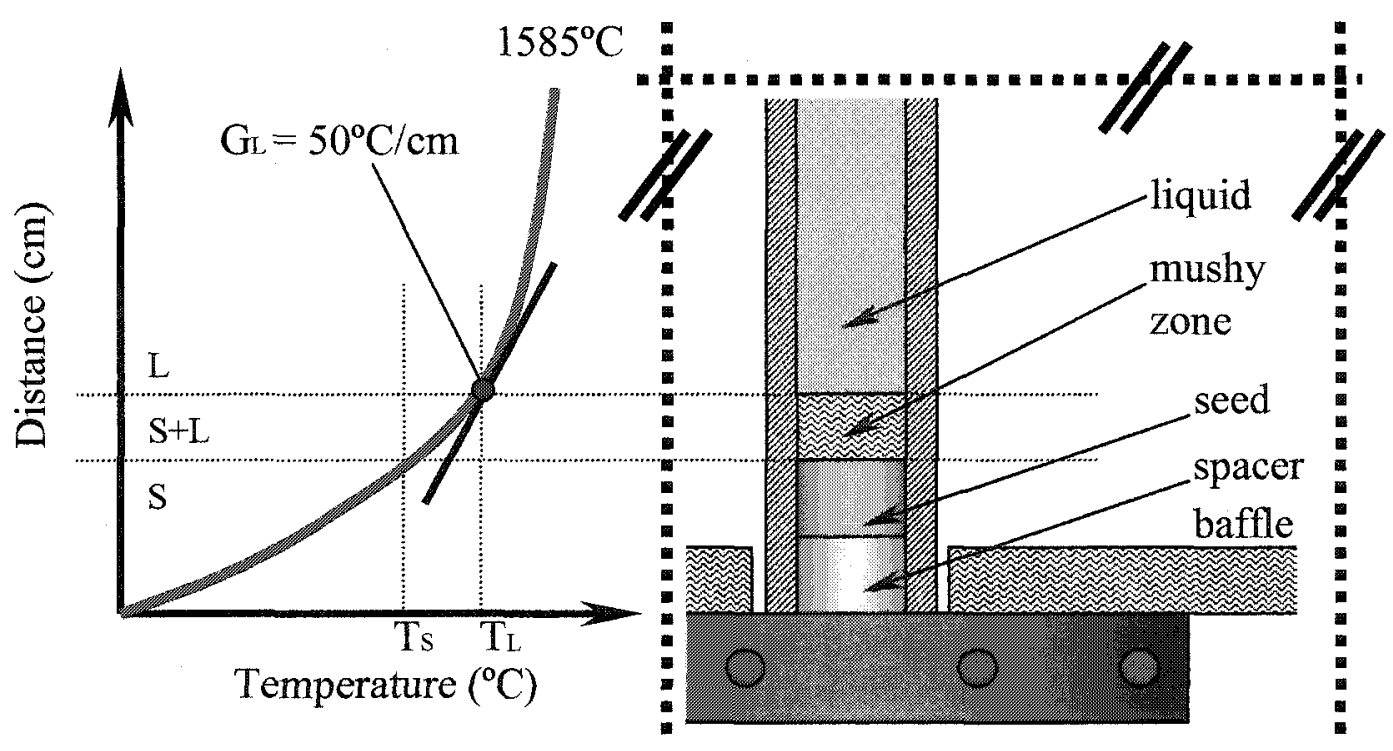

Figure 56: Schematic of temperature gradient $\left(G_{L}\right)$ within the casting as measured at the liquidus temperature $\left(T_{L}\right)$. 


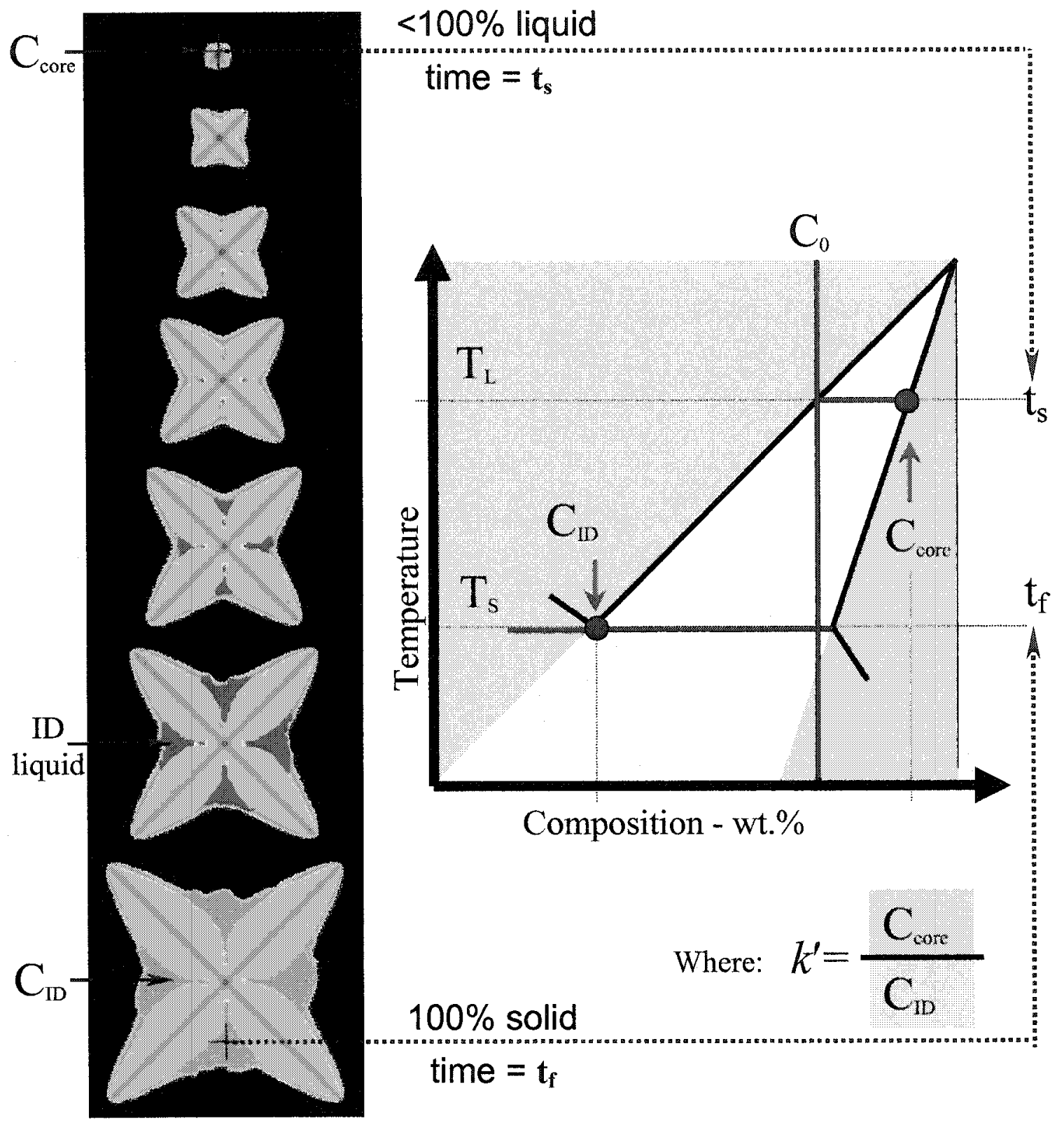

Figure 57: Left: Typical solidification behaviour of an individual dendrite. At the start of solidification, time $t_{s}$, the nucleation of the dendrite core first appears with the composition, $C_{\text {core }}$ At the end of solidification, time $t_{f}$, the final interdendritic liquid solidifies to form the $\gamma$ $\gamma^{\prime}$ eutectic phase of composition $\mathrm{C}_{\mathrm{ID}}$. Right: A pseudo phase diagram illustrating the solidification path of the alloy of composition, $C_{0}$, from the liquid phase through the solid+liquid phase field until the final solidification temperature of the solidus is reached as $T_{\mathrm{S}}$. The microsegregation coefficient, $k^{\prime}$, is defined as the ratio of the composition of the $1^{\text {st }}$ solid phase that forms to the composition of the last liquid phase to solidify. 


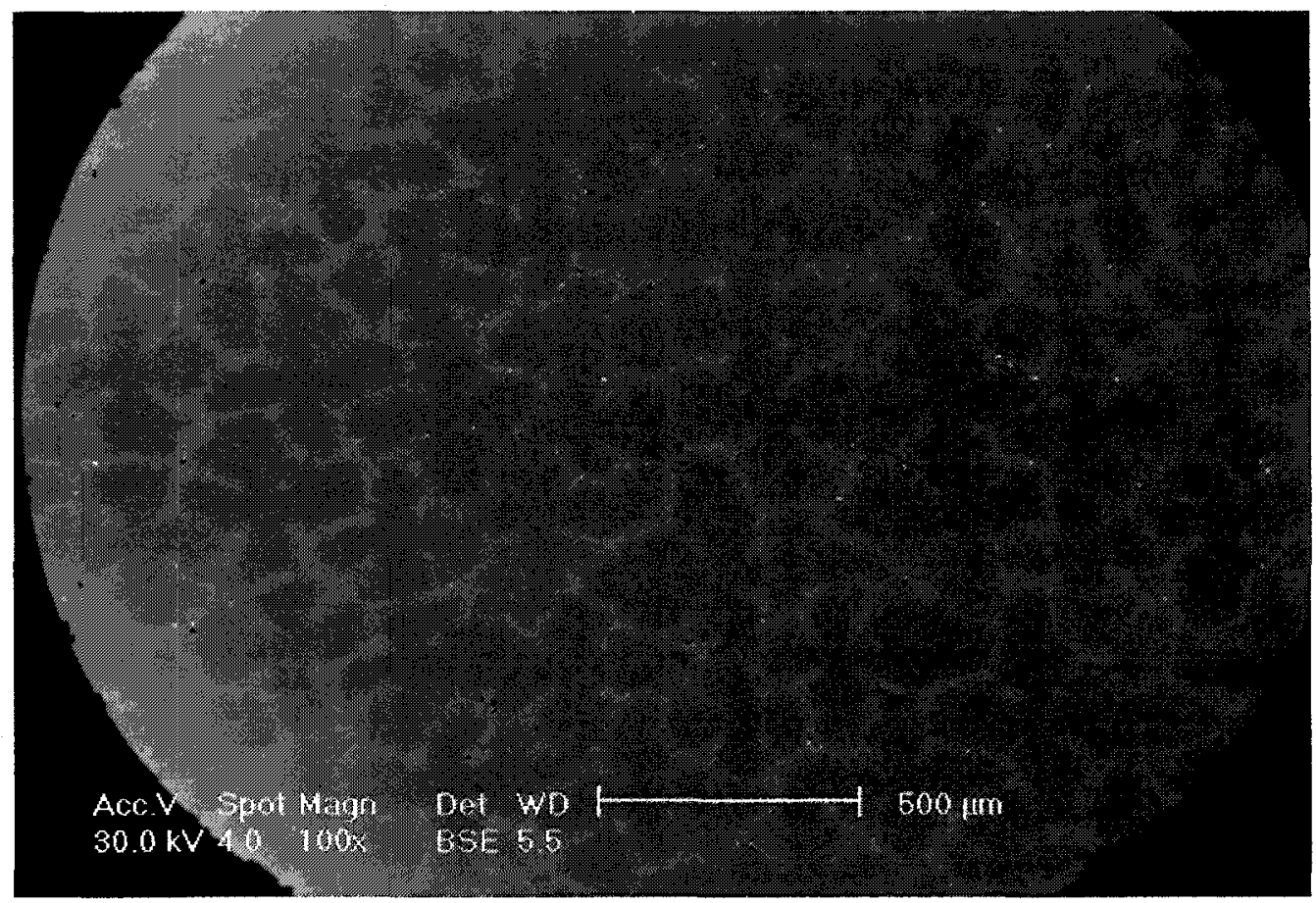

Figure 58: SEM image of unetched Alloy B solidification structure using the BSE detector of the Philips XL-30S SEM.

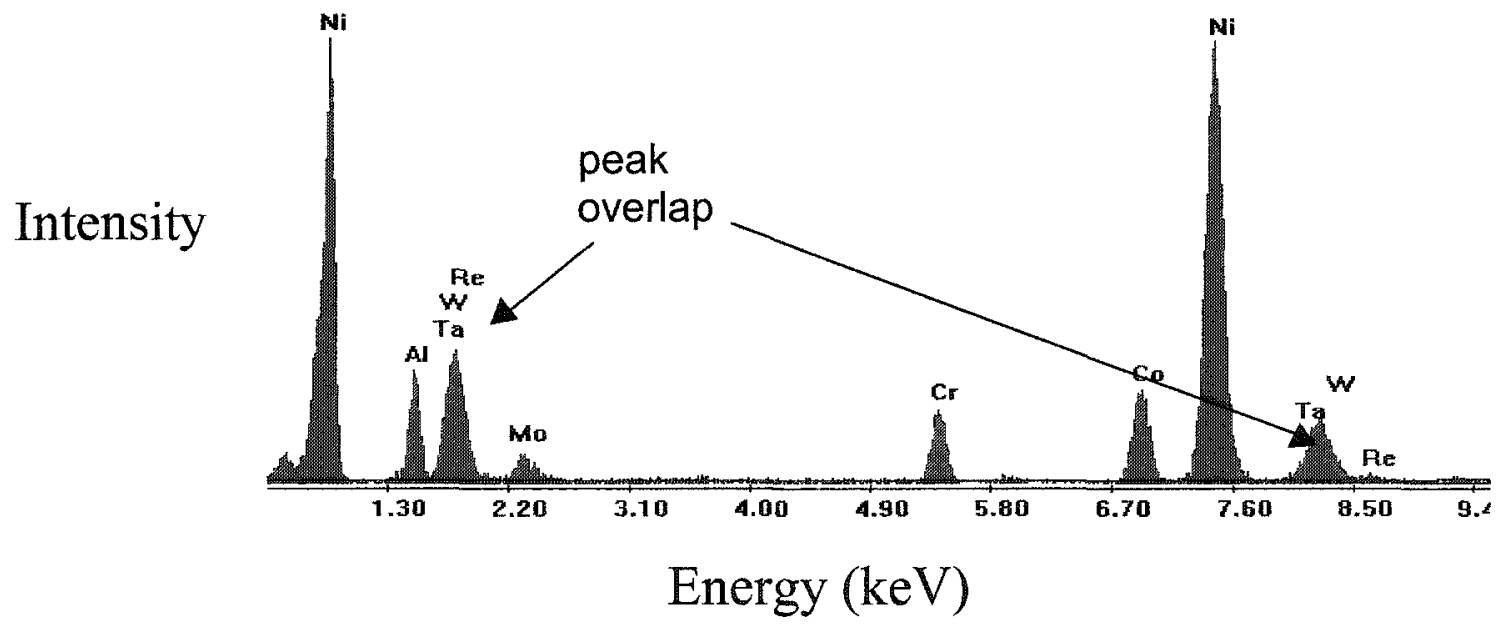

Figure 59: EDX spectrum showing peak overlap of W, Re and Ta for a representative spot analysis performed on Alloy B. 


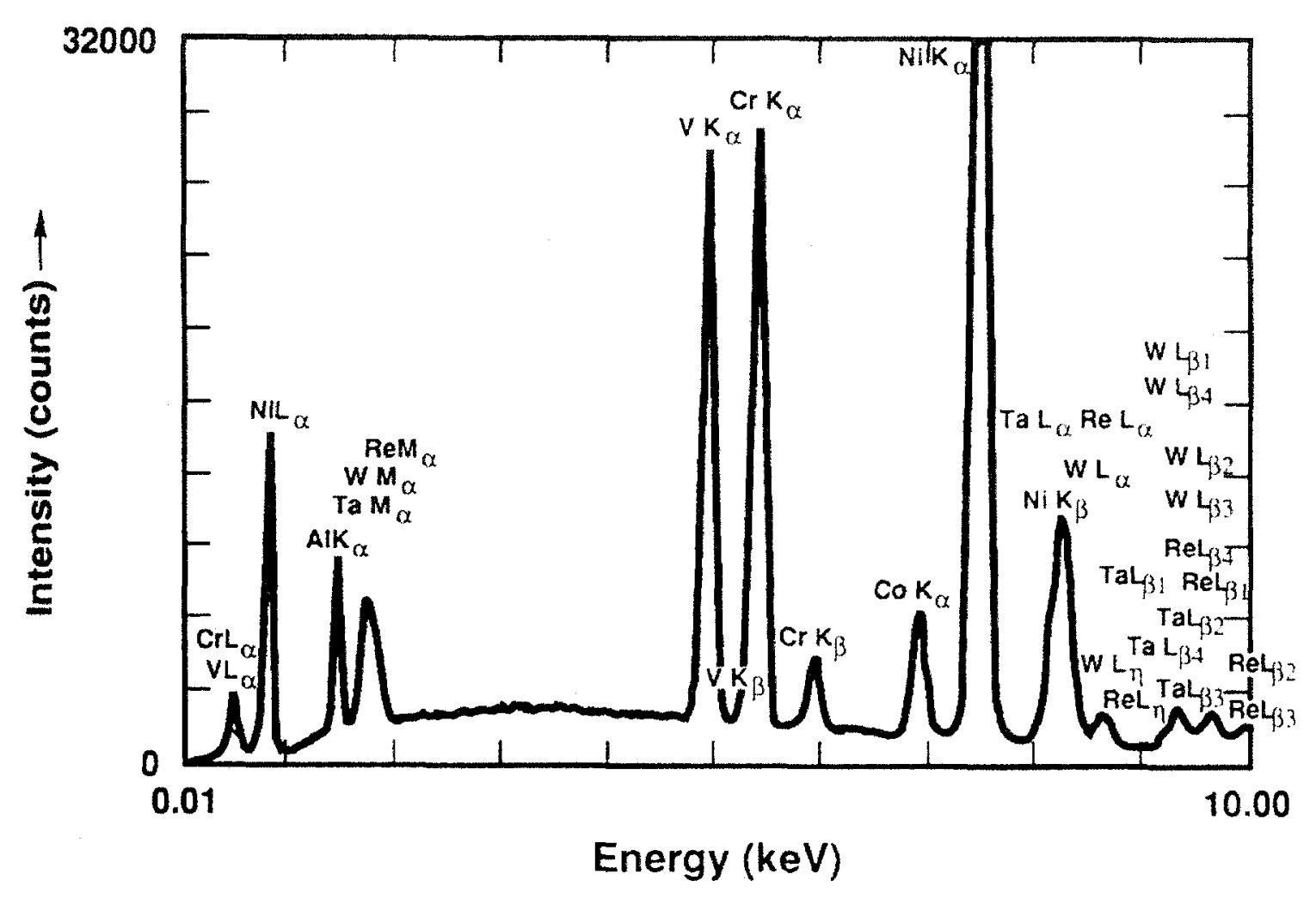

Figure 60: EDX spectrum for a high temperature superalloy [97]. 

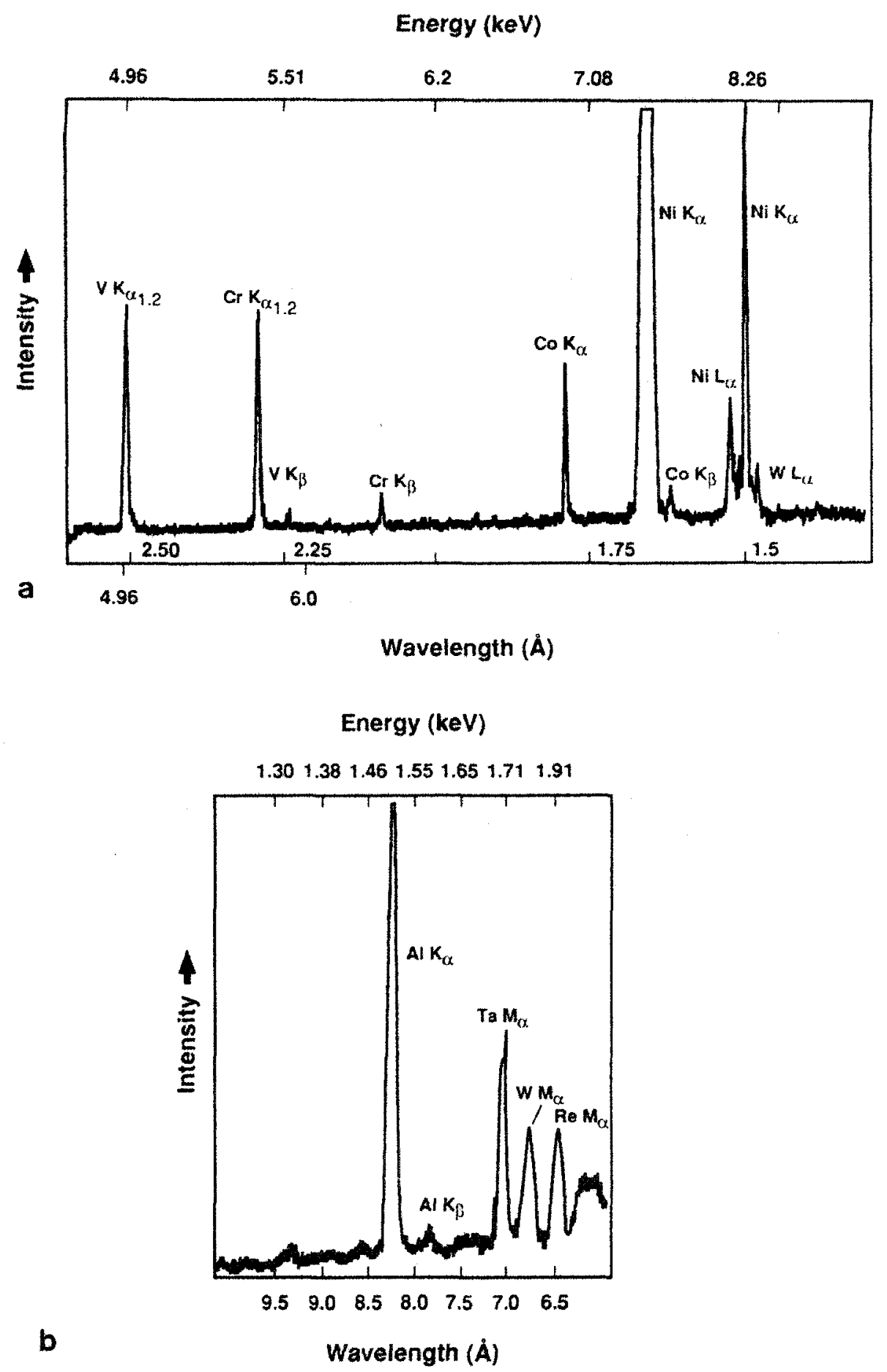

Figure 61: WDX spectrum for the same superalloy, a) scan using LiF crystal and b) scan using TAP crystal [97]. 


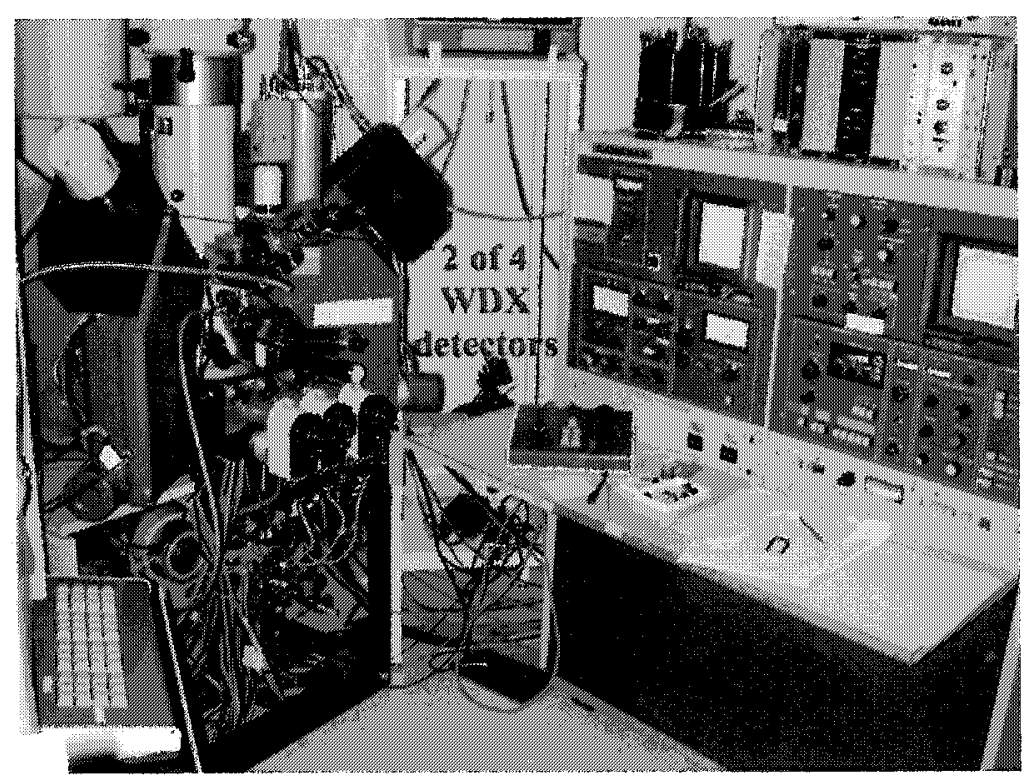

Figure 62: Camebax MBX Electron Microprobe located at Carleton University equipped with 4 WDX spectrometers.

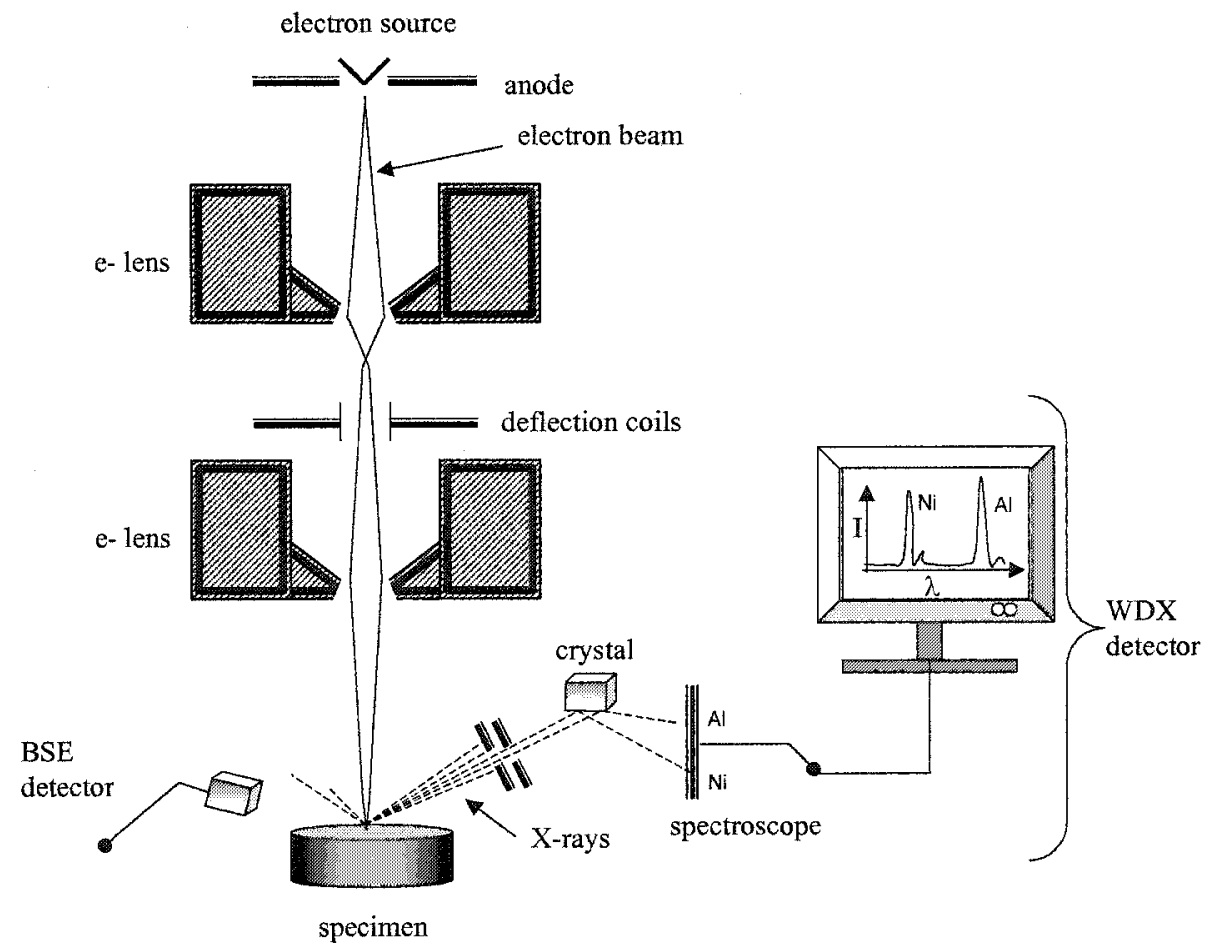

Figure 63: Schematic of a typical electron microprobe highlighting the WDX detector arrangement. 


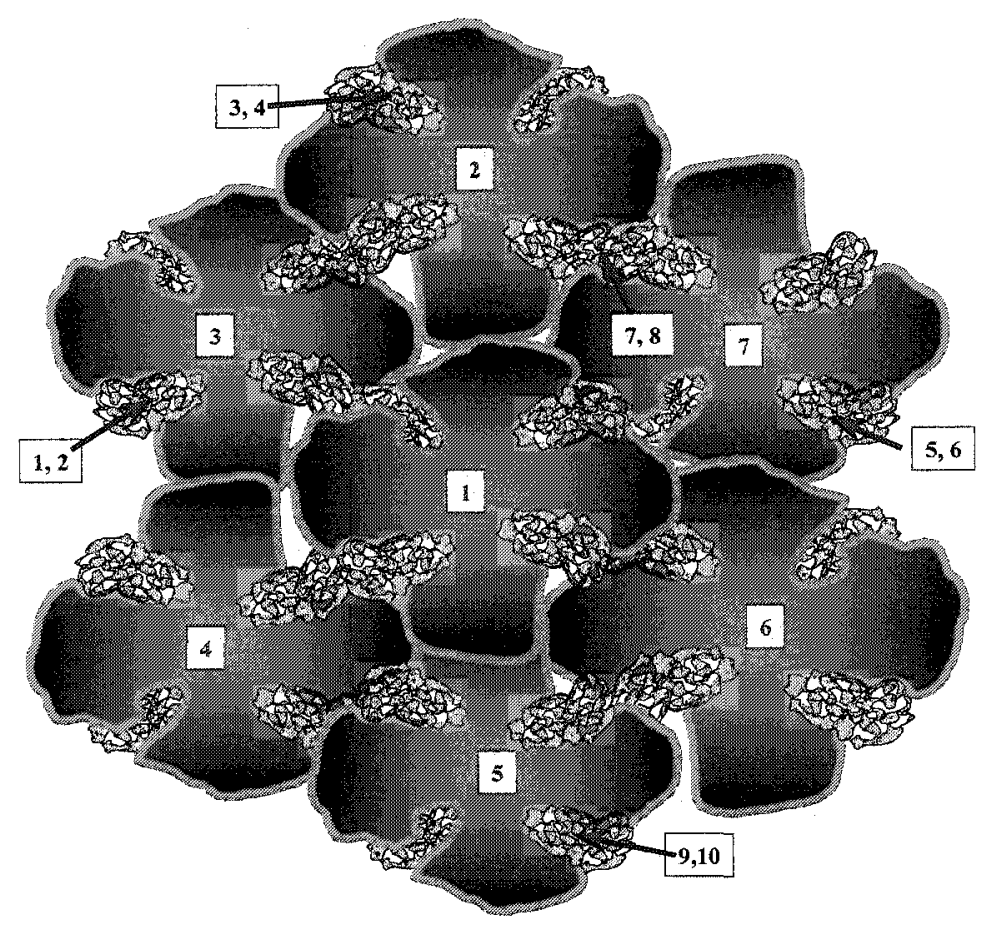

Figure 64: Schematic of EPMA spot-analysis procedure, illustrating the sampling method used to determine the dendrite core and interdendritic $\gamma-\gamma^{\prime}$ eutectic compositions.

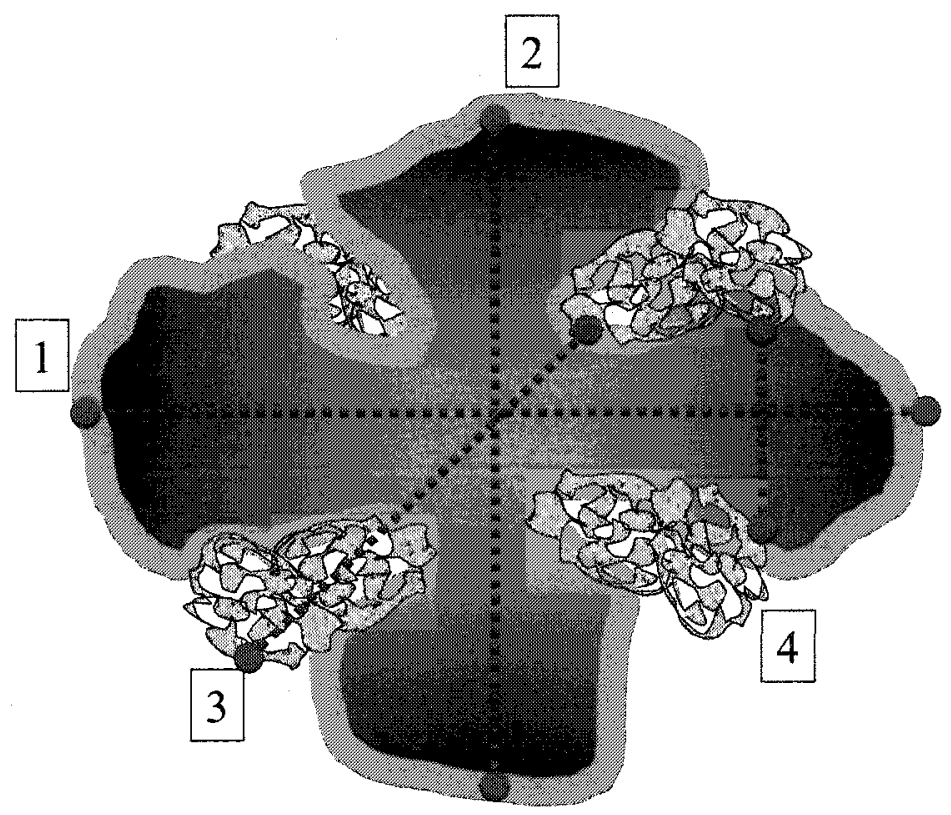

Figure 65: Schematic of EPMA line scan procedure, illustrating the different crystallographic directions used to determine compositional gradients across the dendritic solidification structure. 


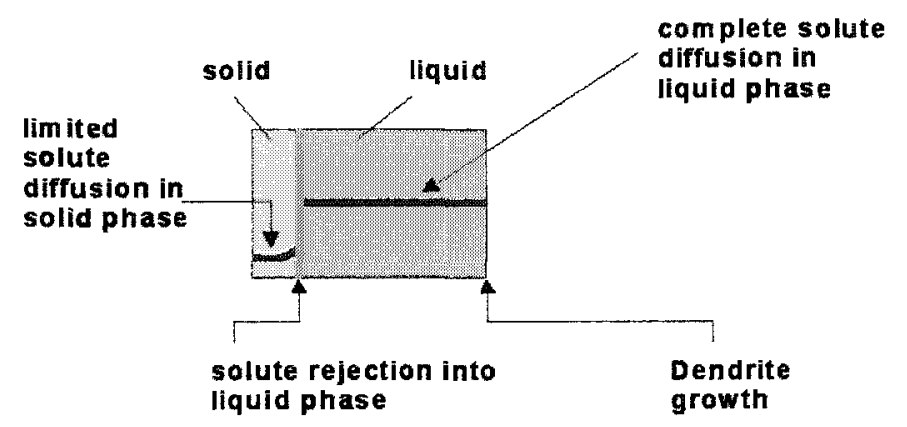

$$
\text { Time }=\boldsymbol{t}_{\boldsymbol{s}}
$$
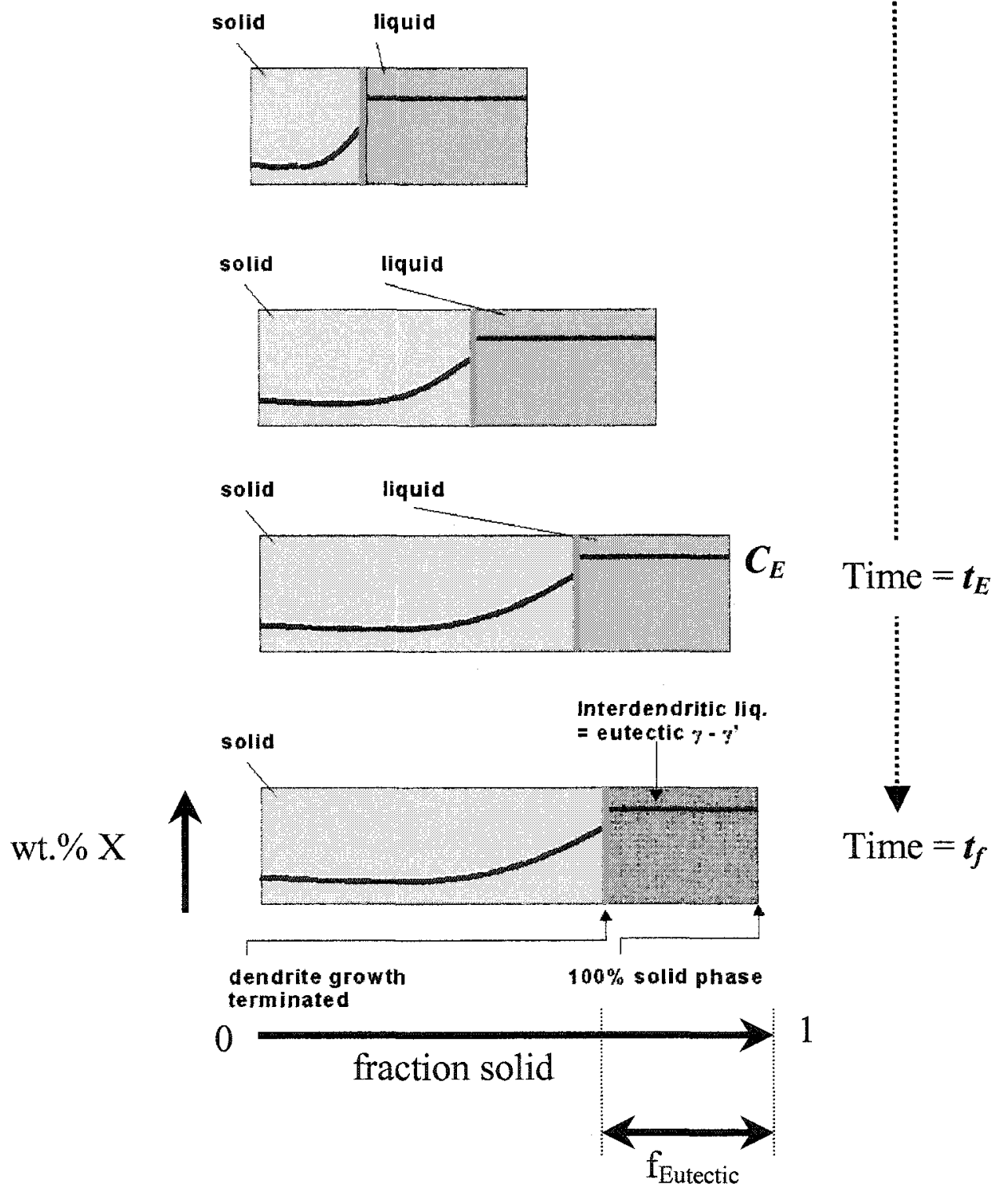

Figure 66: Schematic of solute rejection across the solid-liquid interface during dendritic growth. At time, $t_{E}$, the liquid composition reaches the final eutectic composition and the remaining liquid solidifies as the $\gamma-\gamma^{\prime}$ eutectic phase. 


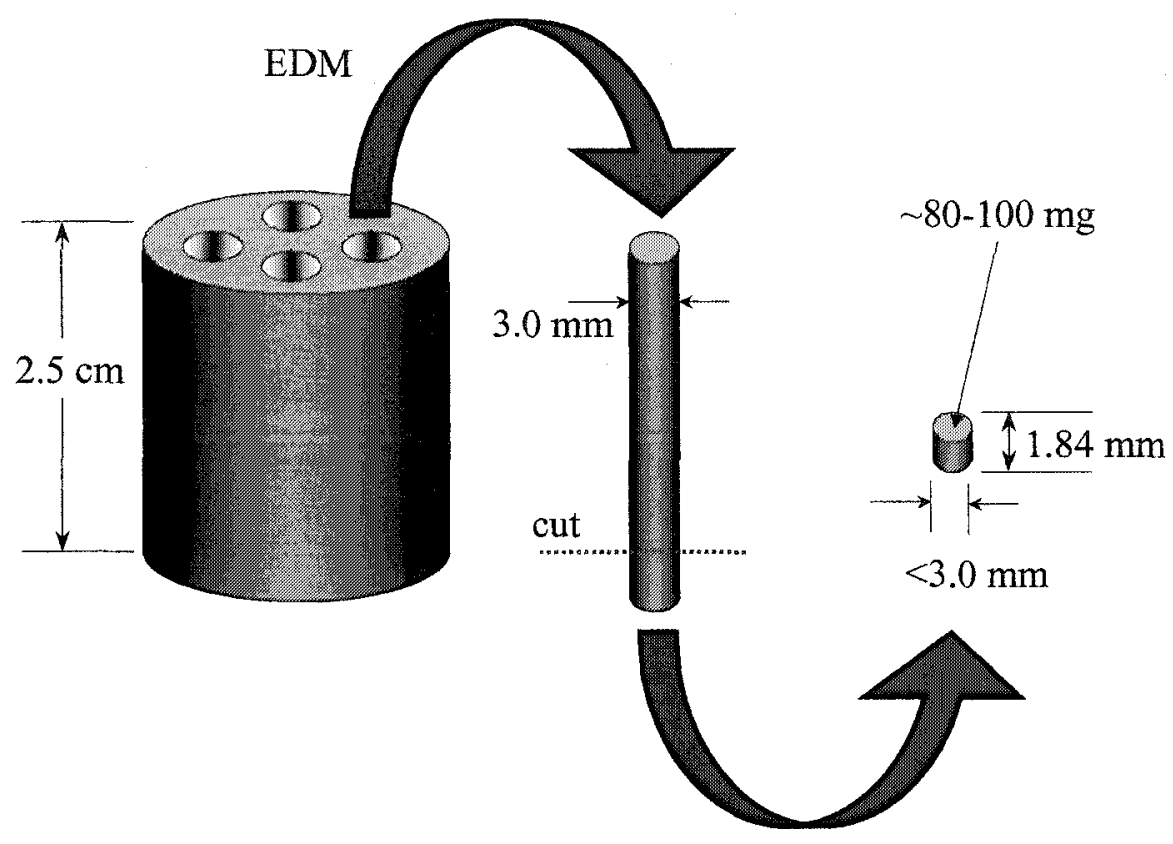

Figure 67: Schematic of the DSC sample preparation procedure.

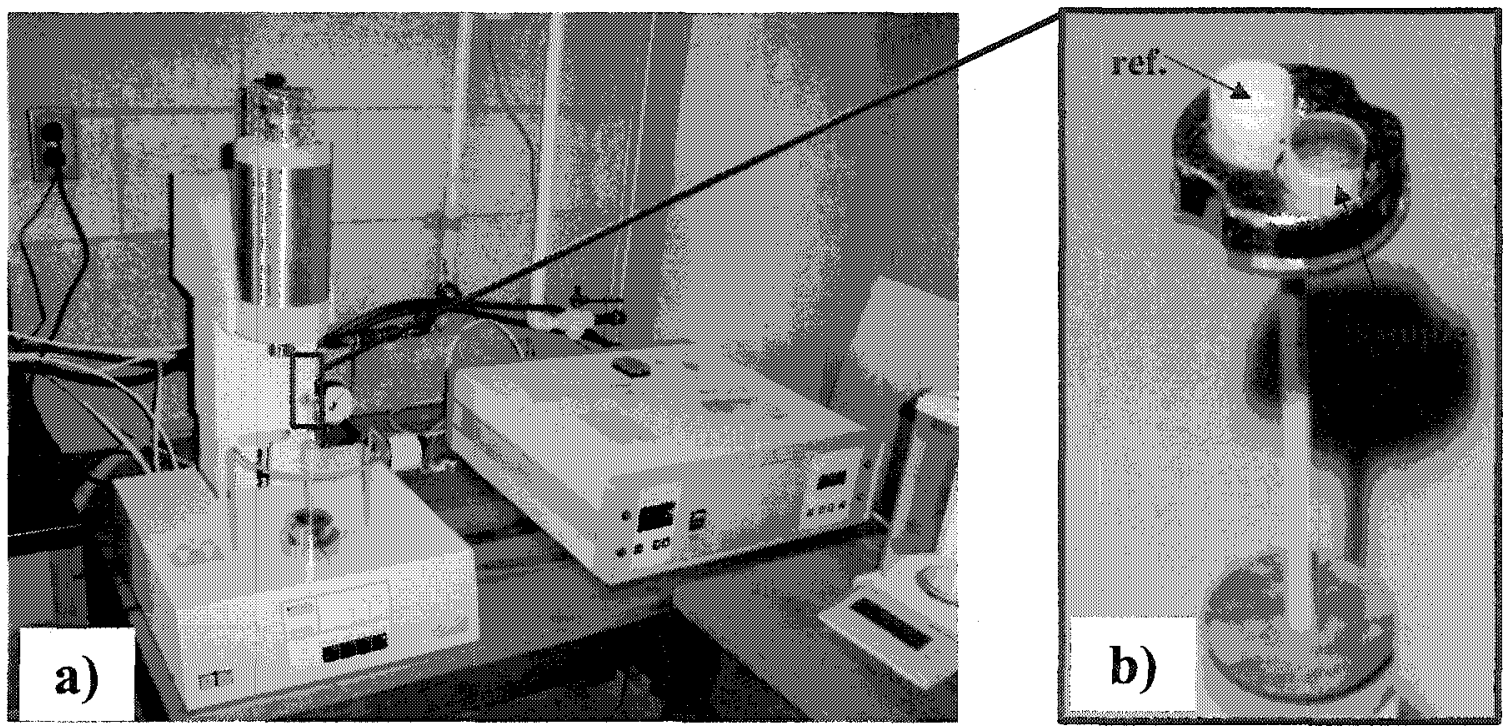

Figure 68: a) Netzsch ${ }^{\mathrm{TM}}$ 404-C Pegasus DSC, b) close-up of DSC measuring-head showing the reference and specimen crucible locations. 


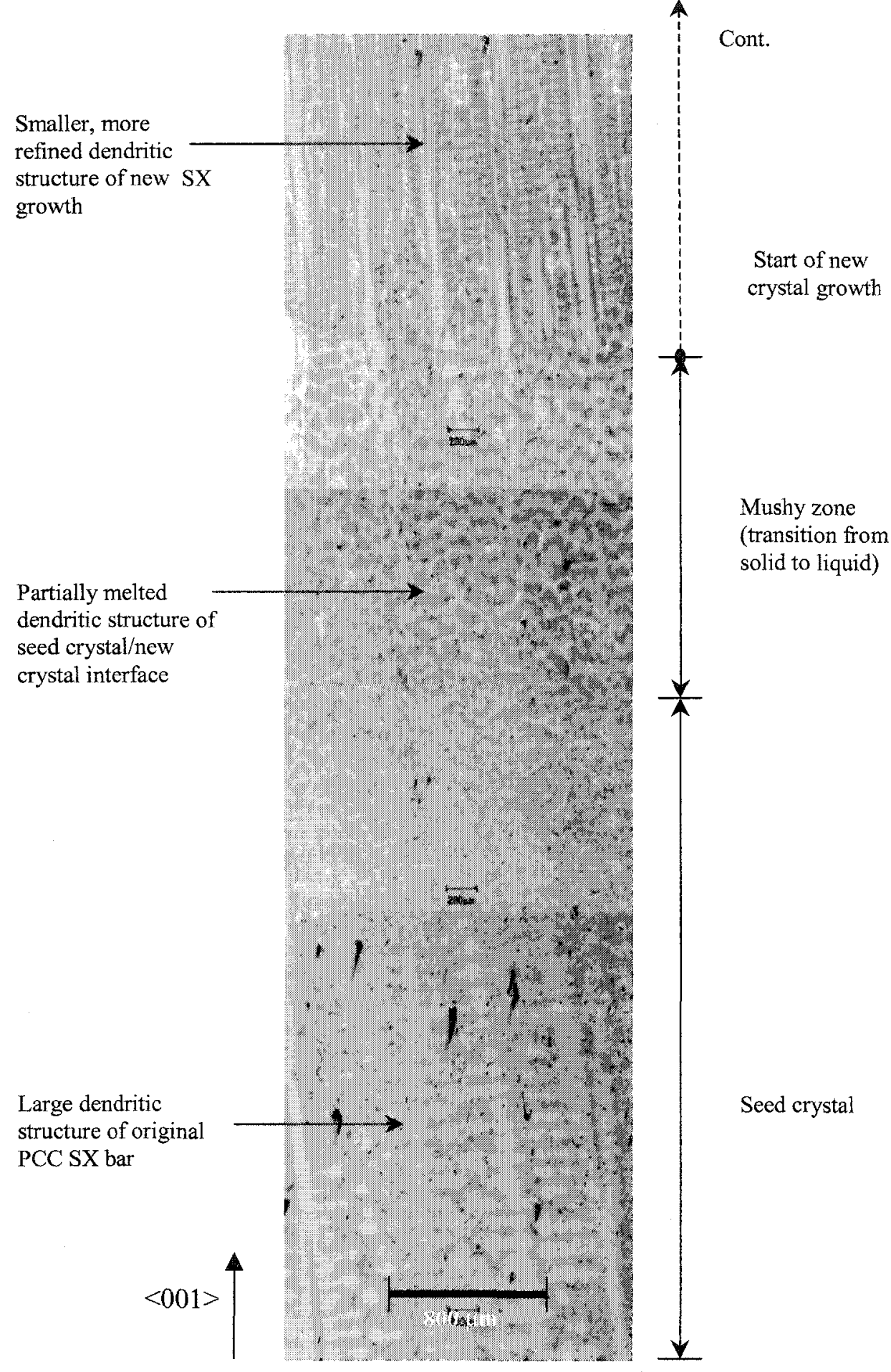

Figure 69: Partial longitudinal cross-section of SX PWA-1484 test bar showing dendritic transition from the seed, through the mushy zone into the new SX region. 
Finer dendritic structure of new SX growth

Partially melted dendritic structure of mushy zone

transverse dendritic structure of SX seed
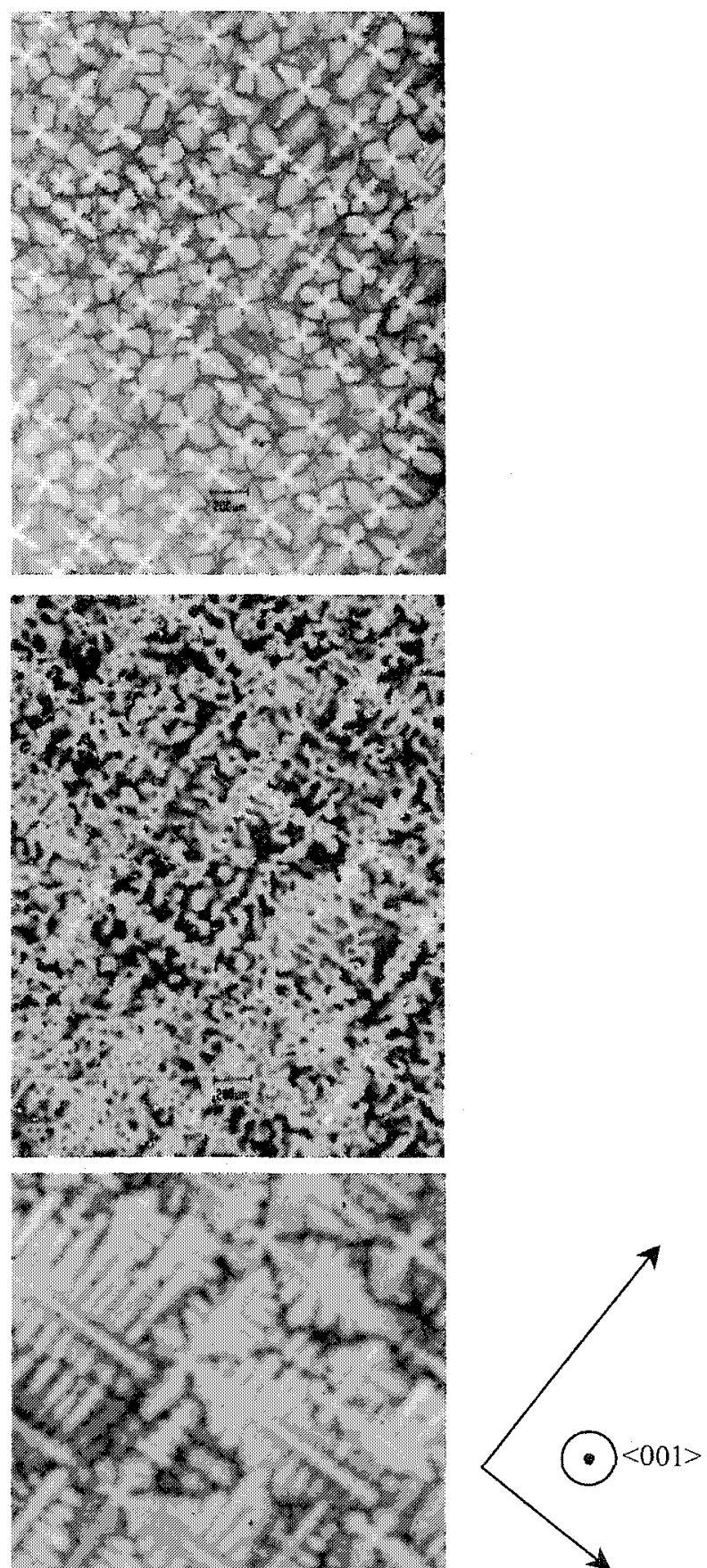

Primary dendrite arm axes

Figure 70: Transverse sections of SX PWA 1484 test bar showing dendritic transition from the seed to the new SX growth region. Apparent in the micrographs is the conservation of dendrite orientation throughout the new SX bar. 


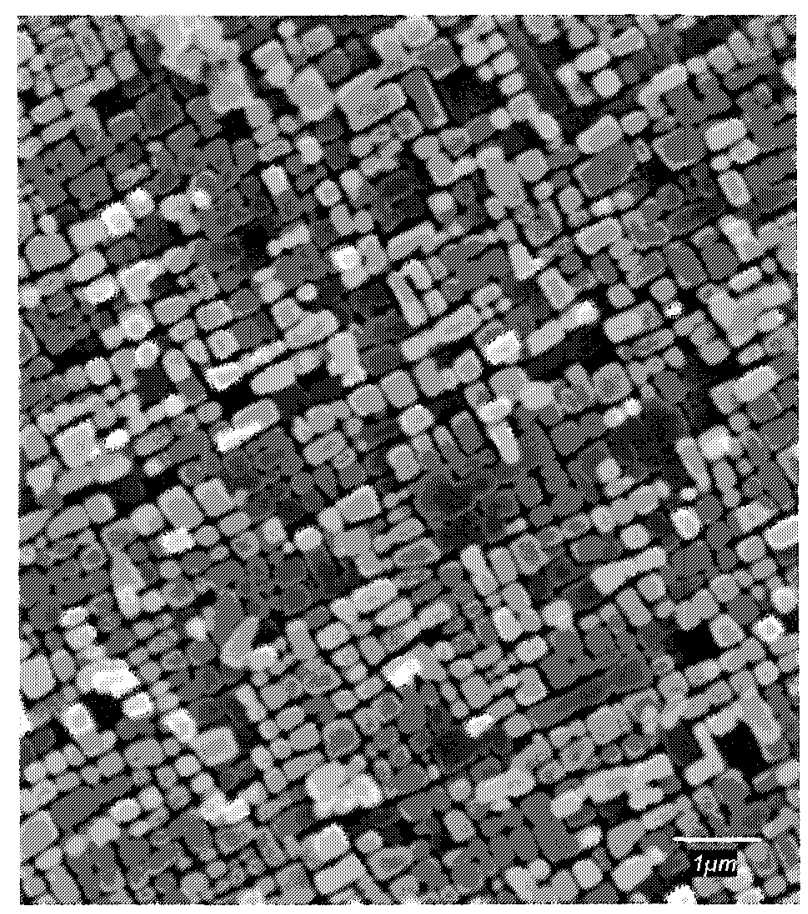

Figure 71: Morphology and distribution of $\gamma^{\prime}$ in Carleton University trial SX casting (heattreated PWA-1484).

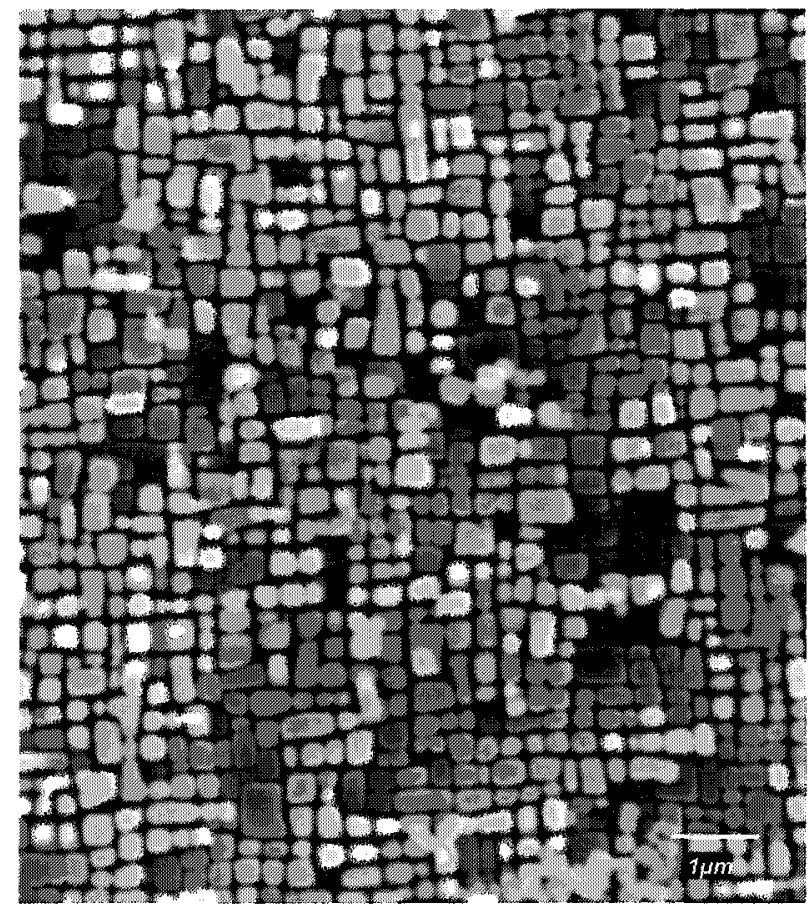

Figure 72: Morphology and distribution of $\gamma^{\prime}$ in PCC SX casting (heat-treated PWA-1484). 


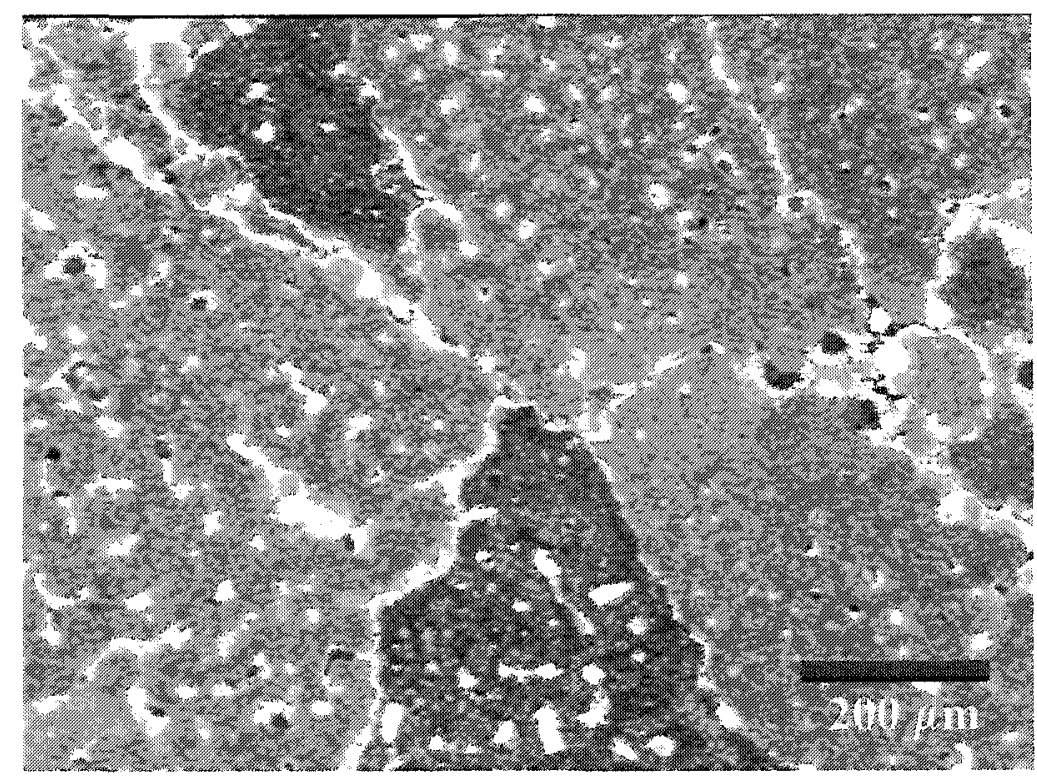

Figure 73: Transverse micrograph of SX-A1 showing the directionally solidified columnar grain structure due to insufficient superheat conditions.

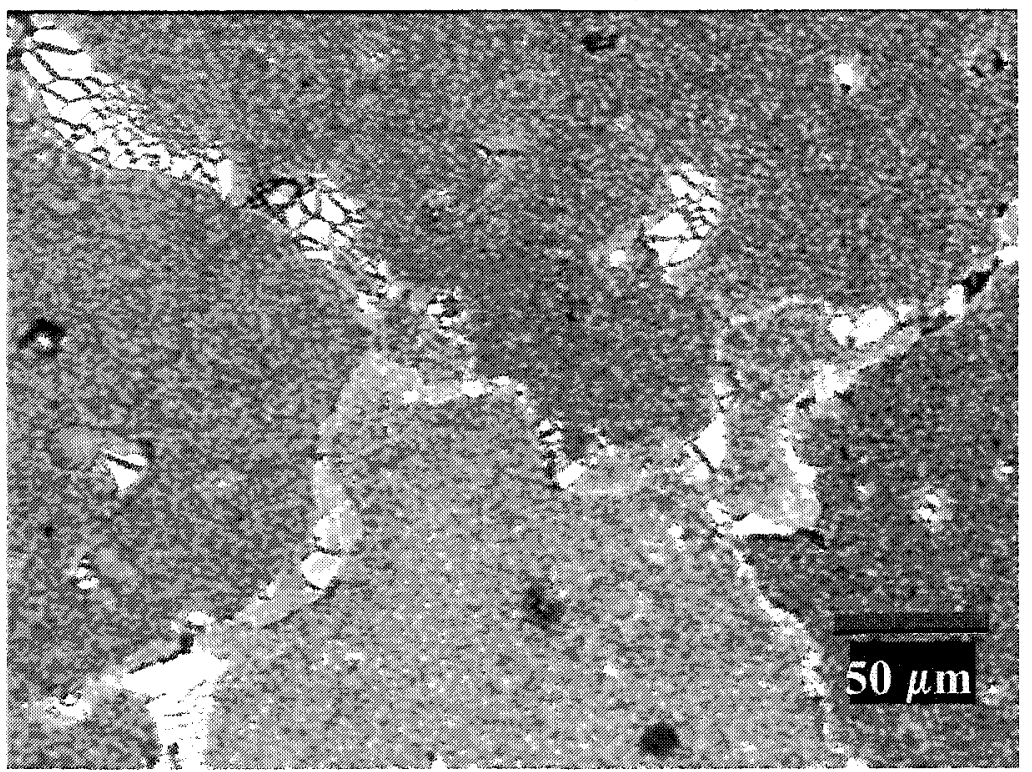

Figure 74: Higher magnification image of SX-A1 showing the grain boundaries heavily decorated in the $\gamma-\gamma^{\prime}$ eutectic phase. 


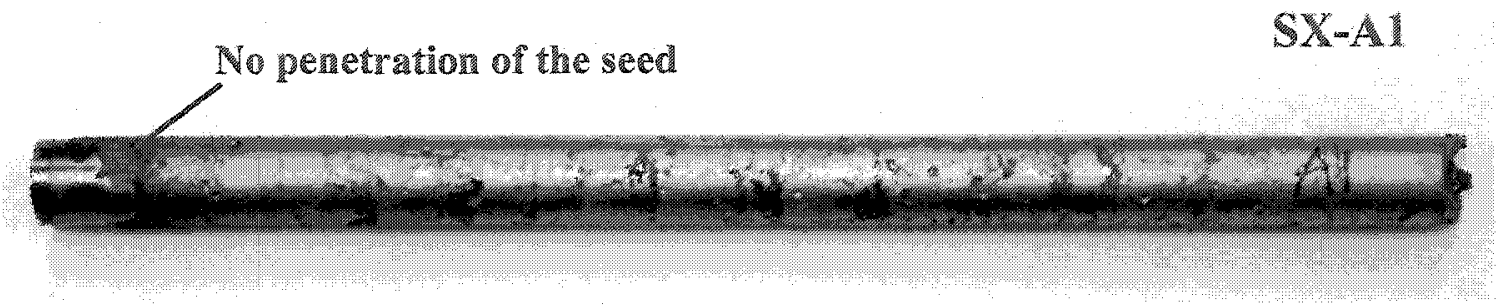

Figure 75: Unsuccessful casting of Alloy A due to insufficient superheat present to partially melt the seed.

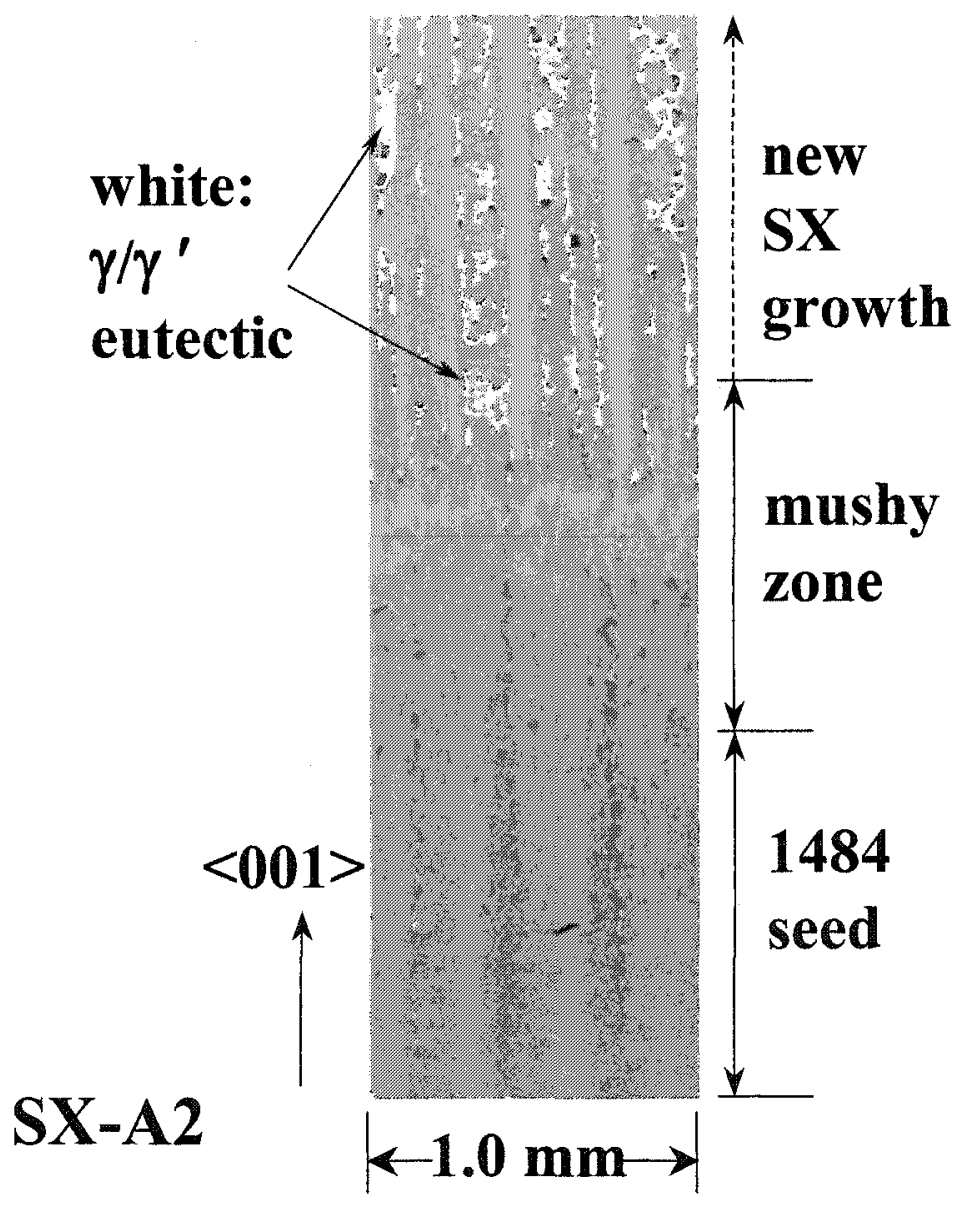

Figure 76: Partial longitudinal cross-section of bottom-end of cast bar SX-A2, illustrating transition from the large dendritic structure of seed material, through the partially melted mushy zone, into the new region of SX growth. Large white areas are interdendritic $\gamma / \gamma^{\prime}$ eutectic. 


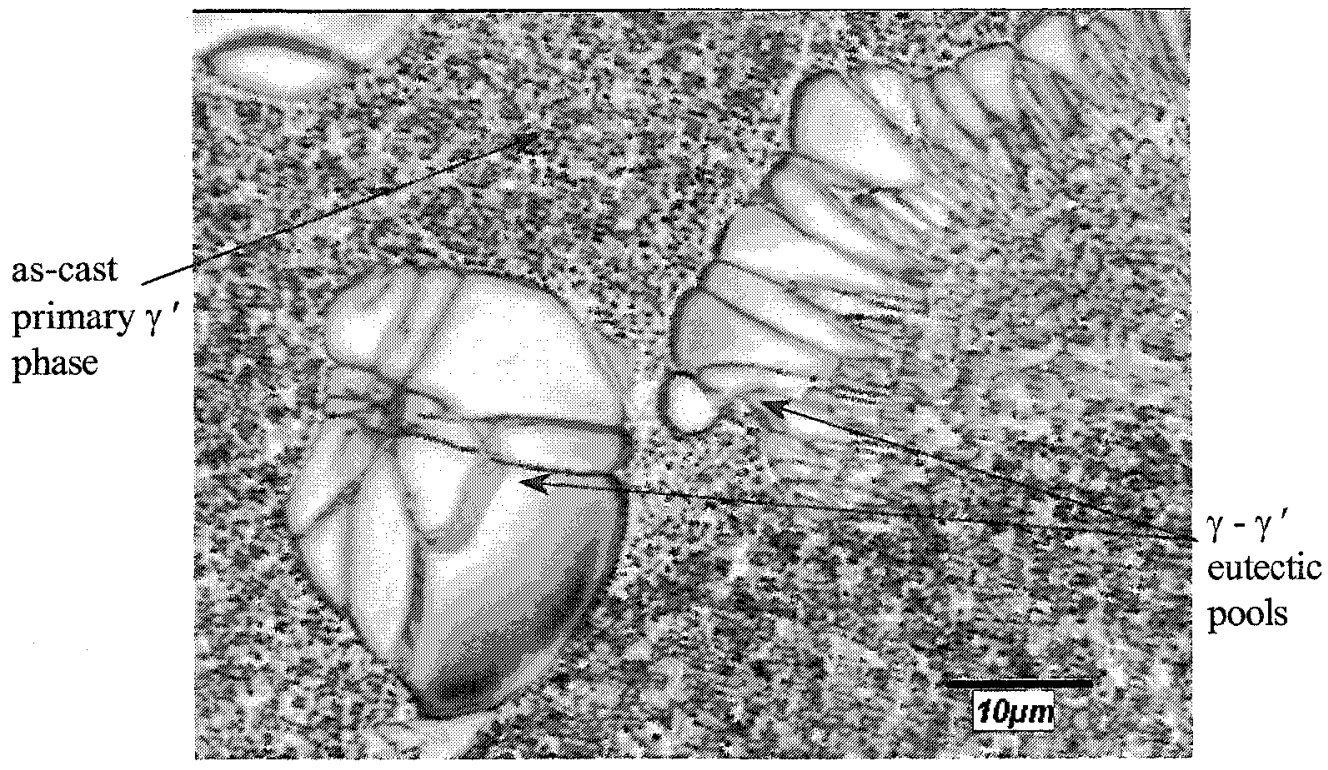

Figure 77: Transverse optical micrograph showing the morphology and size of the interdendritic $\gamma-\gamma^{\prime}$ eutectic phase in comparison to the primary $\gamma^{\prime}$ phase.

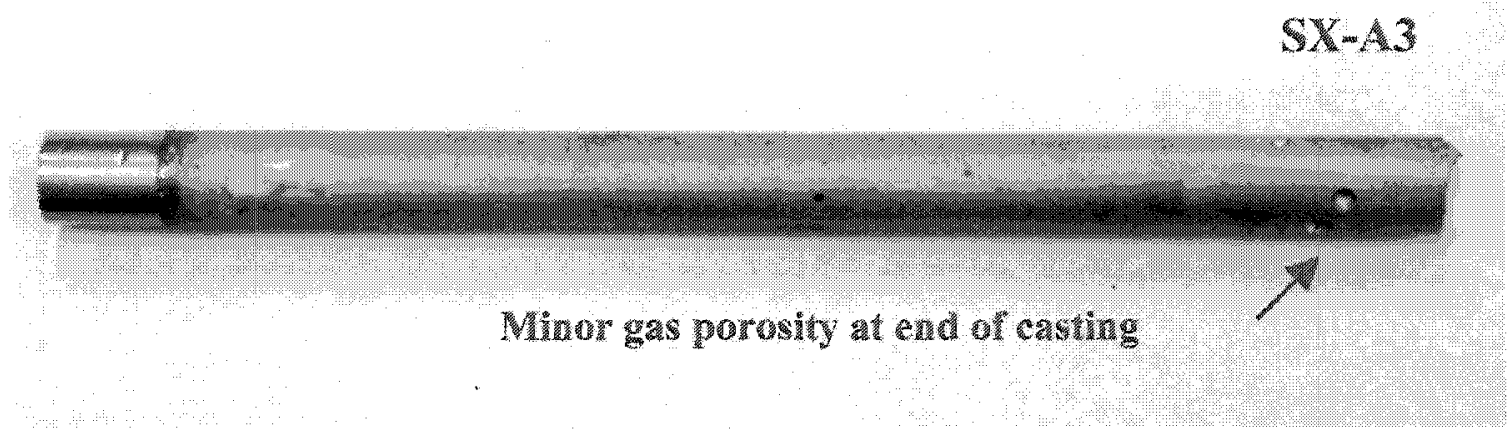

Figure 78: Photograph of SX-A3 showing excellent surface finish with only minor amounts of gas porosity present at the end of the cast bar due to vacuum environment. 


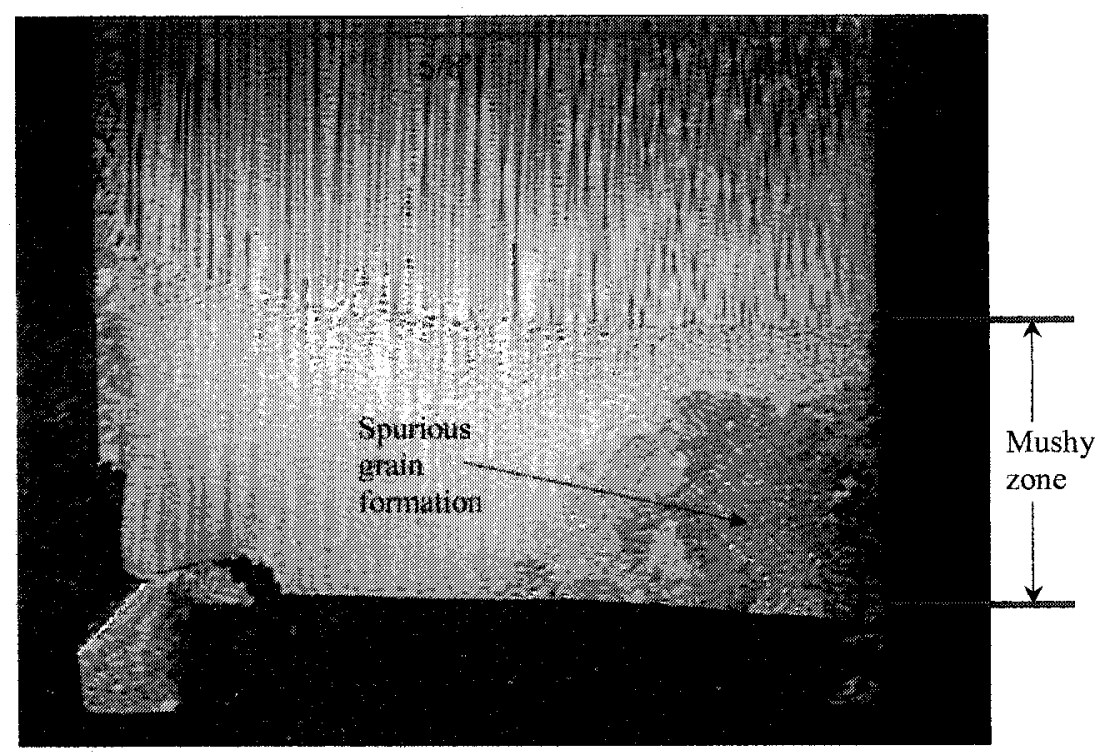

Figure 79: Macroscopic image of SX-A3 illustrating extensive seed melting to the base of the seed material.

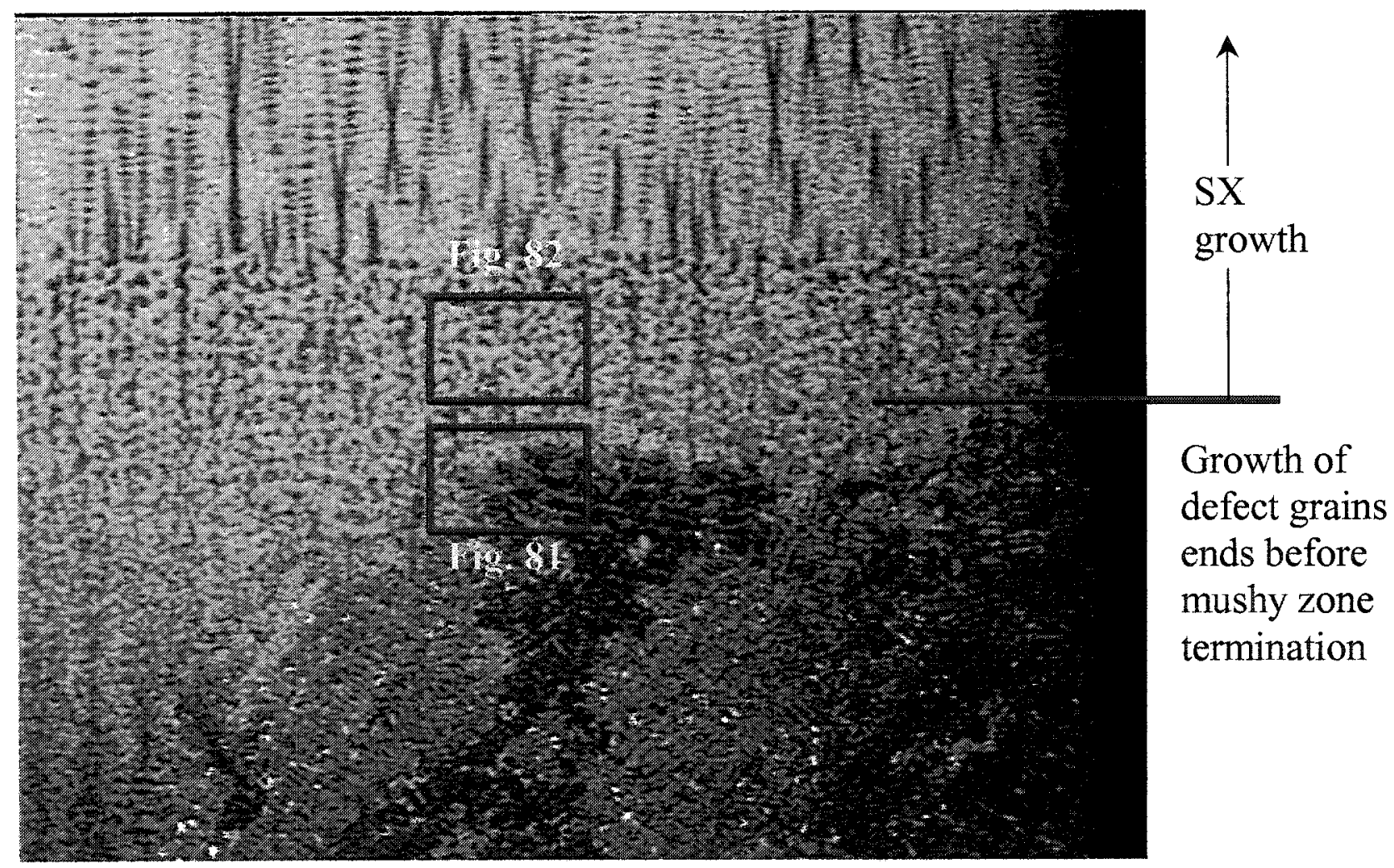

Figure 80: Close-up of spurious grain growth region resulting from liquid metal run-off between the mold and SX seed. 


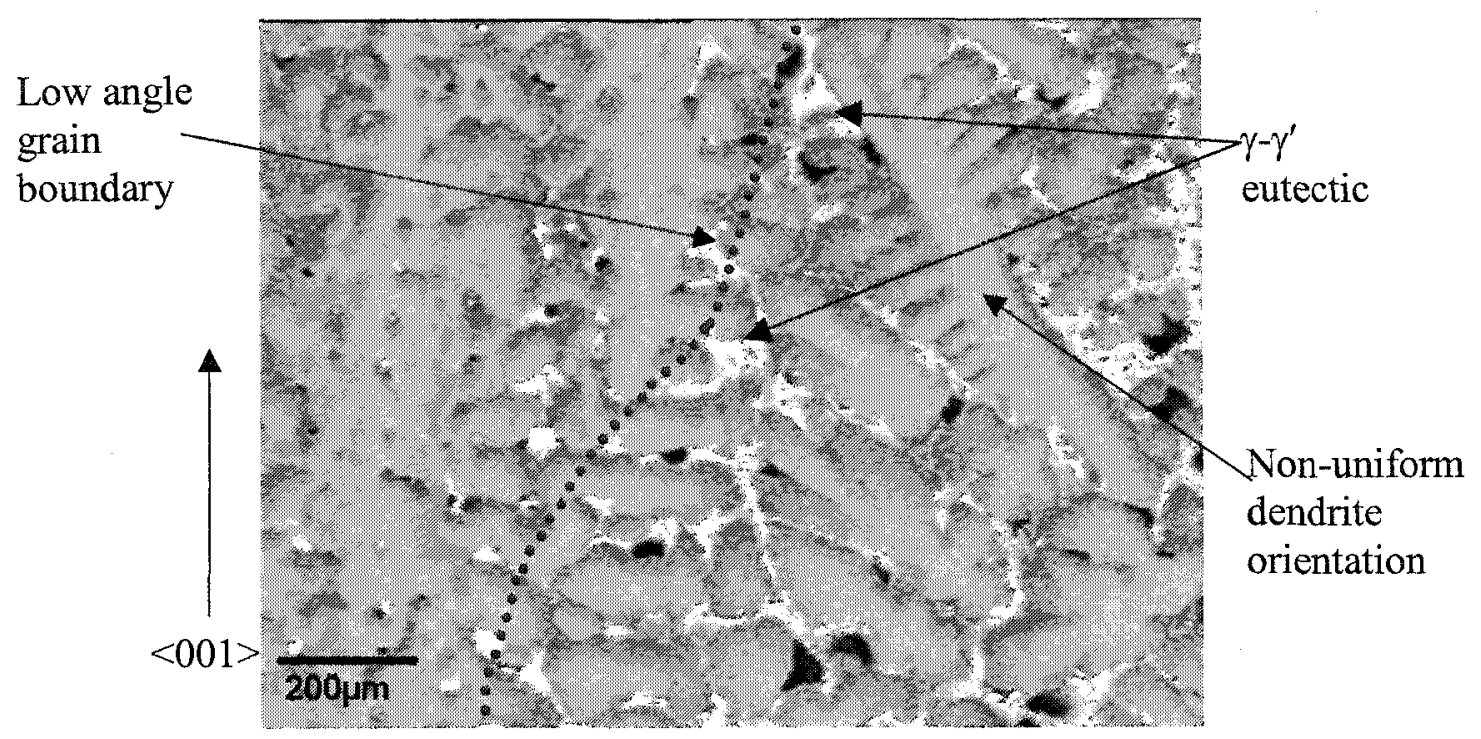

Figure 81: Spurious grain formation within the partially melted SX seed depicting the presence of low angle grain boundaries and significant amounts of eutectic $\gamma-\gamma^{\prime}$ phase.

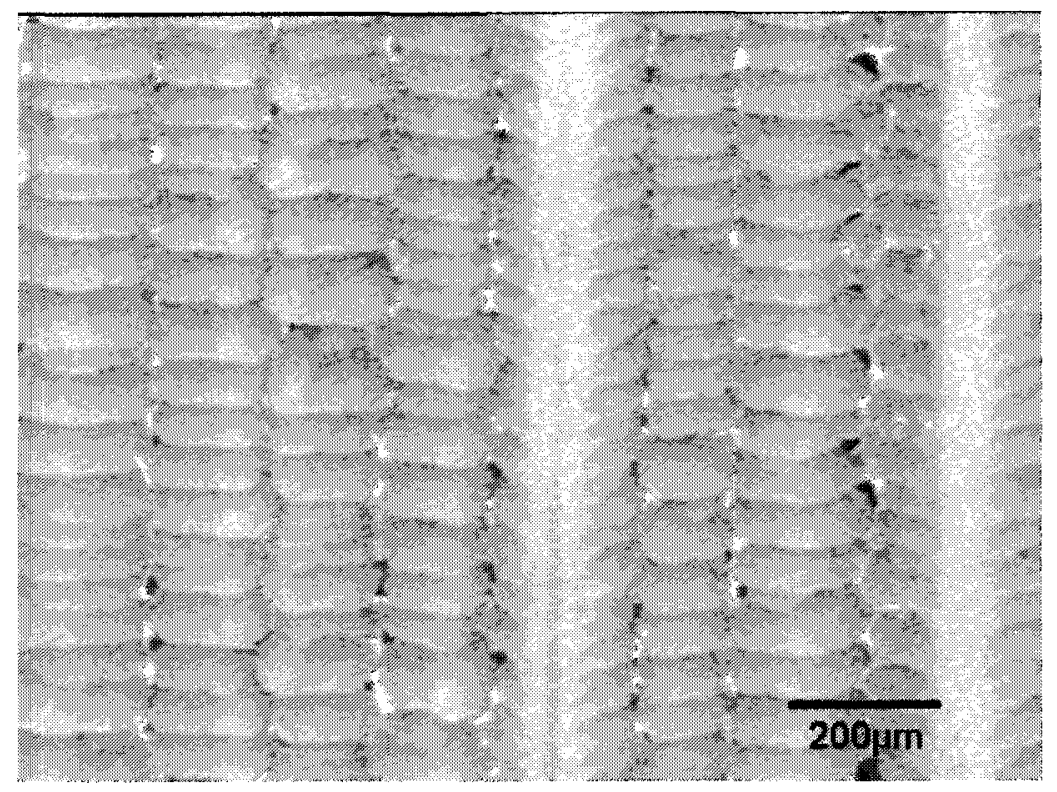

Figure 82: Unaffected SX structure located directly above the grain defects in the seed. 


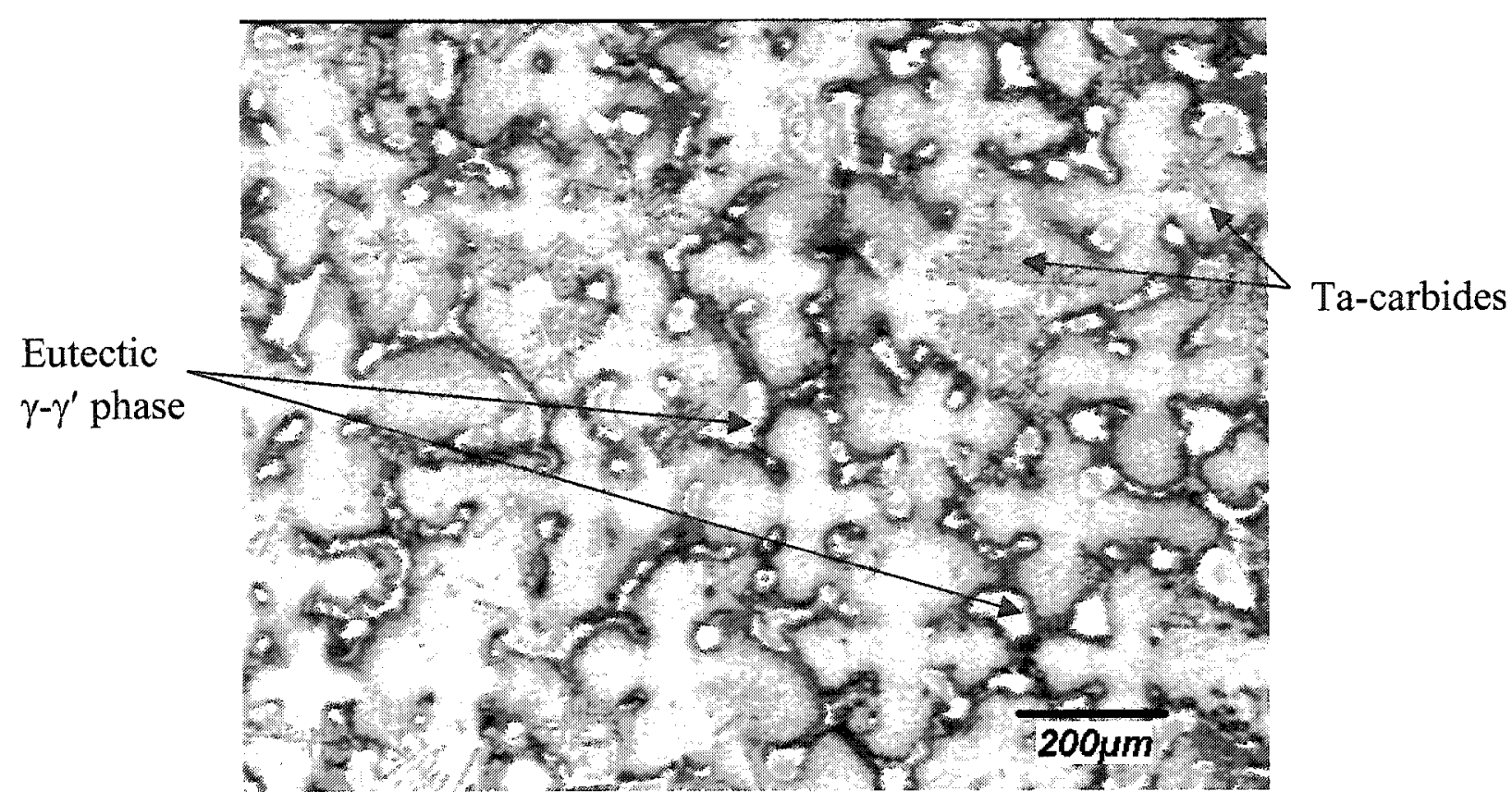

Figure 83: Transverse optical micrograph of Alloy A from the middle section of the cast bar.

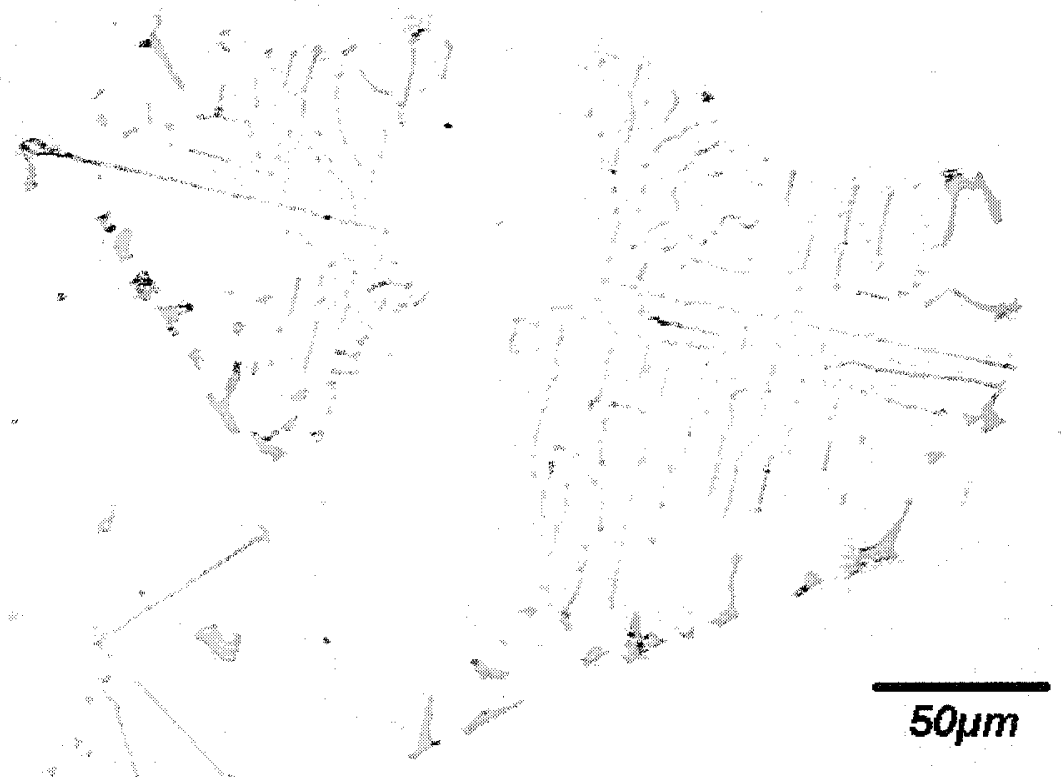

Figure 84: Unetched view of Ta-carbide phase present in Alloy A (script like morphology). 


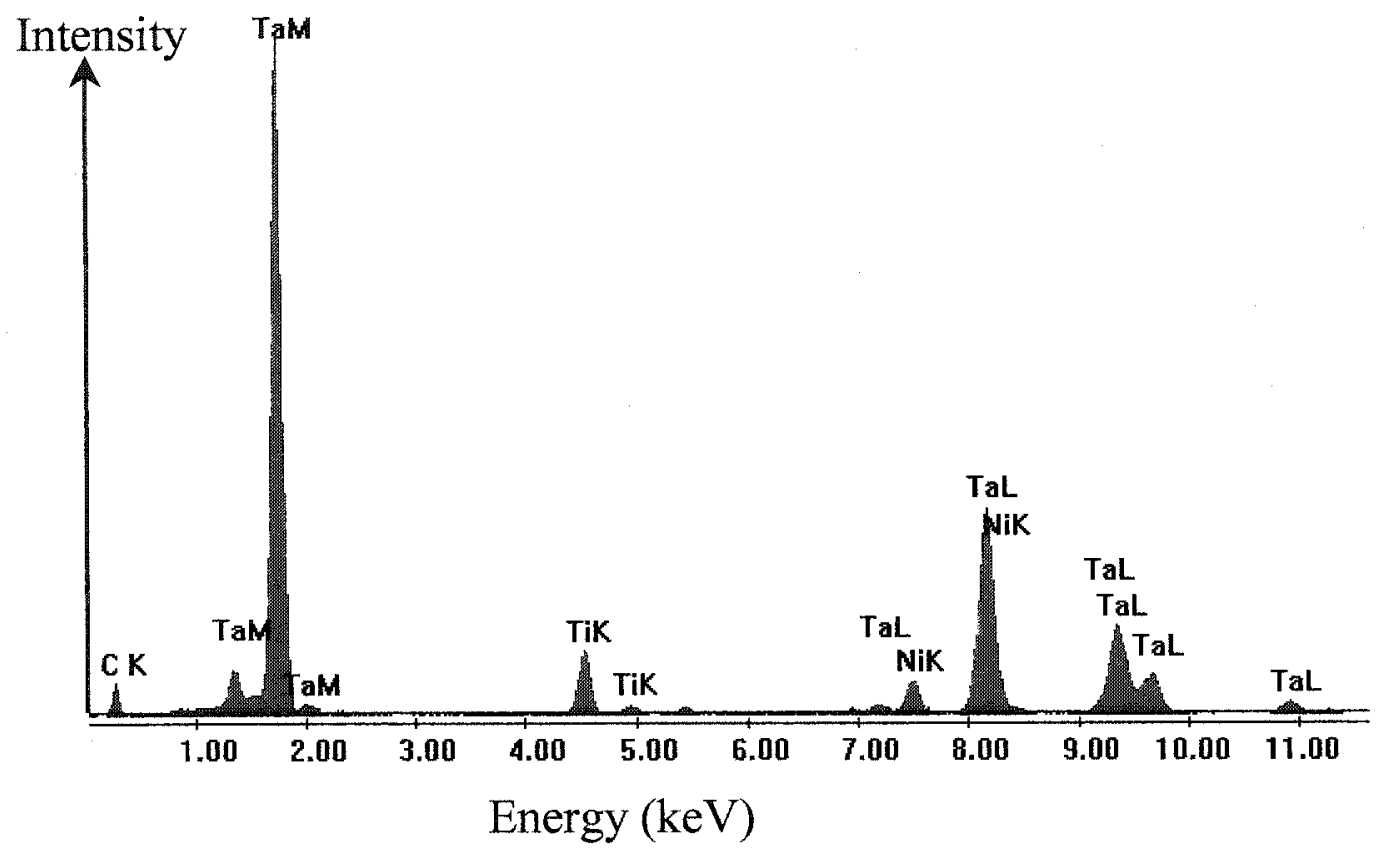

Figure 85: EDX spectrum of Ta-rich carbide phase found in Alloy A.

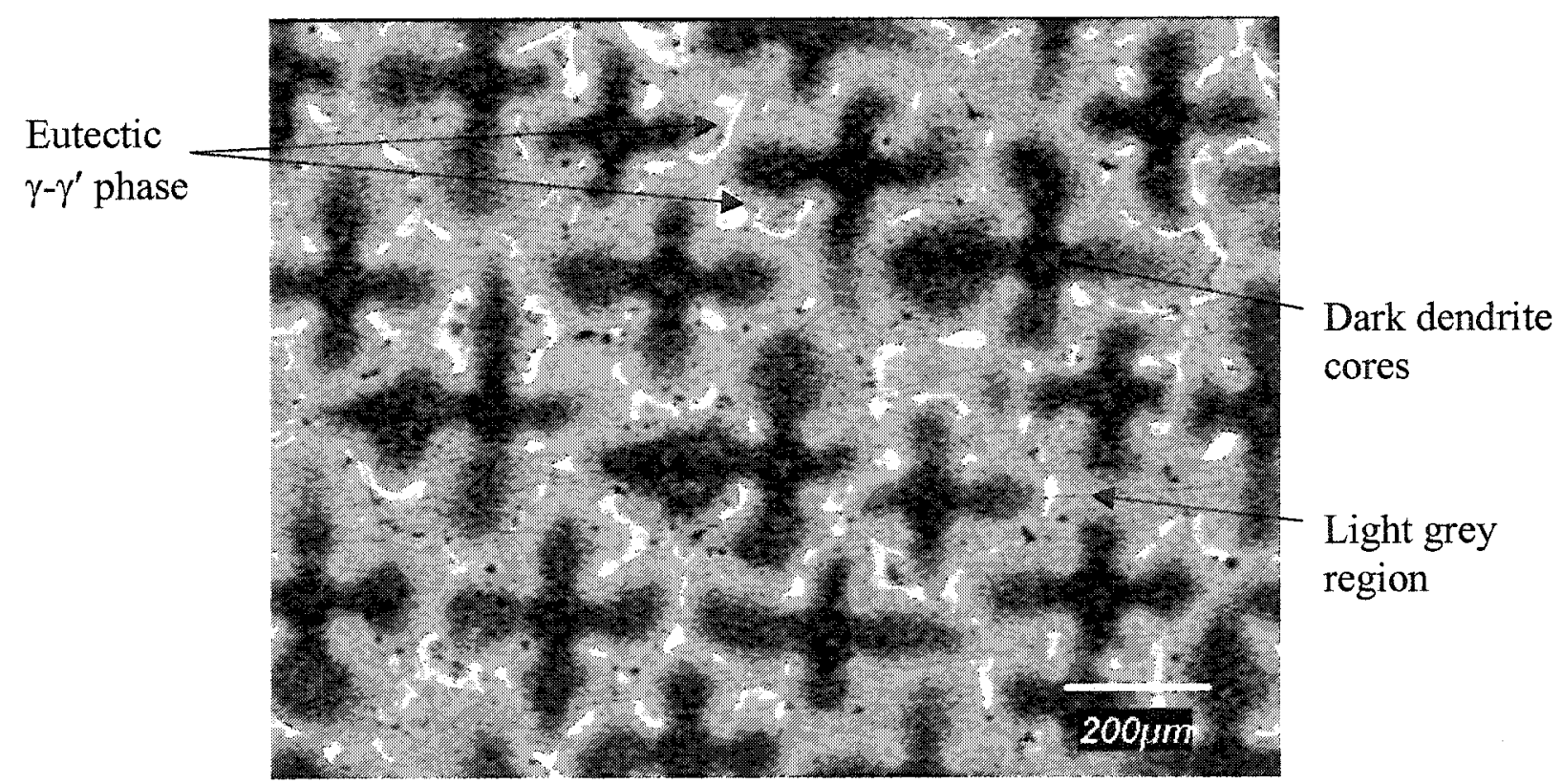

Figure 86: Transverse optical micrograph of Alloy B from the middle section of the cast bar. 


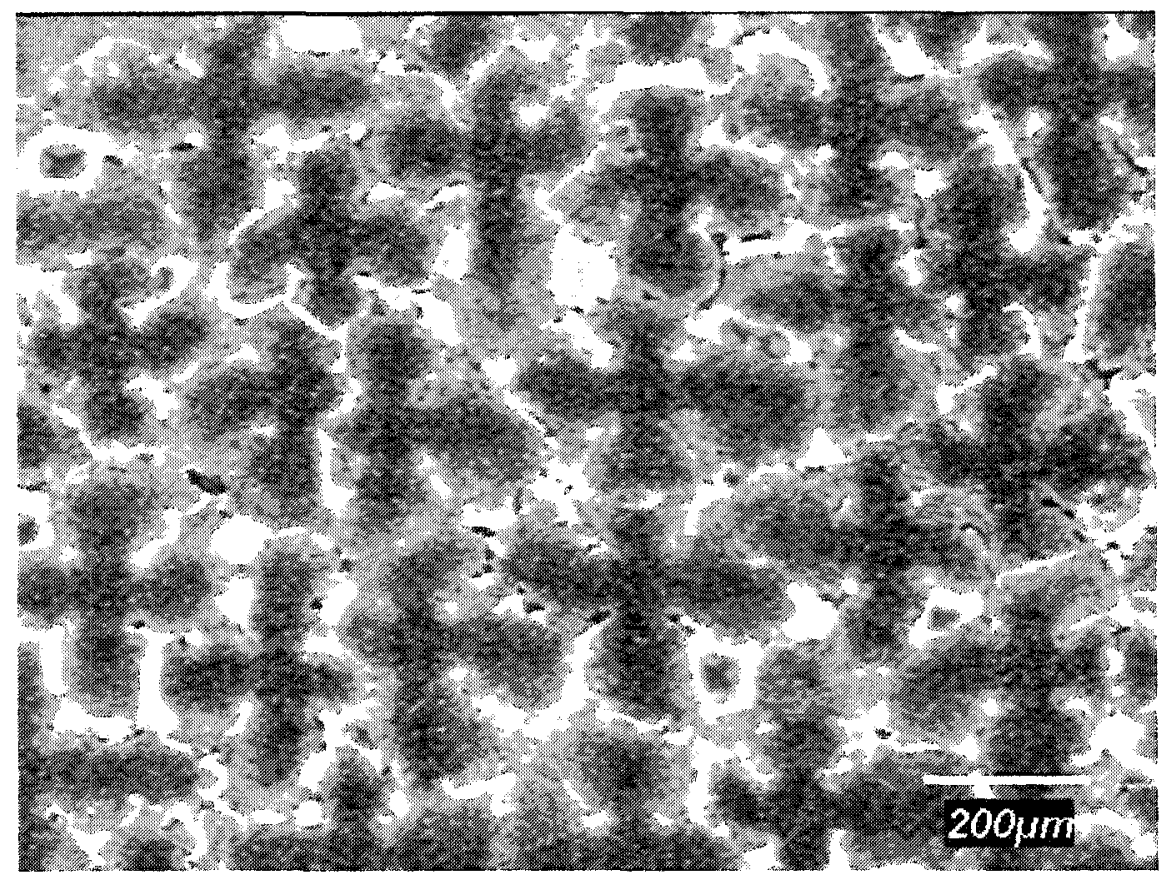

Figure 87: Transverse optical micrograph of Alloy $\mathrm{C}$ from the middle section of the cast bar.

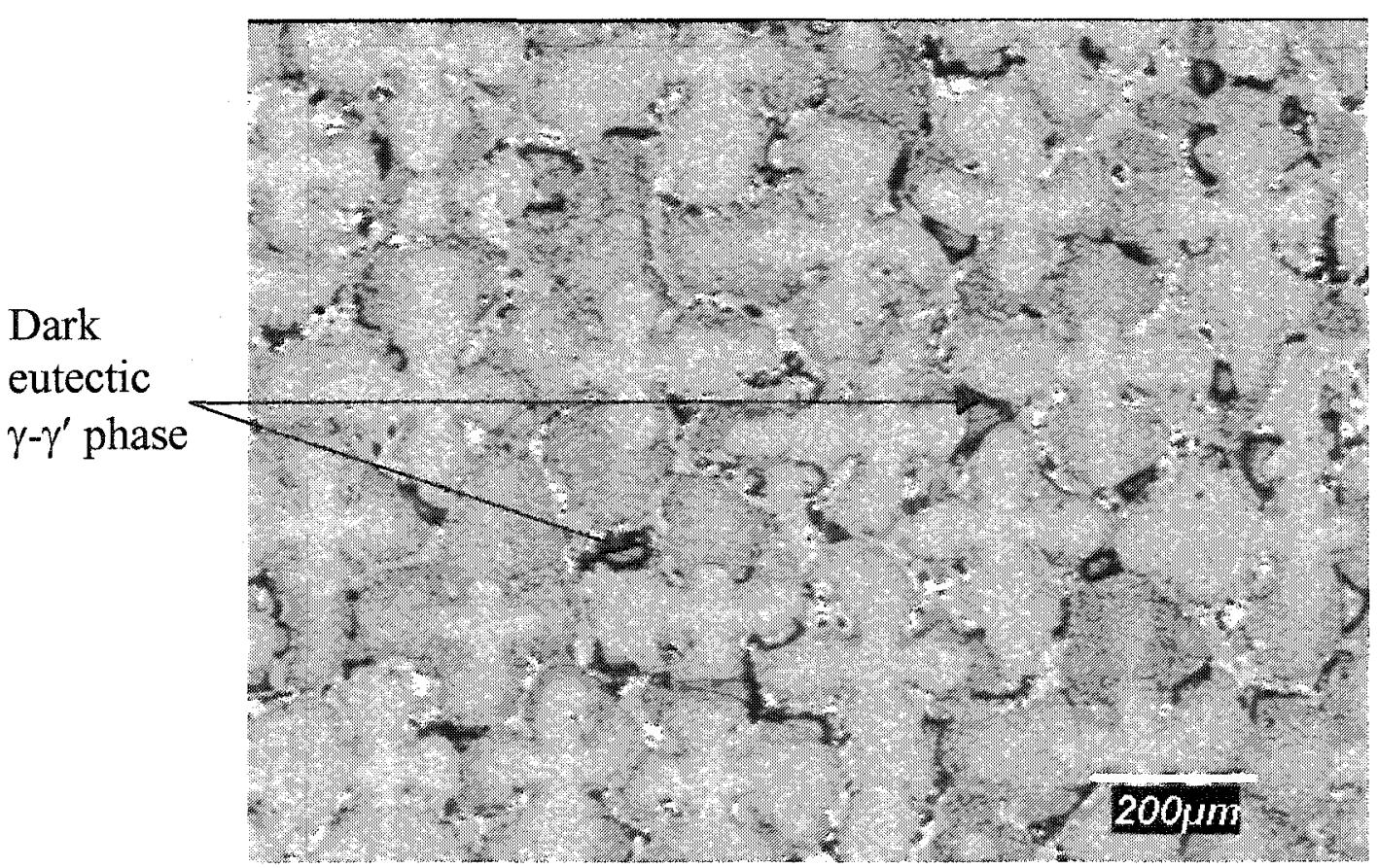

Figure 88: Transverse optical micrograph of Alloy $D$ from the middle section of the cast bar. 


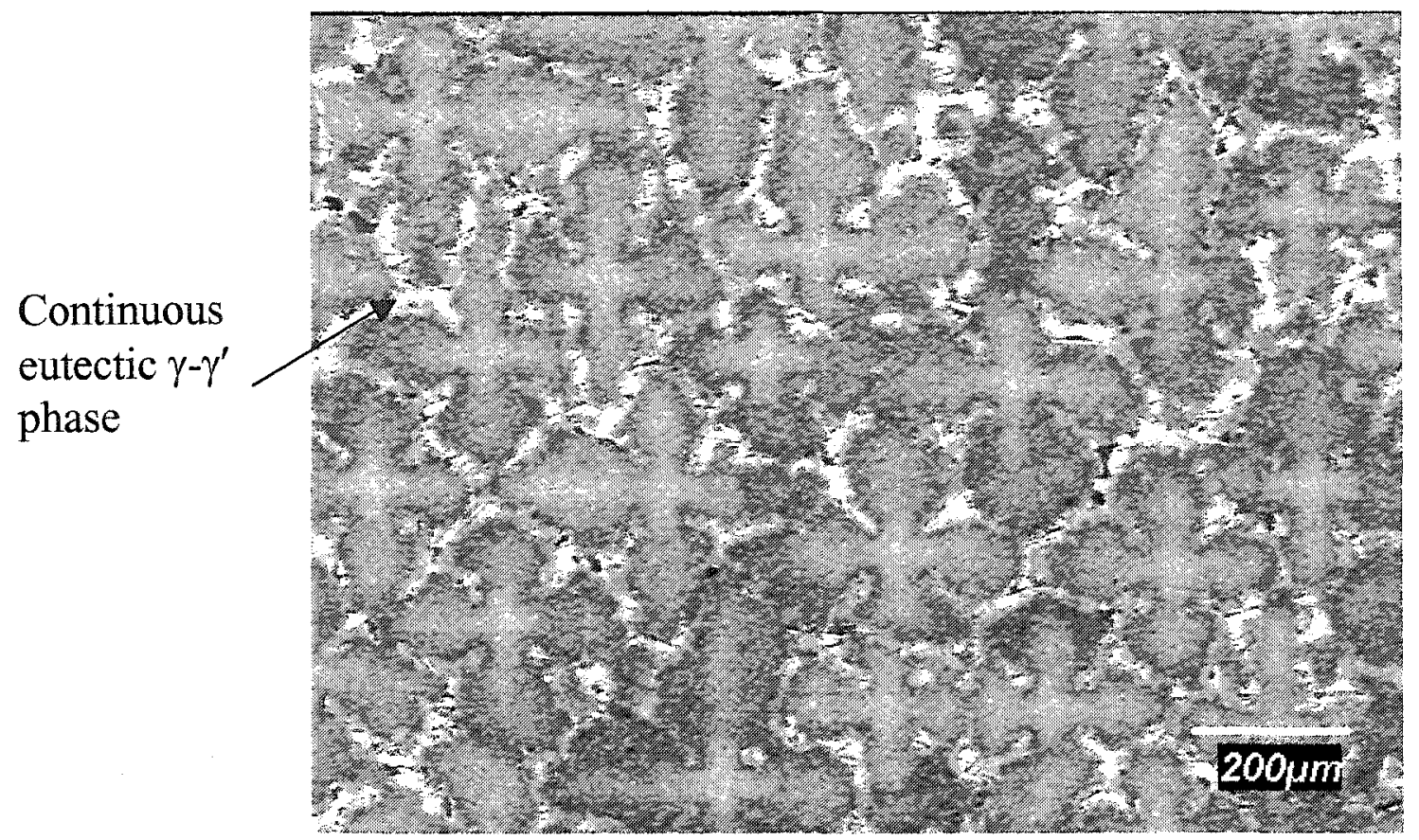

Figure 89: Transverse optical micrograph of Alloy $\mathbf{E}$ from the middle section of the cast bar.

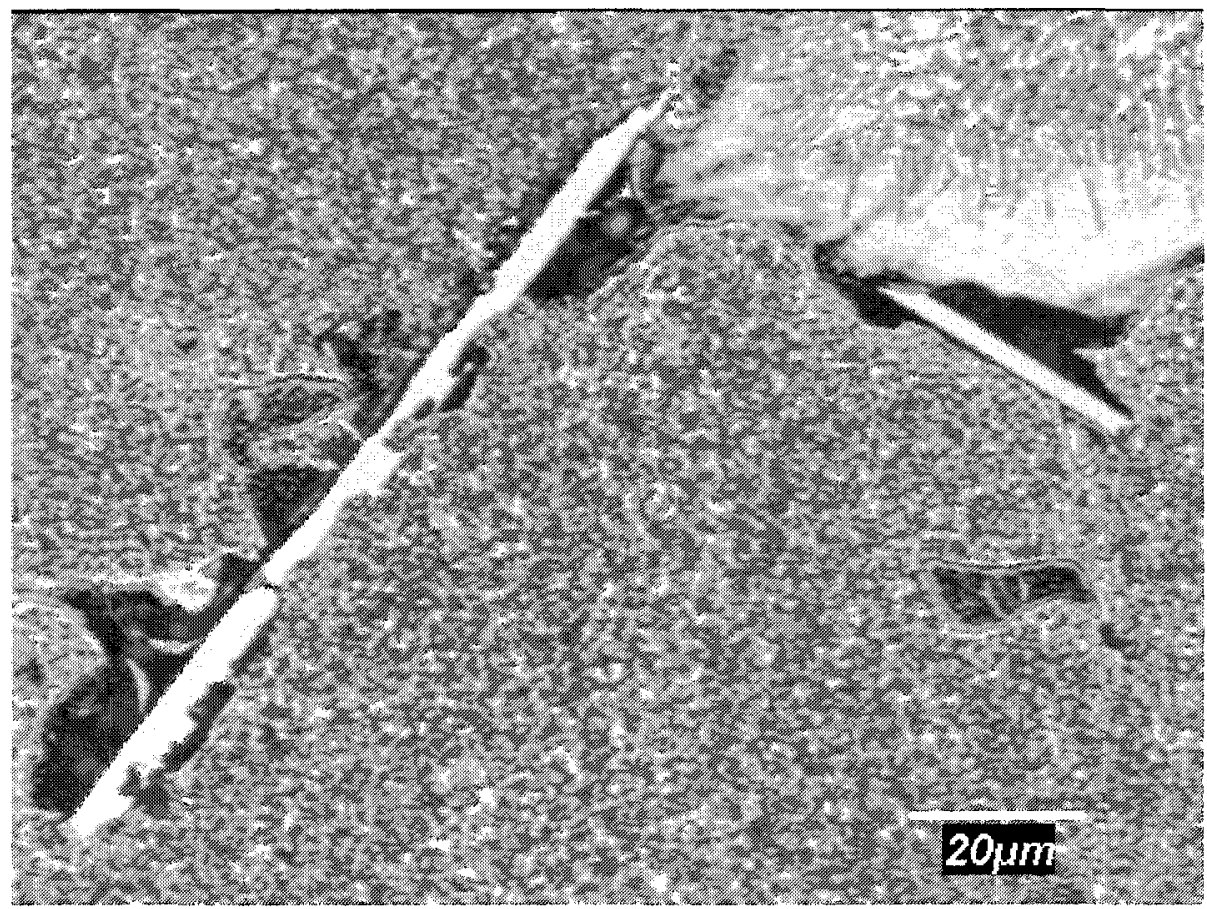

Figure 90: Close-up view of transverse section of Alloy $\mathbf{E}$ revealing the presence of Ta-rich carbide phase (needle-like in appearance). 


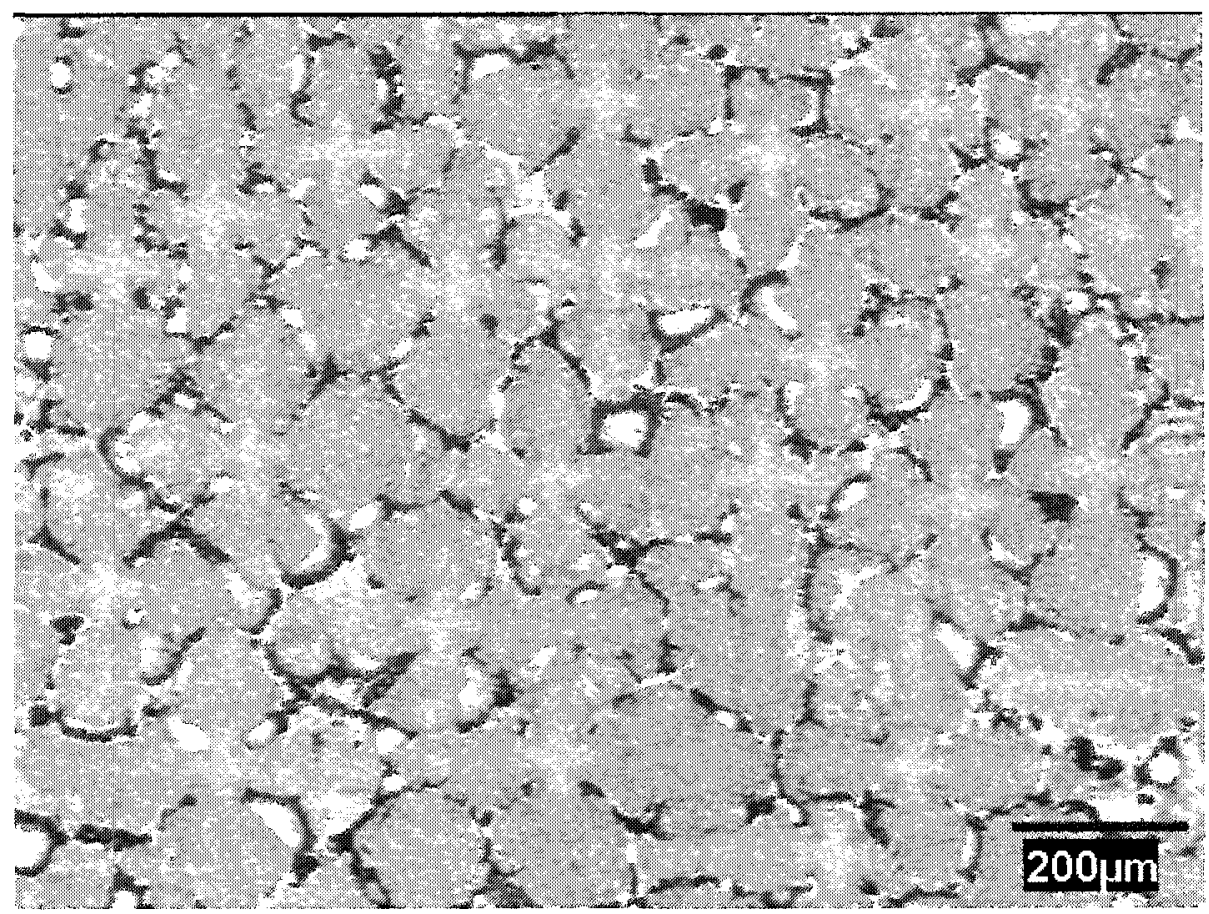

Figure 91: Transverse optical micrograph of Alloy F from the middle section of the cast bar.

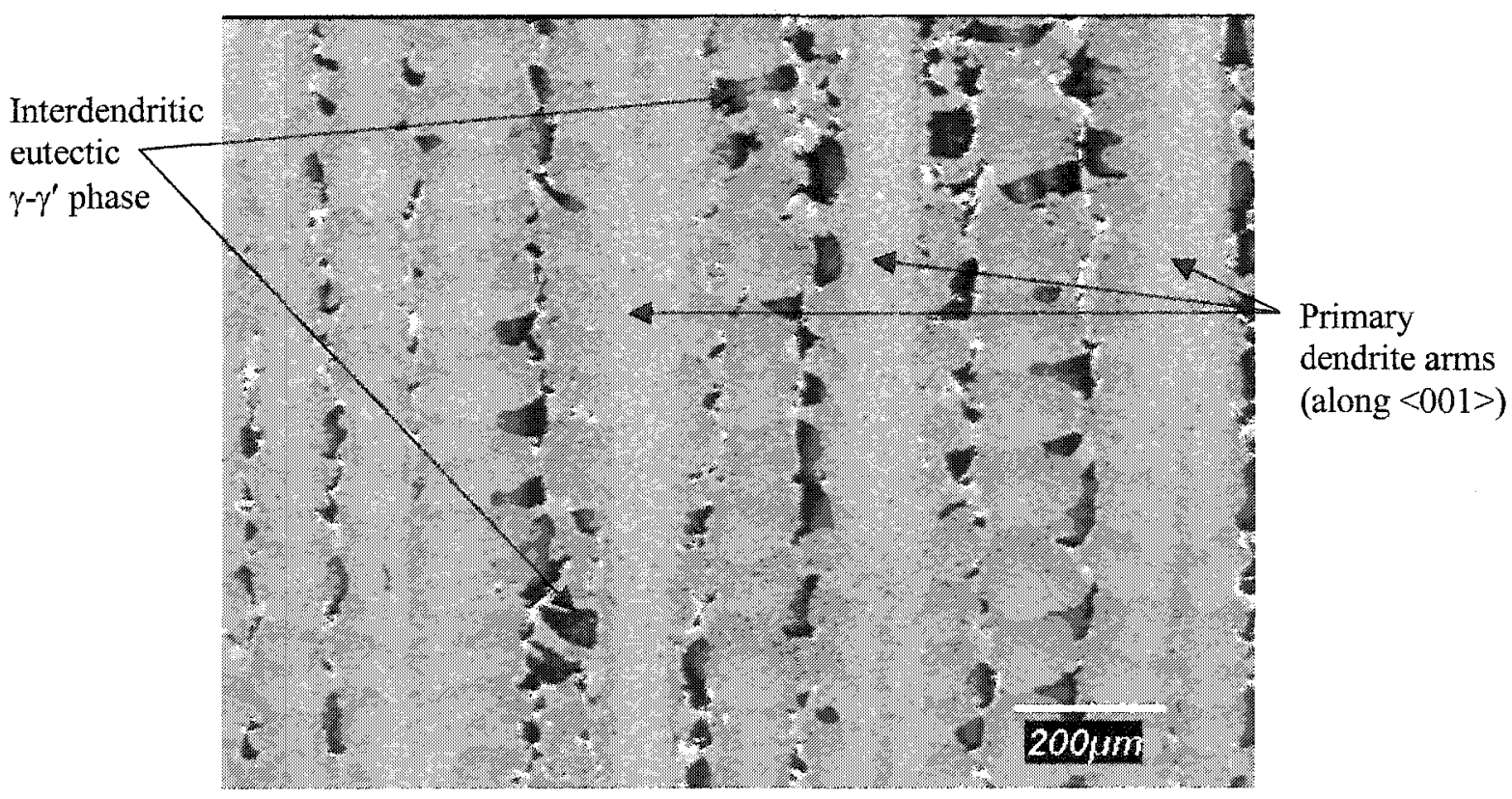

Figure 92: Longitudinal cross-sectional image of the dendritic solidification structure of Alloy $D$ taken in the mid-length region of the cast bar. 


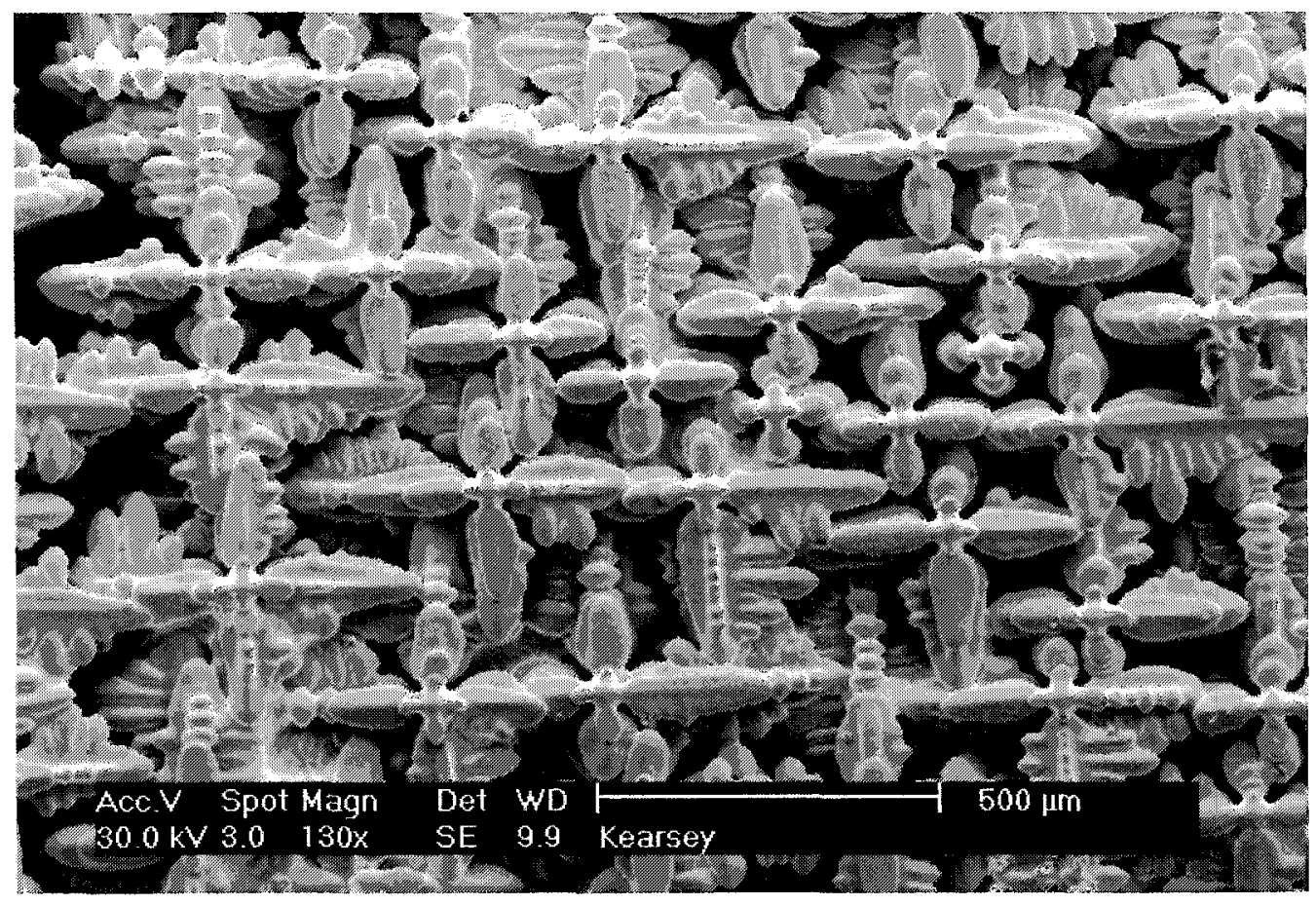

Figure 93: Low-magnification SEM image of Alloy B showing the transverse 3-dimensional morphology of the SX dendritic structure ( $<100>$ out of page).

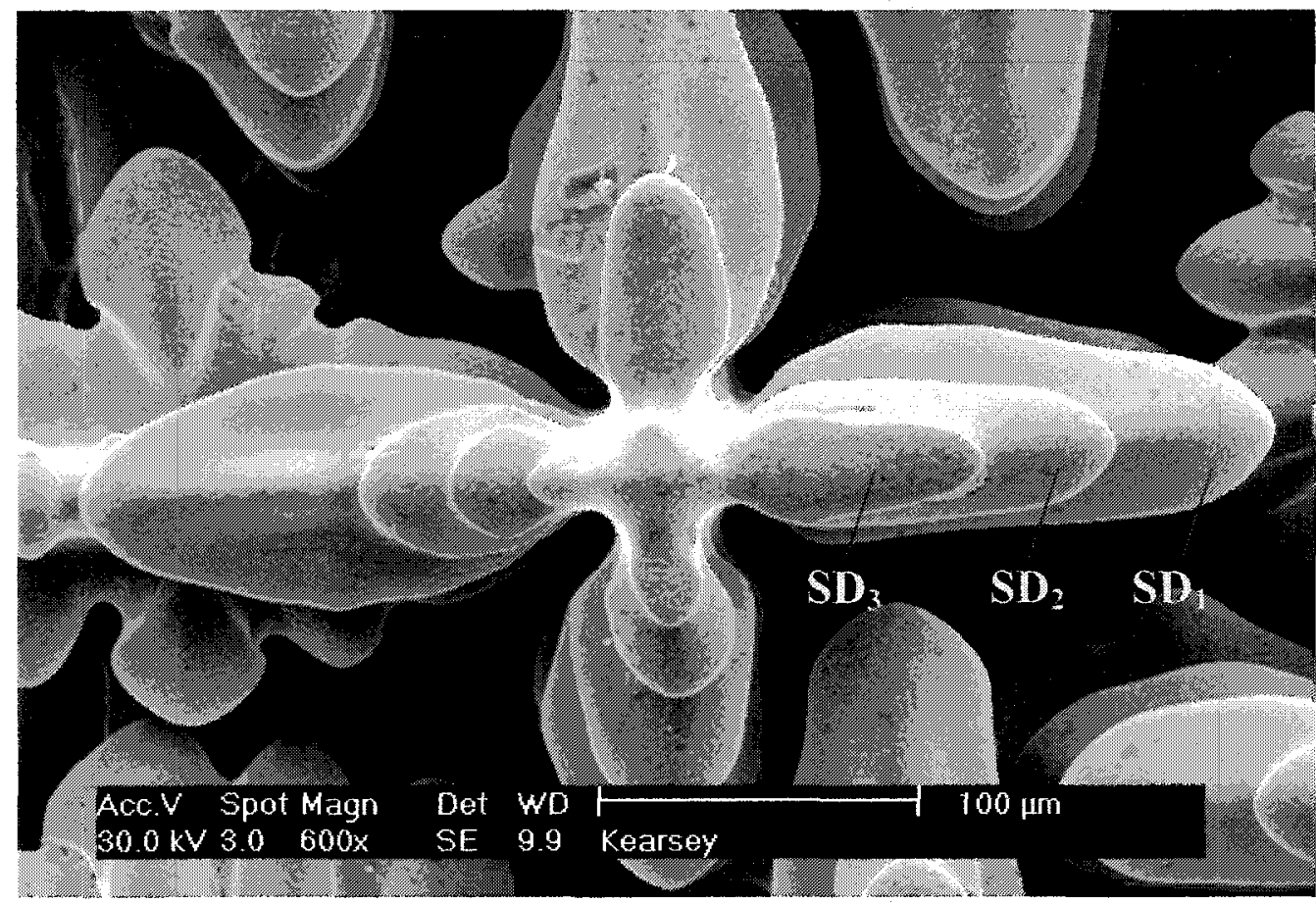

Figure 94: Transverse SEM image of an individual dendrite from Alloy $B$ in the final stages of SX solidification (interdendritic region not present). 


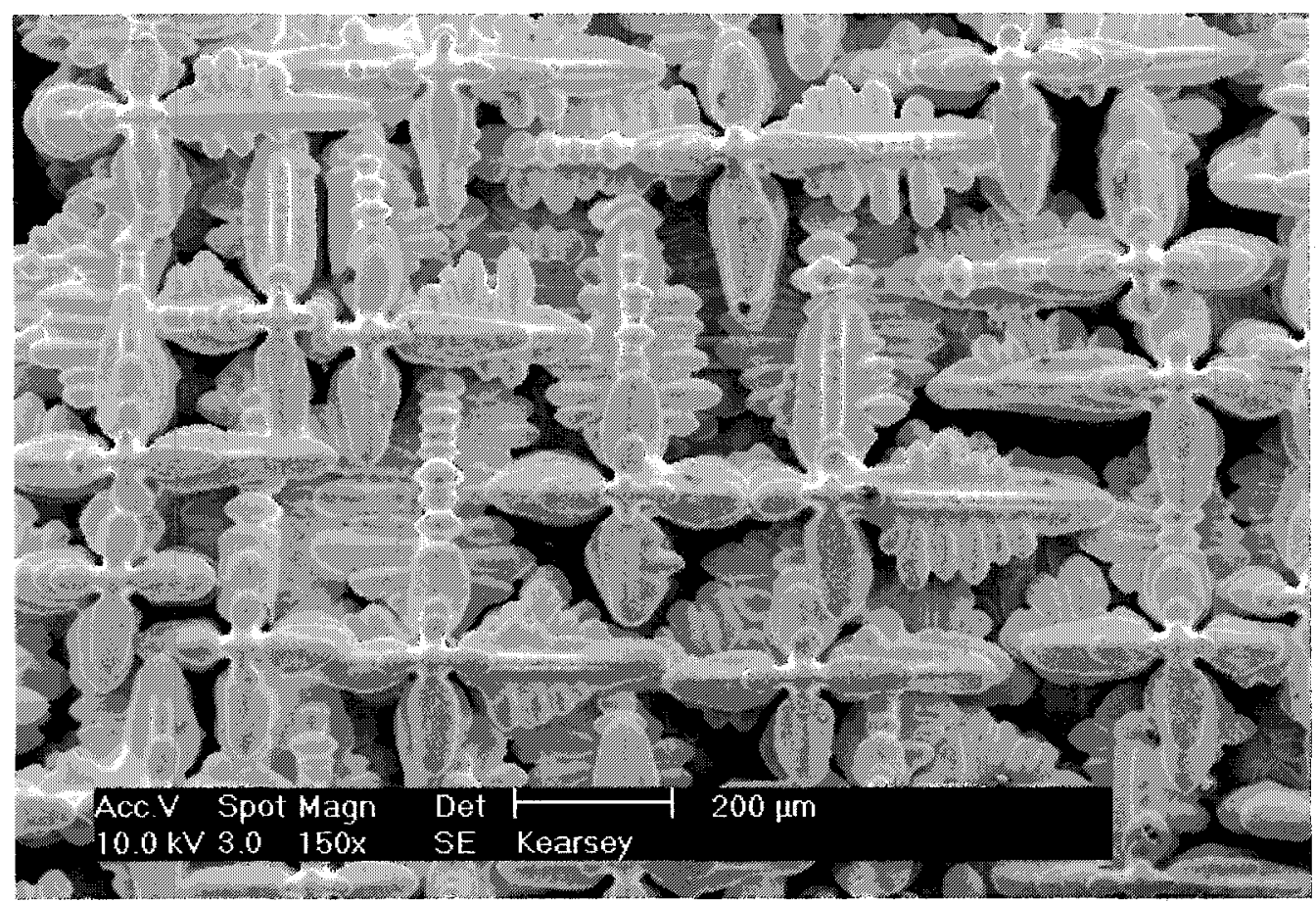

Figure 95: Low-magnification SEM image of Alloy F showing the transverse 3-dimensional morphology of the SX dendritic structure ( $<100>$ out of page).

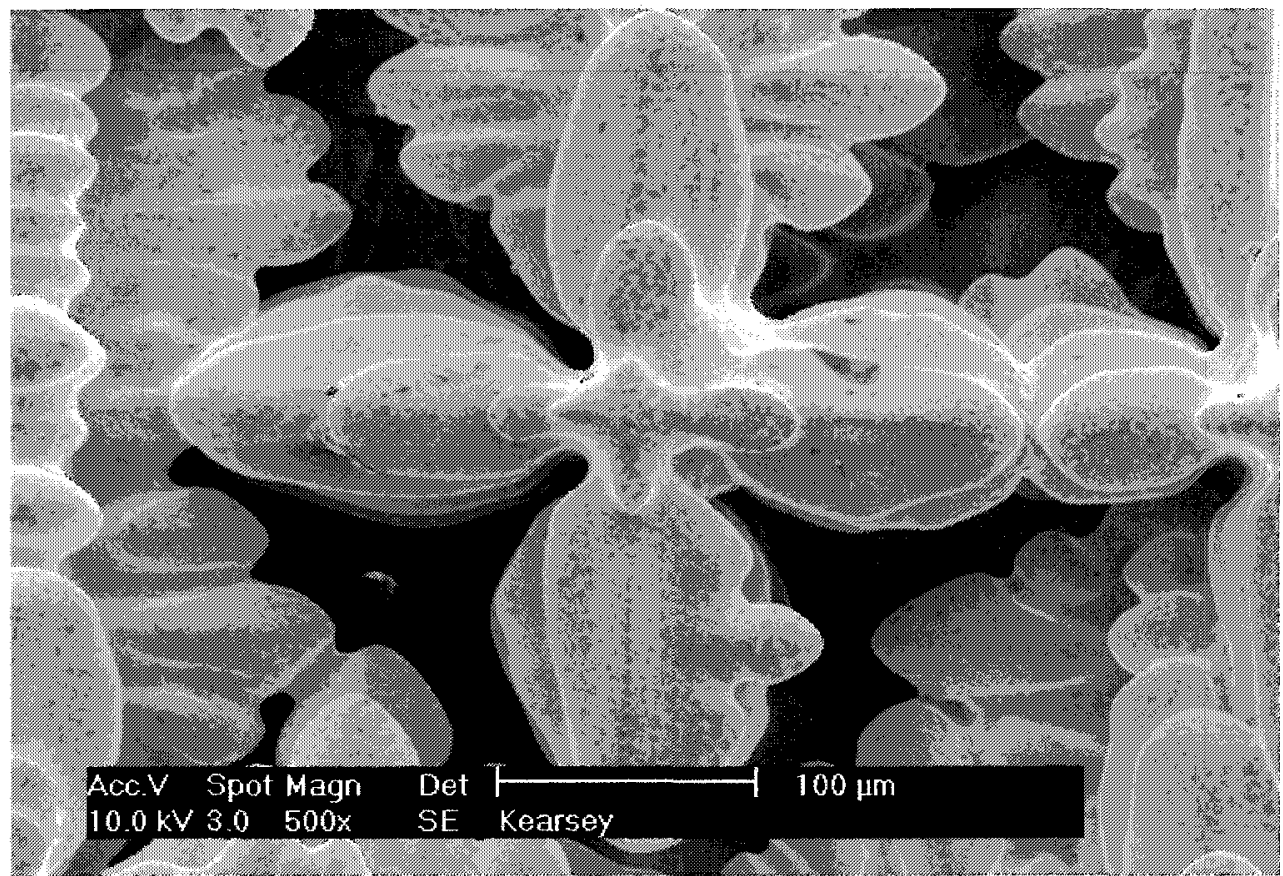

Figure 96: Transverse SEM image of an individual dendrite from Alloy $F$ in the final stages of SX solidification (interdendritic region not present). 


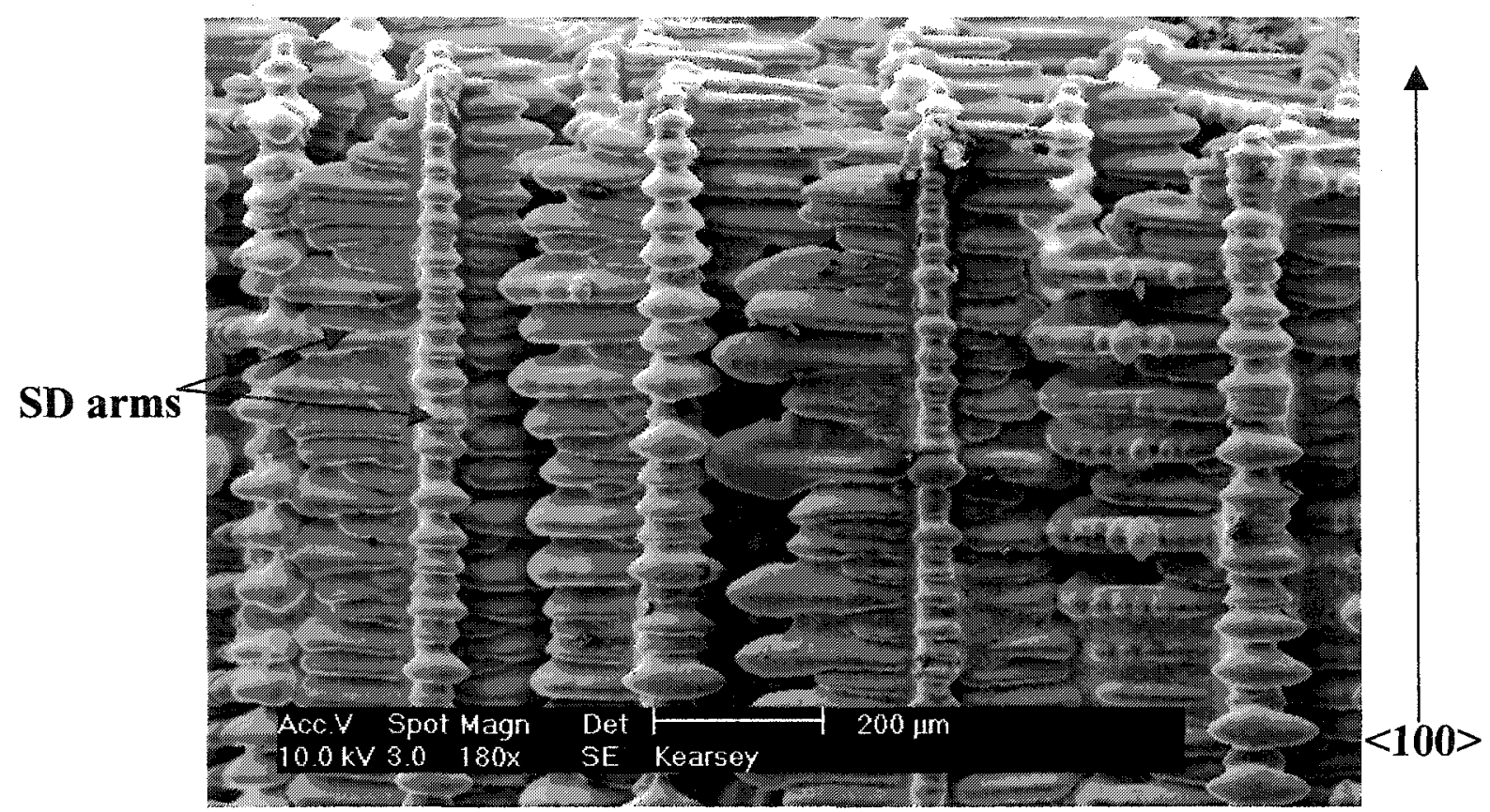

Figure 97: Low magnification SEM image of Alloy $F$ along the longitudinal direction, showing the direction of crystal growth and the equidistant spacing of the dendrites.

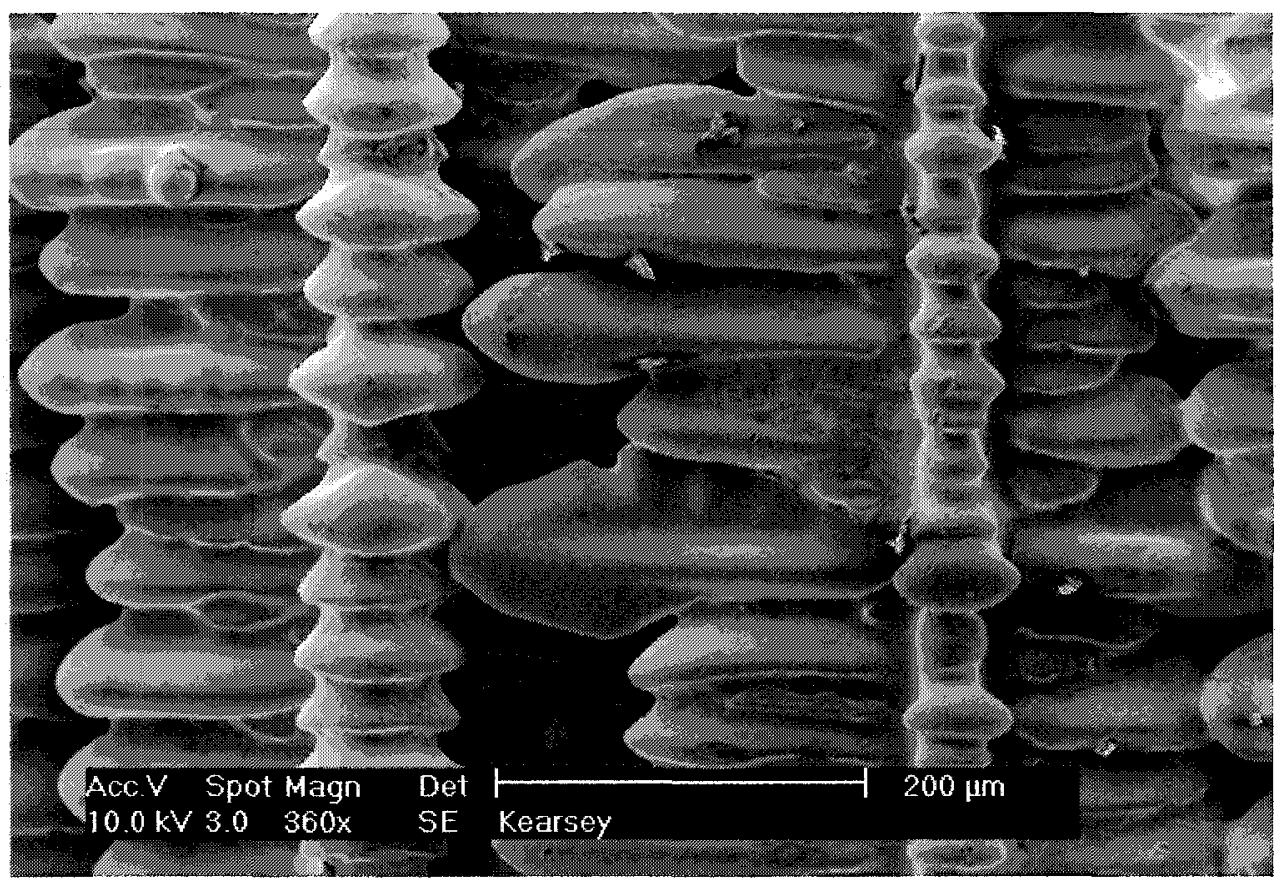

Figure 98: Close-up view of Alloy F showing the close-packed stacking of the secondary dendrite arms and their relatively equal arm lengths. 

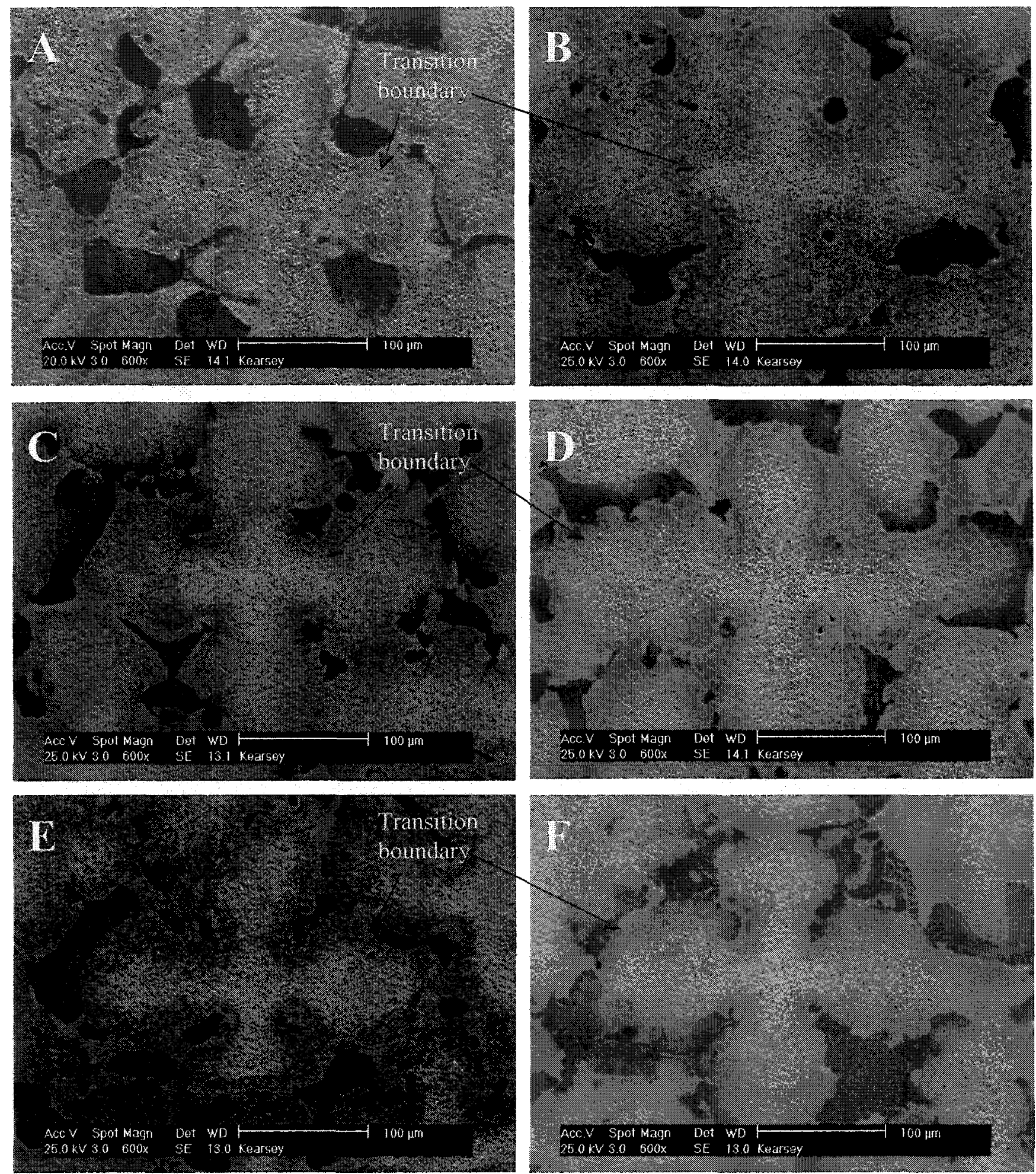

Figure 99: Secondary electron SEM images of transverse dendritic structures of Alloy A-F as resolved using the $\gamma$-matrix extraction etchant. All six images demonstrate a lighter dendritic interior surrounded by a darker grey transition boundary layer. 


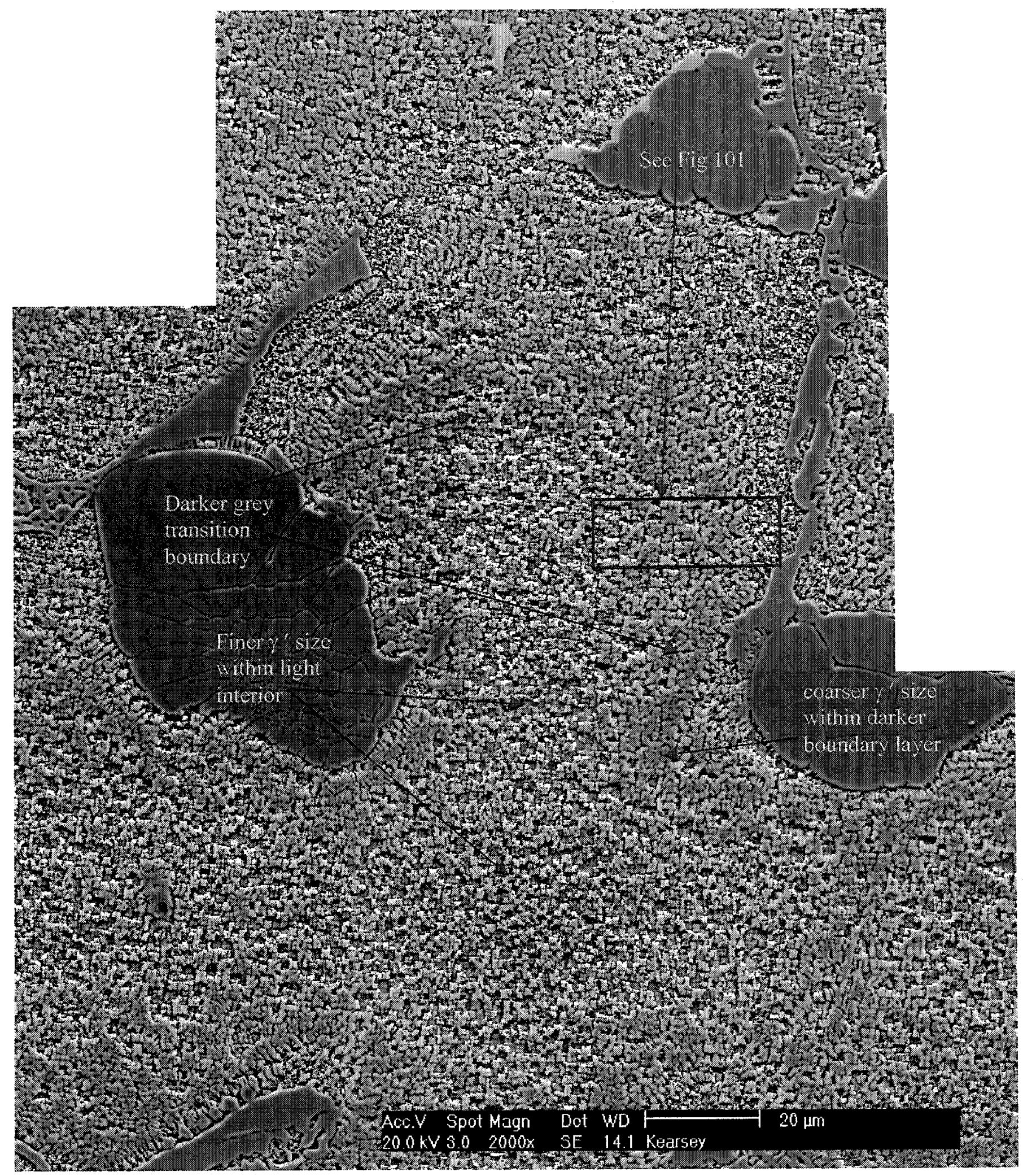

Figure 100:Variation in primary $\gamma^{\prime}$ size along the dendritic structure of Alloy A. Finer $\gamma^{\prime}$ structure exists within the lighter coloured interior with a noticeably larger $\gamma^{\prime}$ size within the dark grey boundary. 


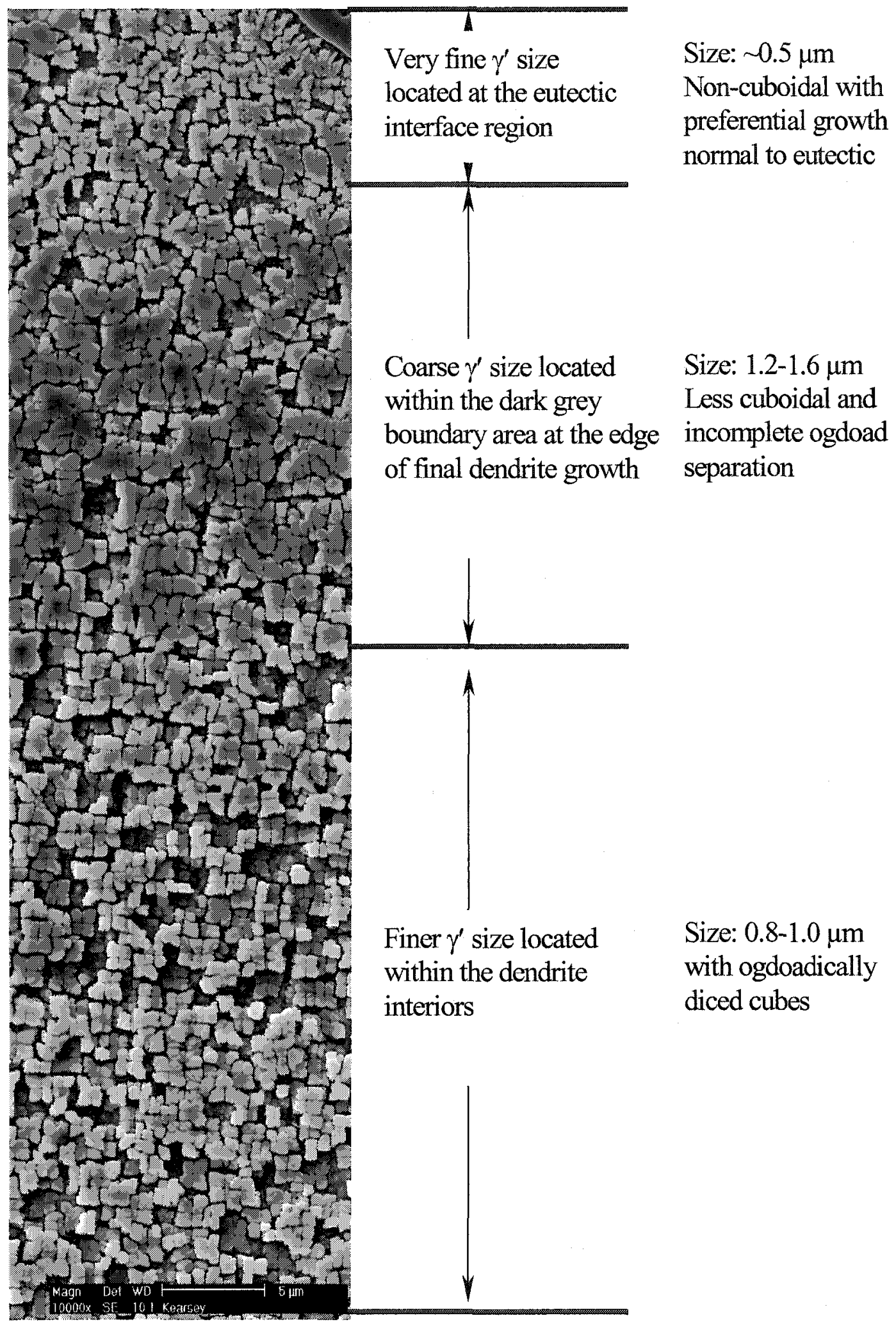

Figure 101: Transition sizes in primary $\gamma^{\prime}$ precipitate: 1) fine-uniform morphology located within the lighter dendrite interiors, 2) coarse $\gamma^{\prime}$ within the dark grey boundaries of the dendrites, and 3) very fine $\gamma^{\prime}$ located immediately adjacent to relatively large eutectic $\gamma^{\prime}$ phase. 

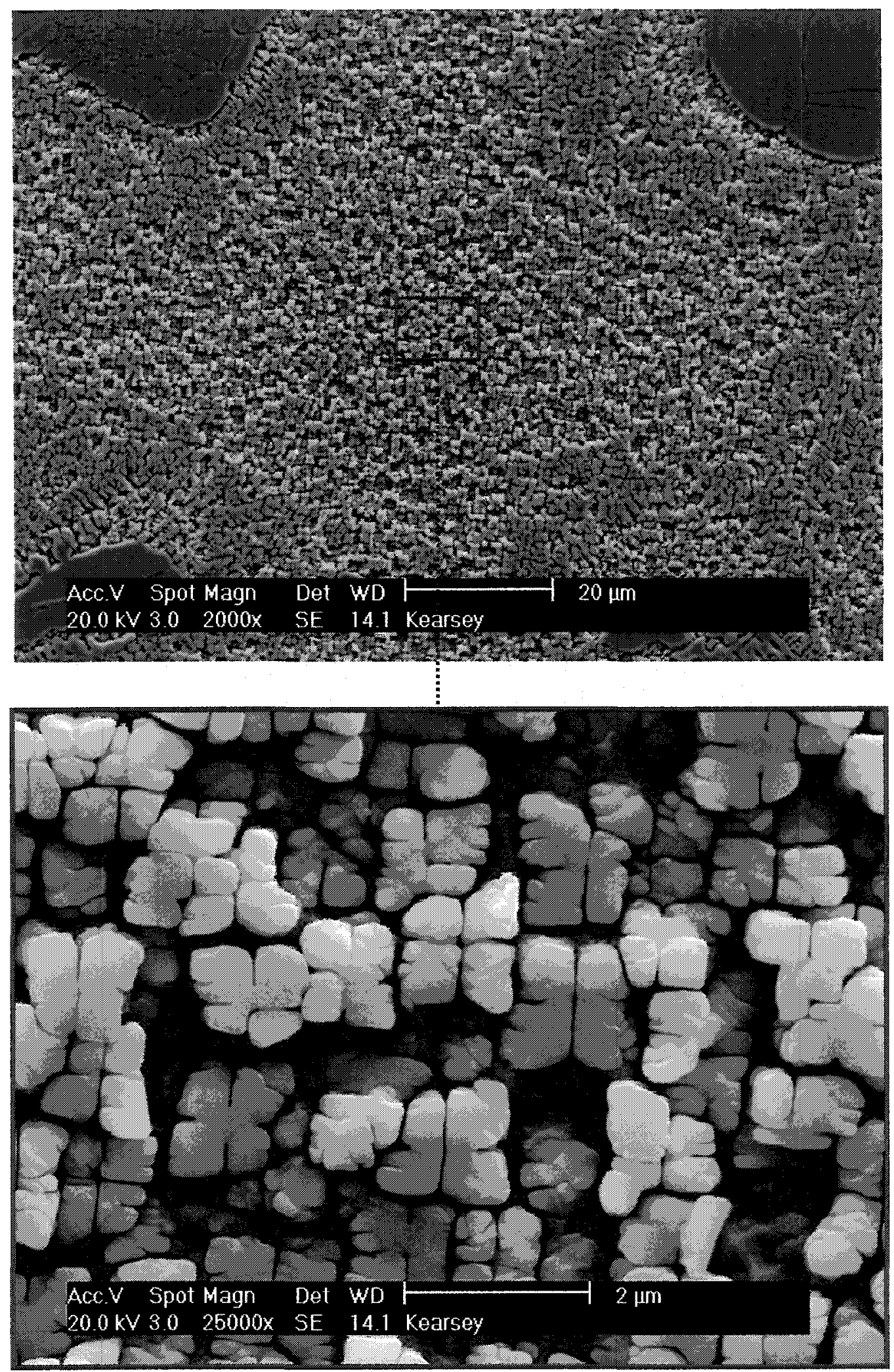

Figure 102: Alloy $\mathbf{A}-\gamma^{\prime}$ within primary dendrite core. 

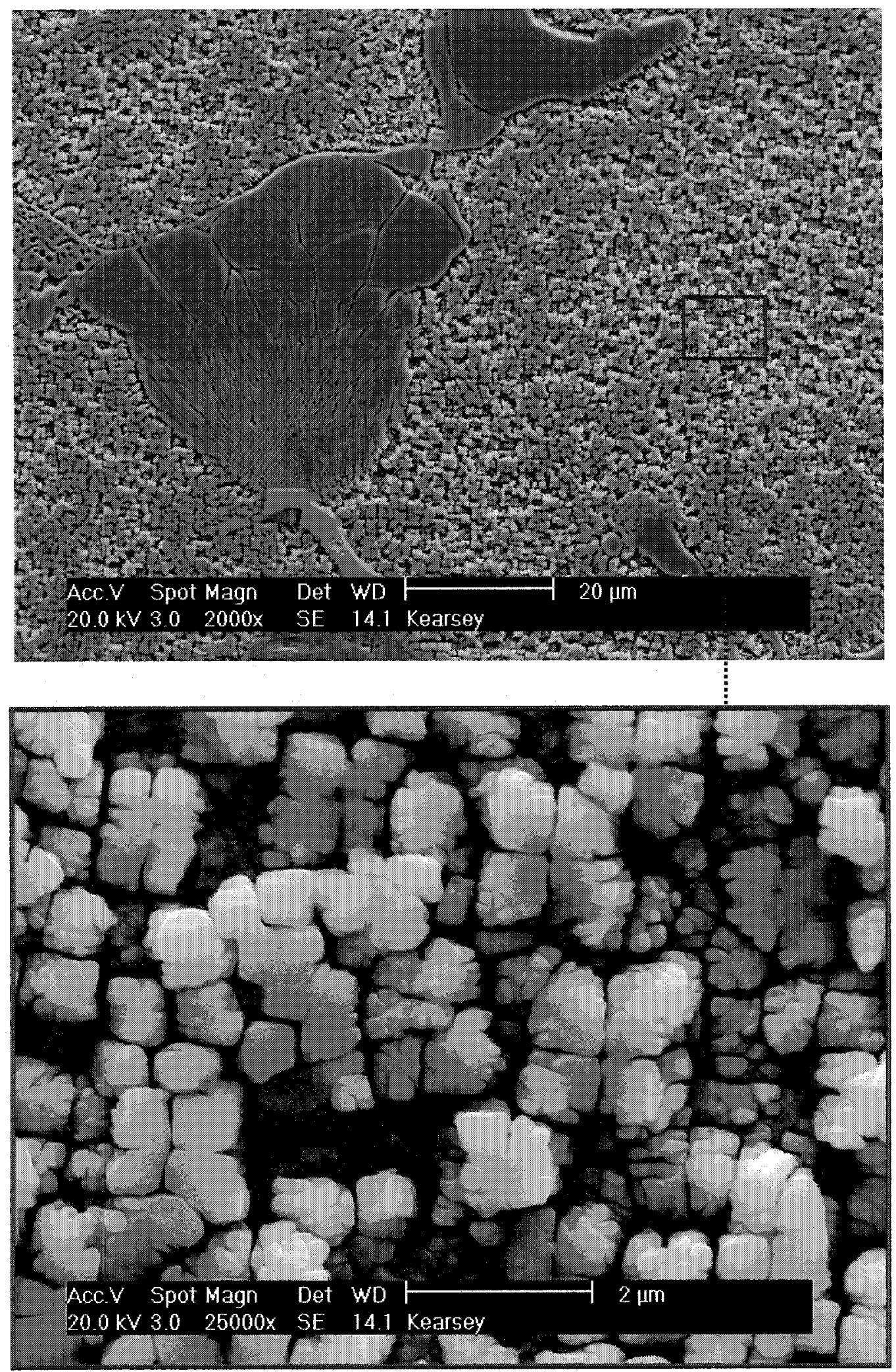

Figure 103: Alloy $\mathbf{A}-\gamma^{\prime}$ within left secondary dendrite arm. 

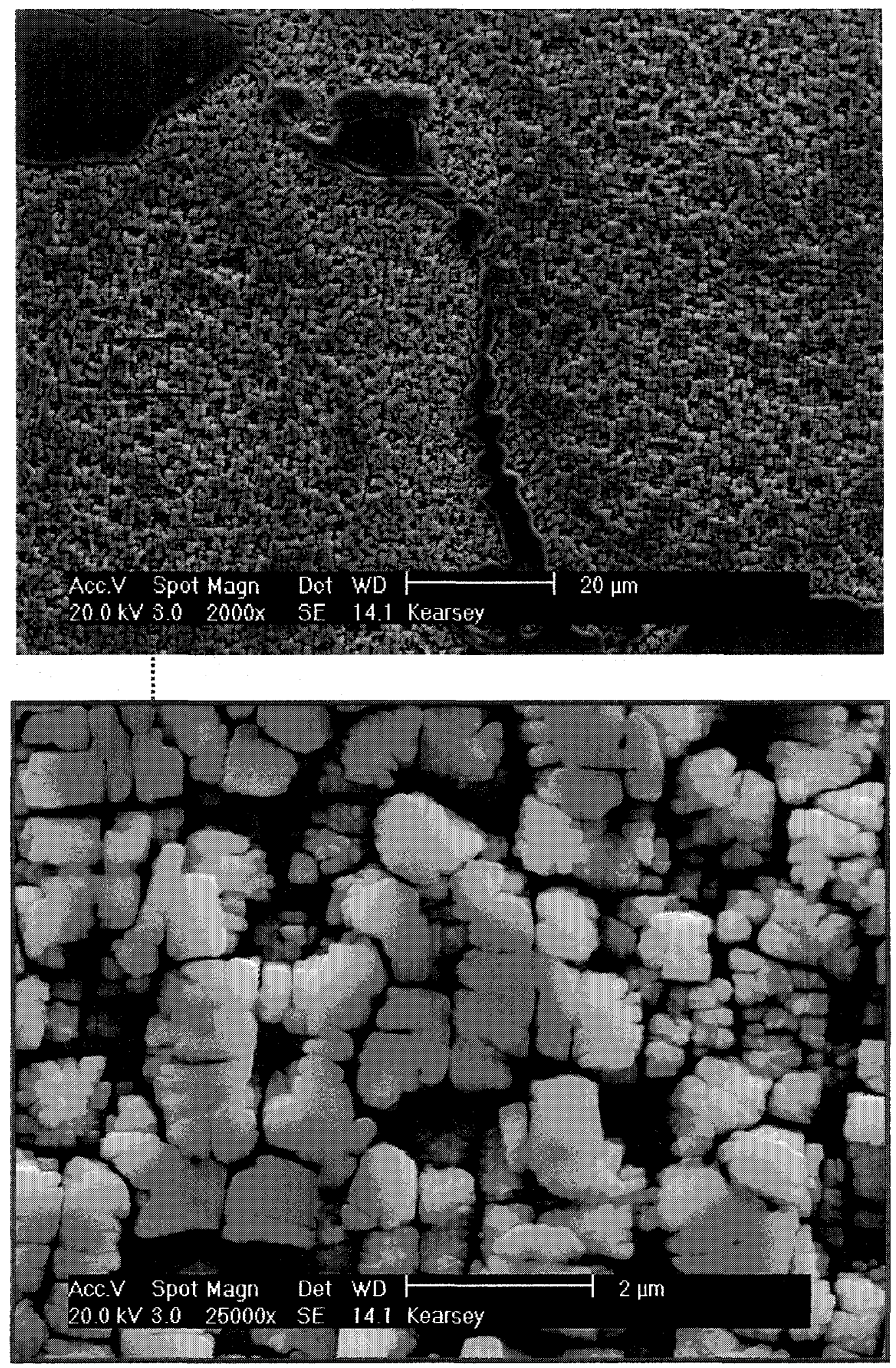

Figure 104: Alloy $\mathbf{A}-\gamma^{\prime}$ within right secondary dendrite arm. 

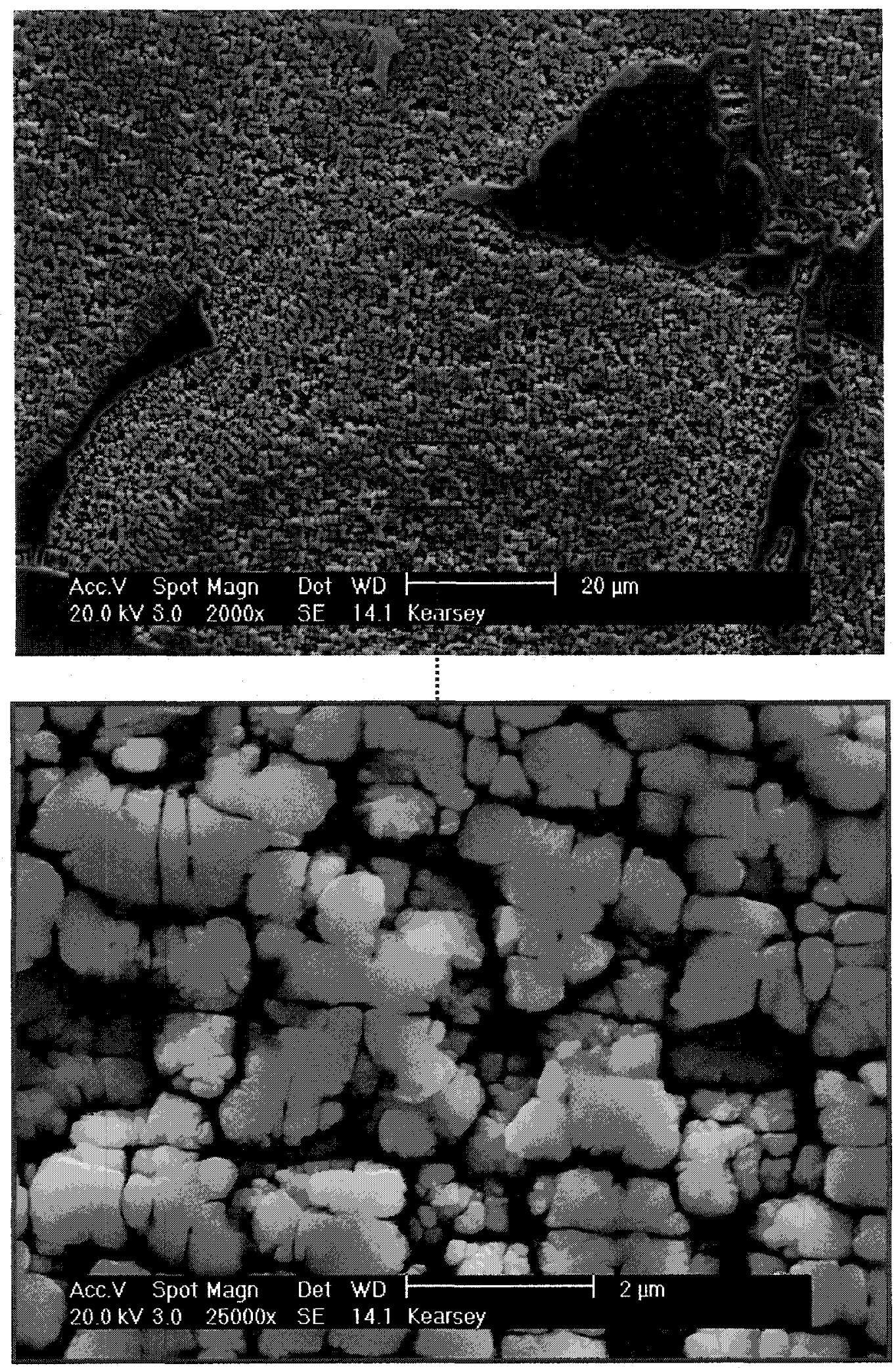

Figure 105: Alloy $\mathbf{A}-\gamma^{\prime}$ within top secondary dendrite arm. 

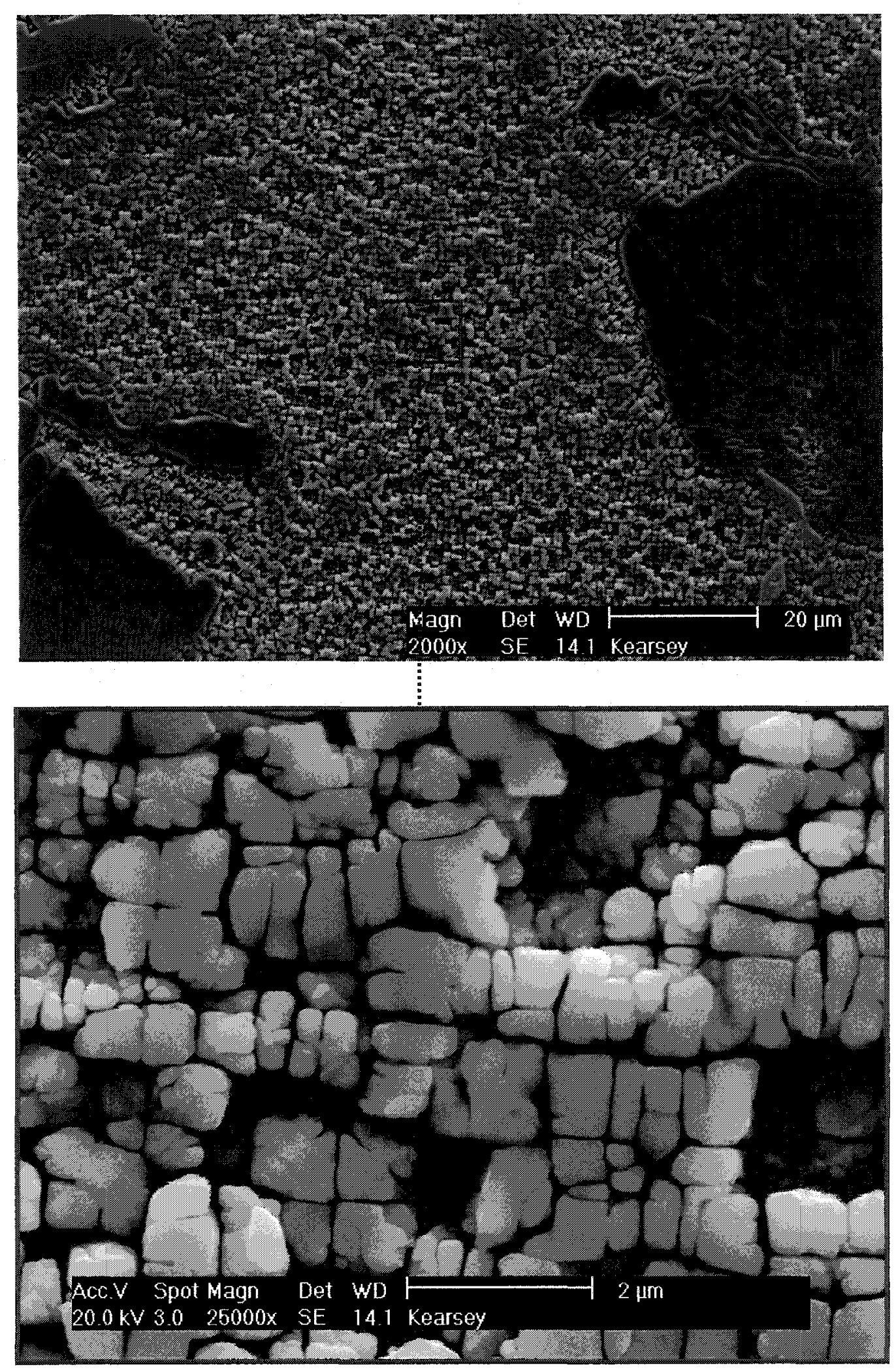

Figure 106: Alloy $\mathrm{A}-\gamma^{\prime}$ within bottom secondary dendrite arm. 

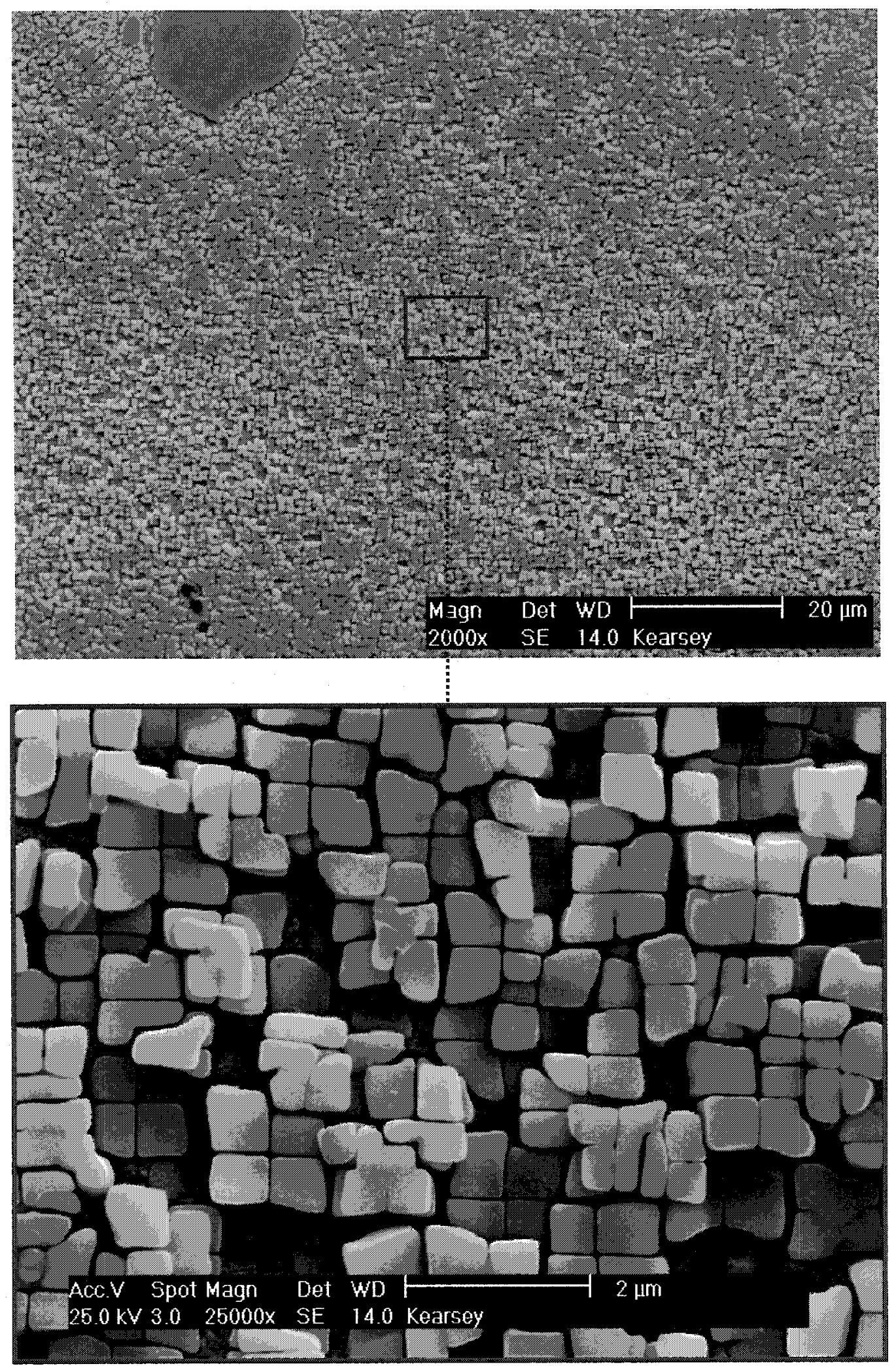

Figure 107: Alloy $B-\gamma^{\prime}$ within primary dendrite core. 


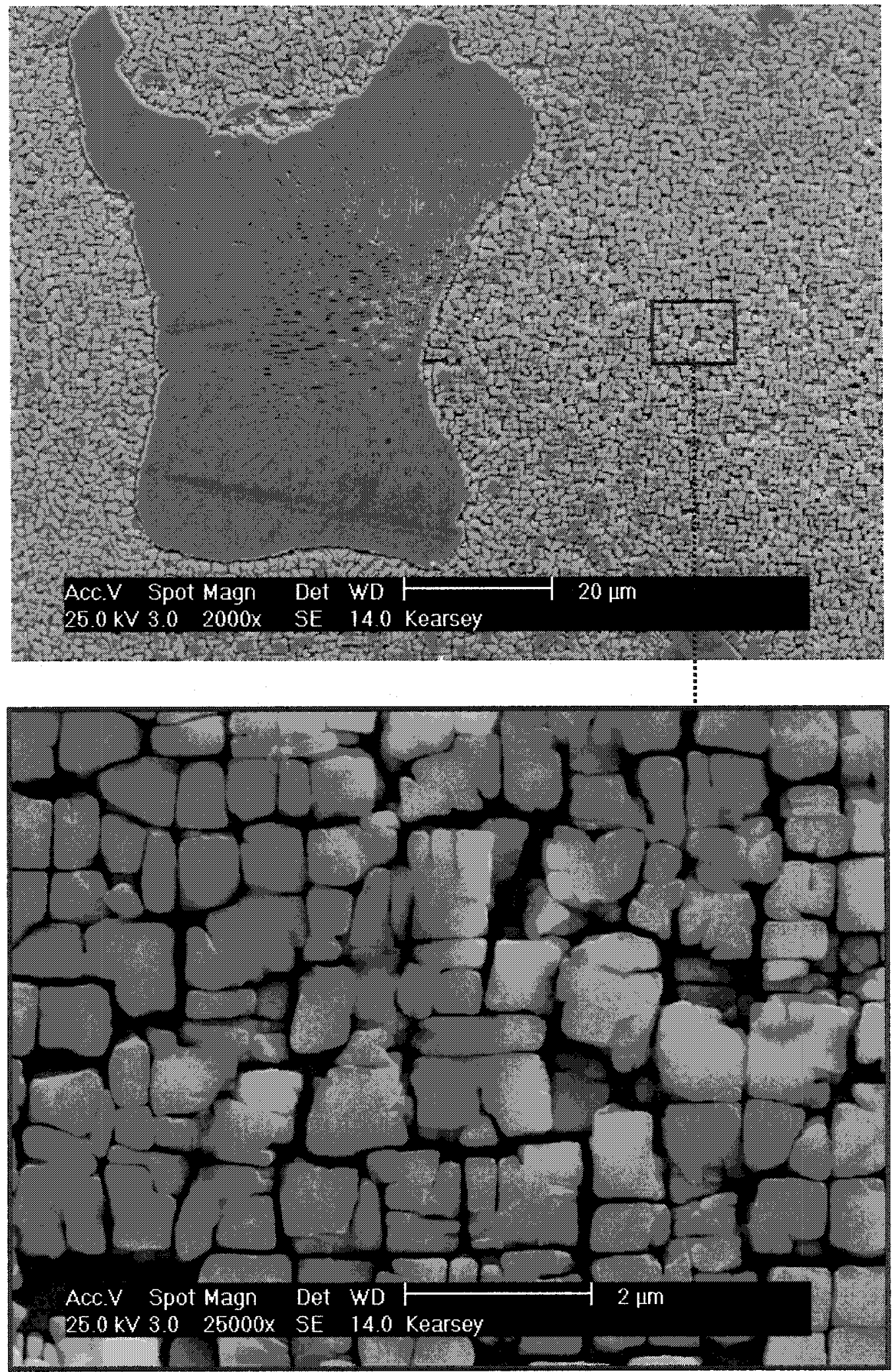

Figure 108: Alloy $B-\gamma^{\prime}$ within left secondary dendrite arm. 

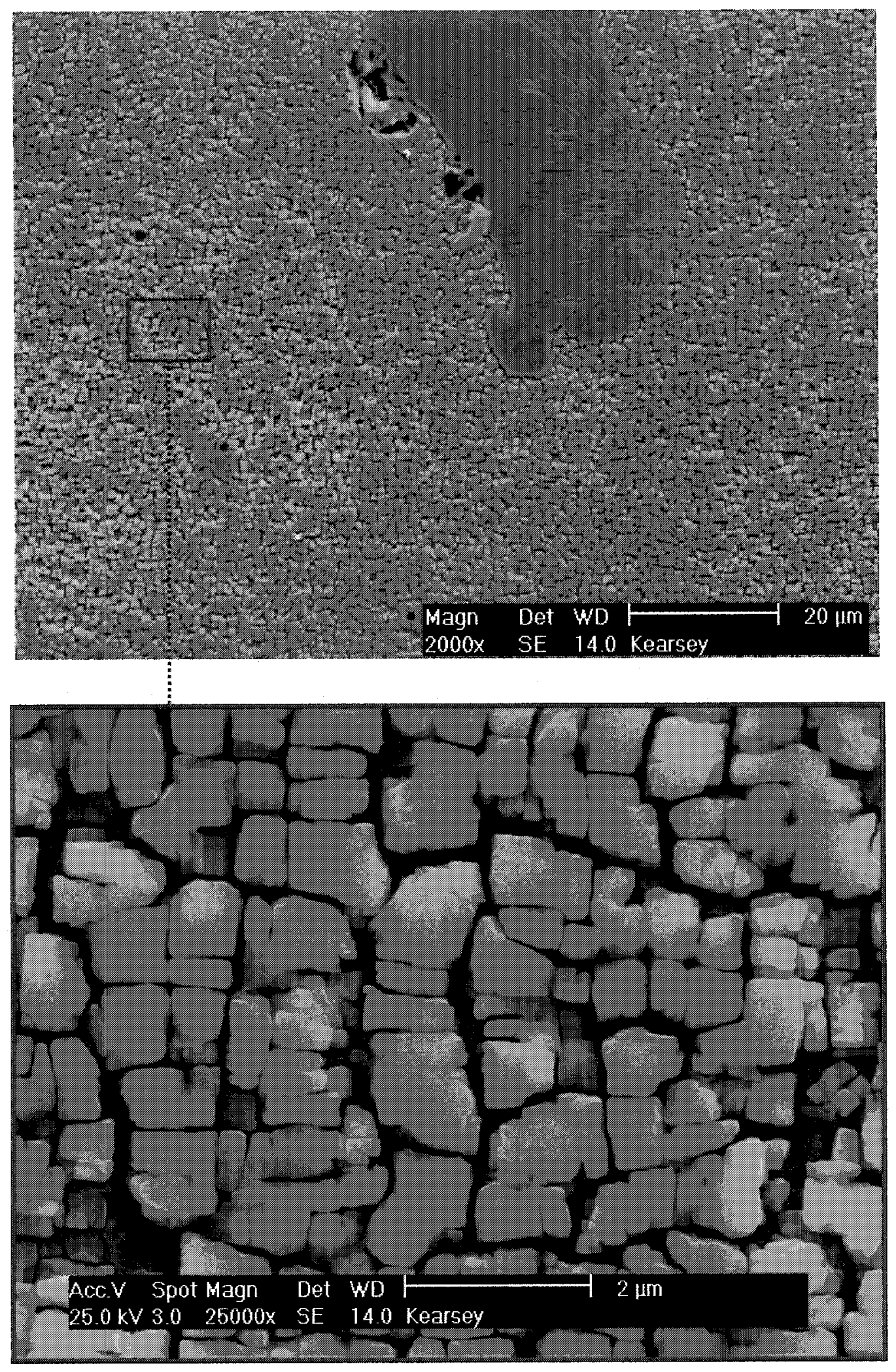

Figure 109: Alloy $B-\gamma^{\prime}$ within right secondary dendrite arm. 


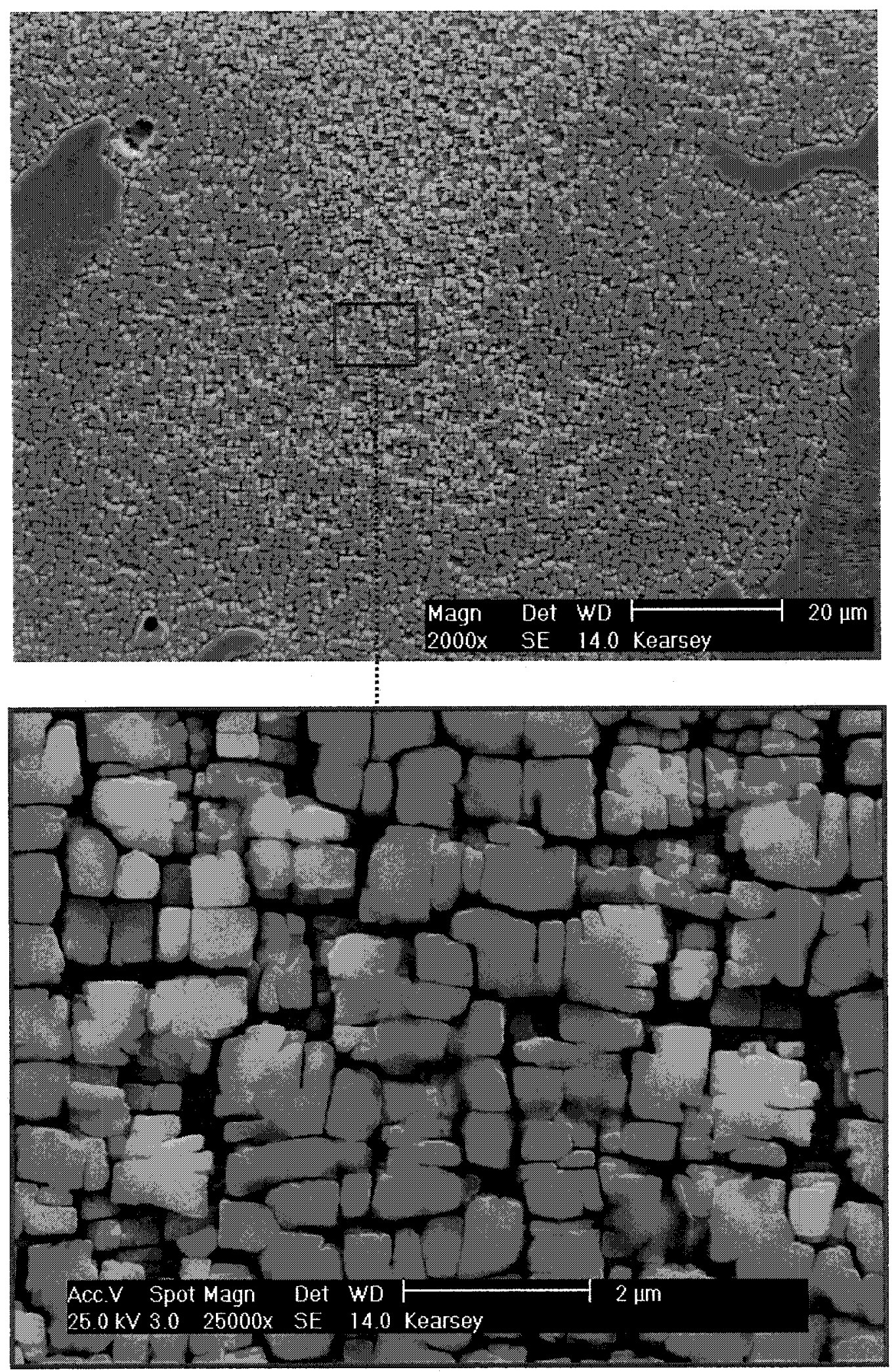

Figure 110: Alloy $\mathbf{B}-\gamma^{\prime}$ within top secondary dendrite arm. 


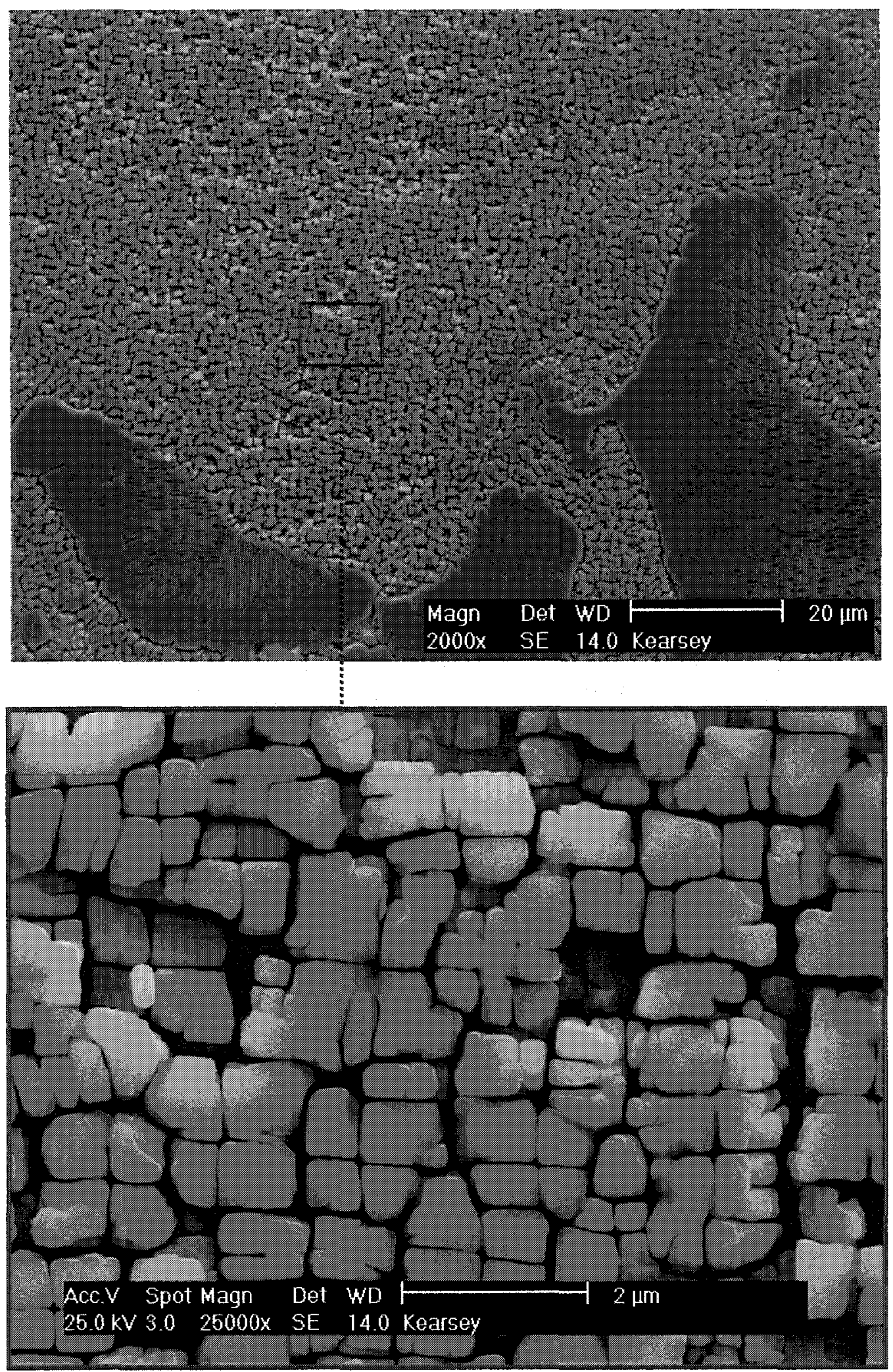

Figure 111: Alloy $\mathbf{B}-\gamma^{\prime}$ within bottom secondary dendrite arm. 


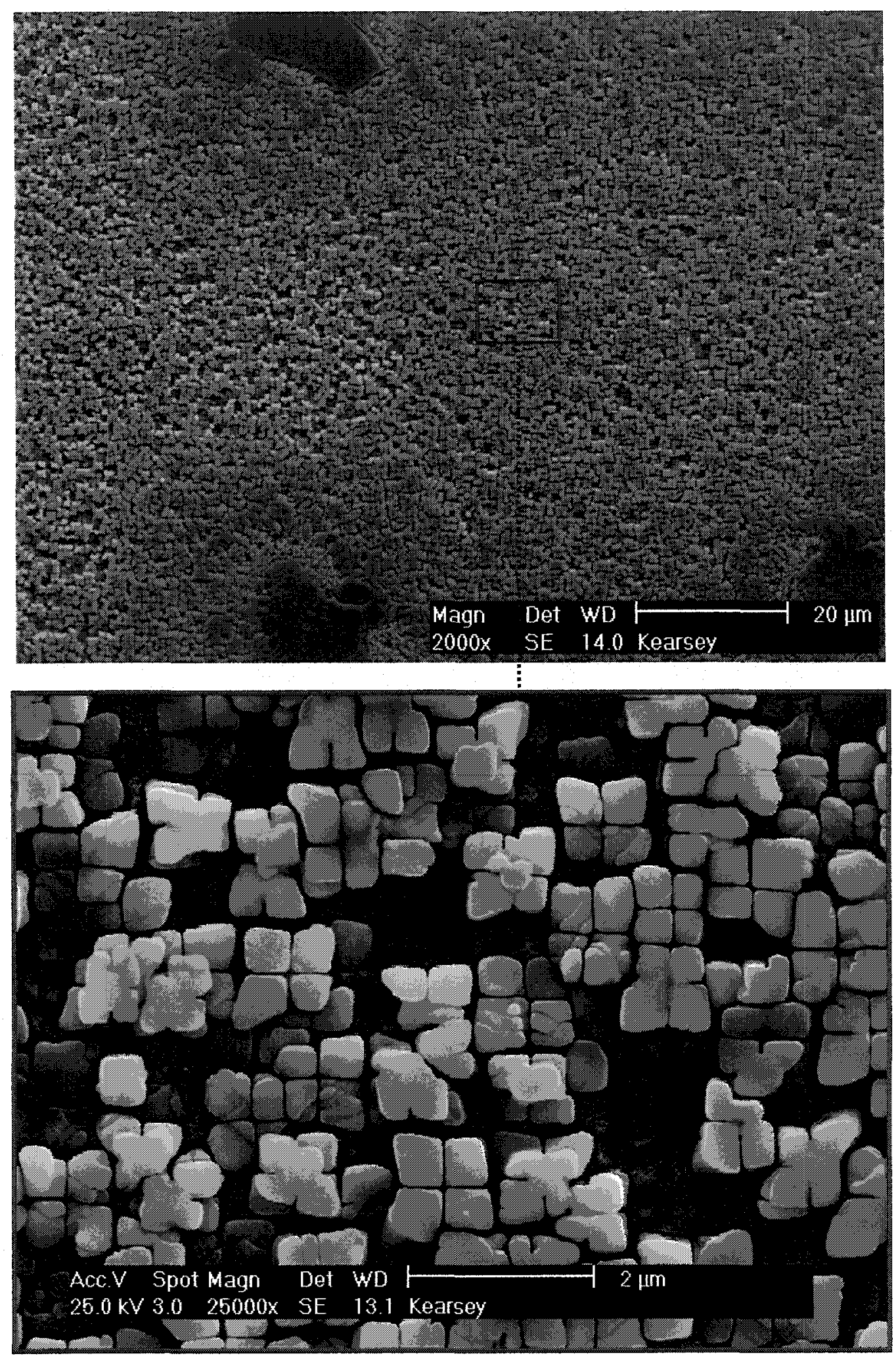

Figure 112: Alloy $\mathrm{C}-\gamma^{\prime}$ within primary dendrite arm. 

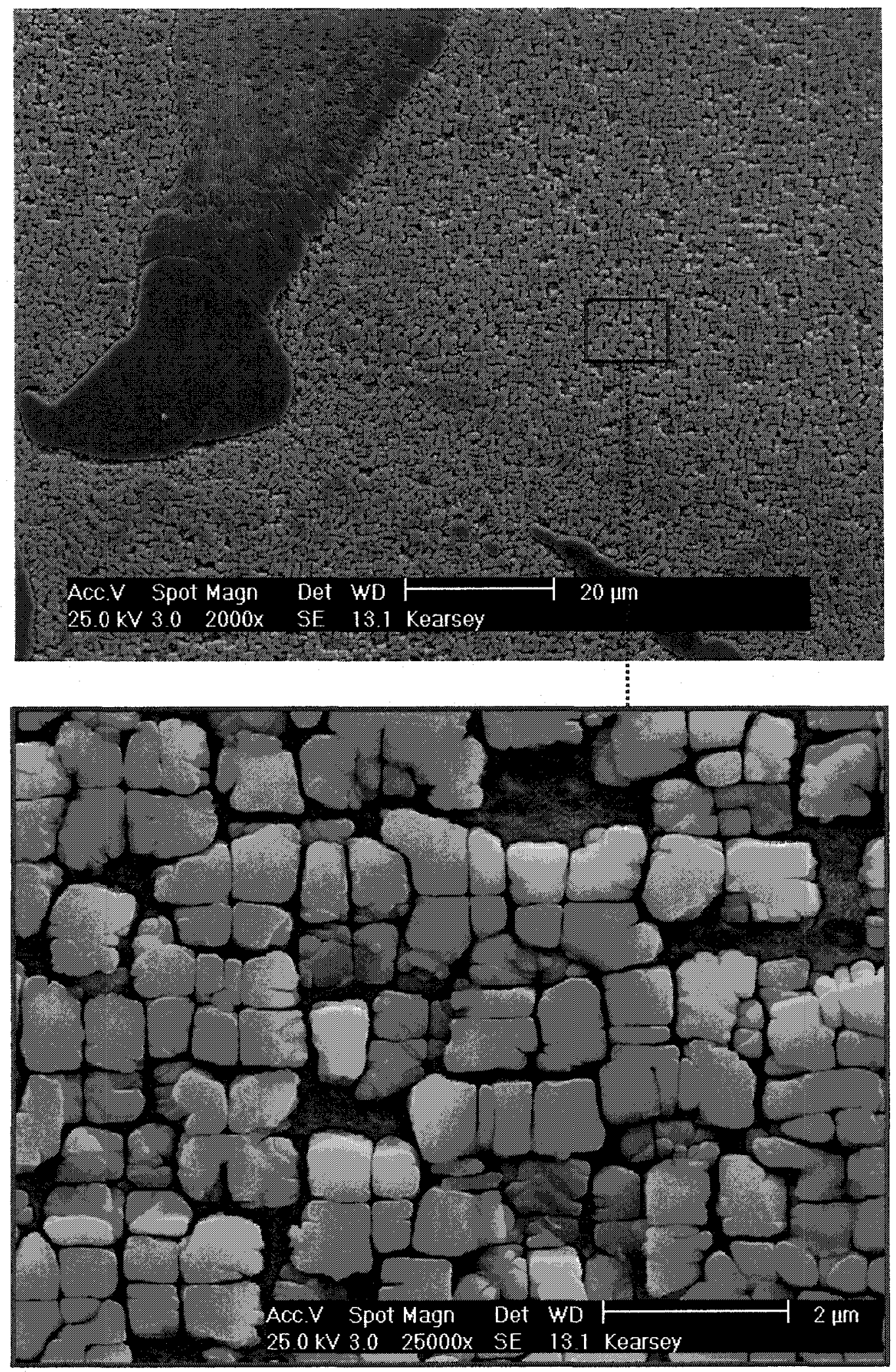

Figure 113: Alloy $\mathrm{C}-\gamma^{\prime}$ within left secondary dendrite arm. 

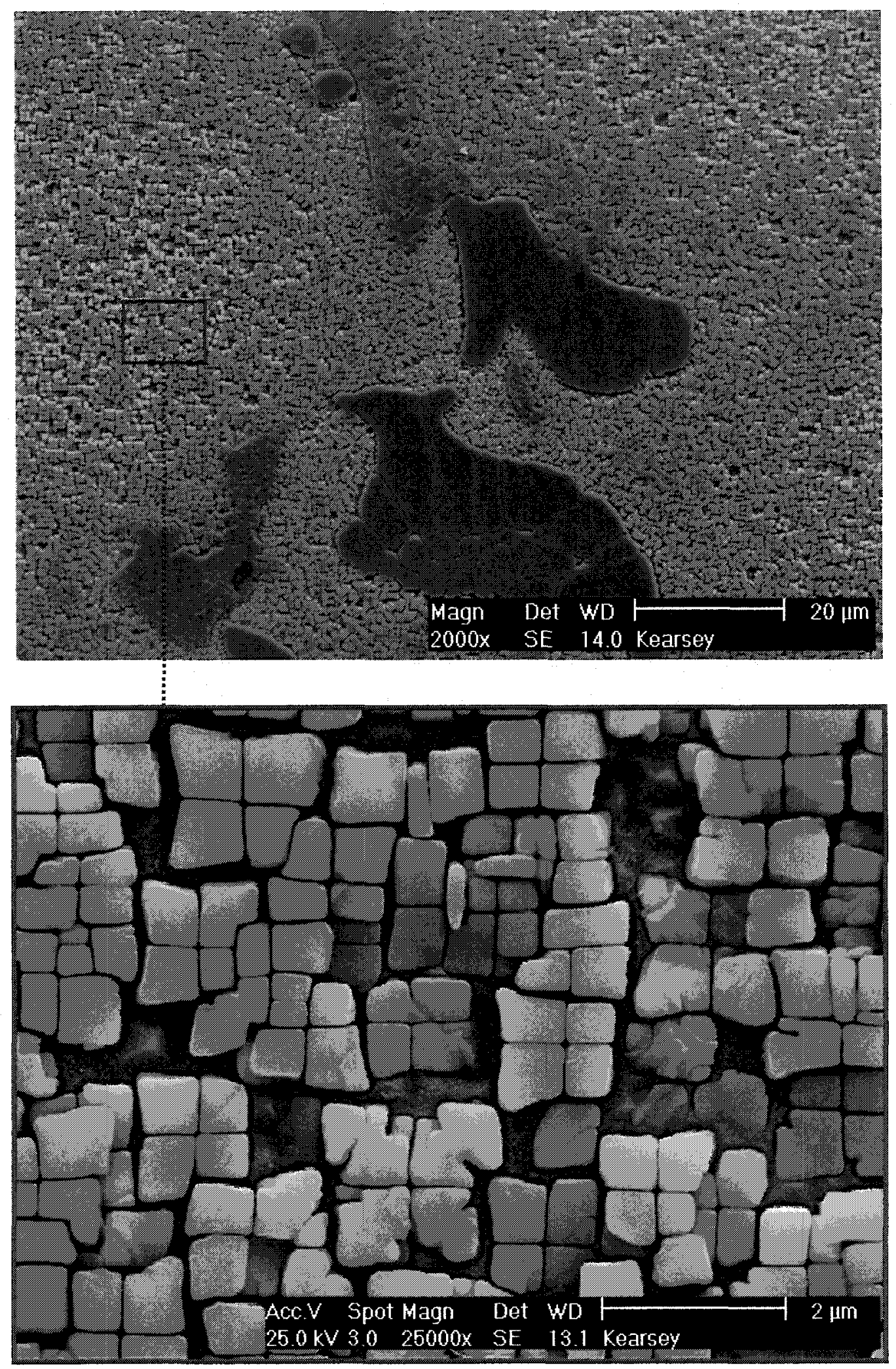

Figure 114: Alloy $\mathbf{C}-\gamma^{\prime}$ within right secondary dendrite arm. 

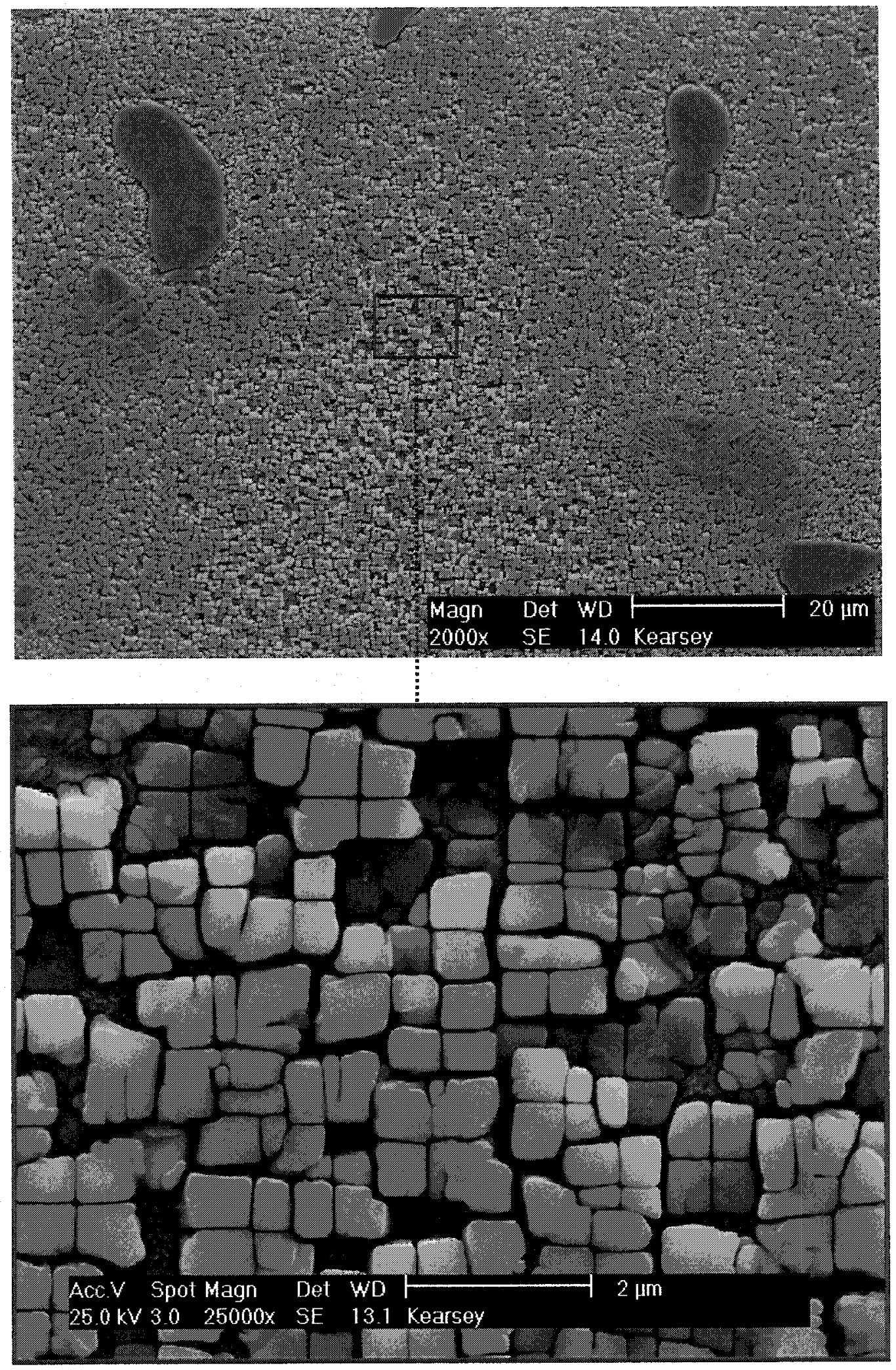

Figure 115: Alloy $\mathrm{C}-\gamma^{\prime}$ within top secondary dendrite arm. 

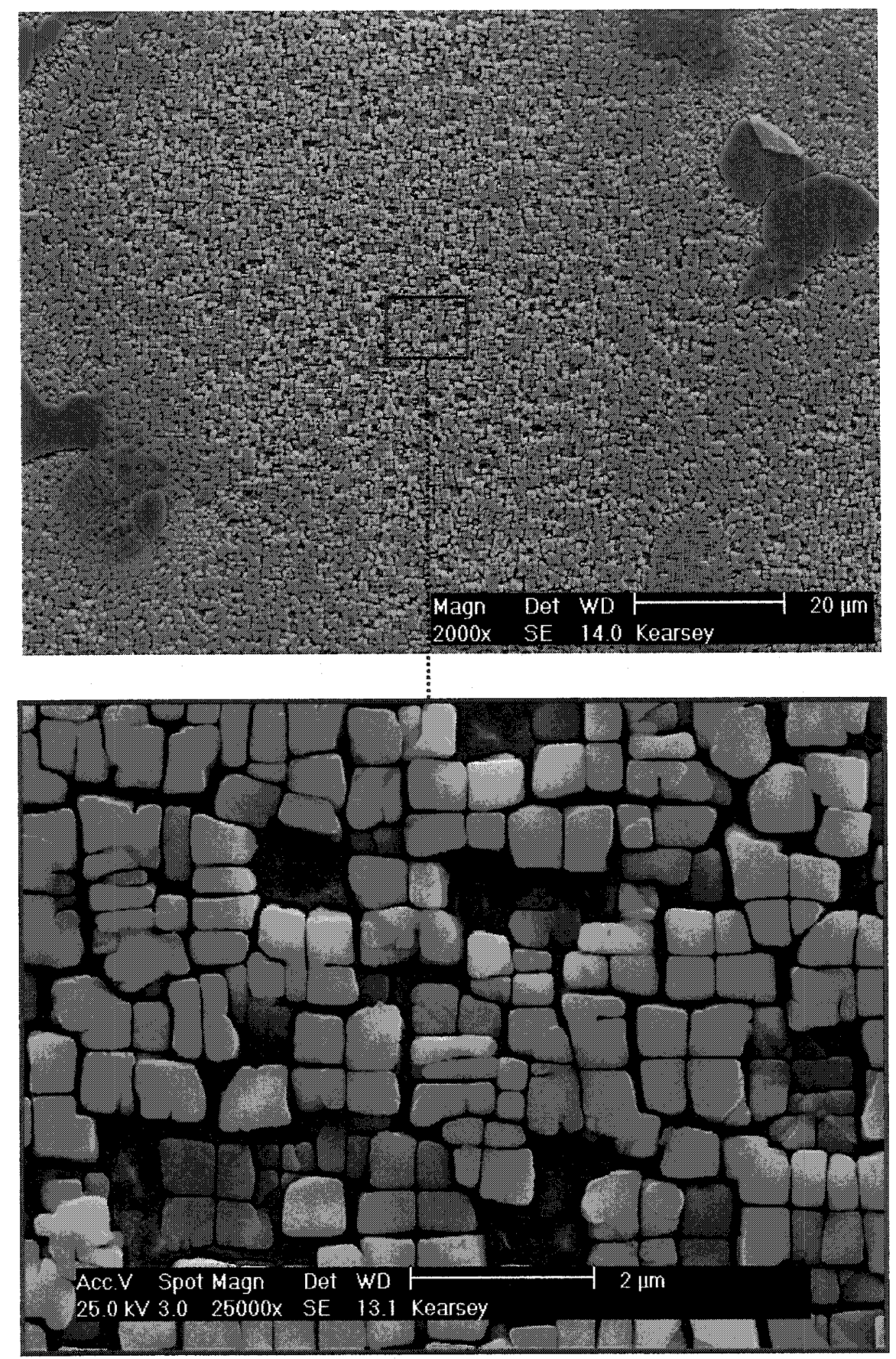

Figure 116: Alloy $\mathrm{C}-\gamma^{\prime}$ within bottom secondary dendrite arm. 

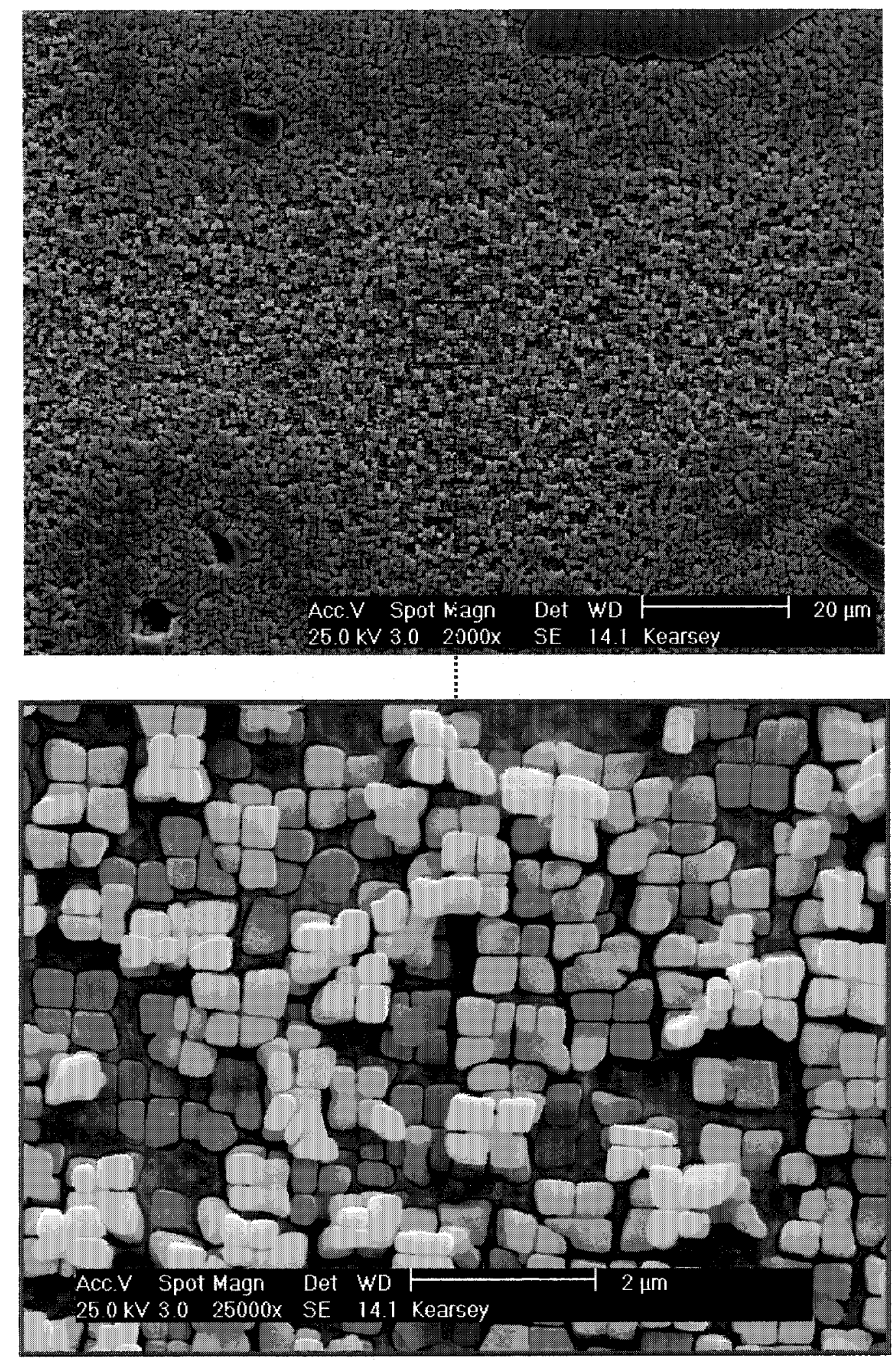

Figure 117: Alloy $D-\gamma^{\prime}$ within primary dendrite arm. 

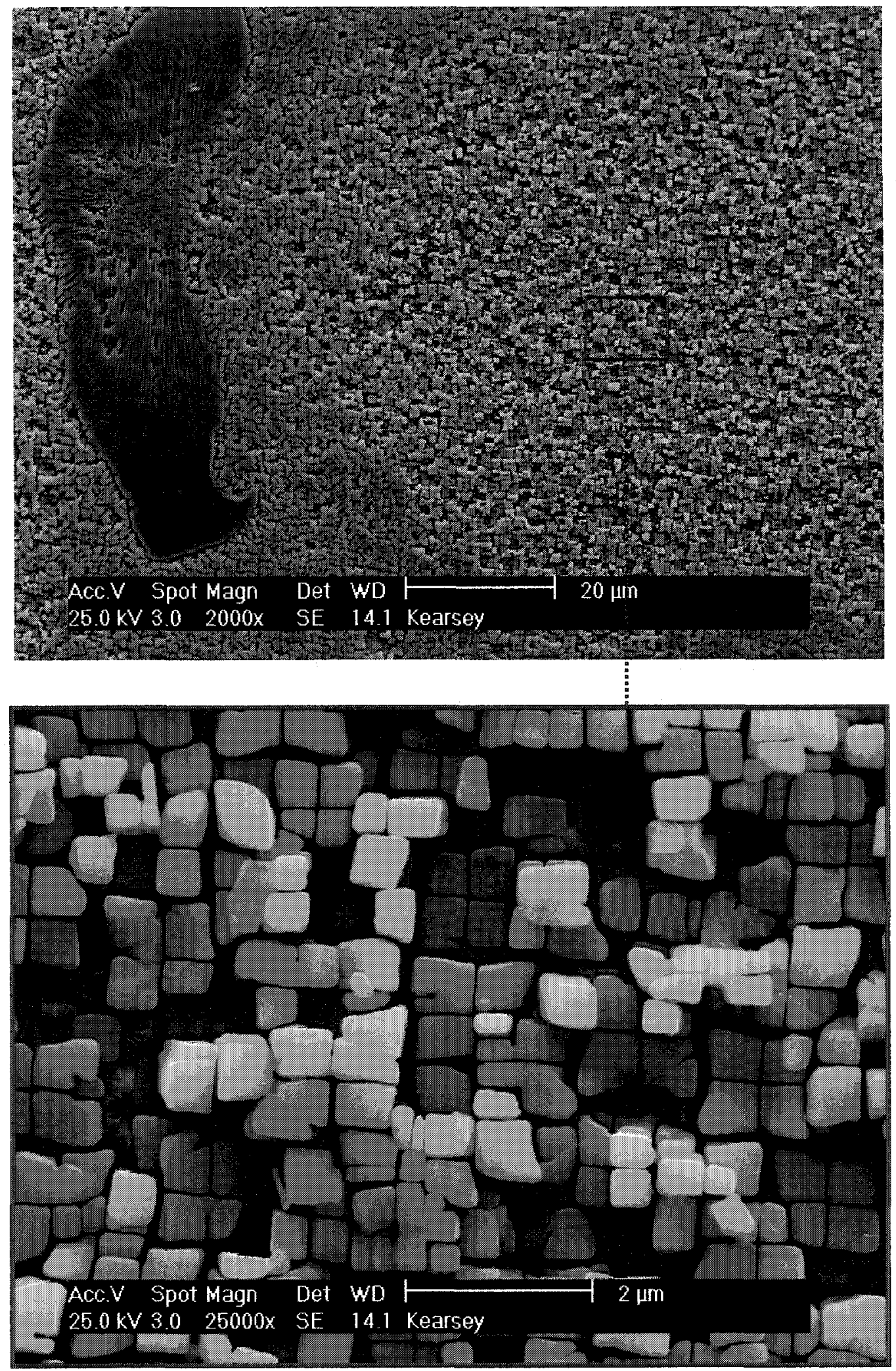

Figure 118: Alloy $\mathbf{D}-\gamma^{\prime}$ within left secondary dendrite arm. 

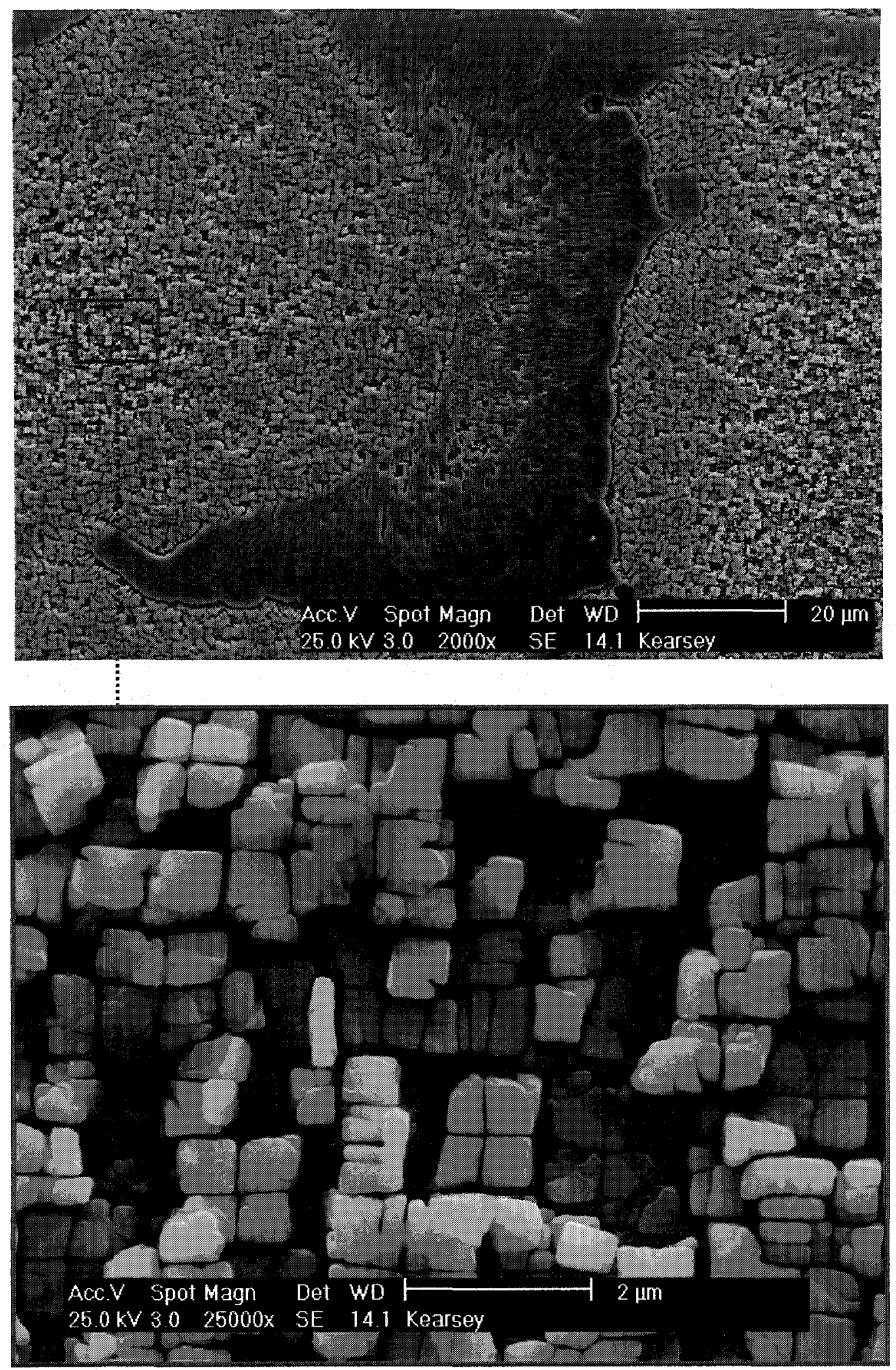

Figure 119: Alloy $\mathrm{D}-\gamma^{\prime}$ within right secondary dendrite arm. 

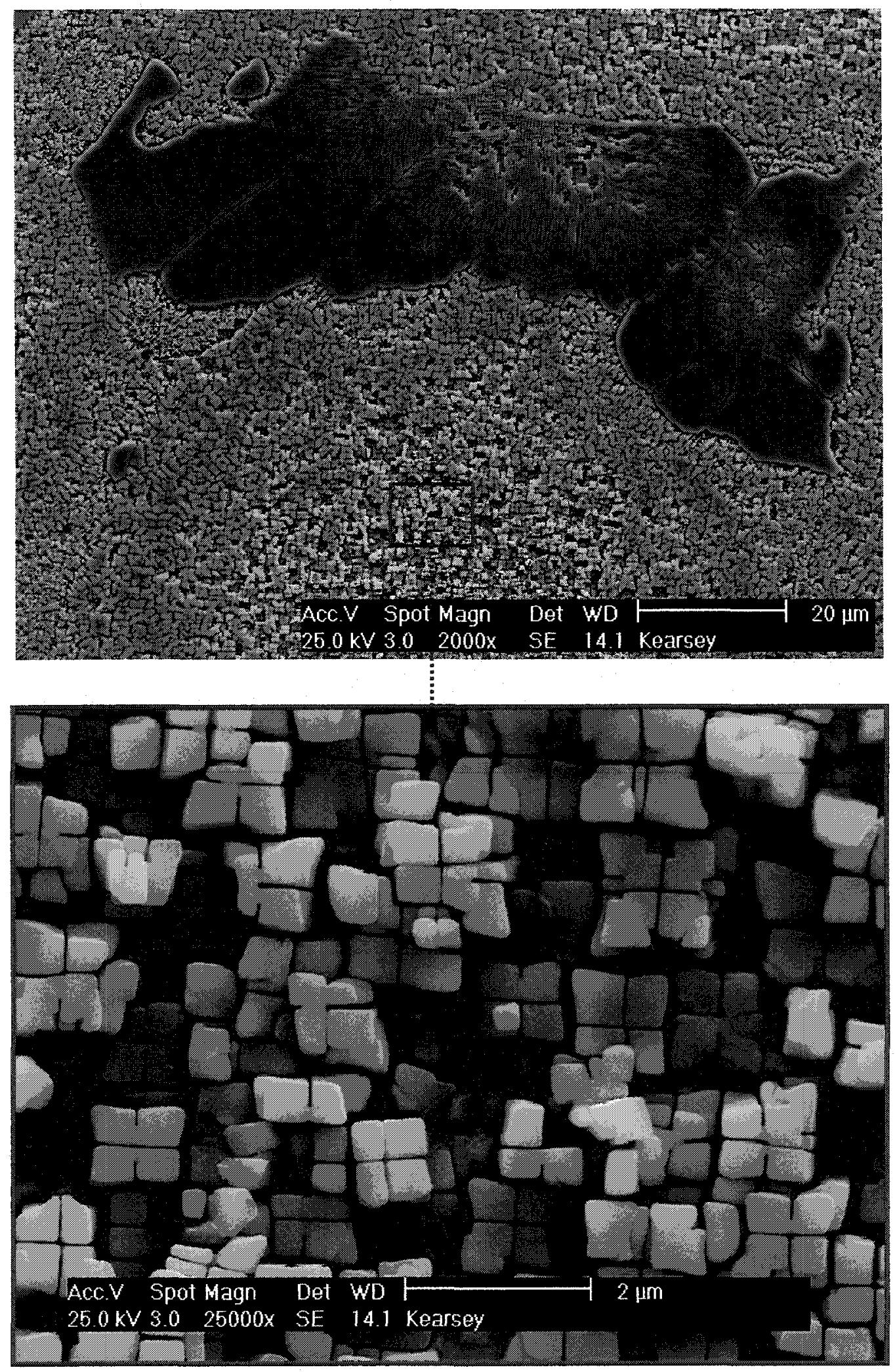

Figure 120: Alloy $\mathbf{D}-\gamma^{\prime}$ within top secondary dendrite arm. 

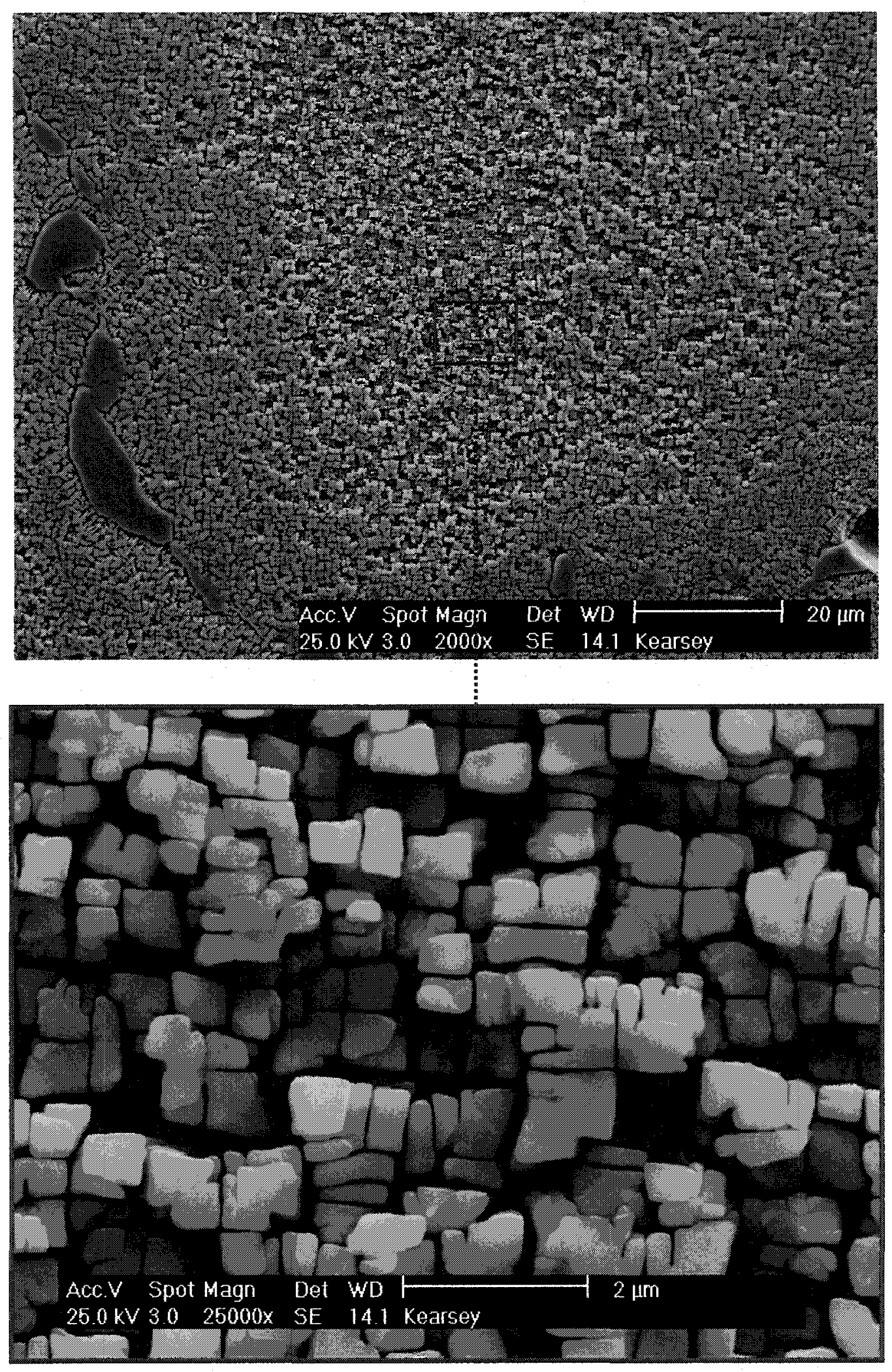

Figure 121: Alloy $D-\gamma^{\prime}$ within bottom secondary dendrite arm. 

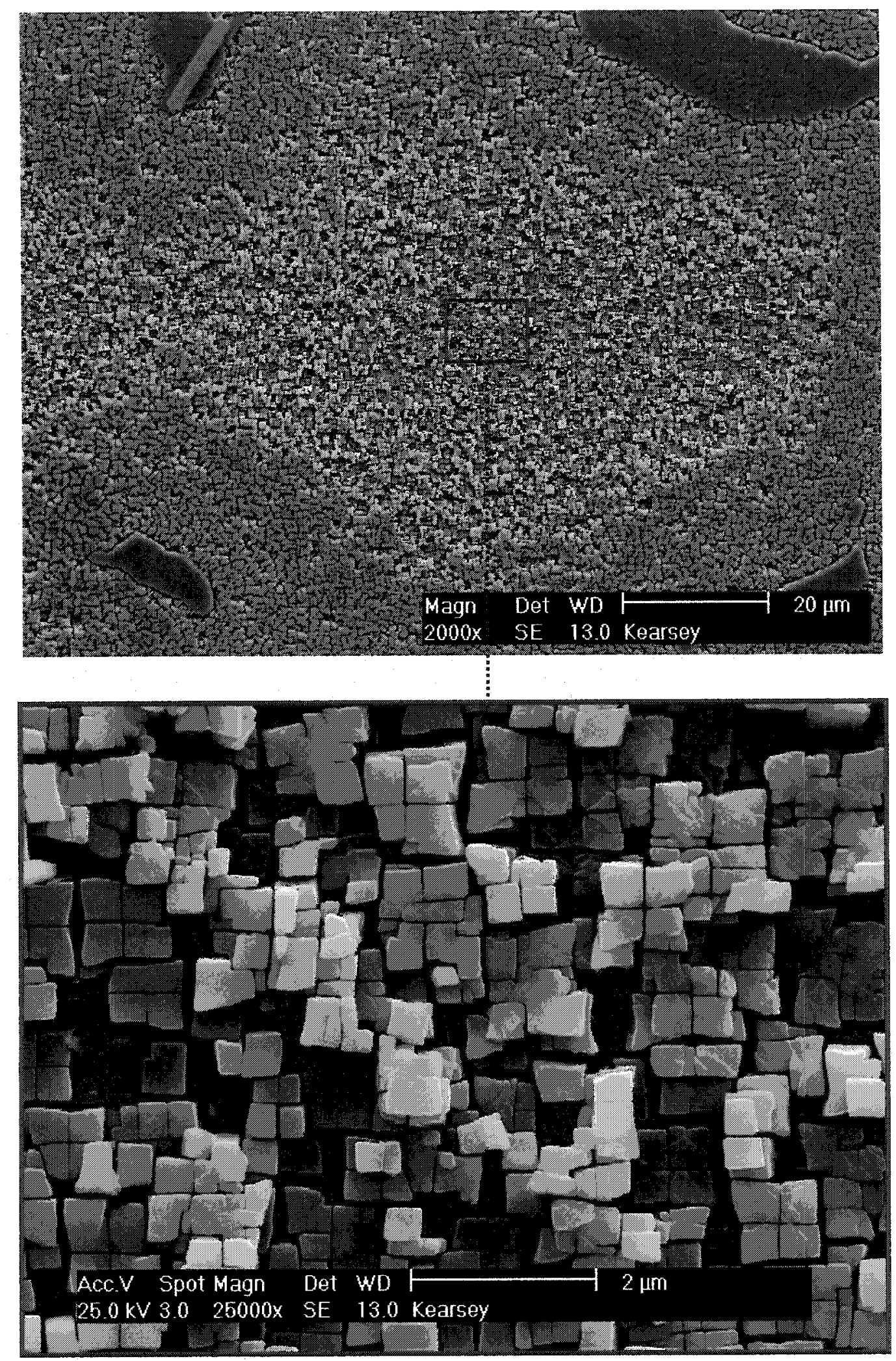

Figure 122: Alloy $\mathbb{E}-\gamma^{\prime}$ within primary dendrite core. 

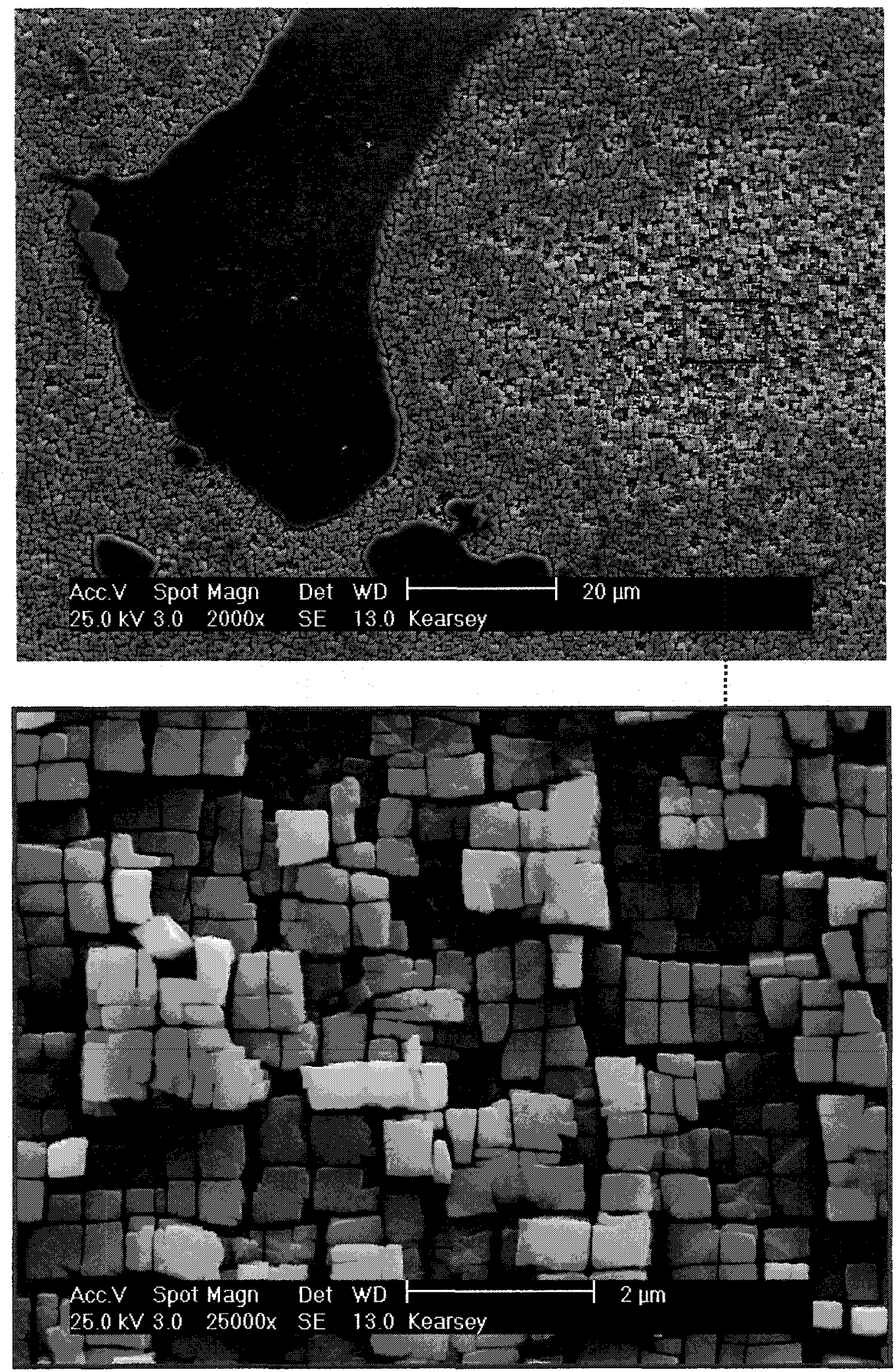

Figure 123: Alloy $\mathbf{E}-\gamma^{\prime}$ within left secondary dendrite arm. 

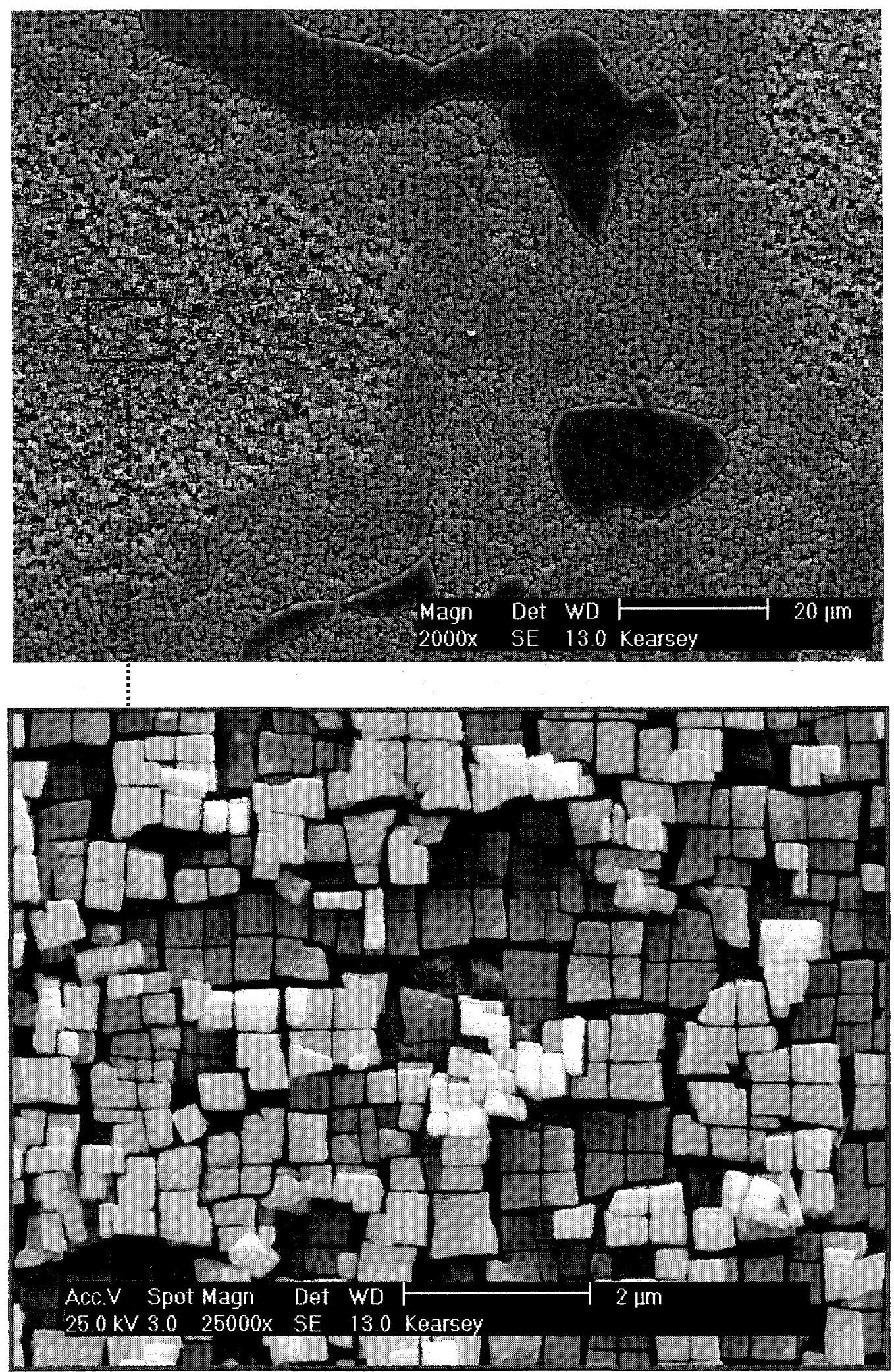

Figure 124: Alloy $\mathbf{E}-\gamma^{\prime}$ within right secondary dendrite arm. 

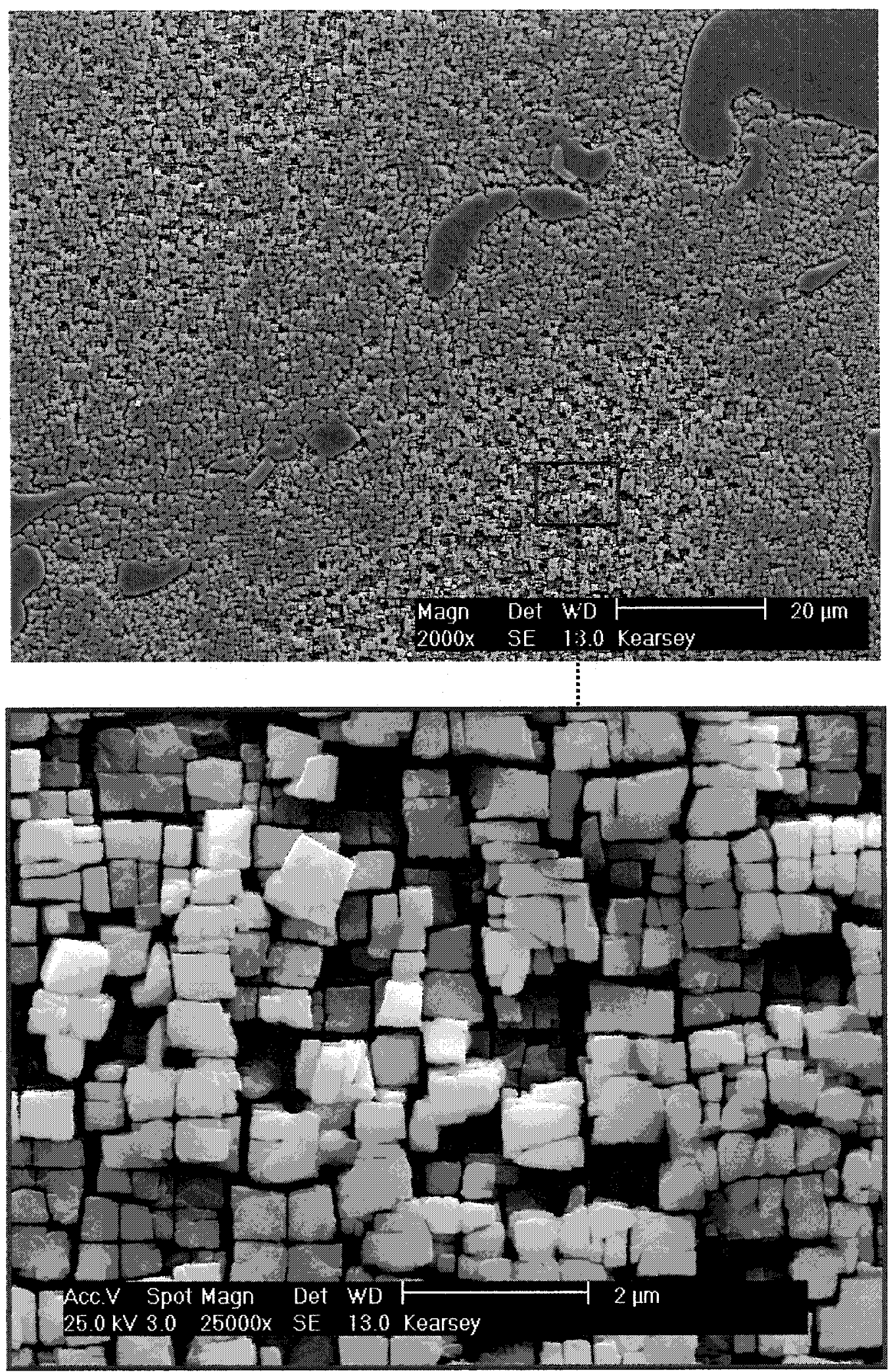

Figure 125: Alloy $\mathbf{E}-\gamma^{\prime}$ within top secondary dendrite arm. 

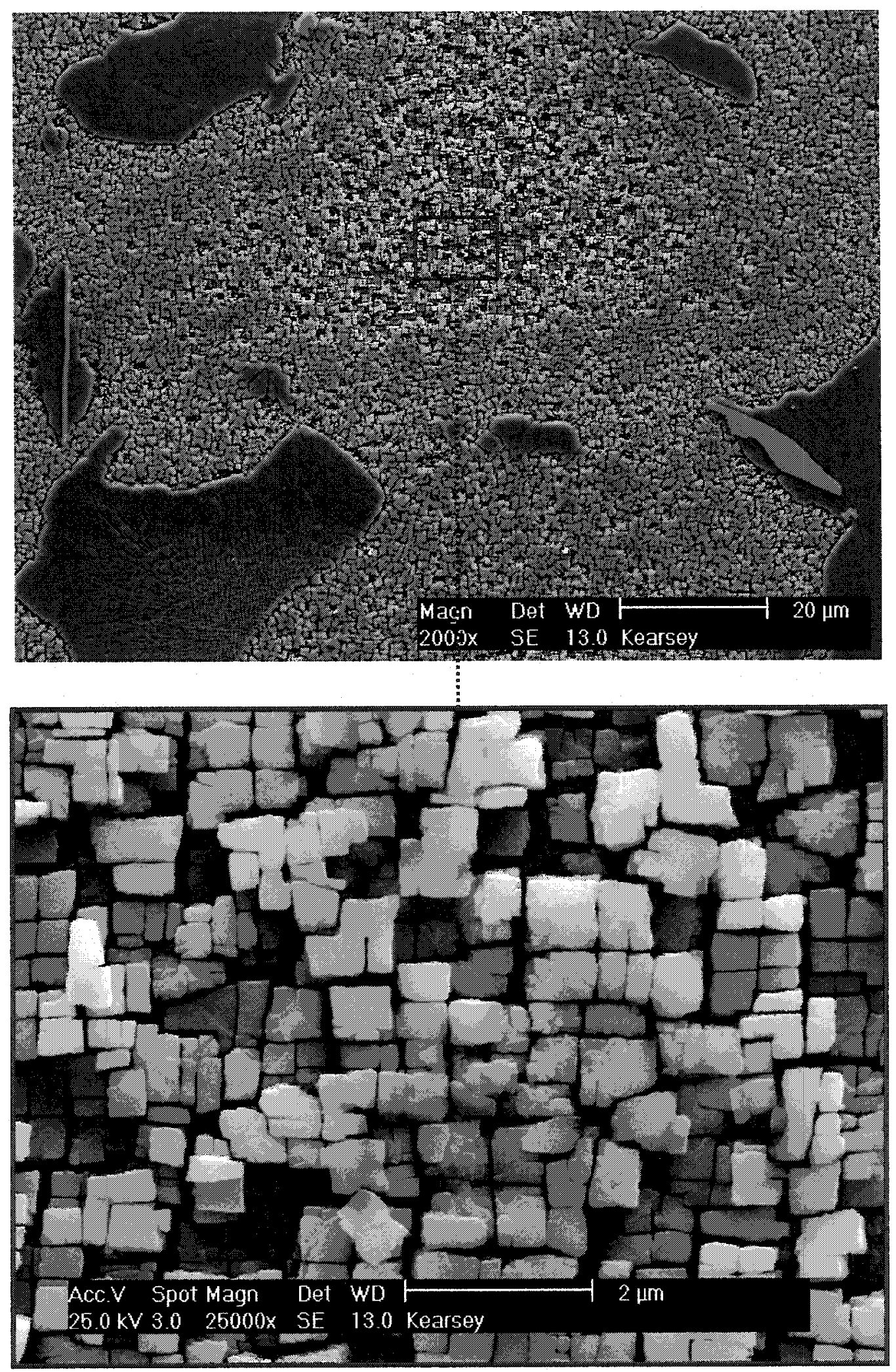

Figure 126: Alloy $\mathbf{E}-\gamma^{\prime}$ within bottom secondary dendrite arm. 

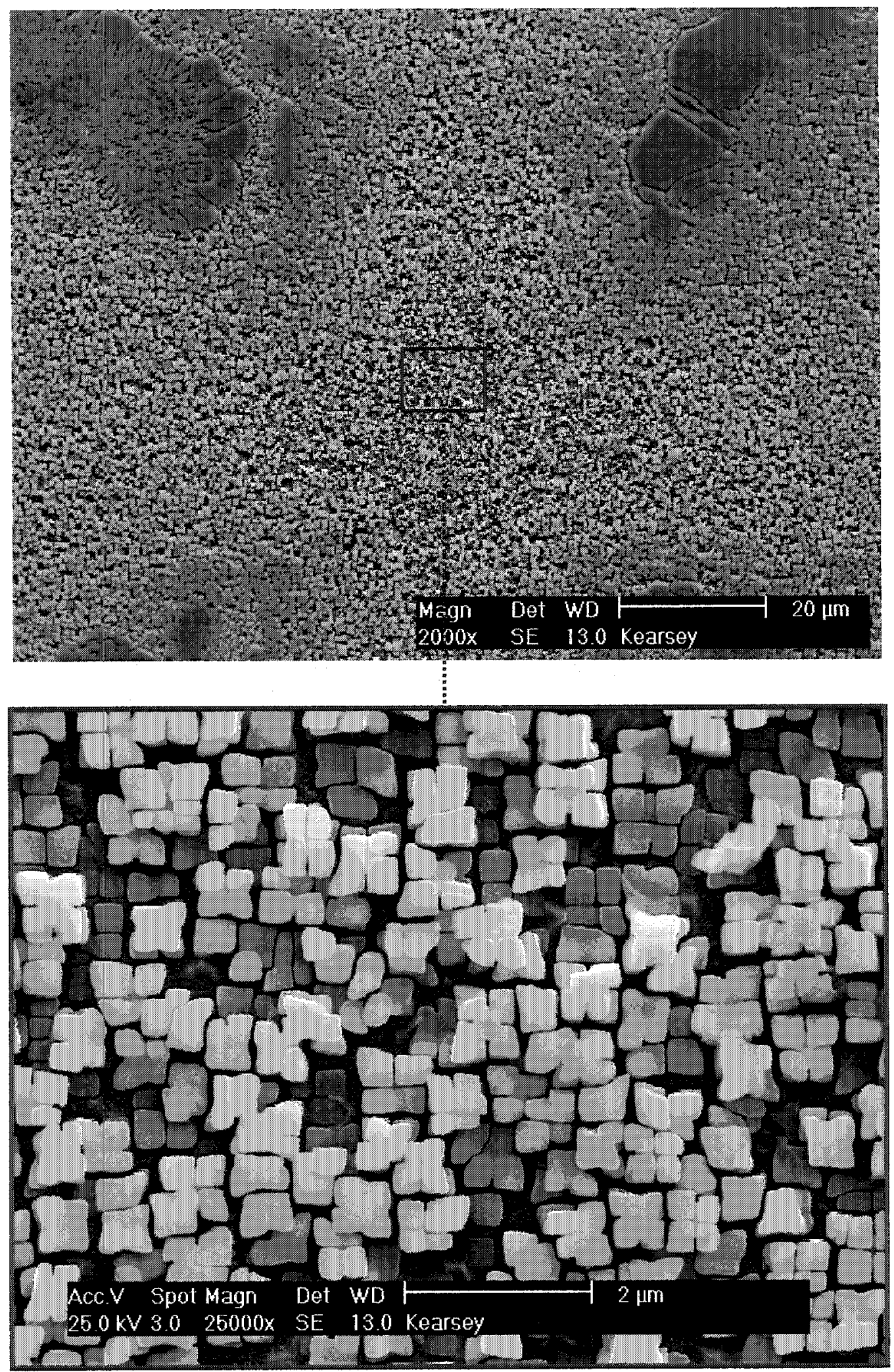

Figure 127: Alloy $\mathrm{F}-\gamma^{\prime}$ within primary dendrite core. 

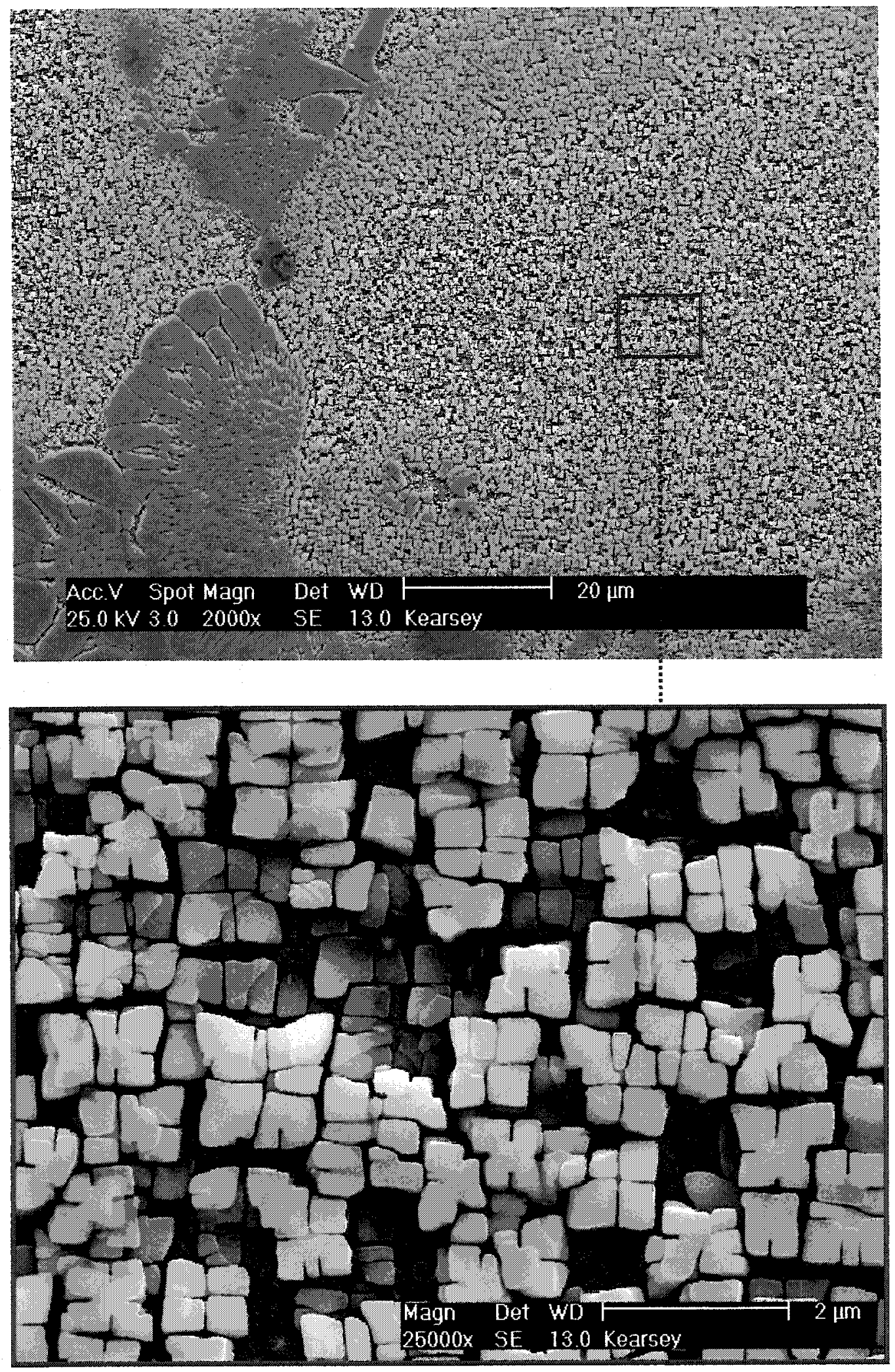

Figure 128: Alloy $F-\gamma^{\prime}$ within left secondary dendrite arm. 

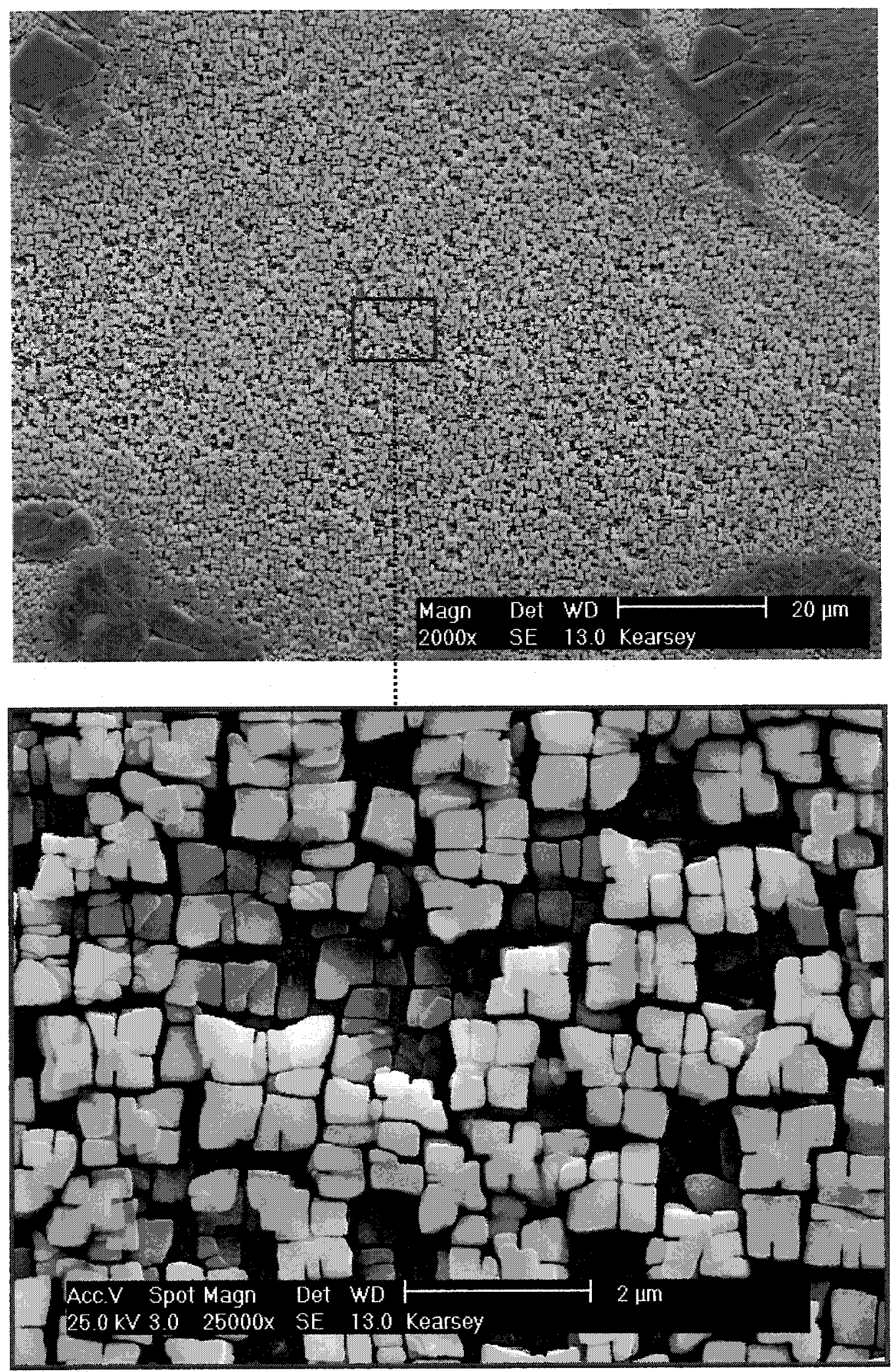

Figure 129: Alloy $\mathrm{F}-\gamma^{\prime}$ within right secondary dendrite arm. 

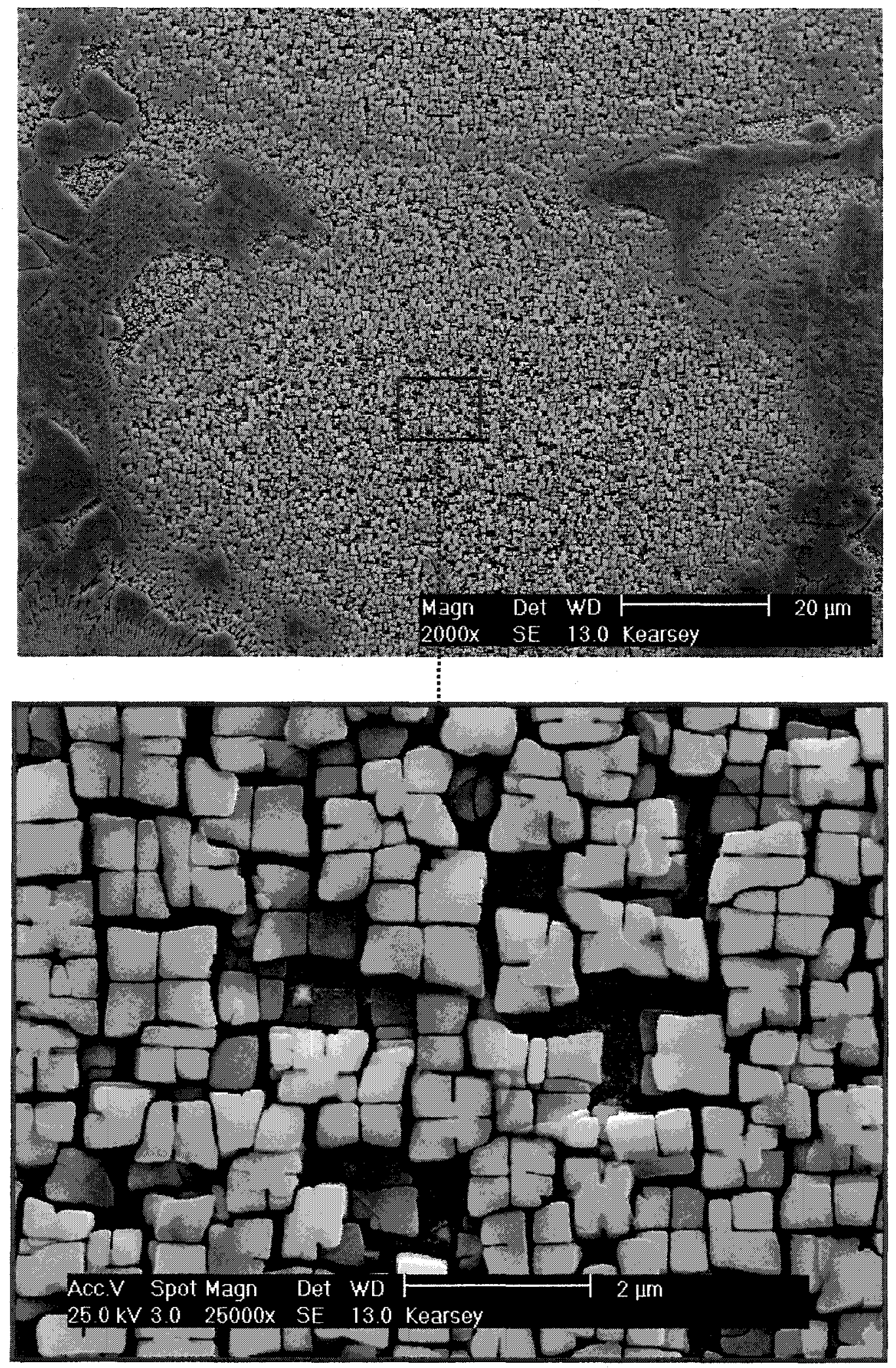

Figure 130: Alloy F $-\gamma^{\prime}$ within top secondary dendrite arm. 

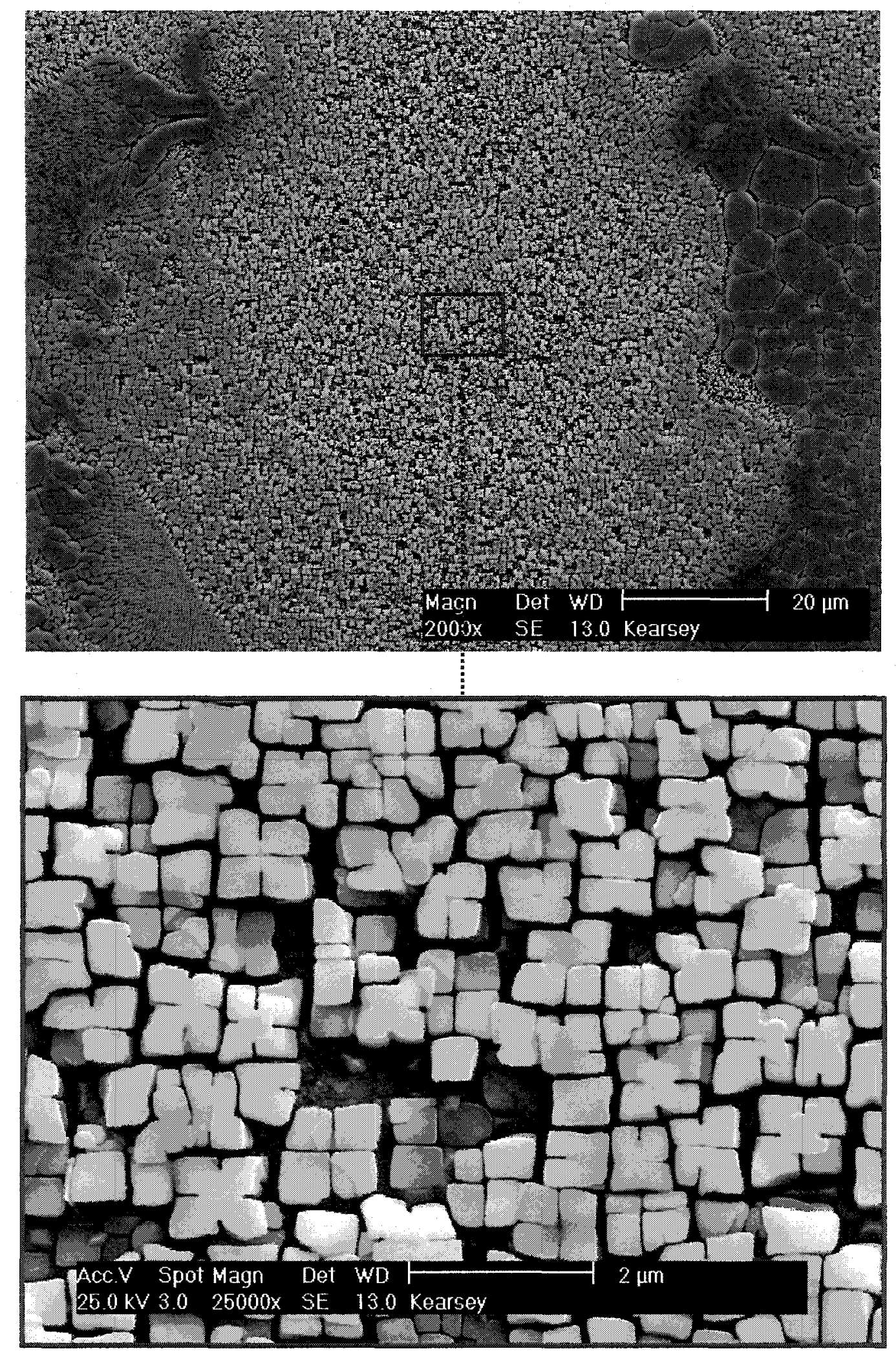

Figure 131: Alloy $\mathbf{F}-\gamma^{\prime}$ within bottom secondary dendrite arm. 


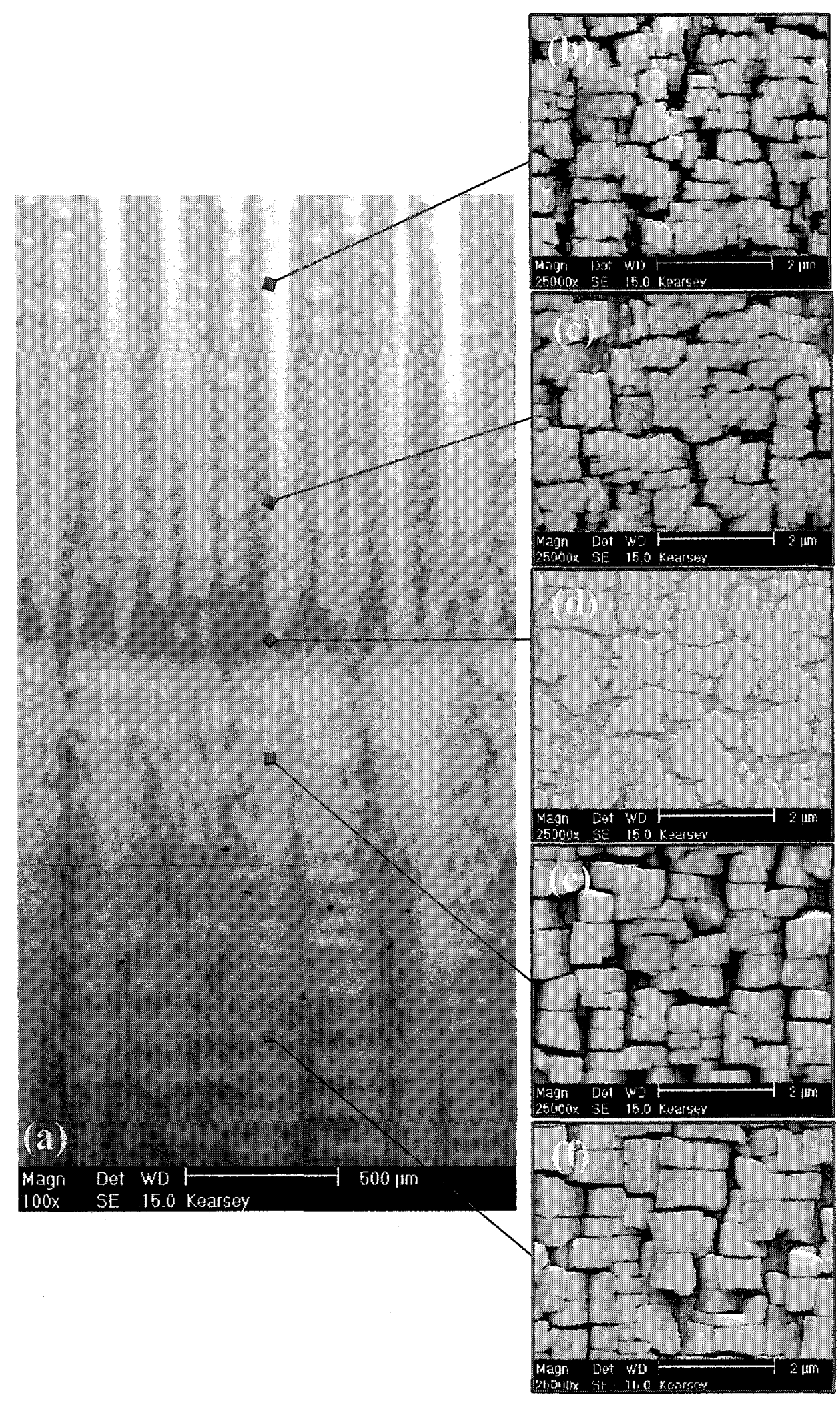

Figure 132: Precipitate structure in the longitudinal direction. a) Low magnification image of Alloy $E$ showing transition from the PWA-1484 seed, across the mushy zone, into the new SX growth region, b) $\gamma^{\prime}$ in the new SX region, c) just above the solid-liquid interface, d) within the interface region, e) just below the interface in the mushy zone, f) within the solid 1484 seed structure. 


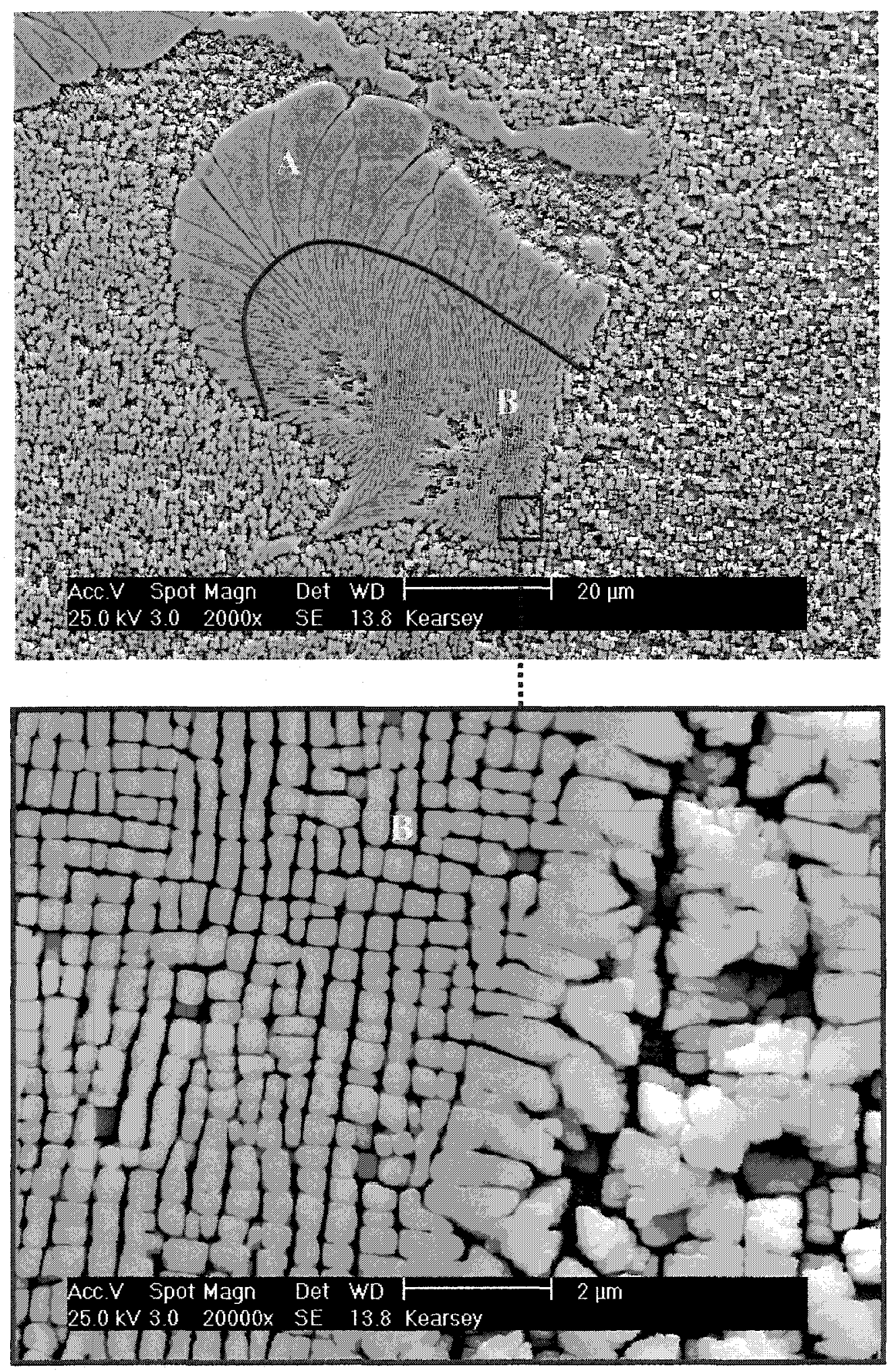

Figure 133: Typical Eutectic $\gamma-\gamma^{\prime}$ morphology commonly seen within the interdendritic region of Alloys A-F. Region A: eutectic cap is the coarse fan structure of $\gamma^{\prime}$ that occurs during the final stages of eutectic growth, Region B: eutectic core contains extremely fine eutectic $\gamma^{\prime}$ during the initial growth stages. 

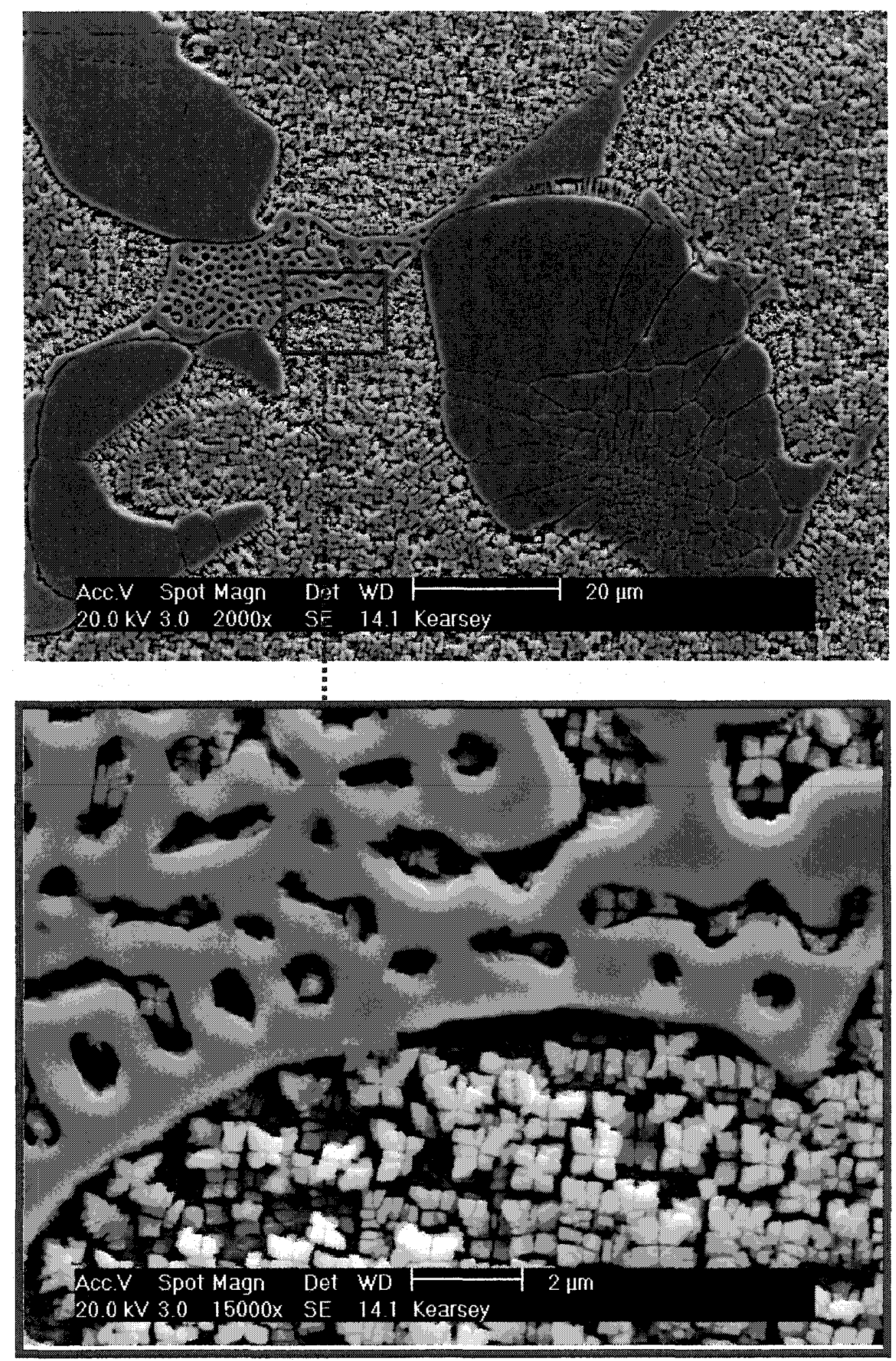

Figure 134: Alternative eutectic structure observed in Alloy A. The structure appears to be short $\gamma$-like rods in a matrix of possibly $\gamma^{\prime}$ (rods have been removed during etching). 


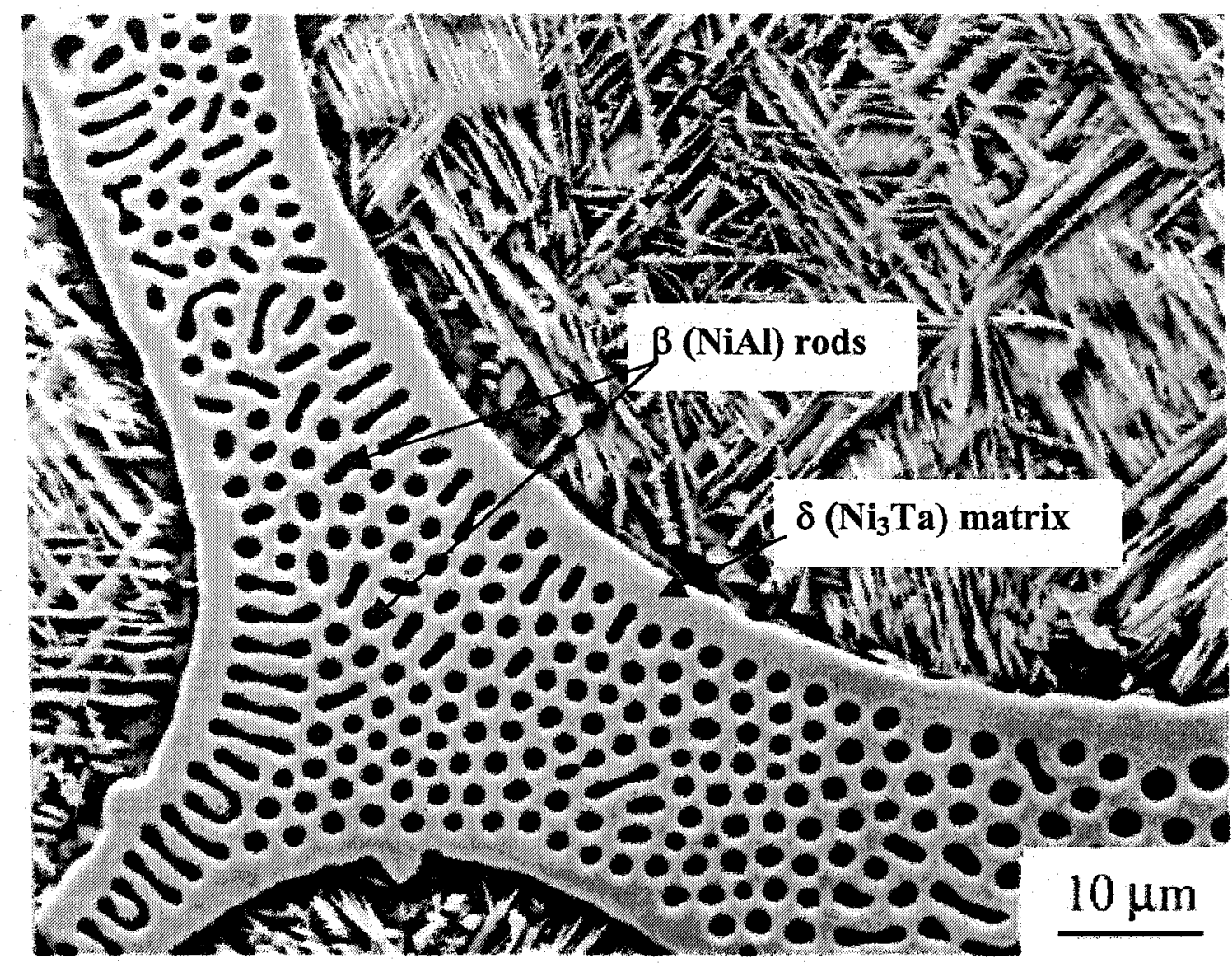

Figure 135: Eutectic structure observed in a rapidly cooled Ni-27.6 Al-9.7 Ta alloy. Consists of $\beta$ (NiAl) rods in a $\delta\left(\mathrm{Ni}_{3} \mathrm{Ta}\right)$ matrix [100]. 

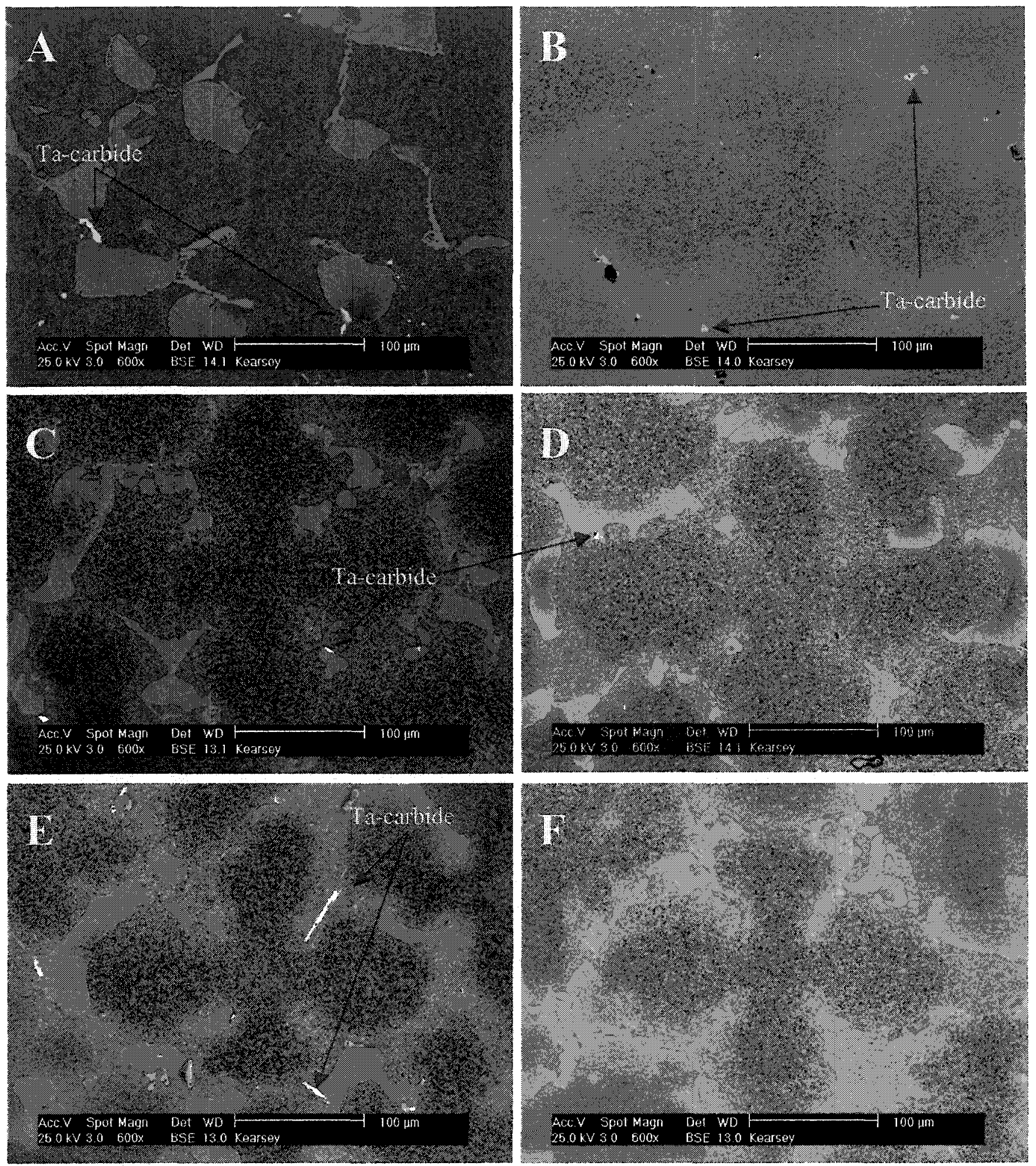

Figure 136: Back-scattered electron SEM images of transverse dendritic structures of Alloy A-F. The presence of small amounts of Ta-rich carbide phase (bright white in colour) appears in most of the alloys, but is slightly higher in Alloys $A$ and $E$. 

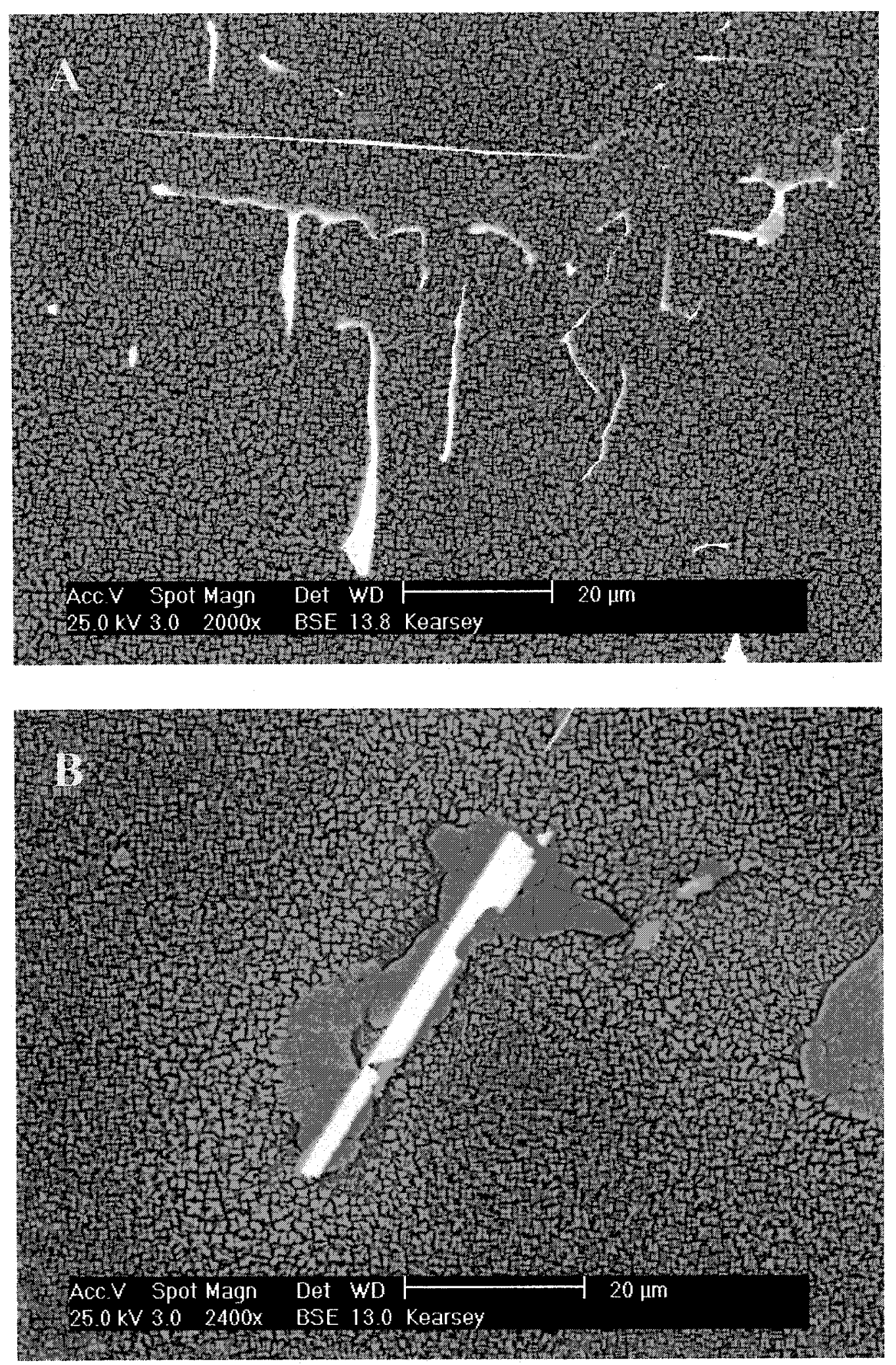

Figure 137: (a) Script-like Ta-rich carbide morphology observed within Alloy A, (b) large needle-like morphology located within the eutectic $\gamma^{\prime}$ of Alloy $E$. 


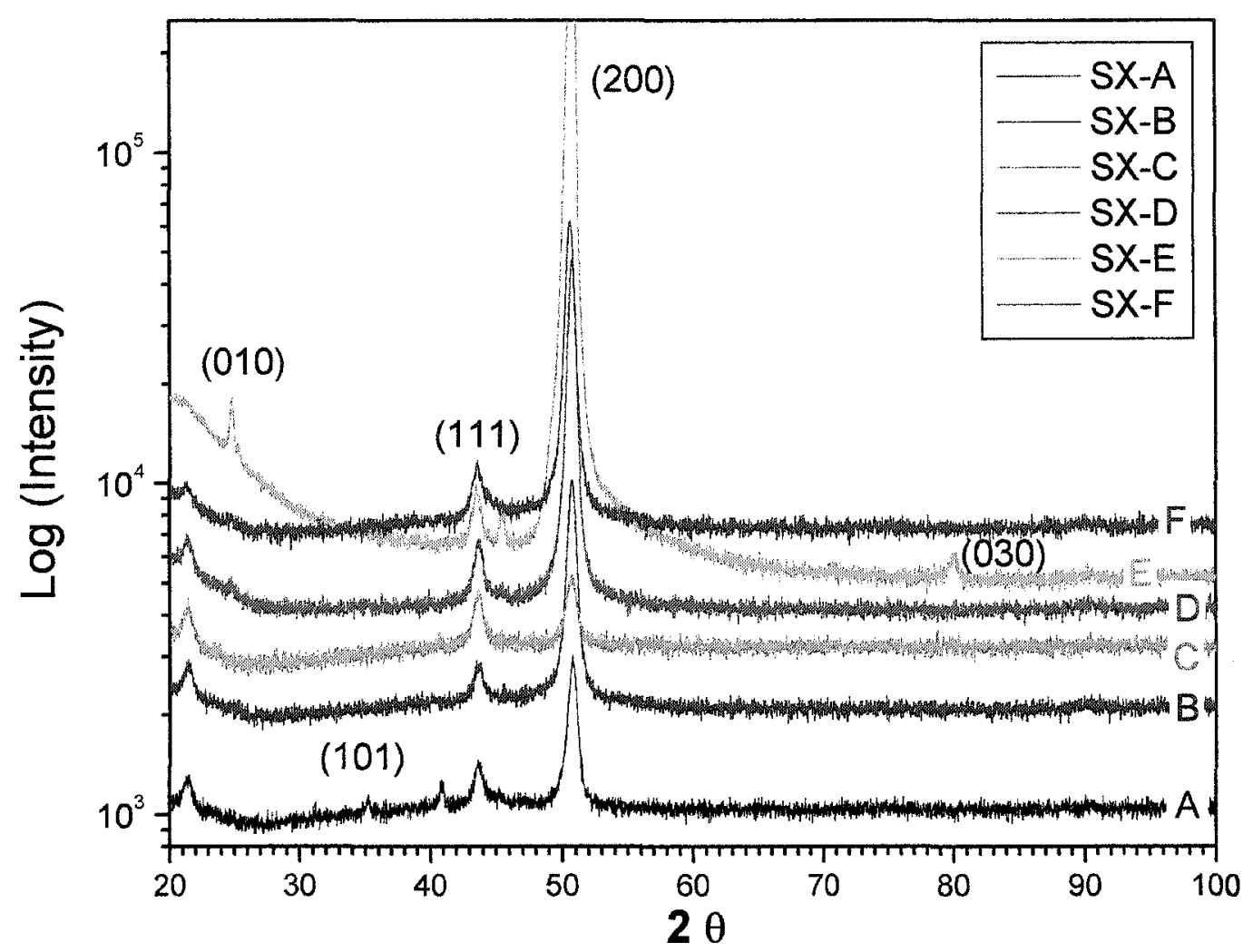

Figure 138: XRD $2 \theta$ diffraction patterns for Alloys A-F showing a preferred FCC single crystal structure.

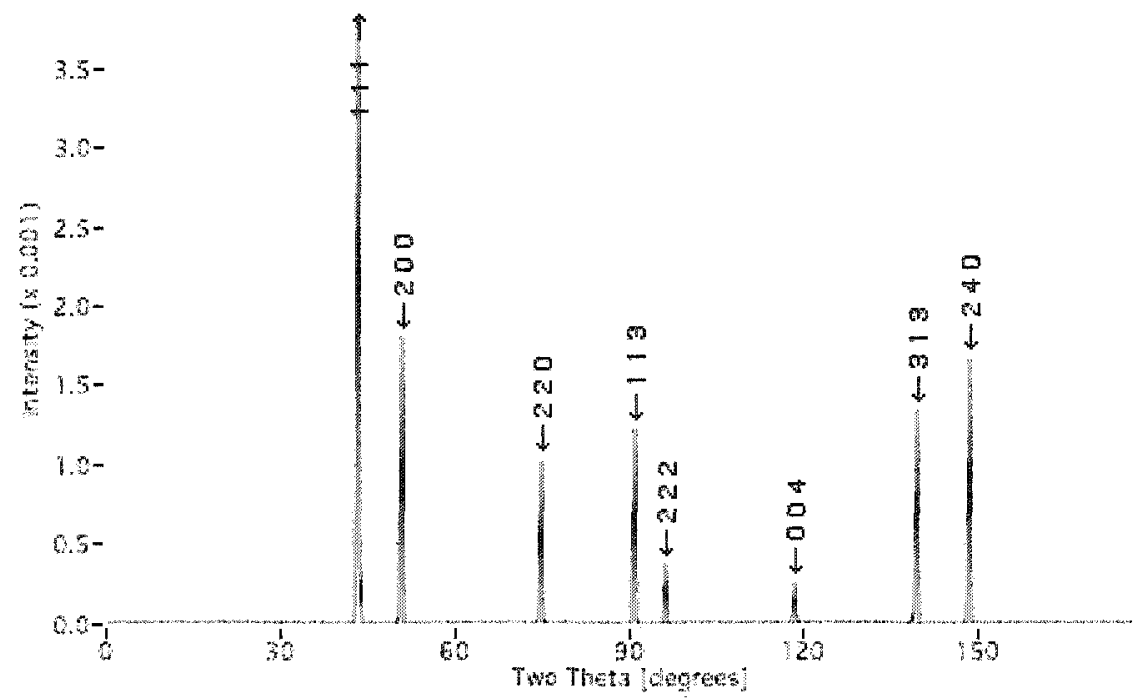

Figure 139: XRD powder diffraction pattern for the $\gamma$-phase [102]. 


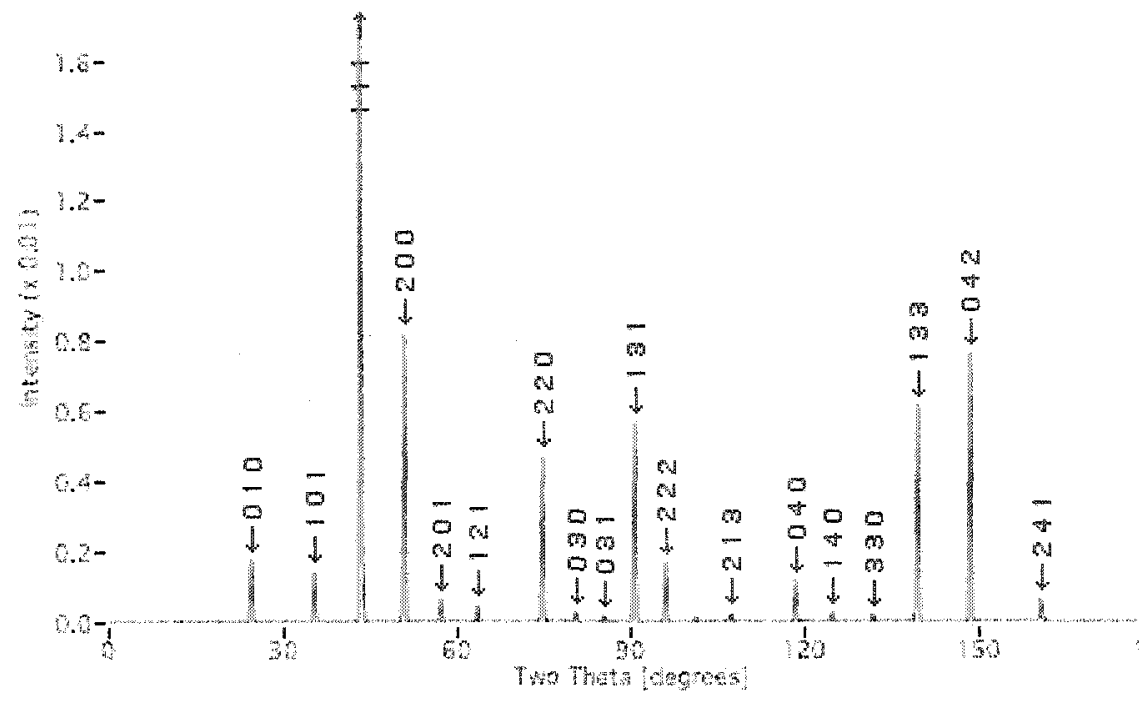

Figure 140: XRD powder diffraction pattern for the $\gamma^{\prime}$ phase [102].

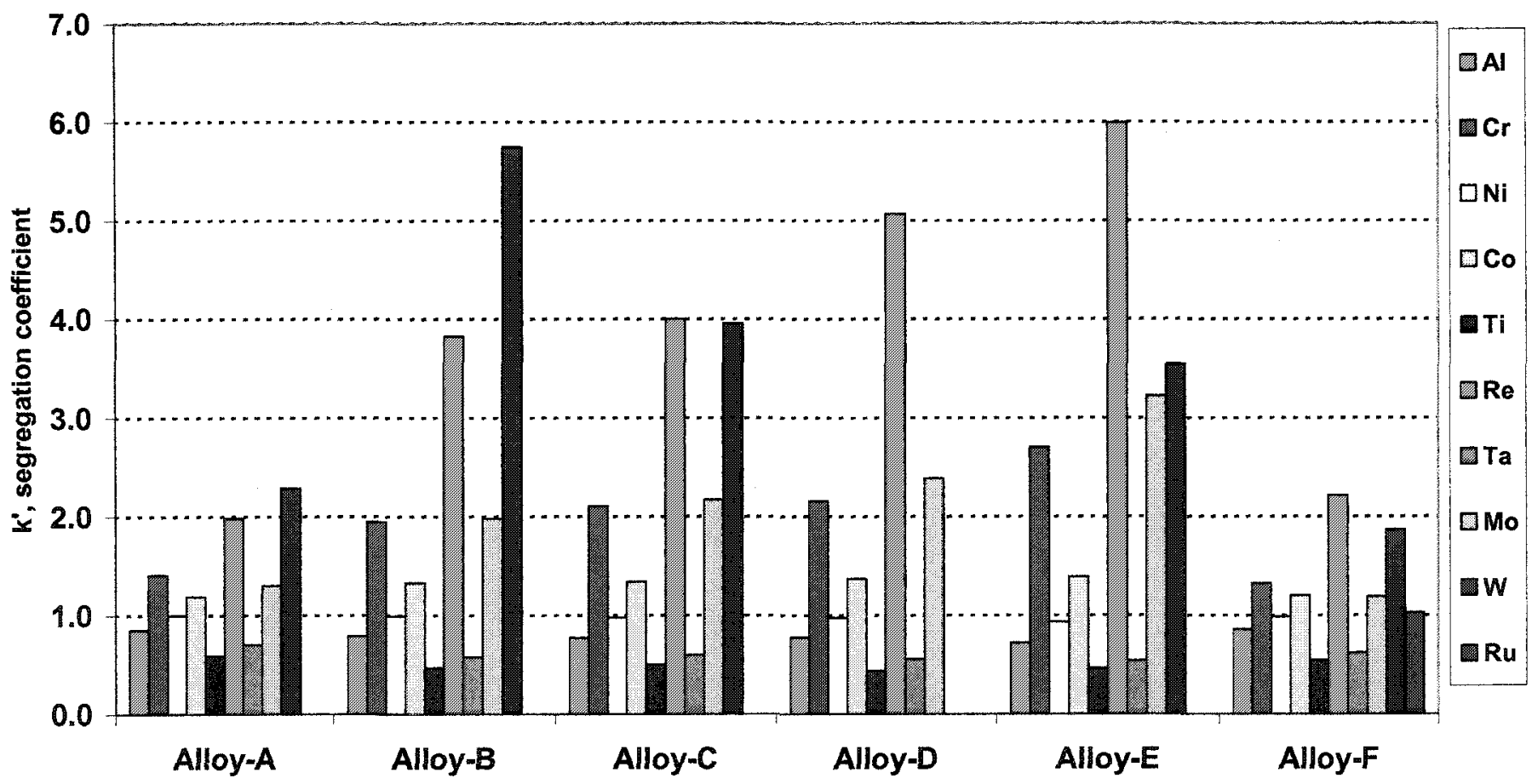

Figure 141: Segregation behavior of Alloys A-F. The $\mathbf{k}^{\prime}$ values greater than unity indicate segregation to the dendrite cores, less than unity indicates interdendritic segregation. 


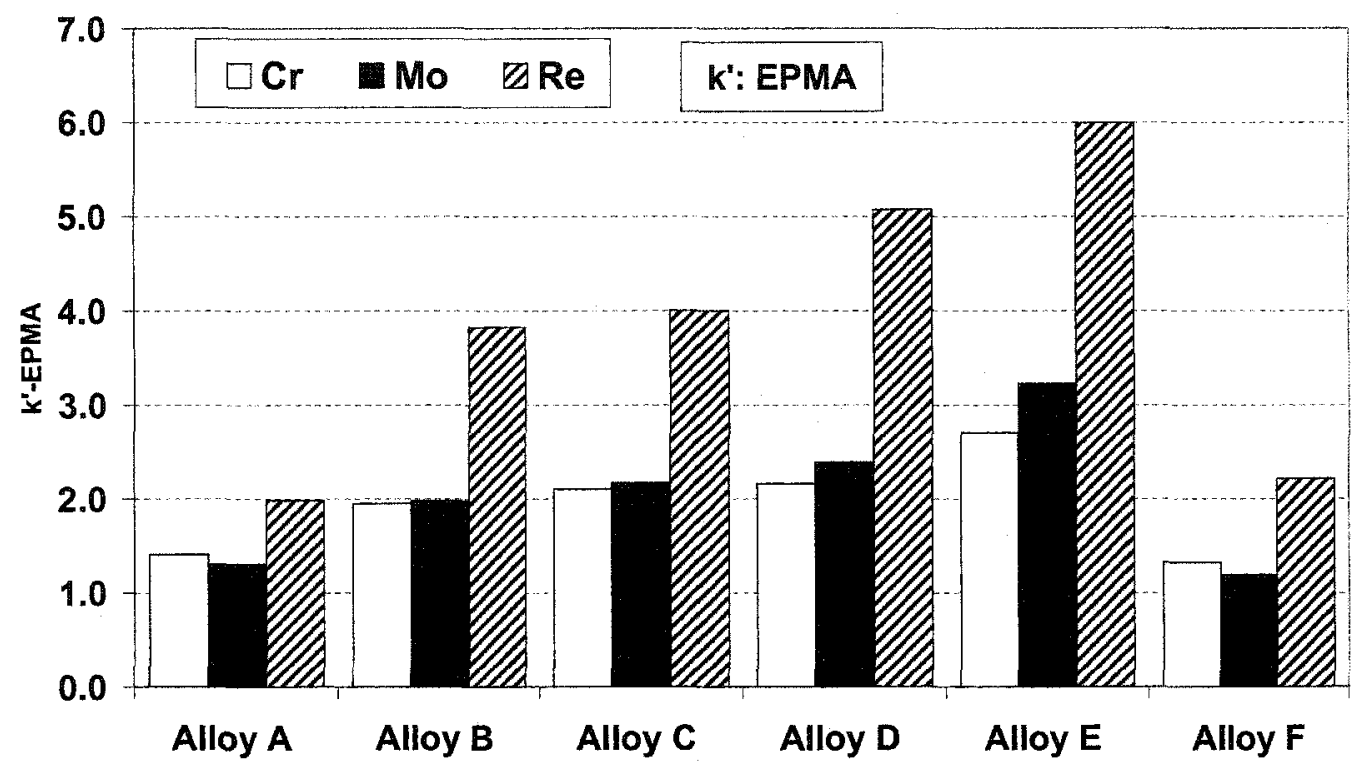

Figure 142: Measured segregation behavior of $\mathrm{Cr}, \mathrm{Re}$ and Mo. Alloys A-E show increased microsegregation with elevated nominal Re levels. Alloy $\mathrm{F}$ shows decreased segregation as a result of an additional $4 \mathrm{wt}$. $\% \mathrm{Ru}$.
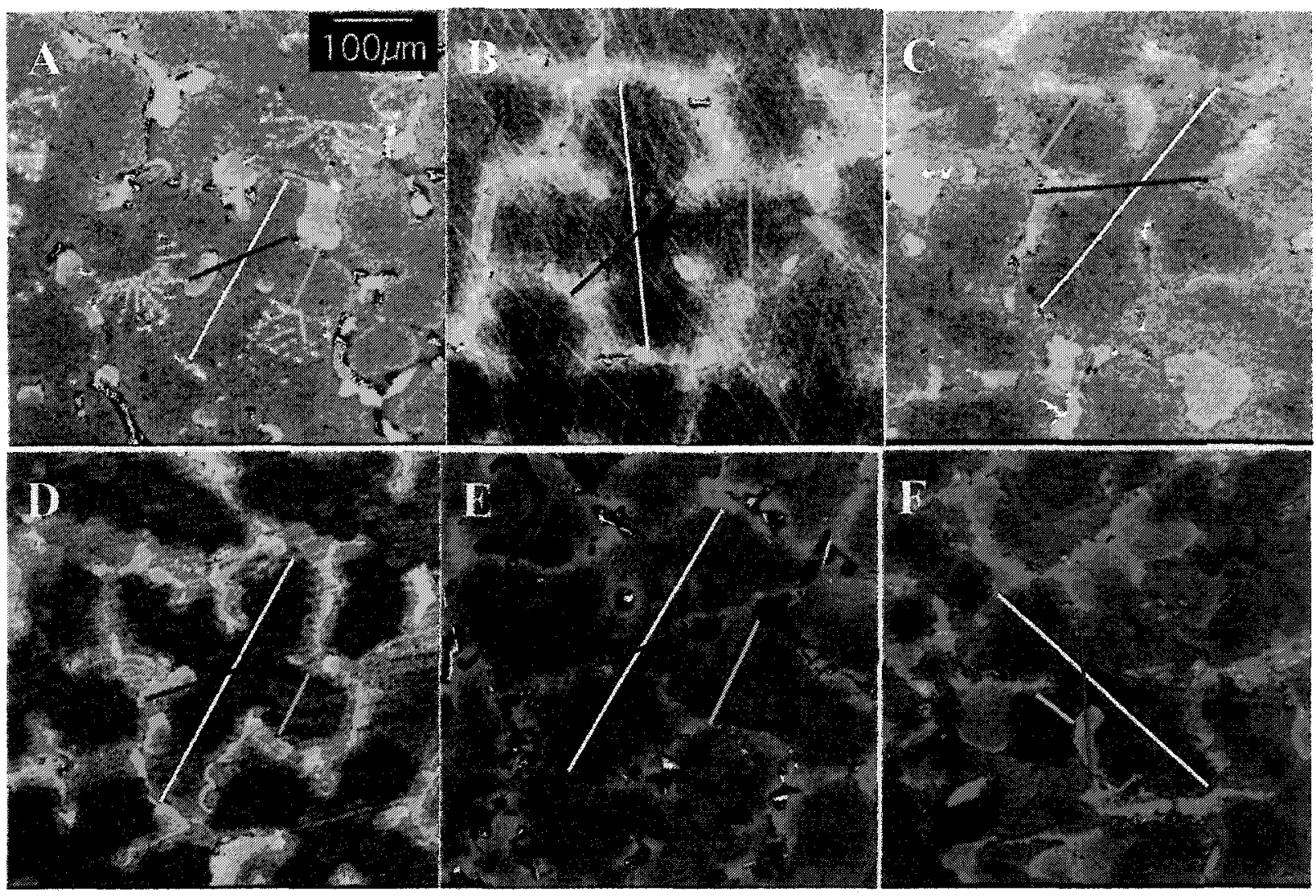

Figure 143: EPMA line-scan profiles of Alloys A-F (yellow line: direction \#1, red line: direction \#3, green line: direction \#4). 

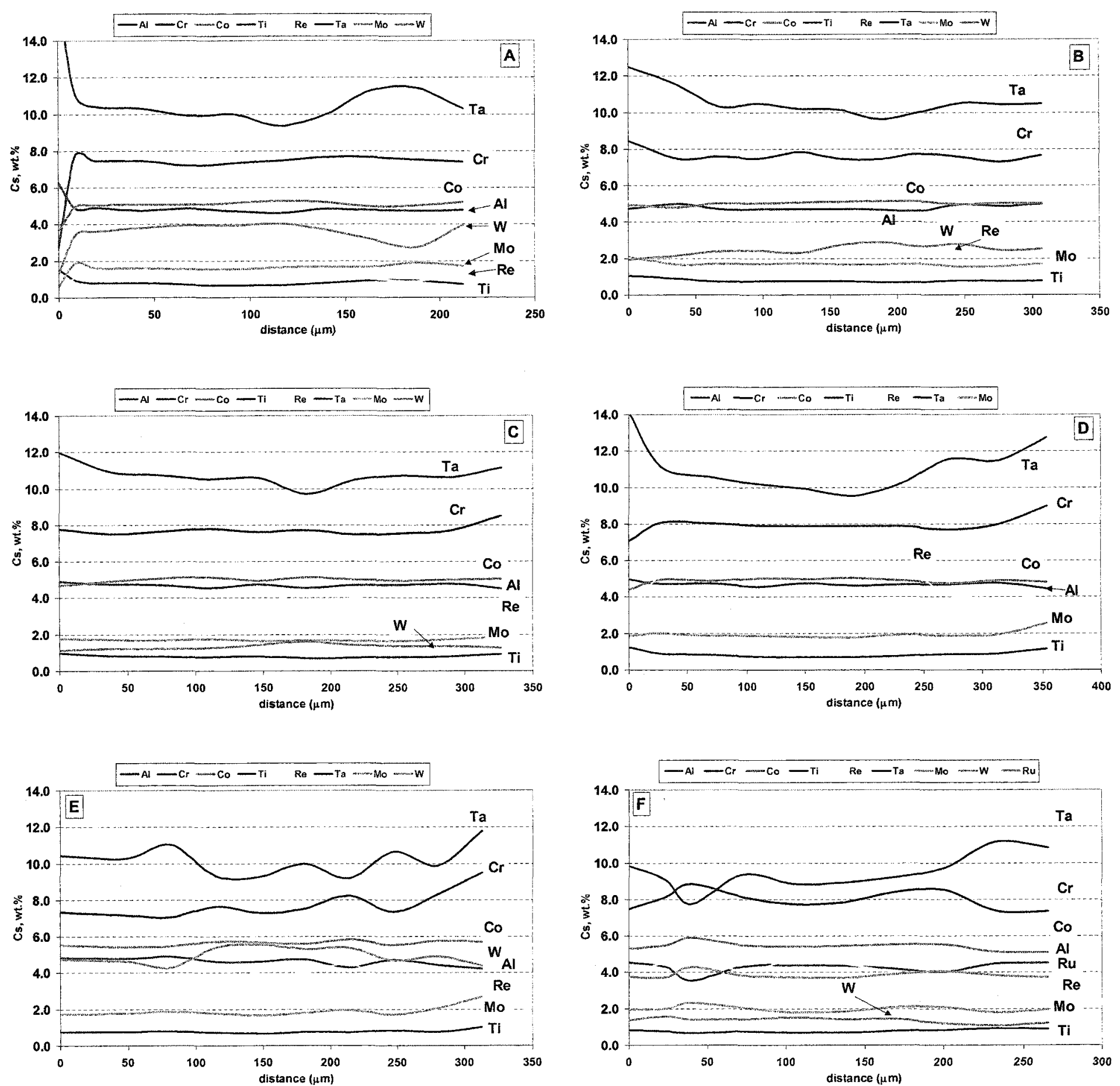

Figure 144: EPMA composition profiles of Alloys A-F along direction \#1. The scans start at the end of one secondary arm, pass through the dendrite core, to end of the opposite secondary arm. Each scan demonstrates relatively flat concentration profiles, except at the beginning and end of the secondary arms where there is some interference due to neighboring eutectic $\gamma-\gamma^{\prime}$. 

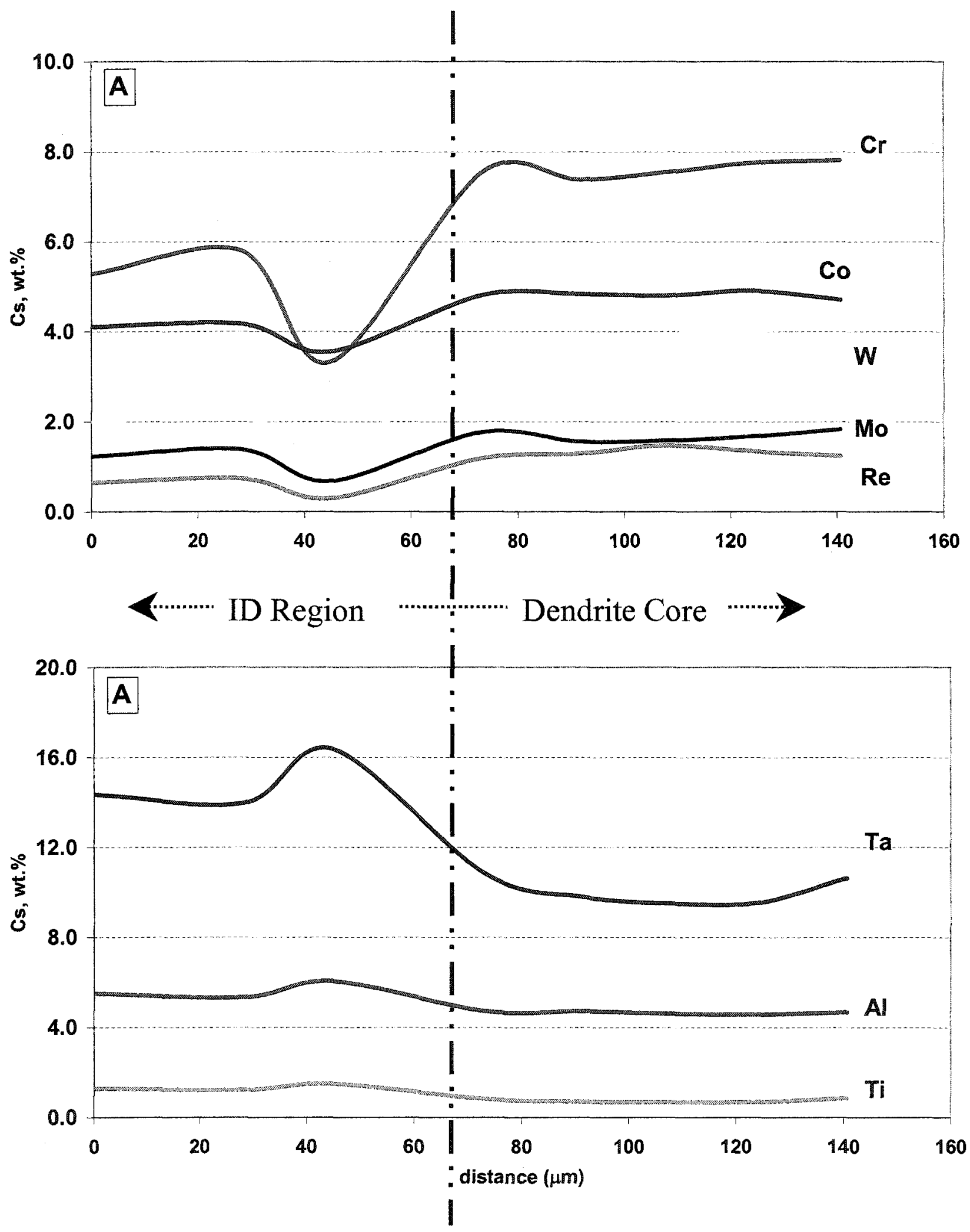

Figure 145: EPMA profile for Alloy $A$ in direction $\# 3$ across the dendrite core and interdendritic (ID) eutectic region. 


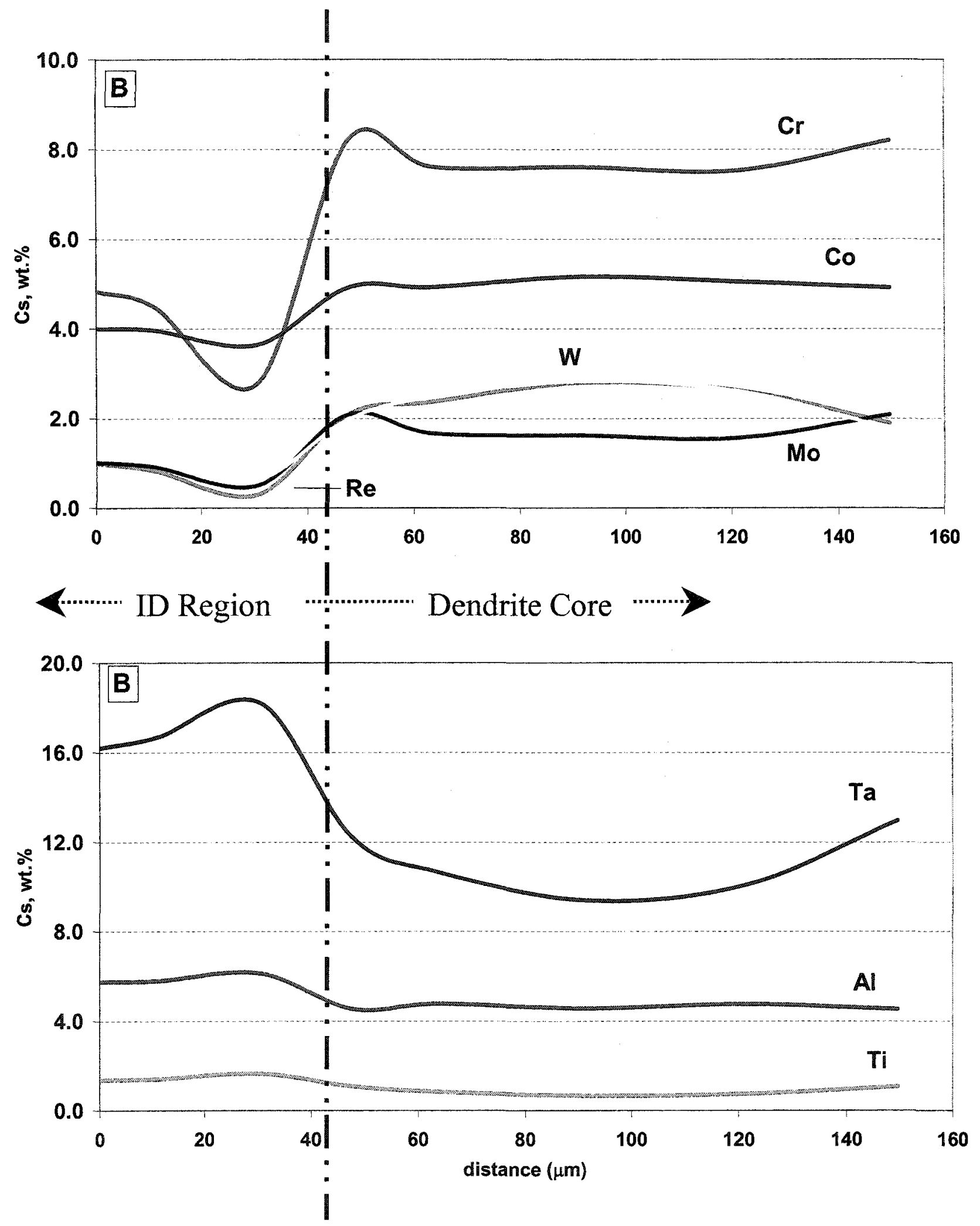

Figure 146: EPMA profile for Alloy $B$ in direction \#3 across the dendrite core and interdendritic (ID) eutectic region. 

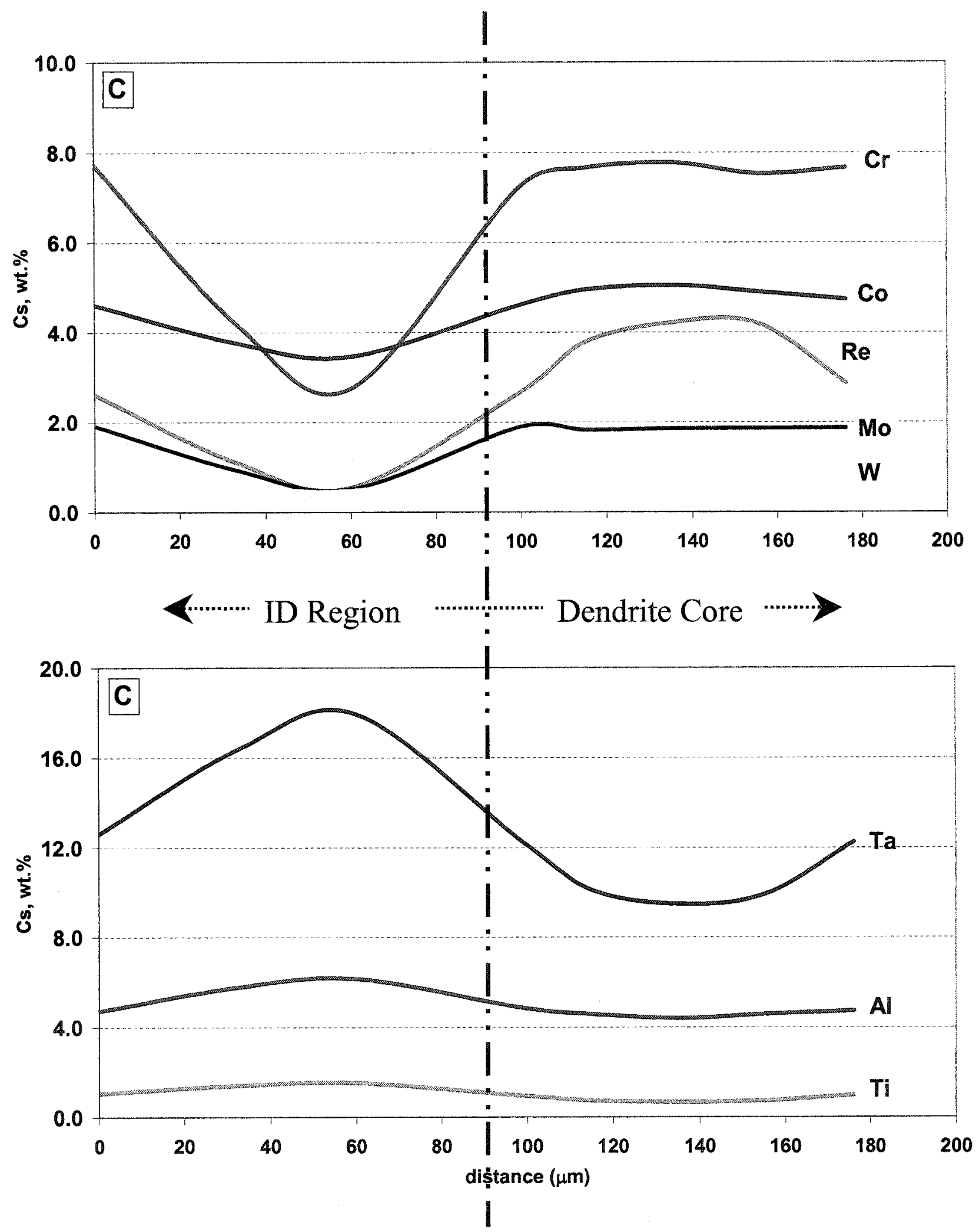

Figure 147: EPMA profile for Alloy $C$ in direction \#3 across the dendrite core and interdendritic (ID) eutectic region. 

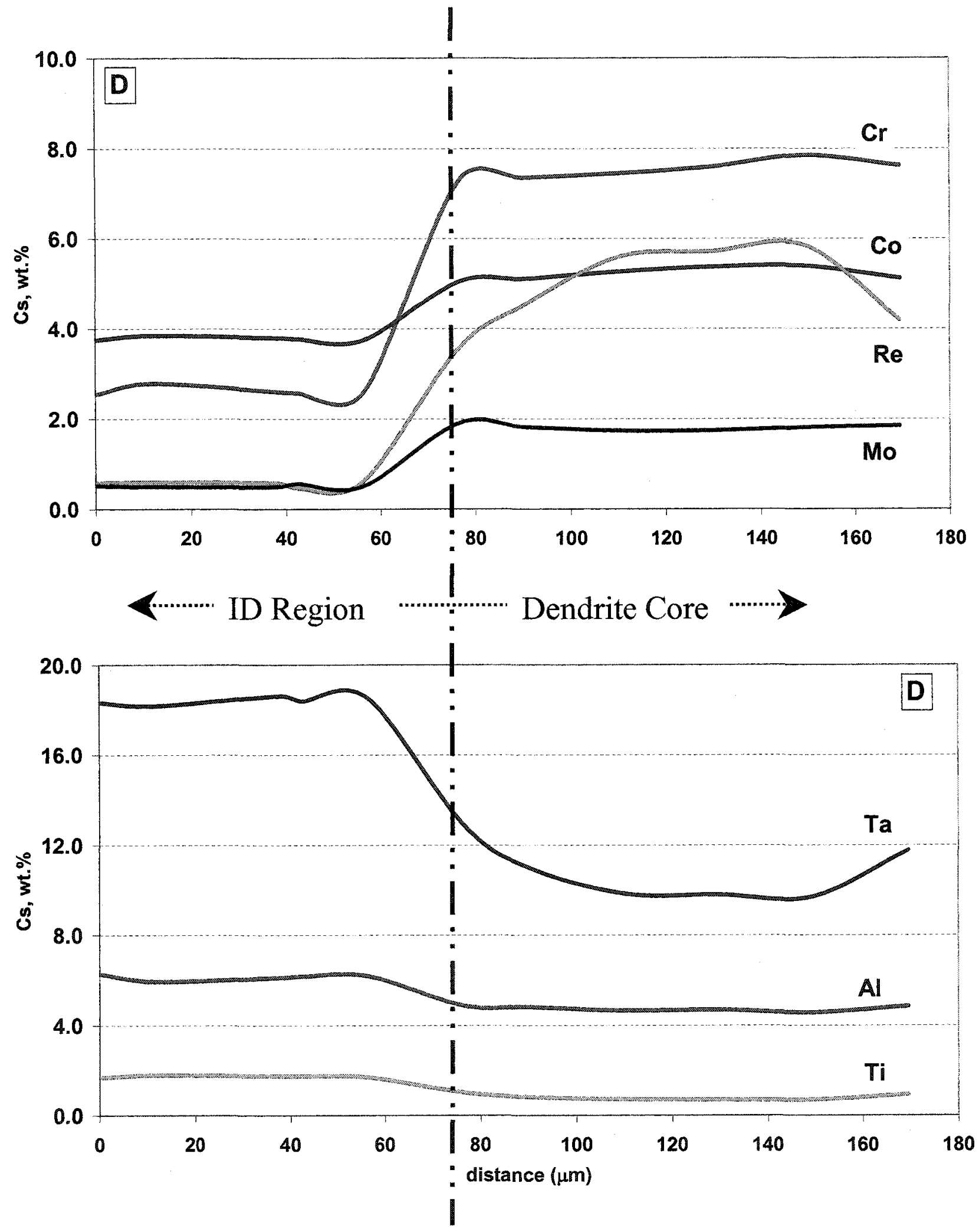

Figure 148: EPMA profile for Alloy $D$ in direction \#3 across the dendrite core and interdendritic (ID) eutectic region. 

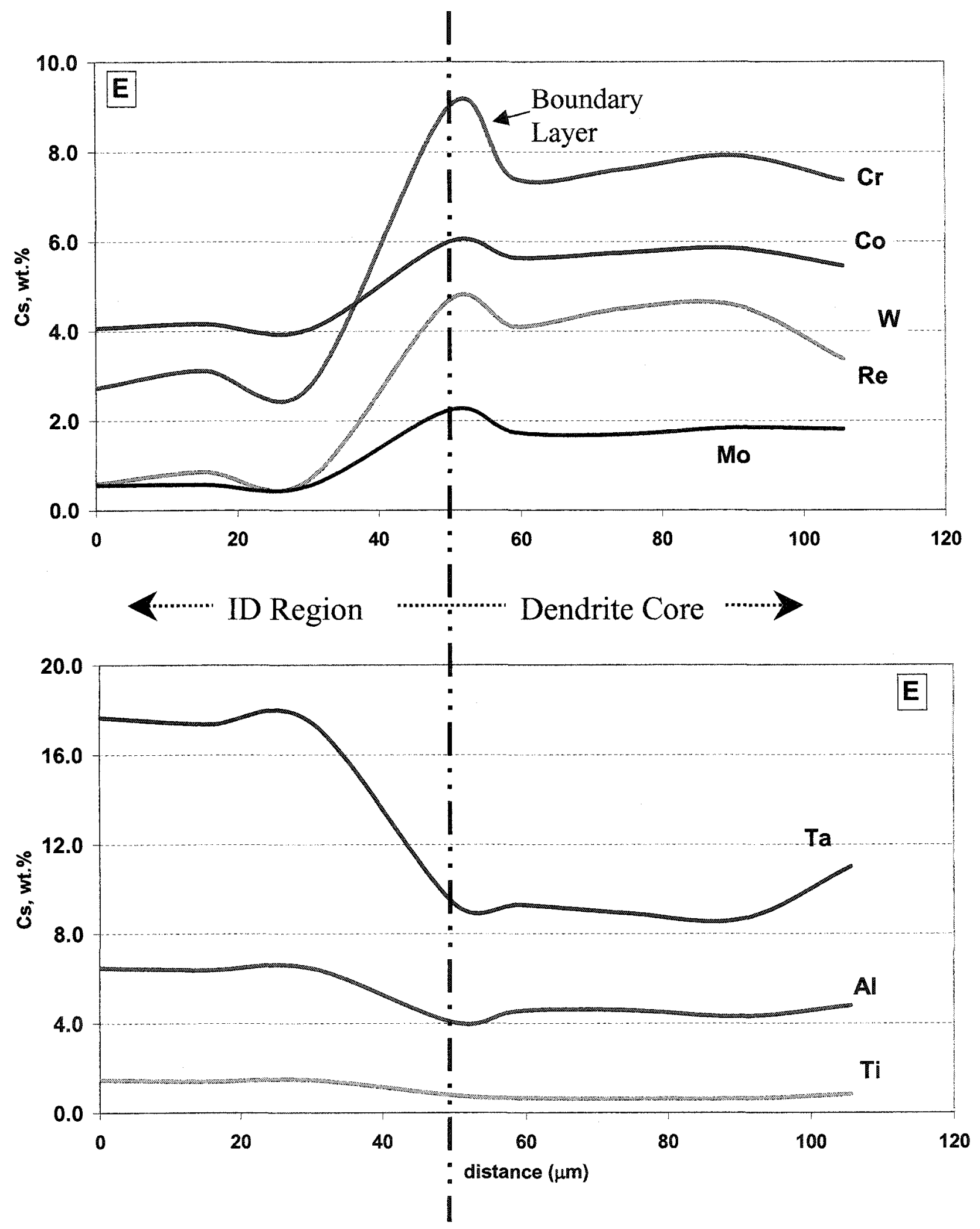

Figure 149: EPMA profile for Alloy $\mathrm{E}$ in direction \#3 across the dendrite core and interdendritic (ID) eutectic region. 

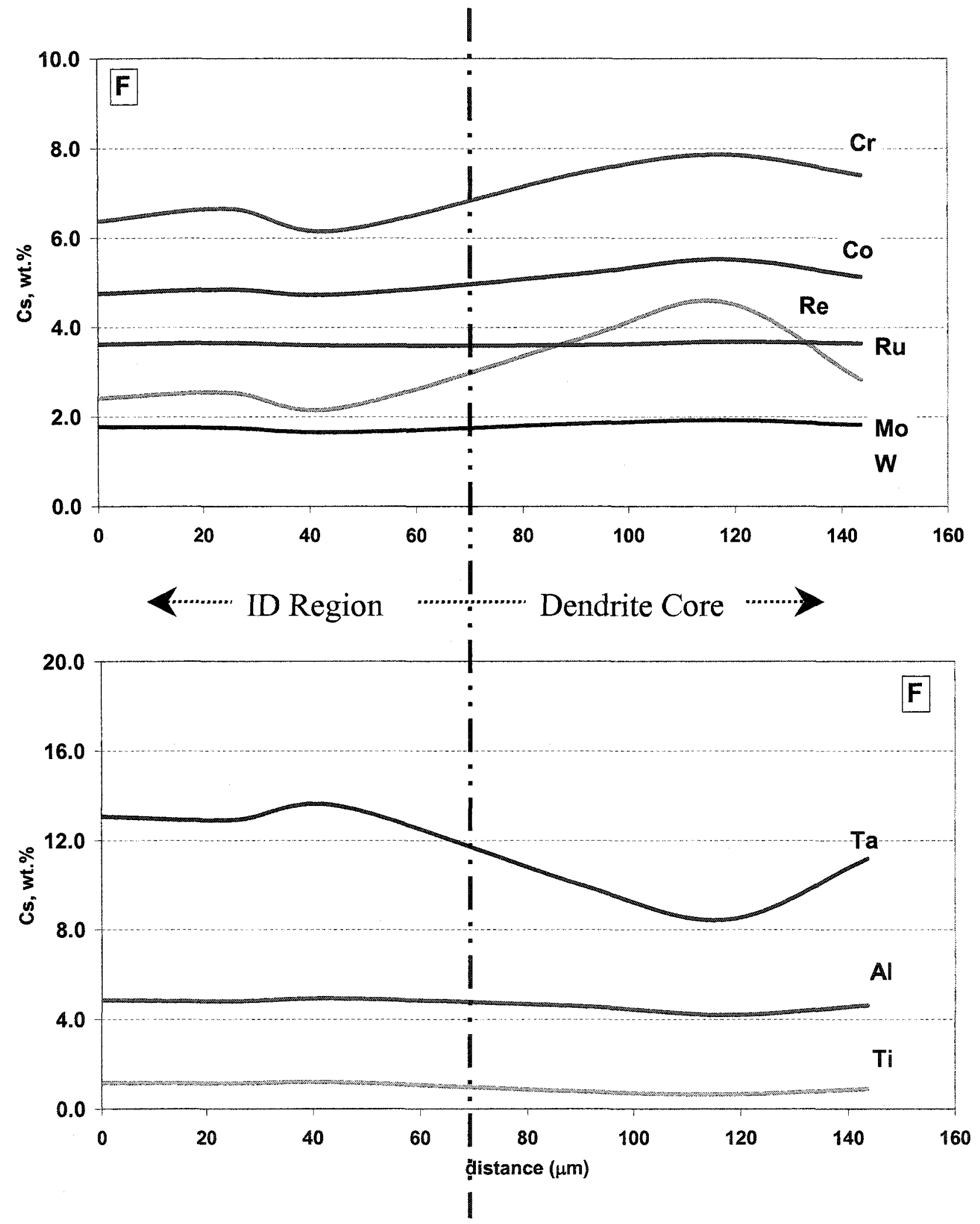

Figure 150: EPMA profile for Alloy $F$ in direction \#3 across the dendrite core and interdendritic (ID) eutectic region. 


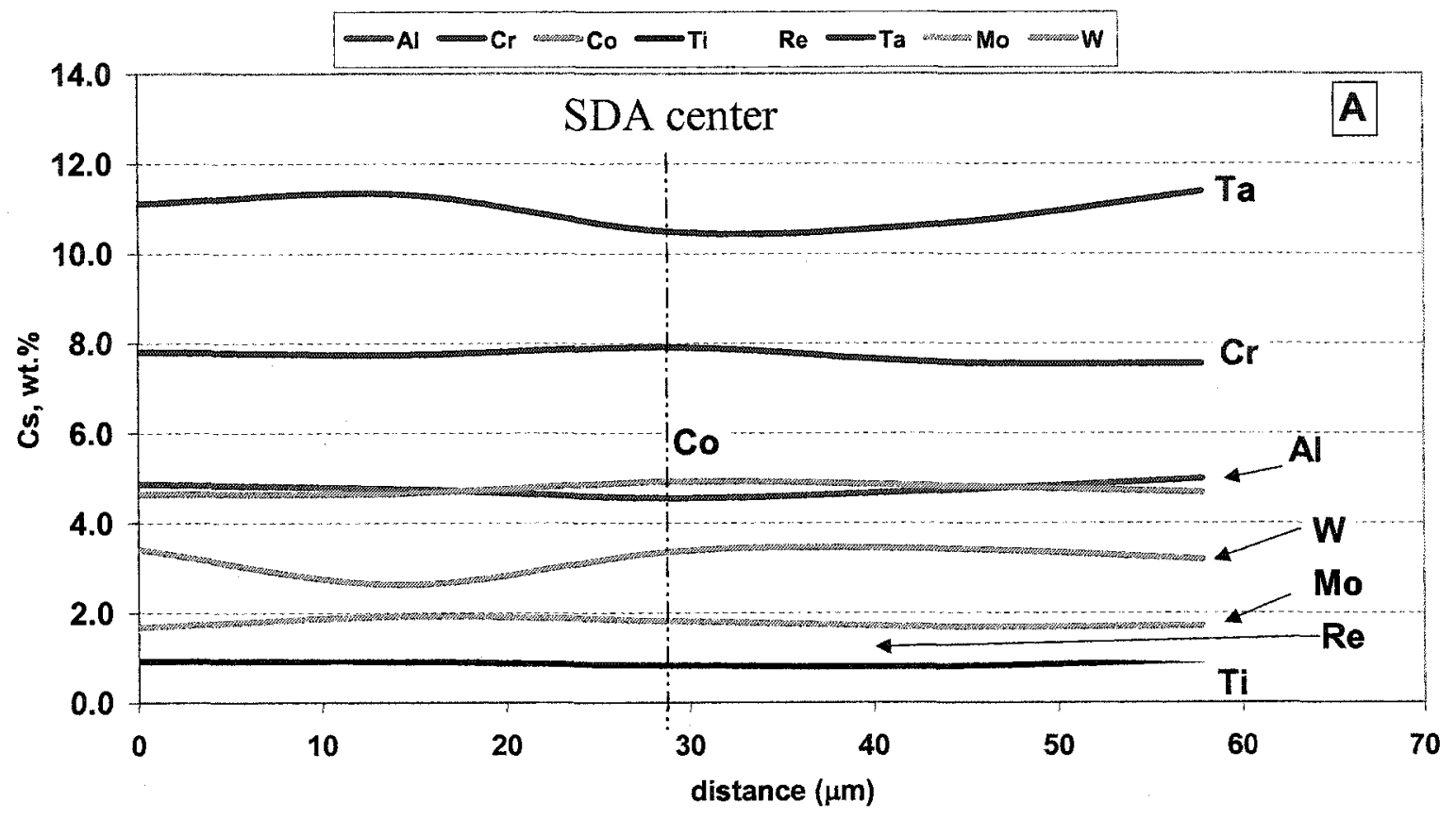

Figure 151: EPMA profile for Alloy $A$ in direction \#4 across the thickness of the secondary dendrite arm (SDA).

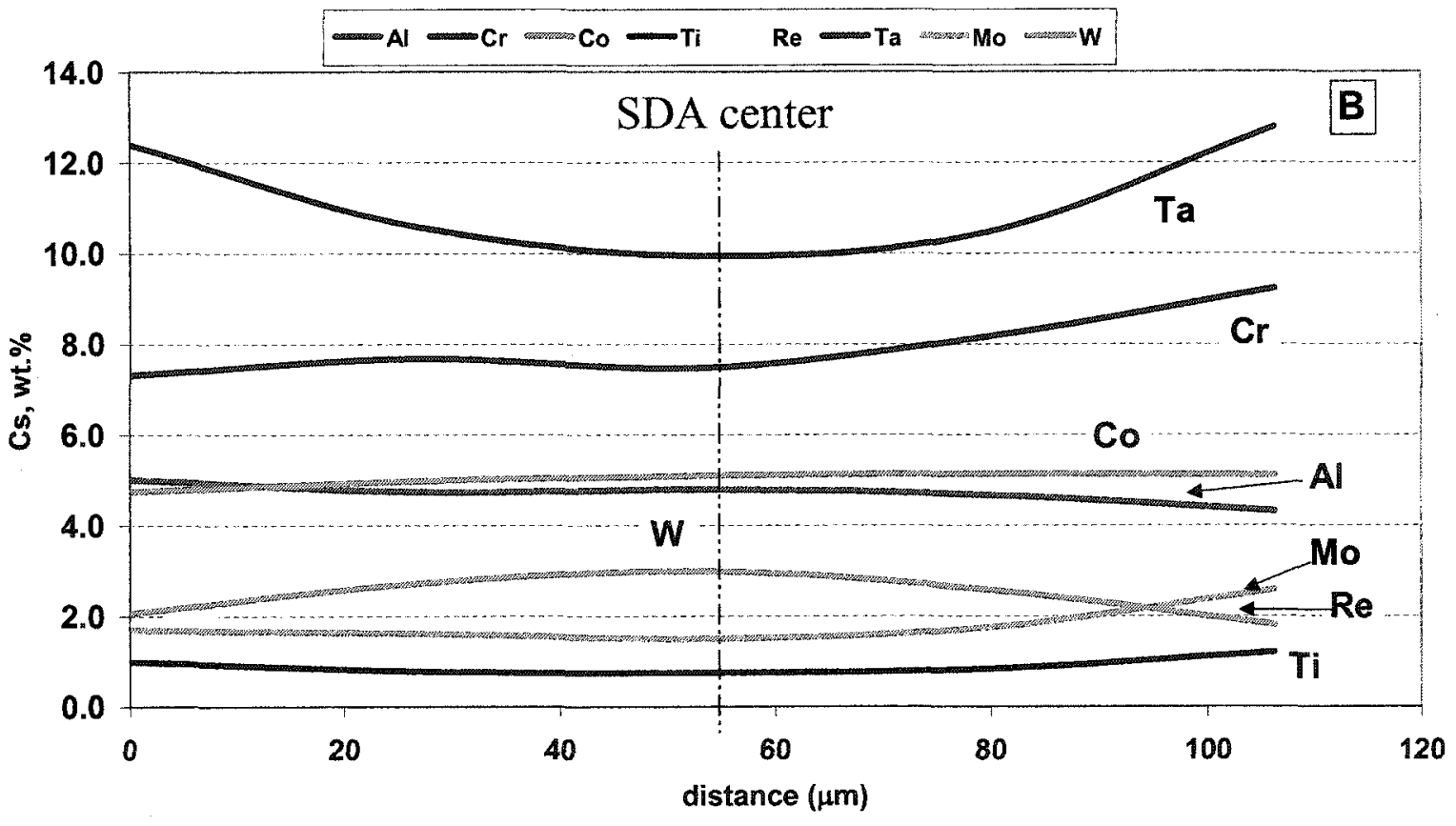

Figure 152: EPMA profile for Alloy $B$ in direction $\# 4$ across the thickness of the secondary dendrite $\operatorname{arm}($ SDA). 


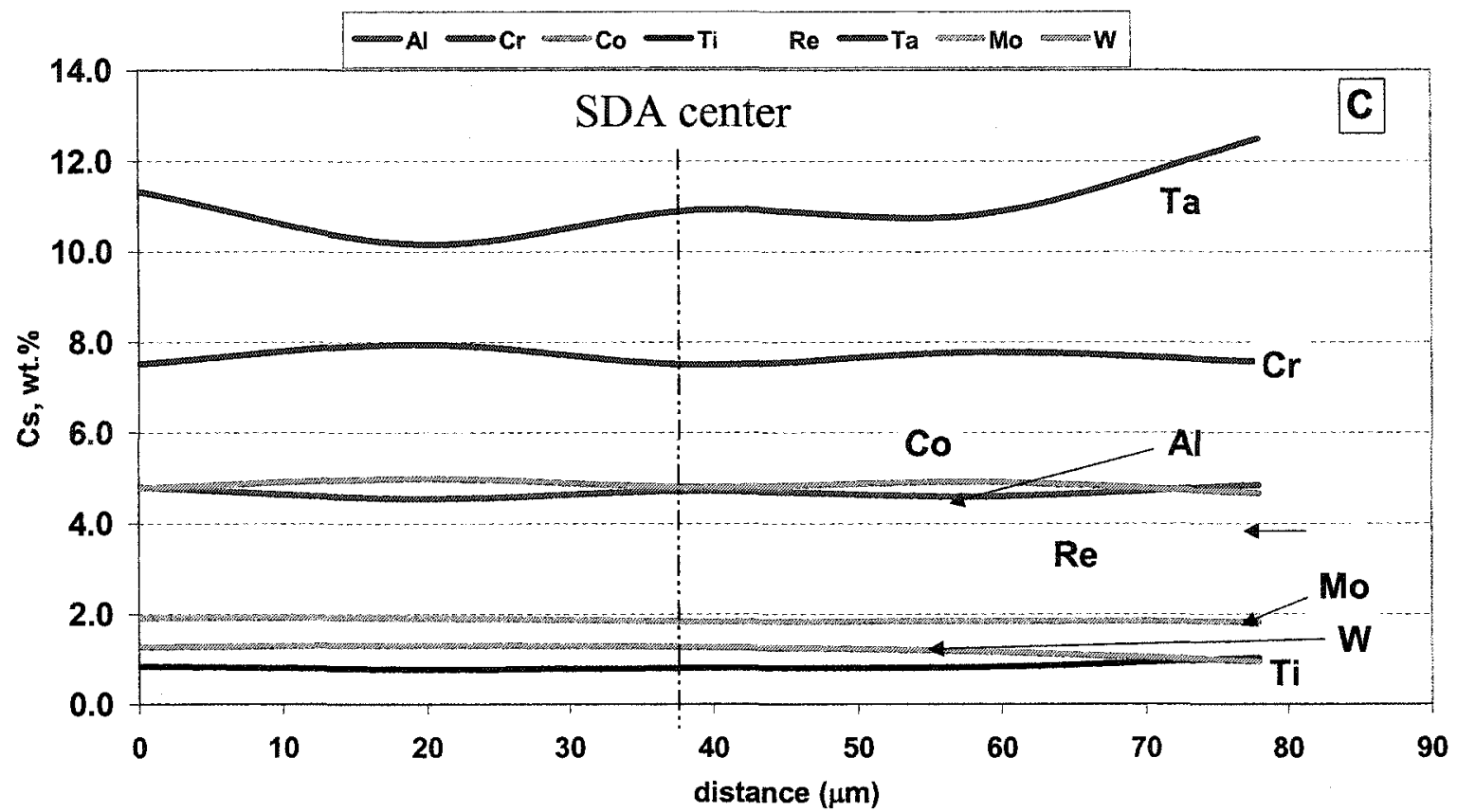

Figure 153: EPMA profile for Alloy $C$ in direction $\# 4$ across the thickness of the secondary dendrite arm (SDA).

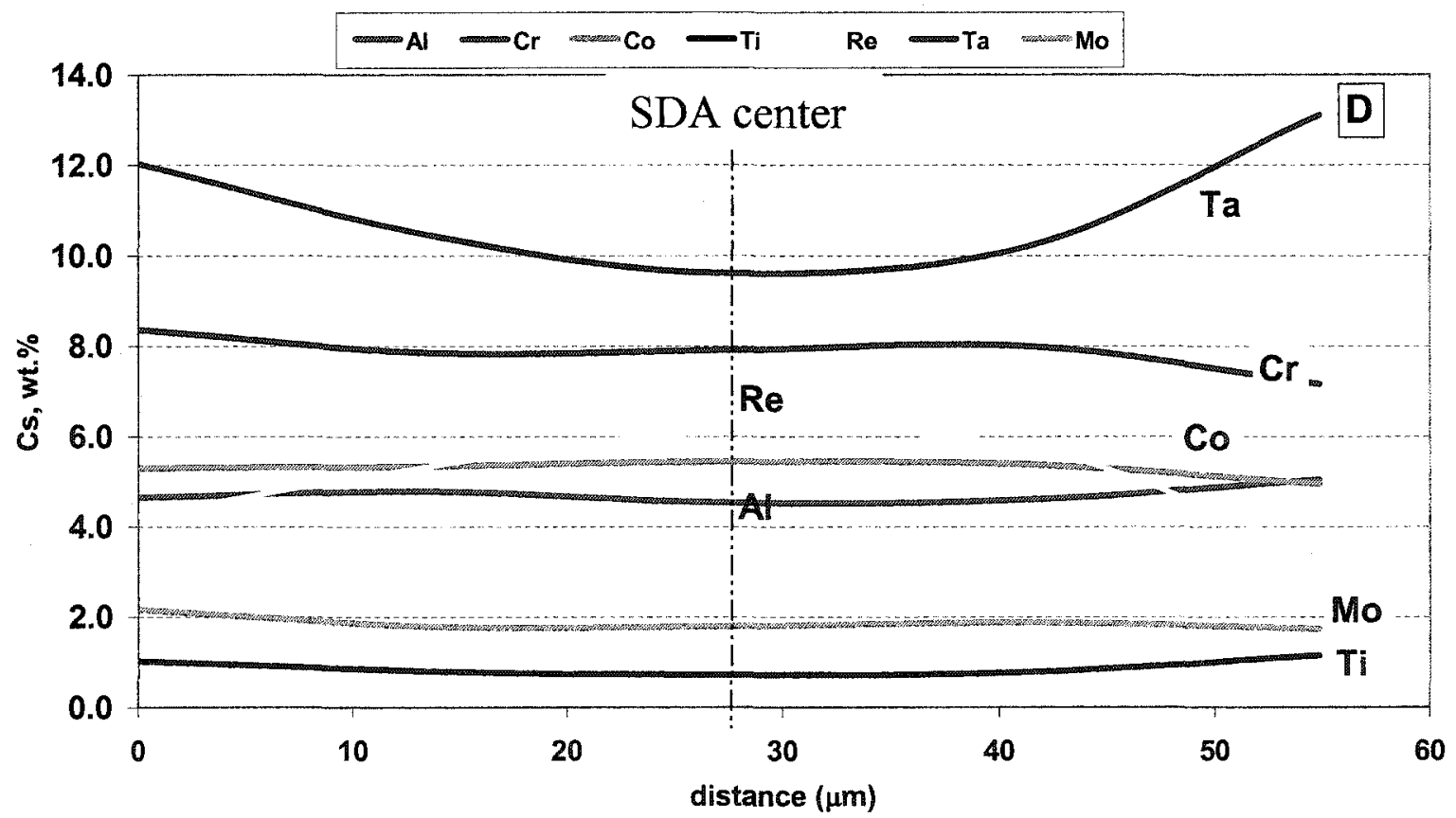

Figure 154: EPMA profile for Alloy $D$ in direction \#4 across the thickness of the secondary dendrite arm (SDA). 


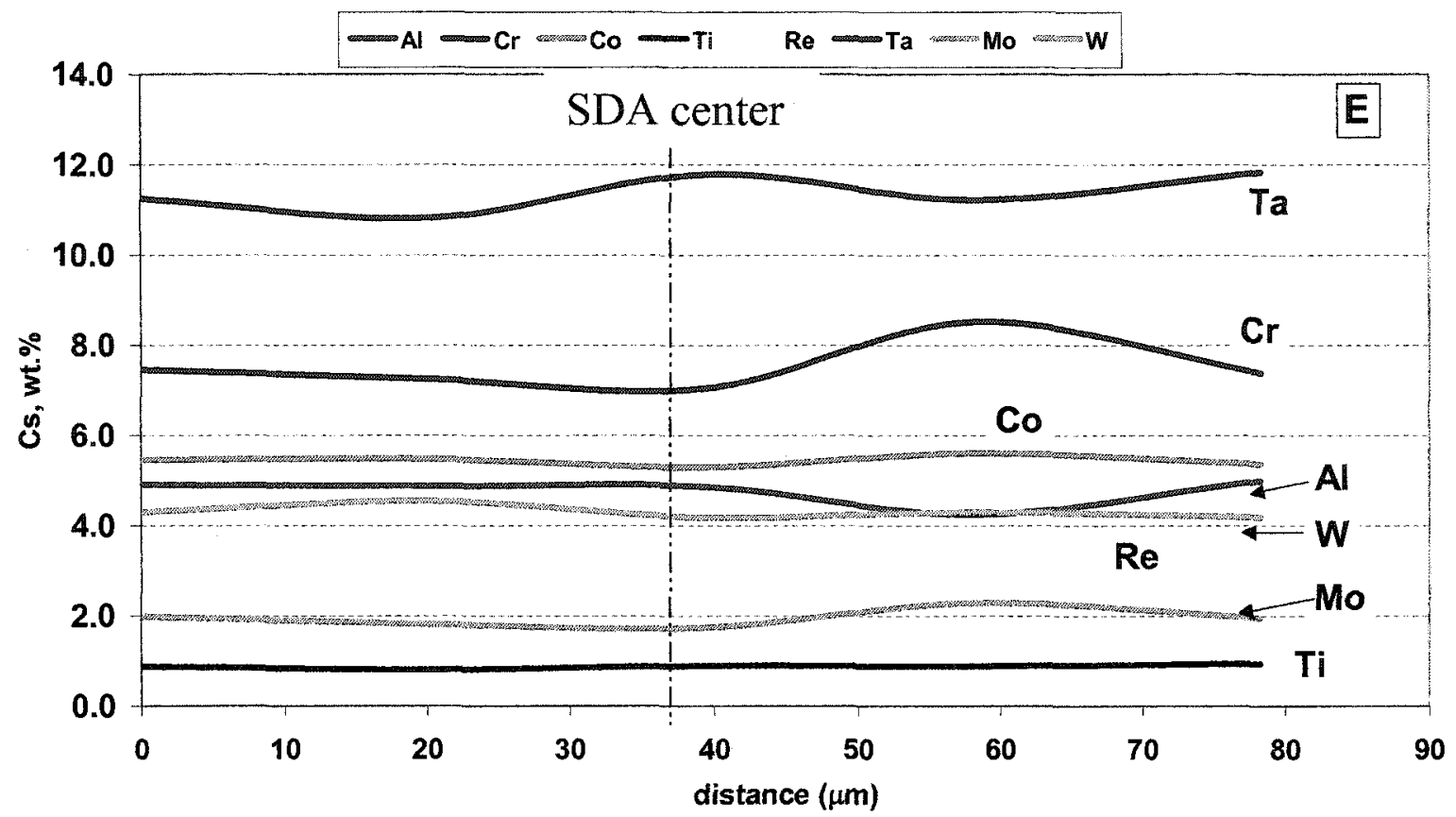

Figure 155: EPMA profile for Alloy $E$ in direction \#4 across the thickness of the secondary dendrite arm (SDA).

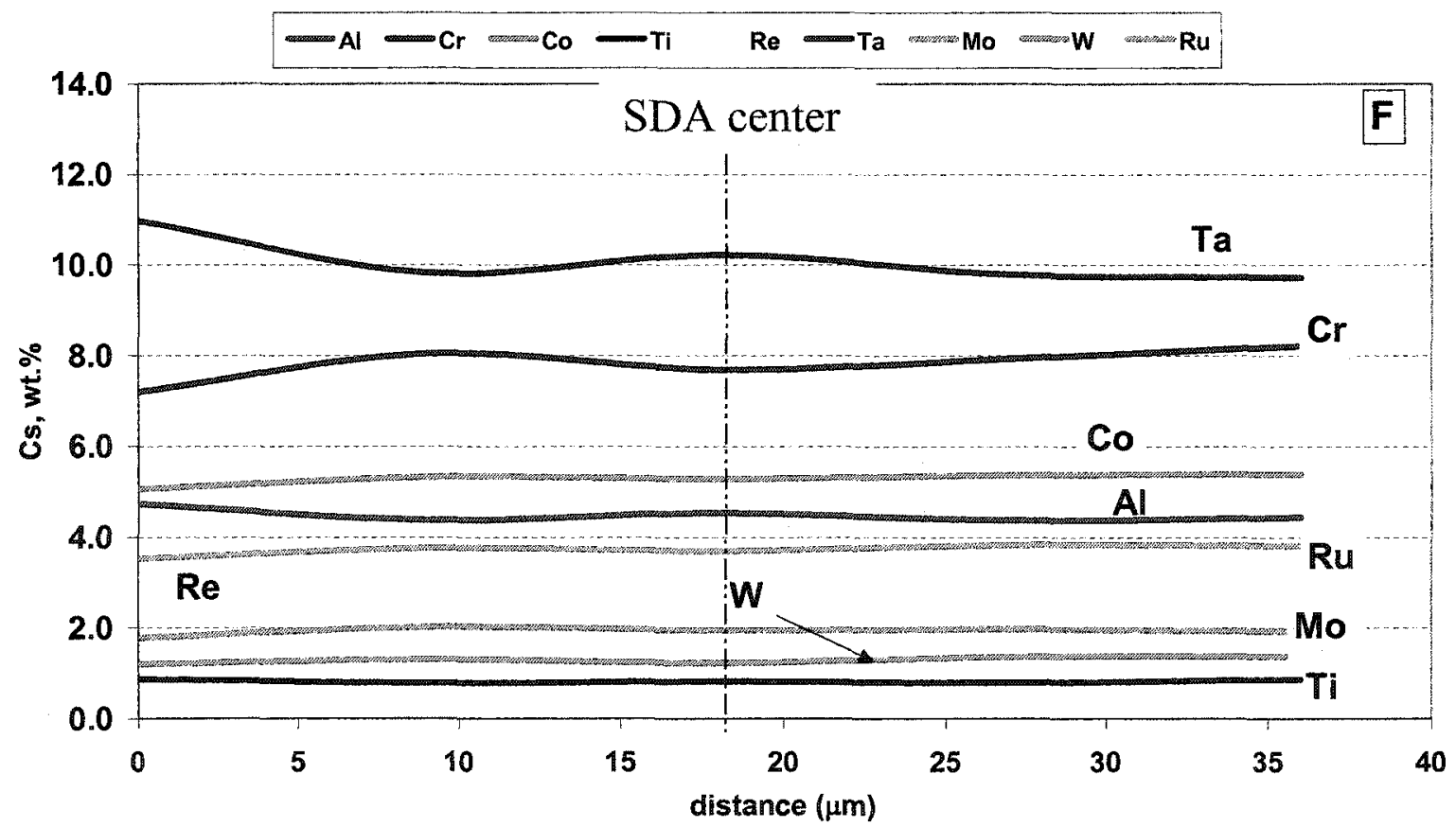

Figure 156: EPMA profile for Alloy $F$ in direction \#4 across the thickness of the secondary dendrite $\operatorname{arm}(\mathrm{SDA})$. 


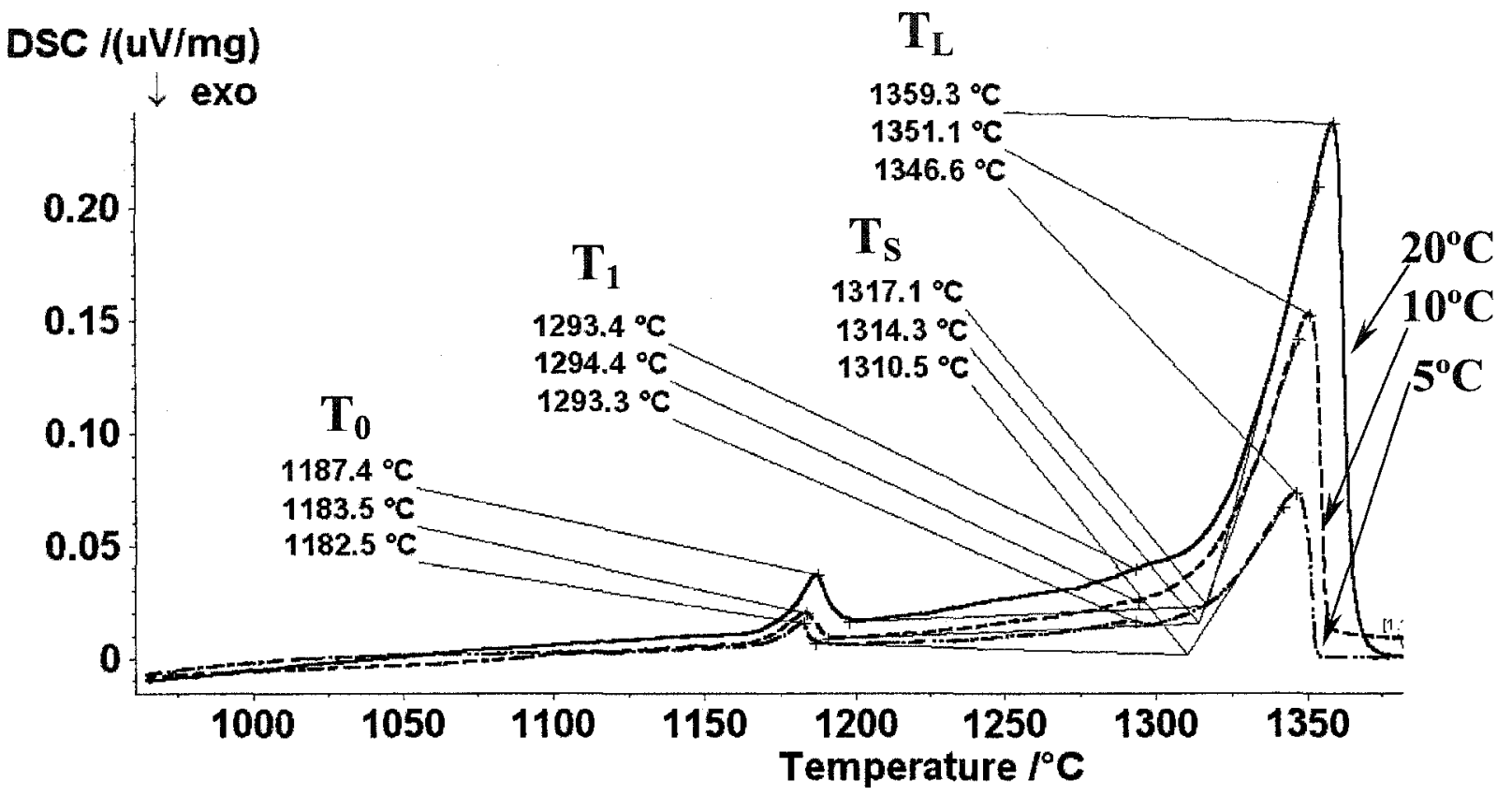

Figure 157: DSC energetic curves for as-cast Alloy-F at heating rates of 5,10 and $20^{\circ} \mathrm{C} / \mathrm{min}$.

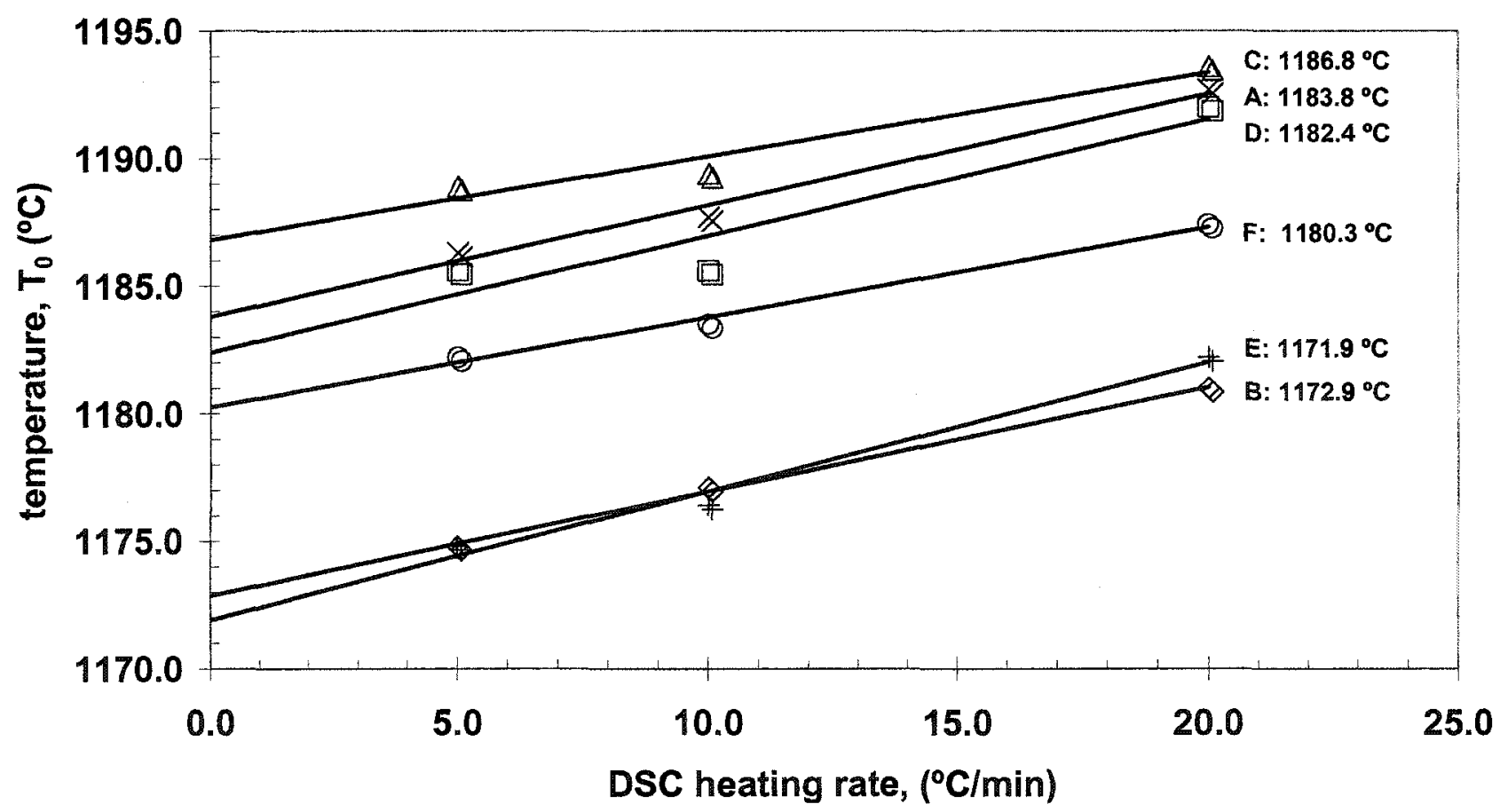

Figure 158: $T_{0}$ extrapolation from $D S C$ heating rate results. 


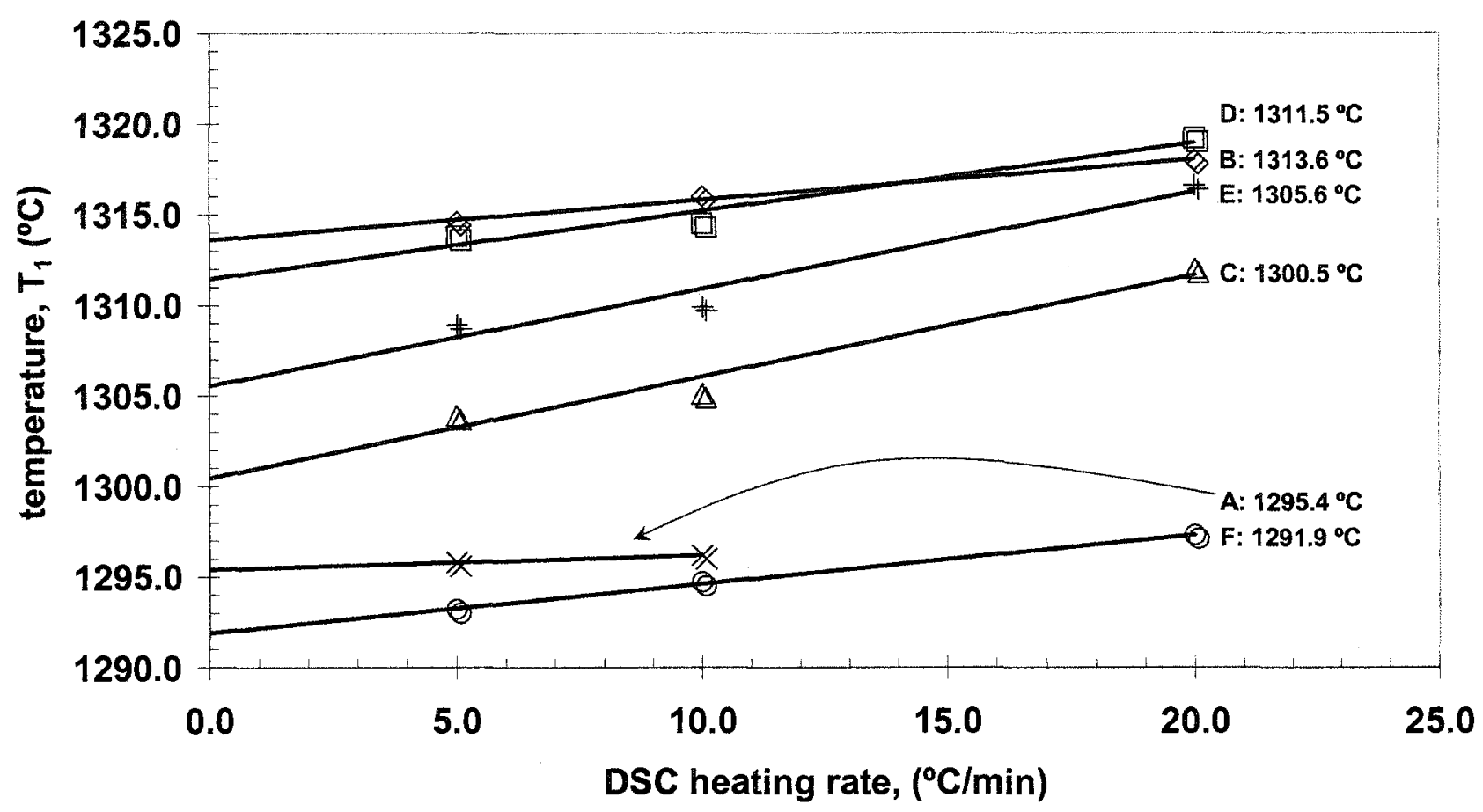

Figure 159: $T_{1}$ Extrapolation from DSC heating rate results.

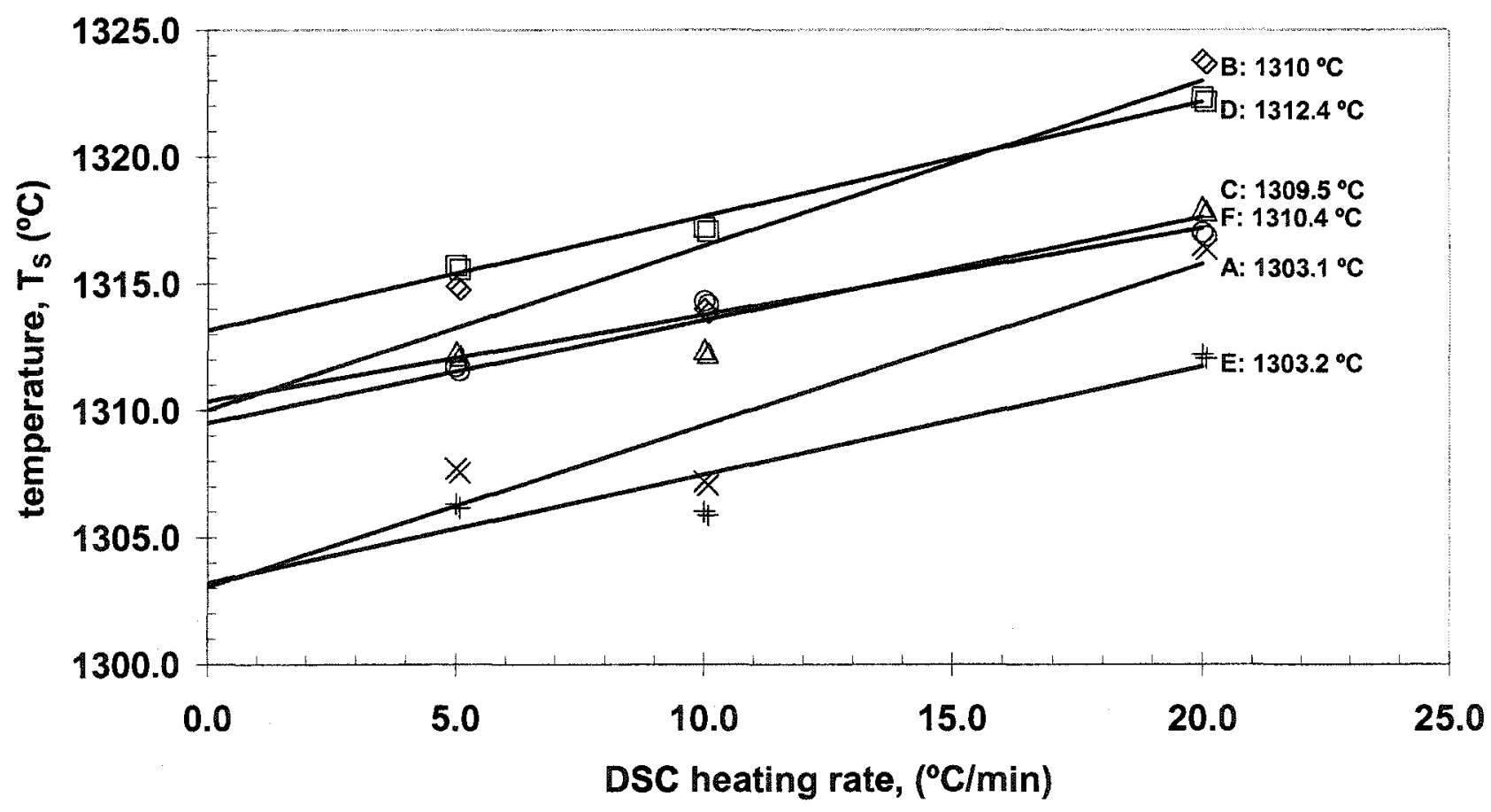

Figure 160: $T_{S}$ Extrapolation from DSC heating rate results. 


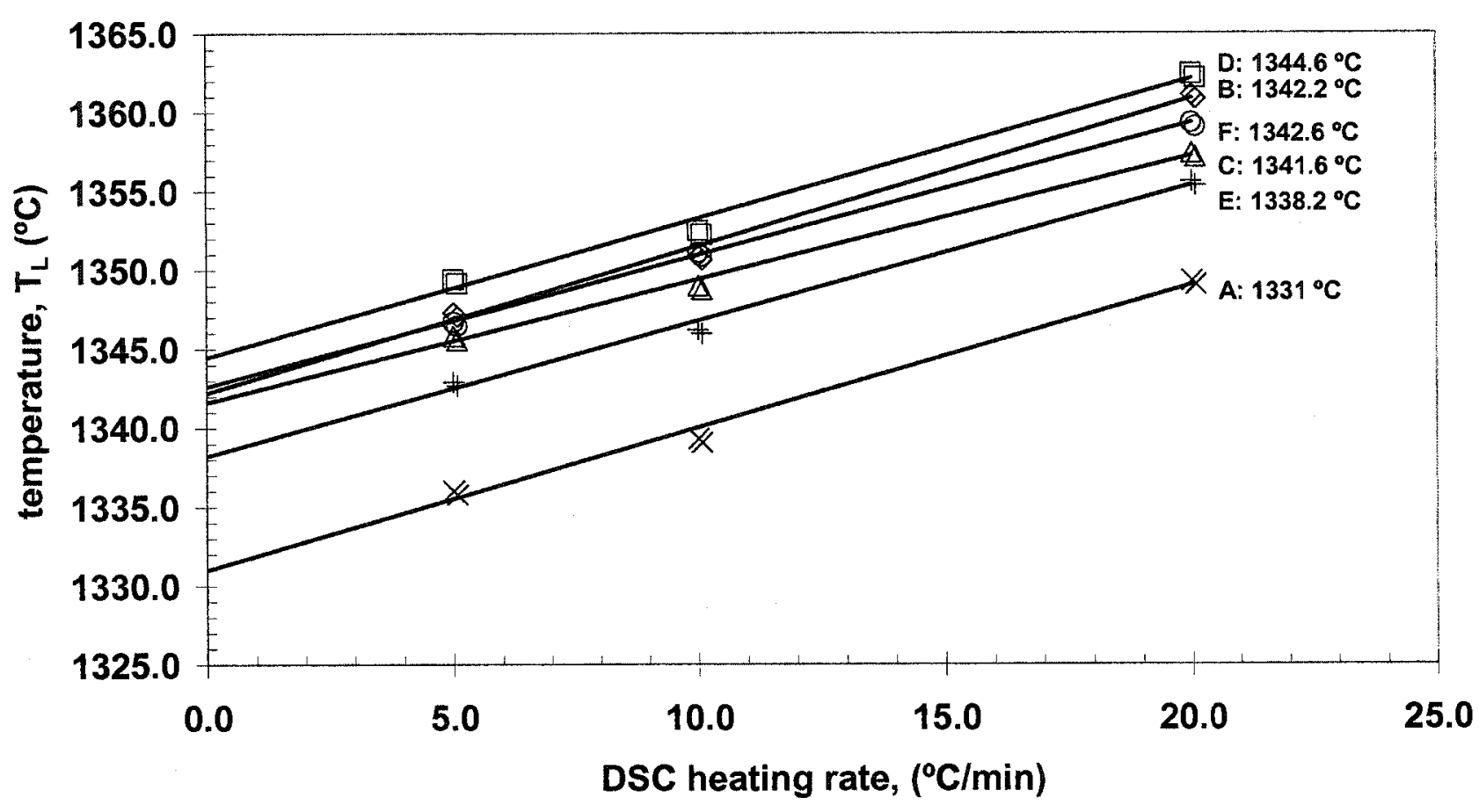

Figure 161: $T_{L}$ Extrapolation from DSC heating rate results.

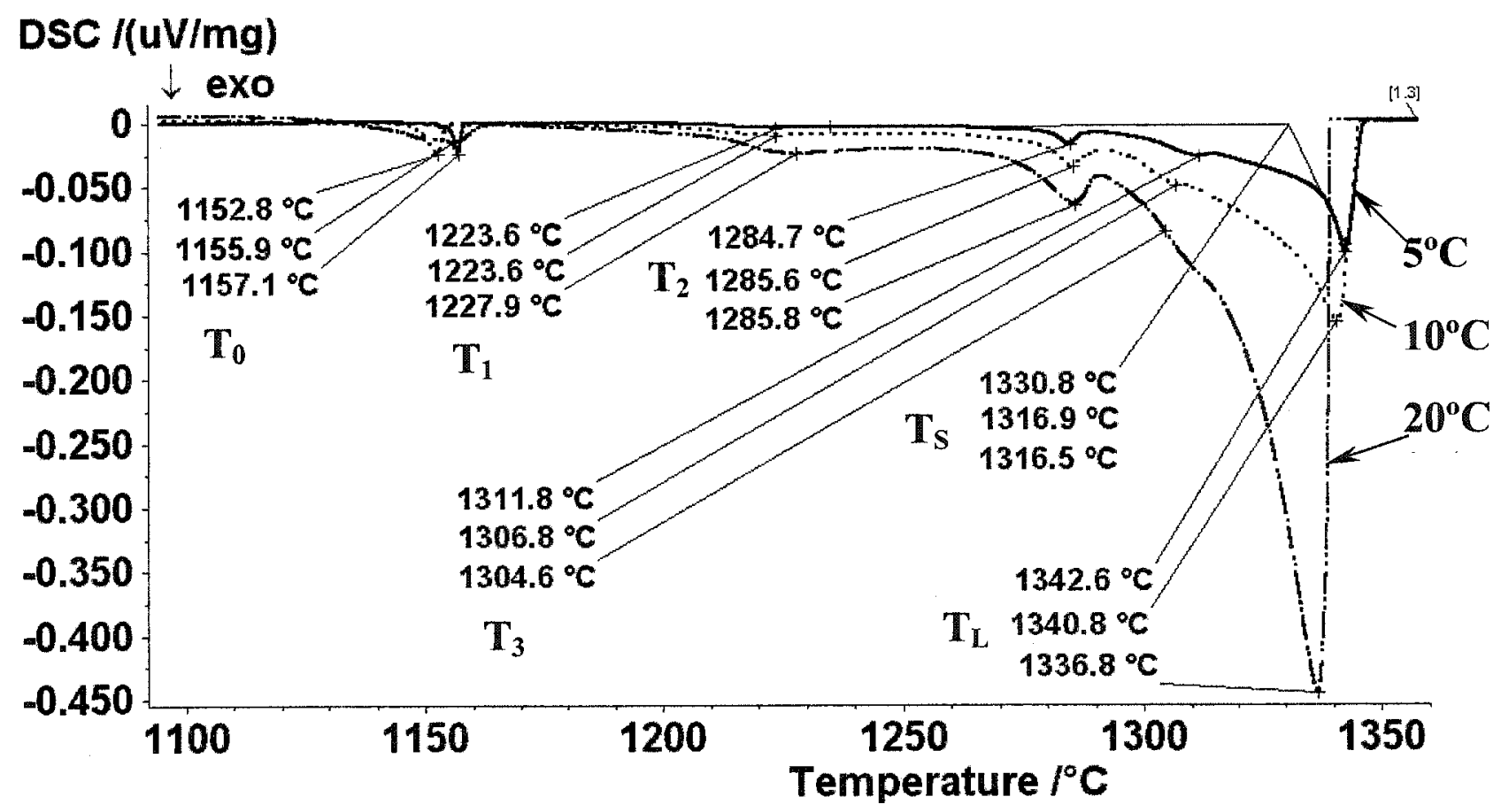

Figure 162: DSC energetic curves for as-cast Alloy-F at cooling rates of 5,10 and $20^{\circ} \mathrm{C} / \mathrm{min}$. 

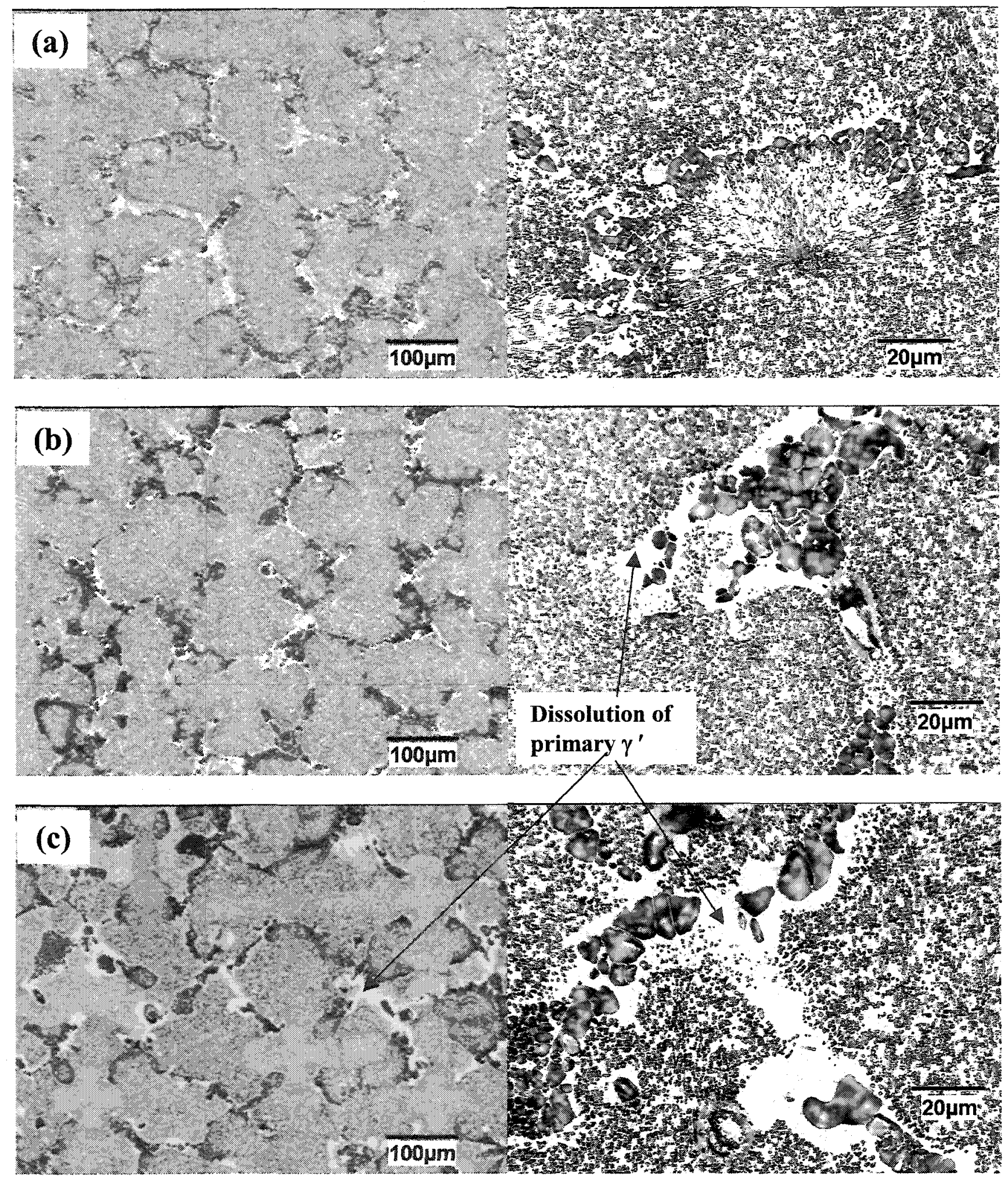

Figure 163: Optical micrographs of Alloy $F$ quenching experiments: a) $1160^{\circ} \mathrm{C} / 2 \mathrm{hrs} / \mathrm{WQ}$, b) $\left.1180^{\circ} \mathrm{C} / 2 \mathrm{hrs} / \mathrm{WQ}, \mathrm{c}\right) 1220^{\circ} \mathrm{C} / 2 \mathrm{hrs} / \mathrm{WQ}$. 

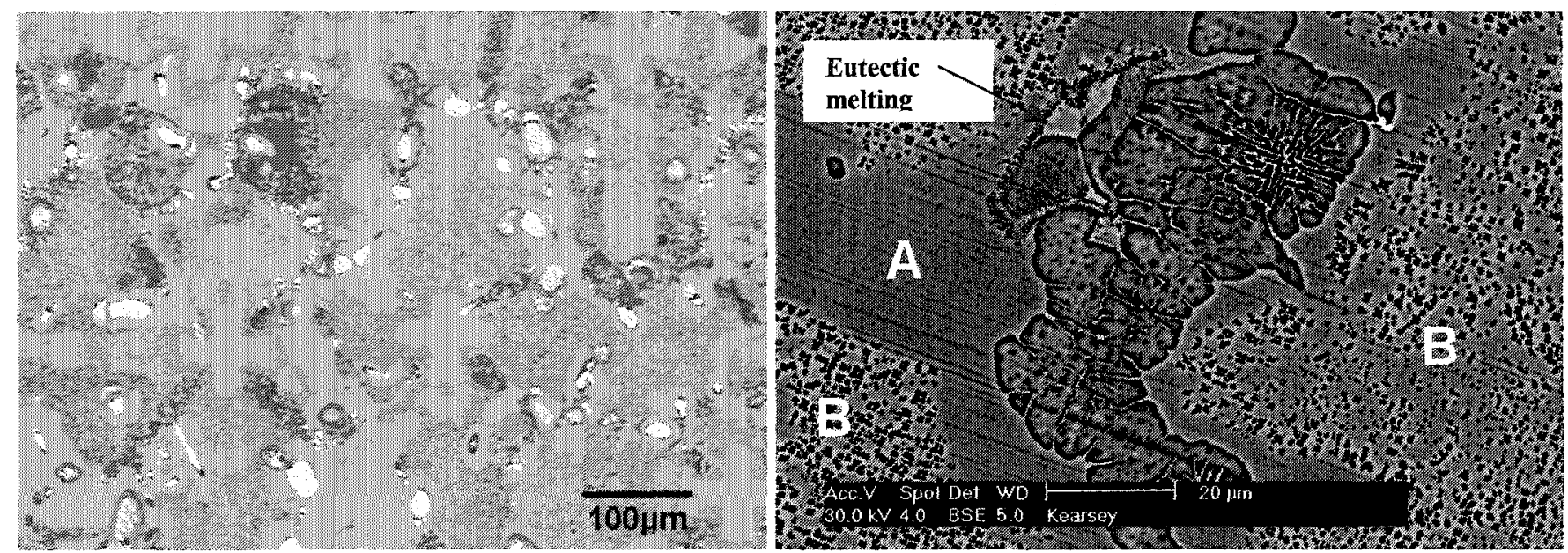

Figure 164: Micrographs from $1250^{\circ} \mathrm{C} / 2 \mathrm{hr} / \mathrm{WQ}$. (Left) Optical micrograph of Alloy F showing extensive $\gamma^{\prime}$ solutioning and minor interdendritic melting. (Right) SEM image showing the resulting $\gamma^{\prime}$ denuded zone [A] surrounding the blocky eutectic phase and region B containing fine $\gamma^{\prime}$ located within the dendritic region.

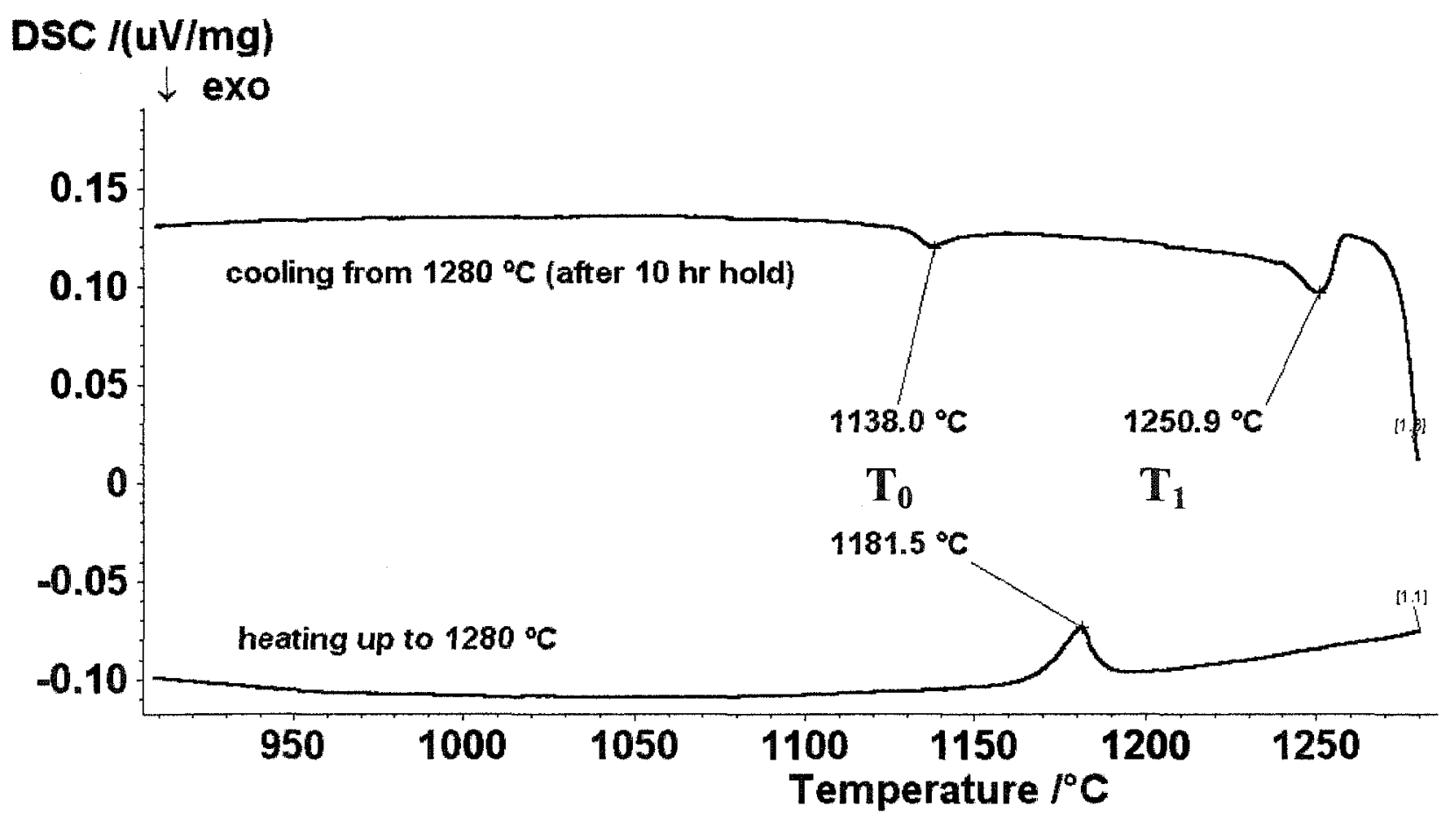

Figure 165: Additional endothermic peak, $\mathrm{T}_{1}$, identified after $10 \mathrm{hr}$ hold at $1280^{\circ} \mathrm{C}$. 


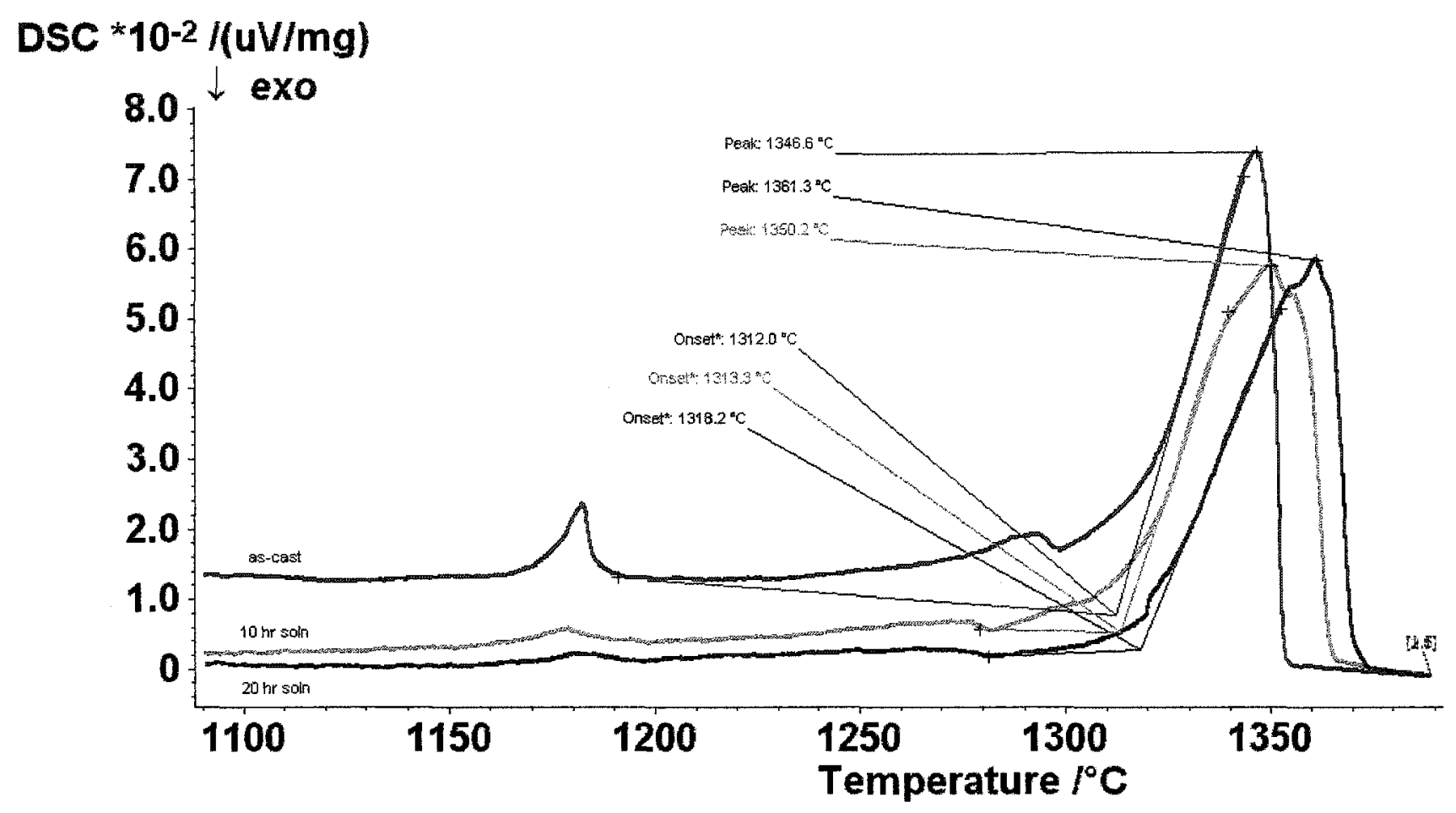

Figure 166: Solute redistribution of lower $\gamma^{\prime}$ solvus precipitate using 10 and 20 hour soak times. 

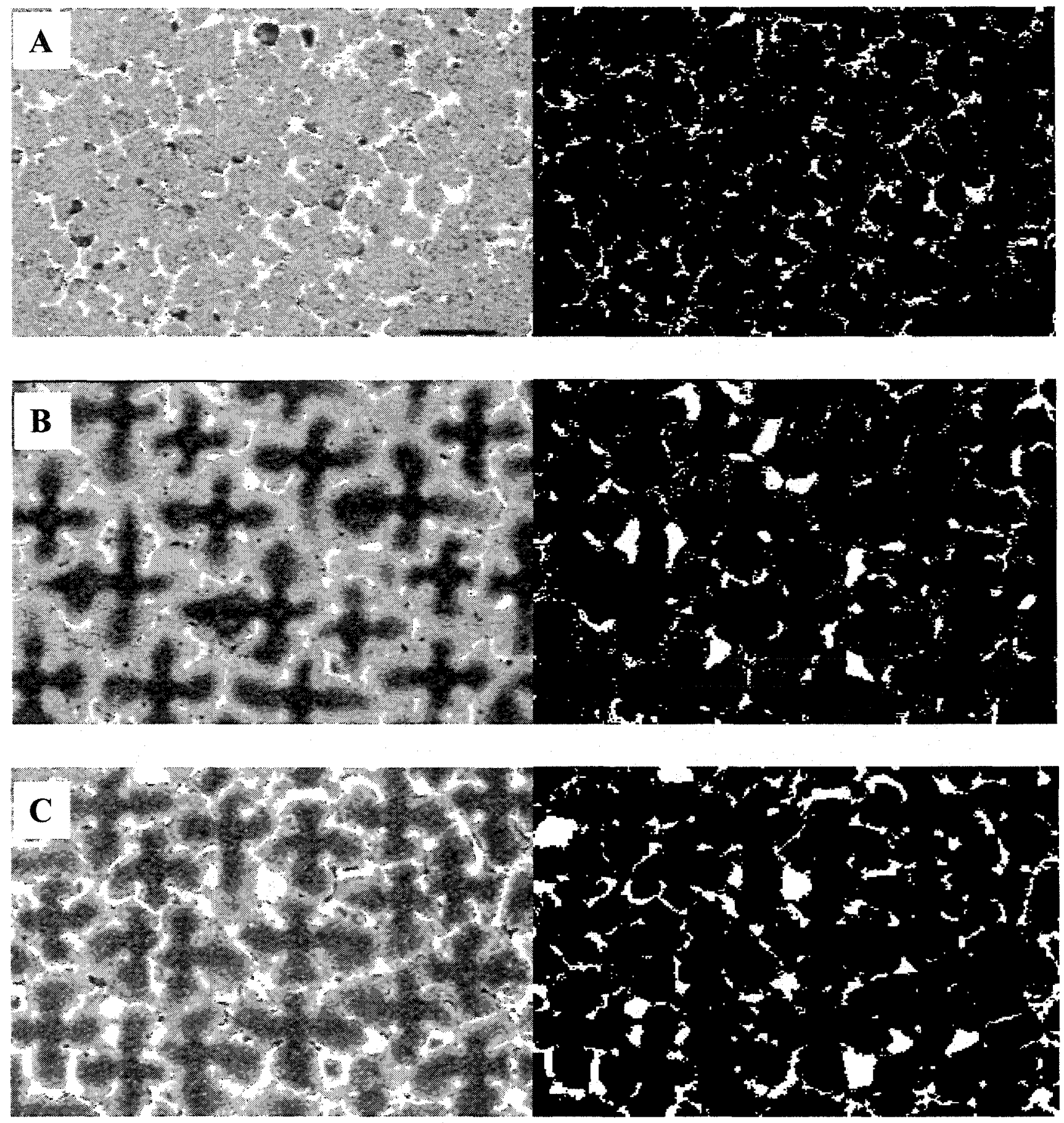

Figure 167: Transverse cross-section of Alloys A to C: (left) etched optical images (right) black \& white threshold images used to determine the fraction of eutectic phase present. 

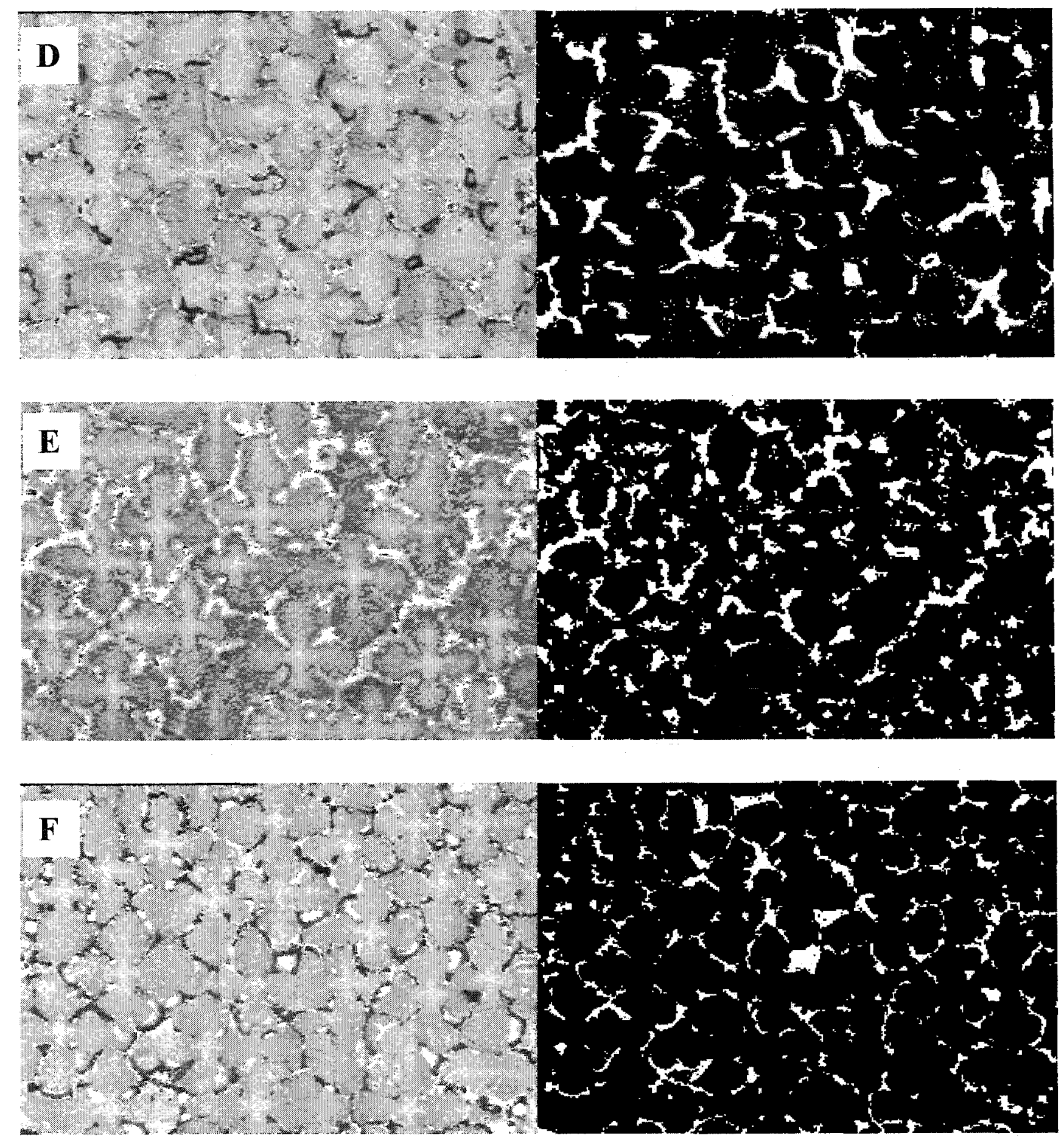

Figure 168: Transverse cross-section of Alloys D to F: (left) etched optical images (right) black \& white threshold images used to determine the fraction of eutectic phase present. 


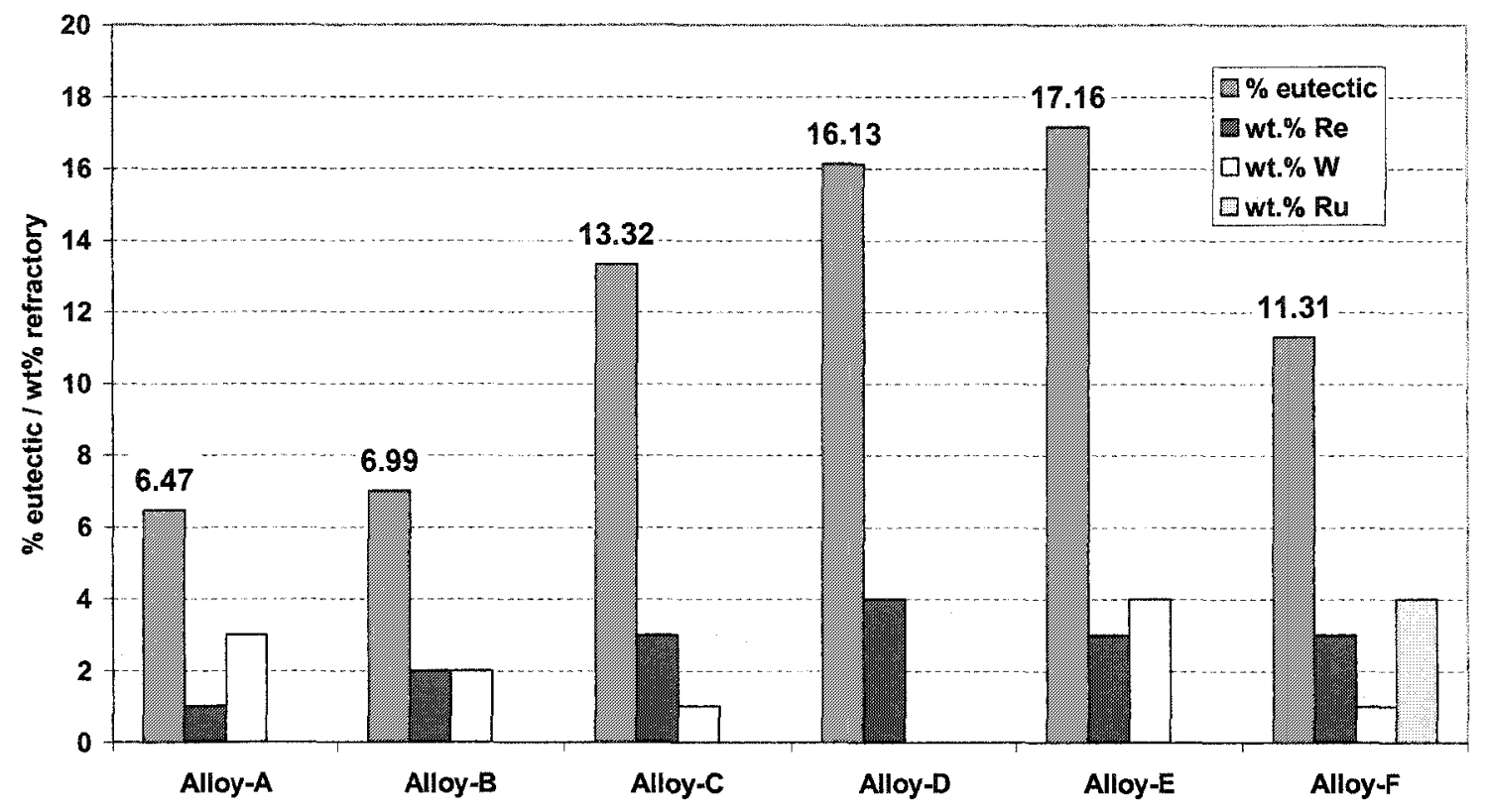

Figure 169: Eutectic phase fraction as a function of nominal alloying addition level.

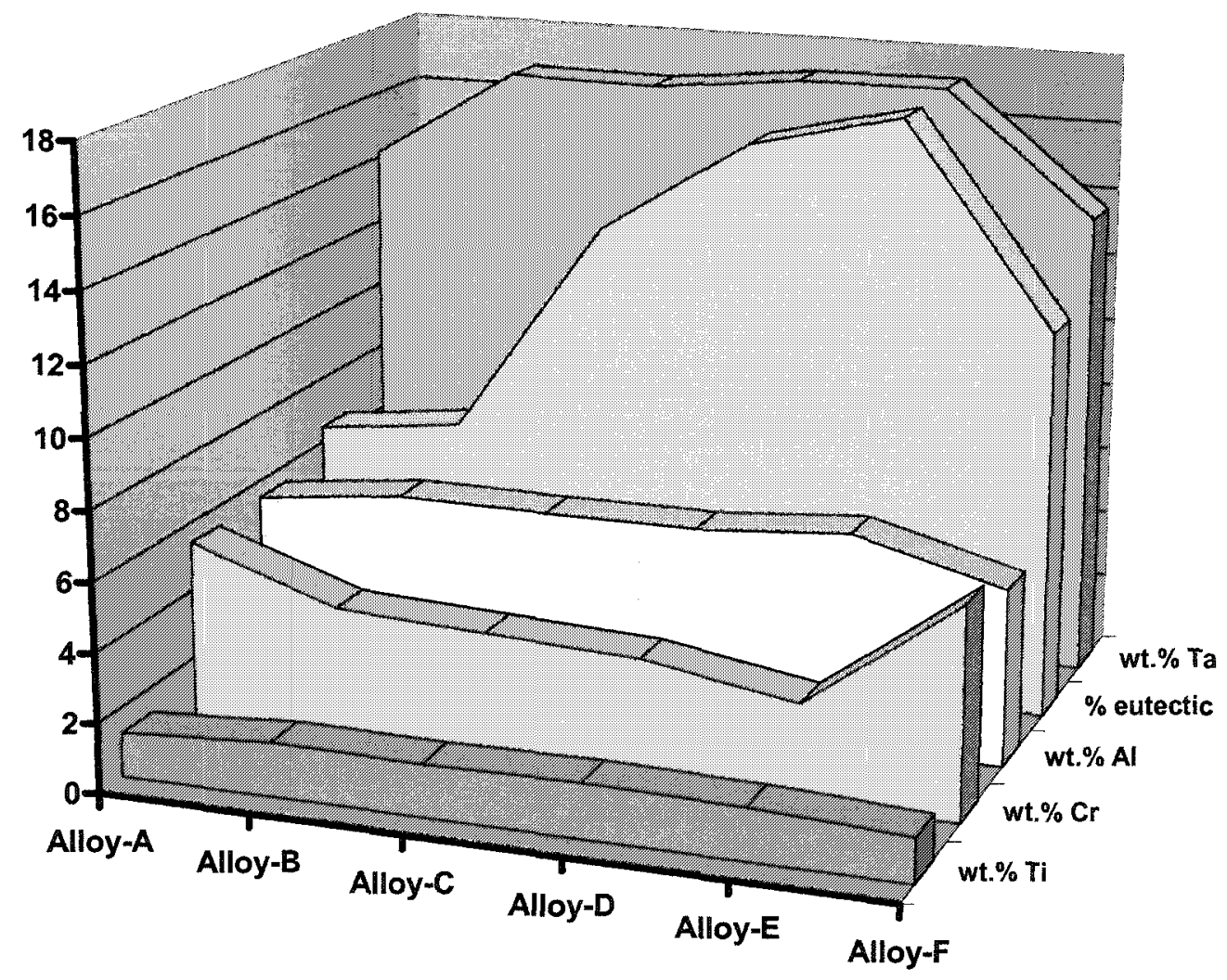

$\square \mathrm{wt} . \% \mathrm{Ti}$

$\square$ wt. \% Cr

$\square$ wt.\% Al

$\square \%$ eutectic

$\square$ wt.\% Ta

Figure 170: Comparison of eutectic phase fraction and associated eutectic composition levels. 


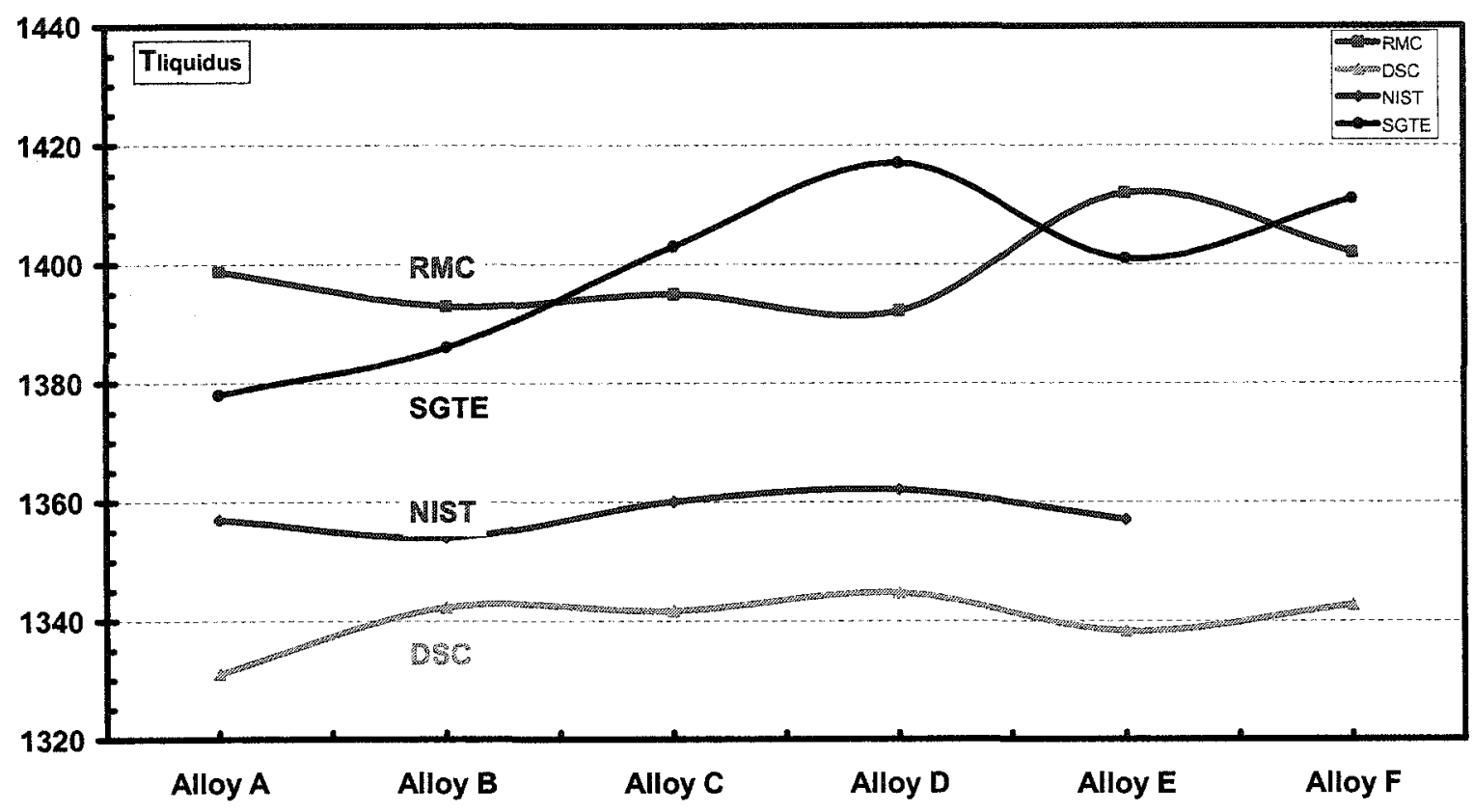

Figure 171: Comparison of liquidus temperature predictions and DSC measurements.

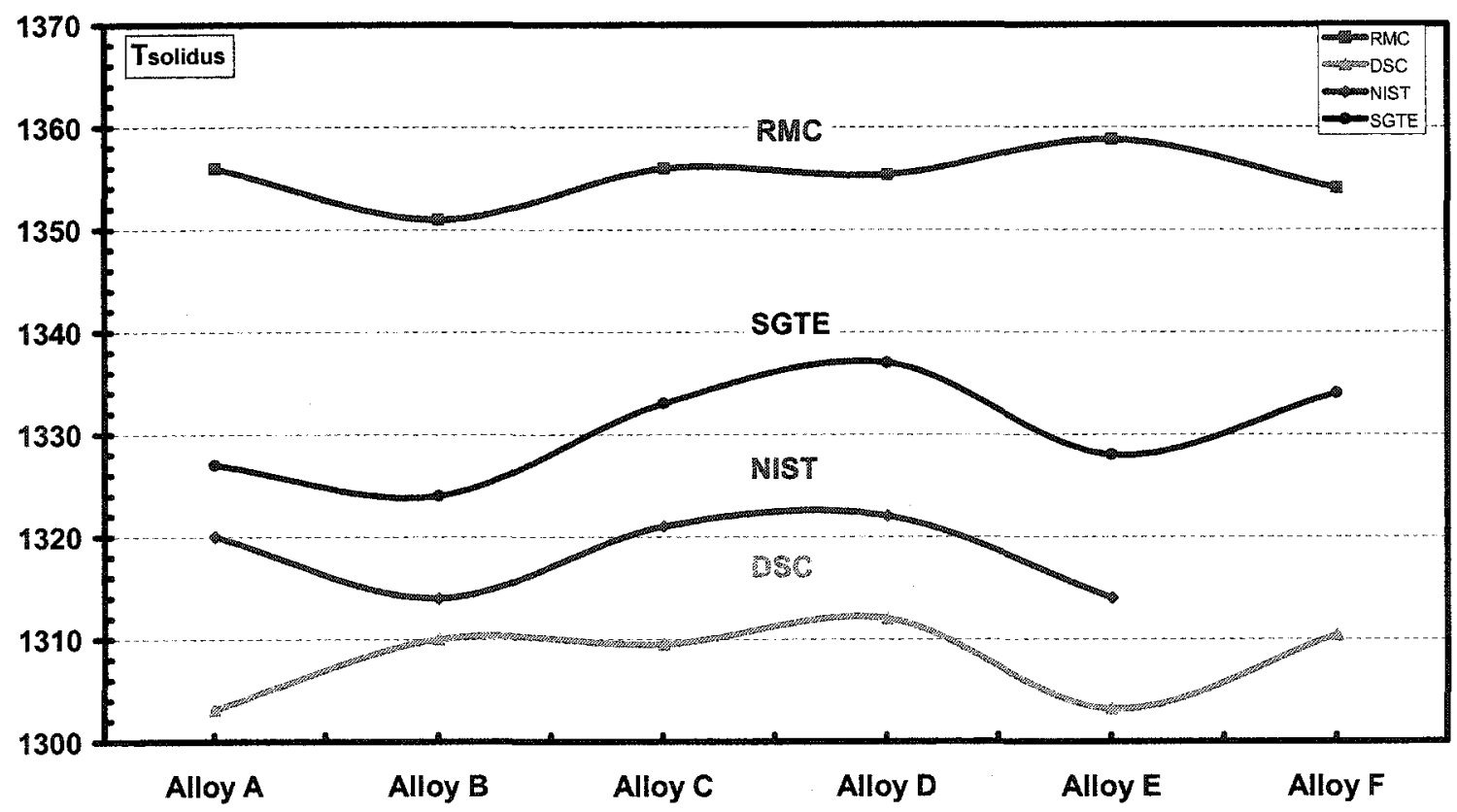

Figure 172: Comparison of solidus temperature predictions and DSC measurements. 


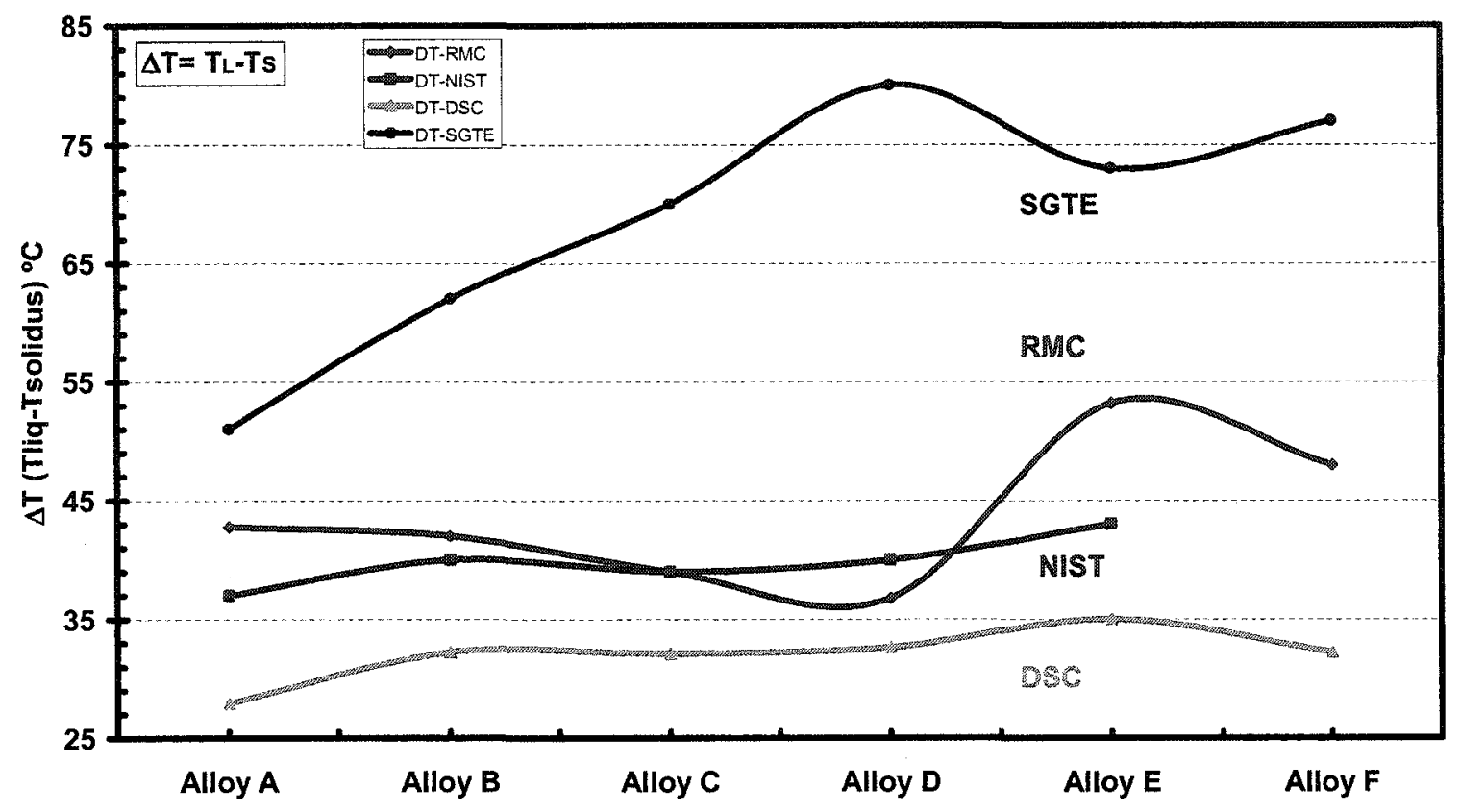

Figure 173: Comparison of solidification temperature ranges.

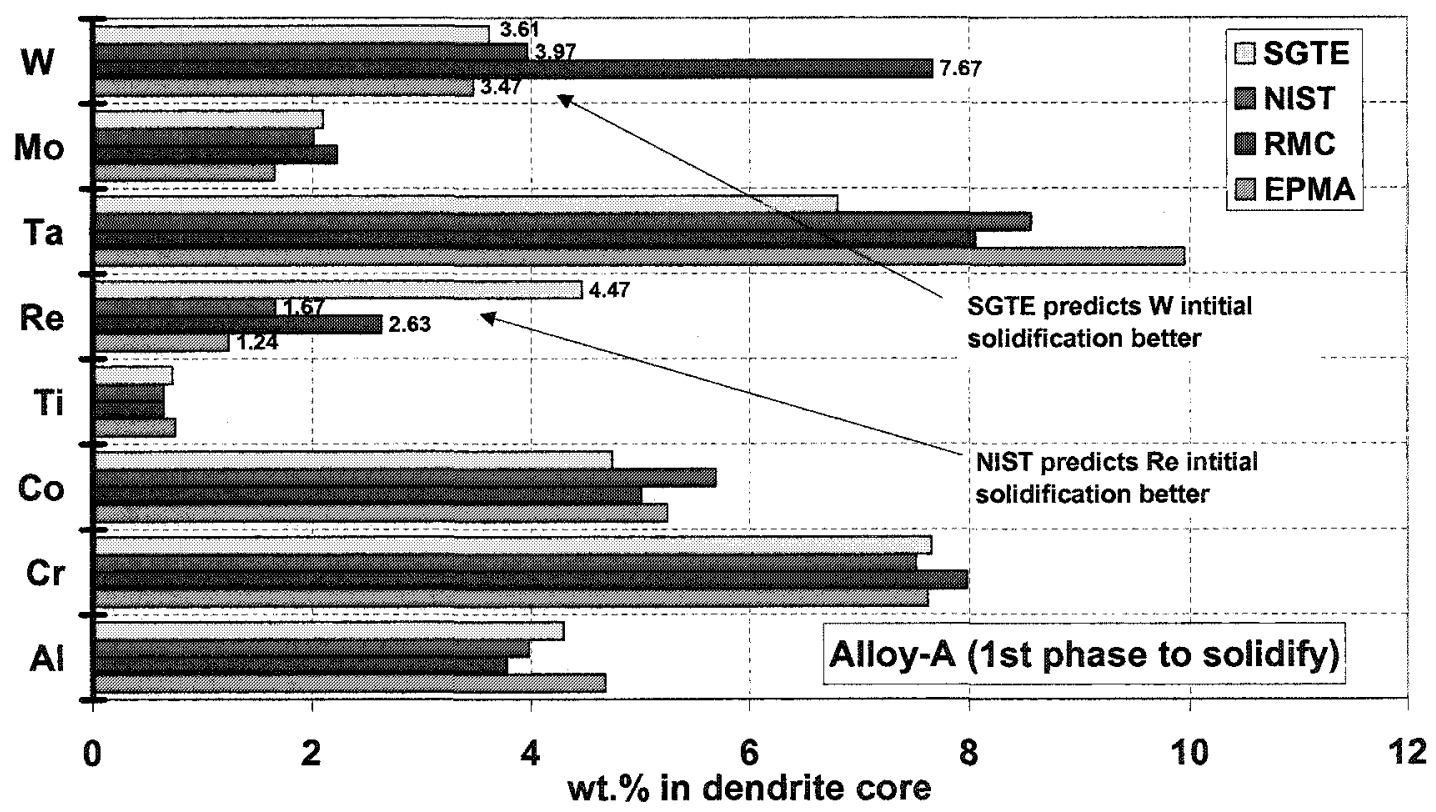

Figure 174: Comparison of the composition predictions for the dendrite core in Alloy A. 


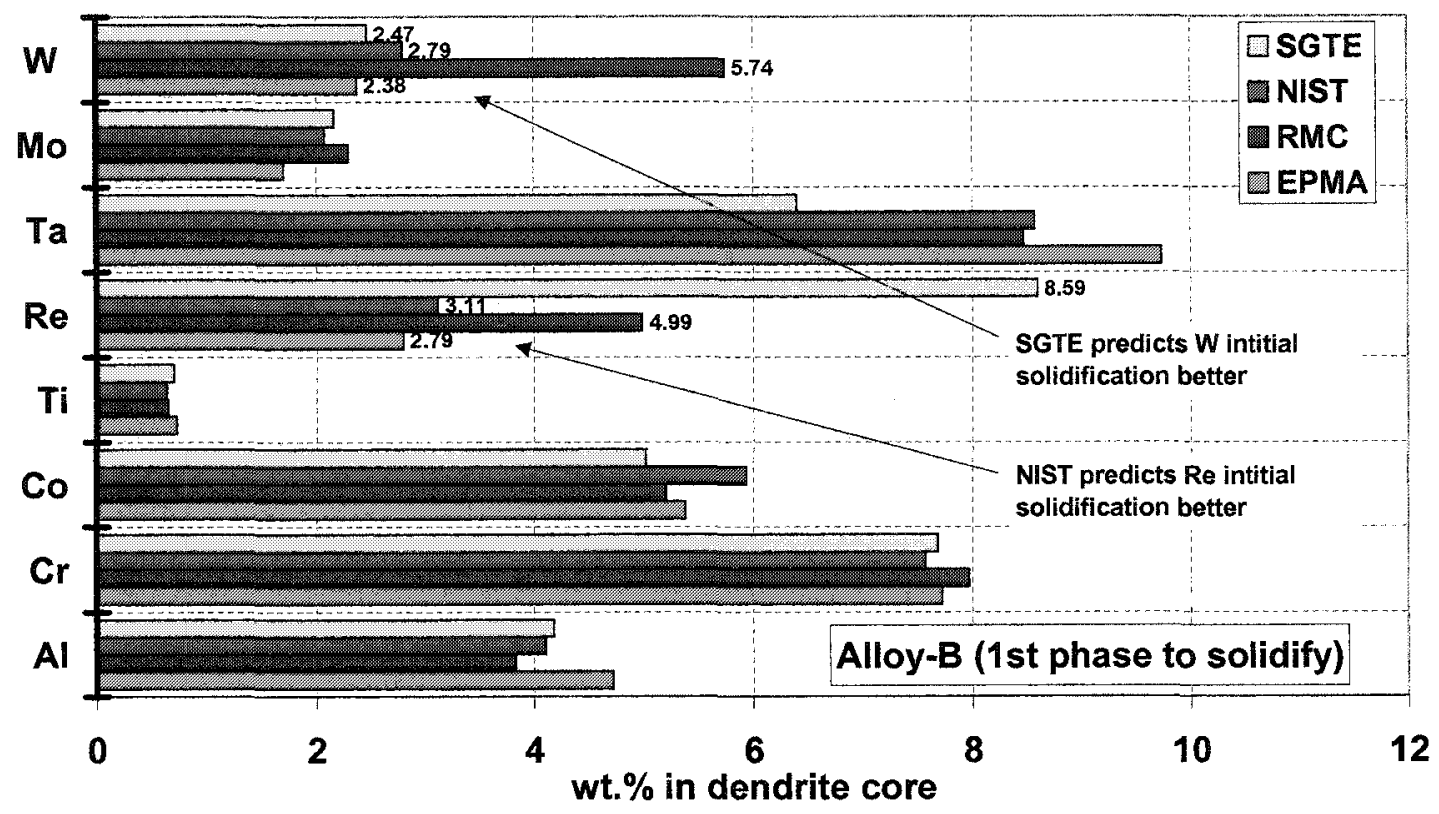

Figure 175: Comparison of the composition predictions for the dendrite core in Alloy $B$.

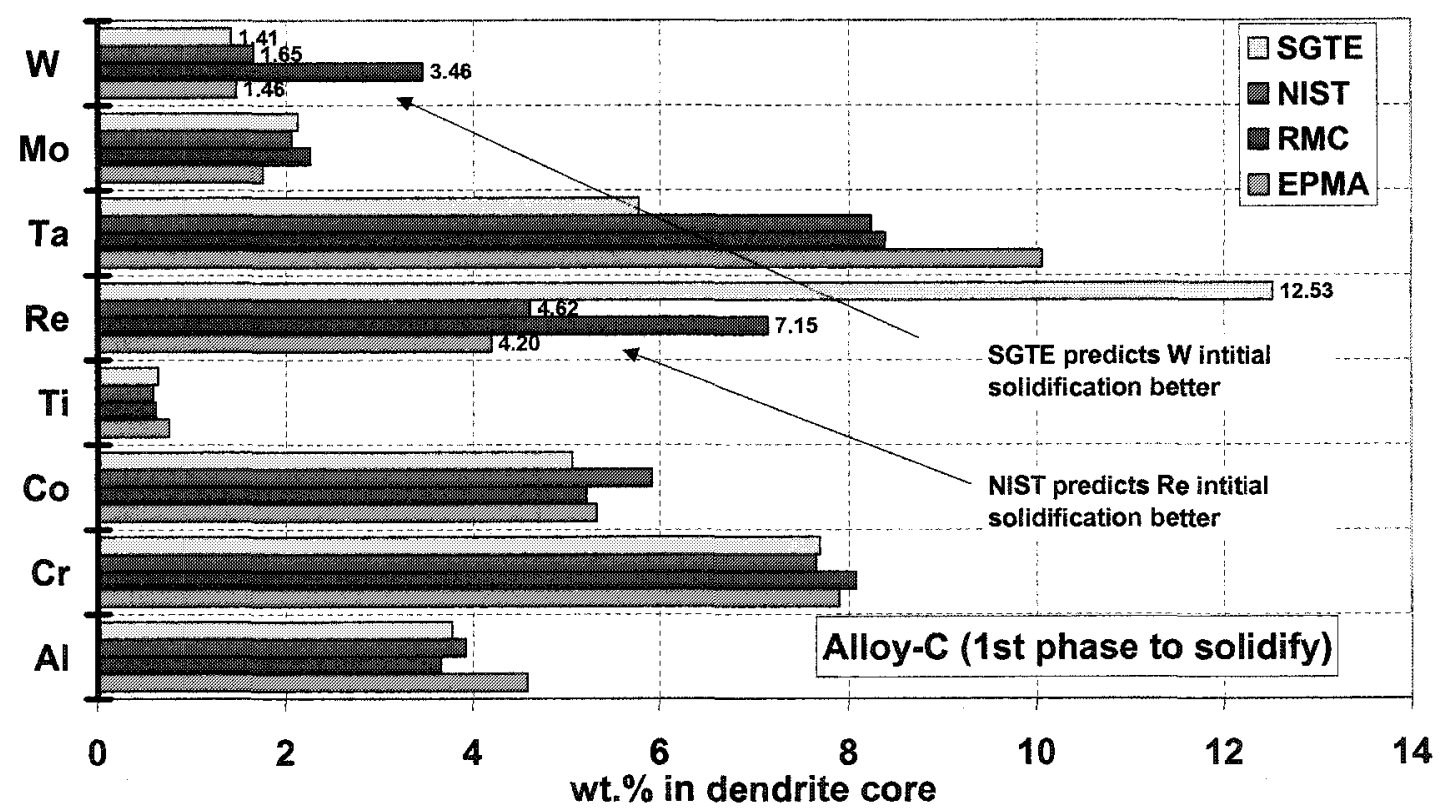

Figure 176: Comparison of the composition predictions for the dendrite core in Alloy $C$. 


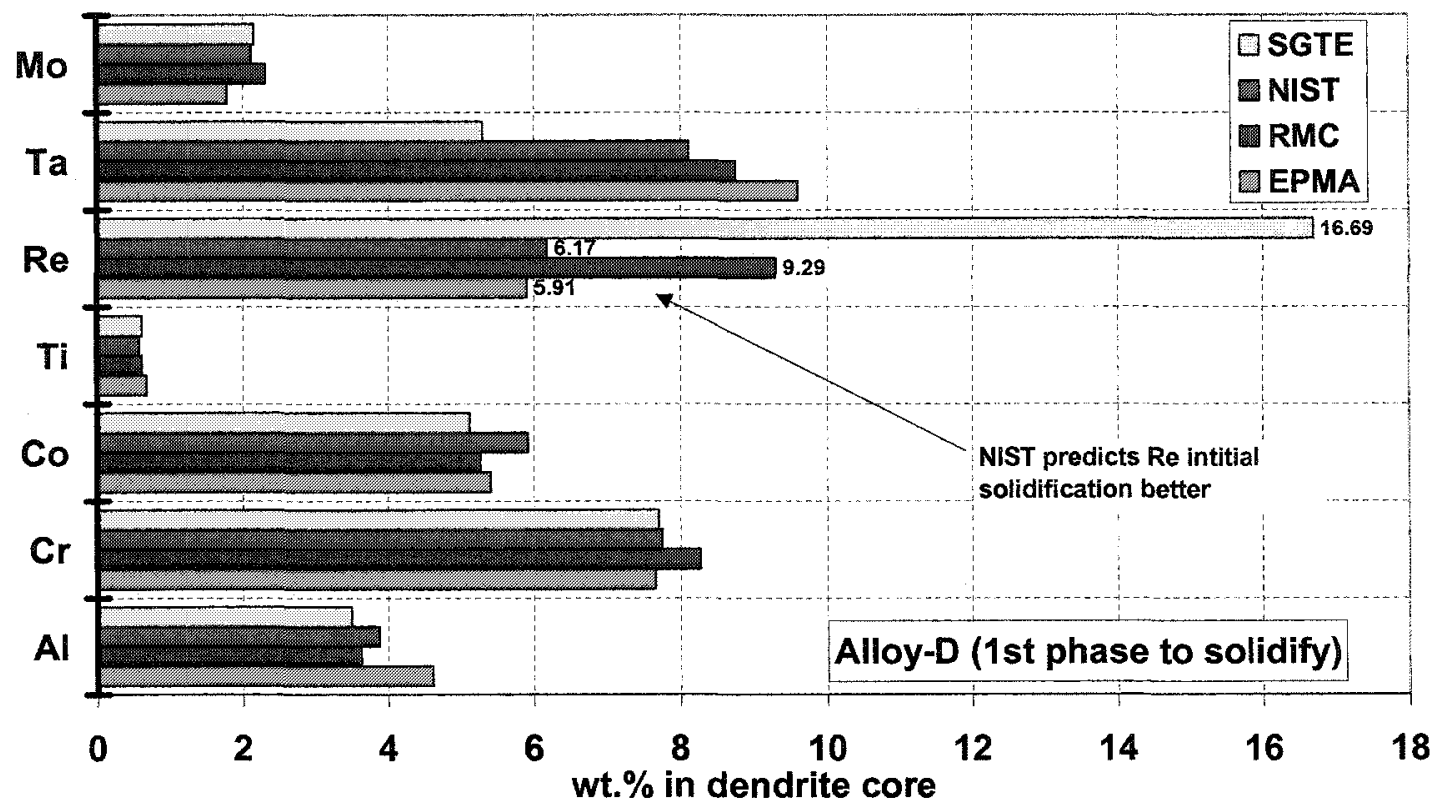

Figure 177: Comparison of the composition predictions for the dendrite core in Alloy D.

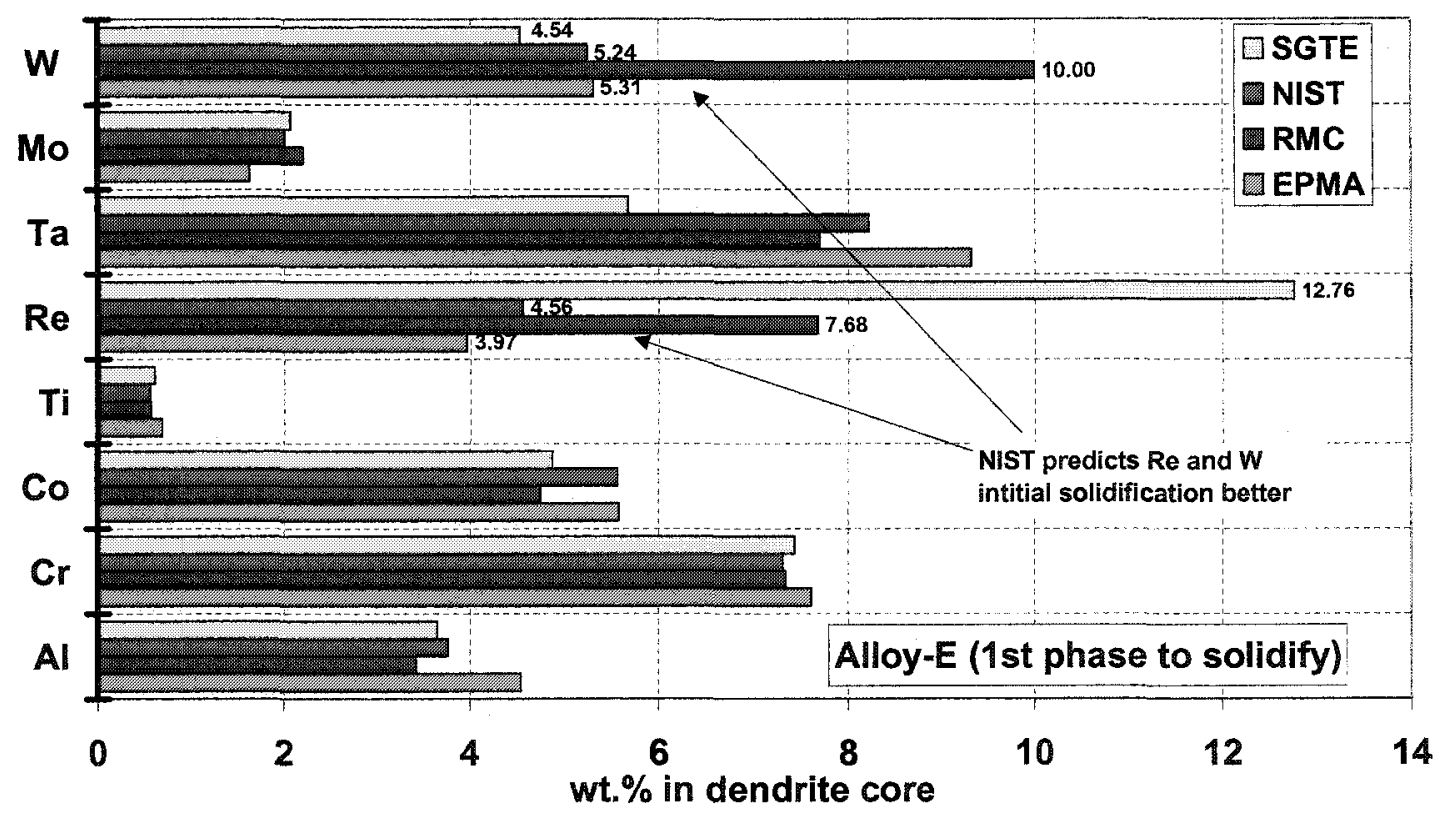

Figure 178: Comparison of the composition predictions for the dendrite core in Alloy $\mathbf{E}$. 


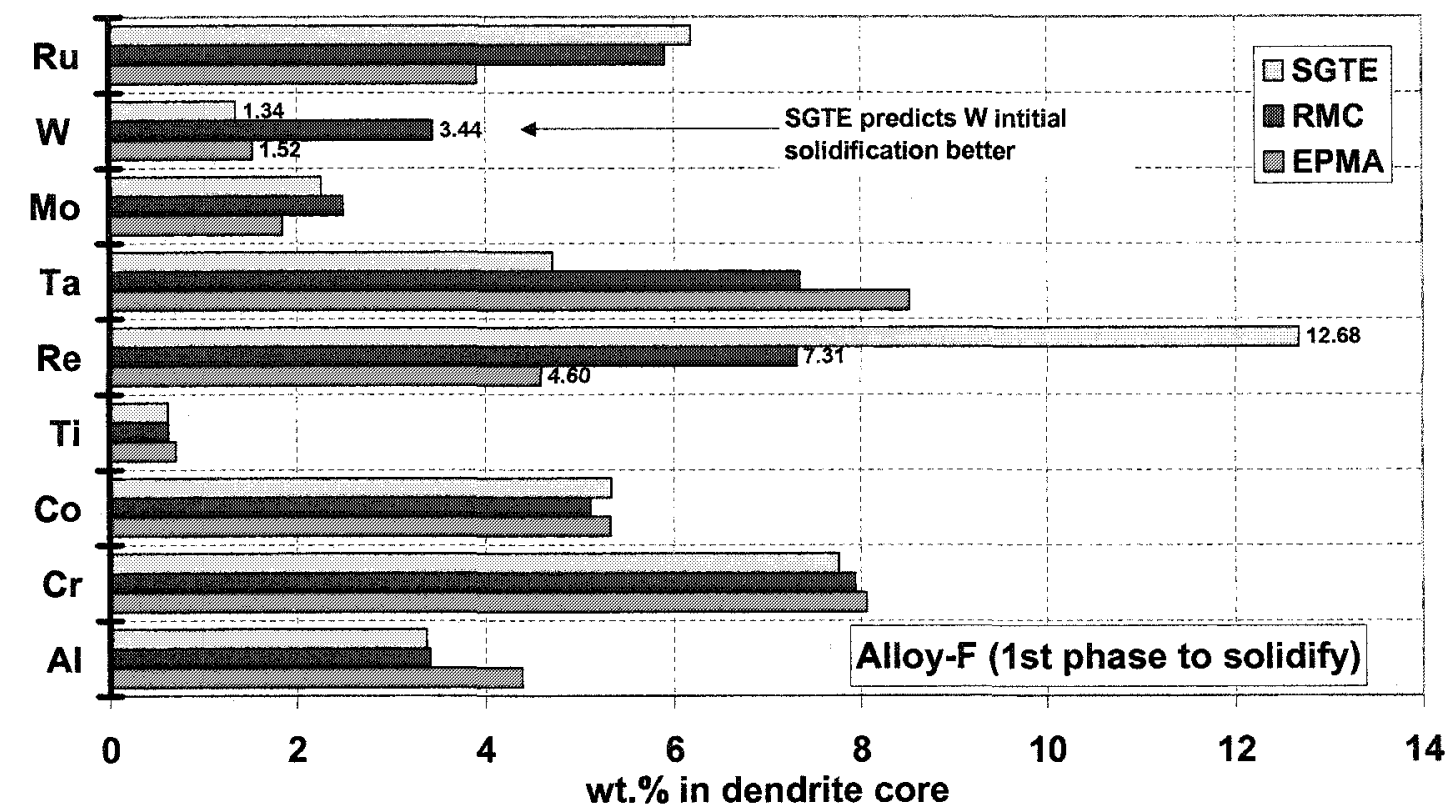

Figure 179: Comparison of the composition predictions for the dendrite core in Alloy $F$.

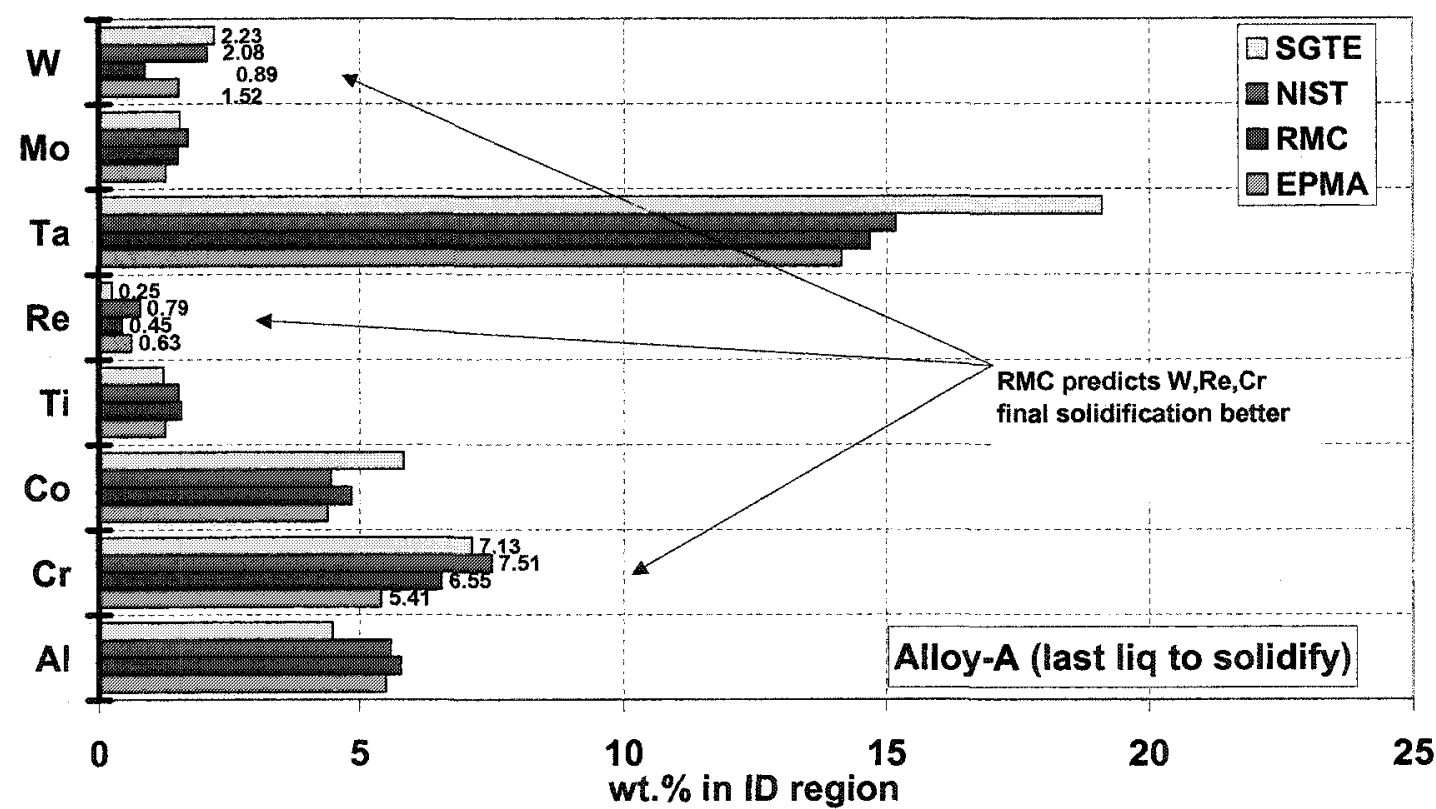

Figure 180: Comparison of the composition predictions for the interdendritic region in Alloy A. 


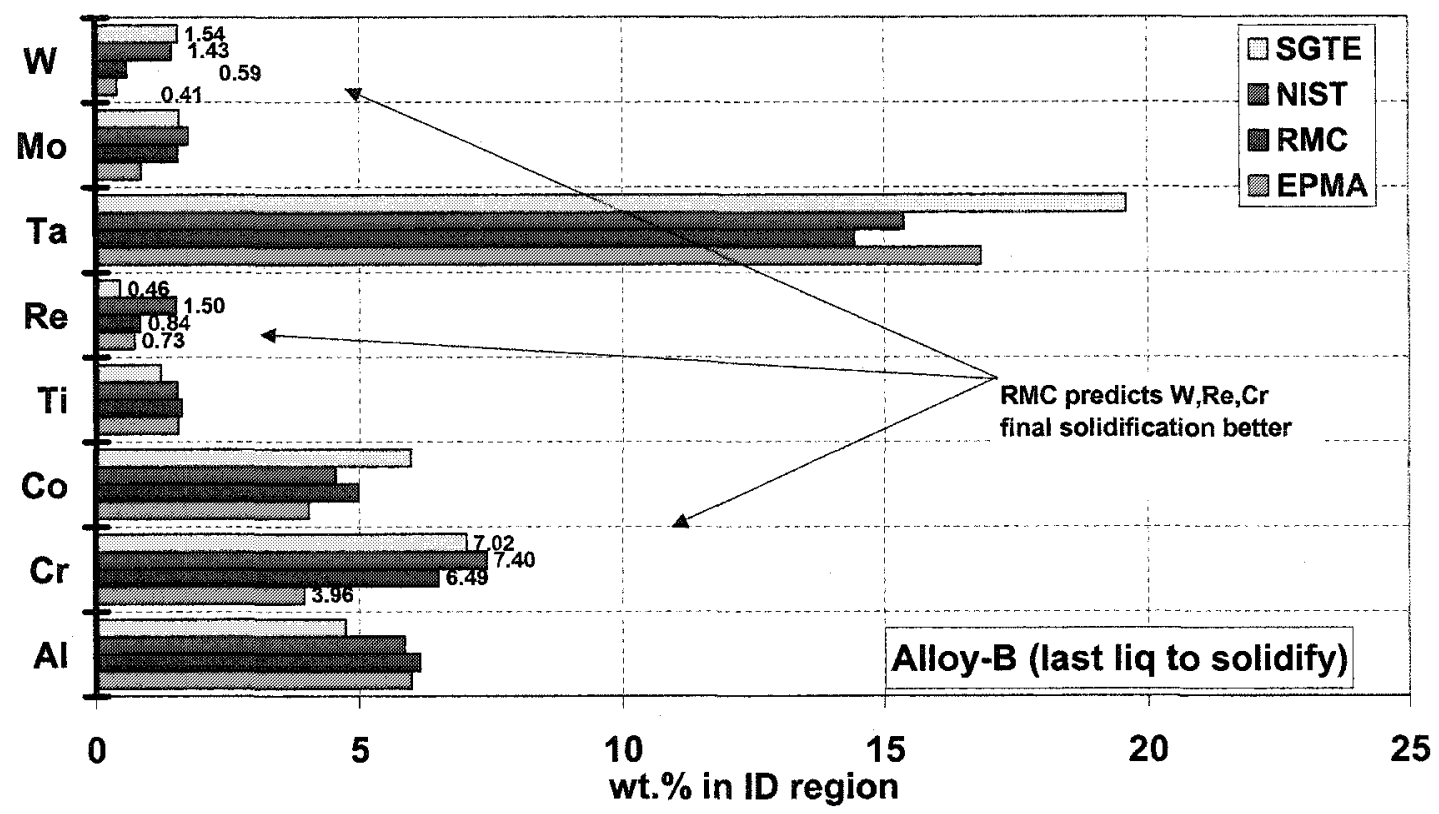

Figure 181: Comparison of the composition predictions for the interdendritic region in Alloy $B$.

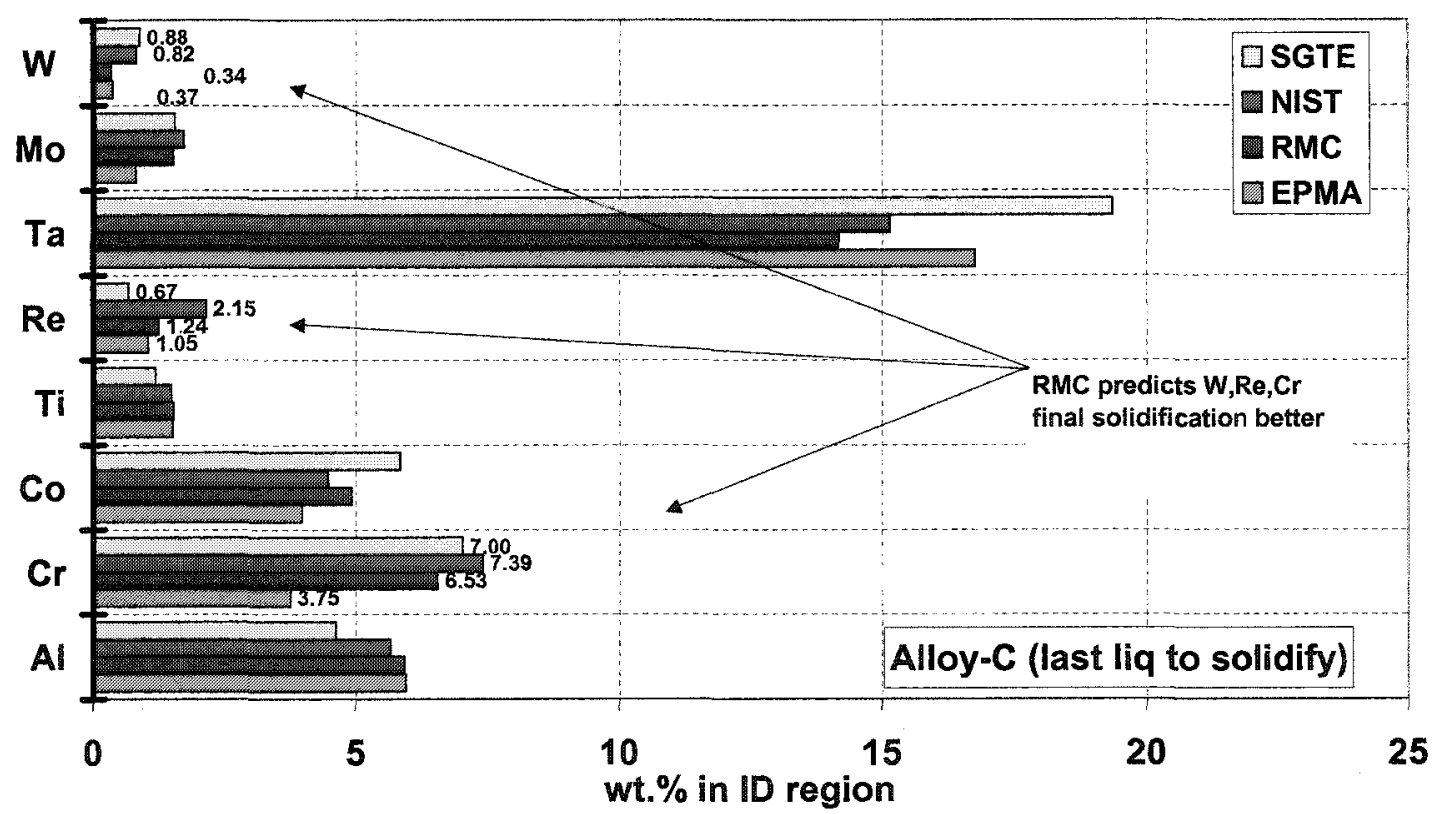

Figure 182: Comparison of the composition predictions for the interdendritic region in Alloy $\mathrm{C}$. 


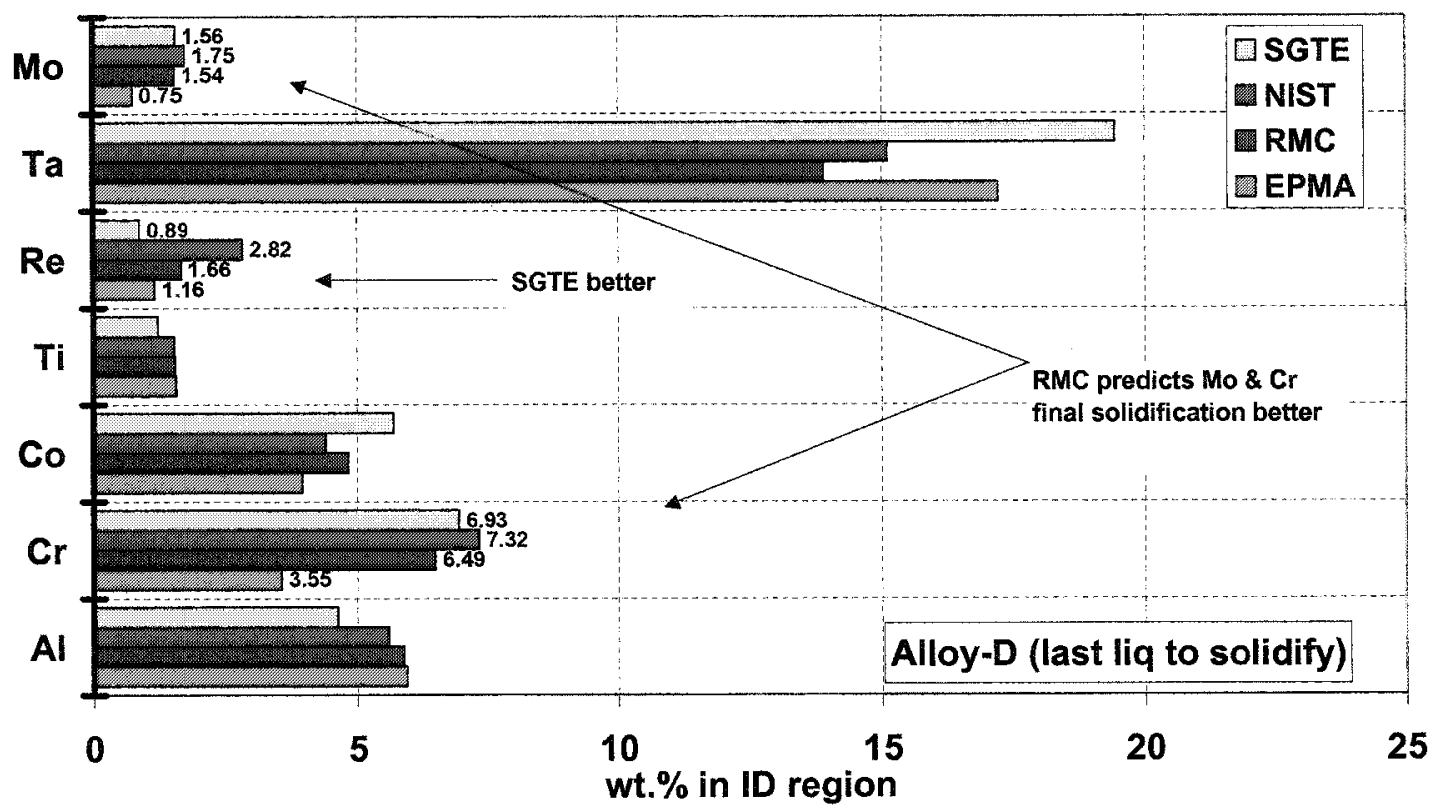

Figure 183: Comparison of the composition predictions for the interdendritic region in Alloy D.

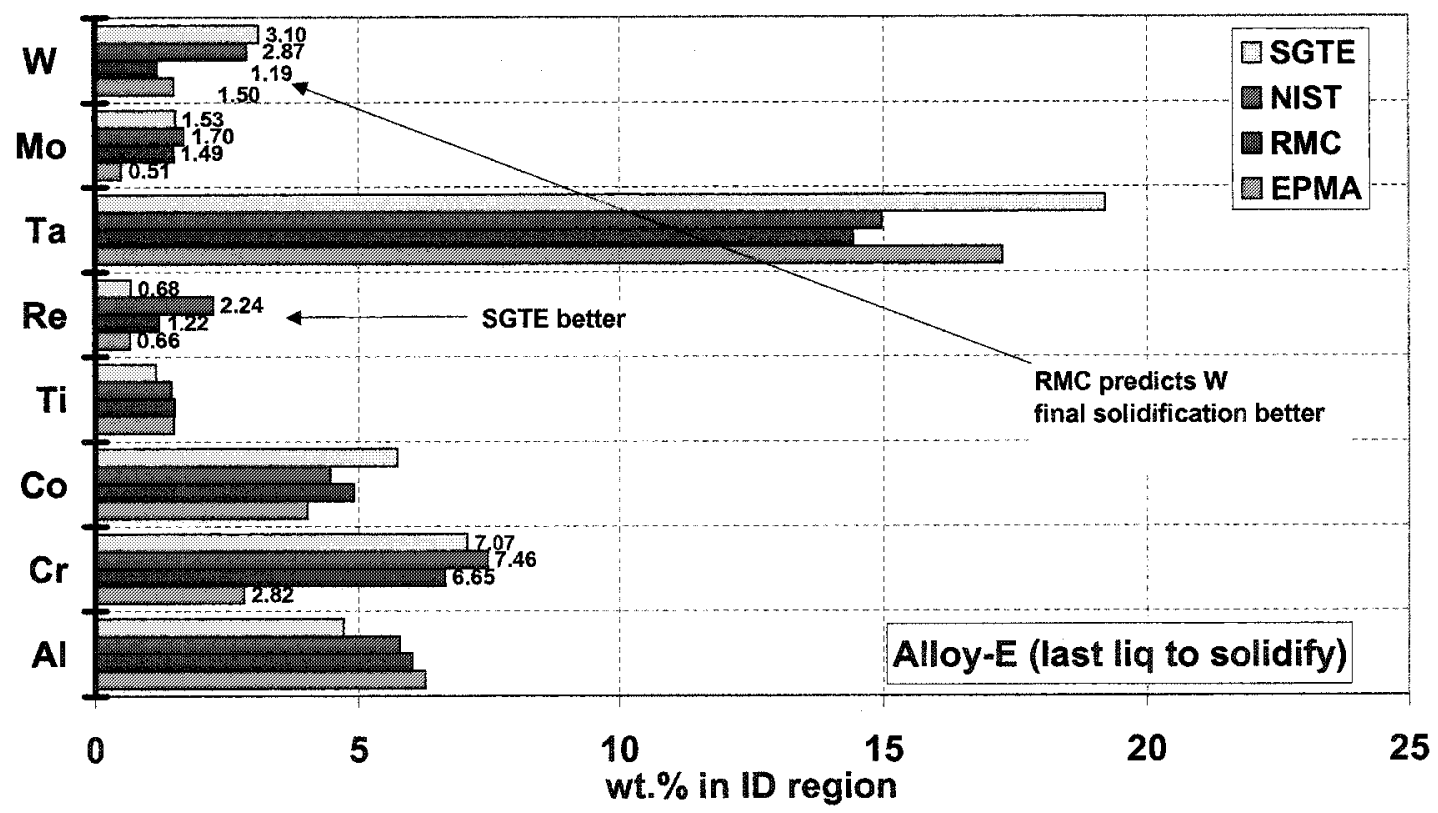

Figure 184: Comparison of the composition predictions for the interdendritic region in Alloy $E$. 


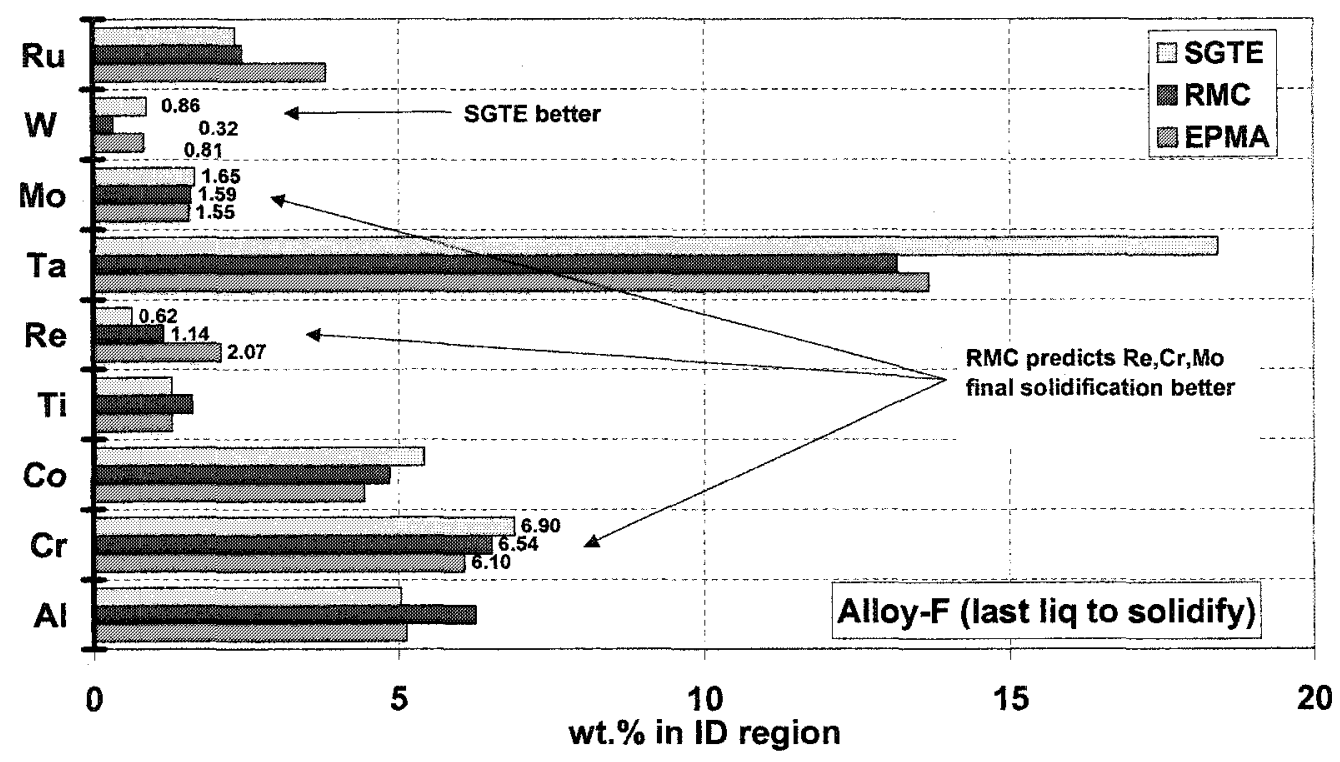

Figure 185: Comparison of the composition predictions for the interdendritic region in Alloy F.

EPMA
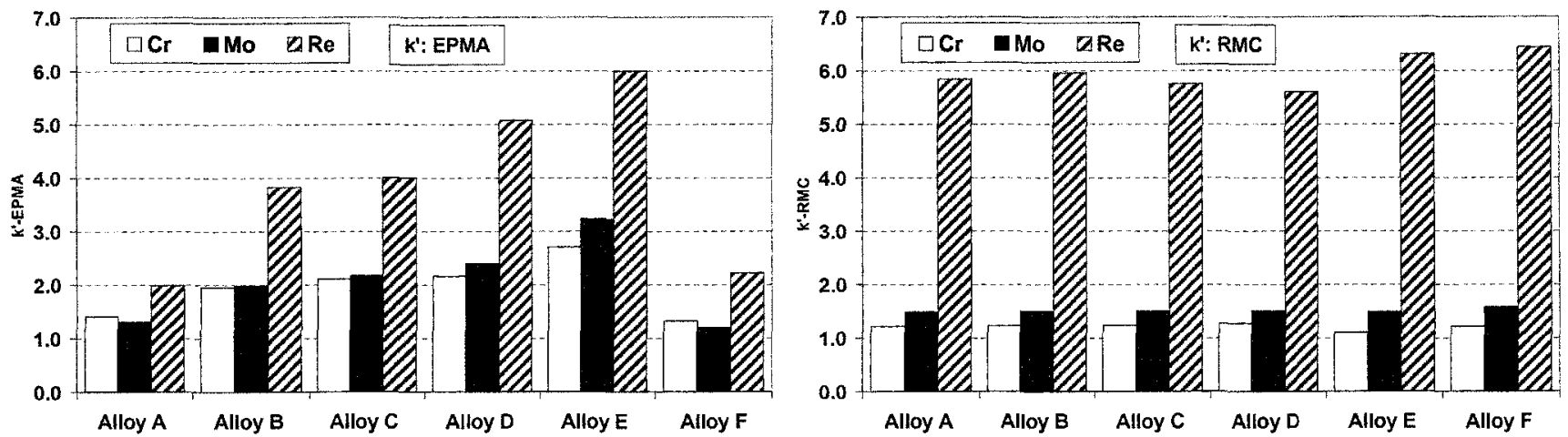

NIST
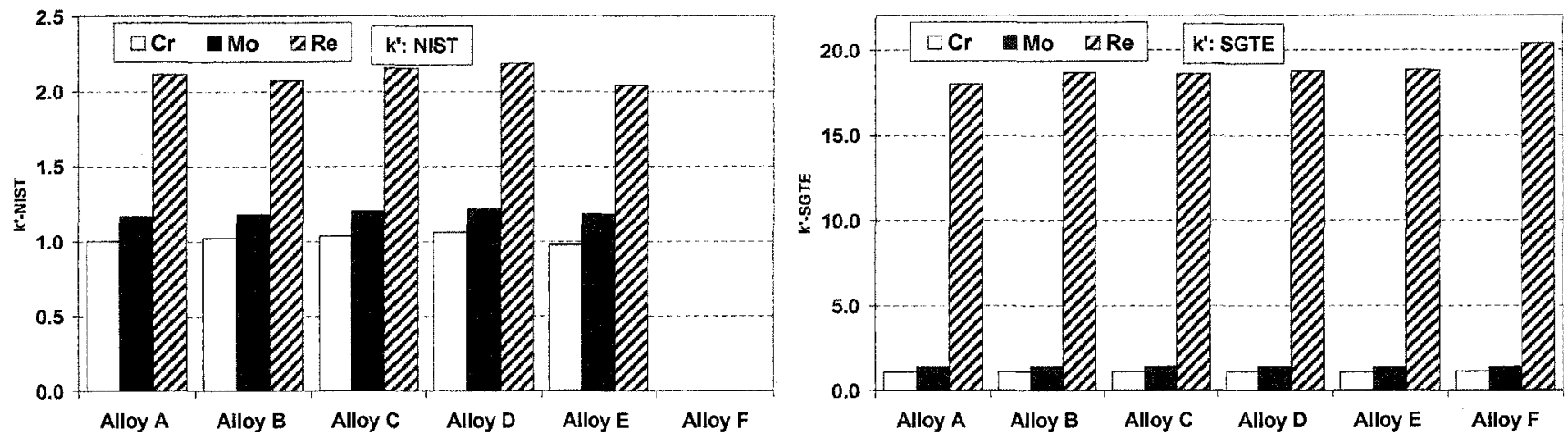

Figure 186: Comparison of predicted $k^{\prime}$ segregation coefficients to measured EPMA $k^{\prime}$ results. 


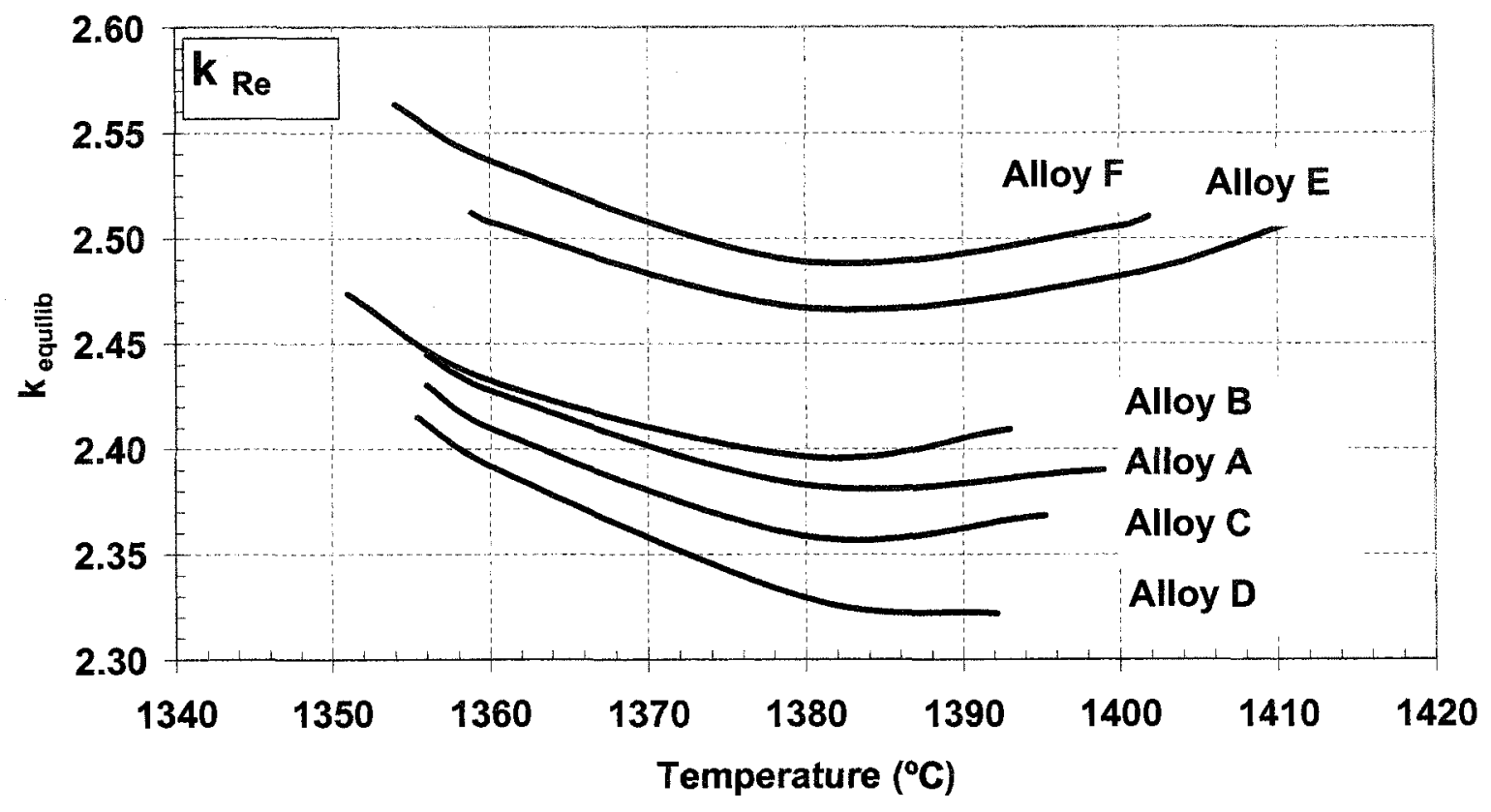

Figure 187: $R M C$ Segregation results for $\operatorname{Re}$ over $T_{L}-T_{S}$ range.

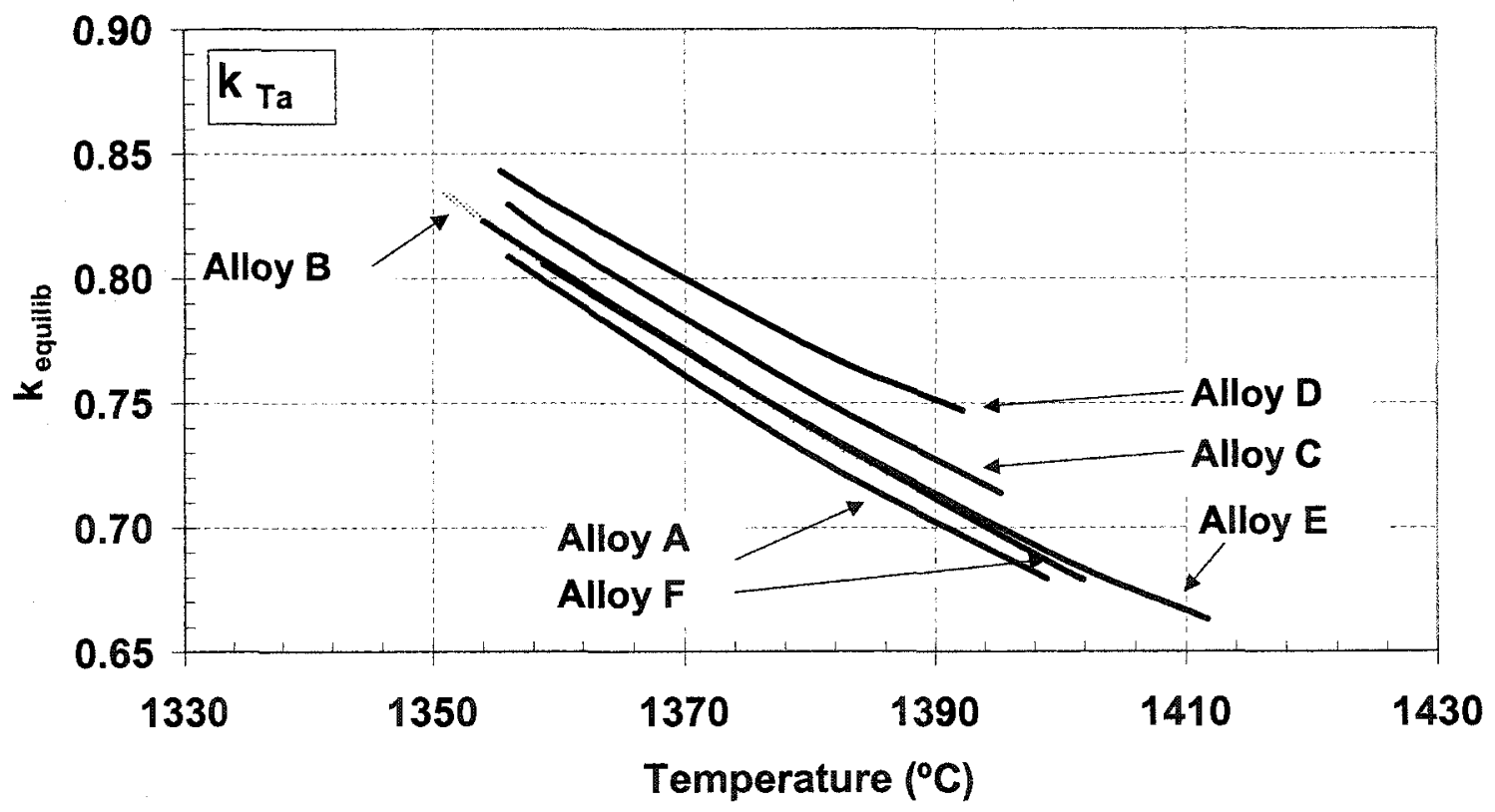

Figure 188: $R M C$ Segregation results for $T$ a over $T_{L}-T_{S}$ range. 


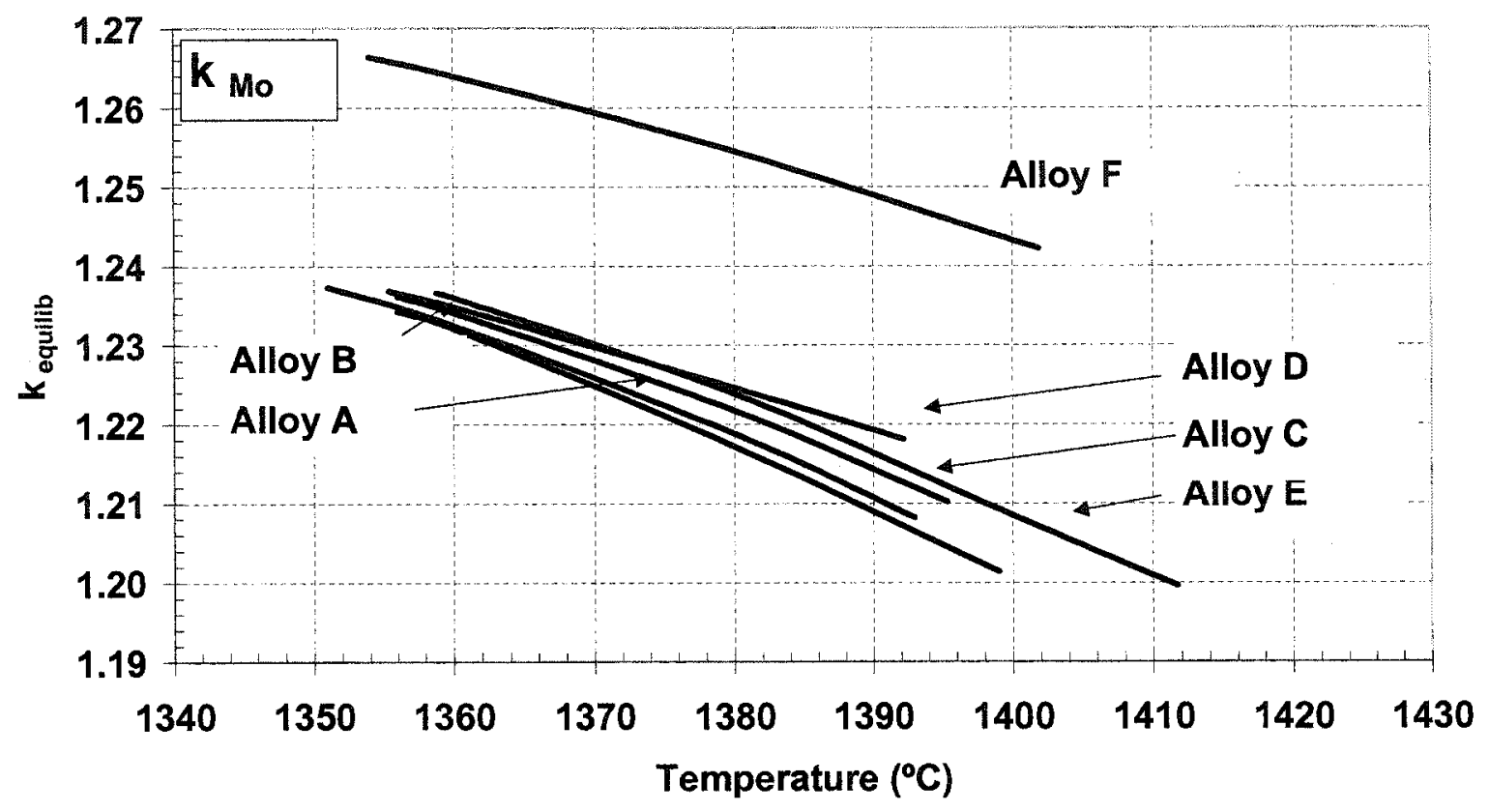

Figure 189: $R M C$ Segregation results for $M o$ over $T_{L}-T_{S}$ range.

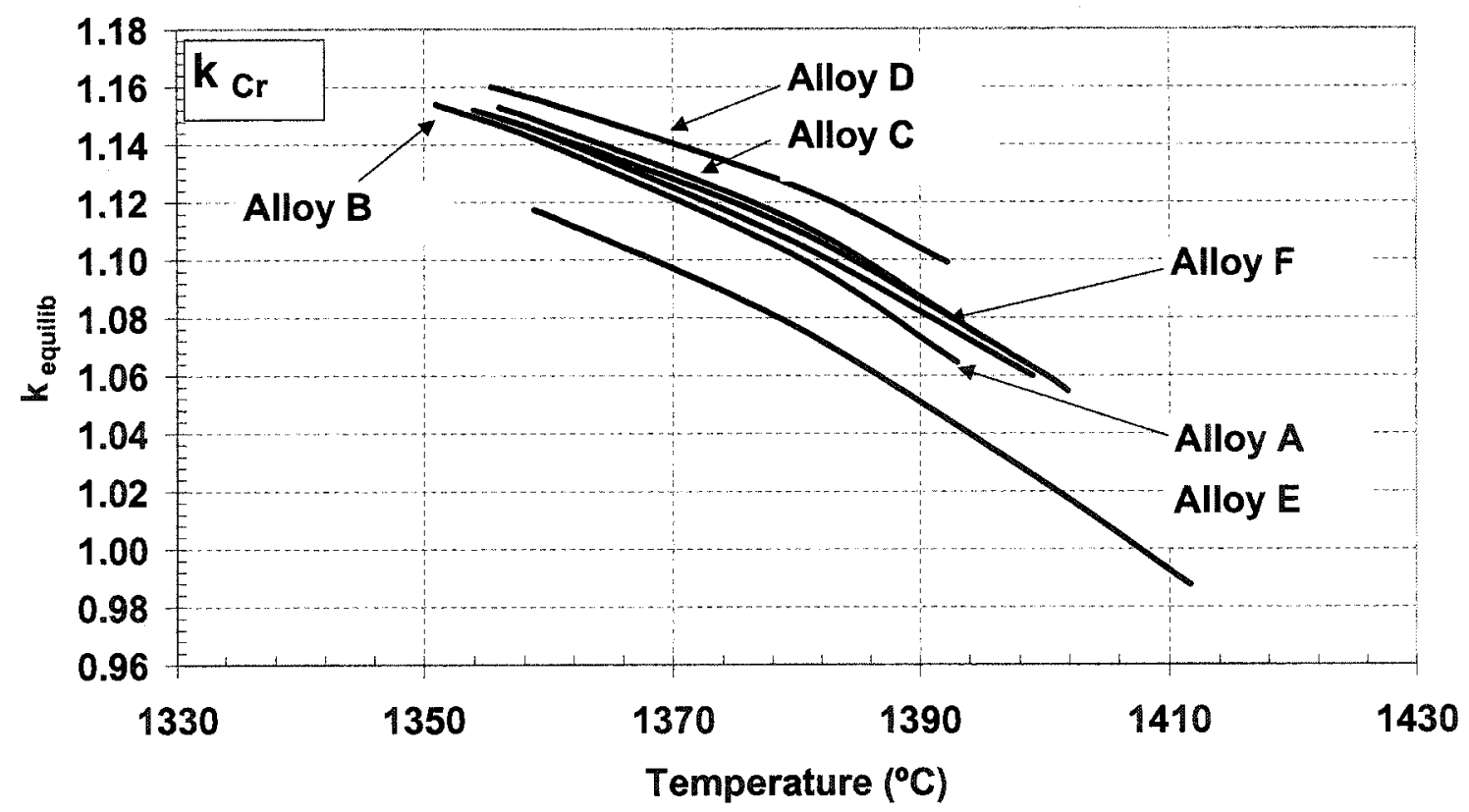

Figure 190: RMC Segregation results for $\mathrm{Cr}$ over $\mathrm{T}_{L}-\mathrm{T}_{\mathrm{S}}$ range. 


\section{Appendix A: Fundamentals of CALPHAD Modeling}

As previously mentioned, much of the detailed information contained within the RMC thermodynamic database is considered proprietary by the developers. Therefore, details of the database development work cannot be disclosed. However, an example of the methodology used to develop the thermodynamic solution database can be provided. The following section will describe the CALPHAD thermodynamic modeling procedure used to simulate the $\mathrm{Ni}-\mathrm{Ru}$ binary system. The procedure will demonstrate the iterative process required to model a simple binary system.

When developing a thermodynamic model for a given system, the developer can attain the required thermodynamic data experimentally (e.g. calorimetric studies for determination of enthalpy and heat capacity properties) or the unknown thermodynamic properties can be derived from existing equilibria phase diagrams. In reality, the use of both experimentally determined thermodynamic quantities and binary phase diagrams are required to develop a self-consistent thermodynamic model.

Provided in Figure 191 is the latest binary phase diagram from literature for the Ni-Ru system, assessed by Nash in 1991. The system itself is rather simple as there are few phases to model compared to such systems as the Ni-Ti binary, where a plethora of intermetallic species exists. The binary phase diagram consists of a Ni-rich FCC solid phase with an opposing Ru-rich HCP phase. Between these end phases resides the intermediate $(\mathrm{Ni})-(\mathrm{Ru})$ two-phase region. The most 
prominent feature of this diagram is the peritectic reaction at $1550{ }^{\circ} \mathrm{C}$. Also labeled on this figure are the melting points for pure $\mathrm{Ni}\left(1455^{\circ} \mathrm{C}\right)$ and pure $\mathrm{Ru}\left(2334^{\circ} \mathrm{C}\right)$. As with all CALPHAD modeling, it is essential that the critical phase diagram features be accurately represented thermodynamically.

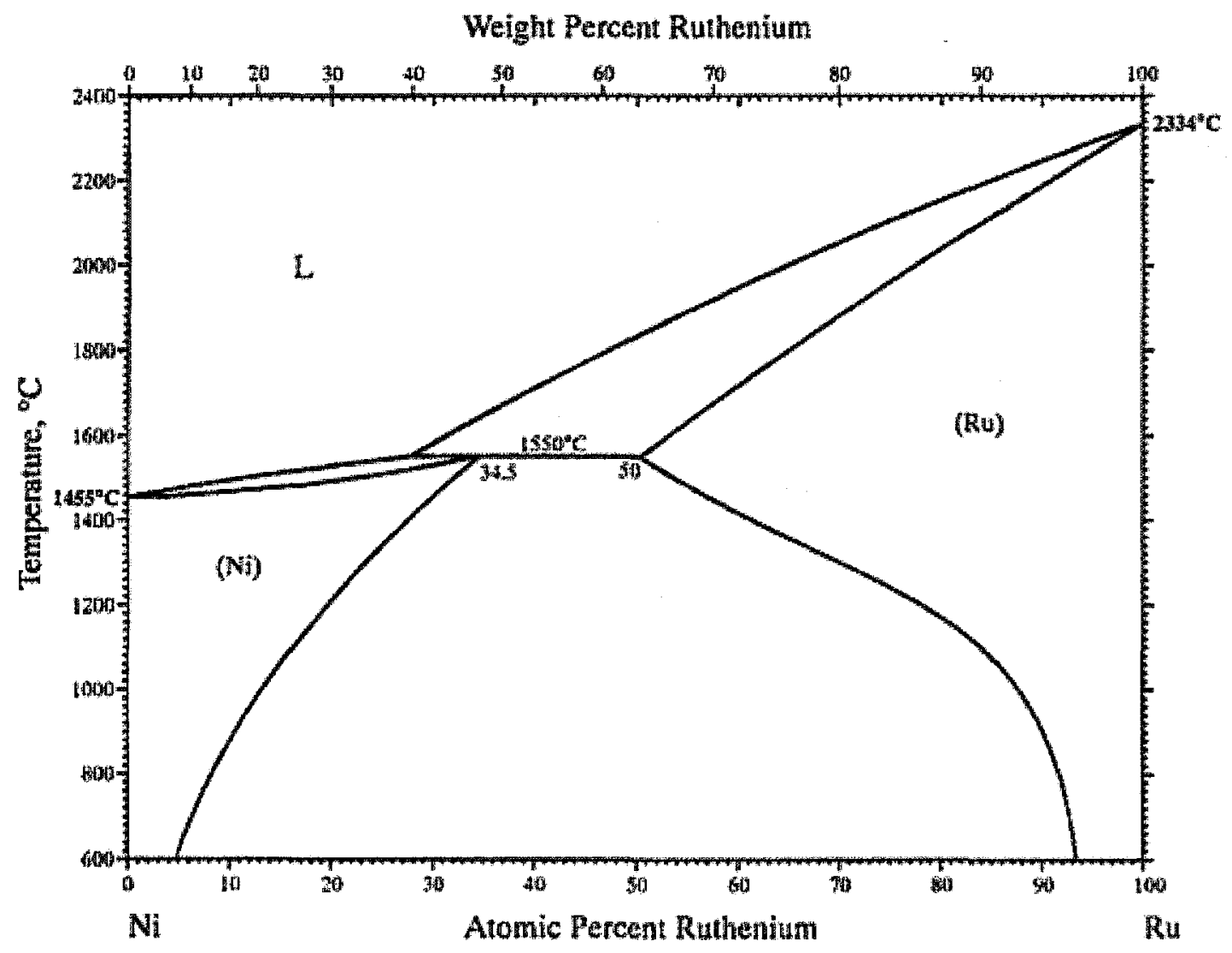

Figure 191: Ni-Ru system [Nash 1991-ASM International].

The following section will describe the procedure used to break down the Ni-Ru phase diagram so that it can be represented in terms of thermodynamic quantities that can later be incorporated into much larger multi-component models. Several iterations in the selection of the solution model for excess parameter representation will be provided. 


\section{Thermodynamic Modeling of the Ni-Ru System}

- In general, three terms are required to model phase equilibrium:

$\Delta G=\Delta G^{\circ}+\Delta G_{m i x}^{I D}+\Delta G_{m i x}^{E}$

Where:

$$
\begin{array}{ll}
\Delta G^{\circ}=X_{A}\left(H_{A}^{\circ}-T S_{A}^{\circ}\right)+X_{B}\left(H_{B}^{\circ}-T S_{B}^{\circ}\right): & \text { Lattice stabilities } \\
\Delta G_{m i x}^{I D}=X_{A} R T \ln X_{A}+X_{B} R T \ln X_{B}: & \text { Ideal mixing term } \\
\Delta G_{m i x}^{E}=\sum_{i=0}^{n} X_{A} X_{B}\left(\left(h_{i}-s_{i} T\right) X_{B}^{i}:\right. & \text { Excess Gibbs Energy term }
\end{array}
$$

- From these three required terms, the ideal mixing term is easily solved. The lattice stability terms are sometimes available in literature; however, they are often determined using a system of equations. The excess term, $\mathrm{G}^{\mathrm{E}}$, is a function of concentration and depends on the model used to describe the thermodynamic properties. The easiest way to represent this term is a polynomial description of concentration.

$$
\Delta G_{m i x}^{E}=X_{A} X_{B} \sum_{i=0}^{n} p_{i} X_{B}^{i}: \quad \text { Margules }
$$

- The Margules Formalism will be used in these samples calculations for $\Delta G_{m i x}^{E}$ representation.

Where:

$$
\Delta G_{\text {mix }}^{E}=X_{A} X_{B} \sum_{i=0}^{n} p_{i} X_{B}^{i}=X_{A} X_{B}\left(p_{0}+p_{1} X_{B}+p_{2} X_{B}^{2}+\ldots\right)
$$

- Binary solution phases (e.g. liquid and disordered solid solutions) can usually be adequately described as random mixtures of the elements using this "regular" solution type model. When $n=0$, we have the regular solution, when $n=1$, we have the subregular solution, and when $n$ $=2$, we have the sub-subregular solution model:

$$
\begin{aligned}
& \Delta G_{m i x}^{E} \quad=X_{A} X_{B} p_{0} \quad \text { Regular } \\
& =X_{A} X_{B}\left(p_{0}+p_{1} X_{B}\right) \quad \text { Subregular } \\
& =X_{A} X_{B}\left(p_{0}+p_{1} X_{B}+p_{2} X_{B}^{2}\right) \quad \text { Sub-subregular. }
\end{aligned}
$$


- In the Margules formalism, the $p_{i}$ terms represent the thermal part of the Gibbs energy of the alloys. They consist of two parts; the enthalpy and thermal entropy terms:

$$
\begin{array}{ll}
\text { e.g.: } & p_{0}=a_{0}+b_{0} T \\
& p_{1}=a_{1}+b_{1} T \\
& p_{2}=a_{2}+b_{2} T
\end{array}
$$

Now for the Ni-Ru binary system with focus on L+HCP phase region:

- The Ru rich solid solution (HCP) will be called the $\beta$ phase.

- At the peritectic, $\left(1550^{\circ} \mathrm{C}=1823 \mathrm{~K}\right)$, the $\beta$ phase co-exists with the liquid phase, $\mathbf{L}$, which is the focus at this point.

For the Ni component (at peritectic $\mathrm{T}_{1}=1823 \mathrm{~K}$ )

Condition \#1: $\quad \bar{G}_{N i}^{L}=\bar{G}_{N i}^{\beta}$

Where: $\quad \bar{G}_{N i}^{L}=G_{N i}^{\circ L}+R T \ln X_{N i}^{L}+\left(\bar{G}_{N i}^{E}\right)_{L}$

And $\quad \bar{G}_{N i}^{\beta}=G_{N i}^{\circ \beta}+R T \ln X_{N i}^{\beta}+\left(\bar{G}_{N i}^{E}\right)_{\beta}$.

- Assume that for the regular solution: $\quad \bar{G}_{A}^{E}=p_{0} X_{B}^{2}$

So:

$$
\begin{aligned}
\bar{G}_{N i}^{L} & =G_{N i}^{\mathrm{o} L}+R T \ln X_{N i}^{L}+\left(\bar{G}_{N i}^{E}\right)_{L} \\
& =G_{N i}^{\circ L}+R T \ln X_{N i}^{L}+p_{0}^{L}\left(X_{R u}^{L}\right)^{2}
\end{aligned}
$$

And:

$$
\begin{aligned}
\bar{G}_{N i}^{\beta} & =G_{N i}^{\circ \beta}+R T \ln X_{N i}^{\beta}+\left(\bar{G}_{N i}^{E}\right)_{\beta} \\
& =G_{N i}^{\circ \beta}+R T \ln X_{N i}^{\beta}+p_{0}^{\beta}\left(X_{R u}^{\beta}\right)^{2}
\end{aligned}
$$

- Now substituting in for atomic molar fractions and $\mathrm{T}$, along with lattice stabilities from

Dinsdale [74]: $\left(T=1823 \mathrm{~K}, \mathrm{X}_{\mathrm{Ni}, \mathrm{L}}=0.7293, \mathrm{X}_{\mathrm{Ni}, \beta}=0.5028, \mathrm{X}_{\mathrm{Ru}, \mathrm{L}}=0.2708, \mathrm{X}_{\mathrm{Ru}, \beta}=0.4972\right)$

$$
\begin{aligned}
\bar{G}_{N i}^{L} & =(0)+8.314(1823) \ln (0.7293)+p_{0}^{L}(0.2708)^{2} \\
& =-4784.429+0.07333 p_{0}^{L}:
\end{aligned}
$$

And:

$$
\begin{aligned}
\bar{G}_{N i}^{\beta} & =(-16440+11.464(1823))+8.314(1823) \ln (0.5028)+p_{0}^{\beta}(0.4972)^{2} \\
& =4458.872-10420.992+0.2472 p_{0}^{\beta} \\
& =-5962.12+0.2472 p_{0}^{\beta}:
\end{aligned}
$$


- Rearranging and subtracting (2) from (1):

$$
\begin{aligned}
& \bar{G}_{N i}^{L}-\bar{G}_{N i}^{\beta}=0 \\
& \left(-4784.429+0.07333 p_{0}^{L}\right)-\left(-5962.12+0.2472 p_{0}^{\beta}\right)=0 \\
& -4784.429+5962.12+0.07333 p_{0}^{L}-0.24272 p_{0}^{\beta}=0 \\
& 1177.691+0.07333 p_{0}^{L}-0.24272 p_{0}^{\beta}=0:
\end{aligned}
$$

For the $\mathrm{Ru}$ component (at peritectic $\mathrm{T}_{1}=1823 \mathrm{~K}$ )

Condition \#2: $\quad \bar{G}_{R u}^{L}=\bar{G}_{R u}^{\beta}$

Where: $\quad \bar{G}_{R u}^{L}=G_{R u}^{\circ L}+R T \ln X_{R u}^{L}+\left(\bar{G}_{R u}^{E}\right)_{L}$

And $\quad \bar{G}_{R u}^{\beta}=G_{R u}^{\mathrm{o} \beta}+R T \ln X_{R u}^{\beta}+\left(\bar{G}_{R u}^{E}\right)_{\beta}$.

- Again, assume that for the regular solution: $\quad \bar{G}_{A}^{E}=p_{0} X_{B}^{2}$

So:

$$
\begin{aligned}
\bar{G}_{R u t}^{L} & =G_{R u}^{\mathrm{o}}+R T \ln X_{R u}^{L}+\left(\bar{G}_{R u}^{E}\right)_{L} \\
& =G_{R u}^{\mathrm{o}}+R T \ln X_{R u}^{L}+p_{0}^{L}\left(X_{N i}^{L}\right)^{2}
\end{aligned}
$$

And:

$$
\begin{aligned}
\bar{G}_{R u}^{\beta} & =G_{R u}^{\circ \beta}+R T \ln X_{R u}^{\beta}+\left(\bar{G}_{R u}^{E}\right)_{\beta} \\
& =G_{R u}^{\mathrm{o} \beta}+R T \ln X_{R u}^{\beta}+p_{0}^{\beta}\left(X_{N i}^{\beta}\right)^{2}
\end{aligned}
$$

- Once again, substituting in for atomic molar fractions and $\mathrm{T}$, along with lattice stabilities from Dinsdale [74]: $\left(\mathrm{T}=1823 \mathrm{~K}, \mathrm{X}_{\mathrm{Ni}, \mathrm{L}}=0.7293, \mathrm{X}_{\mathrm{Ni}, \beta}=0.5028, \mathrm{X}_{\mathrm{Ru}, \mathrm{L}}=0.2708, \mathrm{X}_{\mathrm{Ru}, \beta}=\right.$ 0.4972)

$$
\begin{aligned}
\bar{G}_{R u}^{L} & =(0)+8.314(1823) \ln (0.2708)+p_{0}^{L}(0.7293)^{2} \\
& =-19799.967+0.5319 p_{0}^{L}:
\end{aligned}
$$

And:

$$
\begin{aligned}
\bar{G}_{R u}^{\beta} & =(-38589+14.80(1823))+8.314(1823) \ln (0.4972)+p_{0}^{\beta}(0.5028)^{2} \\
& =-11608.6-10590.746+0.2528 p_{0}^{\beta} \\
& =-22199.346+0.2528 p_{0}^{\beta}
\end{aligned}
$$

- Rearranging and subtracting (4) from (3):

$$
\begin{aligned}
& \bar{G}_{R u}^{L}-\bar{G}_{R u}^{\beta}=0 \\
& \left(-19799.967+0.5319 p_{0}^{L}\right)-\left(-22199.346+0.2528 p_{0}^{\beta}\right)=0 \\
& -19799.967+22199.346+0.5319 p_{0}^{L}-0.2528 p_{0}^{\beta}=0 \\
& 2399.379+0.5319 p_{0}^{L}-0.2528 p_{0}^{\beta}=0:
\end{aligned}
$$


- Now we have two equations, (a) and (b), and two unknowns:

$1177.691+0.07333 p_{0}^{L}-0.24272 p_{0}^{\beta}=0$

$2399.379+0.5319 p_{0}^{L}-0.2528 p_{0}^{\beta}=0$

Solving for the system yields:

$p_{0}^{L}=-2574.57$

$p_{0}^{\beta}=+4074.23$

- Hence, the Excess Gibbs free energy for the liquid and HCP phases can be represented using the regular solution model as:

$$
G_{L}^{E}=p_{0}^{L} X_{N i} X_{R u}=-2574.57 \cdot X_{N i} X_{R u}
$$

And:

$$
G_{\beta}^{E}=p_{0}^{\beta} X_{N i} X_{R u}=+4074.23 \cdot X_{N i} X_{R u}
$$

- The next step is to check the excess Gibbs energy terms in the FACT-Sage programming environment to ensure that the X-T relationship at the peritectic agrees with the experimental data (P. Nash, 1991). The calculated regular solution parameters $\left(p_{0}\right)$, as well as published lattice stability data $\left(G^{0}\right)$ for $\mathrm{Ni}$ and $\mathrm{Ru}$ in the stable and metastable conditions are entered into the Solution database model program. This program can be used to calculate integral and partial free energies as well as plot a binary phase diagram with respect to the phases entered into the system. Upon examining the resulting partial phase diagram, Figure 192, it is apparent that the general trend for the L+HCP phase is followed (c.f. Figure 191). The predicted phase region ranges from the pure HCP-Ru side of the diagram to the metastable $\mathrm{HCP}-\mathrm{Ni}$ side of the diagram.

- The next obvious step here would be to model the Ni-rich FCC-solid solution phase, $\alpha$, and include it into the phase diagram. A similar approach can be implemented as used for the $\mathbf{L}$ and $\beta$ phase regular solutions. 


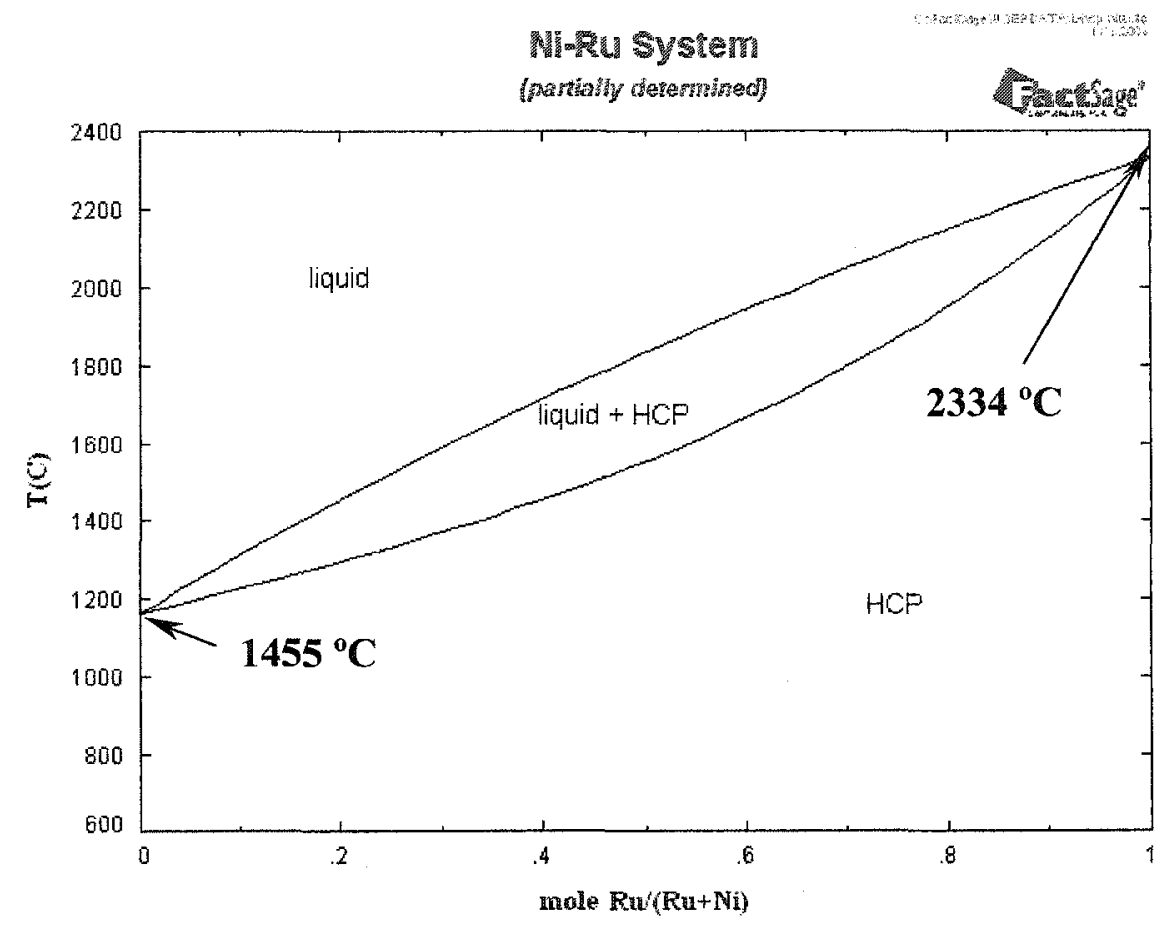

Figure 192: Preliminary Ni-Ru phase diagram depicting the $L+H C P$ phase region. Due to the absence of the $\mathrm{Ni}$ solid solution phase, the $\mathrm{L}+\boldsymbol{\beta}$ phase extends to the $\mathrm{Ni}$ rich side of the diagram suggesting a metastable $\mathrm{Ni}-\mathrm{HCP}$ region.

Now for the Ni-Ru binary system with focus on $(\mathbf{L}+\alpha)$ :

- As mentioned, the Ni-rich solid solution (FCC) will be called the $\alpha$ phase.

- At the peritectic, $\left(1550^{\circ} \mathrm{C}=1823 \mathrm{~K}\right)$, the $\alpha$ phase co-exists with $\mathrm{L}$, which is the focus at this point.

For the Ni component (at peritectic)

Condition \#3: $\quad \bar{G}_{N i}^{L}=\bar{G}_{N i}^{\alpha}$

Where: $\quad \bar{G}_{N i}^{L}=G_{N i}^{\circ L}+R T \ln X_{N i}^{L}+\left(\bar{G}_{N i}^{E}\right)_{L}$

And $\bar{G}_{N i}^{\alpha}=G_{N i}^{\circ \alpha}+R T \ln X_{N i}^{\alpha}+\left(\bar{G}_{N i}^{E}\right)_{\alpha}$.

- Assume that for the regular solution: $\quad \bar{G}_{A}^{E}=p_{0} X_{B}^{2}$

So:

$$
\begin{aligned}
\bar{G}_{N i}^{L} & =G_{N i}^{\circ L}+R T \ln X_{N i}^{L}+\left(\bar{G}_{N i}^{E}\right)_{L} \\
& =G_{N i}^{\circ L}+R T \ln X_{N i}^{L}+p_{0}^{L}\left(X_{R u}^{L}\right)^{2}
\end{aligned}
$$


And:

$$
\begin{aligned}
\bar{G}_{N i}^{\alpha} & =G_{N i}^{\circ \alpha}+R T \ln X_{N i}^{\alpha}+\left(\bar{G}_{N i}^{E}\right)_{\alpha} \\
& =G_{N i}^{\circ \alpha}+R T \ln X_{N i}^{\alpha}+p_{0}^{\alpha}\left(X_{R u}^{\alpha}\right)^{2}
\end{aligned}
$$

- Now substituting in for atomic molar fractions and $\mathrm{T}$, along with lattice stabilities from Dinsdale reference: $\left(T=1823 \mathrm{~K}, \mathrm{X}_{\mathrm{Ni}, \mathrm{L}}=0.7293, \mathrm{X}_{\mathrm{Ni}, \alpha}=0.6547, \mathrm{X}_{\mathrm{Ru}, \mathrm{L}}=0.2708, \mathrm{X}_{\mathrm{Ru}, \alpha}=\right.$ $0.3454)$. Also, noting that the partial free energy for the liquid-Ni phase is the same as determined above in equation (1).

$$
\begin{aligned}
\bar{G}_{N i}^{L} & =(0)+8.314(1823) \ln (0.7293)+p_{0}^{L}(0.2708)^{2} \\
& =-4784.429+0.07333 p_{0}^{L}: \Leftarrow \text { Previously calculated from }(1) \\
& =-4784.429+0.07333 \cdot(-2574.57) \\
& =-4973.22 \mathrm{~J} / \mathrm{mol}
\end{aligned}
$$

And:

$$
\begin{aligned}
\bar{G}_{N i}^{\alpha} & =(-17642.2+10.209(1823))+8.314(1823) \ln (0.6547)+p_{0}^{\alpha}(0.3454)^{2} \\
& =968.807-6419.93+0.1193 p_{0}^{\alpha} \\
& =-5451.123+0.1193 p_{0}^{\alpha}:
\end{aligned}
$$

- Rearranging and subtracting (4) from (3):

$$
\begin{aligned}
& \bar{G}_{N i}^{L}-\bar{G}_{N i}^{\alpha}=0 \\
& (-4973.22)-\left(-5451.123+0.1193 p_{0}^{\alpha}\right)=0 \\
& -4973.22+5451.123-0.1193 p_{0}^{\alpha}=0 \\
& 477.903-0.1193 p_{0}^{\alpha}=0 \\
& p_{0}^{\alpha}=477.903 / 0.1193 \\
& p_{0}^{\alpha}=+4005.89:
\end{aligned}
$$

Hence:

$$
G_{\alpha}^{E}=p_{0}^{\alpha} X_{N i} X_{R u}=+4005.89 \cdot X_{N i} X_{R u}
$$

For the $\mathrm{Ru}$ component (at peritectic)

$\begin{array}{ll}\text { Condition \#4: } & \bar{G}_{R u}^{L}=\bar{G}_{R u}^{\alpha} \\ \text { Where: } & \bar{G}_{R u}^{L}=G_{R u}^{\circ L}+R T \ln X_{R u}^{L}+\left(\bar{G}_{R u}^{E}\right)_{L} \\ \text { And } & \bar{G}_{R u}^{\alpha}=G_{R u}^{\circ \alpha}+R T \ln X_{R u}^{\alpha}+\left(\bar{G}_{R u}^{E}\right)_{\alpha} .\end{array}$

- Again, assume that for the regular solution: $\quad \bar{G}_{A}^{E}=p_{0} X_{B}^{2}$ 
So:

$$
\begin{aligned}
\bar{G}_{R u}^{L} & =G_{R u}^{\circ L}+R T \ln X_{R u}^{L}+\left(\bar{G}_{R u}^{E}\right)_{L} \\
& =G_{R u}^{\mathrm{o}}{ }_{R u}+R T \ln X_{R u}^{L}+p_{0}^{L}\left(X_{N i}^{L}\right)^{2}
\end{aligned}
$$

And:

$$
\begin{aligned}
\bar{G}_{R u}^{\alpha} & =G_{R u}^{\circ \alpha}+R T \ln X_{R u}^{\alpha}+\left(\bar{G}_{R u}^{E}\right)_{\alpha} \\
& =G_{R u}^{\circ \alpha}+R T \ln X_{R u}^{\alpha}+p_{0}^{\alpha}\left(X_{N i}^{\alpha}\right)^{2}
\end{aligned}
$$

- Substituting in for atomic molar fractions and $\mathrm{T}$, along with lattice stabilities from Dinsdale reference: $\left(T=1823 \mathrm{~K}, \mathrm{X}_{\mathrm{Ni}, \mathrm{L}}=0.7293, \mathrm{X}_{\mathrm{Ni}, \alpha}=0.6547, \mathrm{X}_{\mathrm{Ru}, \mathrm{L}}=0.2708, \mathrm{X}_{\mathrm{Ru}, \alpha}=0.3454\right)$. Also, noting that the partial free energy for the liquid-Ru phase is the same as determined above in equation (3). It should also be mentioned here that the lattice stability parameters for $\mathrm{Ru}$ in the metastable $\alpha$-fcc condition are unknown.

$$
\begin{aligned}
\bar{G}_{R u}^{L} & =(0)+8.314(1823) \ln (0.2708)+p_{0}^{L}(0.7293)^{2} \\
& =-19799.967+(-2574.57) \cdot 0.5319 \\
& =-21169.381 \mathrm{~J} / \mathrm{mol}
\end{aligned}
$$

And:

$$
\begin{aligned}
& \bar{G}_{R u}^{\alpha}=\left(G_{R u}^{\circ \alpha}\right)+8.314(1823) \ln (0.3454)+p_{0}^{\alpha}(0.6547)^{2} \\
& =G_{R u}^{\circ \alpha}-16112.066+0.4286 p_{0}^{\alpha} \\
& \text { Subs. (c): } \quad=G_{R u}^{\circ \alpha}-16112.066+0.4286 \cdot(4005.89) \\
& =G_{R u}^{\circ \alpha}-14395.013
\end{aligned}
$$

- $\quad$ Rearranging and subtracting (8) from (7):

$$
\begin{aligned}
& \bar{G}_{R u}^{L}-\bar{G}_{R u}^{\alpha}=0 \\
& (-21169.381)-\left(G_{R u}^{\circ \alpha}-14395.013\right)=0 \\
& -21169.381+14395.013-G_{R u}^{\circ \alpha}=0 \\
& G_{R u}^{\circ \alpha}=-6774.368 \mathrm{~J} / \mathrm{mol}
\end{aligned}
$$

- At this point, the regular solution parameter for the fcc- $\alpha$ phase has been determined ( $p_{0}^{\alpha}=+4005.89$ ) using the regular solution approach. Also, the lattice stability for the fcc$\mathrm{Ru}$ phase has been determined to be $-6774.368 \mathrm{~J} / \mathrm{mol}$. In general, the lattice stability terms is represented as a function of temperature.

$$
\begin{aligned}
& G_{R u}^{\circ \alpha}=H_{R u}^{\circ \alpha}+S_{R u}^{\circ \alpha} \cdot T=-6774.368 \mathrm{~J} / \mathrm{mol} . \\
& G_{R u}^{\circ \alpha}=a+b \cdot T=-6774.368
\end{aligned}
$$

- If we assume that the $S_{R u}^{\circ \alpha}=S_{R u}^{\circ \beta}$ then $\mathbf{b}=14.80$ and $\mathbf{a}$ can be solved accordingly: $-6774.368=a+14.80 \cdot T$ 
Where: $\mathrm{T}=1823 \mathrm{~K}$,

$$
a=-6774.368-14.8 \cdot 1823=-33754.768 \mathrm{~J} / \mathrm{mol}
$$

Hence: $\quad G_{R u}^{\circ \alpha}=H_{R u}^{\circ \alpha}+S_{R u}^{\circ \alpha} \cdot T$

$$
G_{R u}^{\circ \alpha}=-33754.768+14.80 \cdot T
$$

Also, when: $\quad G_{R u}^{\circ \alpha}=(-33754.768+14.80 \cdot T)=0$

Then:

$$
T=\frac{33754.768}{14.80}=2280 \mathrm{~K}=2007^{\circ} \mathrm{C} \text {. }
$$

- This value of $\mathrm{T}=2007^{\circ} \mathrm{C}$ (theoretical melting point of fcc-Ru) appears to be reasonable at first glance if we extrapolate the $\boldsymbol{\alpha}+\mathbf{L}$ phase field across to the pure $\mathrm{Ru}$ end of the binary. The next step is to enter in the new $\alpha$ phase and its associated lattice stabilities into the FACTSage Solution model and generate a new Ni-Ru binary phase diagram, as shown in Figure 193.

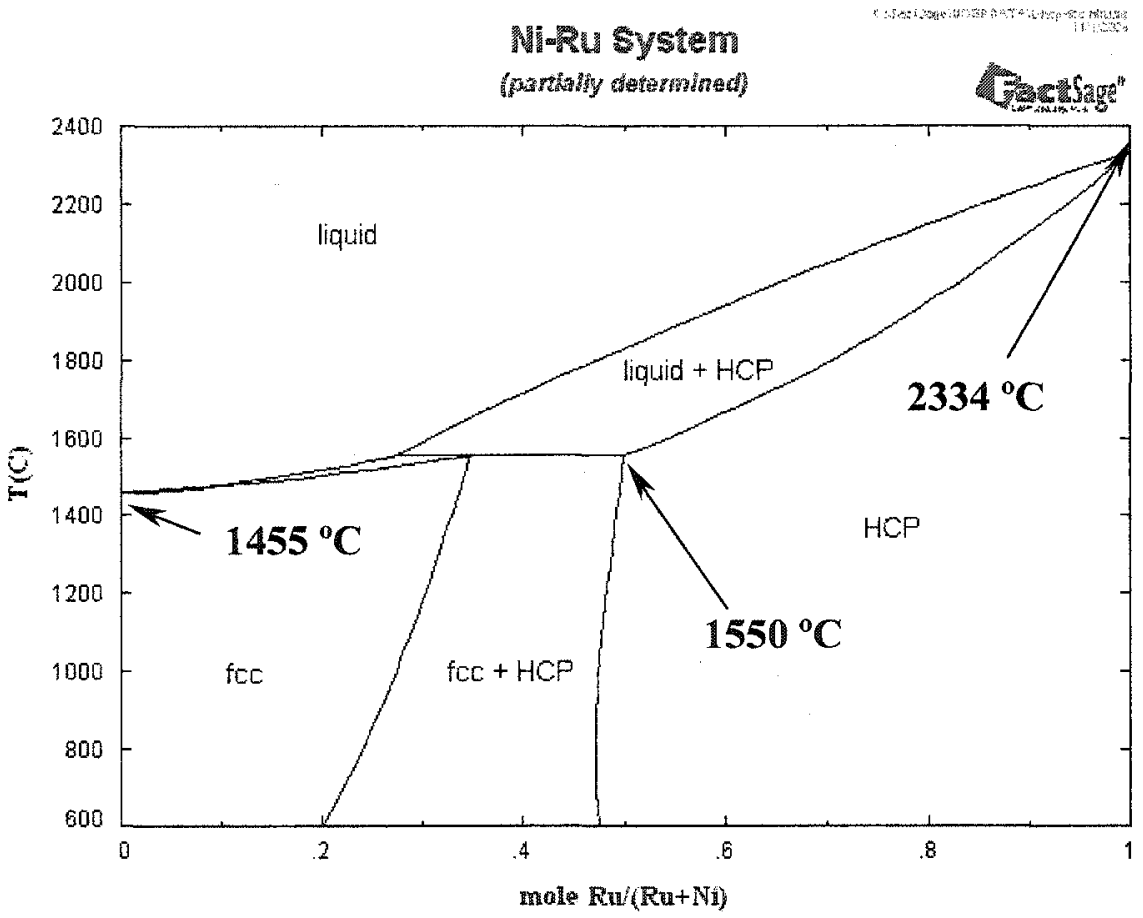

Figure 193: Preliminary Ni-Ru phase diagram depicting the $\mathrm{L}+\beta$ (HCP) $+\alpha$ (FCC) phase fields. The Ni solid solution phase, $\alpha-F C C$, has now been added effectively cutting the $L+\beta$ phase region along the peritectic line at $1550^{\circ} \mathrm{C}$. 
Comparing Figure 193 with the Nash binary in Figure 191 shows that the thermodynamic prediction is not perfect, but a pretty good first attempt. All the critical temperatures (peritectic and $T_{M}$ of the pure metals) appear to match the experimental phase diagram. The most notable difference between the two diagrams is the undersized prediction of the $\alpha+\beta$ phase region. The predicted $\beta$-solvus is largely overestimated providing for an unrealistically large $\beta$-phase region. It is apparent that changes need to be made to the thermodynamic model parameters to increase the width of the miscibility gap and to correct for the reverse curvature of the $\alpha+\beta$ solvi lines.

The final solution to this problem was to go back to the first step and begin again. However, instead of modeling the L-phase as a regular solution, it was decided to assume that the liquid behaves ideally. That is, the liquid phase field does not deviate from ideal solution behavior and therefore does not require excess energy terms to model its deviation from ideality. Using this valid assumption for the liquid phase and performing the same calculation procedure above with regular solution models for Ni-FCC, Ni-HCP, Ru-HCP and Ru-FCC the thermodynamic parameters shown in Table 24 were determined. This new thermodynamic dataset was then entered into the Solution model in FACT-Sage and a binary phase diagram was generated, as shown in Figure 194. It is apparent that the new thermodynamic model parameters accurately simulate the published phase diagram assessment shown in Figure 191. It should be noted that the previous example is a shortened version of the full set of assessment calculations for the Ni$\mathrm{Ru}$ system. Several iterations were produced before arriving at the final set of thermodynamic parameters. It therefore becomes evident at the length of time and the extent of work required to generate all the necessary data required for a multi-component system that can contain as many as 10 elements with countless binary and ternary systems of interest. Even for the simplified 
Liquid- $\gamma$ model used in the present study, it was necessary to assess the following binaries in the same manner shown above: Ni-Co, Ni-Cr, Co-Cr, Al-Ni, Ni-Ta, Ni-Ti, Ni-Ru, Ni-Mo, Ni-Re, Ni-W, Al-Co, Al-Cr, Co-Ta, Co-Re, and Co-W.

*For FACT data entry:

Reference phase: S1-solid of pure components (FACT-data entry)

\begin{tabular}{|c|c|c|c|c|c|}
\hline Phase & Parameter & A & B & $\mathrm{X}_{\mathrm{Ni}}{ }^{\prime}$ & $X_{R u}{ }^{j}$ \\
\hline \multirow[t]{3}{*}{ Liquid } & $\mathrm{G}_{(\mathrm{N} i \mathrm{~L})}^{0}$ & 17642.2 & -10.209 & & \\
\hline & $\mathrm{G}_{(\mathrm{Ru}, \mathrm{L})}^{0}$ & 38589 & -14.8 & & \\
\hline & $\Delta G^{E}$ & ideal & soln & & \\
\hline $\mathrm{fcc}$ & $\mathrm{G}_{(\mathrm{Ni}, \mathrm{fCC})}^{0}$ & 0 & 0 & & \\
\hline \multirow[t]{2}{*}{$(\mathrm{Ni})$} & $\mathrm{G}_{(\mathrm{Ru}, \mathrm{fcc})}^{0}$ & 17570 & -5.86 & & \\
\hline & $\Delta \mathrm{G}^{\mathrm{E}}$ & 16000 & -6.736 & 1 & 1 \\
\hline hcp & $G_{(N i, h c p)}^{0}$ & 1202.2 & 1.255 & & \\
\hline \multirow[t]{2}{*}{$(\mathrm{Ru})$} & $G_{(\mathrm{Ru}, \mathrm{h} p \mathrm{p})}^{0}$ & 0 & 0 & & \\
\hline & $\Delta \mathrm{G}^{\mathrm{E}}$ & 40000 & -17.5 & 1 & 1 \\
\hline
\end{tabular}

Table 24: Finalized thermodynamic parameters for the Ni-Ru system using the ideal solution model for the L-phase and regular solution models for $\mathrm{Ni}$ and $\mathrm{Ru}$ solid phases.

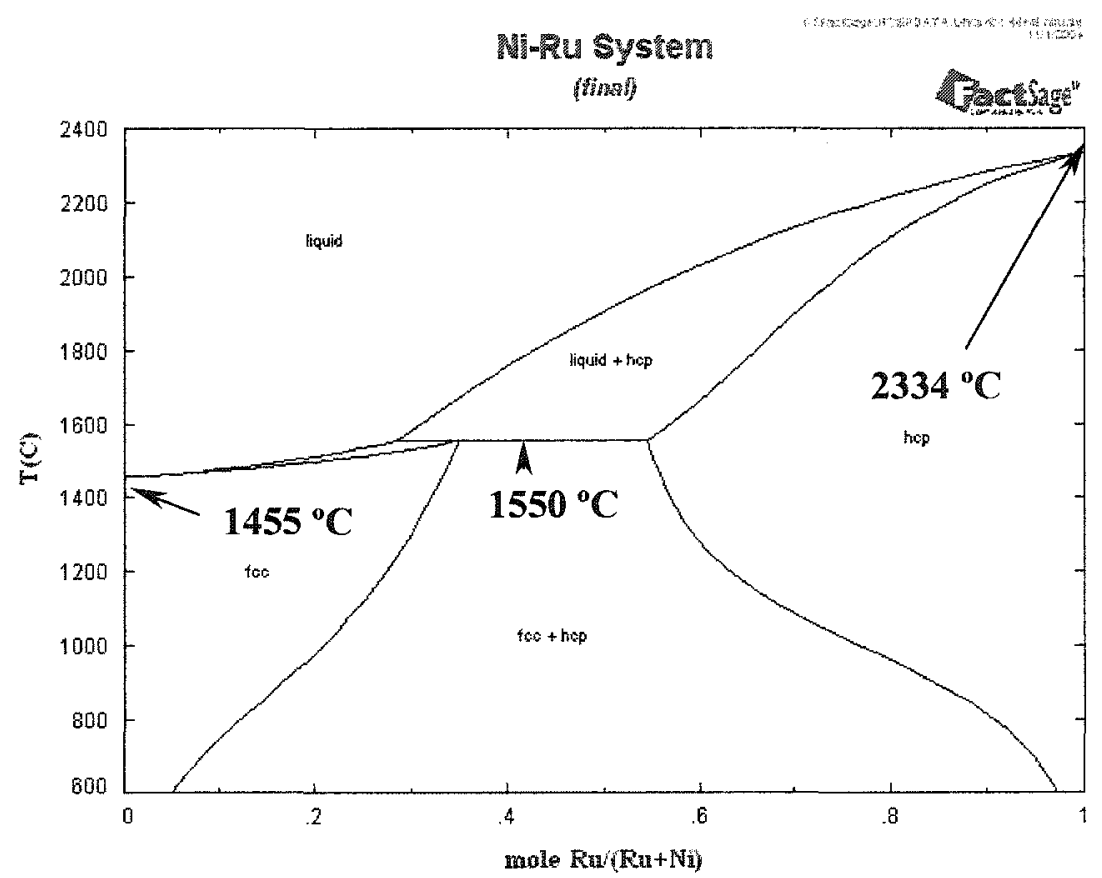

Figure 194: Final iteration of the modeled Ni-Ru phase diagram. 


\section{Appendix B: 1-Sigma Error Analysis of Microprobe Results}

Upon examining the microprobe measurements in Table 12 and Table 13, it is apparent that extremely accurate quantitative results were obtained due to the high degree of sampling and also because of the care taken in determining the limits of background X-ray noise for elements present in trace amounts (e.g. W and Re). However, as with all quantitative analysis procedures that correlate X-ray intensity data to atomic mass percentage values, there is some degree of error due to population statistics. One procedure for determining the extent of error is the 1 sigma method.

For the present work, a corresponding 1-sigma error value was determined for each analysis point using the Cameca PAP matrix correction software. These 1-sigma values are proportional to the weight percentage (i.e. X-ray intensity) of the elements being analyzed for each point analysis. Hence, elements that are present in trace amounts (e.g. W and Re) would have a larger window of error than statistically more viable elements such as Ni. Below in Table 25 and Table 26 are the 1-sigma error values for each EPMA analysis point measured for Alloys A-C and Alloys D-F respectively. To further simplify these results, an average of the 1-sigma values was made for each sample area. In other words, the averaged 1-sigma values reported in Table 27 correspond to the average value of the ten measurements obtained. These averaged error values were then used to determine the actual range of chemical segregation coefficients for each element in each of the experimental alloys. Recorded in Table 28 are the minimum, maximum and average partitioning coefficients as determined using the appropriate error ranges. 


\begin{tabular}{|c|c|c|c|c|c|c|c|c|c|}
\hline Description & Al 1-sigma & Cr 1-sigma & Ni 1-sigma & Co 1-sigma & Ti 1-sigma & Re 1-sigma & Ta 1-sigma & Mo 1-sigma & W 1-sigma \\
\hline ACORE & 0.032 & 0.054 & 0.451 & 0.047 & 0.011 & 0.059 & 0.116 & 0.057 & 0.076 \\
\hline A-CORE & 0.034 & 0.052 & 0.458 & 0.046 & 0.011 & 0.059 & 0.113 & 0.056 & 0.079 \\
\hline ACORE & 0.033 & 0.052 & 0.456 & 0.042 & 0.010 & 0.060 & 0.107 & 0.054 & 0.079 \\
\hline A.GORE & 0.032 & 0.054 & 0.454 & 0.043 & 0.010 & 0.061 & 0.103 & 0.056 & 0.080 \\
\hline ACORE & 0.033 & 0.051 & 0.460 & 0.042 & 0.010 & 0.060 & 0.106 & 0.055 & 0.079 \\
\hline A.NTER & 0.043 & 0.027 & 0.468 & 0.034 & 0.015 & 0.053 & 0.144 & 0.042 & 0.072 \\
\hline AINTER & 0.040 & 0.032 & 0.459 & 0.037 & 0.013 & 0.054 & 0.135 & 0.047 & 0.071 \\
\hline A.WTER & 0.038 & 0.038 & 0.458 & 0.040 & 0.014 & 0.055 & 0.127 & 0.050 & 0.071 \\
\hline AINTER & 0.038 & 0.040 & 0.454 & 0.040 & 0.013 & 0.055 & 0.137 & 0.052 & 0.072 \\
\hline ANTER & 0.038 & 0.040 & 0.449 & 0.040 & 0.013 & 0.054 & 0.125 & 0.053 & 0.070 \\
\hline A-CORE2 & 0.034 & 0.053 & 0.449 & 0.041 & 0.011 & 0.058 & 0.117 & 0.056 & 0.075 \\
\hline ACORE2 & 0.032 & 0.055 & 0.449 & 0.042 & 0.008 & 0.024 & 0.090 & 0.042 & 0.044 \\
\hline A-CORE? & 0.033 & 0.055 & 0.454 & 0.043 & 0.007 & 0.023 & 0.088 & 0.041 & 0.047 \\
\hline ACORE2 & 0.033 & 0.053 & 0.455 & 0.041 & 0.008 & 0.024 & 0.090 & 0.041 & 0.045 \\
\hline A.CORE2 & 0.032 & 0.055 & 0.452 & 0.042 & 0.008 & 0.022 & 0.086 & 0.043 & 0.046 \\
\hline AWINTER2 & 0.036 & 0.044 & 0.451 & 0.042 & 0.013 & 0.055 & 0.133 & 0.053 & 0.071 \\
\hline AINTER? & 0.036 & 0.044 & 0.454 & 0.038 & 0.010 & 0.015 & 0.117 & 0.040 & 0.029 \\
\hline AINTER2 & 0.037 & 0.042 & 0.450 & 0.037 & 0.011 & 0.015 & 0.109 & 0.039 & 0.025 \\
\hline A.NTER2 & 0.038 & 0.039 & 0.448 & 0.035 & 0.012 & 0.014 & 0.113 & 0.037 & 0.024 \\
\hline A-NTER2 & 0.040 & 0.035 & 0.457 & 0.034 & 0.012 & 0.011 & 0.117 & 0.033 & 0.023 \\
\hline B-CORE & 0.033 & 0.054 & 0.451 & 0.042 & 0.010 & 0.071 & 0.109 & 0.055 & 0.074 \\
\hline B-CORE & 0.032 & 0.055 & 0.448 & 0.043 & 0.008 & 0.043 & 0.094 & 0.045 & 0.036 \\
\hline B-CORE & 0.034 & 0.053 & 0.453 & 0.043 & 0.008 & 0.041 & 0.097 & 0.043 & 0.033 \\
\hline B-CORE & 0.033 & 0.055 & 0.449 & 0.043 & 0.008 & 0.042 & 0.096 & 0.045 & 0.033 \\
\hline B-CORE & 0.033 & 0.053 & 0.447 & 0.042 & 0.008 & 0.039 & 0.093 & 0.045 & 0.035 \\
\hline B-INTER & 0.041 & 0.031 & 0.450 & 0.038 & 0.013 & 0.016 & 0.130 & 0.033 & 0.012 \\
\hline B-INTER & 0.040 & 0.036 & 0.448 & 0.039 & 0.014 & 0.058 & 0.141 & 0.048 & 0.076 \\
\hline B-INTER & 0.040 & 0.036 & 0.448 & 0.035 & 0.013 & 0.020 & 0.124 & 0.036 & 0.010 \\
\hline B-INTER & 0.042 & 0.033 & 0.454 & 0.037 & 0.013 & 0.017 & 0.128 & 0.033 & 0.008 \\
\hline B-INTER & 0.040 & 0.032 & 0.448 & 0.037 & 0.013 & 0.016 & 0.130 & 0.034 & 0.009 \\
\hline B-INTER2 & 0.043 & 0.019 & 0.456 & 0.034 & 0.015 & 0.008 & 0.149 & 0.020 & 0.002 \\
\hline B-INTER2 & 0.044 & 0.019 & 0.455 & 0.034 & 0.014 & 0.009 & 0.146 & 0.020 & 0.003 \\
\hline B-INTER2 & 0.044 & 0.021 & 0.459 & 0.034 & 0.013 & 0.012 & 0.143 & 0.022 & 0.004 \\
\hline B-INTER2 & 0.043 & 0.023 & 0.456 & 0.035 & 0.014 & 0.012 & 0.138 & 0.025 & 0.006 \\
\hline B-INTER2 & 0.042 & 0.028 & 0.451 & 0.037 & 0.013 & 0.015 & 0.135 & 0.029 & 0.009 \\
\hline B-CORE2 & 0.034 & 0.055 & 0.446 & 0.043 & 0.011 & 0.071 & 0.107 & 0.056 & 0.072 \\
\hline B-CORE2 & 0.034 & 0.053 & 0.450 & 0.042 & 0.008 & 0.042 & 0.088 & 0.043 & 0.034 \\
\hline B-CORE2 & 0.032 & 0.055 & 0.447 & 0.044 & 0.008 & 0.042 & 0.094 & 0.043 & 0.037 \\
\hline B-CORE2 & 0.032 & 0.055 & 0.447 & 0.044 & 0.007 & 0.044 & 0.086 & 0.043 & 0.035 \\
\hline B-CORE2 & 0.033 & 0.054 & 0.447 & 0.043 & 0.008 & 0.041 & 0.090 & 0.043 & 0.035 \\
\hline C.OORE & 0.031 & 0.056 & 0.435 & 0.042 & 0.011 & 0.078 & 0.113 & 0.056 & 0.067 \\
\hline C-OORE & 0.033 & 0.053 & 0.443 & 0.042 & 0.011 & 0.077 & 0.109 & 0.055 & 0.068 \\
\hline C.CORE & 0.032 & 0.055 & 0.445 & 0.043 & 0.008 & 0.056 & 0.090 & 0.042 & 0.019 \\
\hline COORE & 0.031 & 0.056 & 0.447 & 0.043 & 0.008 & 0.057 & 0.086 & 0.045 & 0.020 \\
\hline C-GORE & 0.032 & 0.055 & 0.439 & 0.043 & 0.008 & 0.057 & 0.088 & 0.044 & 0.020 \\
\hline COORE & 0.033 & 0.056 & 0.441 & 0.043 & 0.008 & 0.057 & 0.090 & 0.041 & 0.018 \\
\hline C.CORE2 & 0.033 & 0.055 & 0.445 & 0.043 & 0.008 & 0.050 & 0.098 & 0.045 & 0.015 \\
\hline C.CORE2 & 0.033 & 0.056 & 0.445 & 0.042 & 0.008 & 0.053 & 0.094 & 0.045 & 0.018 \\
\hline C.CORE2 & 0.032 & 0.057 & 0.446 & 0.043 & 0.008 & 0.056 & 0.093 & 0.043 & 0.020 \\
\hline C-CORE2 & 0.031 & 0.056 & 0.445 & 0.044 & 0.008 & 0.058 & 0.088 & 0.043 & 0.019 \\
\hline C.GORE2 & 0.032 & 0.055 & 0.447 & 0.043 & 0.008 & 0.056 & 0.089 & 0.043 & 0.019 \\
\hline C-NTER & 0.040 & 0.033 & 0.448 & 0.038 & 0.014 & 0.062 & 0.141 & 0.047 & 0.000 \\
\hline C.NTER & 0.040 & 0.034 & 0.447 & 0.038 & 0.014 & 0.060 & 0.141 & 0.048 & 0.120 \\
\hline C.NTER T750 & 0.041 & 0.034 & 0.451 & 0.042 & 0.014 & 0.058 & 0.157 & 0.045 & 0.058 \\
\hline C-NTER & 0.041 & 0.030 & 0.454 & 0.037 & 0.014 & 0.059 & 0.145 & 0.046 & 0.000 \\
\hline C.NTER & 0.041 & 0.031 & 0.450 & 0.033 & 0.012 & 0.023 & 0.128 & 0.030 & 0.001 \\
\hline CWNTER & 0.040 & 0.032 & 0.444 & 0.034 & 0.012 & 0.025 & 0.127 & 0.031 & 0.003 \\
\hline G-INTER2 & 0.043 & 0.019 & 0.456 & 0.034 & 0.013 & 0.012 & 0.143 & 0.021 & 0.000 \\
\hline C.NTER2 & 0.043 & 0.020 & 0.455 & 0.034 & 0.013 & 0.014 & 0.141 & 0.021 & 0.000 \\
\hline CINTER2 & 0.043 & 0.021 & 0.453 & 0.034 & 0.013 & 0.015 & 0.139 & 0.023 & 0.000 \\
\hline C-INTER2 & 0.043 & 0.021 & 0.459 & 0.034 & 0.013 & 0.014 & 0.140 & 0.022 & 0.000 \\
\hline C-INTER2 & 0.043 & 0.019 & 0.460 & 0.033 & 0.013 & 0.013 & 0.144 & 0.019 & 0.000 \\
\hline
\end{tabular}

Table 25: 1-Sigma error values for the point-scans performed on Alloy A-C. 


\begin{tabular}{|c|c|c|c|c|c|c|c|c|c|c|}
\hline Descrip. & Al 1-sigma & Cr 1-sigma & Ni 1-sigma & Co 1-sigma & Ti1-sigma & Re 1-sigma & Ta 1-sigma & Mo 1-sigma & W 1-sigma & Ru 1-sigma \\
\hline D CORE & 0.032 & 0.055 & 0.450 & 0.044 & 0.010 & 0.102 & 0.102 & 0.056 & 0.000 & 0.000 \\
\hline DCOREIB & 0.032 & 0.054 & 0.445 & 0.044 & 0.010 & 0.104 & 0.104 & 0.056 & 0.000 & 0.000 \\
\hline D-CORETB & 0.032 & 0.053 & 0.445 & 0.043 & 0.010 & 0.104 & 0.104 & 0.056 & 0.000 & 0.000 \\
\hline DOOOREIB & 0.032 & 0.055 & 0.445 & 0.044 & 0.010 & 0.105 & 0.103 & 0.058 & 0.000 & 0.000 \\
\hline D.OOREIB & 0.033 & 0.053 & 0.445 & 0.043 & 0.010 & 0.105 & 0.104 & 0.055 & 0.000 & 0.000 \\
\hline DCORE2 & 0.031 & 0.053 & 0.451 & 0.044 & 0.010 & 0.106 & 0.102 & 0.055 & 0.026 & 0.025 \\
\hline D.GORE2 & 0.034 & 0.054 & 0.446 & 0.043 & 0.010 & 0.104 & 0.110 & 0.055 & 0.000 & 0.000 \\
\hline D.CORE? & 0.033 & 0.052 & 0.451 & 0.043 & 0.010 & 0.104 & 0.109 & 0.055 & 0.000 & 0.000 \\
\hline D-CORE2 & 0.034 & 0.053 & 0.447 & 0.042 & 0.010 & 0.100 & 0.111 & 0.054 & 0.000 & 0.000 \\
\hline D-CORE2 & 0.031 & 0.056 & 0.449 & 0.044 & 0.010 & 0.104 & 0.106 & 0.056 & 0.000 & 0.000 \\
\hline DUNTER2 & 0.043 & 0.022 & 0.462 & 0.034 & 0.015 & 0.065 & 0.145 & 0.038 & 0.000 & 0.000 \\
\hline D-1NTER2 & 0.043 & 0.021 & 0.456 & 0.033 & 0.015 & 0.064 & 0.164 & 0.038 & 0.000 & 0.000 \\
\hline D-WTER2 & 0.043 & 0.022 & 0.468 & 0.037 & 0.015 & 0.064 & 0.163 & 0.039 & 0.000 & 0.000 \\
\hline DUTER? & 0.042 & 0.023 & 0.465 & 0.035 & 0.015 & 0.064 & 0.163 & 0.040 & 0.000 & 0.000 \\
\hline DNNTER2 & 0.043 & 0.023 & 0.462 & 0.034 & 0.015 & 0.064 & 0.162 & 0.039 & 0.000 & 0.027 \\
\hline DINTERT & 0.043 & 0.021 & 0.463 & 0.034 & 0.015 & 0.064 & 0.146 & 0.039 & 0.000 & 0.025 \\
\hline DINTER 1 & 0.038 & 0.040 & 0.452 & 0.041 & 0.013 & 0.080 & 0.133 & 0.051 & 0.000 & 0.026 \\
\hline DUNTER 1 & 0.038 & 0.040 & 0.450 & 0.040 & 0.013 & 0.078 & 0.135 & 0.052 & 0.000 & 0.000 \\
\hline DINTERT & 0.039 & 0.036 & 0.450 & 0.039 & 0.014 & 0.077 & 0.141 & 0.049 & 0.000 & 0.000 \\
\hline DNTERT & 0.044 & 0.021 & 0.464 & 0.037 & 0.015 & 0.064 & 0.160 & 0.039 & 0.000 & 0.000 \\
\hline E-CORE1 & 0.033 & 0.049 & 0.431 & 0.043 & 0.010 & 0.089 & 0.108 & 0.053 & 0.097 & 0.000 \\
\hline E-CORE1 & 0.031 & 0.056 & 0.421 & 0.045 & 0.010 & 0.091 & 0.106 & 0.055 & 0.101 & 0.000 \\
\hline E-CORE1 & 0.032 & 0.052 & 0.430 & 0.044 & 0.010 & 0.092 & 0.101 & 0.054 & 0.098 & 0.000 \\
\hline E-CORE1 & 0.031 & 0.053 & 0.429 & 0.045 & 0.010 & 0.092 & 0.107 & 0.056 & 0.100 & 0.000 \\
\hline E-CORE1 & 0.032 & 0.055 & 0.426 & 0.045 & 0.010 & 0.090 & 0.102 & 0.056 & 0.094 & 0.000 \\
\hline$E=C O R E 2$ & 0.031 & 0.056 & 0.424 & 0.046 & 0.010 & 0.091 & 0.100 & 0.056 & 0.101 & 0.000 \\
\hline E-CORE2 & 0.030 & 0.057 & 0.421 & 0.046 & 0.010 & 0.089 & 0.100 & 0.057 & 0.097 & 0.000 \\
\hline E-CORE2 & 0.033 & 0.050 & 0.432 & 0.044 & 0.010 & 0.091 & 0.104 & 0.056 & 0.094 & 0.000 \\
\hline E-CORE2 & 0.032 & 0.051 & 0.431 & 0.044 & 0.010 & 0.091 & 0.102 & 0.055 & 0.096 & 0.000 \\
\hline E-CORE2 & 0.033 & 0.054 & 0.426 & 0.044 & 0.011 & 0.086 & 0.113 & 0.055 & 0.093 & 0.000 \\
\hline E-INTER1 & 0.044 & 0.025 & 0.458 & 0.037 & 0.014 & 0.065 & 0.150 & 0.041 & 0.070 & 0.000 \\
\hline E-INTER1 & 0.043 & 0.025 & 0.454 & 0.038 & 0.014 & 0.065 & 0.150 & 0.041 & 0.072 & 0.000 \\
\hline E-INTER1 & 0.044 & 0.022 & 0.461 & 0.036 & 0.015 & 0.065 & 0.153 & 0.039 & 0.069 & 0.000 \\
\hline E-INTERI & 0.043 & 0.022 & 0.455 & 0.036 & 0.015 & 0.064 & 0.157 & 0.041 & 0.069 & 0.026 \\
\hline E-INTER1 & 0.043 & 0.021 & 0.456 & 0.036 & 0.015 & 0.062 & 0.159 & 0.039 & 0.069 & 0.026 \\
\hline E-INTER2 & 0.044 & 0.020 & 0.458 & 0.035 & 0.015 & 0.063 & 0.160 & 0.037 & 0.067 & 0.027 \\
\hline E-INTER2 & 0.044 & 0.021 & 0.458 & 0.036 & 0.015 & 0.063 & 0.156 & 0.038 & 0.071 & 0.000 \\
\hline E-INTER2 & 0.045 & 0.022 & 0.455 & 0.035 & 0.015 & 0.063 & 0.156 & 0.039 & 0.071 & 0.000 \\
\hline E-INTER2 & 0.044 & 0.022 & 0.465 & 0.035 & 0.015 & 0.064 & 0.155 & 0.038 & 0.070 & 0.000 \\
\hline EAINTER2 & 0.044 & 0.024 & 0.458 & 0.036 & 0.015 & 0.065 & 0.156 & 0.041 & 0.068 & 0.000 \\
\hline FCORE & 0.031 & 0.056 & 0.419 & 0.043 & 0.010 & 0.094 & 0.104 & 0.057 & 0.068 & 0.070 \\
\hline F CORE & 0.030 & 0.056 & 0.422 & 0.043 & 0.010 & 0.095 & 0.103 & 0.057 & 0.067 & 0.071 \\
\hline FOORE 1 & 0.030 & 0.056 & 0.419 & 0.043 & 0.010 & 0.094 & 0.100 & 0.057 & 0.068 & 0.070 \\
\hline F.CORE & 0.030 & 0.055 & 0.417 & 0.043 & 0.010 & 0.095 & 0.103 & 0.056 & 0.069 & 0.071 \\
\hline $\mathrm{F}$ GORE 1 & 0.031 & 0.057 & 0.417 & 0.042 & 0.010 & 0.095 & 0.104 & 0.057 & 0.069 & 0.071 \\
\hline FCORE2 & 0.030 & 0.057 & 0.406 & 0.043 & 0.010 & 0.096 & 0.098 & 0.058 & 0.068 & 0.070 \\
\hline FCORE2 & 0.031 & 0.056 & 0.414 & 0.042 & 0.010 & 0.096 & 0.101 & 0.056 & 0.070 & 0.072 \\
\hline F-CORE2 & 0.030 & 0.056 & 0.415 & 0.042 & 0.010 & 0.091 & 0.103 & 0.057 & 0.069 & 0.070 \\
\hline FCORE2 & 0.032 & 0.056 & 0.421 & 0.043 & 0.011 & 0.095 & 0.102 & 0.058 & 0.069 & 0.072 \\
\hline F-CORE? & 0.032 & 0.059 & 0.413 & 0.043 & 0.010 & 0.095 & 0.104 & 0.058 & 0.068 & 0.071 \\
\hline F-NTER & 0.036 & 0.044 & 0.417 & 0.040 & 0.014 & 0.076 & 0.136 & 0.054 & 0.063 & 0.069 \\
\hline FINTER 1 & 0.036 & 0.042 & 0.424 & 0.040 & 0.014 & 0.074 & 0.126 & 0.053 & 0.063 & 0.070 \\
\hline F-INTER1 & 0.036 & 0.042 & 0.421 & 0.039 & 0.013 & 0.075 & 0.125 & 0.055 & 0.066 & 0.072 \\
\hline F-INTERI & 0.035 & 0.046 & 0.417 & 0.043 & 0.014 & 0.076 & 0.129 & 0.055 & 0.064 & 0.072 \\
\hline FINTERI & 0.036 & 0.043 & 0.422 & 0.040 & 0.014 & 0.076 & 0.123 & 0.055 & 0.065 & 0.072 \\
\hline FMINTER2 & 0.035 & 0.046 & 0.422 & 0.041 & 0.014 & 0.079 & 0.131 & 0.056 & 0.064 & 0.069 \\
\hline FINTER2 & 0.036 & 0.043 & 0.423 & 0.040 & 0.014 & 0.076 & 0.123 & 0.054 & 0.060 & 0.068 \\
\hline FINTER2 & 0.036 & 0.042 & 0.423 & 0.039 & 0.014 & 0.074 & 0.125 & 0.054 & 0.059 & 0.068 \\
\hline FINTER2 & 0.036 & 0.042 & 0.425 & 0.039 & 0.013 & 0.076 & 0.123 & 0.054 & 0.064 & 0.072 \\
\hline FINTER2 & 0.038 & 0.037 & 0.431 & 0.037 & 0.014 & 0.073 & 0.130 & 0.051 & 0.062 & 0.067 \\
\hline C-CORE-1850 & 0.033 & 0.053 & 0.454 & 0.041 & 0.010 & 0.094 & 0.104 & 0.054 & 0.068 & 0.000 \\
\hline C-CORE 900 & 0.033 & 0.053 & 0.449 & 0.041 & 0.011 & 0.091 & 0.111 & 0.053 & 0.078 & 0.000 \\
\hline C - NTER 900 & 0.040 & 0.033 & 0.454 & 0.036 & 0.014 & 0.071 & 0.141 & 0.047 & 0.000 & 0.026 \\
\hline CANTER-1850 & 0.040 & 0.035 & 0.458 & 0.035 & 0.014 & 0.068 & 0.141 & 0.048 & 0.064 & 0.025 \\
\hline
\end{tabular}

Table 26: 1-Sigma error values for the point-scans performed on Alloy A-C. 


\begin{tabular}{|c|c|c|c|c|c|c|c|c|c|c|}
\hline & average /\% & Igma values & & & & & & & & \\
\hline Description & Al 1-sigma & Cr 1-sigma & Ni 1-sigma & Co 1-sigma & Ti 1-sigma & Re 1-sigma & Ta 1-sigma & Mo 1-sigma & W 1-sigma & Ru 1-sigma \\
\hline AGORE & 0.033 & 0.053 & 0.454 & 0.043 & 0.009 & 0.045 & 0.102 & 0.050 & 0.065 & 0.000 \\
\hline A-INTER & 0.038 & 0.038 & 0.455 & 0.038 & 0.013 & 0.038 & 0.126 & 0.045 & 0.053 & 0.000 \\
\hline B-CORE & 0.033 & 0.054 & 0.449 & 0.043 & 0.008 & 0.048 & 0.095 & 0.046 & 0.042 & 0.000 \\
\hline BUNTER & 0.042 & 0.028 & 0.453 & 0.036 & 0.013 & 0.018 & 0.136 & 0.030 & 0.014 & 0.000 \\
\hline C.CORE & 0.032 & 0.055 & 0.443 & 0.043 & 0.008 & 0.060 & 0.094 & 0.046 & 0.028 & 0.000 \\
\hline C.NTER & 0.041 & 0.027 & 0.452 & 0.036 & 0.013 & 0.032 & 0.141 & 0.032 & 0.017 & 0.000 \\
\hline D.CORE & 0.032 & 0.054 & $0 . \overline{448}$ & 0.043 & 0.010 & 0.104 & 0.105 & 0.056 & 0.003 & 0.000 \\
\hline E-CORE & 0.032 & 0.053 & 0.427 & 0.045 & 0.010 & 0.090 & 0.104 & 0.055 & 0.097 & 0.000 \\
\hline EINTER & 0.044 & 0.023 & 0.458 & 0.036 & 0.015 & 0.064 & 0.155 & 0.039 & 0.070 & 0.000 \\
\hline FCORE & 0.031 & 0.056 & 0.416 & 0.043 & 0.010 & 0.095 & 0.102 & 0.057 & 0.069 & 0.071 \\
\hline FINTER & 0.036 & 0.043 & 0.423 & 0.040 & 0.014 & 0.076 & 0.127 & 0.054 & 0.063 & 0.070 \\
\hline
\end{tabular}

Table 27: Averaged 1-Sigma error values for Alloys A-F.

\begin{tabular}{|c|c|c|c|c|c|c|c|c|c|c|}
\hline Description & AI & Cr & N. & Co & TI & Re & $\mathrm{Ta}$ & $\mathrm{Mo}$ & W & Ru \\
\hline A-CORE (avg) & 4.68 & 7.62 & 64.83 & 5.24 & 0.75 & 1.24 & 9.95 & 1.66 & 3.47 & 0.00 \\
\hline average 1 -sigma & 0.03 & 0.05 & 0.45 & 0.04 & 0.01 & 0.05 & 0.10 & 0.05 & 0.07 & 0.00 \\
\hline A. NTER (avg) & 5.49 & 5.41 & 64.99 & 4.40 & 1.27 & 0.63 & 14.14 & 1.27 & 1.52 & 0.00 \\
\hline average / sigma & 0.04 & 0.04 & 0.45 & 0.04 & 0.01 & 0.04 & 0.13 & 0.04 & 0.05 & 0.00 \\
\hline$k^{\prime} a v g$ & 0.85 & 1.41 & 1.00 & 1.19 & 0.59 & 1.99 & 0.70 & 1.30 & 2.29 & 0.00 \\
\hline$k^{\prime} \min$ & 0.84 & 1.38 & 0.98 & 1.17 & 0.58 & 1.80 & 0.69 & 1.22 & 2.17 & 0.00 \\
\hline$k^{\prime} \max$ & 0.86 & 1.43 & 1.01 & 1.21 & 0.60 & 2.19 & 0.72 & 1.39 & 2.41 & 0.00 \\
\hline B.CORE (OVO) & 4.73 & 7.72 & 64.09 & 5.38 & 0.72 & 2.79 & 9.73 & 1.71 & 2.38 & 0.00 \\
\hline B-INTER (avg) & 5.98 & 3.96 & 64.64 & 4.05 & 1.54 & 0.73 & 16.85 & 0.86 & 0.41 & 0.00 \\
\hline average I-sigma & 0.04 & 0.03 & 0.45 & 0.04 & 0.01 & 0.02 & 0.14 & 0.03 & 0.01 & 0.00 \\
\hline$k^{\prime} a v g$ & 0.79 & 1.95 & 0.99 & 1.33 & 0.47 & 3.83 & 0.58 & 1.98 & 5.75 & 0.00 \\
\hline$k^{\prime} \min$ & 0.78 & 1.92 & 0.98 & 1.31 & 0.46 & 3.67 & 0.57 & 1.86 & 5.46 & 0.00 \\
\hline$k^{\prime} \max$ & 0.80 & 1.98 & 1.01 & 1.35 & 0.48 & 3.99 & 0.59 & 2.11 & 6.06 & 0.00 \\
\hline C-CORE (avg) & 4.59 & 7.90 & 63.34 & 5.33 & 0.75 & 4.20 & 10.07 & 1.75 & 1.46 & 0.00 \\
\hline average 1 sigme & 0.03 & 0.06 & 0.44 & 0.04 & 0.01 & 0.06 & 0.09 & 0.05 & 0.03 & 0.00 \\
\hline C.NTER (avg) & 5.94 & 3.75 & 64.64 & 3.98 & 1.50 & 1.05 & 16.77 & 0.81 & 0.37 & 0.00 \\
\hline$k^{\prime}$ avg & 0.77 & 2.11 & 0.98 & 1.34 & 0.50 & 4.00 & 0.60 & 2.17 & 3.96 & 0.00 \\
\hline$k^{\prime} \min$ & 0.76 & 2.08 & 0.97 & 1.32 & 0.49 & 3.83 & 0.59 & 2.04 & 3.72 & 0.00 \\
\hline$k^{\prime} \max$ & 0.78 & 2.14 & 0.99 & 1.36 & 0.51 & 4.19 & 0.61 & 2.32 & 4.22 & 0.00 \\
\hline D-CORE (avg) & 4.62 & 7.67 & 63.93 & 5.41 & 0.69 & 5.91 & 9.59 & 1.78 & 0.00 & 0.00 \\
\hline Gverage 1 -signa & 0.03 & 0.05 & 0.45 & 0.04 & 0.01 & 0.10 & 0.11 & 0.06 & 0.00 & 0.00 \\
\hline D-NTER (aVg) & 5.94 & 3.55 & 65.60 & 3.95 & 1.57 & 1.16 & 17.21 & 0.75 & 0.00 & 0.00 \\
\hline average 1 -sigma & 0.04 & 0.03 & 0.46 & 0.04 & 0.01 & 0.07 & 0.15 & 0.04 & 0.00 & 0.00 \\
\hline$k^{\prime} a v g$ & 0.78 & 2.16 & 0.97 & 1.37 & 0.44 & 5.07 & 0.56 & 2.39 & 0.00 & 0.00 \\
\hline$k^{\prime} \min$ & 0.77 & 2.13 & 0.96 & 1.35 & 0.43 & 4.71 & 0.55 & 2.19 & 0.00 & 0.00 \\
\hline$k^{\prime} \max$ & 0.79 & 2.19 & 0.99 & 1.39 & 0.45 & 5.48 & 0.57 & 2.61 & 0.00 & 0.00 \\
\hline E-CORE (avg) & 4.54 & 7.61 & 61.01 & 5.58 & 0.69 & 3.97 & 9.32 & 1.64 & 5.31 & 0.00 \\
\hline average 1 -sigma & 0.03 & 0.05 & 0.43 & 0.04 & 0.01 & 0.09 & 0.10 & 0.06 & 0.10 & 0.00 \\
\hline E-NTER (avo) & 6.28 & 2.82 & 65.39 & 4.02 & 1.49 & 0.66 & 17.25 & 0.51 & 1.50 & 0.00 \\
\hline average 1 -sigma & 0.04 & 0.02 & 0.46 & 0.04 & 0.01 & 0.06 & 0.16 & 0.04 & 0.07 & 0.00 \\
\hline$k^{\prime} a v g$ & 0.72 & 2.70 & 0.93 & 1.39 & 0.46 & 5.99 & 0.54 & 3.22 & 3.55 & 0.00 \\
\hline$k^{\prime} \min$ & 0.71 & 2.66 & 0.92 & 1.37 & 0.45 & 5.34 & 0.53 & 2.89 & 3.33 & 0.00 \\
\hline$k^{\prime} \max$ & 0.73 & 2.74 & 0.95 & 1.41 & 0.47 & 6.79 & 0.55 & 3.61 & 3.79 & 0.00 \\
\hline FINTER (avo) & 5.13 & 6.10 & 60.37 & 4.44 & 1.28 & 2.07 & 13.67 & 1.55 & 0.81 & 3.80 \\
\hline Guerage 1 - signe & 0.04 & 0.04 & 0.42 & 0.04 & 0.01 & 0.08 & 0.13 & 0.05 & 0.06 & 0.07 \\
\hline$k^{\prime} a v g$ & 0.86 & 1.32 & 0.99 & 1.20 & 0.55 & 2.22 & 0.62 & 1.19 & 1.87 & 1.03 \\
\hline$k^{\prime} \min$ & 0.84 & 1.30 & 0.97 & 1.18 & 0.53 & 2.09 & 0.61 & 1.11 & 1.66 & 0.99 \\
\hline$k^{\prime} \max$ & 0.87 & 1.34 & 1.00 & 1.22 & 0.56 & 2.35 & 0.64 & 1.27 & 2.12 & 1.07 \\
\hline
\end{tabular}

Table 28: Range of segregation coefficient values based on 1-Sigma error. 
It is apparent from Table 28 that the average segregation coefficients are sufficient for comparison purposes as there is a small range of error for elements such as $\mathrm{Al}, \mathrm{Cr}, \mathrm{Ni}, \mathrm{Co}$, $\mathrm{Ti}$, and Ta. In these cases, the difference between the minimum and maximum $k^{\prime}$ values is insignificant. However, there is a more appreciable amount of quantitative error present for the $\mathrm{Re}, \mathrm{W}$, and Mo concentration levels. The variance in these partitioning coefficients due to the 1-Sigma error is more clearly illustrated in Figure 195 to Figure 200. These figures show the relatively narrow error bars for most of the elements except for those few mentioned above. However, It should be mentioned that the degree of error calculated is still far superior to the EDS measurement technique.

The general consensus amongst researchers is to use the average partitioning coefficient for comparison purposes. In many cases, the equipment or statistical error values are not provided in literature, however, if EPMA or WDX methods have been utilized, then it can be assumed that reasonable estimates of composition levels have been obtained. It is important to document the error involved in making such measurements, however, the introduction of two additional partitioning terms (upper and lower bounds) often adds unnecessary confusion and detracts from the research findings. 


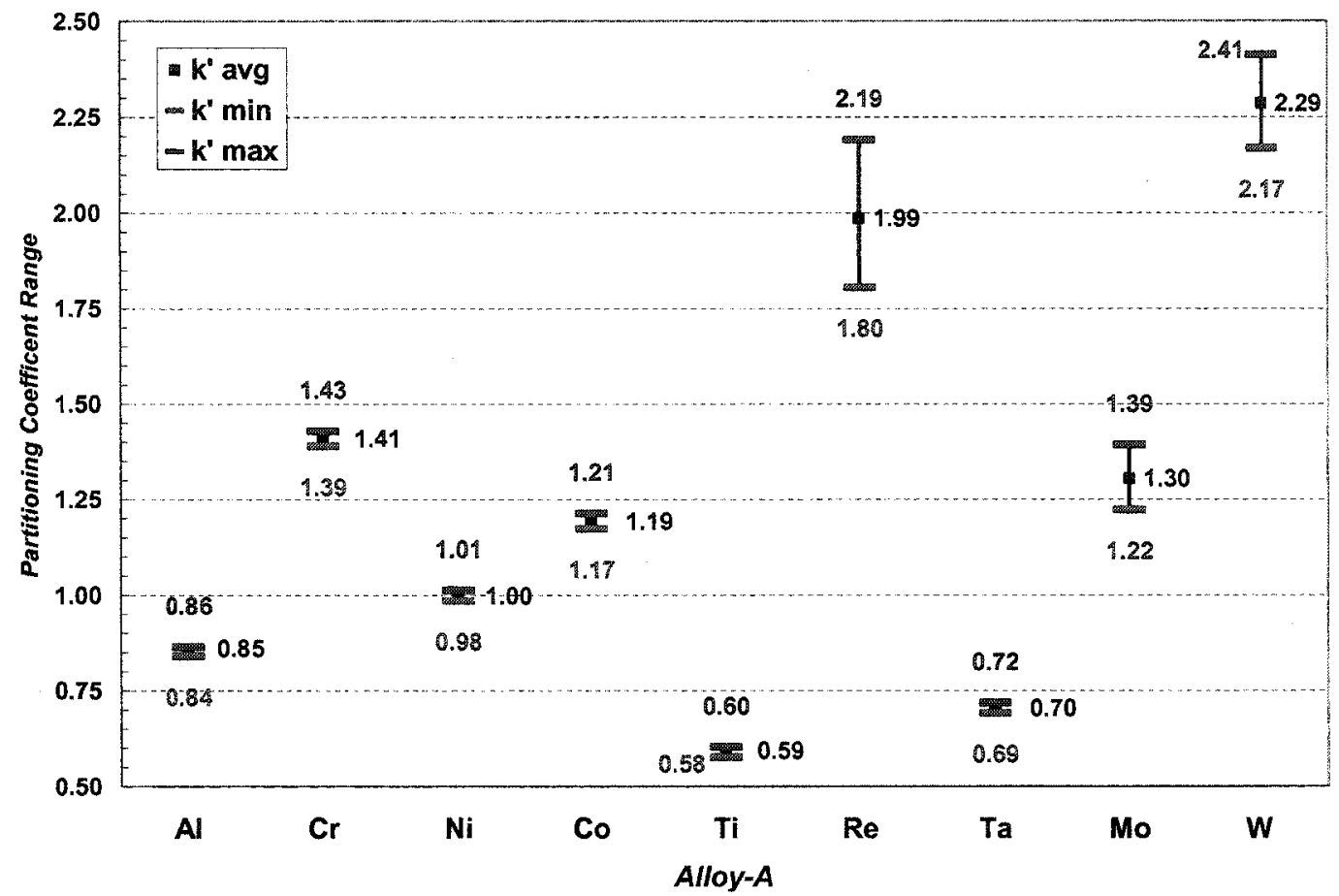

Figure 195: Partitioning coefficient range for Alloy-A.

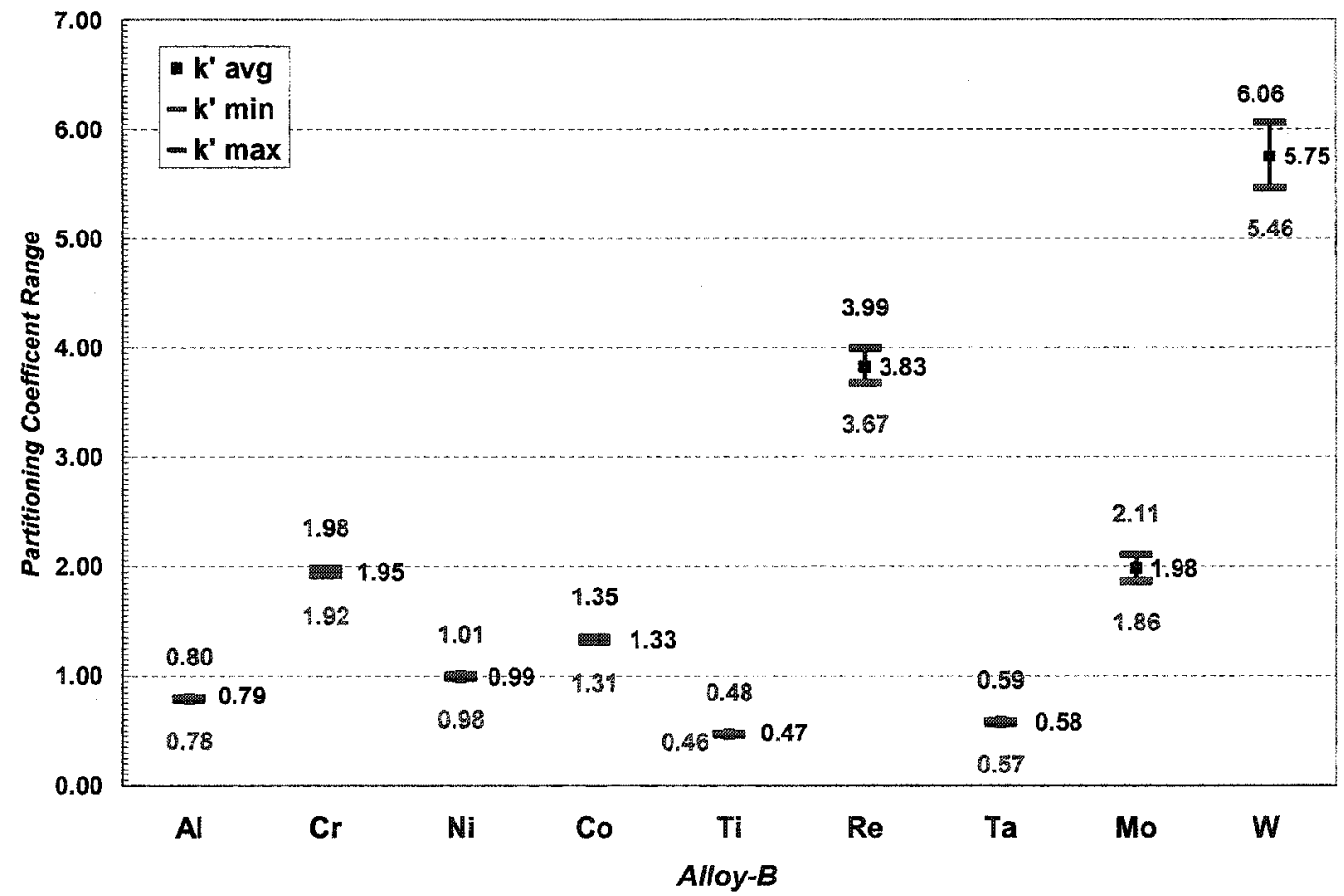

Figure 196: Partitioning coefficient range for Alloy-B. 


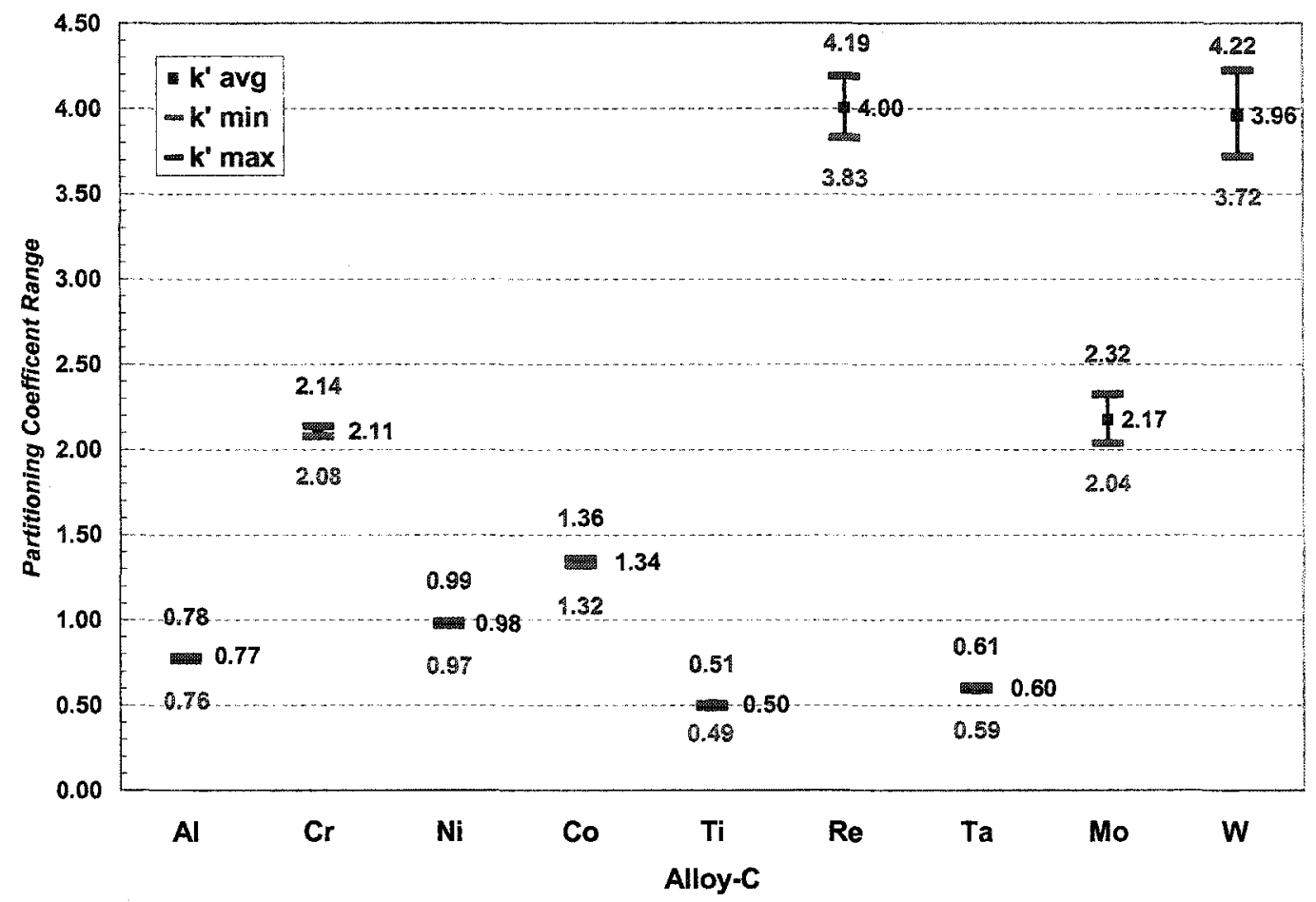

Figure 197: Partitioning coefficient range for Alloy-C.

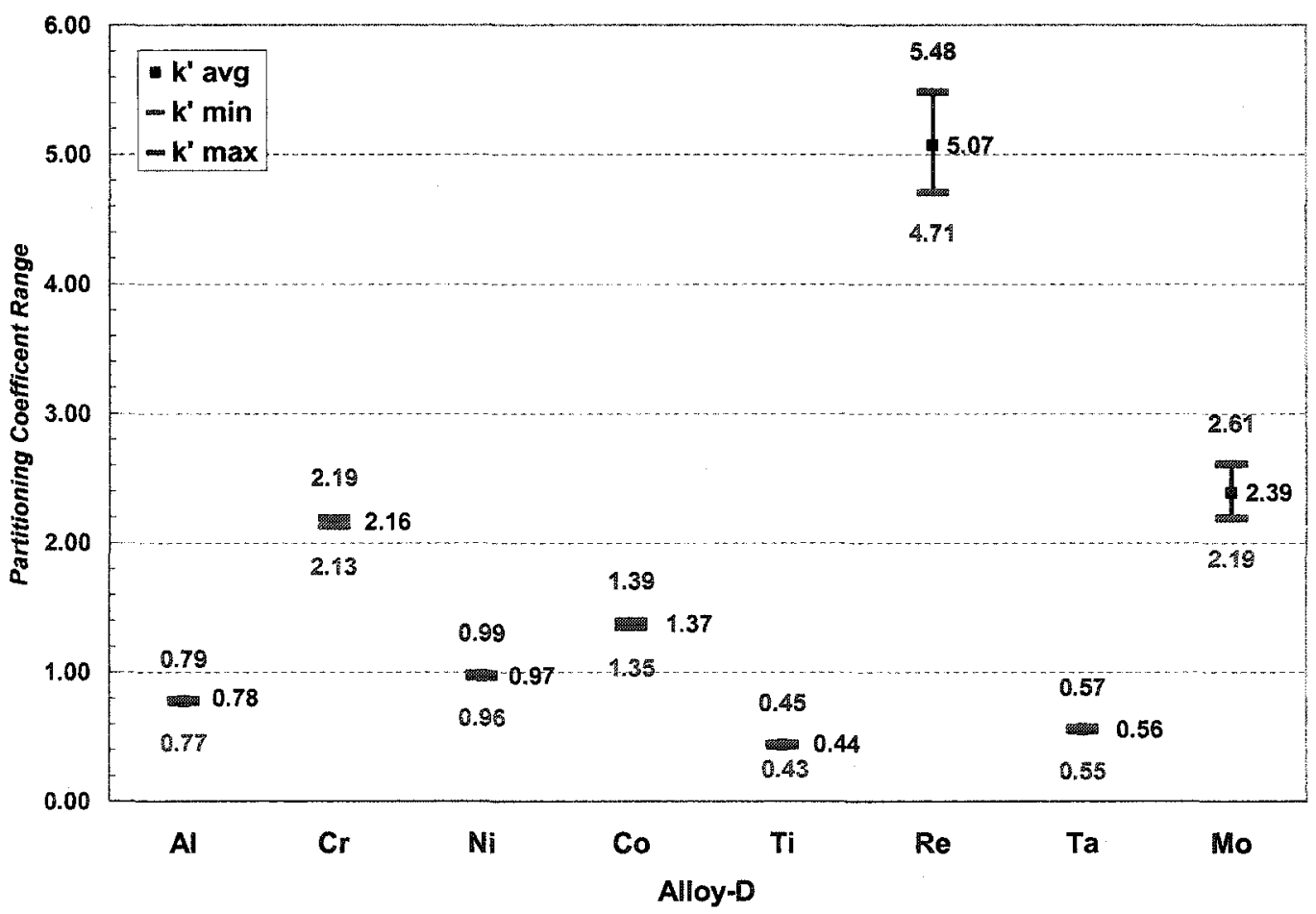

Figure 198: Partitioning coefficient range for Alloy-D. 


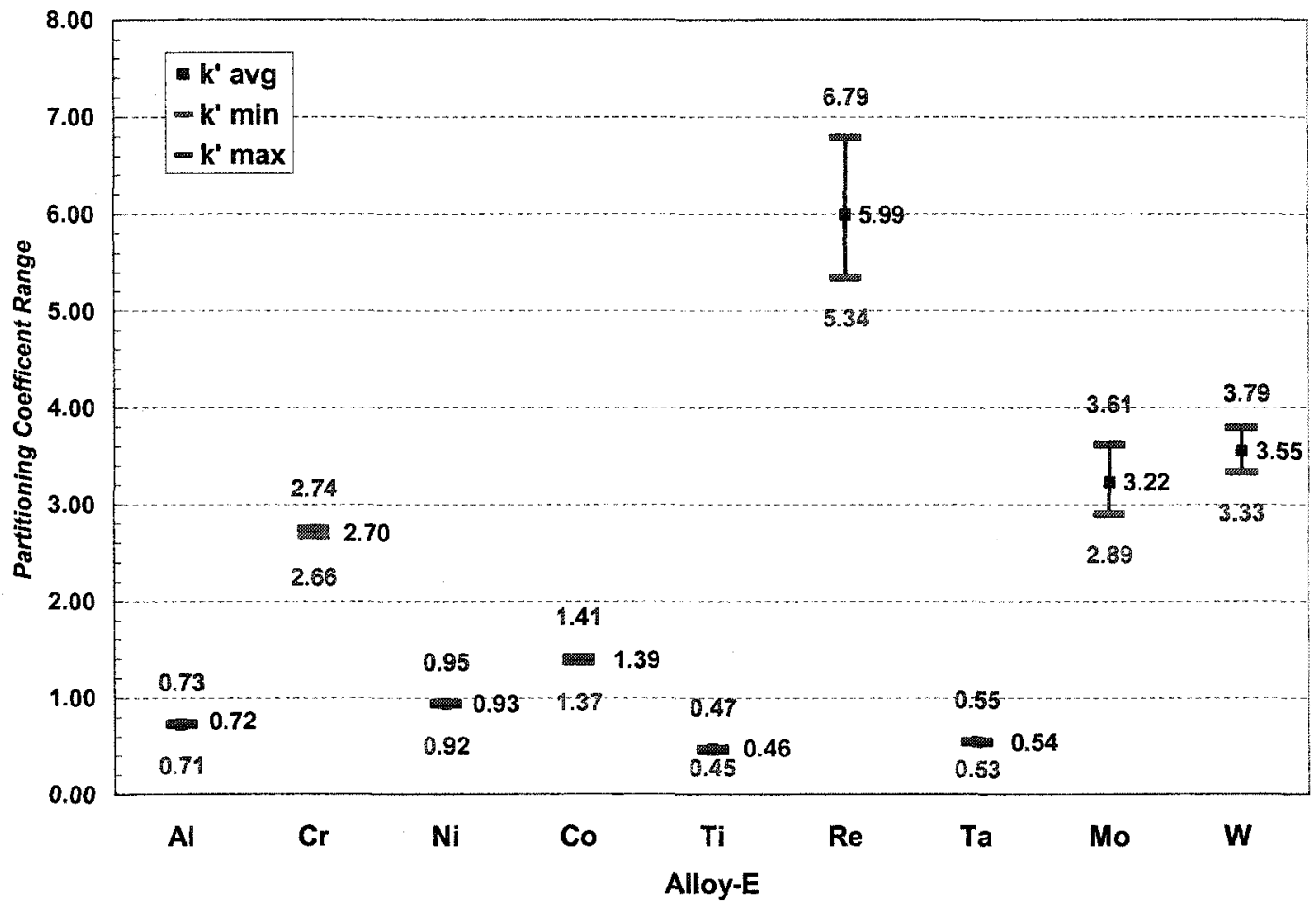

Figure 199: Partitioning coefficient range for Alloy-E.

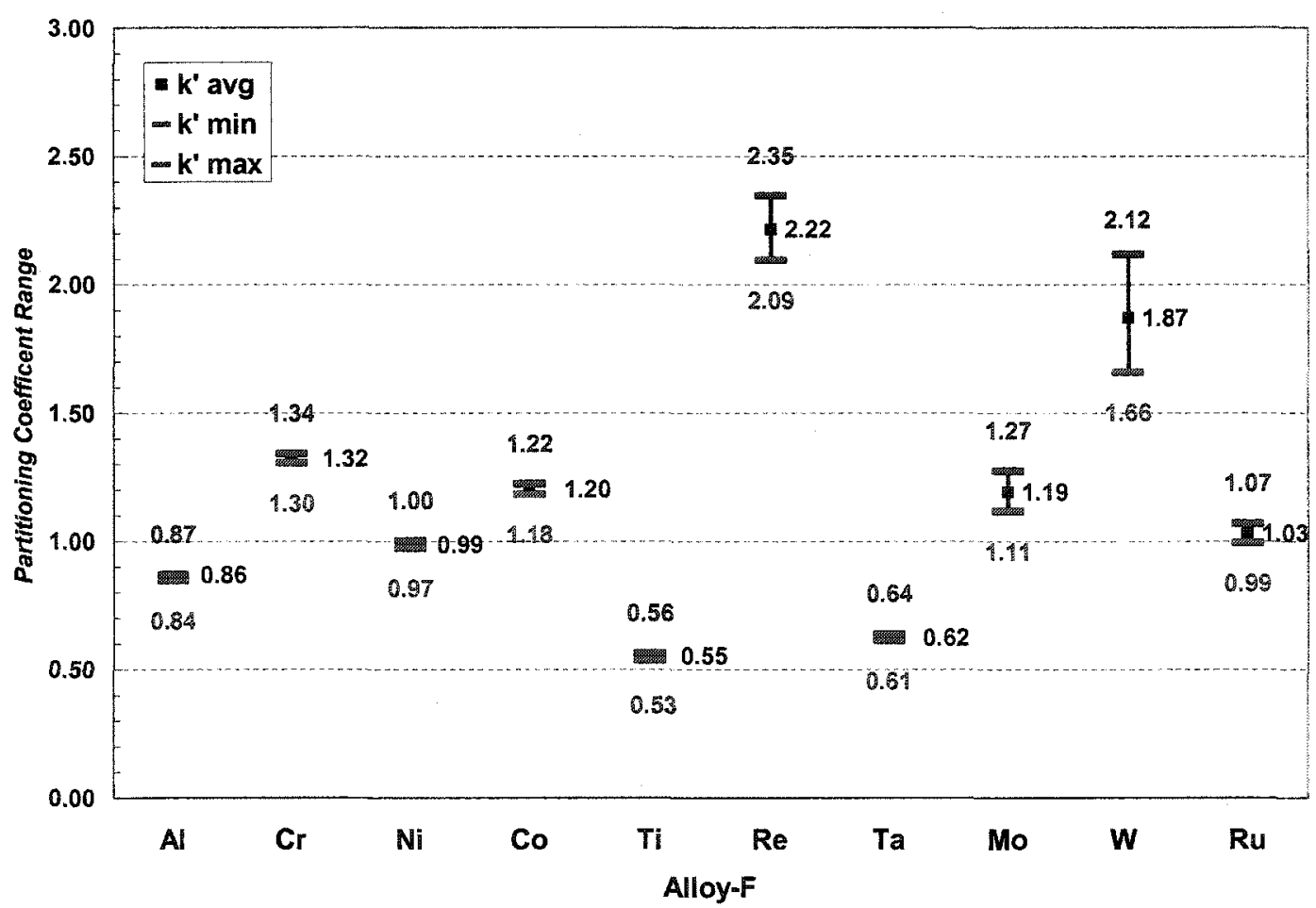

Figure 200: Partitioning coefficient range for Alloy-F. 